\title{
Neutron Radiography (NRAD) Reactor 64-Element Core Upgrade
}

John D. Bess

J. Blair Briggs

Richard M. Lell

March 2014

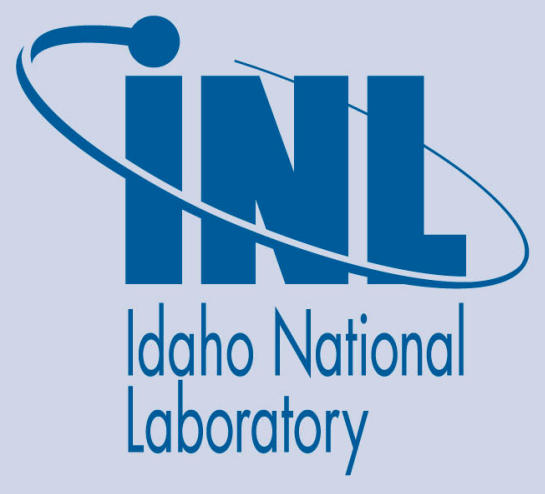

The INL is a U.S. Department of Energy National Laboratory operated by Battelle Energy Alliance 
INL/EXT-13-29628

\title{
Neutron Radiography (NRAD) Reactor 64-Element Core Upgrade
}

\author{
John D. Bess \\ J. Blair Briggs \\ Richard M. Lell ${ }^{1}$ \\ ${ }^{1}$ Argonne National Laboratory
}

March 2014

Idaho National Laboratory
Idaho Falls, Idaho 83415

http://www.inl.gov

Prepared for the

U.S. Department of Energy

Office of Nuclear Energy

Under DOE Idaho Operations Office

Contract DE-AC07-05ID14517 
NEA/NSC/DOC(2006)1

Fundamental - FUND

NRAD-FUND-RESR-002

CRIT-REAC-COEF

\title{
NEUTRON RADIOGRAPHY (NRAD) REACTOR 64-ELEMENT CORE UPGRADE
}

\author{
Evaluator \\ John D. Bess \\ Idaho National Laboratory \\ Internal Reviewer \\ J. Blair Briggs \\ Idaho National Laboratory \\ Independent Reviewer \\ Richard M. Lell \\ Argonne National Laboratory
}


NRAD-FUND-RESR-002

CRIT-REAC-COEF

\section{ACKNOWLEDGMENTS}

The author would like to express gratitude for the time and effort invested by many individuals into the original Neutron Radiography (NRAD) reactor benchmark evaluation: NRAD-FUND-RESR-001. Much of the information regarding NRAD was obtained during the development of that initial benchmark report, and then reused herein. A summary of those that participated in the initial benchmark evaluation but not this current one is provided here:

- Idaho National Laboratory

- Thomas L. Maddock

- Margaret A. Marshall

- Leland M. Montierth

- Ning Zhang

- Ann Marie Phillips

- Kenneth A. Schreck

- Eric C. Woolstenhulme

- General Atomics

○ John M. Bolin

- Anthony Veca

- Argonne National Laboratory

○ Richard D. McKnight

The author would particularly like to acknowledge the indispensable work of Christine E. White from INL in the preparation most of the drawings and graphics and Andrew T. Smolinski from INL for his assistance in gathering the information needed for the upgrade measurements. The IRPhEP working group provided much appreciated assistance, useful comments, and observations in the final preparation of this evaluation.

This project was supported by the U.S. Department of Energy, Assistant Secretary for Nuclear Energy, under DOE Idaho Operations Office Contract DE-AC07-05ID14517. 
NEA/NSC/DOC(2006)1

Fundamental - FUND

NRAD-FUND-RESR-002

CRIT-REAC-COEF

Status of Compilation / Evaluation / Peer Review

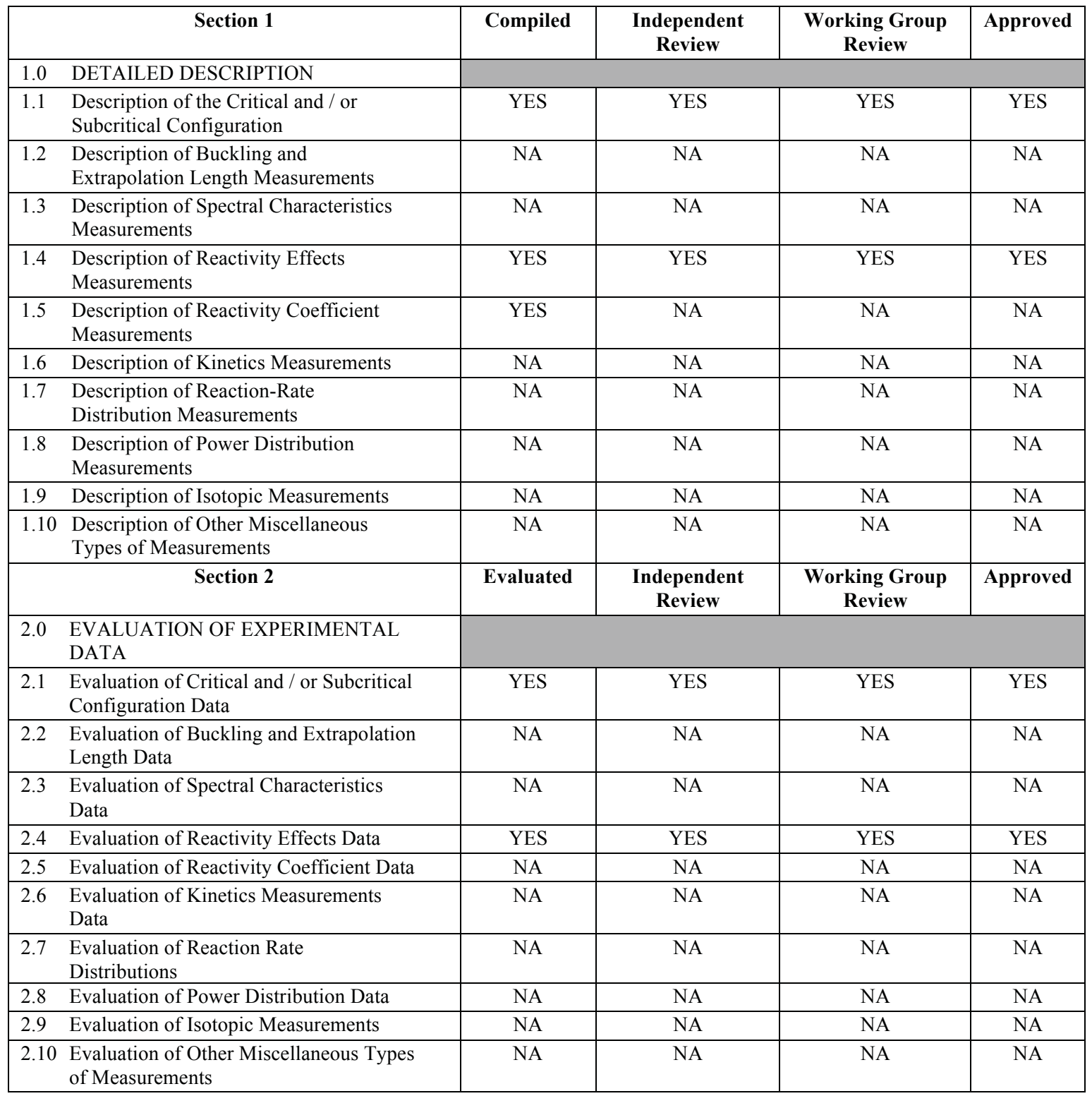


NEA/NSC/DOC(2006)1

Fundamental - FUND

NRAD-FUND-RESR-002

CRIT-REAC-COEF

\begin{tabular}{|c|c|c|c|c|c|}
\hline \multicolumn{2}{|r|}{ Section 3} & \multirow[t]{2}{*}{ Compiled } & \multirow[t]{2}{*}{$\begin{array}{c}\text { Independent } \\
\text { Review }\end{array}$} & \multirow[t]{2}{*}{$\begin{array}{c}\text { Working } \\
\text { Group Review }\end{array}$} & \multirow[t]{2}{*}{ Approved } \\
\hline 3.0 & BENCHMARK SPECIFICATIONS & & & & \\
\hline 3.1 & $\begin{array}{l}\text { Benchmark-Model Specifications for } \\
\text { Critical and / or Subcritical } \\
\text { Measurements }\end{array}$ & YES & YES & YES & YES \\
\hline 3.2 & $\begin{array}{l}\text { Benchmark-Model Specifications for } \\
\text { Buckling and Extrapolation Length } \\
\text { Measurements }\end{array}$ & NA & NA & NA & NA \\
\hline 3.3 & $\begin{array}{l}\text { Benchmark-Model Specifications for } \\
\text { Spectral Characteristics Measurements }\end{array}$ & NA & NA & NA & NA \\
\hline 3.4 & $\begin{array}{l}\text { Benchmark-Model Specifications for } \\
\text { Reactivity Effects Measurements }\end{array}$ & YES & YES & YES & YES \\
\hline 3.5 & $\begin{array}{l}\text { Benchmark-Model Specifications for } \\
\text { Reactivity Coefficient Measurements }\end{array}$ & NA & NA & NA & NA \\
\hline 3.6 & $\begin{array}{l}\text { Benchmark-Model Specifications for } \\
\text { Kinetics Measurements }\end{array}$ & NA & NA & NA & NA \\
\hline 3.7 & $\begin{array}{l}\text { Benchmark-Model Specifications for } \\
\text { Reaction-Rate Distribution } \\
\text { Measurements }\end{array}$ & NA & NA & NA & NA \\
\hline 3.8 & $\begin{array}{l}\text { Benchmark-Model Specifications for } \\
\text { Power Distribution Measurements }\end{array}$ & NA & NA & NA & NA \\
\hline 3.9 & $\begin{array}{l}\text { Benchmark-Model Specifications for } \\
\text { Isotopic Measurements }\end{array}$ & NA & NA & NA & NA \\
\hline 3.10 & $\begin{array}{l}\text { Benchmark-Model Specifications of } \\
\text { Other Miscellaneous Types of } \\
\text { Measurements }\end{array}$ & NA & NA & NA & NA \\
\hline & Section 4 & Compiled & $\begin{array}{l}\text { Independent } \\
\text { Review }\end{array}$ & $\begin{array}{c}\text { Working } \\
\text { Group Review }\end{array}$ & Approved \\
\hline 4.0 & $\begin{array}{l}\text { RESULTS OF SAMPLE } \\
\text { CALCULATIONS }\end{array}$ & & & & \\
\hline 4.1 & $\begin{array}{l}\text { Results of Calculations of the Critical or } \\
\text { Subcritical Configurations }\end{array}$ & YES & YES & YES & YES \\
\hline 4.2 & $\begin{array}{l}\text { Results of Buckling and Extrapolation } \\
\text { Length Calculations }\end{array}$ & NA & NA & NA & NA \\
\hline 4.3 & $\begin{array}{l}\text { Results of Spectral Characteristics } \\
\text { Calculations }\end{array}$ & NA & NA & NA & NA \\
\hline 4.4 & Results of Reactivity Effect Calculations & YES & YES & YES & YES \\
\hline 4.5 & $\begin{array}{l}\text { Results of Reactivity Coefficient } \\
\text { Calculations }\end{array}$ & NA & NA & NA & NA \\
\hline 4.6 & $\begin{array}{l}\text { Results of Kinetics Parameter } \\
\text { Calculations }\end{array}$ & NA & NA & NA & NA \\
\hline 4.7 & $\begin{array}{l}\text { Results of Reaction-Rate Distribution } \\
\text { Calculations }\end{array}$ & NA & NA & NA & NA \\
\hline 4.8 & $\begin{array}{l}\text { Results of Power Distribution } \\
\text { Calculations }\end{array}$ & NA & NA & NA & NA \\
\hline 4.9 & Results of Isotopic Calculations & NA & NA & NA & NA \\
\hline 4.10 & $\begin{array}{l}\text { Results of Calculations of Other } \\
\text { Miscellaneous Types of Measurements }\end{array}$ & NA & NA & NA & NA \\
\hline & \begin{tabular}{|l} 
Section 5 \\
\end{tabular} & Compiled & $\begin{array}{l}\text { Independent } \\
\text { Review }\end{array}$ & $\begin{array}{l}\text { Working Group } \\
\text { Review }\end{array}$ & Approved \\
\hline 5.0 & REFERENCES & YES & YES & YES & YES \\
\hline $\begin{array}{l}\text { Apper } \\
\text { Typic }\end{array}$ & $\begin{array}{l}\text { endix A: Computer Codes, Cross Sections, and } \\
\text { cal Input Listings }\end{array}$ & YES & YES & YES & YES \\
\hline
\end{tabular}


NEA/NSC/DOC(2006)1

Fundamental - FUND

NRAD-FUND-RESR-002

CRIT-REAC-COEF

NEUTRON RADIOGRAPHY (NRAD) REACTOR 64-ELEMENT CORE UPGRADE

\author{
IDENTIFICATION NUMBER: NRAD-FUND-RESR-002 \\ CRIT-REAC-COEF
}

\begin{abstract}
KEY WORDS: acceptable, criticality, enriched uranium, erbium, graphite, graphite-reflected, light water, neutron radiography, NRAD, research reactor, thermal, TRIGA, uranium, uranium-erbium-zirconium-hydride fuel, water-reflected, zirconium-hydride, zirconium-hydride-moderated
\end{abstract}

\title{
SUMMARY INFORMATION
}

\subsection{DETAILED DESCRIPTION}

The neutron radiography (NRAD) reactor is a $250 \mathrm{~kW}$ TRIGA ${ }^{\circledR}$ (Training, Research, Isotopes, General Atomics) Mark II ${ }^{\mathrm{a} b}$ tank-type research reactor located in the basement, below the main hot cell, of the Hot Fuel Examination Facility (HFEF) at the Idaho National Laboratory (INL). It is equipped with two beam tubes with separate radiography stations for the performance of neutron radiography irradiation on small test components. ${ }^{\mathrm{c}}$

The NRAD reactor is currently under the direction of the Battelle Energy Alliance (BEA) and is operated and maintained by the INL and Hot Cell Services Division. It is primarily used for neutron radiography analysis of both irradiated and unirradiated fuels and materials. Typical applications for examining the internal features of fuel elements and assemblies include fuel pellet separations, fuel central-void formation, pellet cracking, evidence of fuel melting, and material integrity under normal and extreme conditions. Examination of the behavior of large test loops and assemblies can also be performed. Due to the intense gamma activity of most irradiated specimens, the HFEF uses an indirect radiography, where a beam of neutrons passes through a specimen, strikes a gamma-insensitive metal foil (typically indium or dysprosium, for epithermal or thermal neutron spectra, respectively), and activates the foil. The foil can then be placed against a sheet of x-ray photographic film. X-rays from the metal foil then render an image on the film, which is then developed. While this method takes longer than the conventional direct method, the results eliminate gamma interference and are more detailed. Neutron tomography capabilities are being developed, where radiographs are obtained from different rotational angles and digitized to reconstruct cross-sections of a specimen. Direct radiography, such as Polaroid or track-etch radiography, and in-tank irradiations and/or experiments with small in-core samples can also be performed in the NRAD reactor.

The NRAD core is designed for steady-state operation with or without in-core and/or in-tank experiments. The combined reactivity worth of all removable experiments within the reactor tank is limited to less than $\$ 0.50$.

The NRAD reactor is a TRIGA-conversion-type reactor originally located at the Puerto Rico Nuclear Center (PRNC). It was converted to a TRIGA-FLIP-(Fuel Life Improvement Program)-fueled system $\left(70 \%{ }^{235} \mathrm{U}\right)$ in 1971 . The 2-MW Puerto Rico research reactor was then closed in 1976; a portion of the

\footnotetext{
${ }^{\text {a }}$ TRIGA ${ }^{\circledR}$ Nuclear Reactors, General Atomics, http://triga.ga.com/ (Accessed October 15, 2009).

${ }^{\mathrm{b}}$ D. M. Fouquet, J. Razvi, W. L. Whittemore, “TRIGA Research Reactors: A Pathway to the Peaceful Applications of Nuclear Energy," Nuclear News, 46(12), 46-56 (2003).

c "NRAD Safety Analysis Report,” DSA-005-NRAD rev. 5, Idaho National Laboratory (April 2, 2009). [This reference is not available for public release.]
} 
NEA/NSC/DOC(2006)1

\author{
Fundamental - FUND \\ NRAD-FUND-RESR-002 \\ CRIT-REAC-COEF
}

TRIGA reactor fuel elements and other components (with a single radiography beam line) were moved in 1977 by the US Department of Energy (DOE) to the Argonne National Laboratory (West), which is now part of INL, in Idaho Falls, Idaho, and rebuilt as the NRAD reactor. The NRAD reactor was first brought to critical in October 1977, and then became operational in 1978. A second beam line was added in $1982 .^{b}$

The Reduced Enrichment for Research and Test Reactors (RERTR) Program, in support of the Global Threat Reduction Initiative (GTRI), required conversion of all civilian reactor facilities from highly enriched uranium (HEU) to low enriched uranium (LEU) fuel $\left(<20 \%{ }^{235} \mathrm{U}\right){ }^{\mathrm{c}}$ Therefore, the NRAD reactor core comprised of FLIP fuel was completely defueled by August 26, 2009. Refueling with LEU began on September 17, 2009 and start-up testing for the HEU/LEU fuel conversion of the NRAD TRIGA reactor began on March 9, 2010 and was completed on June 7, 2010.

Because the core excess reactivity was lower than predicted and would not allow for extended operations, the NRAD reactor core was upgraded via the addition of four fuel elements and four graphite elements. Staff at the HFEF upgraded the NRAD reactor to 64 fuel elements from April 10-23, 2013.

Measurements included critical configurations for an interim core of 62 fuel elements and the final upgraded core of 64 fuel elements. Control rod worths, excess reactivity, and shutdown margin were measured for each core configuration. Calorimetric power calibrations were performed up to $250 \mathrm{~kW}$ for the 64-fuel-element configuration, and excess reactivity was determined at full power $(250 \mathrm{~kW})$. For reactivity measurements in the NRAD reactor, control rod worths are measured and the excess reactivities and shutdown margins are derived from the measured control rod worths.

Available data regarding the materials and configuration of the NRAD reactor is limited to the initial LEU start-up test plan, ${ }^{\mathrm{d}}$ measurement results from the initial LEU start-up tests, ${ }^{\mathrm{e}}$ safety analysis reports, ${ }^{\mathrm{f}, \mathrm{g}}$ a system design description, ${ }^{\mathrm{h}}$ and various component design drawings (Appendix F). Significant information and clarification were provided by Tom Maddock, a former staff member at the HFEF facility, and Ken Schreck, the NRAD Reactor Manager throughout the initial LEU conversion process.

\footnotetext{
${ }^{a}$ A. A. Weeks, D. P. Pruett, and C. C. Heidel, "Modifications to the NRAD Reactor (1977 to Present)," CONF8604117-1, Proc. 10 ${ }^{\text {th }}$ U.S. TRIGA User's Conference, College Station, Texas (April 7-9, 1986).

${ }^{\text {b }}$ G. R. Imel, G. C. McClellan, and D. P. Pruett, “The Neutron Radiography Reactor (NRAD),” CONF-900873--2, Proc. ${ }^{\text {st }}$ Int. Top. Mtg. Neutron Radiography System Design and Characterization, Pembroke, Canada (August 2830, 1990).

${ }^{c}$ C. Landers, "Reactor Identified for Conversion, Reduced Enrichment for Research and Test Reactors (RERTR) Program,” Proc. RERTR 2005, Boston, Massachusetts (November 6-10, 2005).

d "Startup Plan for the NRAD Reactor Final Report," PLN-3285 rev. 3, Idaho National Laboratory (August 2010). [This reference is not available for public release.]

e "Startup Report for the NRAD Reactor," 911195 rev. 0, GA Project 39296, TRIGA Reactor Division of General Atomics (November 4, 2010). [This reference is not available for public release.]

f “NRAD Safety Analysis Report,” DSA-005-NRAD rev. 5, Idaho National Laboratory (April 2, 2009). [This reference is not available for public release.]

g "NRAD Reactor Fuel Core Conversion,” DSA-005-NRAD-ADD-3 rev. 0, Idaho National Laboratory (April 2 , 2009). [This reference is not available for public release.]

h "HFEF/N Neutron Radiography Facility System Design Description,” W0170-0004-SA rev. 2, Idaho National Laboratory (June 1, 1978). [This reference is not available for public release.]
} 
NEA/NSC/DOC(2006)1

Fundamental - FUND

NRAD-FUND-RESR-002

CRIT-REAC-COEF

Additional start-up tests plans were developed to support the upgrade of the NRAD LEU core. ${ }^{\mathrm{a}, \mathrm{b}}$ Supporting documentation and log data for the upgrade were provided by Andrew Smolinski from the HFEF facility, which were incorporated into a start-up report for the 64-fuel-element upgrade. ${ }^{c}$

General Atomics provided some information regarding TRIGA reactor fuel and control rods and developed the start-up plan for the initial LEU conversion of the NRAD., ${ }^{\mathrm{b}, \mathrm{r}}$ Additional material data were obtained from samples analyzed at independent laboratories.

A criticality benchmark of an annular TRIGA Mark II reactor containing U(20)-Zr-H fuel (no erbium content) has already been evaluated. ${ }^{\mathrm{e}}$ The start-up measurements for the LEU core with 56 and 60 fuel elements was previously evaluated (NRAD-FUND-RESR-001).

\subsection{Description of the Critical and / or Subcritical Configuration}

\subsubsection{Overview of Experiment}

The intermediary critical configuration developed during the fuel loading process, which contains only 62 fuel elements, has been evaluated as an acceptable benchmark experiment. The 64-fuel-element upgraded core configuration of the NRAD LEU TRIGA reactor has also been evaluated as an acceptable benchmark experiment.

\subsubsection{Geometry of the Experiment Configuration and Measurement Procedure}

The NRAD reactor (Figure 1.1) is a $250 \mathrm{~kW}$ TRIGA LEU conversion reactor that is a water-moderated, heterogeneous, solid-fuel, tank-type research reactor. The reactor is composed of fuel in three- and fourelement clusters that can be arranged in a variety of lattice patterns, depending on reactivity requirements. Typically, the three-element clusters also include a guide tube in the fourth position, for use as a control rod or irradiation position. The grid plate consists of 36 holes, on a 6-by-6 rectangular pattern, that mate with the end fittings of the fuel cluster assemblies. ${ }^{\mathrm{f}}$

The dimensions obtained from most of the references were reported in feet and inches. Where referenced in this report, the original dimensions are then followed by their converted values in units of meters or centimeters, in parenthesis. The number of decimal places in the converted units does not imply additional precision, but preservation of the original measurement.

\footnotetext{
a "Neutron Radiography Reactor Analysis and Support: LEU Upgrade of the NRAD Reactor, Final Report," 911193 rev. 0, GA Project 39296, TRIGA Reactor Division of General Atomics (August 27, 2010). [This reference is not available for public release.]

b "Neutron Radiography Reactor Analysis and Support: Support Calculations for the LEU Upgrade of the Nrad Reactor, Final Report," 911194, rev. 0, GA Project 39296, TRIGA Reactor Division of General Atomics (June 17, 2011). [This reference is not available for public release.]

c “NRAD 64 Element Core Upgrade Startup Report,” INL/INT-13-29899 [draft], Idaho National Laboratory (publication date pending). [This reference is not available for public release.]

d "Neutron Radiography Reactor Analysis and Support: Startup Plan for the NRAD Reactor, Final Report," 911183 rev. 1, GA Project 39296, TRIGA Reactor Division of General Atomics (January 13, 2010). [This reference is not available for public release.]

${ }^{\mathrm{e}}$ R. Jeraj and M. Ravnik, "TRIGA Mark II Reactor: U(20) - Zirconium Hydride Fuel Rods in Water with Graphite Reflector," Rev. 0 (September 30, 1999), IEU-COMP-THERM-003, International Handbook of Evaluated Criticality Safety Benchmark Experiments, NEA/NSC/DOC(95)03, OECD-NEA (2010).

f “NRAD Reactor Fuel Core Conversion,” DSA-005-NRAD-ADD-3 rev. 0, Idaho National Laboratory (April 2, 2009). [This reference is not available for public release.]
} 
NEA/NSC/DOC(2006)1

Fundamental - FUND

NRAD-FUND-RESR-002

CRIT-REAC-COEF

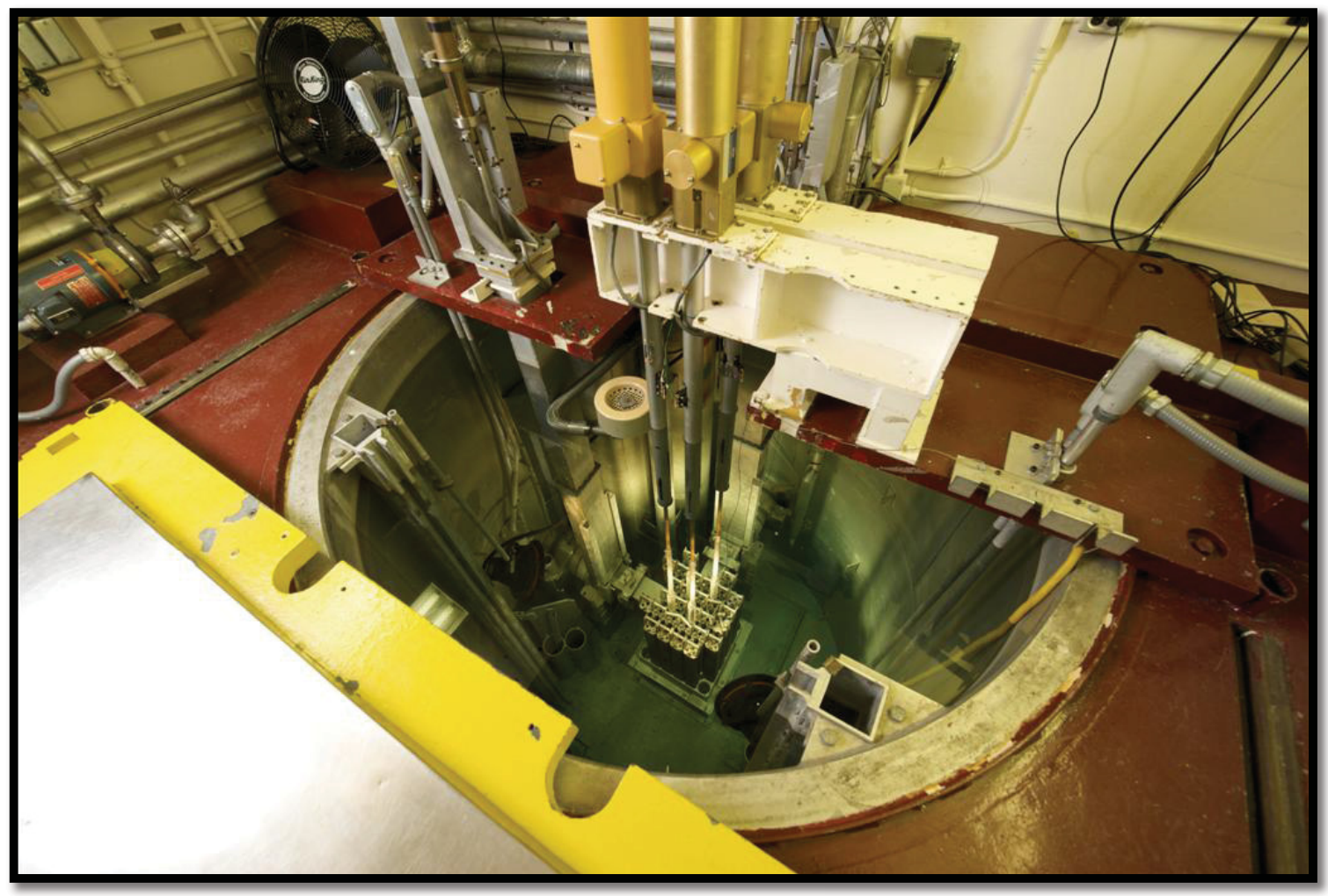

Figure 1.1a. Top-Down View of the NRAD Reactor (60-Fuel-Element Core).

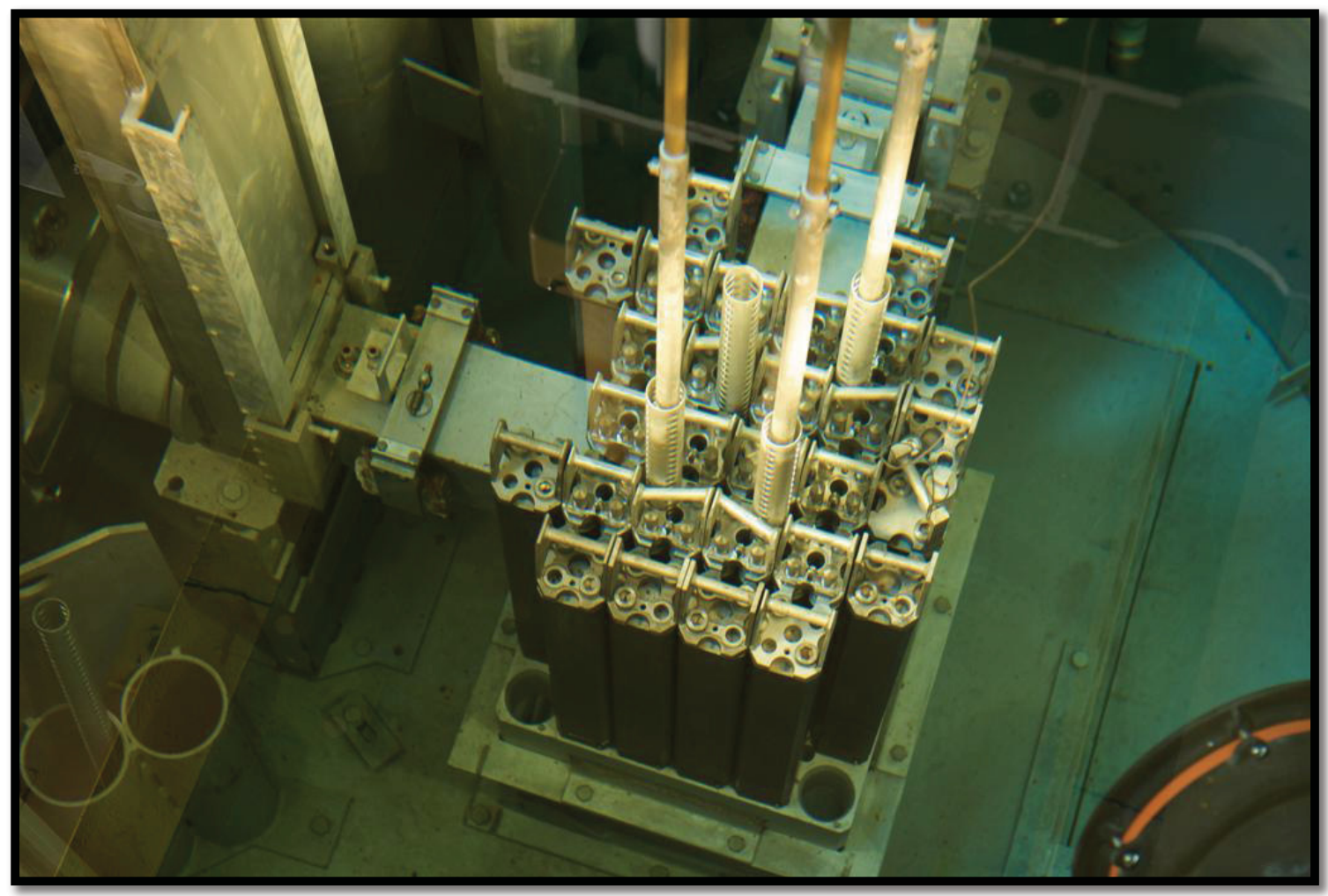

Figure 1.1b. In-Tank View of the NRAD Reactor Core (60-Fuel-Element Core). 


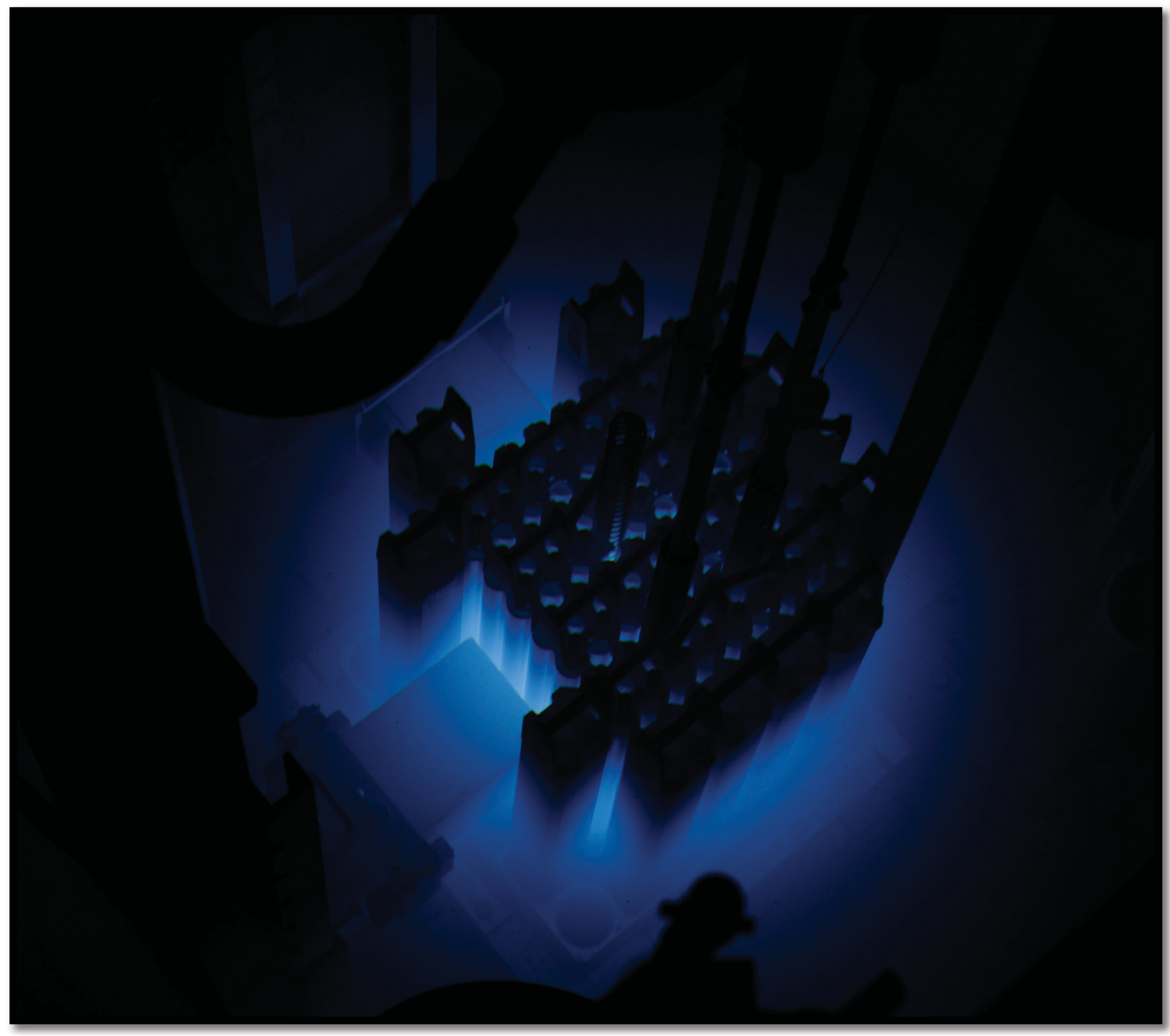

Figure 1.1c. NRAD Reactor Core during Operation (60-Fuel-Element Core).

\subsubsection{Facility Description}

\section{Site and Facility}

The NRAD reactor is located in the basement, below the main hot cell, of the Hot Fuels Examination Facility (HFEF), shown in Figure 1.2, at the Materials and Fuels Complex (MFC) of the Idaho National Laboratory (INL), formerly known as Argonne-West.

The floor area in the reactor room is $11 \mathrm{ft} 6 \mathrm{in} .(3.5052 \mathrm{~m})$ by $12 \mathrm{ft}(3.6576 \mathrm{~m})$ with a height of $16 \mathrm{ft} 9 \mathrm{in}$. $(5.1054 \mathrm{~m})$, and is located at the east end of the HFEF cask tunnel. Prior to placement of the reactor tank, the original floor and soil were excavated down to the rock level and then backfilled with concrete to the depth of the original floor. ${ }^{\mathrm{a}}$

The excavation is approximately $10 \mathrm{ft}(3.048 \mathrm{~m})$ deep.

\footnotetext{
a "HFEF/N Neutron Radiography Facility System Design Description,” W0170-0004-SA rev. 2, Idaho National Laboratory (June 1, 1978). [This reference is not available for public release.]
} 


\section{Fundamental - FUND \\ NRAD-FUND-RESR-002 \\ CRIT-REAC-COEF}

The reactor tank fills most of the room in which it is placed. It is embedded in a massive, reinforcedconcrete block that is surrounded on three sides by reinforced-concrete walls. The concrete serves both as a working platform at the top level of the reactor tank and as a biological shield. ${ }^{\text {a }}$

The reactor tank is surrounded by concrete except around the beam tubes, where additional shielding is required. The concrete around the tank is filled up to the tank top, about $5 \mathrm{ft} 6 \mathrm{in}$. $(1.6764 \mathrm{~m})$ from the ceiling. The North, East, and South walls have a concrete thickness of 2.5, 4, and $5 \mathrm{ft}(76.2,121.92$, and $152.4 \mathrm{~cm})$, respectively. The West wall, to a height of $11.5 \mathrm{ft}(3.5052 \mathrm{~m})$ was formed by the concrete surrounding the tank. The remaining height of the West wall consists of 2 in. $(5.08 \mathrm{~cm})$ thick lead bricks sandwiched between steel plates. Two sections of this shielding wall are fixed at either side with two other sections capable of sliding open to provide access to the reactor room. This opening is $5 \mathrm{ft} 3 \mathrm{in}$. $(1.6002 \mathrm{~m})$ wide and $5 \mathrm{ft} 6 \mathrm{in}$. $(1.6764 \mathrm{~m})$ high. A fixed ladder provides entry for personnel from the cask tunnel. ${ }^{\mathrm{a}}$

The ceiling is made of 42 in. (106.68 cm) thick reinforced high-density concrete. ${ }^{\mathrm{b}}$

Additional shielding was provided by embedding steel plates, borated polyethylene, and lead bricks within the concrete shielding. The maximum thickness of the West shield is $12 \mathrm{in} .(30.48 \mathrm{~cm})$ steel plus 1 in. $(2.54 \mathrm{~cm})$ polyethylene. A 6 in. $(15.24 \mathrm{~cm})$ thick steel slab with 1 in. $(2.54 \mathrm{~cm})$ thick borated polyethylene slab is placed to the north of the reactor around the north beam tube penetration. A 4 in. $(10.16 \mathrm{~cm})$ thick layer of lead bricks is embedded in a rectangular box to the West side of the top of the reactor tank. ${ }^{\mathrm{a}}$

A plan and elevation view of the NRAD is shown in Figures 1.3 and 1.4, respectively. The placement of the fuel handling cask is shown in these two figures; however, the cask is not placed in the tank, except when fuel loading and unloading tasks are being performed.

\footnotetext{
a “NRAD Safety Analysis Report,” DSA-005-NRAD rev. 5, Idaho National Laboratory (April 2, 2009). [This reference is not available for public release.]

b "HFEF/N Neutron Radiography Facility System Design Description,” W0170-0004-SA rev. 2, Idaho National Laboratory (June 1, 1978). [This reference is not available for public release.] 
NEA/NSC/DOC(2006)1

Fundamental - FUND

NRAD-FUND-RESR-002

CRIT-REAC-COEF

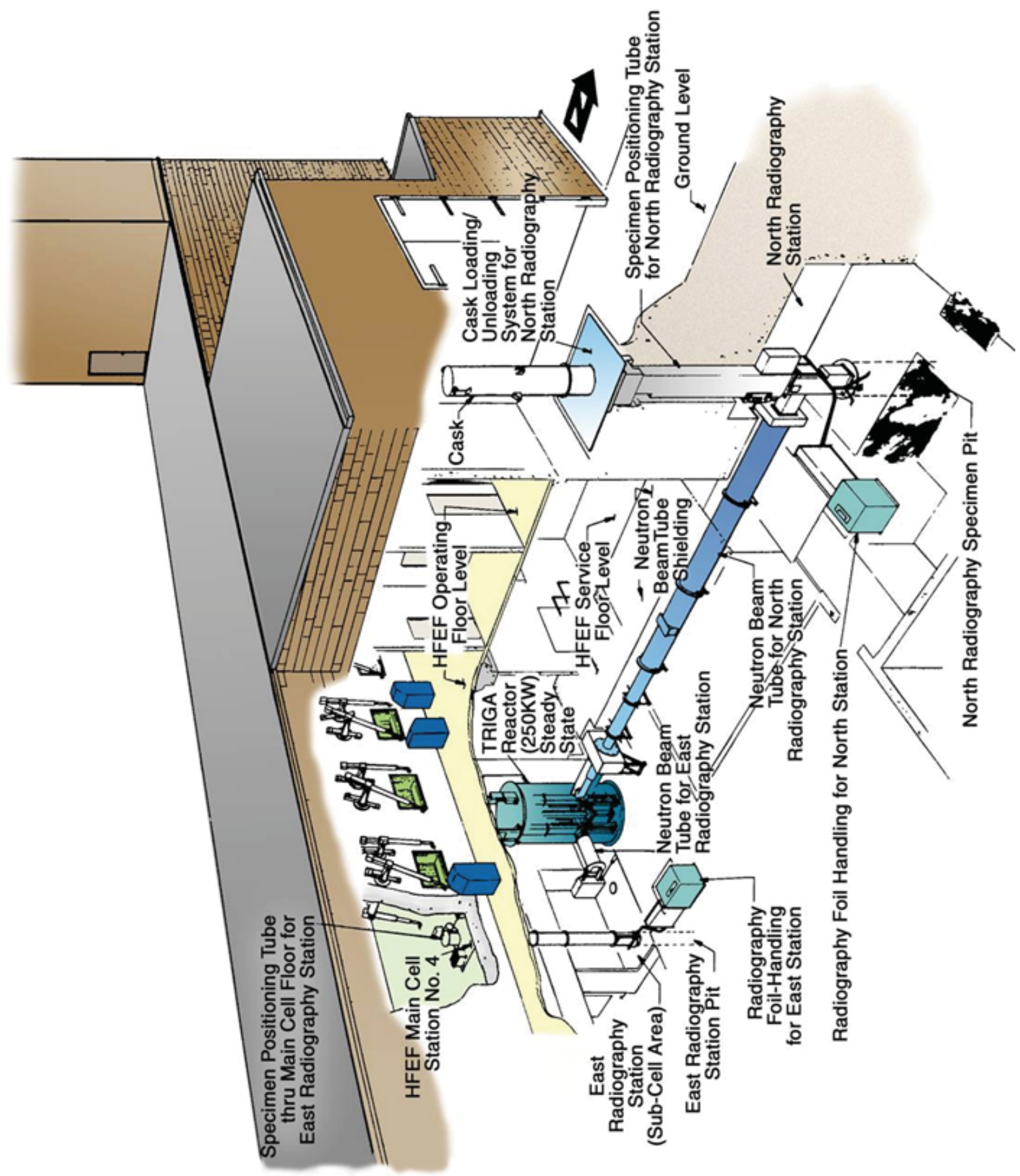

Figure 1.2. Hot Fuels Examination Facility. 
NEA/NSC/DOC(2006)1

Fundamental - FUND

NRAD-FUND-RESR-002

CRIT-REAC-COEF

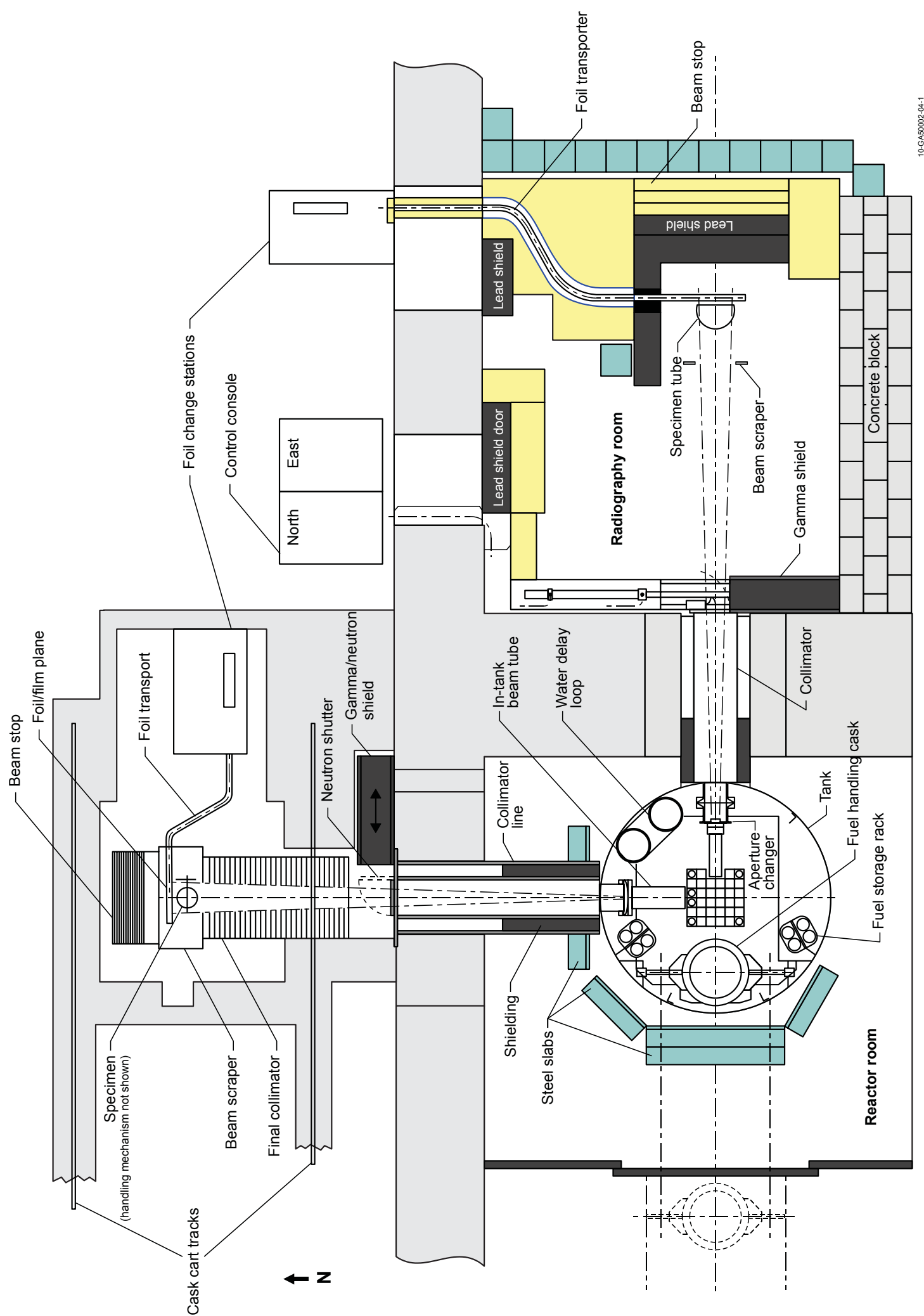

Figure 1.3. Plan View of the NRAD Facility. ${ }^{\mathrm{a}}$

a "NRAD Safety Analysis Report," DSA-005-NRAD rev. 5, Idaho National Laboratory (April 2, 2009). [This reference is not available for public release.] 
NEA/NSC/DOC(2006)1

Fundamental - FUND

NRAD-FUND-RESR-002

CRIT-REAC-COEF

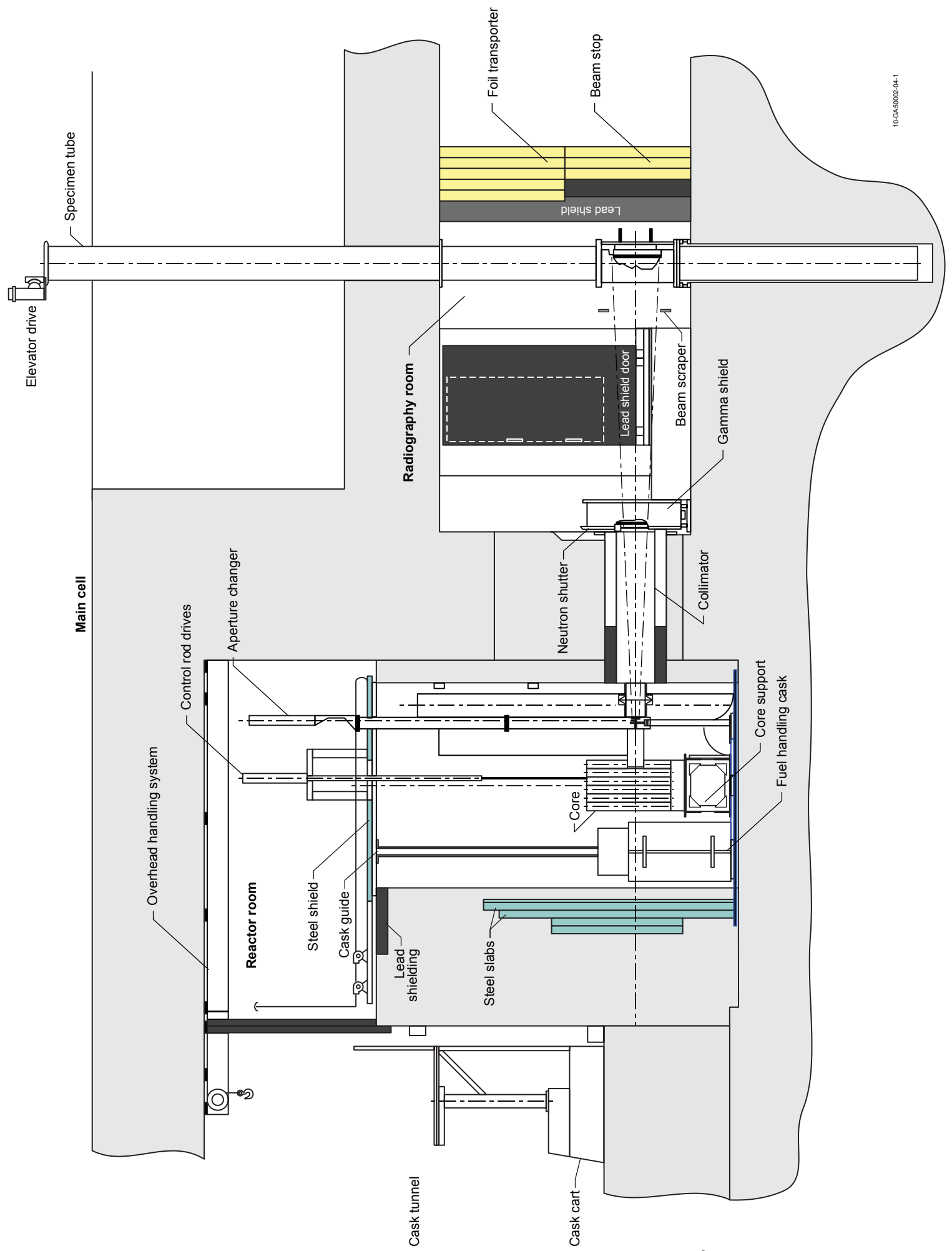

Figure 1.4. Elevation View of the NRAD Facility. ${ }^{\mathrm{a}}$

\footnotetext{
a "NRAD Safety Analysis Report," DSA-005-NRAD rev. 5, Idaho National Laboratory (April 2, 2009). [This
} reference is not available for public release.] 


\section{Reactor Containment}

A reactor tank houses the reactor core and contains the primary coolant. The tank is a welded construction of aluminum 6061-T6 that is $6.5 \mathrm{ft}(1.9812 \mathrm{~m})$ in diameter, $11.5 \mathrm{ft}(3.5052 \mathrm{~m})$ high, has 0.25 in. $(0.635 \mathrm{~cm})$ thick walls, and has a bottom that is $0.5 \mathrm{in} .(1.27 \mathrm{~cm})$ thick. It is open at the top. ${ }^{\text {a }}$

Two collars are butted to the outside surface of the tank to mate with beam-tube liners and two pipe stubs are welded to the inside surface to mate with nozzles. The only penetration in the tank wall is located near the top of the tank for the water-overflow pipe. Delay loops are provided inside the tank to allow ${ }^{16} \mathrm{~N}$ contained in the water to decay prior to entering the primary coolant system. ${ }^{\mathrm{b}}$

A diagram of the NRAD cross-section in the reactor tank is shown in Figure 1.5.

A reactor top shield serves as a working platform and is made of 2 in. $(5.08 \mathrm{~cm})$ thick steel. It is comprised of three sections: one that is fixed and supports the control-rod drives, one that is mounted on rollers and can be moved to access the reactor tank, and one that can be moved, if required, by an overhead handling system (see Figure 1.1a). These slabs are large enough that they cannot be dropped into the reactor core during handling. ${ }^{\mathrm{c}}$

\footnotetext{
a "NRAD Reactor Fuel Core Conversion," DSA-005-NRAD-ADD-3 rev. 0, Idaho National Laboratory (April 2, 2009). [This reference is not available for public release.]

b "HFEF/N Neutron Radiography Facility System Design Description,” W0170-0004-SA rev. 2, Idaho National Laboratory (June 1, 1978). [This reference is not available for public release.]

c "NRAD Safety Analysis Report,” DSA-005-NRAD rev. 5, Idaho National Laboratory (April 2, 2009). [This reference is not available for public release.]
} 


\section{NEA/NSC/DOC(2006)1}

Fundamental - FUND

NRAD-FUND-RESR-002

CRIT-REAC-COEF

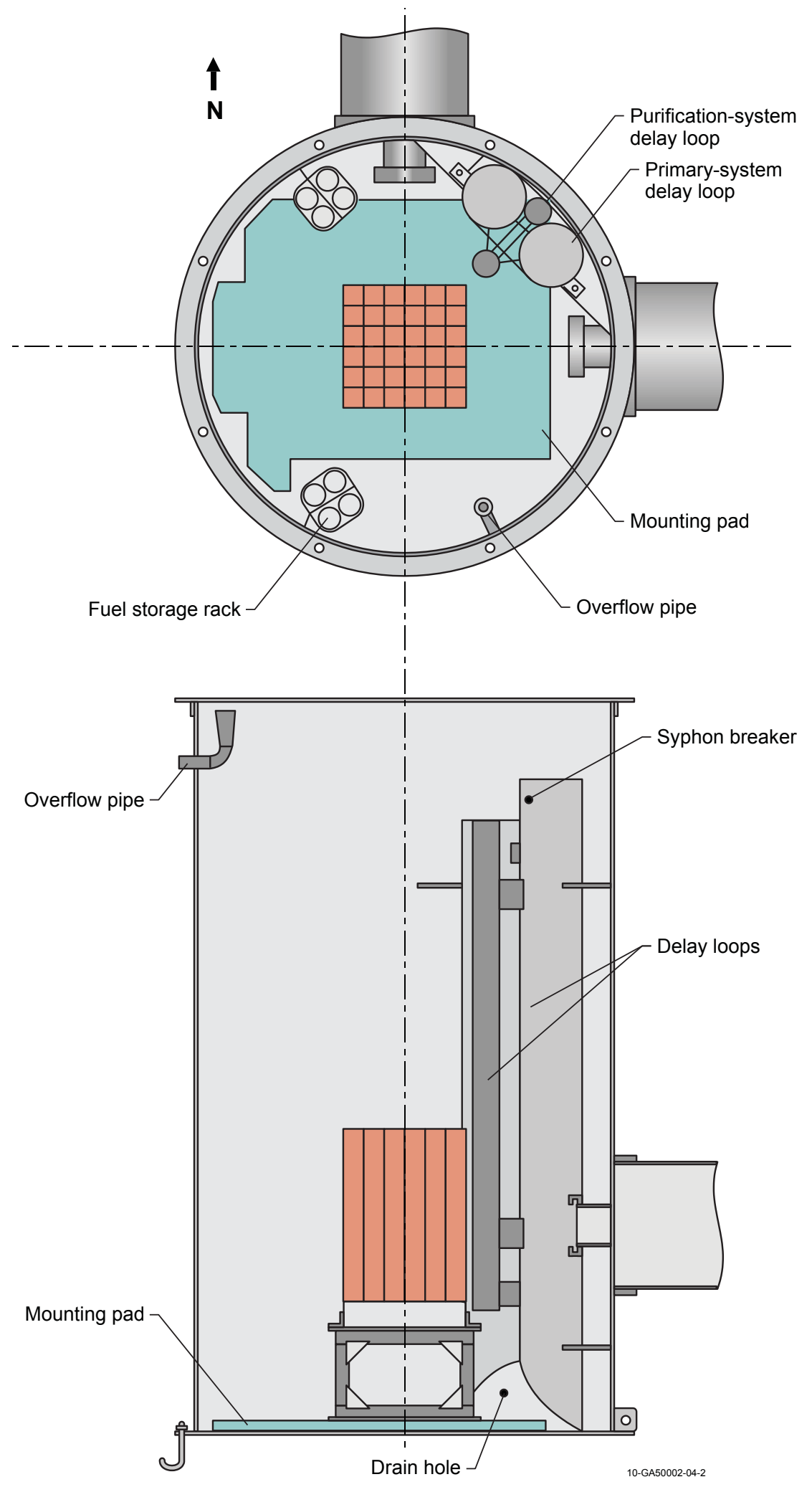

Figure 1.5. NRAD Tank. 
NEA/NSC/DOC(2006)1

Fundamental - FUND

NRAD-FUND-RESR-002

CRIT-REAC-COEF

\section{Non-Nuclear Components}

A 2 in. $(5.08 \mathrm{~cm})$ diameter overflow pipe maintains the maximum water level 2 in. $(5.08 \mathrm{~cm})$ below the top of the tank. The two 24 in. $(60.96 \mathrm{~cm})$ diameter collars butted to the outside of the tank surface are designed to provide support and a seal for the beam-tube liners. The two 9 in. $(22.86 \mathrm{~cm})$ diameter pipe stubs, which are aligned with the collars, are welded inside the tank for mating with nozzles. The nozzles extend between the reactor tank wall and the core skirt to exclude water from the path of the beam line. ${ }^{\text {a }}$

Attached to the inner tank wall is a primary coolant system water delay loop. The holdup tank is shaped like an upright " $U$ " and is made of 12 in. $(30.48 \mathrm{~cm})$ diameter aluminum pipe with a total length of $20 \mathrm{ft}$ $(6.096 \mathrm{~m})$ and a holding capacity of 120 gal. $(\sim 454.25 \mathrm{~L})$.

\section{Moderator/Coolant}

The reactor core is cooled via natural circulation of water within the open reactor tank. Heat is removed from the reactor tank by forced circulation induced by a primary water system through a water-to-water heat exchanger. The secondary side of the heat exchanger is then cooled by the HFEF cooling water system, which is cooled by the HFEF cooling tower. ${ }^{b}$

The tank water also serves as a biological shield for the reactor and is approximately $10 \mathrm{ft}(3.048 \mathrm{~m})$ deep.

\subsubsection{Reactor Core}

The NRAD LEU operational core configuration has been upgraded to contain 64 fuel elements, four graphite elements, two water-followed shim control rods, and one water-followed regulating rod (Figure 1.6). A water hole is provided as an experimental irradiation position via the use of an empty control rod guide tube placed near the center of the core. The NRAD reactor uses graphite neutron reflector assemblies located along the periphery grid plate locations. The number and position of fuel-element and reflector assemblies can be varied to adjust core reactivity.

Core positions are designated by a grid reference system, as labeled in Figure 1.6. The location of individual elements within a grid position is defined in Figure 1.7. Positions in the grid are identified with a letter-number pair. For example, the location of the in-core irradiation assembly is identified as C4. The location of a specific position within an assembly is further designated by its location with respect to the center of the assembly. The location of the in-core irradiation position is identified as C-4 SW.

The circular items labeled "G" through "N", in Figure 1.6, are in-pool storage locations.

\footnotetext{
a "HFEF/N Neutron Radiography Facility System Design Description," W0170-0004-SA rev. 2, Idaho National Laboratory (June 1, 1978). [This reference is not available for public release.]

b "NRAD Reactor Fuel Core Conversion," DSA-005-NRAD-ADD-3 rev. 0, Idaho National Laboratory (April 2, 2009). [This reference is not available for public release.]
} 
NEA/NSC/DOC(2006)1

Fundamental - FUND

NRAD-FUND-RESR-002

CRIT-REAC-COEF

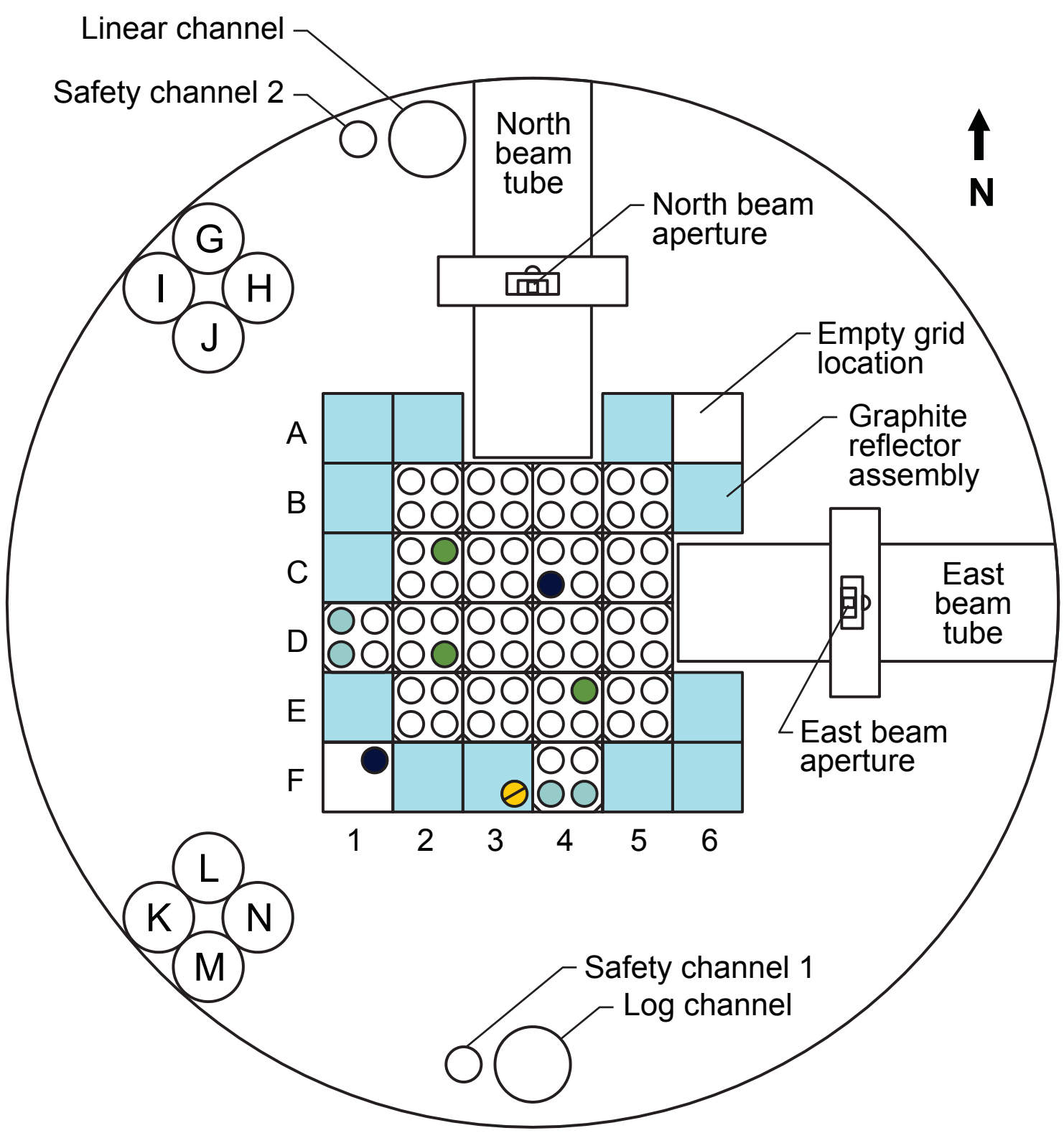

(iia) Fuel cluster assembly

Standard fuel element

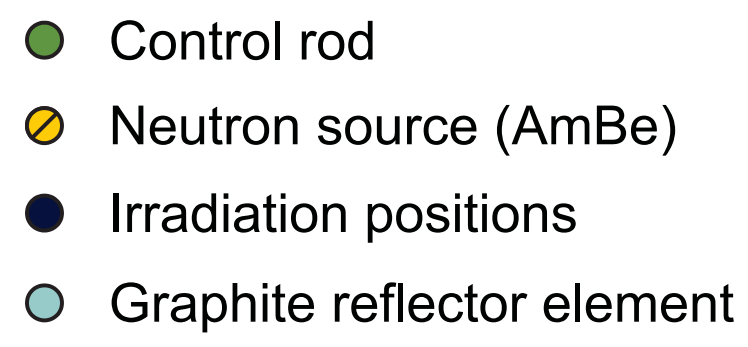

Figure 1.6. Upgraded NRAD LEU Core Configuration. 
NRAD-FUND-RESR-002

CRIT-REAC-COEF

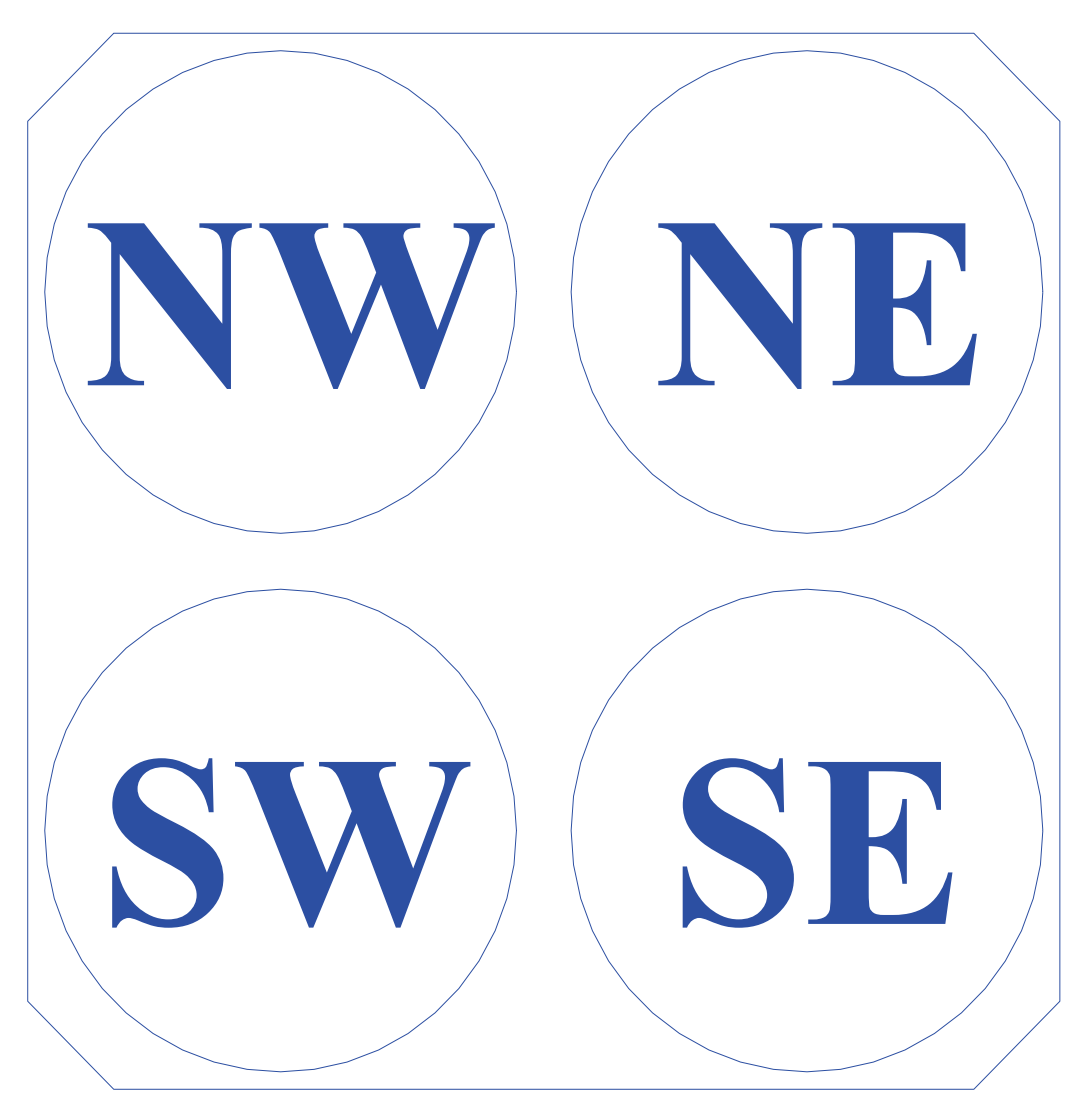

Figure 1.7. Notation for Fuel Element Cluster Position. ${ }^{\mathrm{a}}$

a “NRAD Reactor Fuel Core Conversion," DSA-005-NRAD-ADD-3 rev. 0, Idaho National Laboratory (April 2, 2009). [This reference is not available for public release.] 
NEA/NSC/DOC(2006)1

Fundamental - FUND

NRAD-FUND-RESR-002

CRIT-REAC-COEF

\section{Core Support Structure}

A 1 in. $(2.54 \mathrm{~cm})$ thick aluminum mounting pad (Figures 1.5 and 1.9) is welded to the inside surface of the tank bottom. ${ }^{\text {a }}$

A welded aluminum core support structure (Figure 1.8), which sits below the grid plate, supports the reactor core approximately $16.5 \mathrm{in} .(41.91 \mathrm{~cm})$ above the bottom of the reactor tank (Figure 1.9). It is bolted to the mounting pad of the reactor tank in eight places. ${ }^{b}$

\section{Grid Plate Assembly}

The fuel clusters are supported by a 5 in. $(12.7 \mathrm{~cm})$ thick grid plate composed of aluminum 1100 forgings (Figure 1.10). The grid plate has 36 holes placed in a $6 \times 6$ rectangular pitch lattice for holding the fuel cluster and reflector assemblies. ${ }^{\mathrm{a}}$

The grid plate assembly is bolted to the support structure (Figure 1.9).

The nominal spacing between cluster assemblies in the grid plate is shown in Figure 1.11. There is more space between the rod cluster assemblies in the East-West direction than in the North-South direction. ${ }^{\mathrm{a}}$ The original PRNC grid plate was designed to use Materials Testing Reactor (MTR)-type uraniumaluminum plate fuel. The NRAD reactor is a conversion reactor, where the original plate-type fuel bundles were replaced by TRIGA fuel cluster assemblies designed by General Atomics while still at PRNC. The NRAD reactor is one of thirteen conversion reactors. ${ }^{c}$

Core positions are designated by a grid reference system, as labeled in Figure 1.6. The location of individual elements within a grid position is defined in Figure 1.7.

Each cluster location utilizes a dowel pin to insure proper cluster orientation. Each dowel pin is approximately 0.250 in. $(0.635 \mathrm{~cm})$ in diameter and 1.000 in. $(2.54 \mathrm{~cm})$ in length. There are additional holes in the grid plate that allow for water flow and grid-plate cooling. ${ }^{\mathrm{b}}$

\footnotetext{
a "HFEF/N Neutron Radiography Facility System Design Description," W0170-0004-SA rev. 2, Idaho National Laboratory (June 1, 1978). [This reference is not available for public release.]

b "NRAD Reactor Fuel Core Conversion," DSA-005-NRAD-ADD-3 rev. 0, Idaho National Laboratory (April 2 , 2009). [This reference is not available for public release.]

c R. E. Smith, “TRIGA Fuel Summary Report,” ICP/INT-05-817, Idaho Cleanup Project, Idaho National Laboratory (March 2005). [This reference is not available for public release.]
} 


\section{NEA/NSC/DOC(2006)1}

Fundamental - FUND

NRAD-FUND-RESR-002

CRIT-REAC-COEF
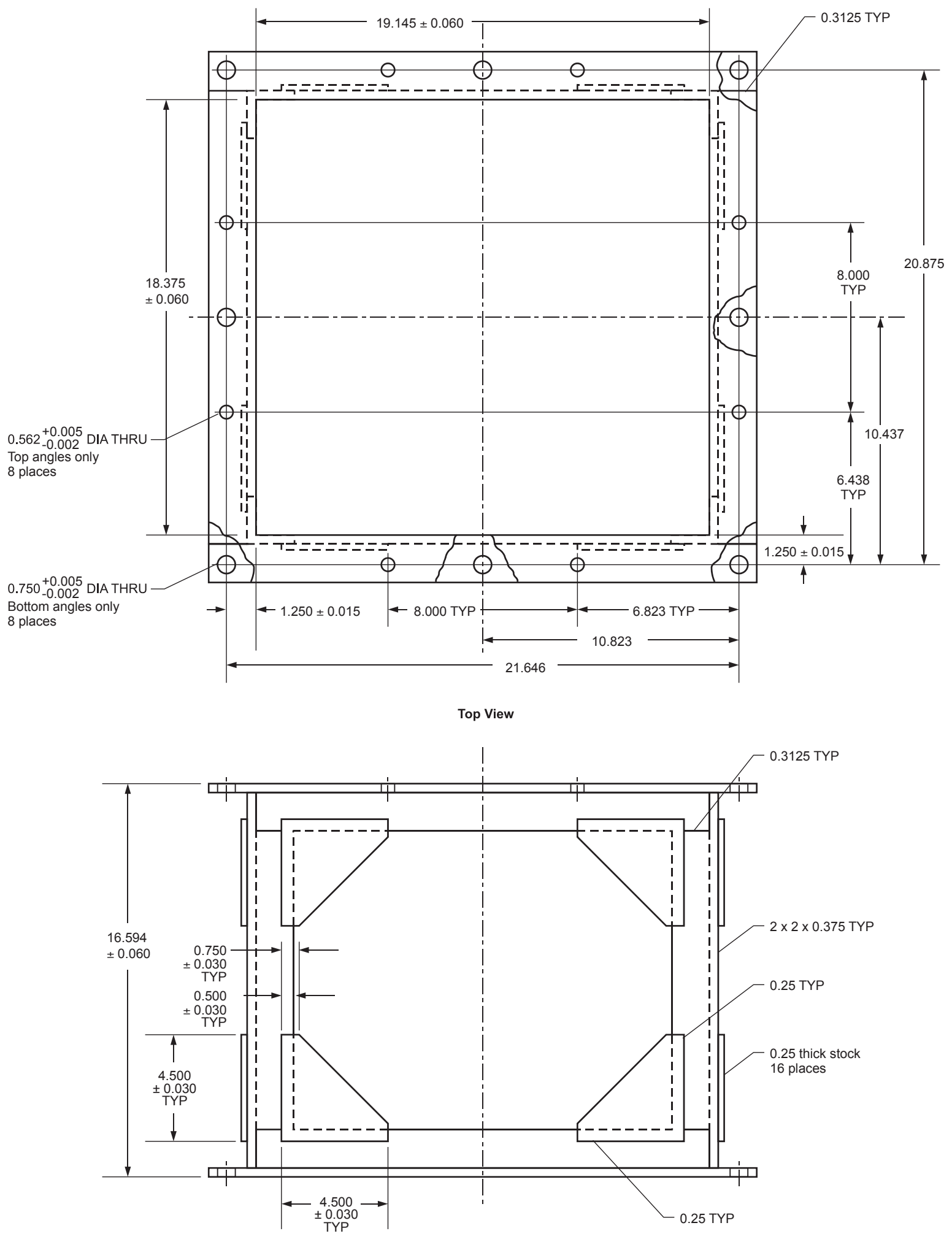

Dimensions in inches

Side View

Figure 1.8. Aluminum Core Support Structure. 


\section{NEA/NSC/DOC(2006)1}

Fundamental - FUND

NRAD-FUND-RESR-002

CRIT-REAC-COEF

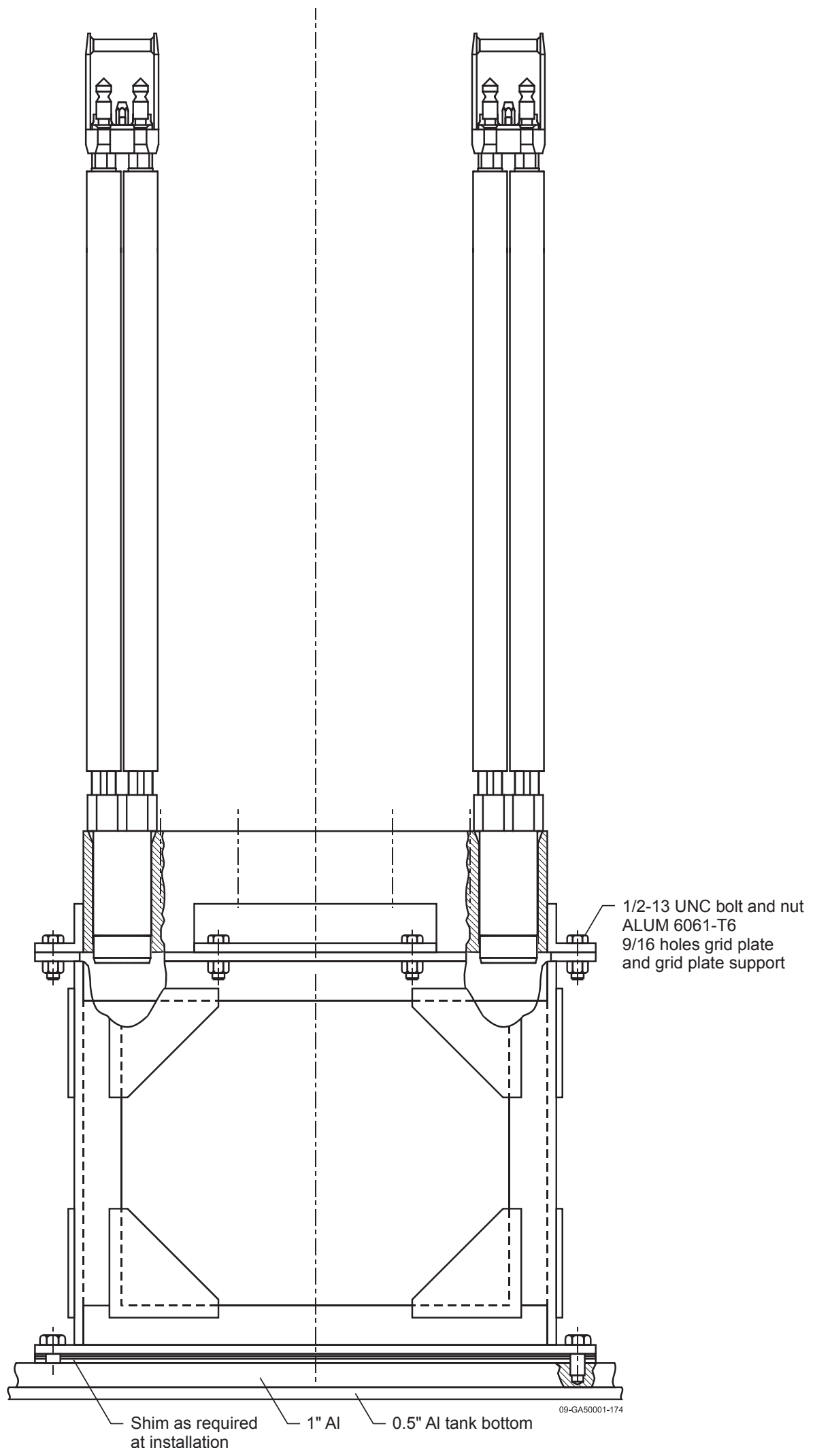

Figure 1.9. Schematic of Core Support Assembly. 


\section{NEA/NSC/DOC(2006)1}

Fundamental - FUND

NRAD-FUND-RESR-002

CRIT-REAC-COEF

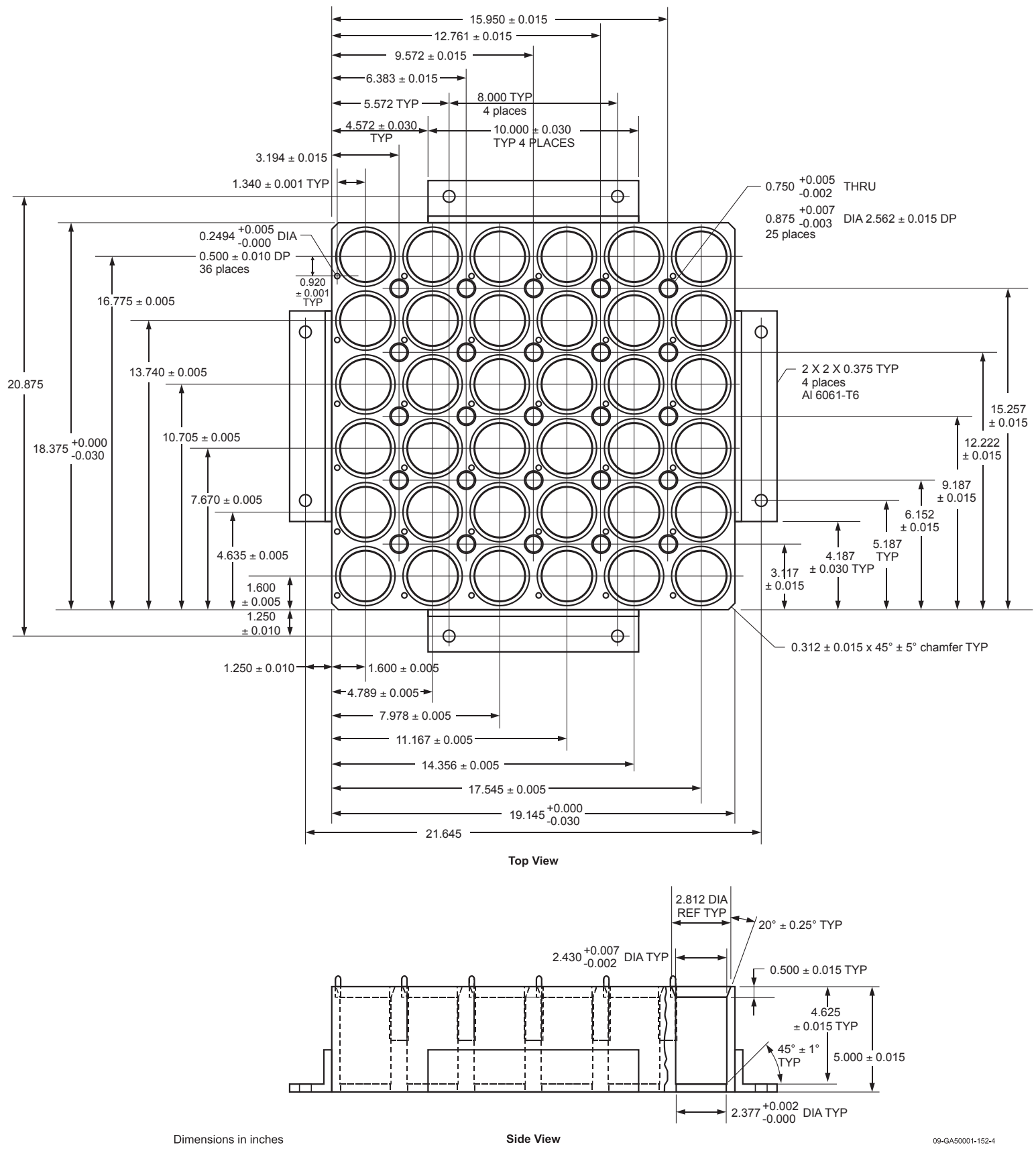

Figure 1.10. Grid Plate Assembly. 
NEA/NSC/DOC(2006)1

Fundamental - FUND

NRAD-FUND-RESR-002

CRIT-REAC-COEF

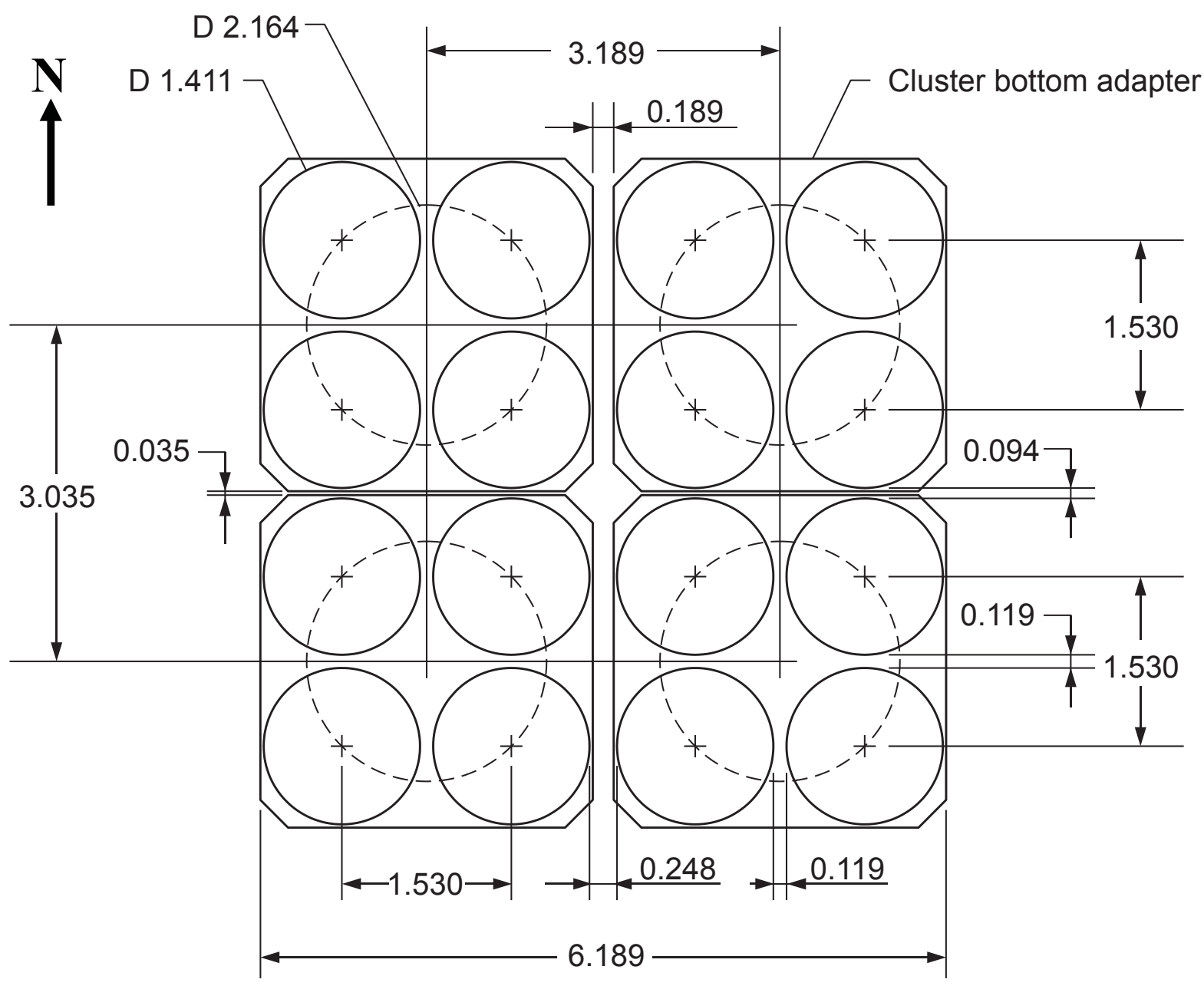

Dimensions in inches

09-GA50001-182

Figure 1.11. Nominal Cluster and Fuel Element Spacing. ${ }^{\mathrm{a}}$

a "NRAD Reactor Fuel Core Conversion," DSA-005-NRAD-ADD-3 rev. 0, Idaho National Laboratory (April 2, 2009). [This reference is not available for public release.] 


\author{
Fundamental - FUND \\ NRAD-FUND-RESR-002 \\ CRIT-REAC-COEF
}

\title{
Fuel Cluster Assembly
}

Conversion cluster assemblies contain two, three, or four TRIGA fuel elements. The three-element variation uses the fourth position to accommodate a control rod or a sample irradiation tube. ${ }^{\mathrm{a}}$ The twoelement variation also utilizes two graphite element reflector rods, and is placed into a core periphery position with the graphite rods on the assembly face away from the core.

Fuel elements are contained within a four-element fuel cluster assembly (Figures 1.12 and 1.13). As depicted in Figure 1.13, the assembly consists of four fuel elements contained within a bottom cluster fitting assembly (Figure 1.14) and a top handle assembly (Figure 1.15). The assembly was designed to fit TRIGA fuel into the conversion reactor grid format. The top handle assembly is comprised of a locking bolt (Figure 1.16), handle with support plate (Figure 1.17), and locking plate (Figure 1.18). The top and bottom end adapters are attached to the fuel elements to hold the clusters together.

A three-element cluster assembly with a guide tube (Figure 1.35) is shown in Figures 1.19 and 1.20. These cluster assemblies (located in grid positions C-2, C-4, D-2, and E-4) allow for the placement and use of either control rods or water-filled sample-irradiation positions within the core. The three-fuelelement top handle assemblies (Figure 1.21) are comprised of special top fittings (Figure 1.22) and locking plates (Figure 1.23) that were designed to accommodate the guide tube. The same bottom adapter (Figure 1.14) and locking bolt (Figure 1.16) used in the four-element cluster assembly are used to complete the three-element cluster assemblies.

A threaded insert (Figure 1.15) is also used in the top assembly. It has a diameter of 0.25 in. $(0.635 \mathrm{~cm})$ and a length of $1.0 \mathrm{in} .(2.54 \mathrm{~cm})$.

\footnotetext{
${ }^{a}$ R. E. Smith, “TRIGA Fuel Summary Report,” ICP/INT-05-817, Idaho Cleanup Project, Idaho National Laboratory (March 2005). [This reference is not available for public release.]
} 
NEA/NSC/DOC(2006)1

Fundamental - FUND

NRAD-FUND-RESR-002

CRIT-REAC-COEF

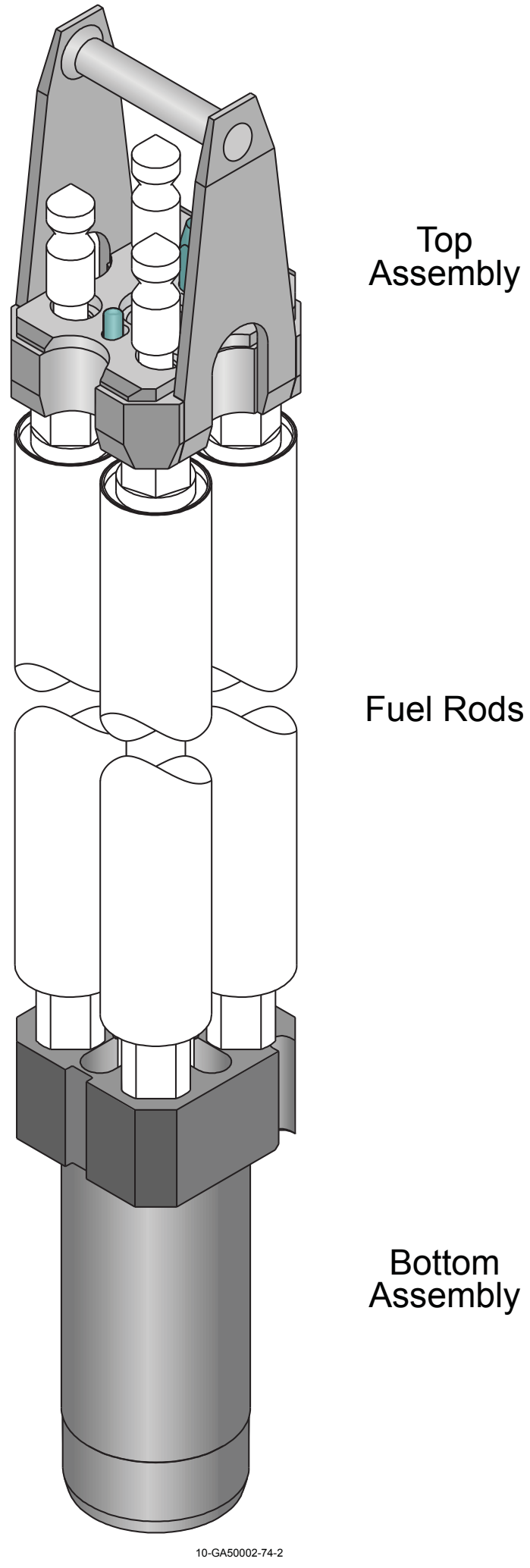

Figure 1.12. Four Fuel Element Cluster Assembly. 
NEA/NSC/DOC(2006)1

Fundamental - FUND

NRAD-FUND-RESR-002

CRIT-REAC-COEF
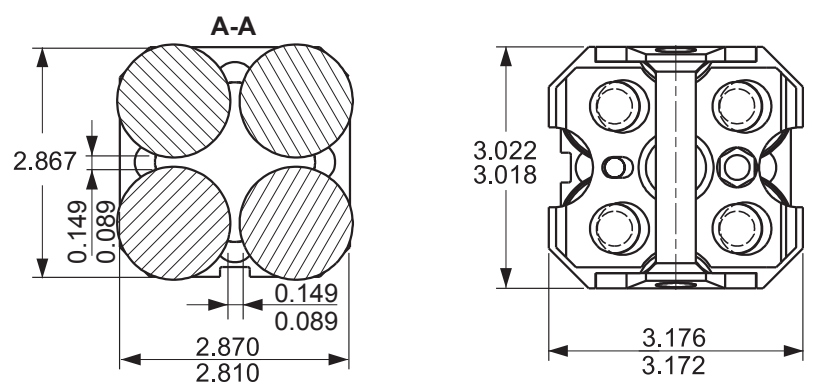

Top

Assembly

Fuel Rods
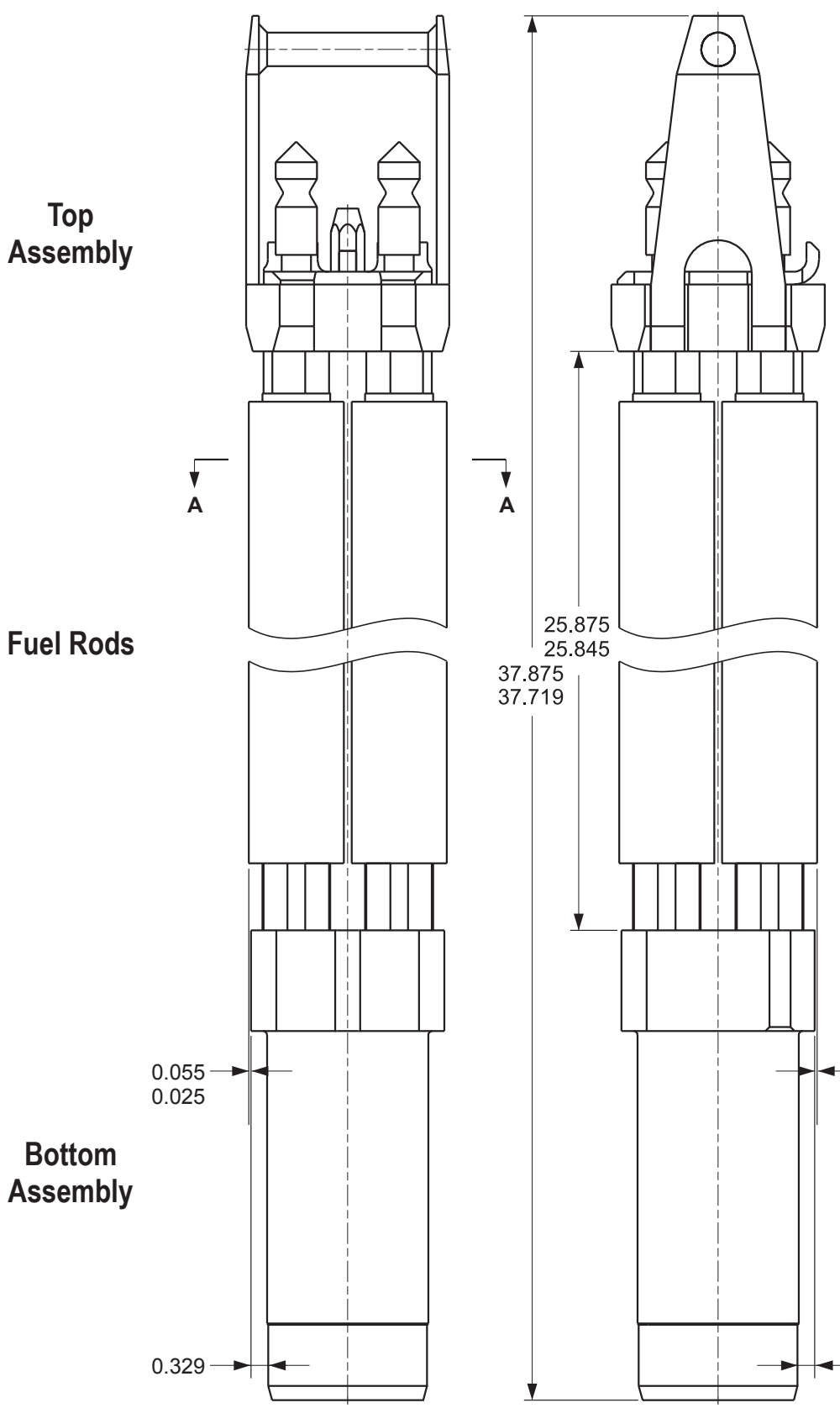

Dimensions in inches

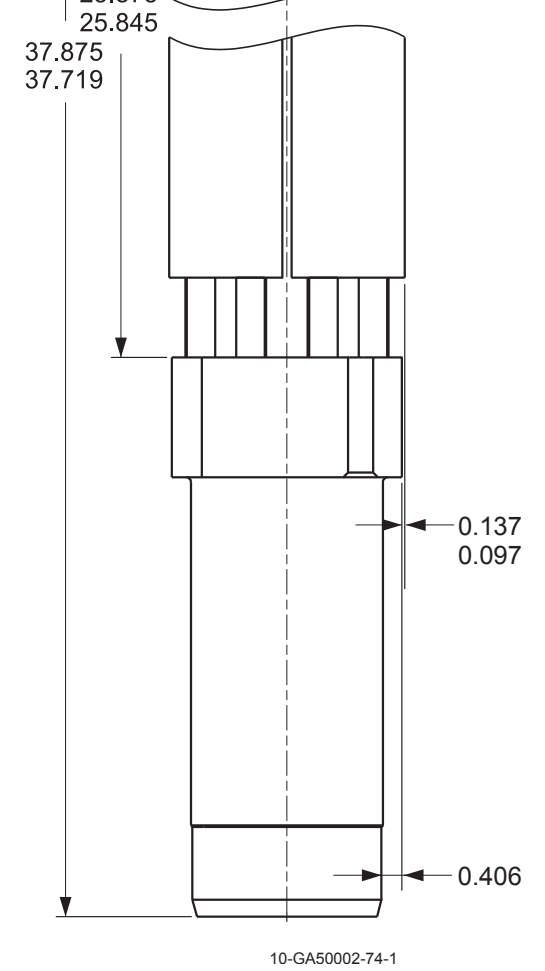

Figure 1.13. Four Fuel Element Cluster Assembly. 


\section{NEA/NSC/DOC(2006)1}

Fundamental - FUND

NRAD-FUND-RESR-002

CRIT-REAC-COEF
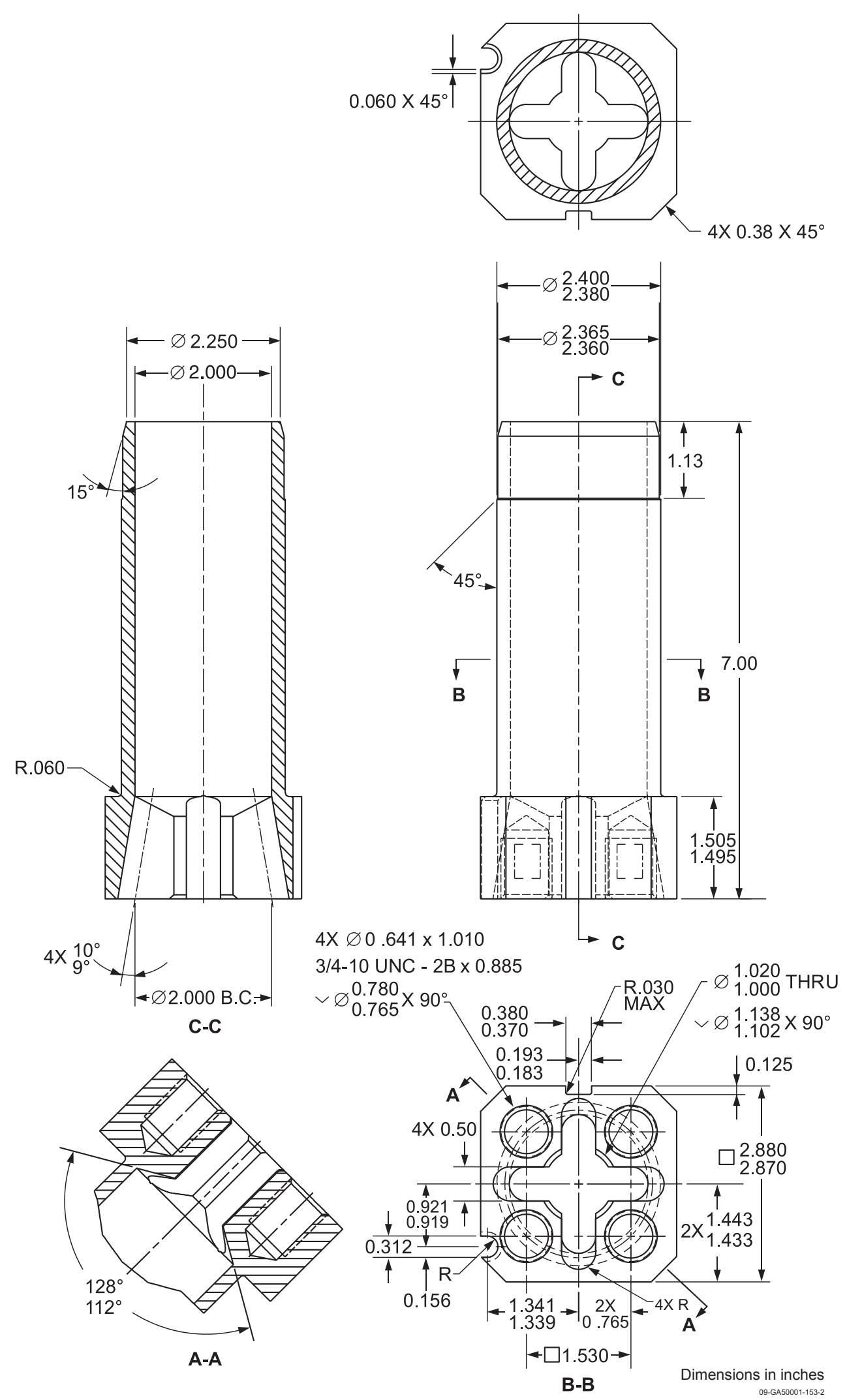

Figure 1.14. Bottom Cluster Fitting Assembly. 
NEA/NSC/DOC(2006)1

Fundamental - FUND

NRAD-FUND-RESR-002

CRIT-REAC-COEF

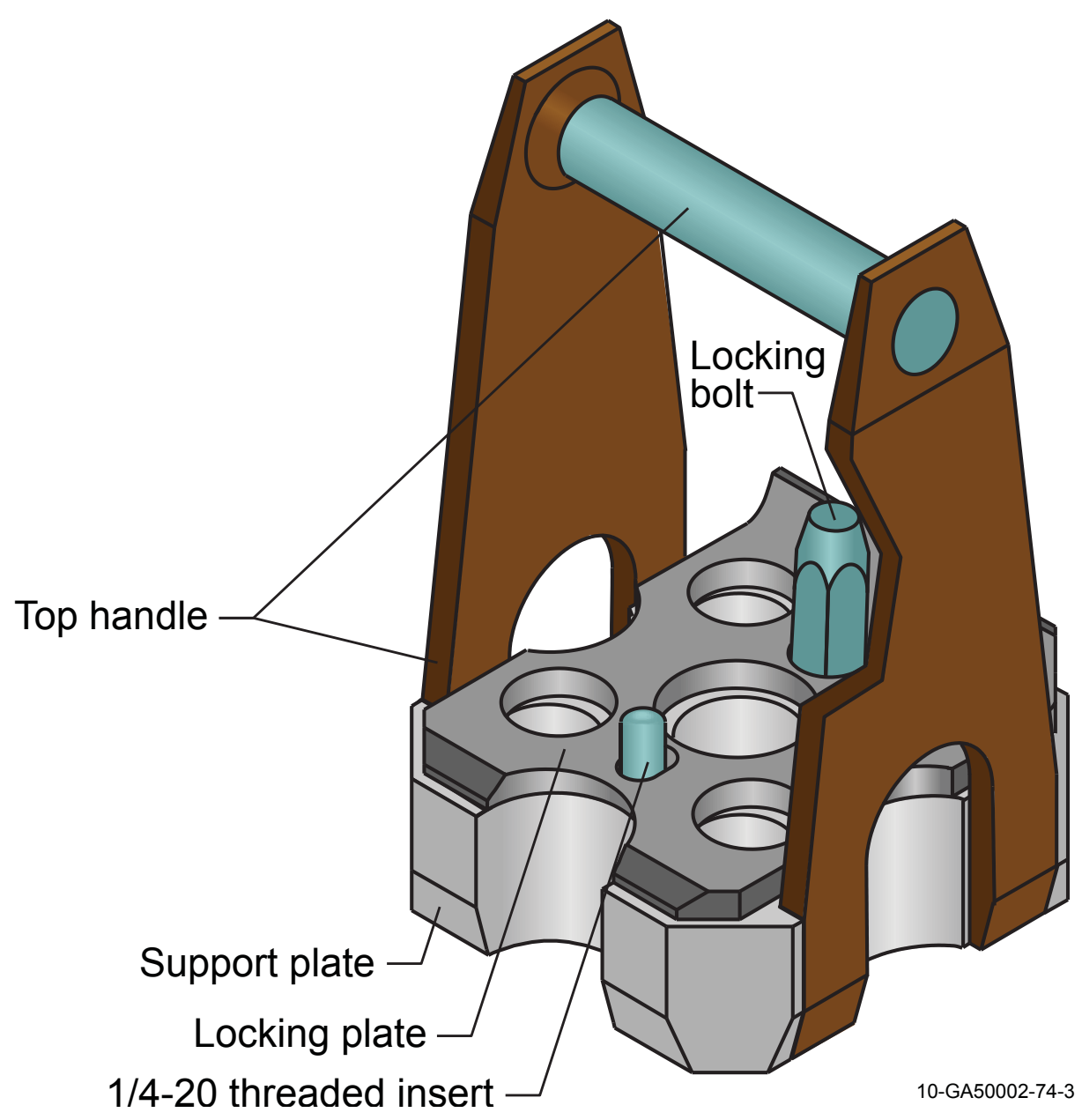

Figure 1.15. Top Handle Assembly for Four Element Cluster Assembly.
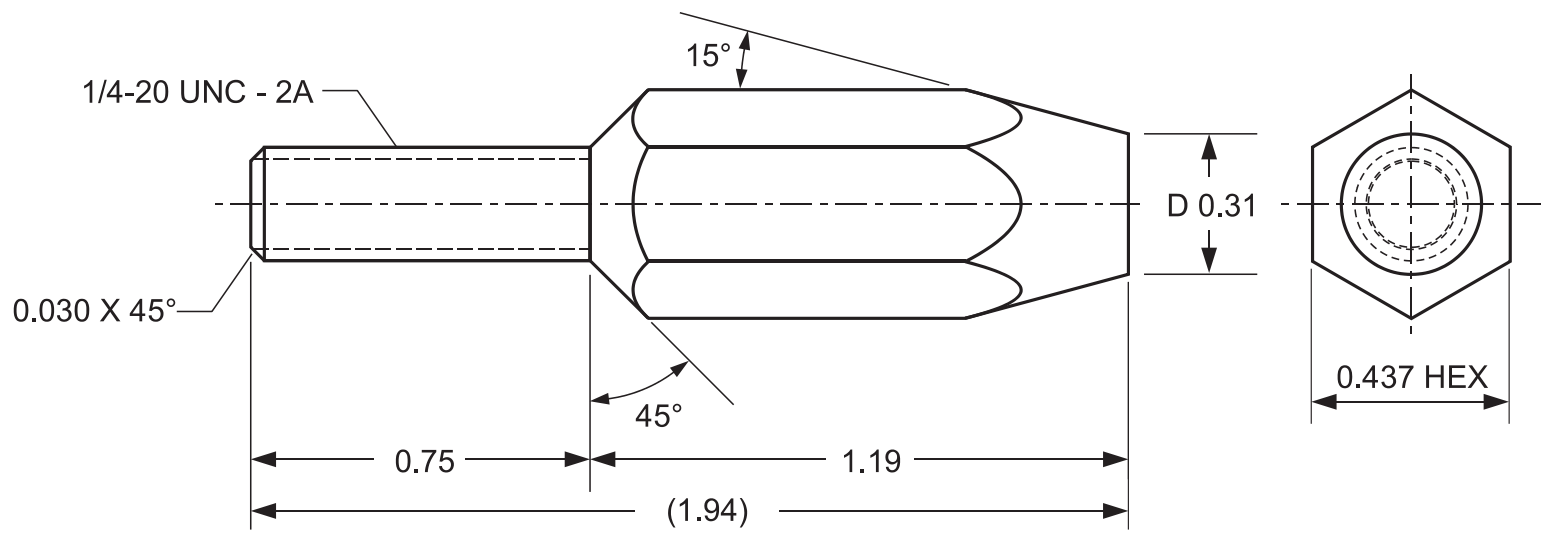

Dimensions in inches

09-GA50001-152-1

Figure 1.16. Locking Bolt for Top Handle Assembly. 


\section{NEA/NSC/DOC(2006)1}

Fundamental - FUND

NRAD-FUND-RESR-002

CRIT-REAC-COEF

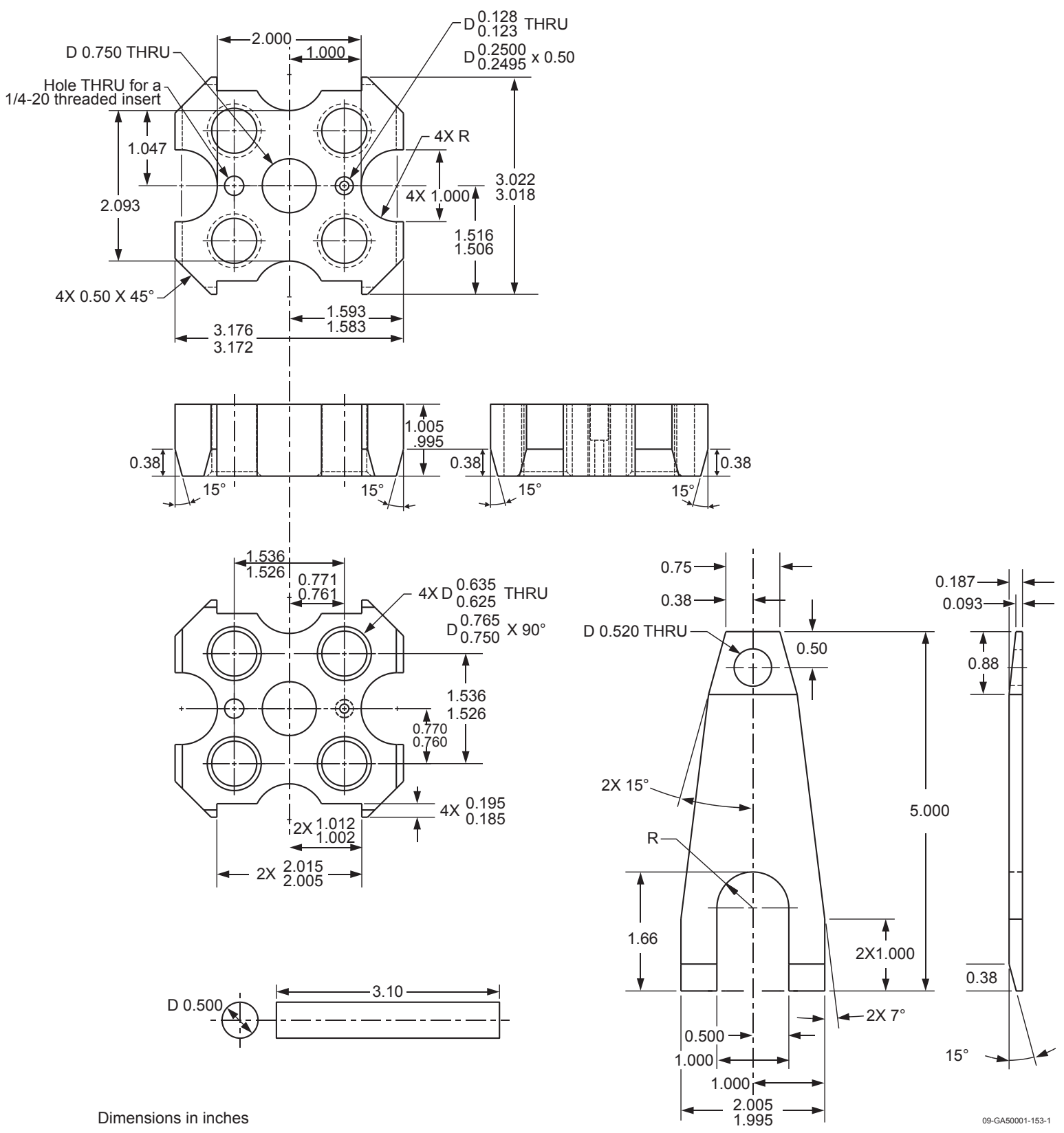

Figure 1.17. Top Handle with Support Plate for Four Element Cluster Assembly. 


\section{NEA/NSC/DOC(2006)1}

Fundamental - FUND

NRAD-FUND-RESR-002

CRIT-REAC-COEF

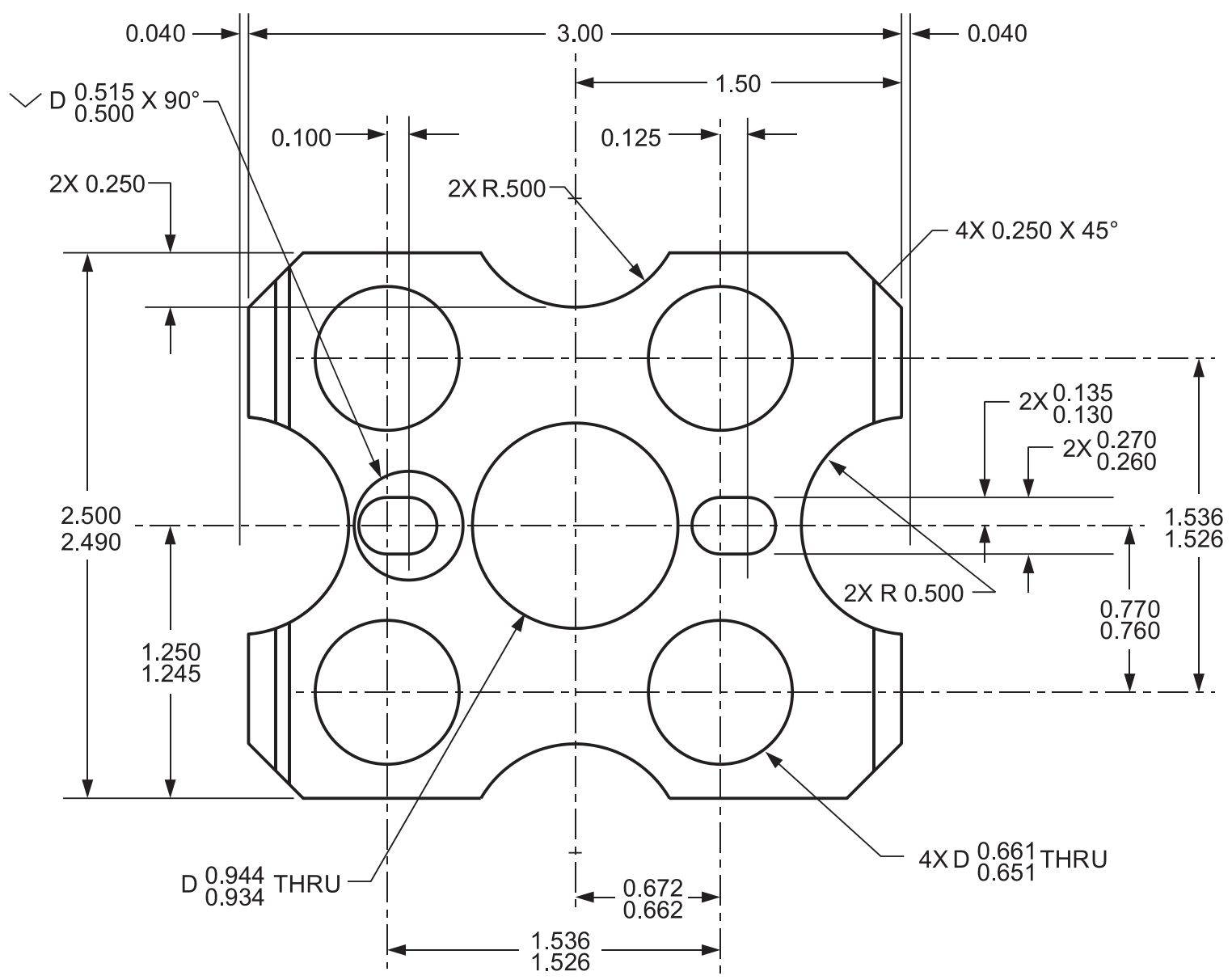

Top View

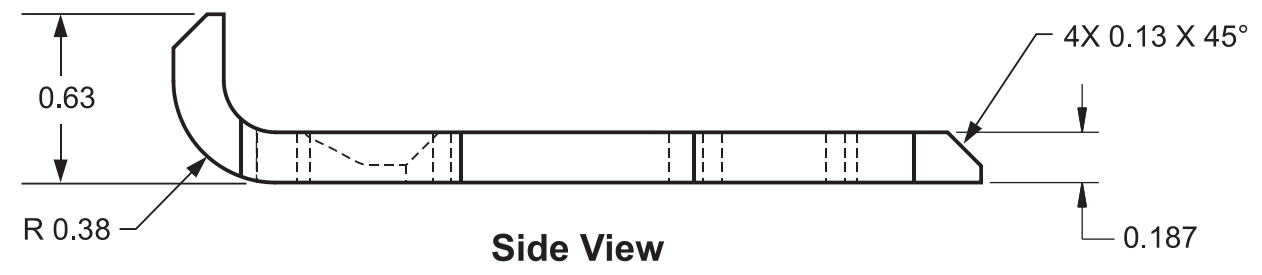

Dimensions in inches

09-GA50001-152-2

Figure 1.18. Locking Plate for Four Element Cluster Assembly. 


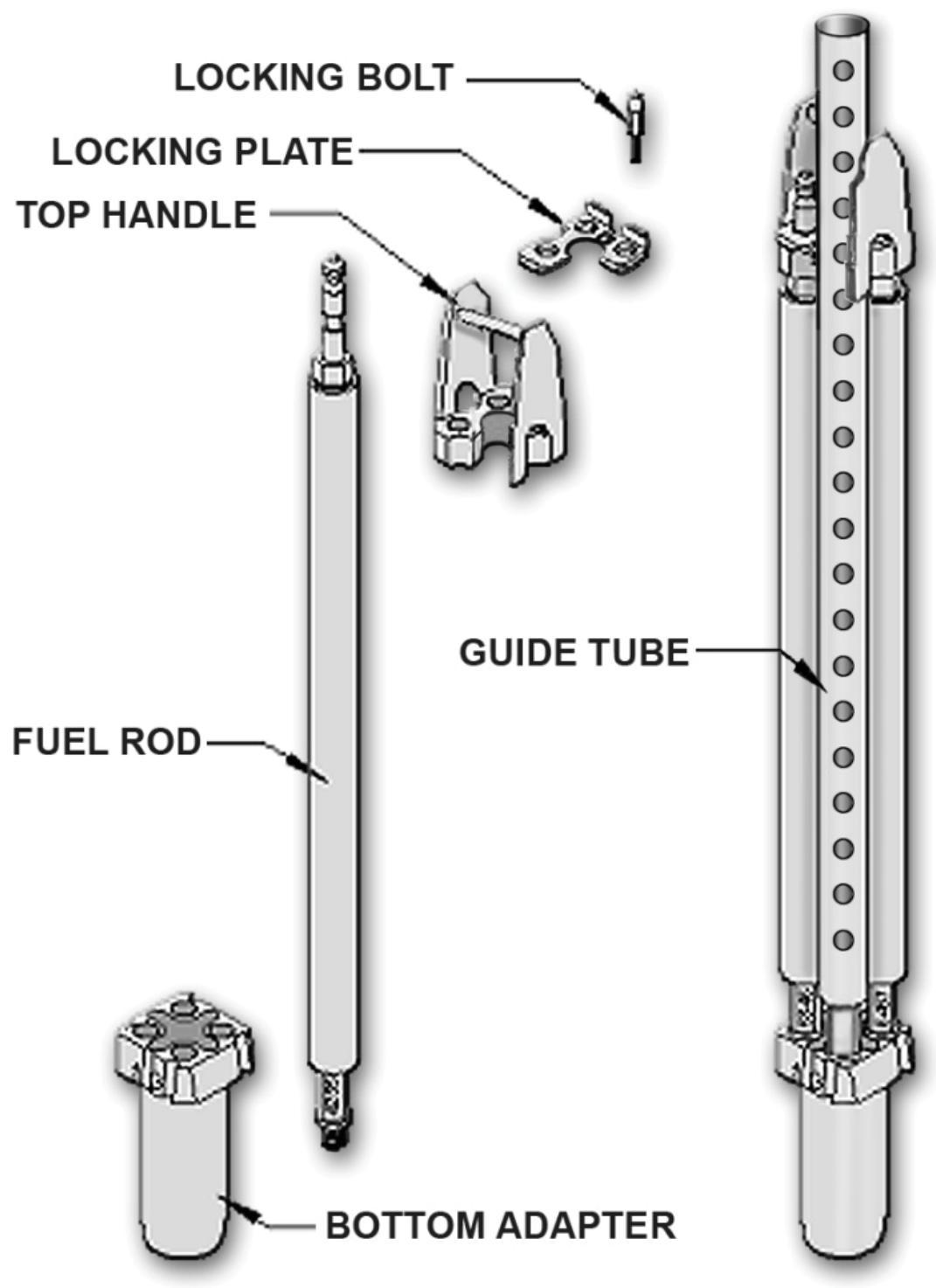

Figure 1.19. Three Fuel Element Cluster Assembly. ${ }^{a}$

(The guide tube is utilized either to guide one of three control rods or as a sample irradiation position.)

a "NRAD Reactor Fuel Core Conversion,” DSA-005-NRAD-ADD-3 rev. 0, Idaho National Laboratory (April 2, 2009). [This reference is not available for public release.] 
NEA/NSC/DOC(2006)1

Fundamental - FUND

NRAD-FUND-RESR-002

CRIT-REAC-COEF

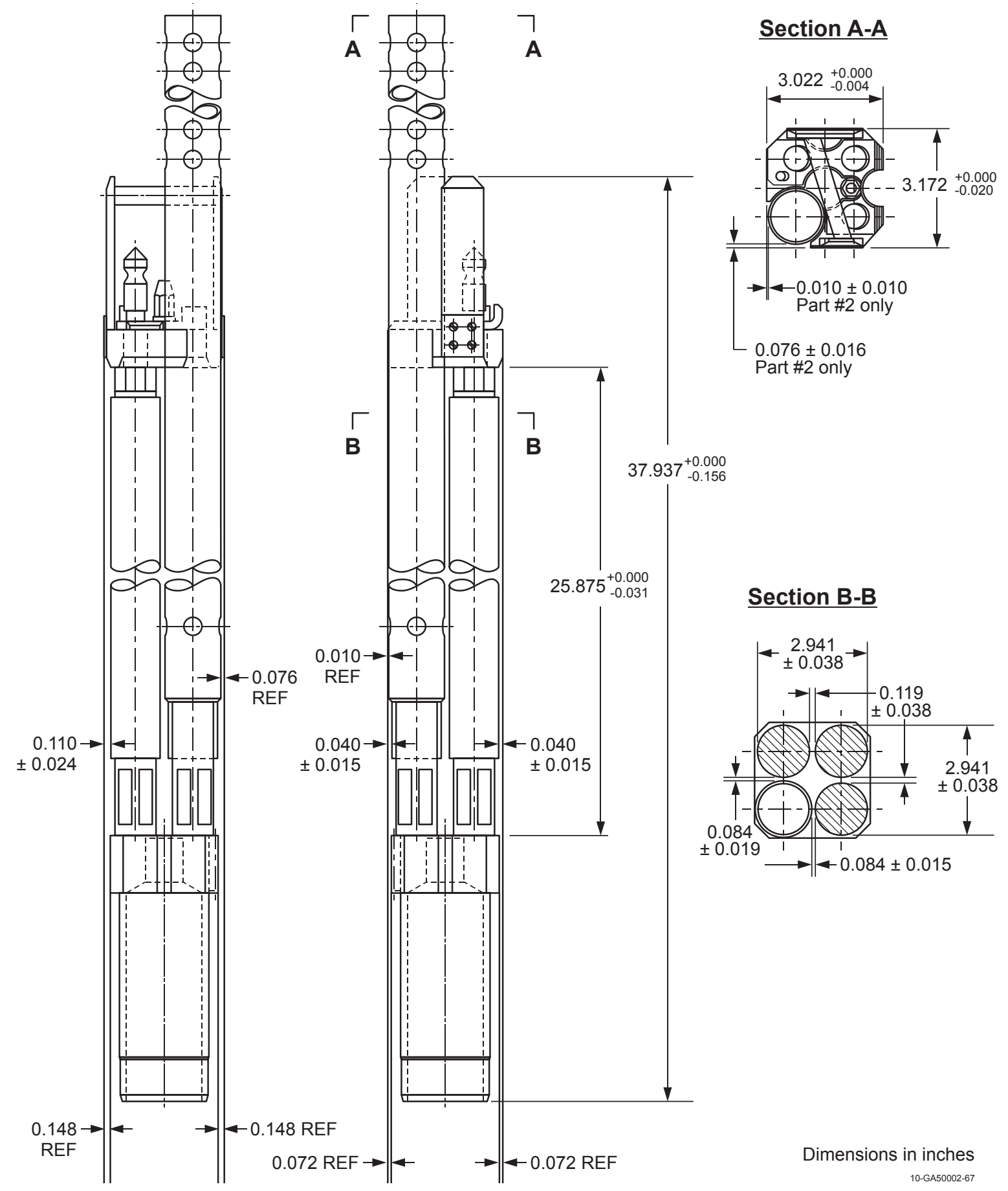

Figure 1.20. Three Fuel Element Cluster Assembly. 
NEA/NSC/DOC(2006)1

Fundamental - FUND

NRAD-FUND-RESR-002

CRIT-REAC-COEF

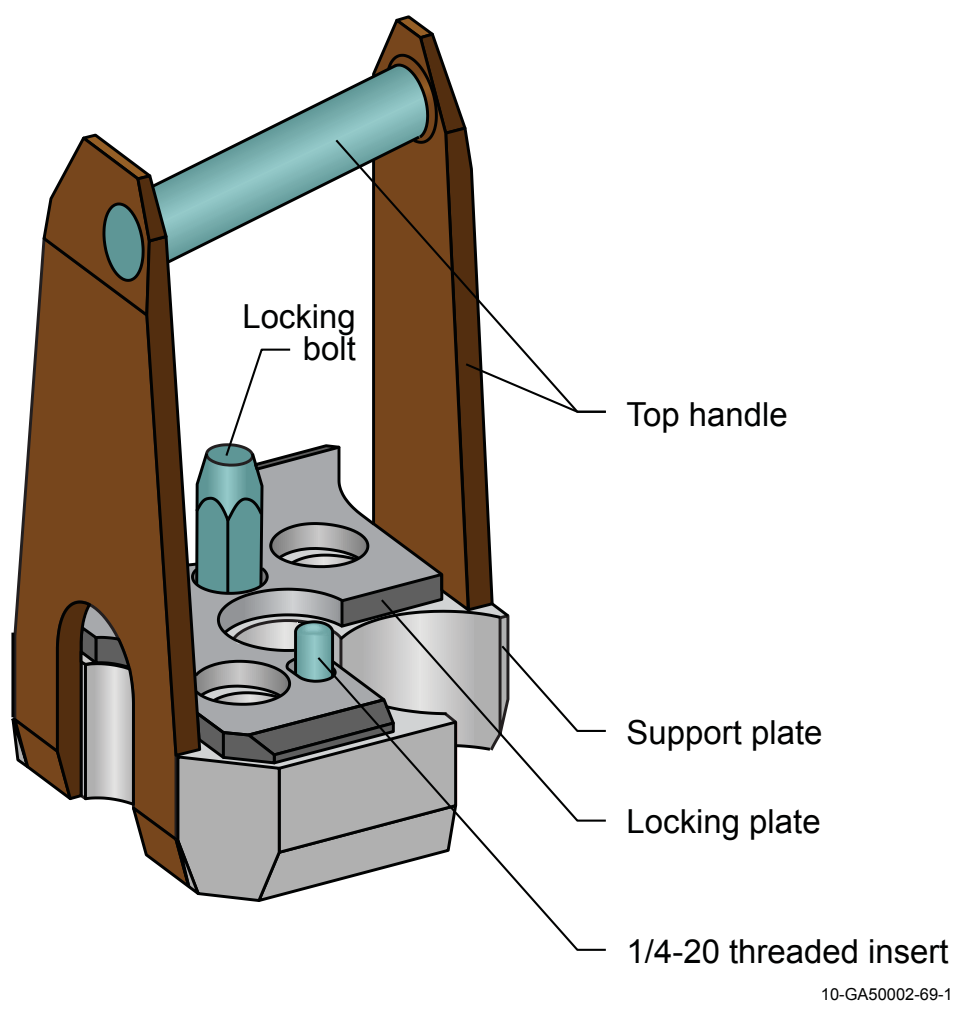

Figure 1.21a. Top Handle Assembly for C2, C4, and E4 Three Element Cluster Assembly.

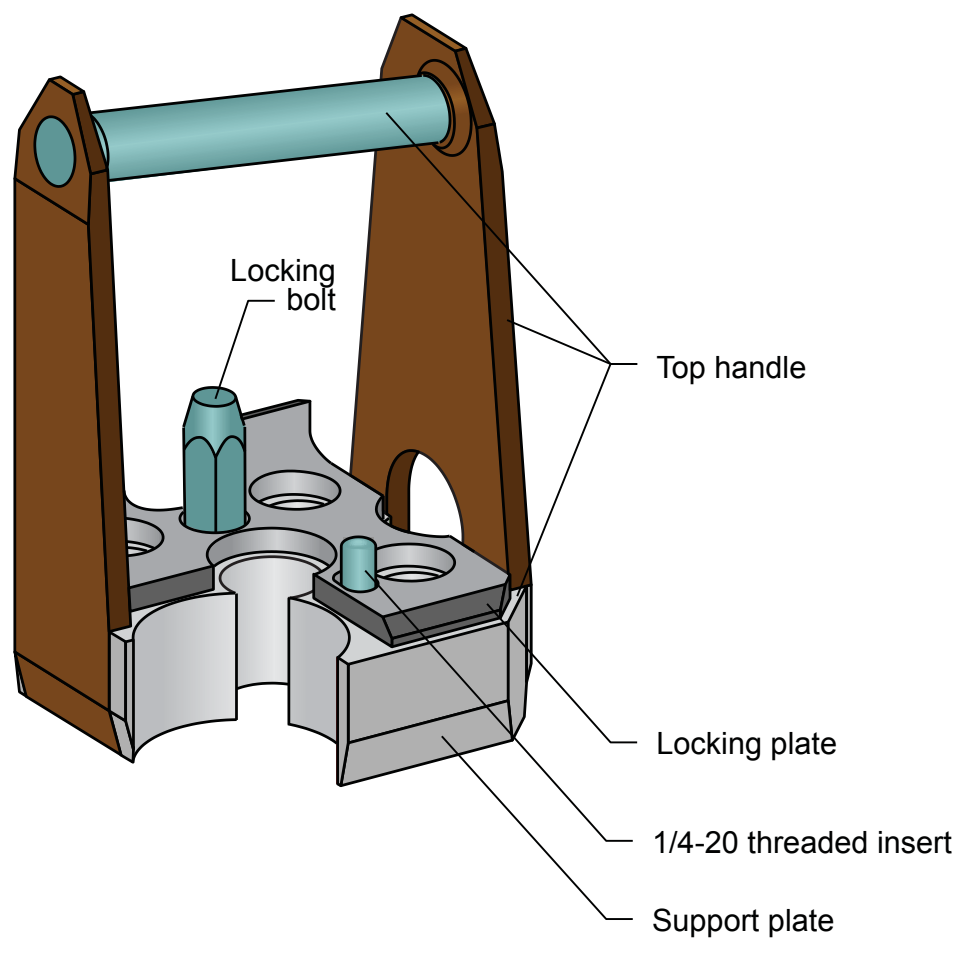

10-GA50002-69-2

Figure 1.21b. Top Handle Assembly for D2 Three Element Cluster Assembly. 
NEA/NSC/DOC(2006)1

Fundamental - FUND

NRAD-FUND-RESR-002

CRIT-REAC-COEF
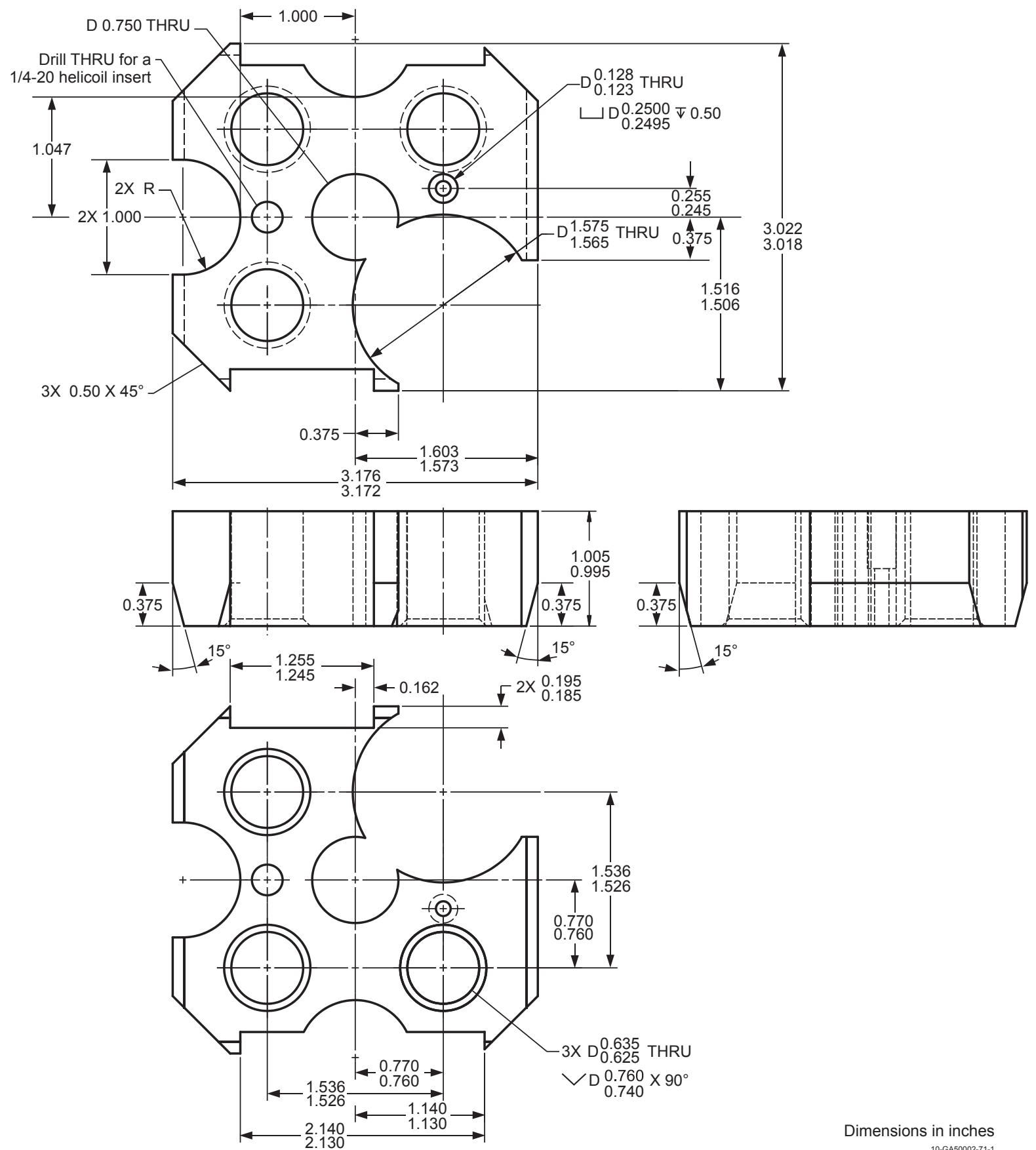

Figure 1.22a. Support Plate for C2, C4, and E4 Three Element Cluster Assembly. 


\section{NEA/NSC/DOC(2006)1}

Fundamental - FUND

NRAD-FUND-RESR-002

CRIT-REAC-COEF
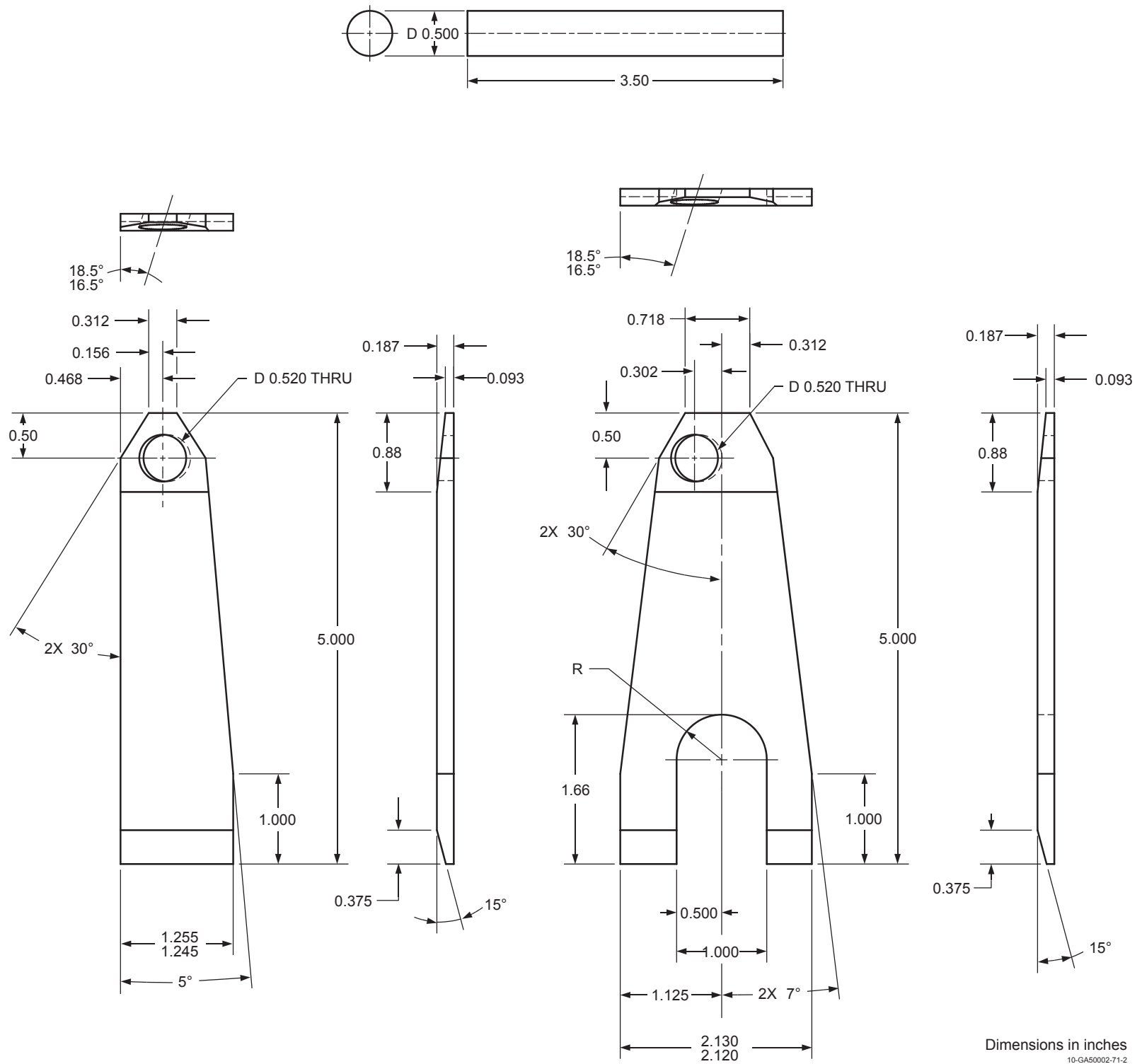

Figure 1.22b. Top Handle for C2, C4, and E4 Three Element Cluster Assembly. 


\section{NEA/NSC/DOC(2006)1}

Fundamental - FUND

NRAD-FUND-RESR-002

CRIT-REAC-COEF
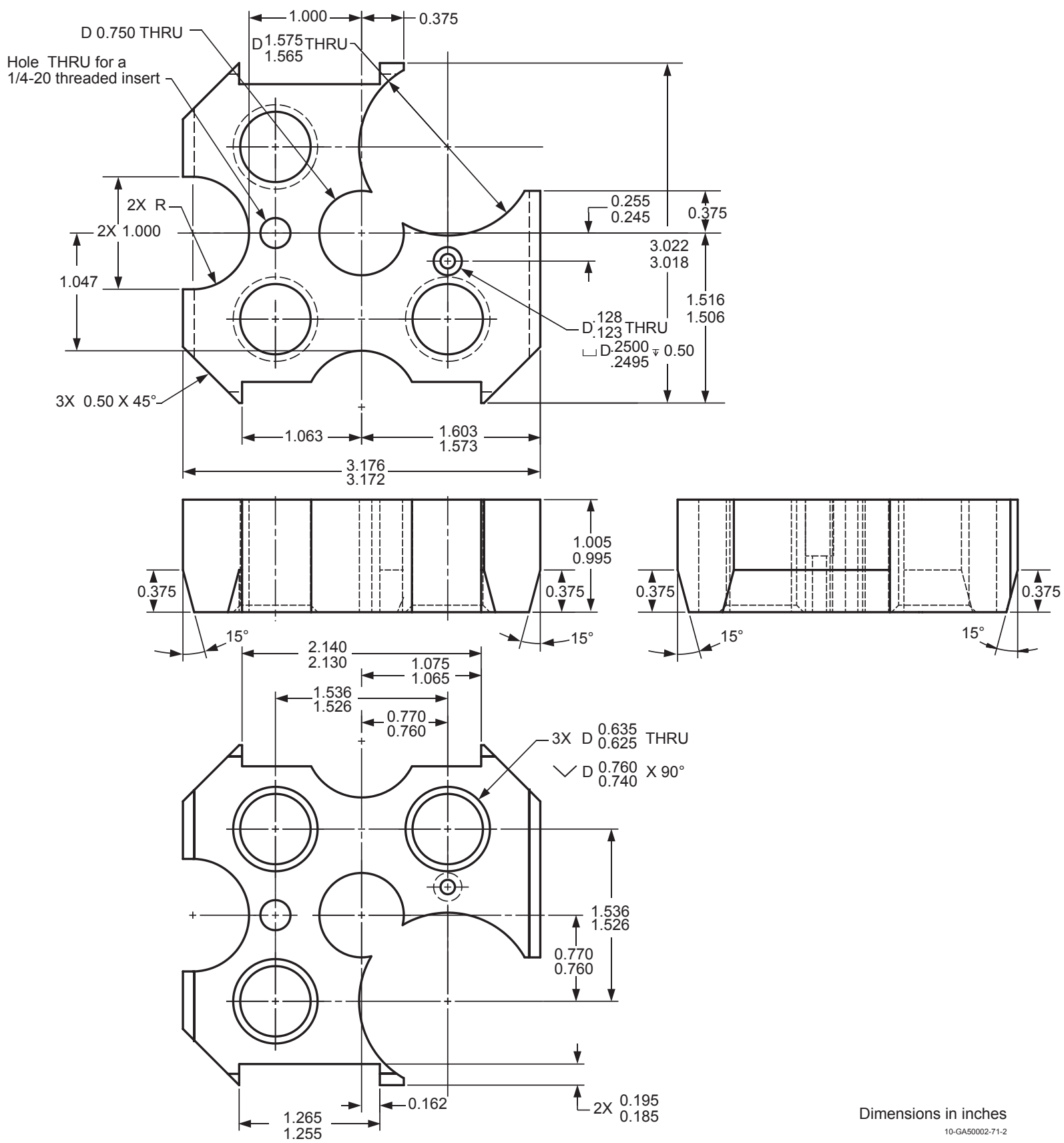

Dimensions in inches

Figure 1.22c. Support Plate for D2 Three Element Cluster Assembly. 


\section{NEA/NSC/DOC(2006)1}

Fundamental - FUND

NRAD-FUND-RESR-002

CRIT-REAC-COEF
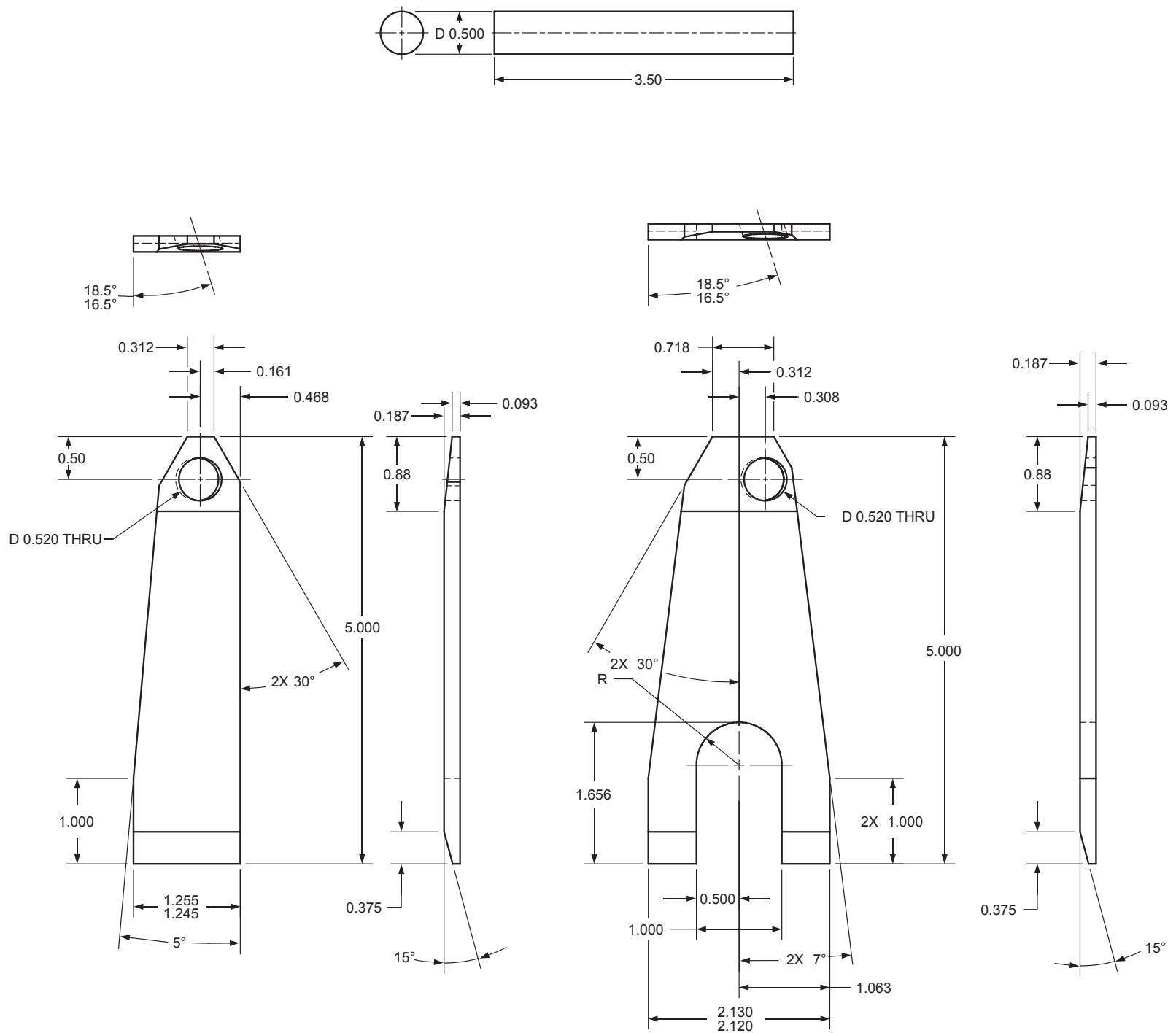

Dimensions in inches

Figure 1.22d. Top Handle for D2 Three Element Cluster Assembly. 


\section{NEA/NSC/DOC(2006)1}

Fundamental - FUND

NRAD-FUND-RESR-002

CRIT-REAC-COEF
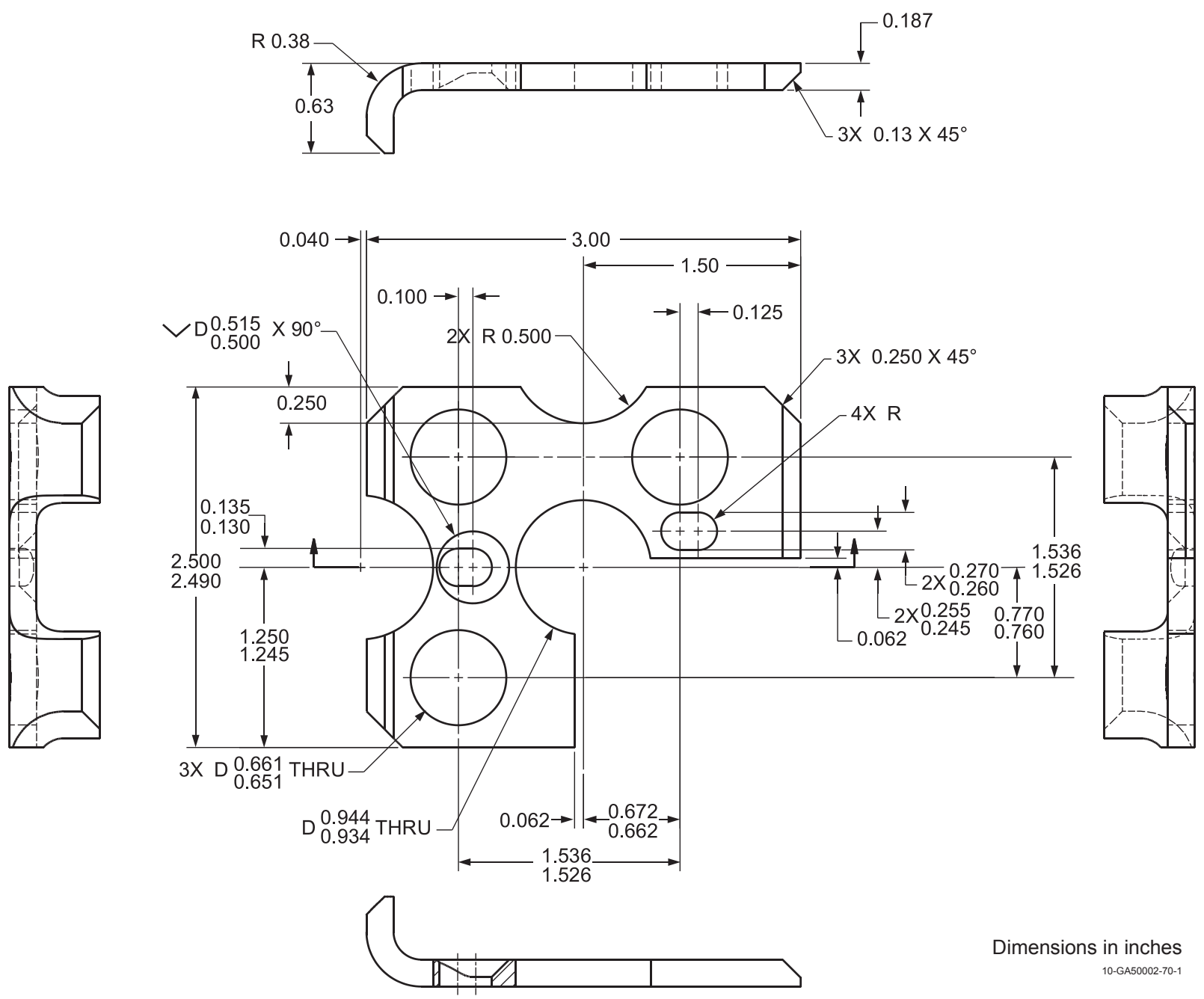

Figure 1.23a. Locking Plate for C2, C4, and E4 Three Element Cluster Assembly. 


\section{NEA/NSC/DOC(2006)1}

Fundamental - FUND

NRAD-FUND-RESR-002

CRIT-REAC-COEF

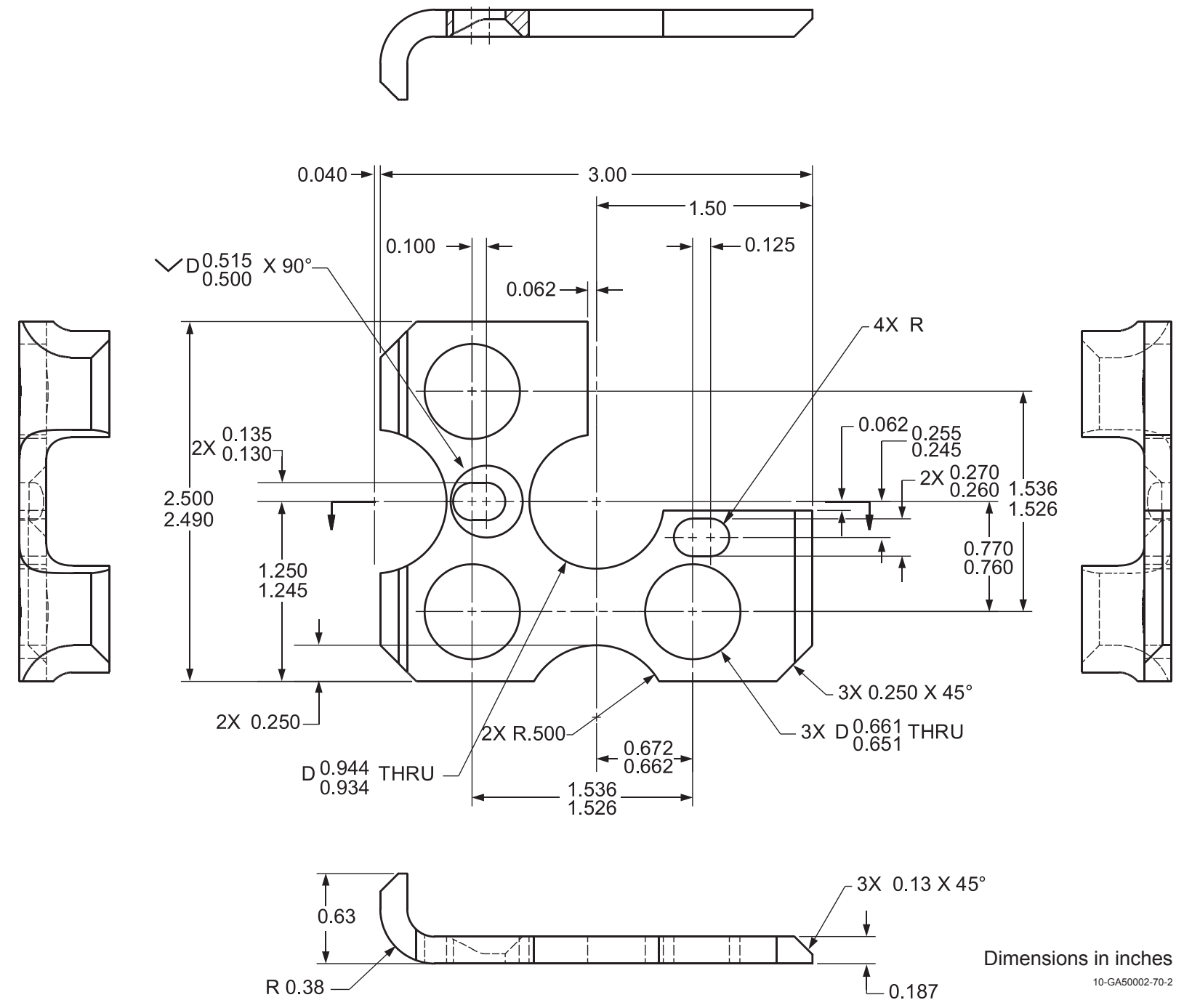

Figure 1.23b. Locking Plate for D2 Three Element Cluster Assembly. 


\section{Fuel Elements}

The fuel is a mixture of uranium, erbium, and zirconium hydride. The uranium is enriched to approximately $19.75 \mathrm{wt} . \%$ in ${ }^{235} \mathrm{U}$ and is approximately $30 \mathrm{wt} . \%$ of the fuel, thus the nomenclature TRIGA LEU (30/20). The elements contain a uniform dispersion of $0.9 \mathrm{wt} . \%$ natural erbium that is used as a burnable poison to offset initial reactivity of the fresh fuel and contribute to the prompt negative temperature coefficient. A hole is drilled through the center of the active fuel section to facilitate hydriding of the fuel, and later filled with a zirconium rod. The zirconium rod provides structural support and prevents fuel damage during reactor operations due to fuel expansion. Finally they are clad with stainless steel. ${ }^{\mathrm{a}}$

A typical fuel element design is shown in Figure 1.24. The fuel element (sometimes referred to as rod) is comprised of three fuel pellets (Figure 1.25), with a zirconium rod in each (Figure 1.26), a molybdenum poison disc (Figure 1.27), and two graphite axial reflectors (Figure 1.28). These components are contained within stainless steel 304 cladding with welded top (Figure 1.29) and bottom (Figure 1.30) end fittings.

Typical design parameters for the LEU fuel to be used in the NRAD reactor are found in Tables 1.1 through 1.4. There are some discrepancies and duplication of data in these four tables. It should be noted that these parameters are typical for the TRIGA fuel used in the NRAD reactor and are reported in various documentation utilized with NRAD operations and analyses.

The gap between the fuel and cladding initially results in higher fuel temperatures for LEU TRIGA fuel. It closes over time due to burnup and fuel swelling due to fission product accumulation. ${ }^{\text {b }}$

\footnotetext{
a "NRAD Reactor Fuel Core Conversion," DSA-005-NRAD-ADD-3 rev. 0, Idaho National Laboratory (April 2, 2009). [This reference is not available for public release.]

${ }^{\mathrm{b}}$ Personal communication with John M. Bolin at General Atomics (April 22, 2010). 


\section{NEA/NSC/DOC(2006)1}

Fundamental - FUND

NRAD-FUND-RESR-002

CRIT-REAC-COEF

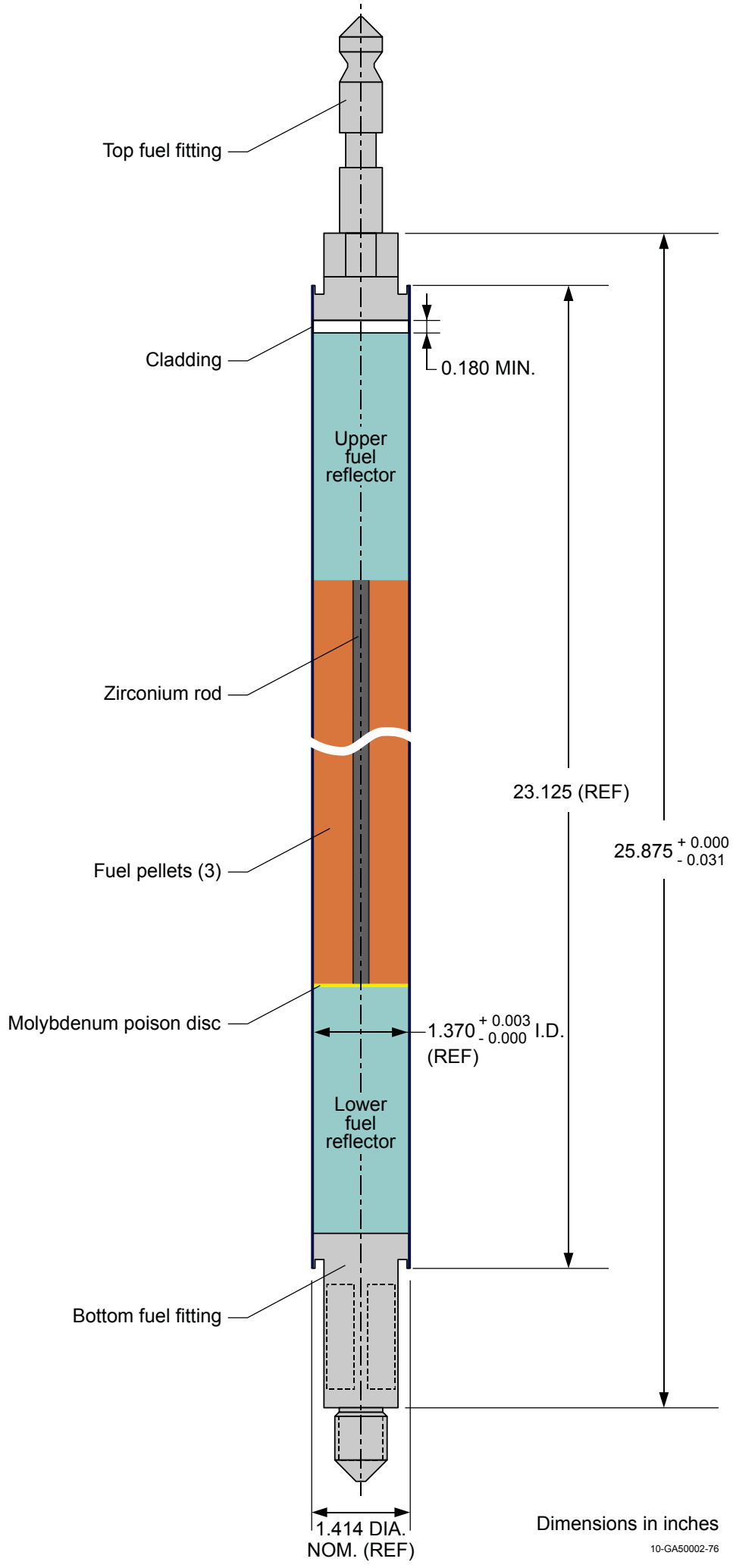

Figure 1.24. Typical TRIGA Fuel Element. 


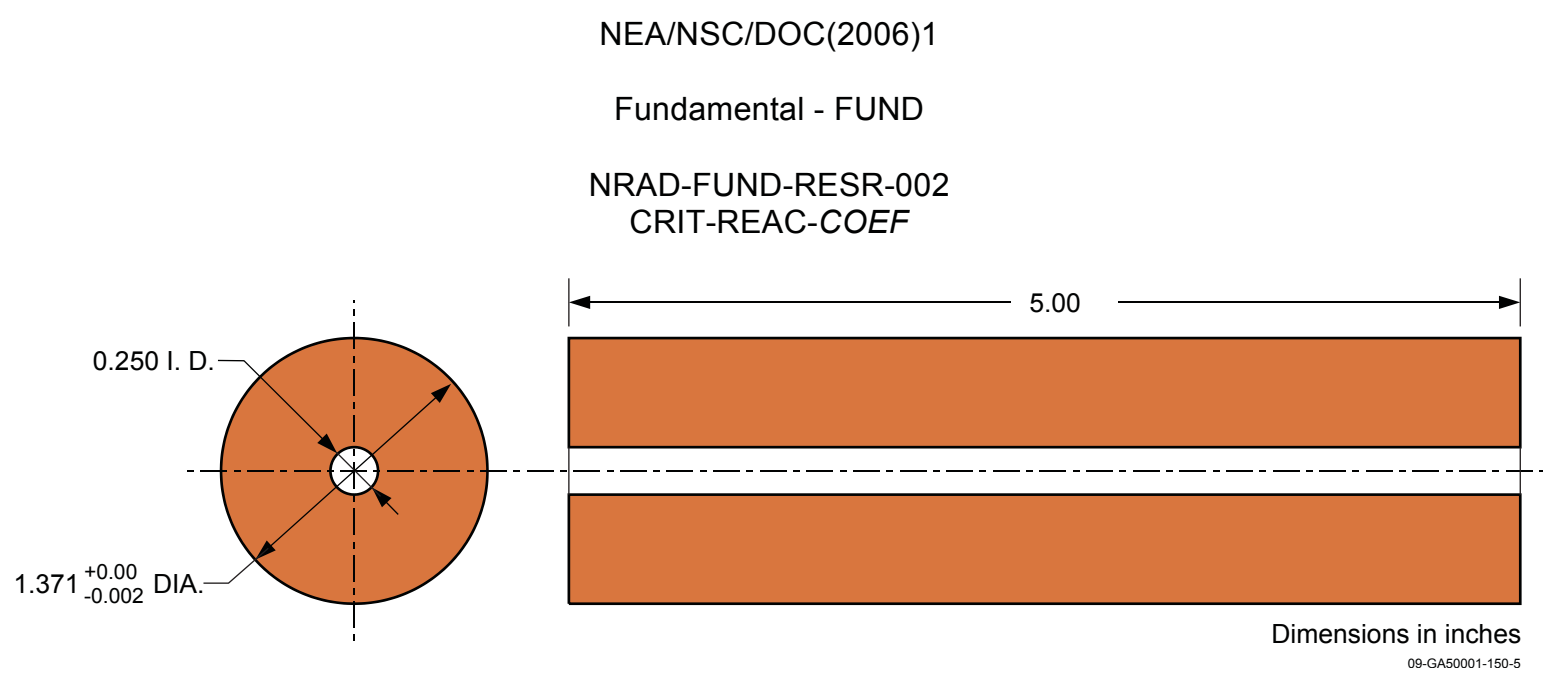

Figure 1.25. Fuel Pellet.

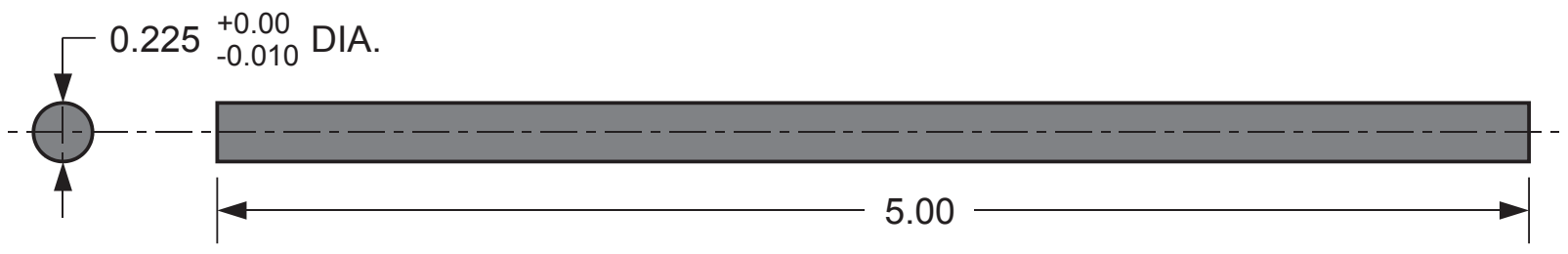

Dimensions in inches

Figure 1.26. Zirconium Rod.

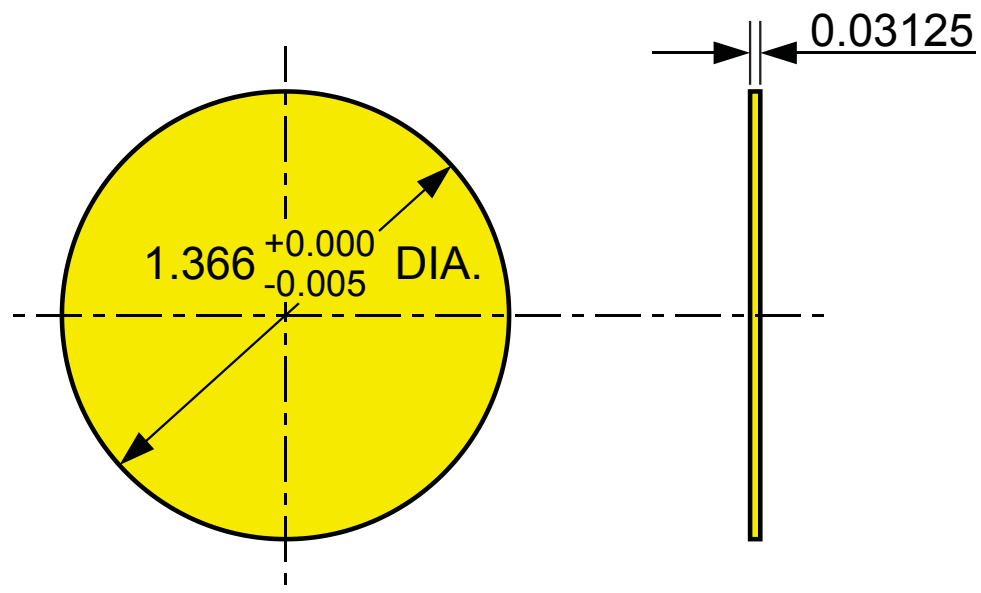

Dimensions in inches

09-GA50001-150-3

Figure 1.27. Molybdenum Poison Disc. 


\section{NEA/NSC/DOC(2006)1}

Fundamental - FUND

NRAD-FUND-RESR-002

CRIT-REAC-COEF

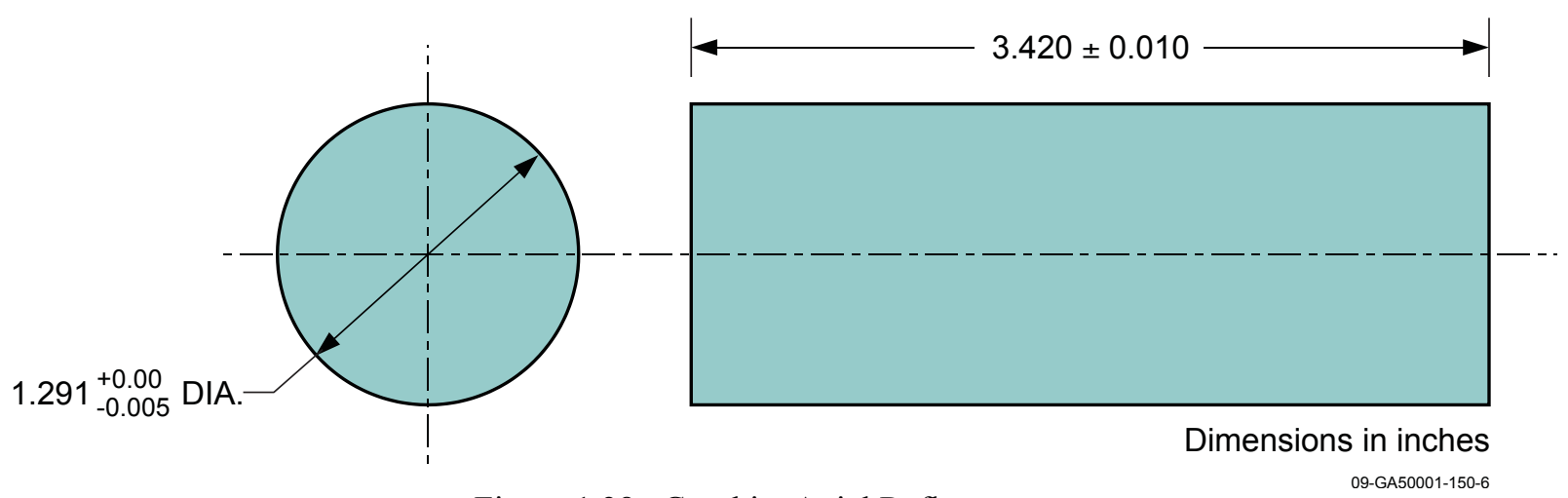

Figure 1.28. Graphite Axial Reflector.

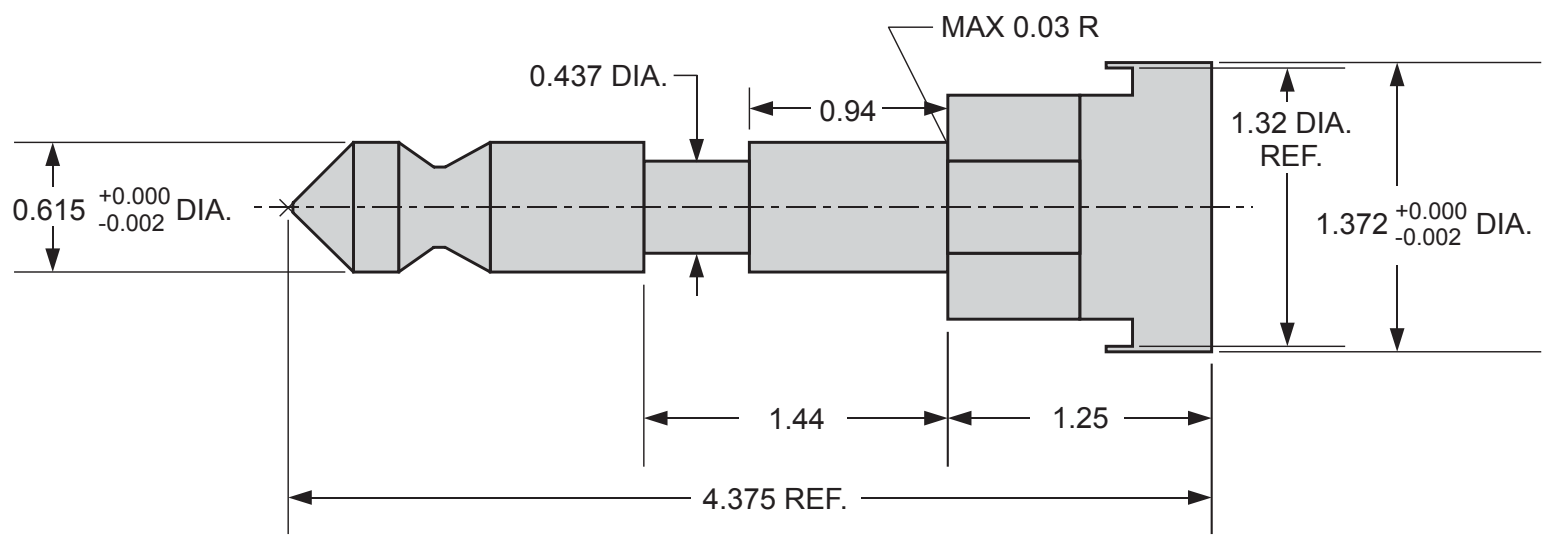

Dimensions in inches

Figure 1.29. Top Fuel Fitting.

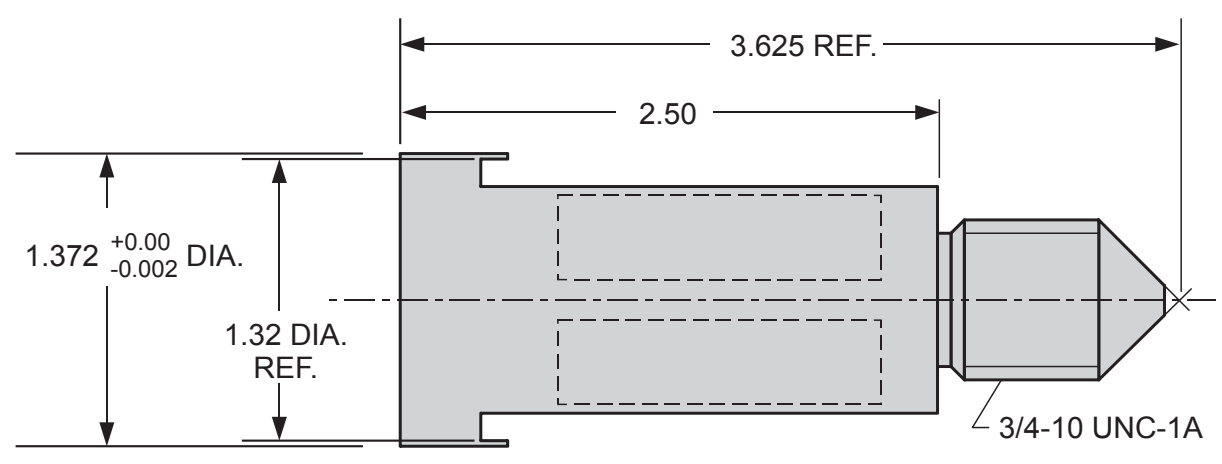

Dimensions in inches

Figure 1.30. Bottom Fuel Fitting. 
Table 1.1. Typical Fuel (30/20) Element Specifications. ${ }^{(a)}$

\begin{tabular}{|c|c|}
\hline Uranium Content (wt.\%) & 30 \\
\hline${ }^{235}$ U Enrichment (wt.\%) & 20 \\
\hline Fuel Meat Length & 15 in. $(38.1 \mathrm{~cm})$ \\
\hline Fuel Meat Outer Diameter & 1.371 in. $(3.48234 \mathrm{~cm})$ \\
\hline Uranium Mass (g) & 750.16 \\
\hline${ }^{235} \mathrm{U}$ Mass (g) & 149 \\
\hline Hydrogen to Zirconium Ratio & 1.6 \\
\hline Erbium Content (wt.\%) & 0.8916 \\
\hline Zirconium Rod Length & 15 in. $(38.1 \mathrm{~cm})$ \\
\hline Zirconium Rod Diameter & 0.225 in. $(0.5715 \mathrm{~cm})$ \\
\hline Overall Element Length & 30.13 in. $(76.5302 \mathrm{~cm})$ \\
\hline Overall Element Outer Diameter & 1.48 in. $(3.7592 \mathrm{~cm})$ \\
\hline Cladding Thickness & 0.02 in. $(0.0508 \mathrm{~cm})$ \\
\hline Graphite Reflector Length (Top/Bottom) & 3.42 in. $(8.6868 \mathrm{~cm}) / 3.42$ in. $(8.6868 \mathrm{~cm})$ \\
\hline Graphite Reflector Outer Diameter & 1.291 in. $(3.27914 \mathrm{~cm})$ \\
\hline Molybdenum Disc? & Yes \\
\hline Number of U-Zr-H and Zr-Rod Sections & 3 \\
\hline
\end{tabular}

(a) L. M. Montierth, "Criticality Safety Evaluation for the NRAD Core Conversion," INL/INT-07-13231 rev. 1, Idaho National Laboratory (September 2008). [This reference is not available for public release.] 
Fundamental - FUND

NRAD-FUND-RESR-002

CRIT-REAC-COEF

Table 1.2. Typical NRAD LEU (30/20) Fuel Design Parameters. ${ }^{(a)}$

\begin{tabular}{|c|c||}
\hline Number of Fuel Elements & 60 \\
Firconium Rod Diameter & UZrH-Er \\
Fuel Meat Outer Diameter & $5.715 \mathrm{~mm}$ \\
Fuel Meat Length & $34.823 \mathrm{~mm}$ \\
Clad Thickness & $381 \mathrm{~mm}$ \\
Clad Material & $0.508 \mathrm{~mm}$ \\
Total Uranium (wt.\%) & $304 \mathrm{SS}$ \\
Uranium Density (g/cm $\left.{ }^{\mathbf{3}}\right)$ & 30.0 \\
Weight of ${ }^{\mathbf{2 3 5}} \mathbf{U}$ (g) & 2.14 \\
Weight of ${ }^{\mathbf{2 3 8}} \mathbf{U}$ (g) & 149.32 \\
Uranium Enrichment (wt.\%) & 599.33 \\
Total Fuel Weight (g) & 19.75 \\
Erbium (wt.\%) & 2519 \\
\hline \hline
\end{tabular}

(a) "NRAD Reactor Fuel Core Conversion," DSA-005-NRAD-ADD-3 rev. 0, Idaho National Laboratory (April 2, 2009). [This reference is not available for public release.] 
NRAD-FUND-RESR-002

CRIT-REAC-COEF

Table 1.3. Additional NRAD LEU (30/20) Fuel Design Data. ${ }^{(a)}$

\begin{tabular}{|c|c|}
\hline Number of Fuel Elements - Critical Test & $53^{(\mathrm{c})}$ \\
\hline Number of Fuel Elements - Full Load & $60 / 64$ \\
\hline Fuel Type & UZrH-Er $(30 / 20)$ \\
\hline Enrichment (\%) & 19.75 \\
\hline Uranium Density $\left(\mathrm{g} / \mathrm{cm}^{3}\right)$ & 2.14 \\
\hline Uranium Density (wt.\%) & 30 \\
\hline Number of Fuel Elements per Cluster & 4 \\
\hline${ }^{235} \mathbf{U}$ per Fuel Cluster (g) & 592.43 \\
\hline${ }^{235}$ U per Fuel Element (g) & 148.11 \\
\hline${ }^{166}$ Er per Fuel Element (g) & 7.46 \\
\hline${ }^{167}$ Er per Fuel Element (g) & 5.15 \\
\hline Erbium Density (wt.\%) & 0.90 \\
\hline Zirconium Rod Outer Diameter (in.) & 0.225 \\
\hline Fuel Meat Inner Diameter (in.) & 0.250 \\
\hline Fuel Meat Outer Diameter (in.) & 1.371 \\
\hline Fuel Meat Length (in.) & 15.0 \\
\hline Cladding Thickness (in.) & 0.020 \\
\hline Cladding Material & $304 \mathrm{SS}$ \\
\hline
\end{tabular}

(a) "Neutron Radiography Reactor Analysis and Support: HEU to LEU Conversion of the NRAD Reactor, Final Report," 911124 rev. 2, GA Project 39296, TRIGA Reactor Division of General Atomics (February 12, 2010). [This reference is not available for public release.]

(b) "Neutron Radiography Reactor Analysis and Support: LEU Upgrade of the NRAD Reactor, Final Report," 911193 rev. 0, GA Project 39296, TRIGA Reactor Division of General Atomics (August 27, 2010). [This reference is not available for public release.]

(c) This number is inconsistent with actual critical test results. This was the initial number of fuel elements estimated to achieve criticality; however, the initial critical was achieved when a cluster of four fuel elements was added to the subcritical core configuration containing 52 fuel elements. 
Table 1.4. Typical $^{(\mathrm{a})}$ TRIGA (30/20) Fuel Design Parameters for Cluster Assemblies . ${ }^{(b)}$

\begin{tabular}{|c|c|}
\hline Catalog Number & 419 \\
Drawing Number & T4S210D105 \\
Fuel Length & 15 in. $(38.1 \mathrm{~cm})$ \\
Fuel Outer Diameter & 1.37 in. $(3.4798 \mathrm{~cm})$ \\
Uranium Content (wt.\%) & $30^{(\mathrm{c})}$ \\
Uranium mass (g) & 710 \\
${ }^{235}$ U Enrichment (wt.\%) & $20^{(\mathrm{d})}$ \\
${ }^{235}$ U mass (g) & 141 \\
Hydrogen to Zirconium Ratio & $1.6^{(\mathrm{e})}$ \\
Erbium Content (wt.\%) & $0.9^{(\mathrm{f})}$ \\
Zirconium Rod Length & $15 \mathrm{in} .(38.1 \mathrm{~cm})^{(\mathrm{g})}$ \\
Fuel Element Overall Length & $30.13 \mathrm{in} .(76.5302 \mathrm{~cm})$ \\
Fuel Element Overall Outer Diameter & $1.41 \mathrm{in} .(3.5814 \mathrm{~cm})$ \\
Cladding Thickness & $0.02 \mathrm{in} .(0.0508 \mathrm{~cm})$ \\
End Fitting Type & Threaded \\
Graphite Reflector Length (Top/Bottom) & 2.6 in. $(6.604 \mathrm{~cm}) / 3.4 \mathrm{in} .(8.636 \mathrm{~cm})$ \\
Graphite Reflector Outer Diameter & $1.3 \mathrm{in.}(3.302 \mathrm{~cm})$ \\
Molybdenum Disc & Yes \\
Samarium Trioxide Disc & No \\
Number of U-Zr-H and Zr-Rod Sections & 3 \\
Molybdenum Disc Thickness & $0.031 \mathrm{in.}(0.07874 \mathrm{~cm})$ \\
\hline
\end{tabular}

(a) Variations from these typical listings do exist.

(b) R. E. Smith, "TRIGA Fuel Summary Report,” ICP/INT-05-817, Idaho Cleanup Project, Idaho National Laboratory (March 2005). [This reference is not available for public release.]

(c) The nominal value of uranium content is 28.5 to $31.5 \mathrm{wt} . \%$ for a single fuel meat and 29.65 to $30.35 \mathrm{wt} . \%$ for a fuel rod assembly.

(d) The ${ }^{235} \mathrm{U}$ enrichment is between 19.5 and $19.99 \mathrm{wt} \% \%$ for all fuel meat.

(e) The fuel element average range of acceptance for the $\mathrm{H} / \mathrm{Z}$ atom ratio is 1.57 to 1.65 . Meats in the range of 1.66 to 1.70 may be used if installed as the top or bottom meat in a fuel rod assembly. The average $\mathrm{H} / \mathrm{Zr}$ ratio for a fuel rod shall not exceed 1.65 .

(f) Fuel erbium content is specified on a per-order basis, which is considered the nominal value. The content in an individual fuel meat is restricted to within $+10 \%$ and $-15 \%$ of the nominal value. A single element is restricted to between $+5 \%$ and $-10 \%$. A cluster of fuel elements (containing either 3 or 4 rods) is restricted between $+3 \%$ and $-6 \%$. Finally, the core content is to remain between $+0 \%$ and $-3 \%$ of the nominal erbium content.

(g) The length of the zirconium rod is always the same length as the fuel segments. 
NEA/NSC/DOC(2006)1

\author{
Fundamental - FUND \\ NRAD-FUND-RESR-002 \\ CRIT-REAC-COEF
}

\title{
Control Rods
}

The NRAD reactor uses PRNC-type control rods, control-rod drives, and instrument console. It is controlled by three boron-carbide cylindrical control rods (two shim rods and one regulating rod). All three control rods are supported from the bridge structure located at the top of the reactor tank and are water-followed when withdrawn from the core. ${ }^{\mathrm{a}}$

Positions of the control rods are shown in Figure 1.6. The shim control rods are in positions D-2 SE and C-2 NE. The regulating control rod is located in position E-4 NE. Any one control rod can shut down the reactor.

The control elements for the NRAD reactor can be either the original PRNC control rods with $0.5 \mathrm{MW}$ year of operation or new ones purchased from General Atomics with the same part number as those used at the PRNC. ${ }^{a}$ All three control rods currently in the core are from the original PRNC reactor.

Each control rod consists of a boron carbide $\left(\mathrm{B}_{4} \mathrm{C}\right)$ poison section that is 15 in. $(38.1 \mathrm{~cm})$ long and 1.19 in. $(3.0226 \mathrm{~cm})$ in diameter contained within an aluminum 6061-T6 tube 24 in. $(60.96 \mathrm{~cm})$ long with an outer diameter of $1.25 \mathrm{in} .(3.175 \mathrm{~cm})$ and a wall thickness of $0.028 \mathrm{in} .(0.07112 \mathrm{~cm})$. The container has a $1 / 2 \times 13$ threaded connection on the upper end for attachment to an extension rod. A diagram of the control rod is shown in Figure 1.31. ${ }^{\mathrm{a}}$

Full travel of an NRAD control rod is 15 in. $(38.1 \mathrm{~cm})$. The rod position indication displays 0-1000 units of travel from a down limit switch to the up limit switch, respectively. Each unit of display is equal to 0.015 in. $(0.0381 \mathrm{~cm})$ of rod travel. A good confidence band $(3 \sigma)$ for knowing the location of the control rod is \pm 4 units $(0.06$ in., $0.1524 \mathrm{~cm})$. The drive travel in the reactor room was physically measured and validated that the full travel length is 15 in. The digital position indication is adjusted at the zero, down limit, and again at 1000 units, or the upper limit, using potentiometers on the back of the reactor console. As much as -3 units to zero units at the lower limit and 999 or 1000 units at the upper limit is allowed. ${ }^{\text {b }}$

Control rod position data are obtained from a potentiometer connected to the drive pinion. Limit switches are provided to indicate the up and down positions of the magnet, and magnet contact with the control rod..$^{\mathrm{c}}$

The bottom of the control rod is 0.75 in. $(1.905 \mathrm{~cm})$ above the inside bottom of the control rod guide tube when the control rod is completely inserted. The bottom end of a control rod is shown in Figure 1.32.

\footnotetext{
a "NRAD Reactor Fuel Core Conversion," DSA-005-NRAD-ADD-3 rev. 0, Idaho National Laboratory (April 2, 2009). [This reference is not available for public release.]

${ }^{\mathrm{b}}$ Personal communication with Ken Schreck at HFEF (April 5-6, 2010).

c “HFEF/N Neutron Radiography Facility System Design Description,” W0170-0004-SA rev. 2, Idaho National Laboratory (June 1, 1978). [This reference is not available for public release.] 


\section{NEA/NSC/DOC(2006)1}

Fundamental - FUND

NRAD-FUND-RESR-002

CRIT-REAC-COEF

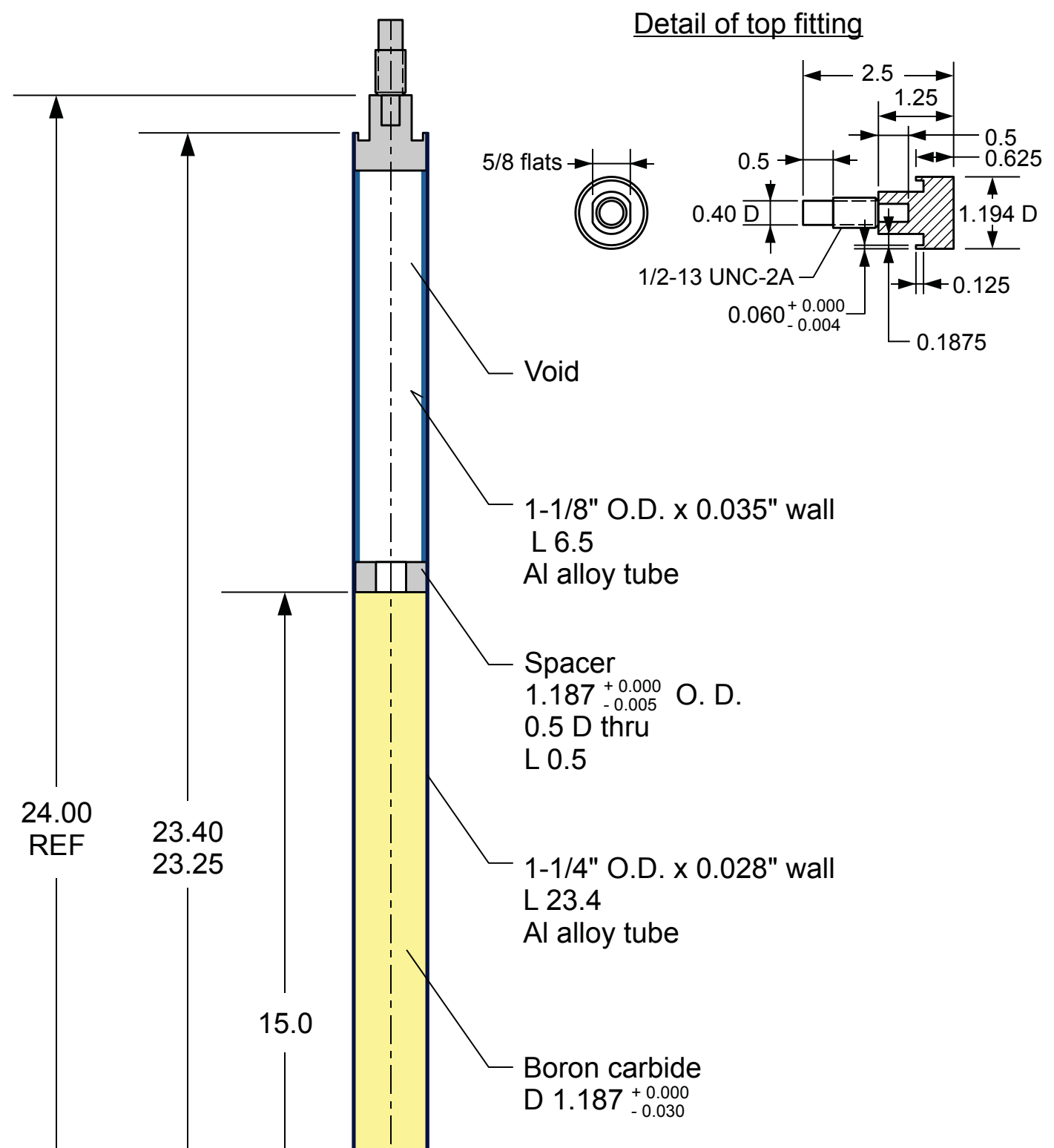

\section{Detail of bottom fitting}

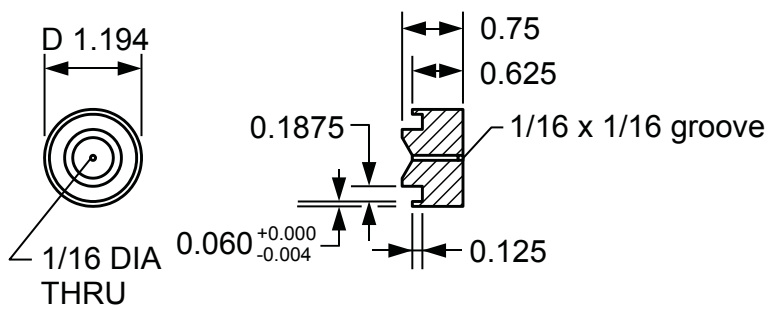

Dimensions in inches 10-GA50002-90

Figure 1.31. NRAD Control Rod. 


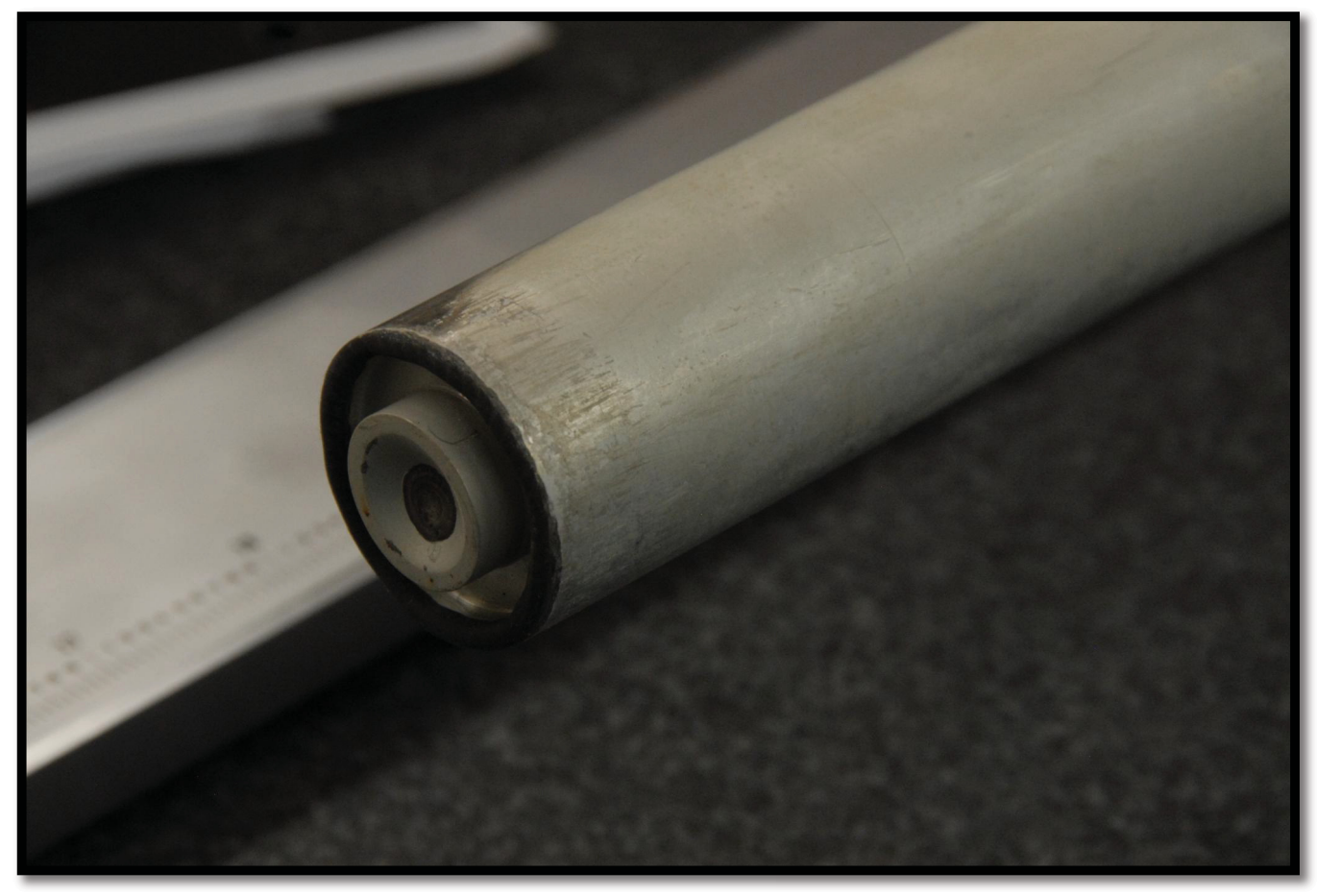

Figure 1.32. Bottom of Control Rod.

An aluminum extension, or connection, rod is attached to the control rod, connecting it to the driveline, control rod drive, instrumentation, and support structure located above the reactor core and tank. The extension rod is $33.750 \mathrm{in}$. $(85.725 \mathrm{~cm})$ long and is a tube with an outer diameter of $0.875 \mathrm{in} .(2.2225 \mathrm{~cm})$ and an inner diameter of 0.635 in. $(1.6129 \mathrm{~cm})$. The assembly interface of the extension rod to the control rod is depicted in Figure 1.33 and a photograph of the interface is shown in Figure 1.34.

A guide tube placed into the three-fuel-element cluster assemblies is used to direct the vertical movement of the control rod. Figure 1.35 shows the guide tube and Figures 1.19 and 1.20 demonstrate how the guide tube is placed into the three fuel element cluster assembly. New guide tubes were fabricated in 2009.

Assembly 2 in Figure 1.35 shows how the weldment goes together, representing an intermediate step in the construction process of the guide tube. Once the tube is connected to the fitting, it is turned and pulled. A 0.1875 in. $(0.47625 \mathrm{~cm})$ diameter, 1.5 in. $(3.81 \mathrm{~cm})$ long, $18-8$ stainless steel dowel pin holds the guide tube base and bottom adapter together.

An empty guide tube is used to guide experiments into an irradiation position in the core. 
TUBING, 0.875 DIA $\times 0.120$ WALL (0.635 ID REF) ALUM 6061-T6

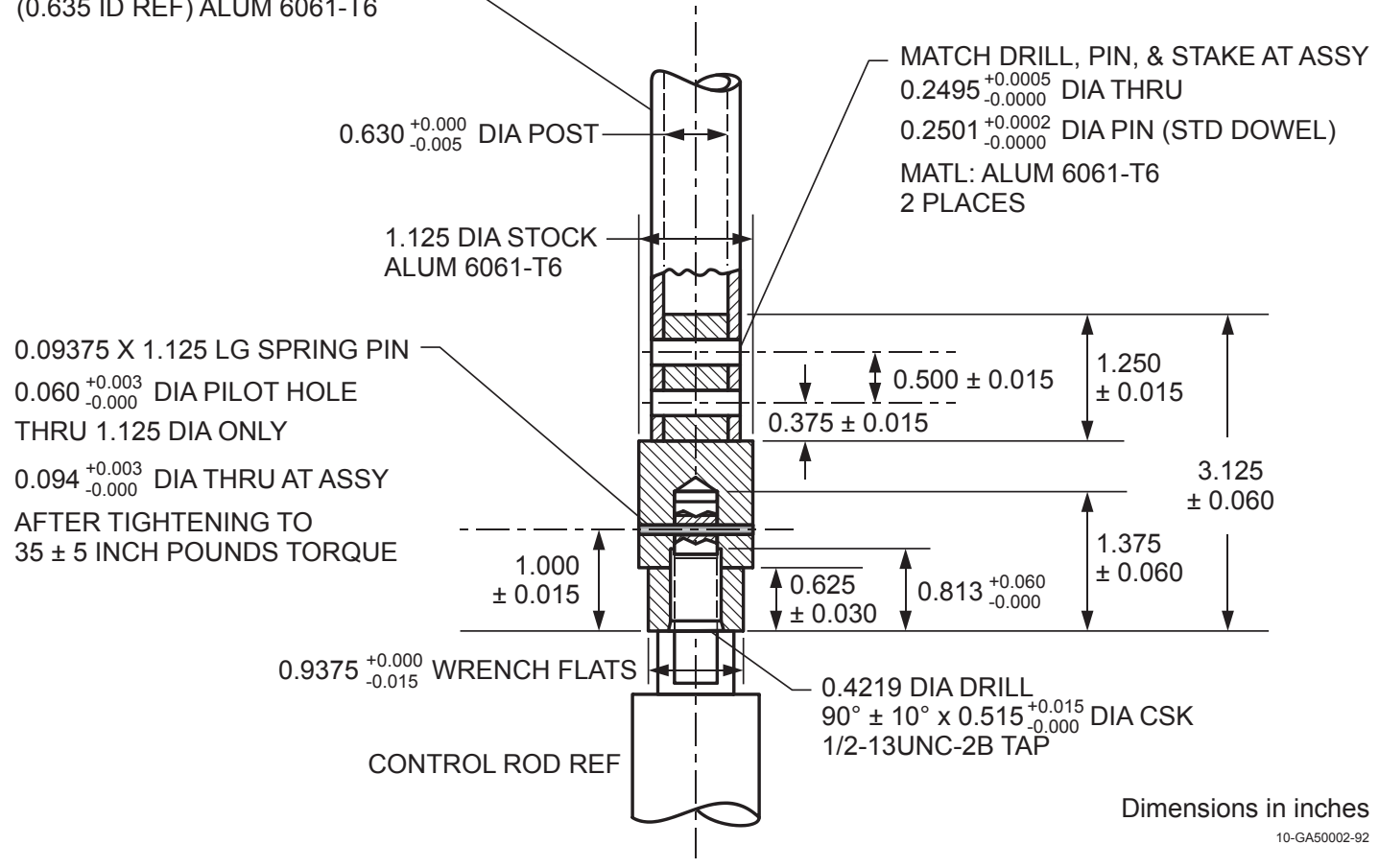

Figure 1.33. Interface between Control Rod and Extension Rod.

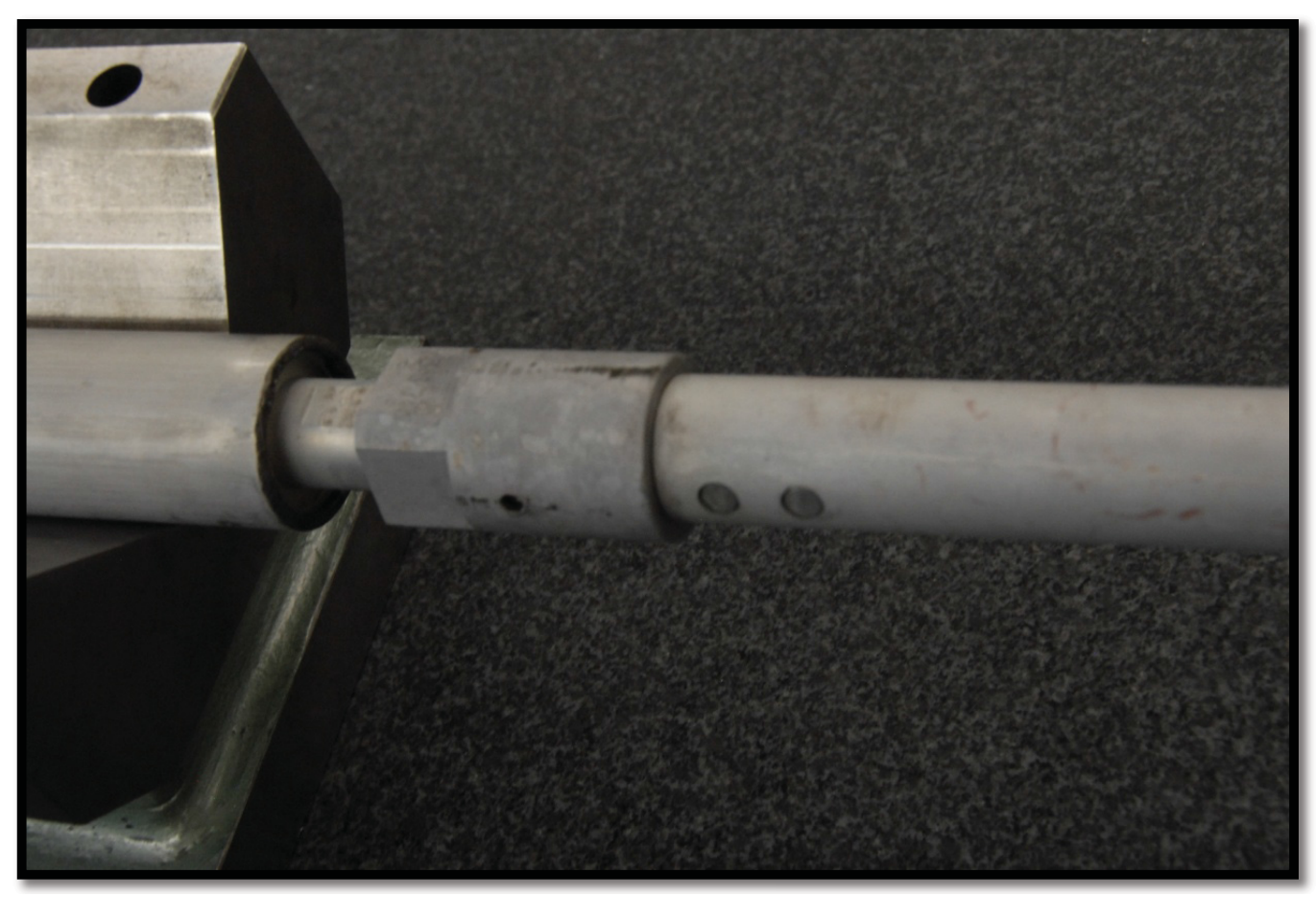

Figure 1.34. Interface between Control Rod and Extension Rod. 


\section{NEA/NSC/DOC(2006)1}

\section{Fundamental - FUND}

NRAD-FUND-RESR-002

CRIT-REAC-COEF
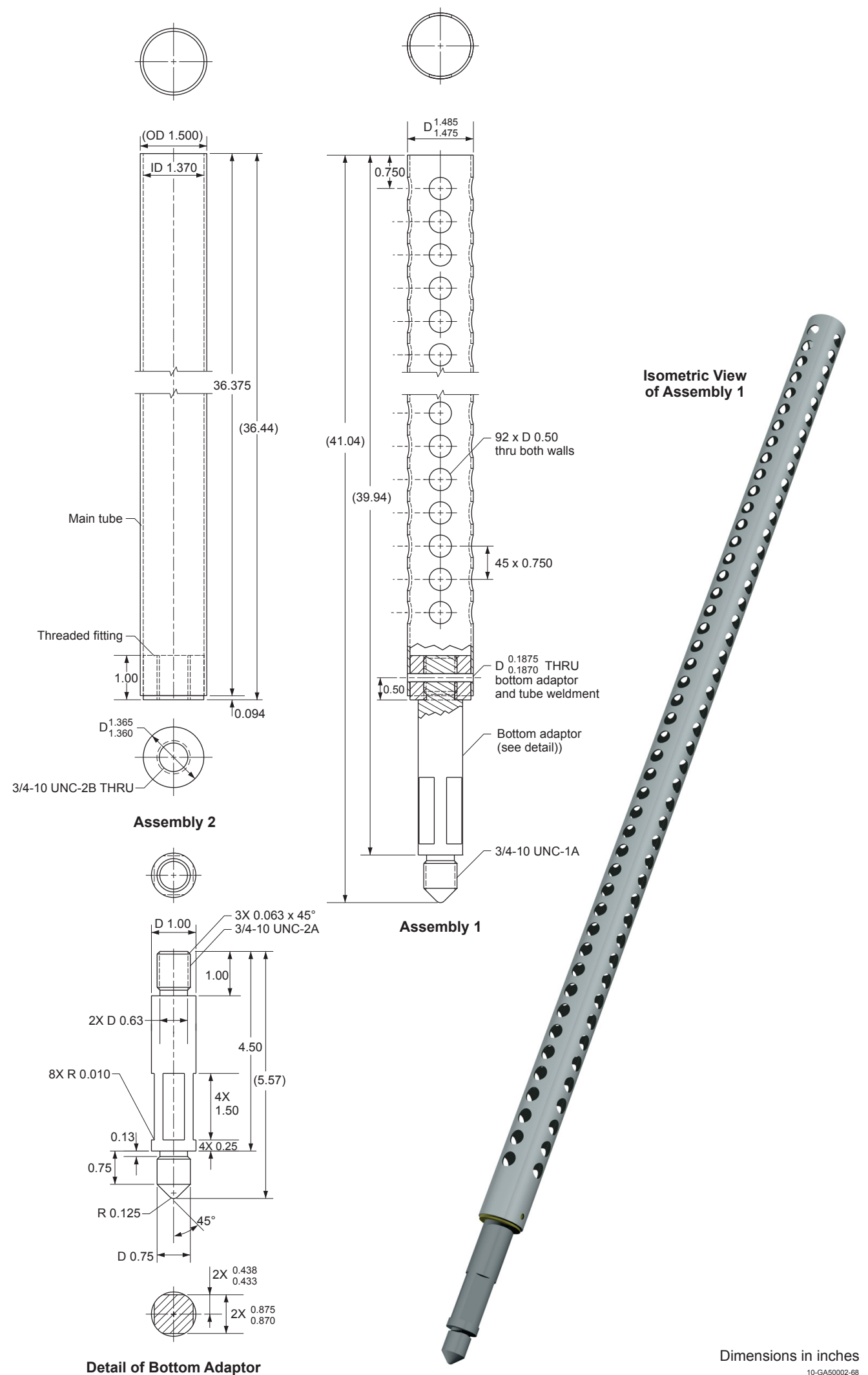

Detail of Bottom Adaptor

Figure 1.35. Control Rod Guide Tube. 


\section{Graphite Reflector Assembly}

Graphite reflector assemblies are located in the periphery grid plate locations. The top and bottom of each reflector assembly have adapters for handling and insertion into the core grid plate. The assemblies, as shown in Figure 1.36, are 25.9 in. $(65.786 \mathrm{~cm})$ long and have a horizontal cross section in a square shape, with each side of the square 2.9 in. $(7.366 \mathrm{~cm})$ in length. ${ }^{\mathrm{a}}$

Dimensions of the graphite block are shown in Figure 1.37. The top cast assembly fitting is shown in Figure 1.38. The bottom fitting was replaced with those used for the fuel assemblies, shown in Figure 1.14. The assembly fittings are attached to the graphite blocks using aluminum 2011-T3 socket head cap screws, tie rod, and stud, as shown in Figure 1.36.

Photographs of unmachined graphite identical to that used in the NRAD graphite assemblies are shown in Figure 1.39.

\footnotetext{
a “HFEF/N Neutron Radiography Facility System Design Description,” W0170-0004-SA rev. 2, Idaho National Laboratory (June 1, 1978). [This reference is not available for public release.]
} 
NEA/NSC/DOC(2006)1

Fundamental - FUND

NRAD-FUND-RESR-002

CRIT-REAC-COEF

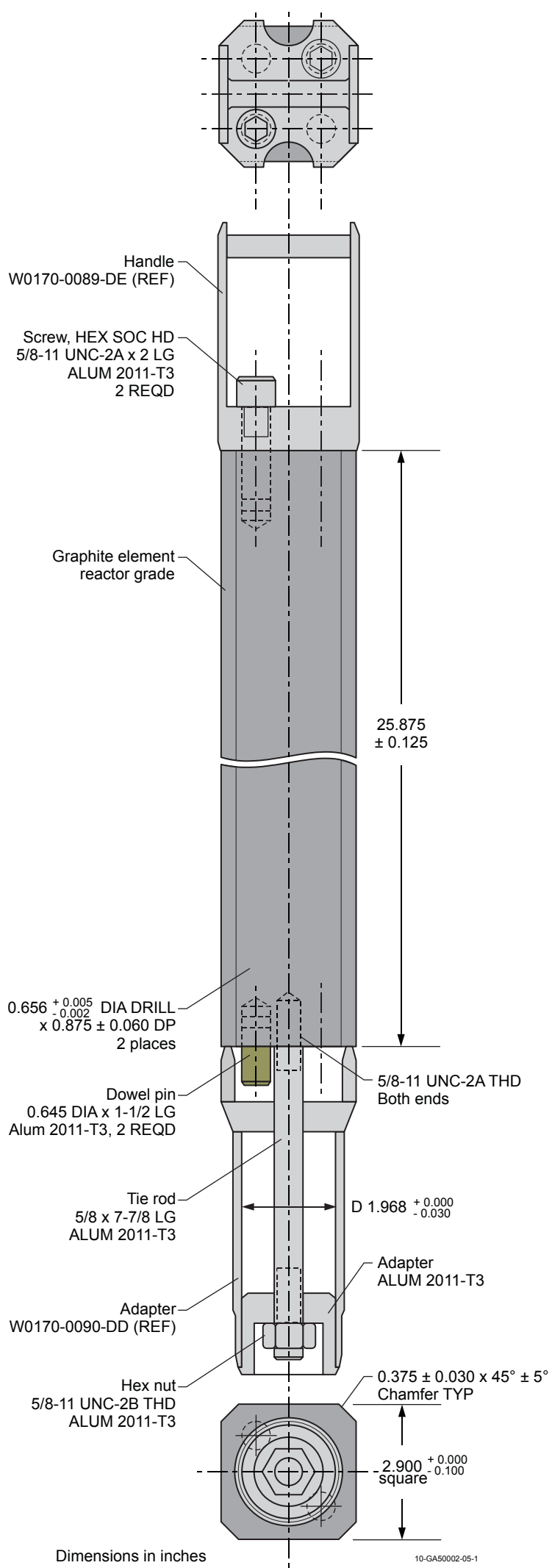

Figure 1.36. NRAD Graphite Reflector Assembly. 


\section{NEA/NSC/DOC(2006)1}

\section{Fundamental - FUND}

NRAD-FUND-RESR-002

CRIT-REAC-COEF

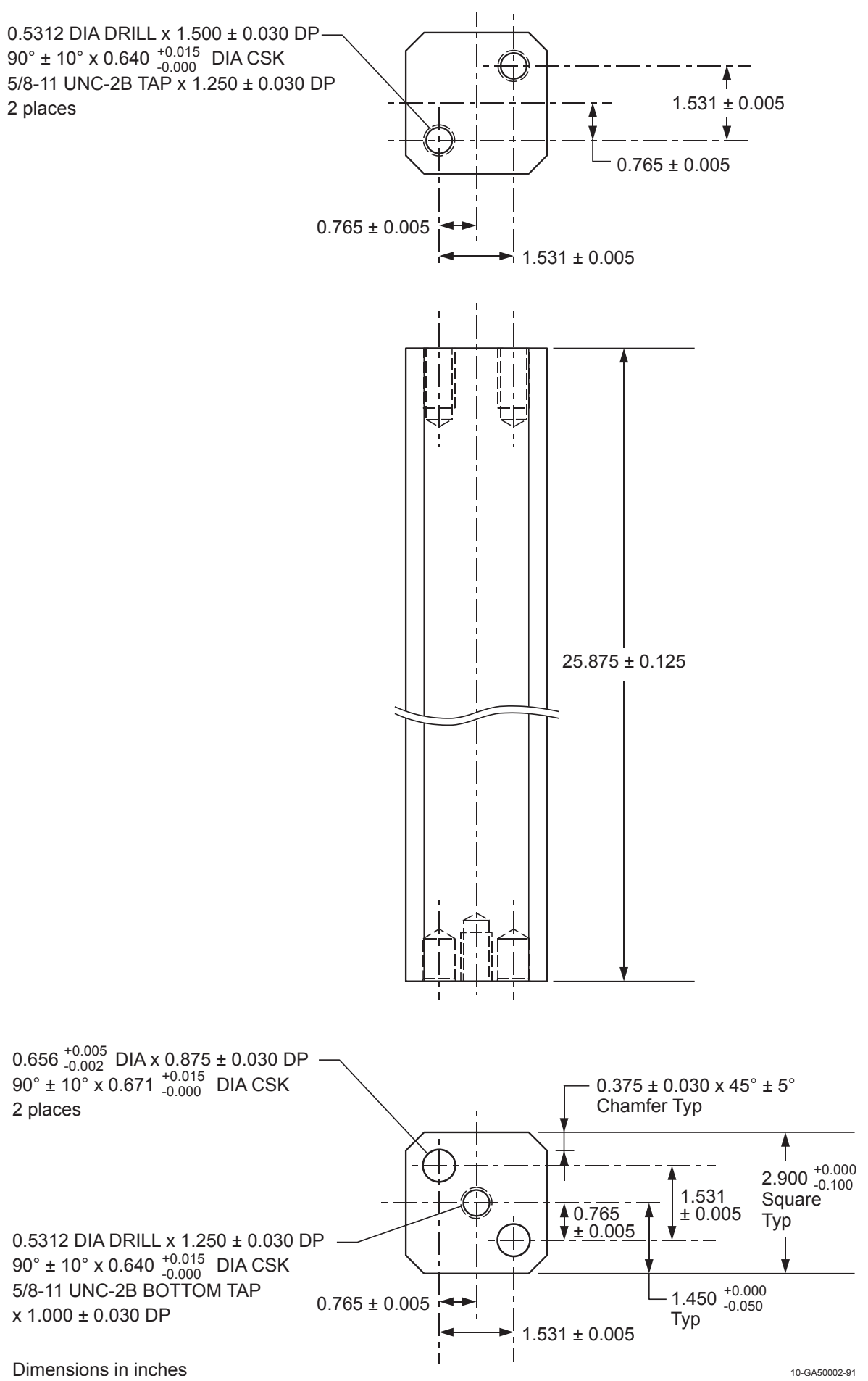

Figure 1.37. Graphite Reflector Block. 


\section{NEA/NSC/DOC(2006)1}

Fundamental - FUND

NRAD-FUND-RESR-002

CRIT-REAC-COEF
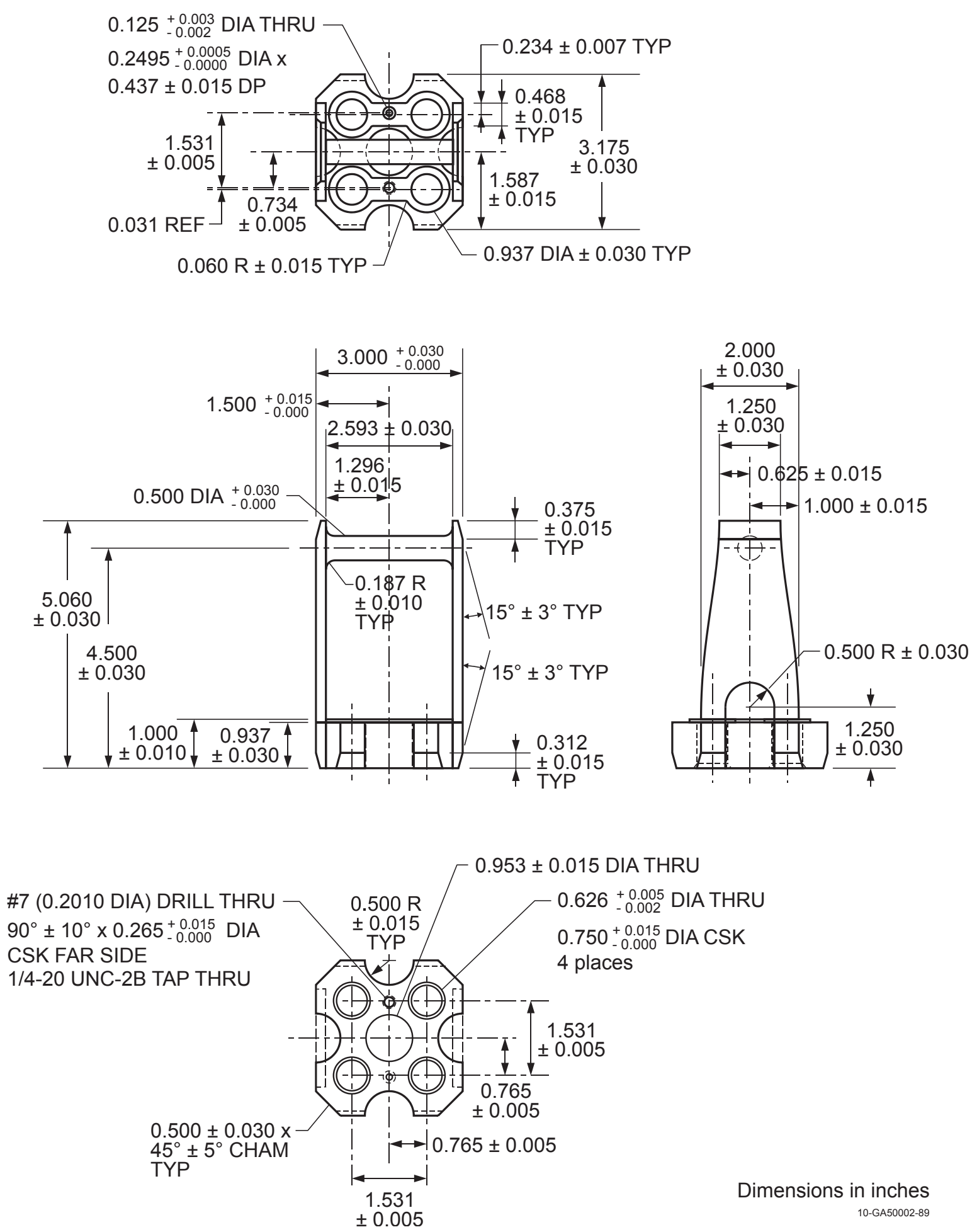

Figure 1.38. Graphite Reflector Top Assembly. 
NEA/NSC/DOC(2006)1

Fundamental - FUND

NRAD-FUND-RESR-002

CRIT-REAC-COEF
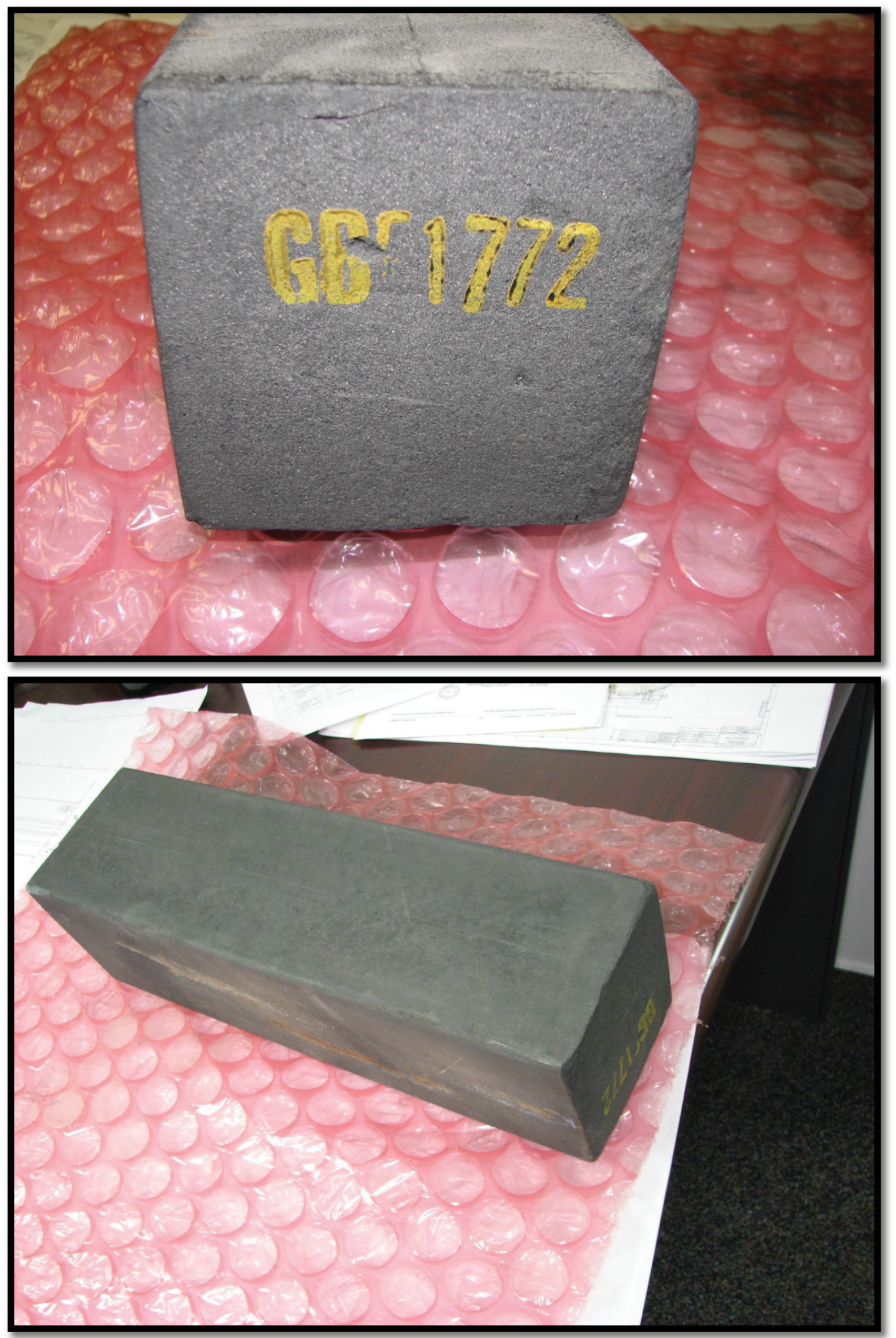

Figure 1.39. Unfinished Graphite Reflector Block. 
NEA/NSC/DOC(2006)1

Fundamental - FUND

NRAD-FUND-RESR-002

CRIT-REAC-COEF

\section{Beam Ports}

The NRAD reactor services two radiography stations, as shown in Figures 1.2 through 1.4. The main radiography station is used to neutron-radiograph highly irradiated fuel elements, fuel assemblies, and loop experiments, which might chemically react with air. This station is located within HFEF's main cell, which contains argon atmosphere. The second neutron radiography station is located outside of the main cell, allowing for the irradiation of either irradiated or unirradiated specimens, and is filled with air at ambient conditions.

The two beam tubes are positioned to the North (to secondary station) and East (to main station) sides of the reactor core. The in-tank portion of the beam lines includes a beam-filter tube and an aperture mechanism that excludes water from the neutron path. A through-the-wall collimator encased in the concrete of the reactor-room shielding and walls then extends from the reactor tank to the radiography station. $^{\mathrm{a}}$

The in-tank portion of the East beam line (Figure 1.40) is an air-filled aluminum tube extending from the reactor core to the reactor tank wall. The aperture mechanism (Figure 1.41) is placed approximately midway and is housed in a water-tight aluminum box, sealed at the top, and extends upward to the top shield. This housing contains the aperture elements and remotely operated mechanism for changing the size of the aperture. The beam filter tube that extends from the core to the aperture mechanism is removable, to allow for loading of additional filter material when required. It is usually filled with helium. The inner end of the tube extends to about $0.8 \mathrm{in} .(2.032 \mathrm{~cm})$ from the outermost fuel elements. ${ }^{\text {a }}$

The beam-filter tube (Figure 1.42) is rectangular in cross section. Clamp rails force the beam-filter tube into intimate contact with the window of the aperture housing, leaving just a thin film of water along the interface. A bolted flange at the top of the tube allows access for loading. The bottom of the aperture housing extends to the tank floor to provide additional support. The source tube then extends from the aperture mechanism to the tank wall, where the flange on the source tube is sealed to the flange of the nozzle welded to the tank wall. The nozzle is equipped with gas-purge fittings to remove water from the tube after any operations requiring the removal and reinstallation of the aperture housing. The fittings also allow for maintenance of a helium-filled atmosphere. A Boral lining, 0.265-inch-(.6731-cm)-thick, is provided to minimize neutron scatter and monitor seal leakage. ${ }^{\mathrm{b}}$

The beam-filter tubes are also referred to as "wet packages" when referenced in reactor operations.

Figure 1.3 provides the general layout of a beam line in the NRAD reactor facility.

A $55 \mathrm{ft}(16.764 \mathrm{~m})$ helium-filled beam tube extends from the north face of the reactor to the secondary radiography station. The aperture mechanism is identical to that of the east beam tube with different neutron beam length/diameter (L/D) ratios because of the difference in beam tube length. ${ }^{a}$

The aperture mechanism provides control of some neutron beam properties. The smaller the aperture, the sharper the definition of the neutron radiograph (with longer exposure time required). There are three apertures: 3.5 in. $(8.89 \mathrm{~cm})$ with an $\mathrm{L} / \mathrm{D}$ of $50,1.39$ in. $(3.5306 \mathrm{~cm})$ with an $\mathrm{L} / \mathrm{D}$ of 125 , and 0.59 in. $(1.4986 \mathrm{~cm})$ with an L/D of 300 . The two smaller apertures are located in a movable aperture block (Figure 1.43) while the largest aperture is in a fixed block (Figure 1.44) that is uncovered when the movable block is driven up out of the way. Both movable and fixed blocks are made from boron nitride. ${ }^{b}$

\footnotetext{
a “NRAD Safety Analysis Report,” DSA-005-NRAD rev. 5, Idaho National Laboratory (April 2, 2009). [This reference is not available for public release.]

b "HFEF/N Neutron Radiography Facility System Design Description,” W0170-0004-SA rev. 2, Idaho National Laboratory (June 1, 1978). [This reference is not available for public release.]
} 


\section{Fundamental - FUND \\ NRAD-FUND-RESR-002 \\ CRIT-REAC-COEF}

The movable aperture block is held within an aperture assembly (Figure 1.45) and is vertically supported by an aperture block guide (Figure 1.46) and aligned with an aperture block adjusting screw (Figure 1.47). A lower tube seal plate (Figure 1.48) is used for the fixed block disc aperture.

The L/D ratios for the North beam tube are 185, 300, and 700 for the same aperture dimensions as the East beam tube. ${ }^{\text {a }}$

Graphite reflector assemblies are not used in the center East and North sides of the core to allow for the beam tubes to have closer access to the fuel, as shown in Figure 1.6. These positions (A-3, A-4, C-6, and D-6) instead contain an in-core beam tube support structure comprised of aluminum 6061 (Figure 1.49). A hex head cap screw can be adjusted to the desired height to provide support for the beam filter tubes extending into the core from the beam apertures. The centerline of the beam tube is located at core midplane.

The aperture setting of the East beam tube at the time of the experiments was at its typical L/D setting of 125. The aperture setting of the North beam tube was also at its typical L/D setting of 300 . Both of these settings indicate that the moveable aperture block (Figure 1.43) was raised such that the lower hole was aligned with the path of the beam tube. The East beam filter tube was filled with air and the North with helium. However, the tubes may be filled with either gas, or evacuated to contain void space (i.e. vacuum).

The original drawings for the beam assemblies are different in regards to beam filter tube length (due to the difference in the length and width of the core grid plate) and the depicted layout of the aperture assembly mechanism. However, the current positioning motors in the reactor room conflict with the description of the North beam tube aperture assembly and match that of the East beam line. Therefore, based on the configuration of the motors, the staff believes that the North beam arrangement is identical to the East beam arrangement, except for the length of the "wet package".

a G. R. Imel, G. C. McClellan, and D. P. Pruett, “The Neutron Radiography Reactor (NRAD),” CONF-900873--2, Proc. $1^{\text {st }}$ Int. Top. Mtg. Neutron Radiography System Design and Characterization, Pembroke, Canada (August 2830, 1990).

${ }^{\mathrm{b}}$ Personal communication with Ken Schreck at HFEF (April 29, 2010). 
NEA/NSC/DOC(2006)1

Fundamental - FUND

NRAD-FUND-RESR-002

CRIT-REAC-COEF

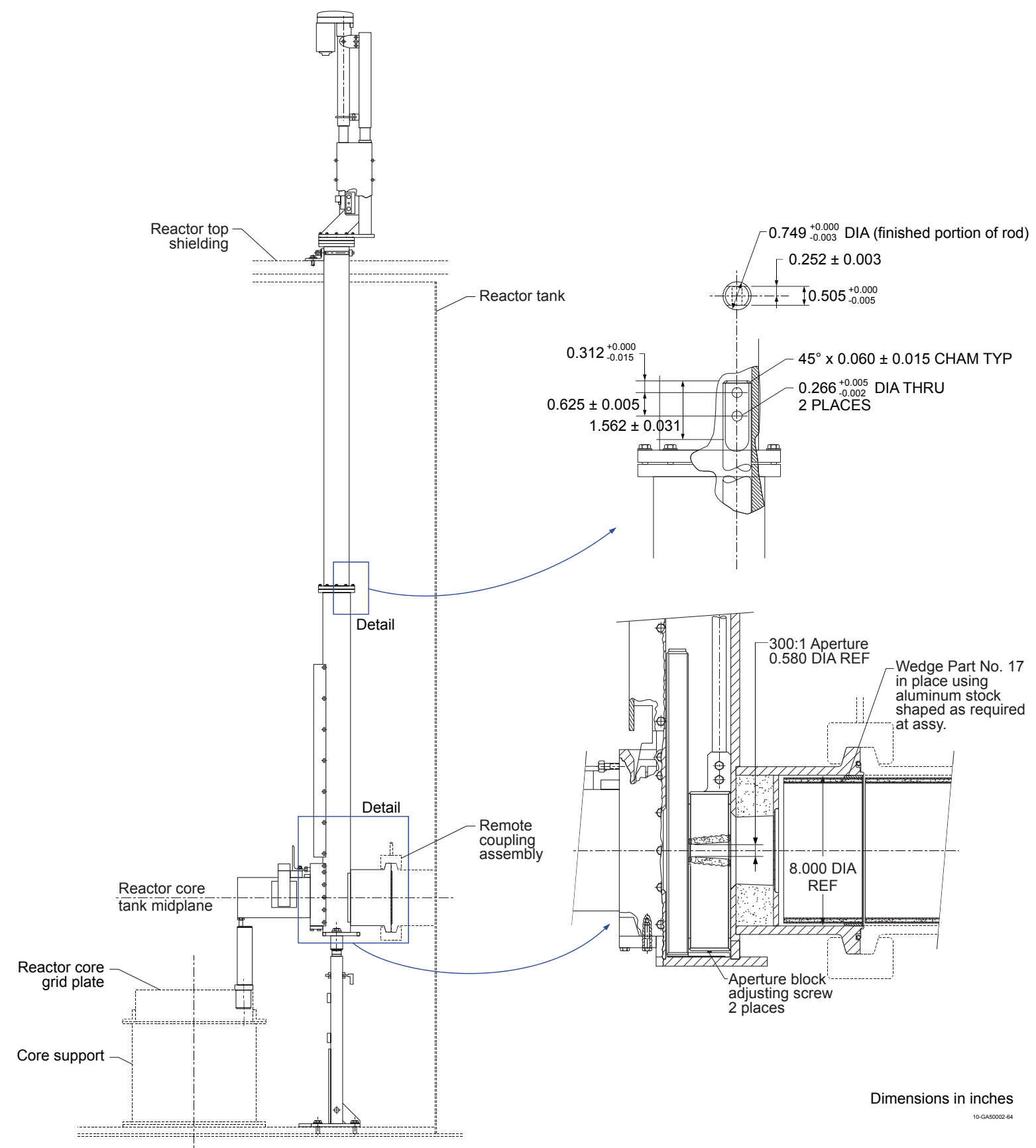

Figure 1.40. In-Tank Portion of the Beam Line. 
Fundamental - FUND

NRAD-FUND-RESR-002

CRIT-REAC-COEF
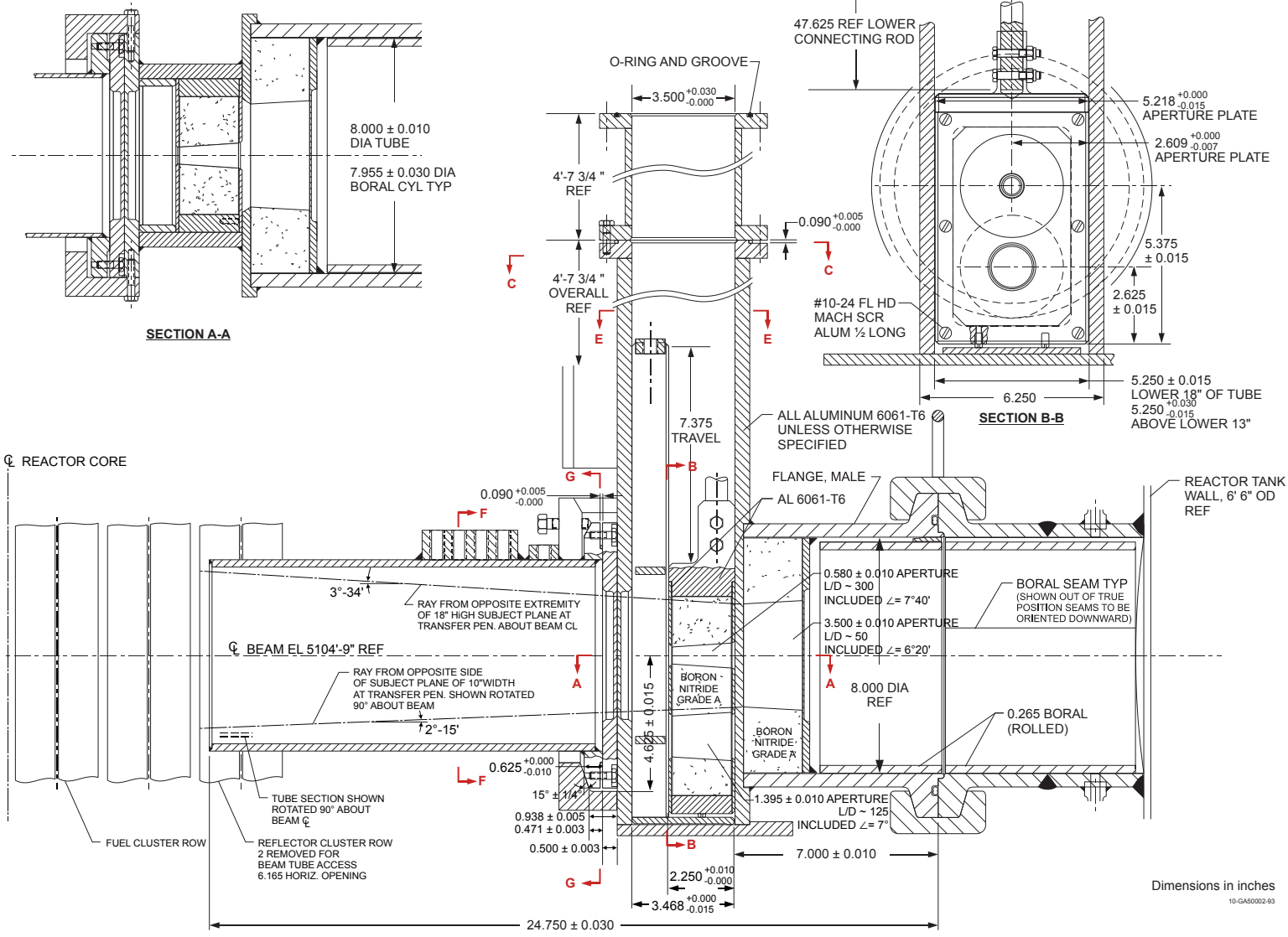

Figure 1.41a. East Beam Line Aperture Mechanism. 
NEA/NSC/DOC(2006)1

Fundamental - FUND

NRAD-FUND-RESR-002

CRIT-REAC-COEF
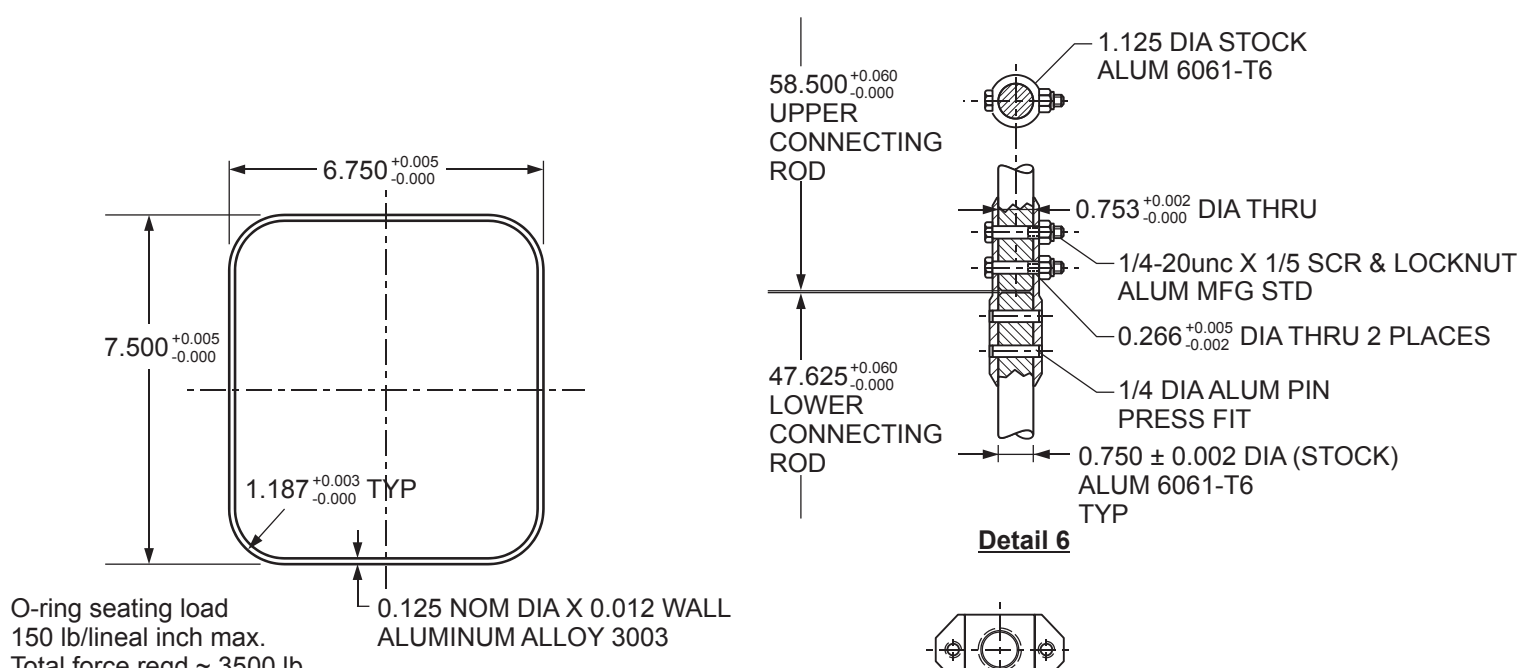

Total force reqd $\sim 3500 \mathrm{lb}$

Detail O-Ring

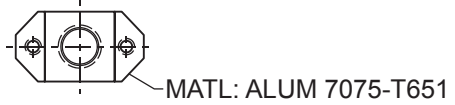

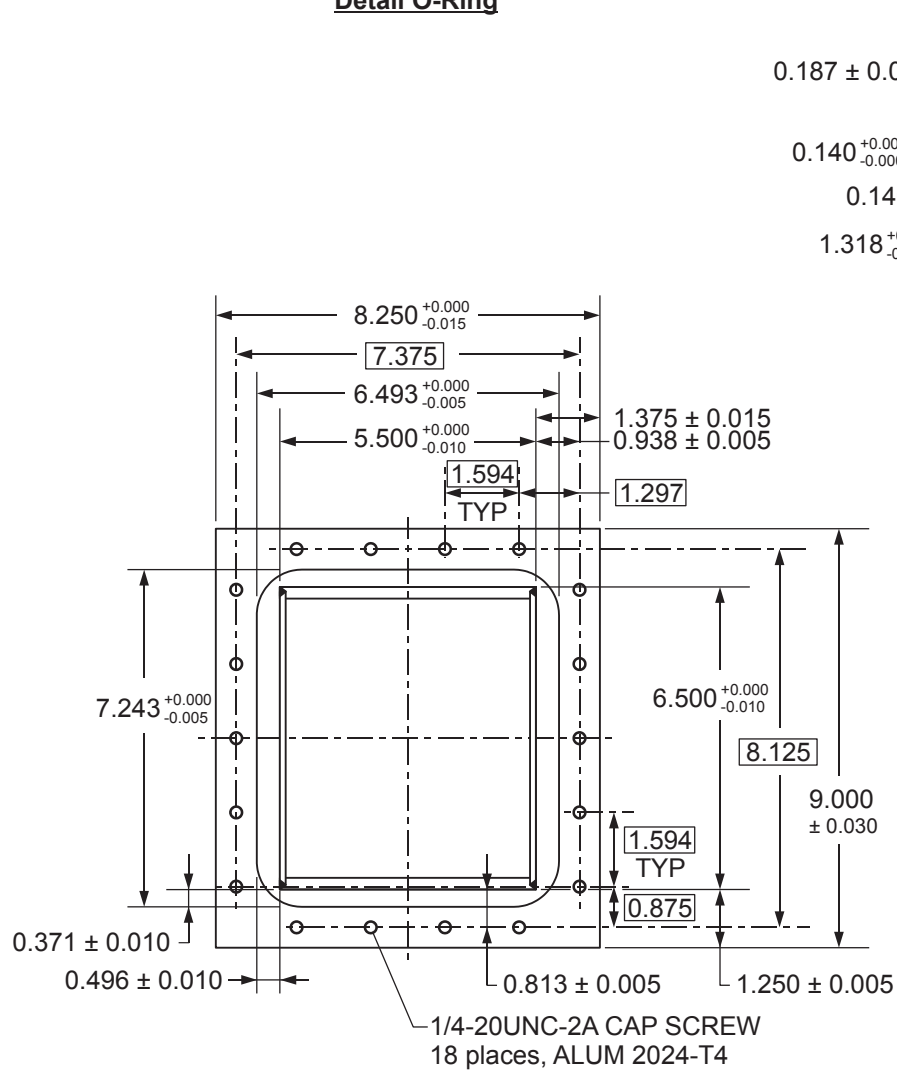

Section G-G

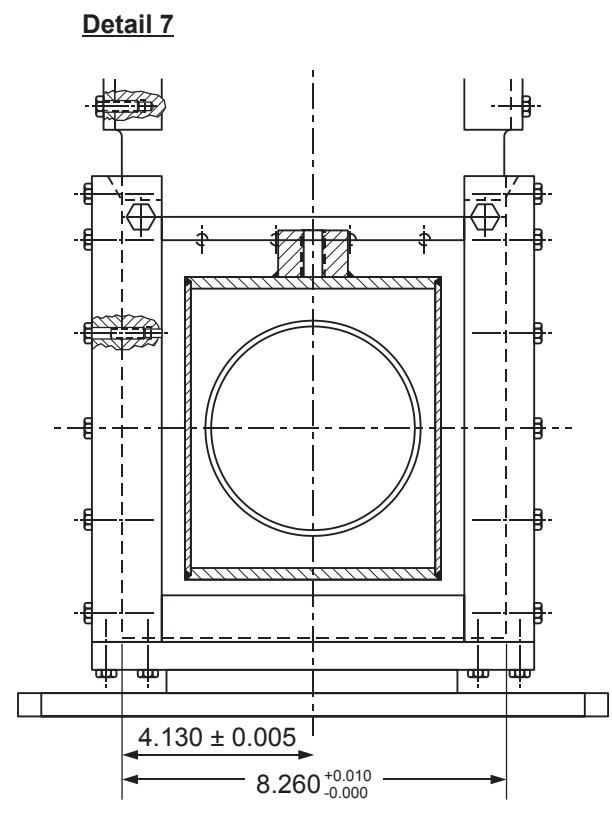

Section F-F

Dimensions in inches

Figure 1.41b. East Beam Line Aperture Mechanism. 


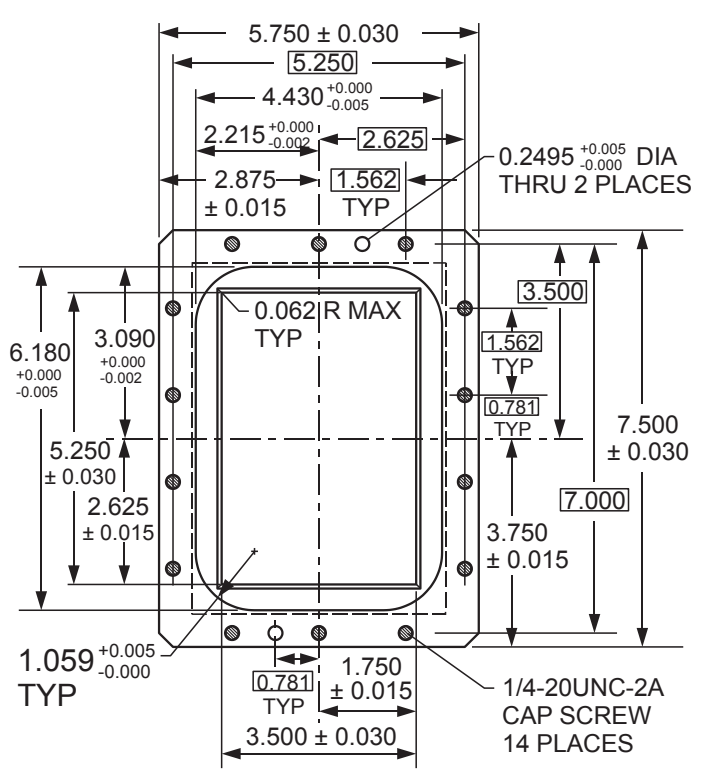

SECTION C-C

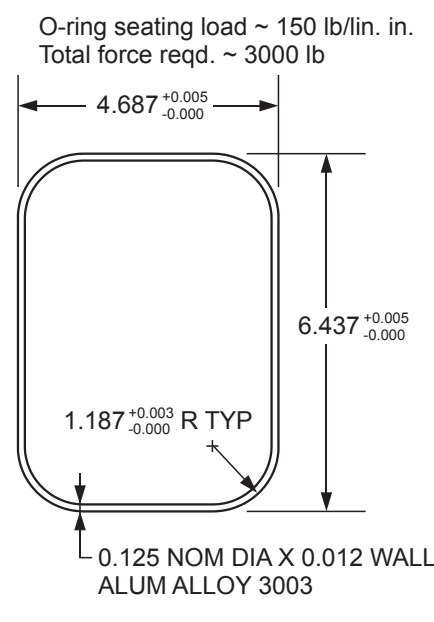

Dimensions in inches

SECTION E-E

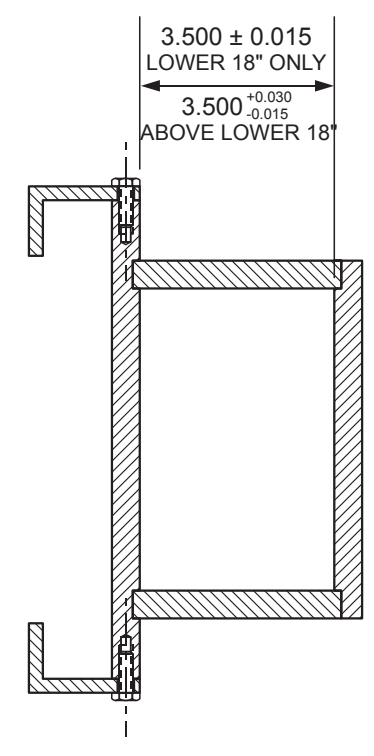

10-GA50002-95

Figure 1.41c. East Beam Line Aperture Mechanism. 
NEA/NSC/DOC(2006)1

\section{Fundamental - FUND}

NRAD-FUND-RESR-002

CRIT-REAC-COEF

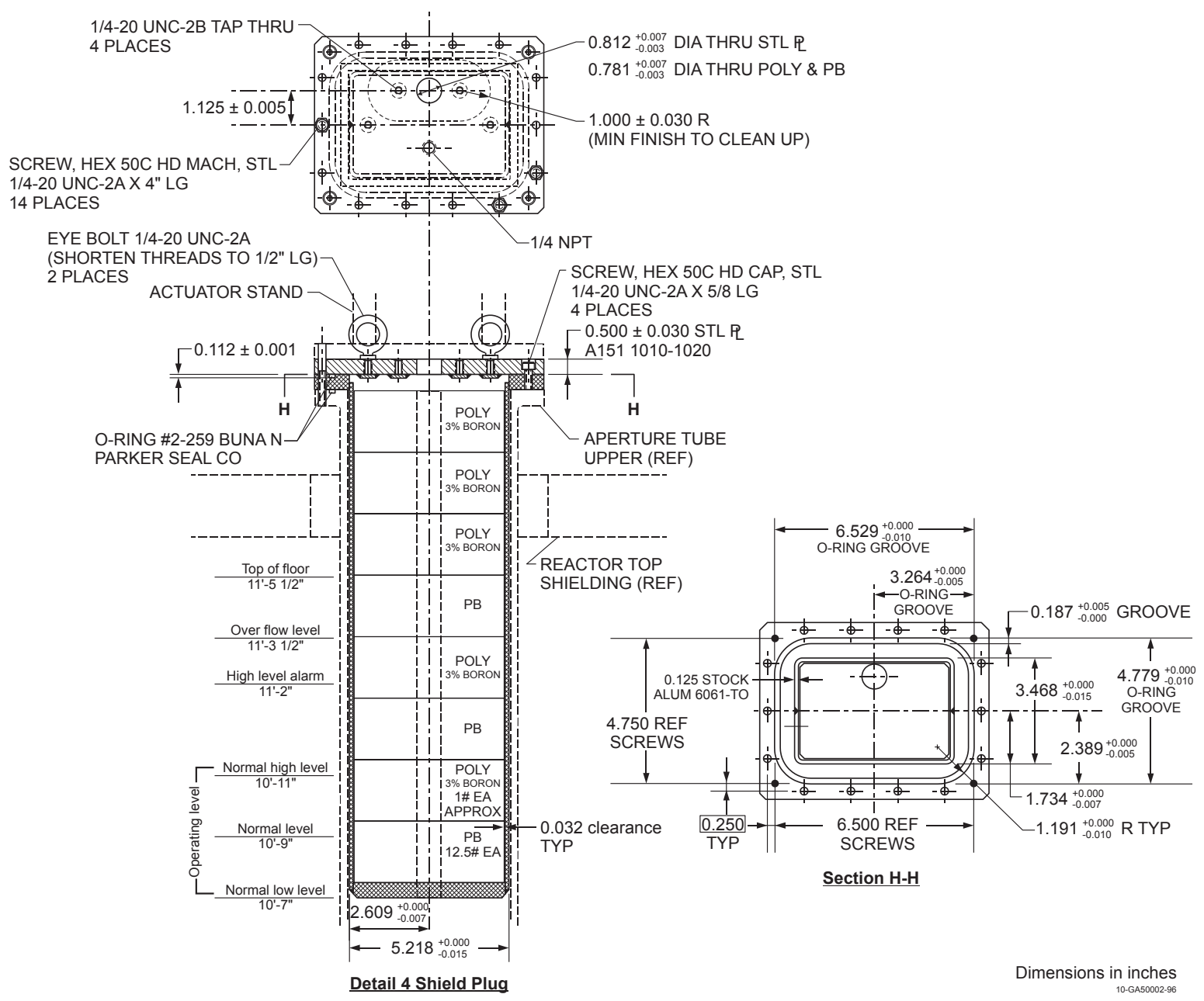

Figure 1.41d. East Beam Line Aperture Mechanism. 
NEA/NSC/DOC(2006)1

Fundamental - FUND

NRAD-FUND-RESR-002

CRIT-REAC-COEF

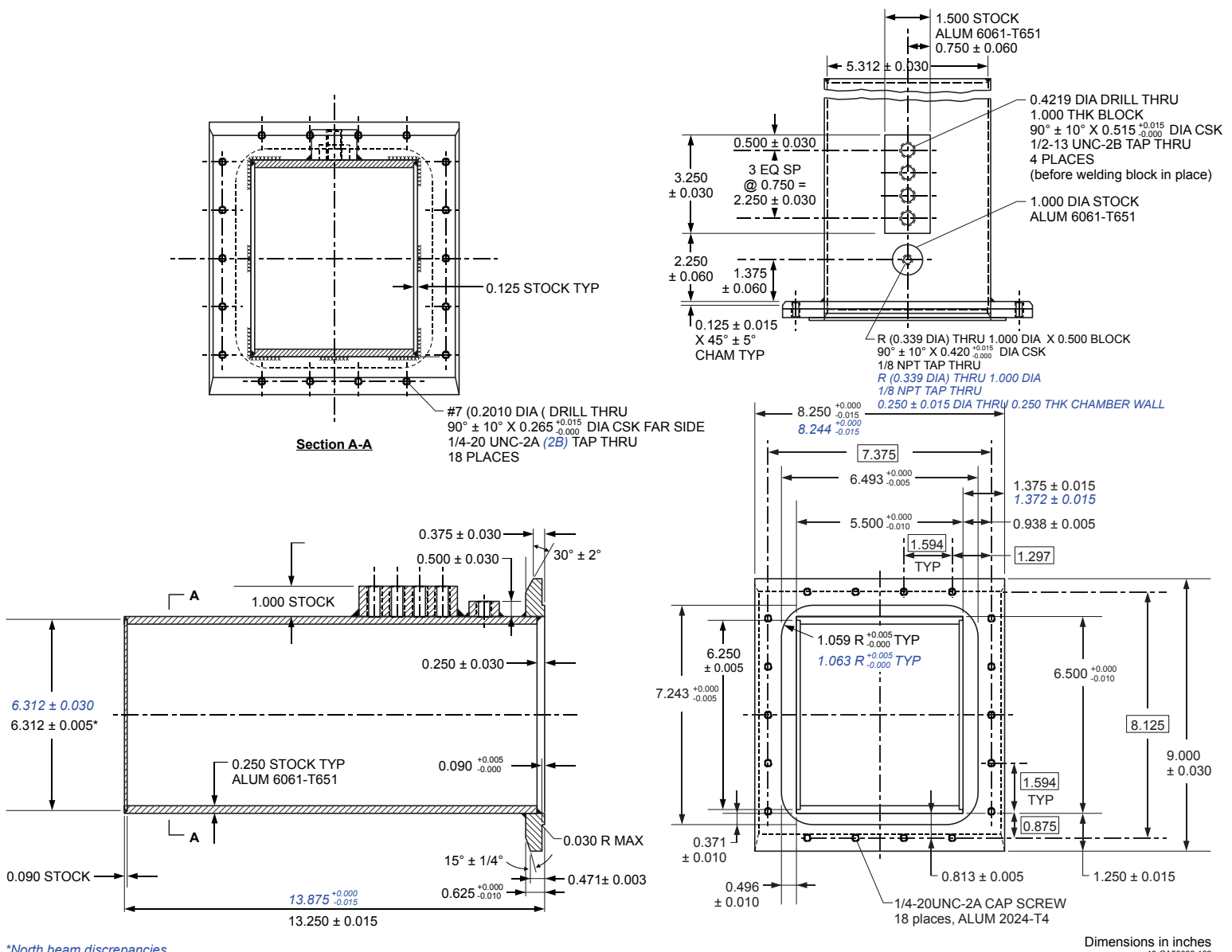

Figure 1.42. East and North Beam Filter Tubes. 


\section{NEA/NSC/DOC(2006)1}

Fundamental - FUND

NRAD-FUND-RESR-002

CRIT-REAC-COEF
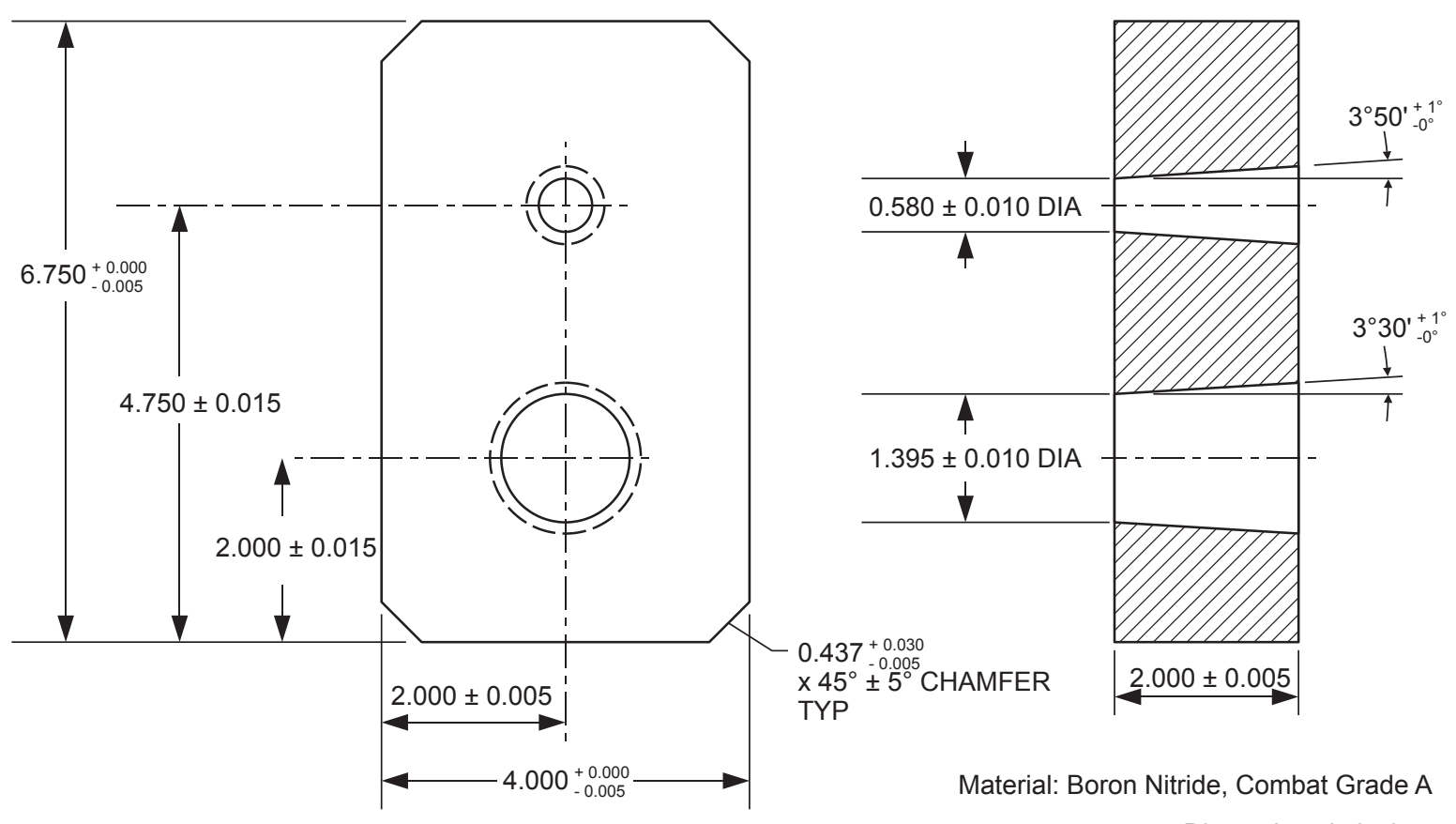

Material: Boron Nitride, Combat Grade A

Dimensions in inches 10-GA50002-101-1

Figure 1.43. Moveable Aperture Block.

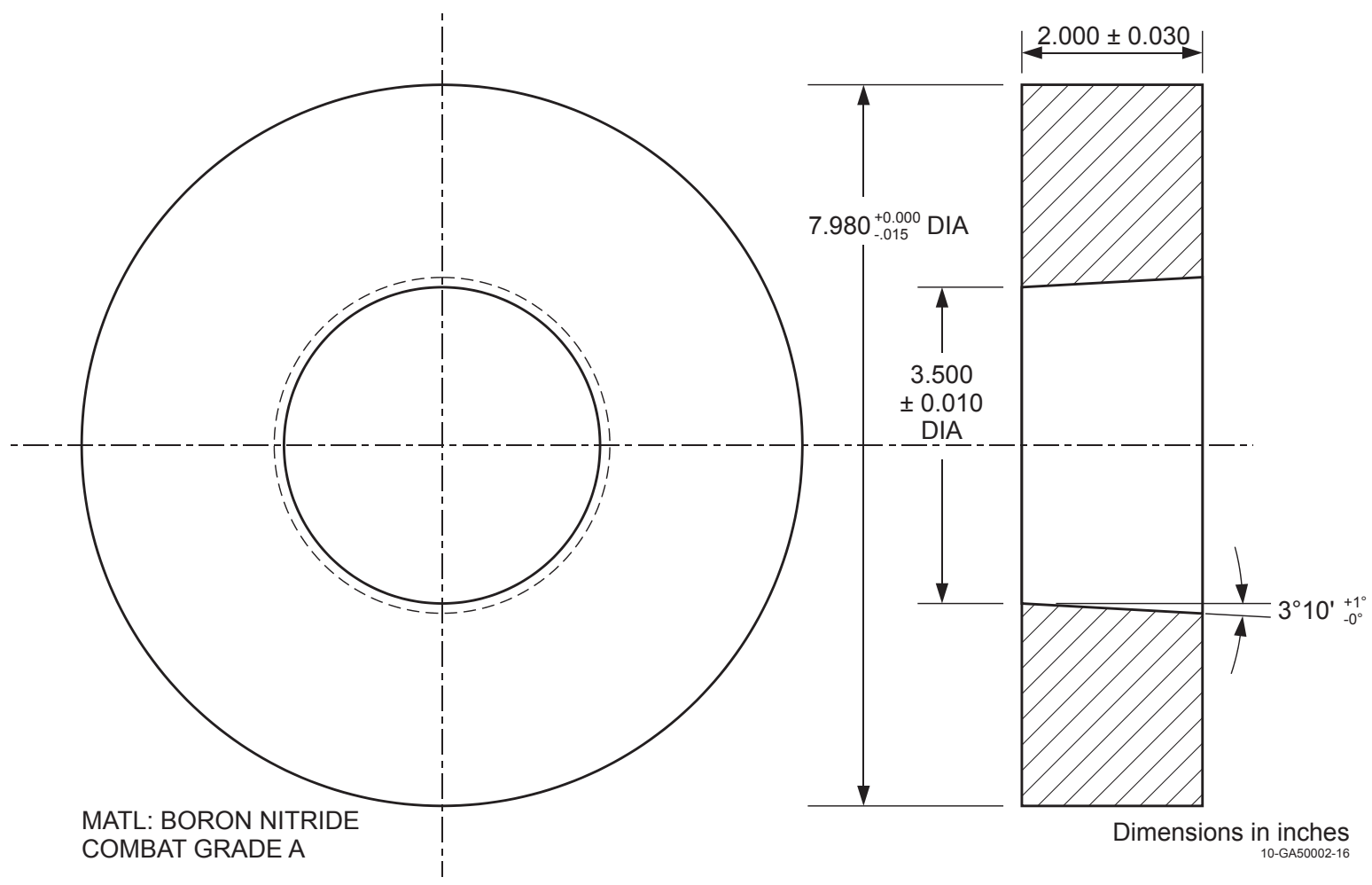

Figure 1.44. Fixed Disc Aperture Block. 


\section{NEA/NSC/DOC(2006)1}

Fundamental - FUND

NRAD-FUND-RESR-002

CRIT-REAC-COEF

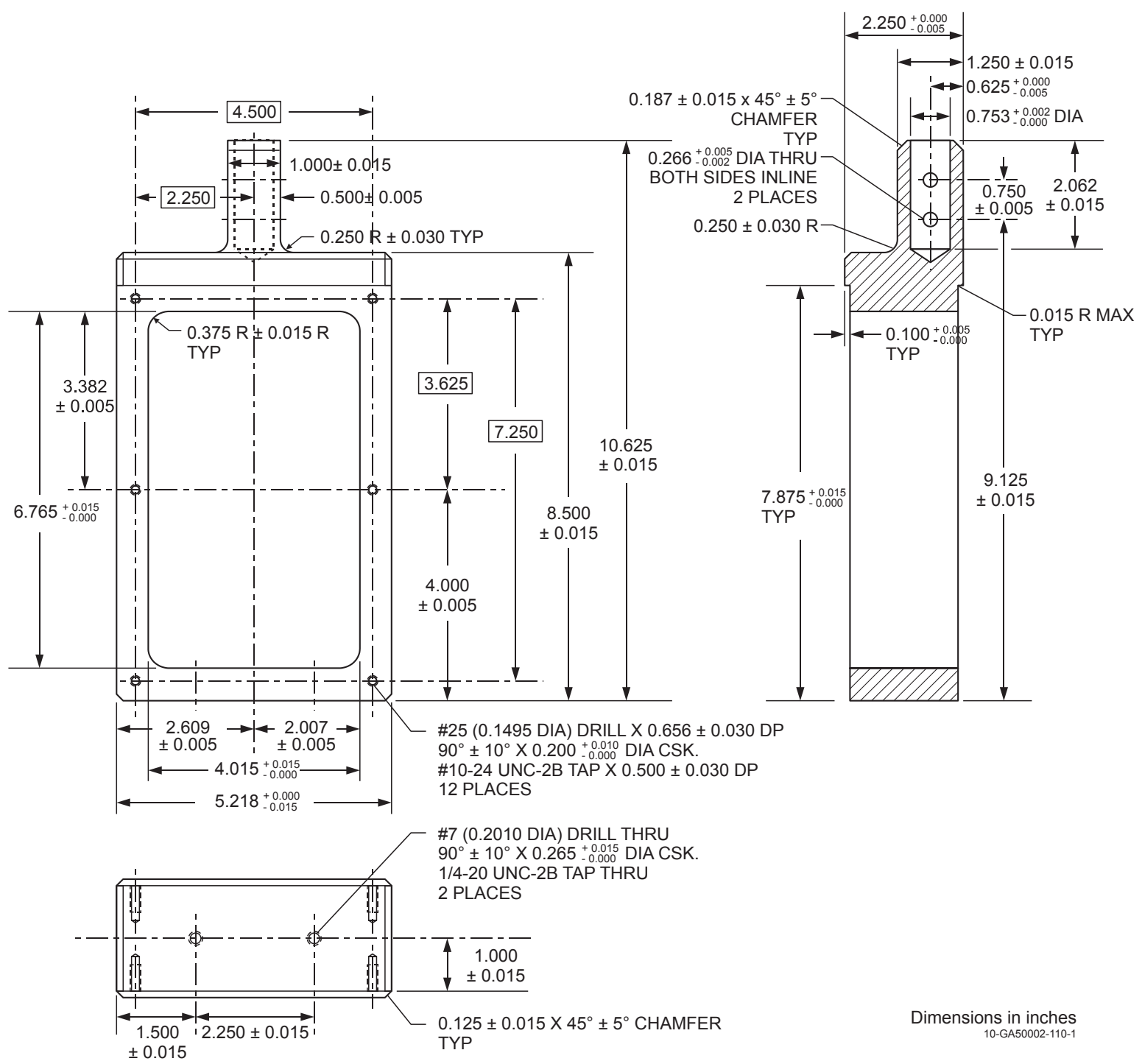

Figure 1.45a. Aperture Block Frame. 


\section{NEA/NSC/DOC(2006)1}

Fundamental - FUND

NRAD-FUND-RESR-002

CRIT-REAC-COEF

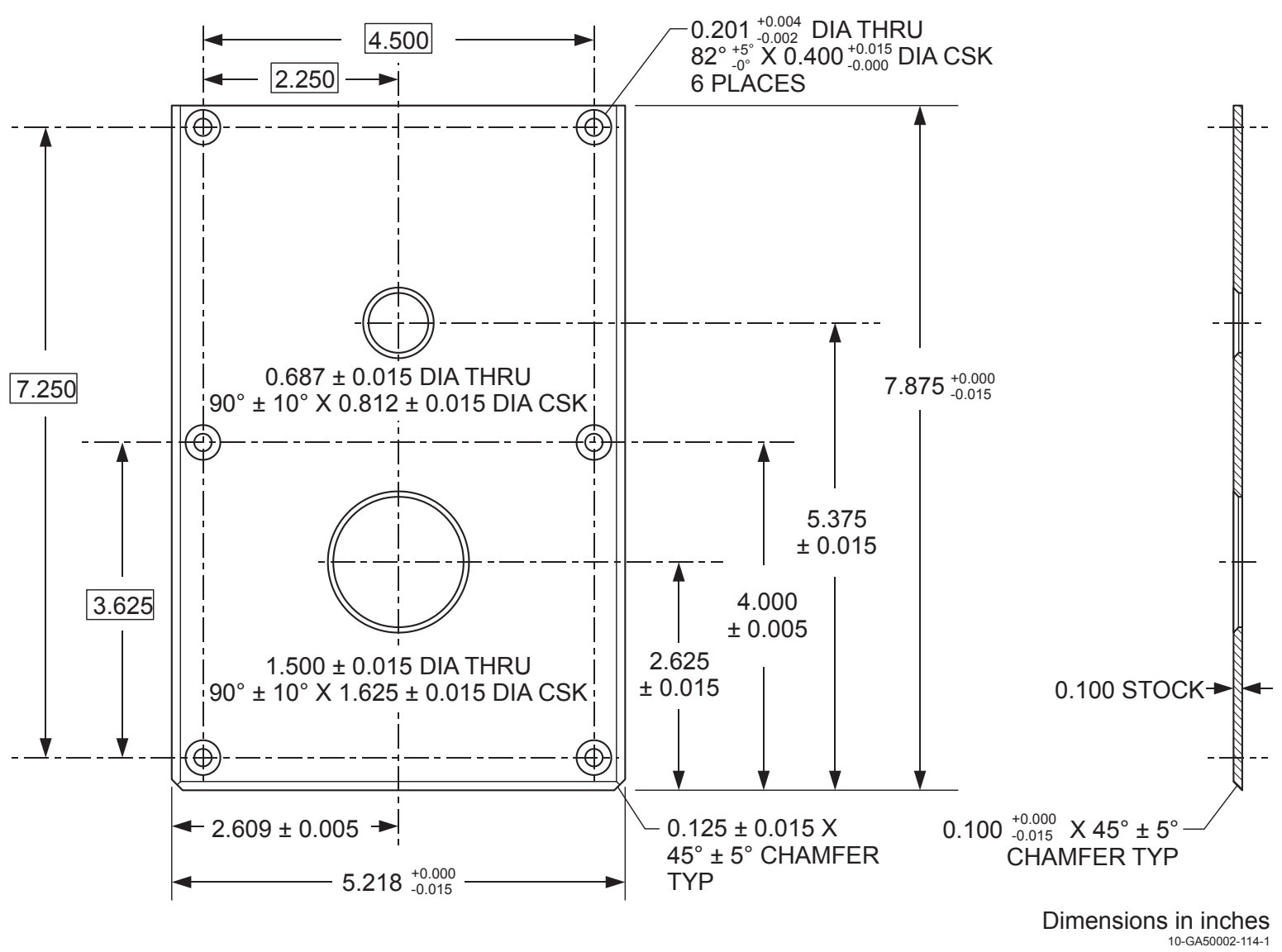

Figure 1.45b. Aperture Block Front Cover. 
NEA/NSC/DOC(2006)1

Fundamental - FUND

NRAD-FUND-RESR-002

CRIT-REAC-COEF

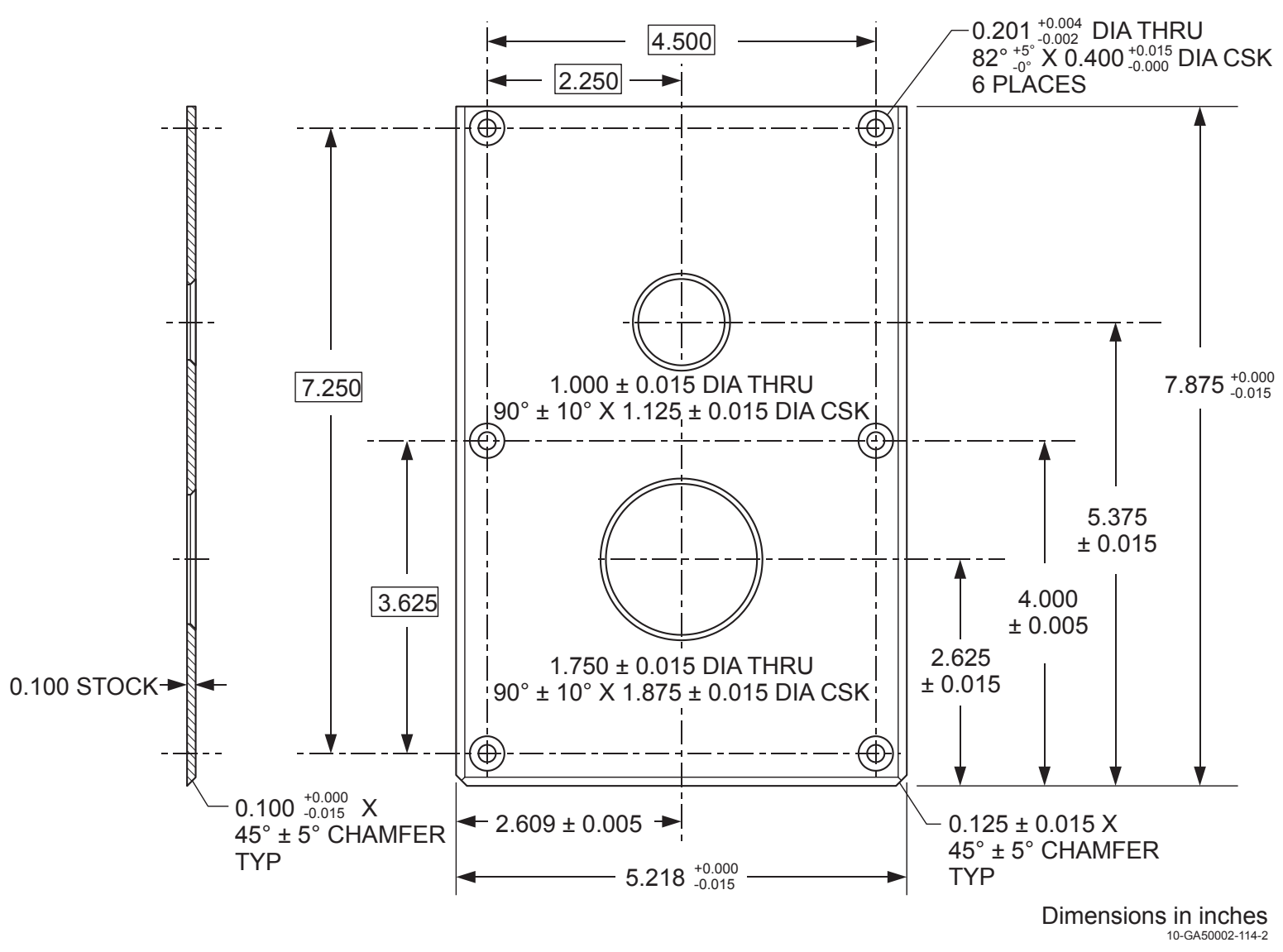

Figure 1.45c. Aperture Block Rear Cover. 


\section{NEA/NSC/DOC(2006)1}

\section{Fundamental - FUND}

NRAD-FUND-RESR-002

CRIT-REAC-COEF

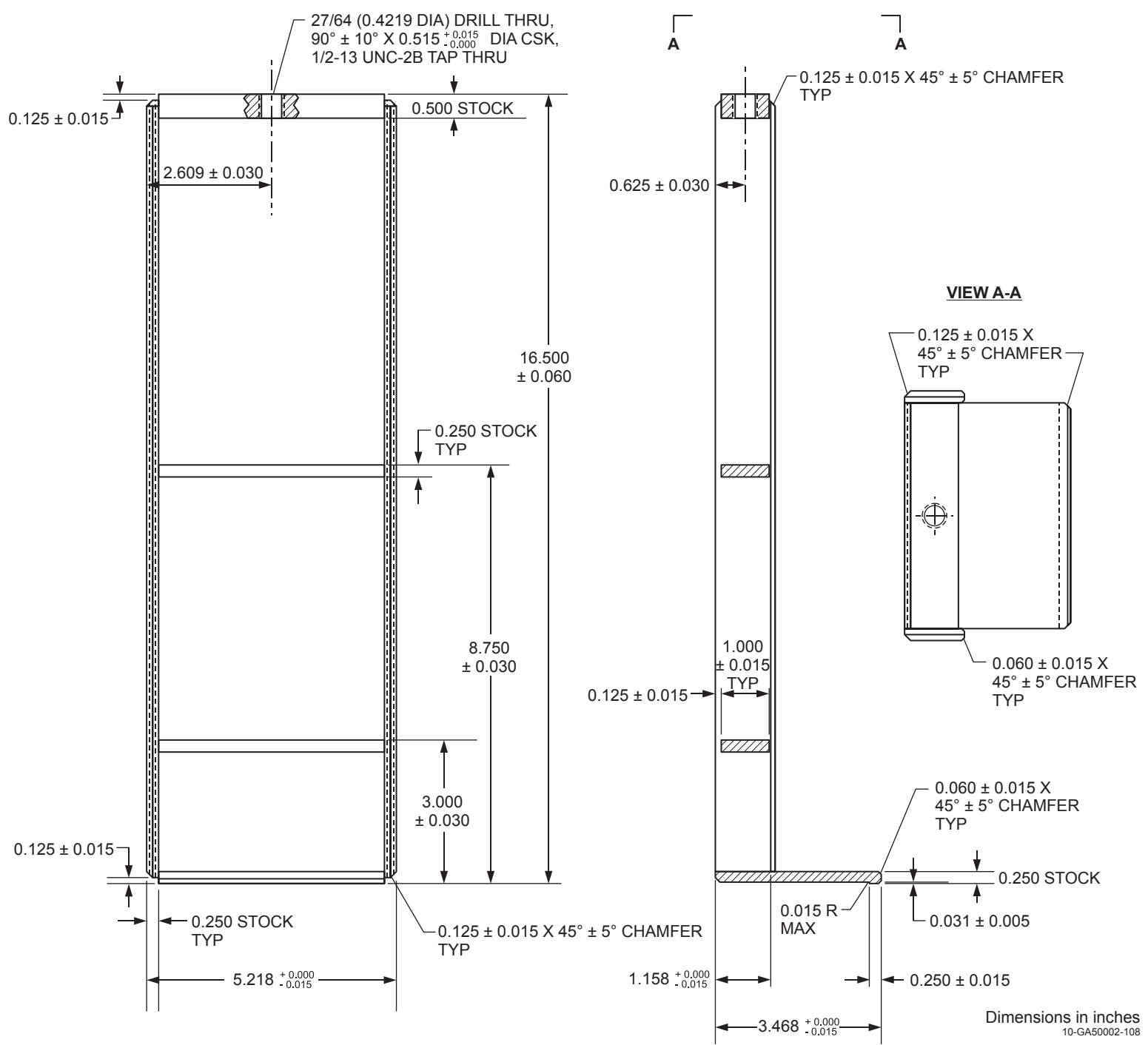

Figure 1.46. Aperture Block Guide.

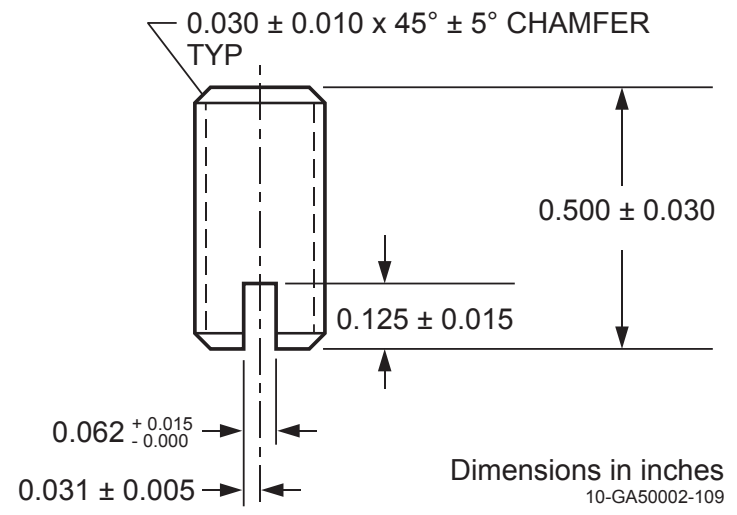

Figure 1.47. Aperture Block Adjusting Screw. 
NEA/NSC/DOC(2006)1

Fundamental - FUND

NRAD-FUND-RESR-002

CRIT-REAC-COEF
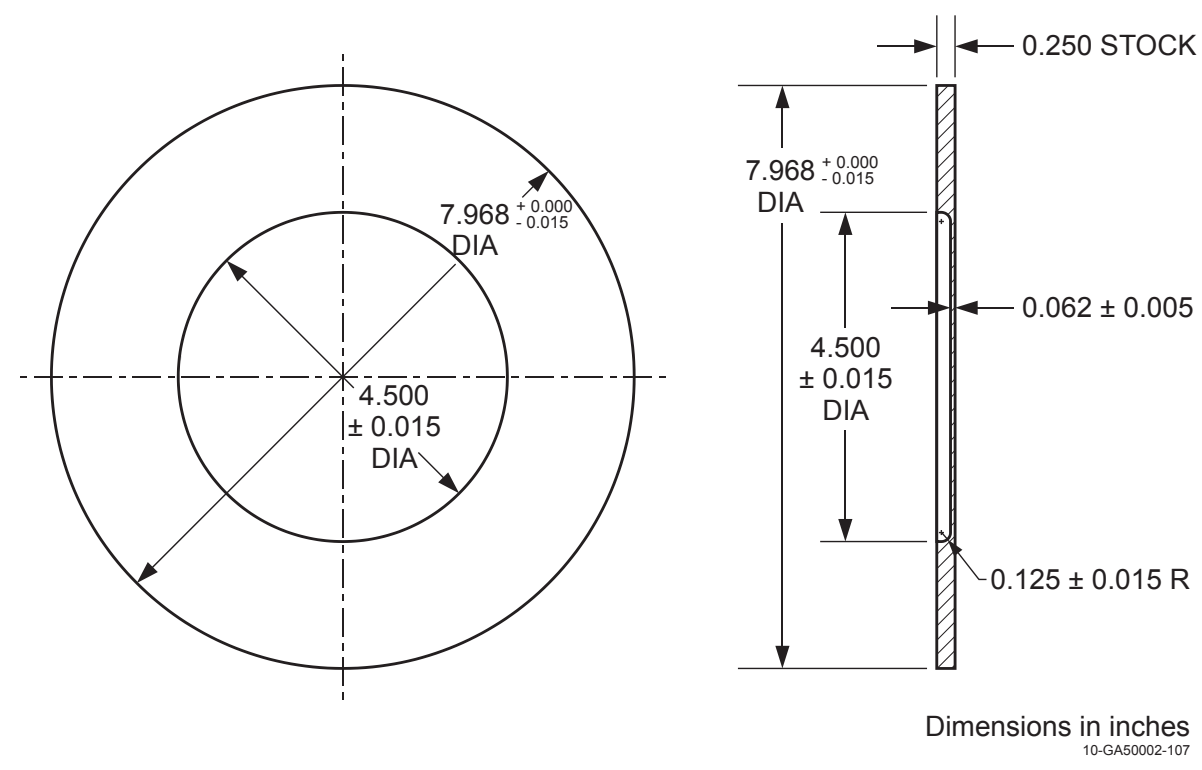

Figure 1.48. Lower Tube Seal Plate. 


\section{NEA/NSC/DOC(2006)1}

Fundamental - FUND

NRAD-FUND-RESR-002

CRIT-REAC-COEF
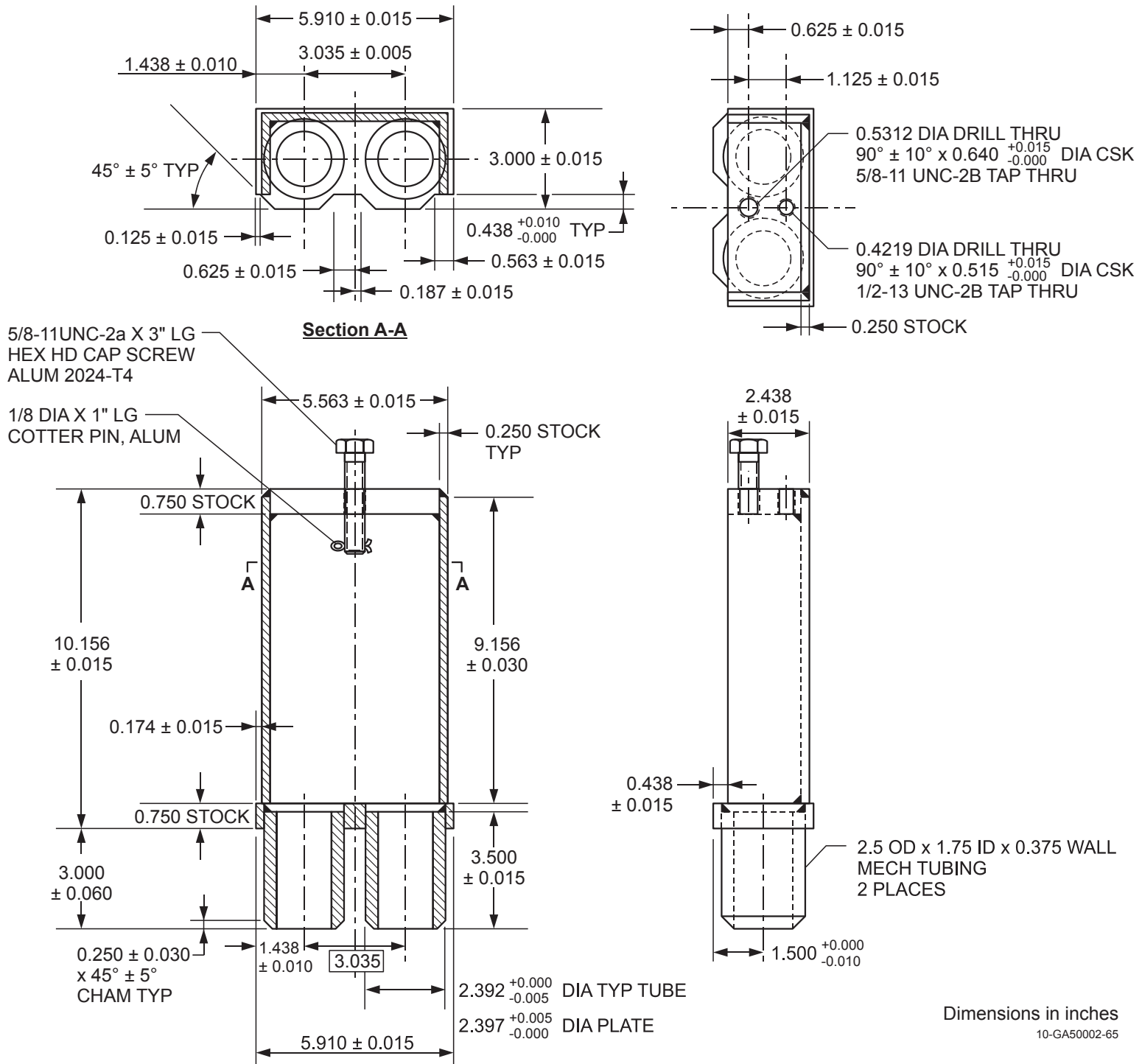

2.438

$\pm 0.015$
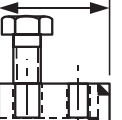

Figure 1.49. Beam Tube Support. 
NEA/NSC/DOC(2006)1

Fundamental - FUND

NRAD-FUND-RESR-002

CRIT-REAC-COEF

\section{Water Hole (Irradiation Position)}

A water hole is provided as an irradiation experimental position (Grid position C-4 SW in Figure 6). It may eventually contain the experiment irradiation section of a pneumatic transfer system. A control rod guide tube (Figure 1.35) is currently located in the position to aid in the alignment of experiment samples. The guide tube was empty (except for water) during the approach to critical and initial core measurements.

\section{Start-Up Source}

The NRAD reactor uses a start-up source to produce a measureable reactor power level during startup. It is a $5 \mathrm{Ci} \mathrm{AmBe}$ source in a sealed stainless steel cylindrical container that is $1.3 \mathrm{in} .(3.302 \mathrm{~cm})$ long and 0.8 in. $(2.032 \mathrm{~cm})$ in diameter. Internal dimensions of the source are not available. The source is mounted in a special graphite reflector assembly (Figure 1.50) and emits $\sim 1 \times 10^{7}$ neutrons $/ \mathrm{sec}^{\text {a }}$ The source was initially received on 5/10/1968 and was provided by Dayton Laboratory - Monsanto Research Corporation (currently Solutia Inc.).

The graphite block in Figure 1.50 replaces the typical graphite block in Figure 1.37 for a completed reflector assembly (Figure 1.51). The graphite reflector assembly containing the AmBe source is located in position F-3 of the NRAD core (Figure 1.6).

The start-up source is located within the graphite reflector assembly in the SE quadrant of the block approximately 14.125 in. $(35.8775 \mathrm{~cm})$ from the top of the graphite. The portions of the block not filled with pins and tie rods are filled with water. The source is placed within a source tube (Figure 1.52) with a cap (Figure 1.53). A wire rope is attached to the source tube cap so that it can be pulled out and moved around the tank. A special top assembly (Figure 1.54) is used to accommodate source placement in the graphite element.

The startup source is left in place during NRAD operations. It is only removed from the core to verify the source range instrument is operational before going to power. The source is swung off to the side of the tank to verify that log power decreases, and then reinstalled into its original position.

\footnotetext{
a "NRAD Reactor Fuel Core Conversion," DSA-005-NRAD-ADD-3 rev. 0, Idaho National Laboratory (April 2, 2009). [This reference is not available for public release.] 
NEA/NSC/DOC(2006)1

Fundamental - FUND

NRAD-FUND-RESR-002

CRIT-REAC-COEF

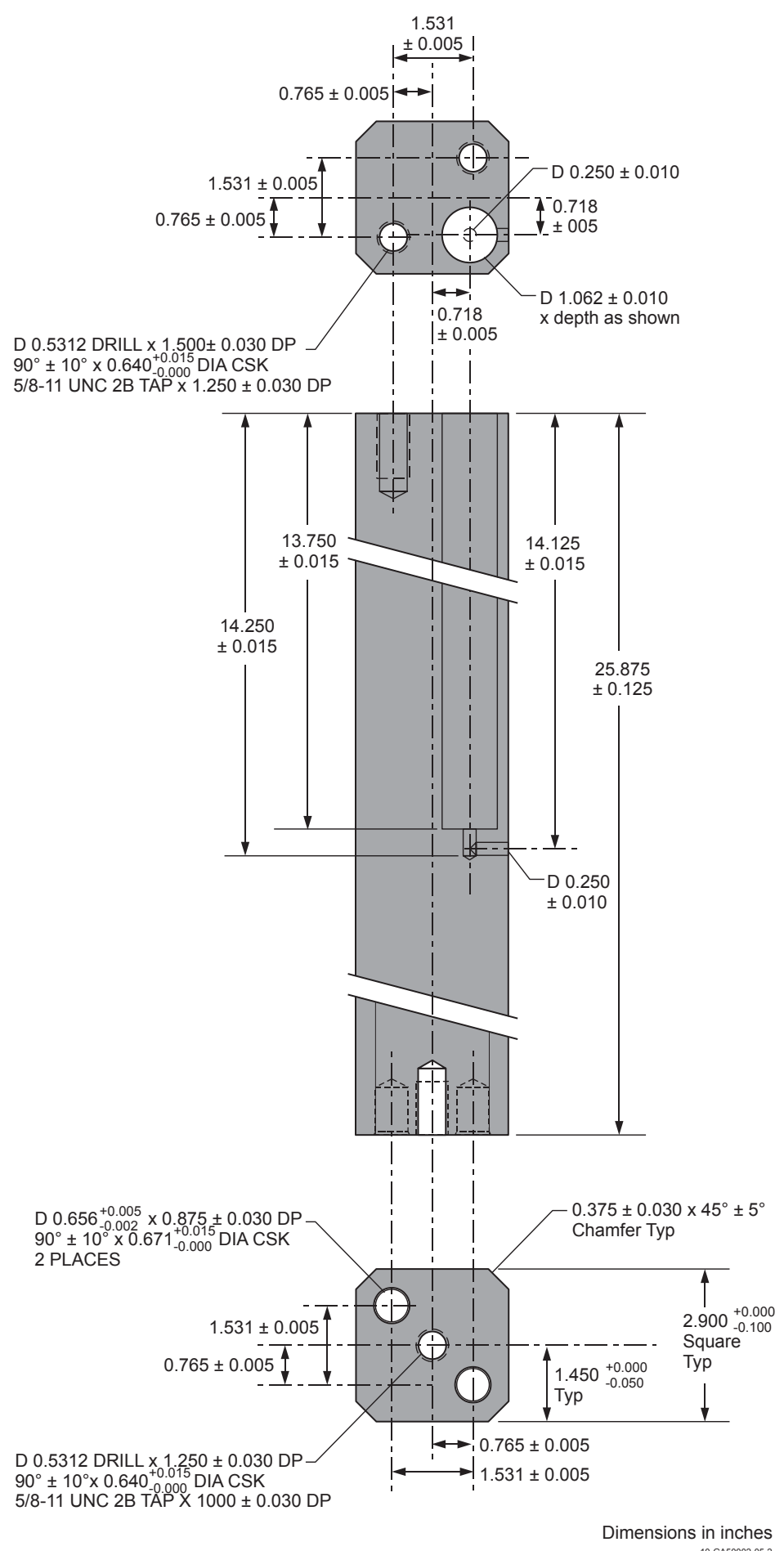

Figure 1.50. Graphite Reflector Block for Start-Up Source. 
NEA/NSC/DOC(2006)1

Fundamental - FUND

NRAD-FUND-RESR-002

CRIT-REAC-COEF

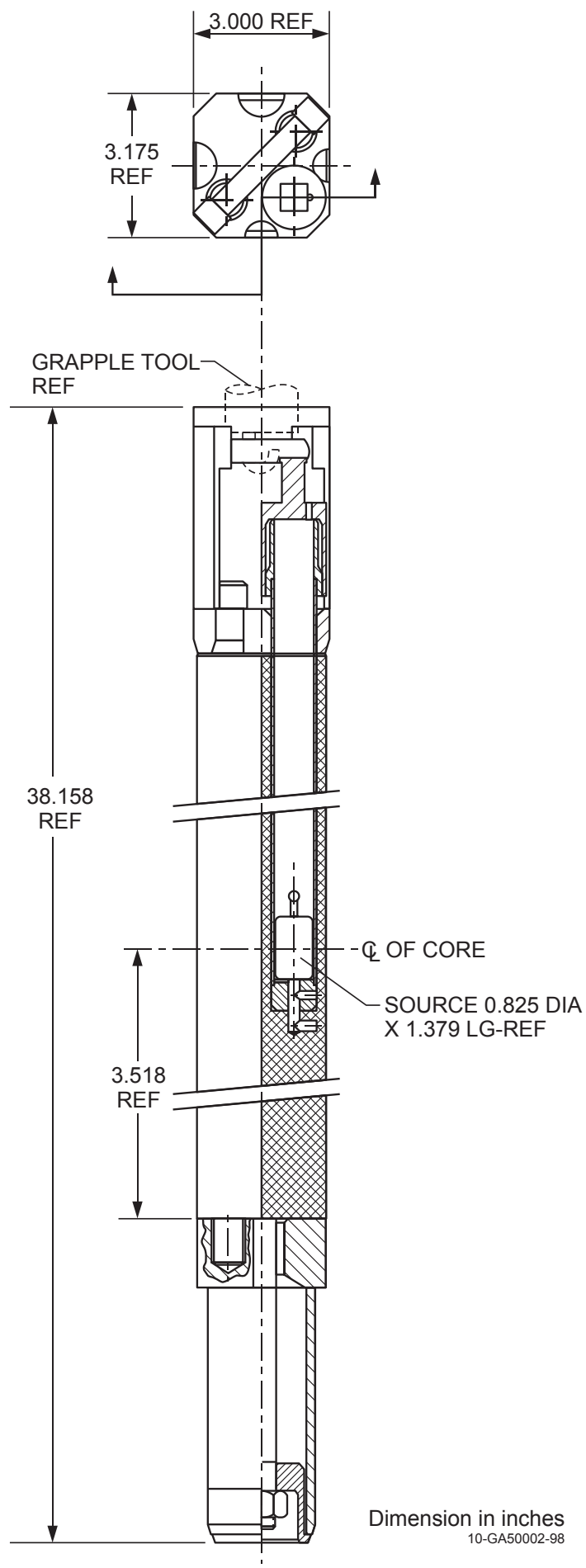

Figure 1.51. Graphite Element with Source Assembly. 
NEA/NSC/DOC(2006)1

Fundamental - FUND

NRAD-FUND-RESR-002

CRIT-REAC-COEF

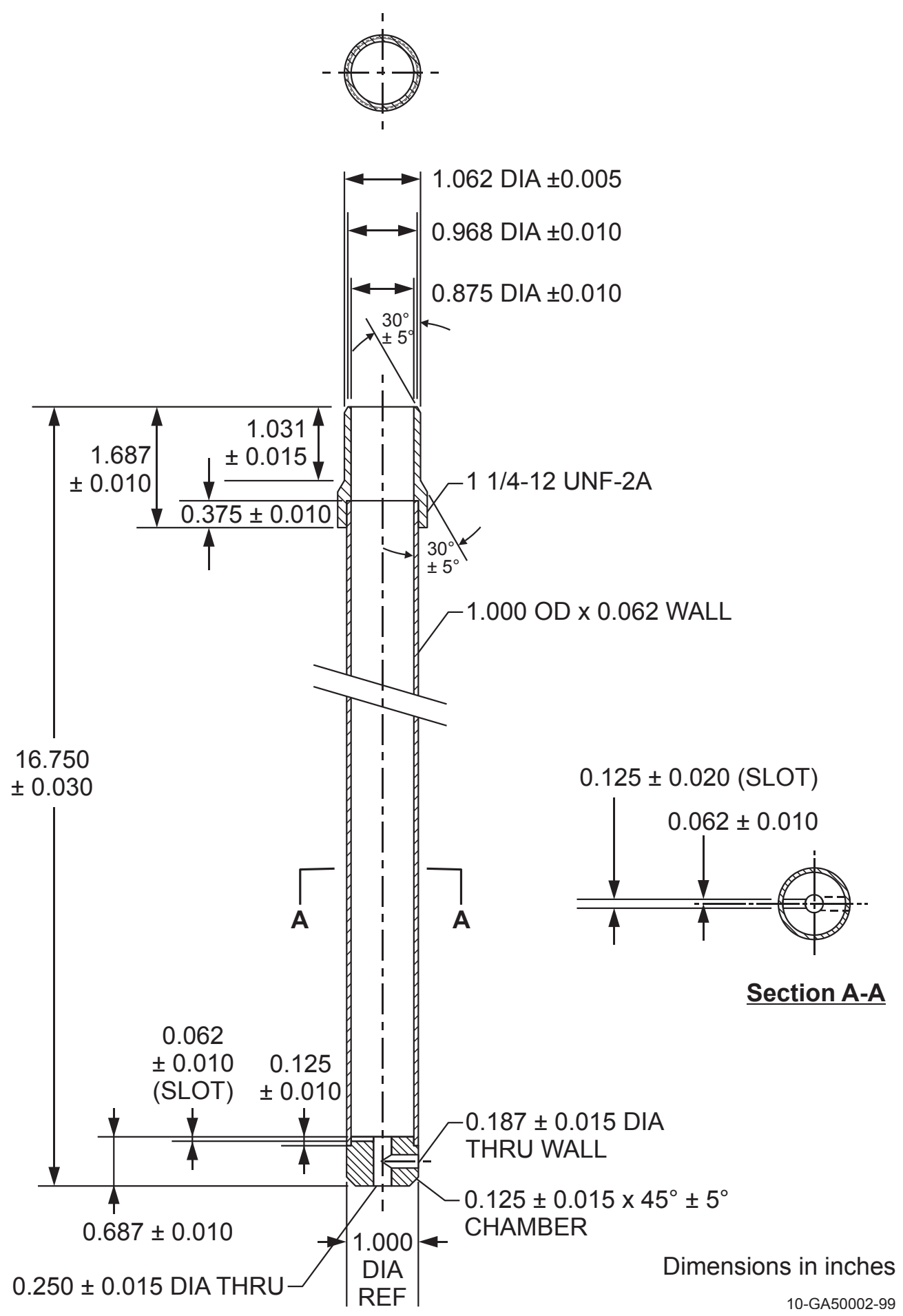

Figure 1.52. Source Tube. 
NEA/NSC/DOC(2006)1

Fundamental - FUND

NRAD-FUND-RESR-002

CRIT-REAC-COEF

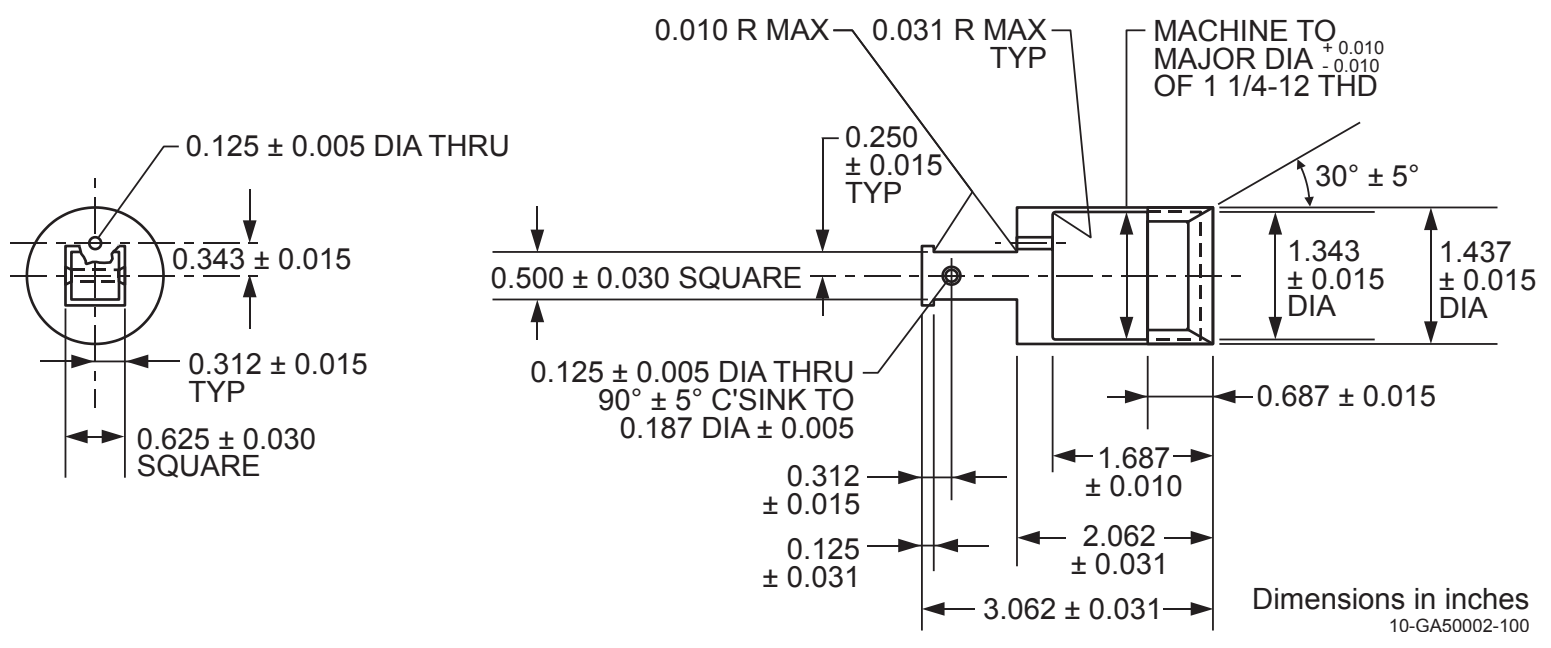

Figure 1.53. Source Tube Cap. 


\section{NEA/NSC/DOC(2006)1}

Fundamental - FUND

NRAD-FUND-RESR-002

CRIT-REAC-COEF
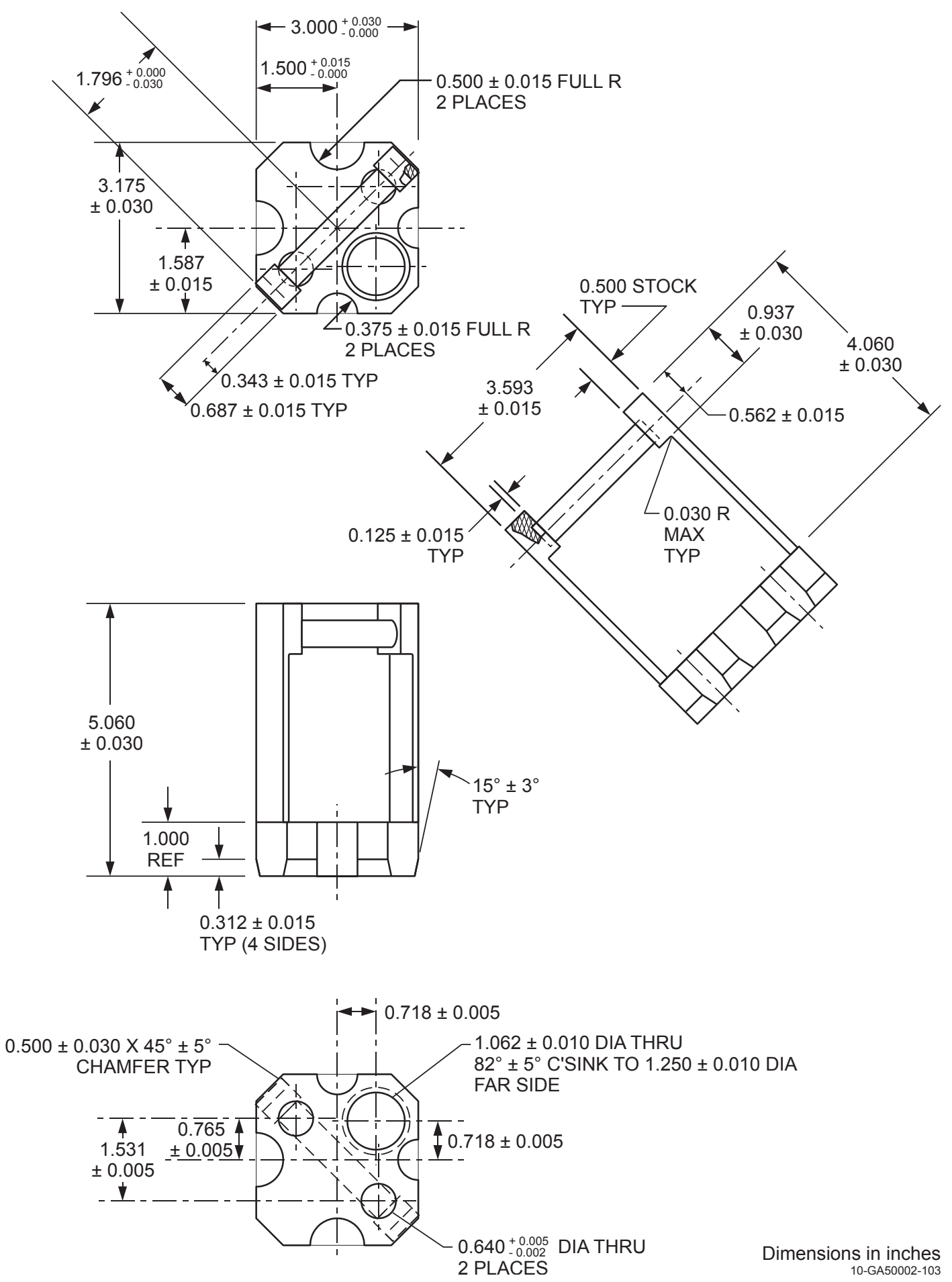

Figure 1.54. Top Assembly for Graphite Element with Source Assembly. 


\section{Detectors}

The pool detectors are located to the south and north of the reactor core, near the edge of the pool (Figures 1.1 and 1.6). They consist of one linear, one log, and two safety channels. Horizontal and vertical placement of these detectors within the tank is shown with detail in Figures 1.55 and 1.56, respectively.

The wide-range (10 decade) log-power channel is a fission-chamber detector that provides indication of power and period from source level to $120 \%$ of design power. It uses both counting and Campbelling techniques to give an accurate log-power indication with very little gamma background error. Period measurements are from $-30 \mathrm{~s}$ to $+3 \mathrm{~s}$ over the full power range. ${ }^{\mathrm{a}}$

Two power-level-safety channels provide indication of reactor power from $0.001 \%$ to $120 \%$ of design power using uncompensated ion-chamber-type detectors. ${ }^{\text {a }}$

The linear-power channel uses an all-solid-state multirange picoammeter that obtains a current signal from a compensated ion chamber. Depending on the gamma background level, this channel can measure power over most of the operating range of the reactor. ${ }^{\text {a }}$ This channel is used to measure reactivity changes to measure reactivity effects such as control rod worths.

Detector power levels were calibrated on April 16-18, 2013 as part of the NRAD reactor startup procedures. $^{\text {b }}$

\footnotetext{
a “HFEF/N Neutron Radiography Facility System Design Description,” W0170-0004-SA rev. 2, Idaho National Laboratory (June 1, 1978). [This reference is not available for public release.]

b "Startup Report for the NRAD Reactor," 911195 rev. 0, GA Project 39296, TRIGA Reactor Division of General Atomics (November 4, 2010). [This reference is not available for public release.]
} 


\section{NEA/NSC/DOC(2006)1}

Fundamental - FUND

NRAD-FUND-RESR-002

CRIT-REAC-COEF

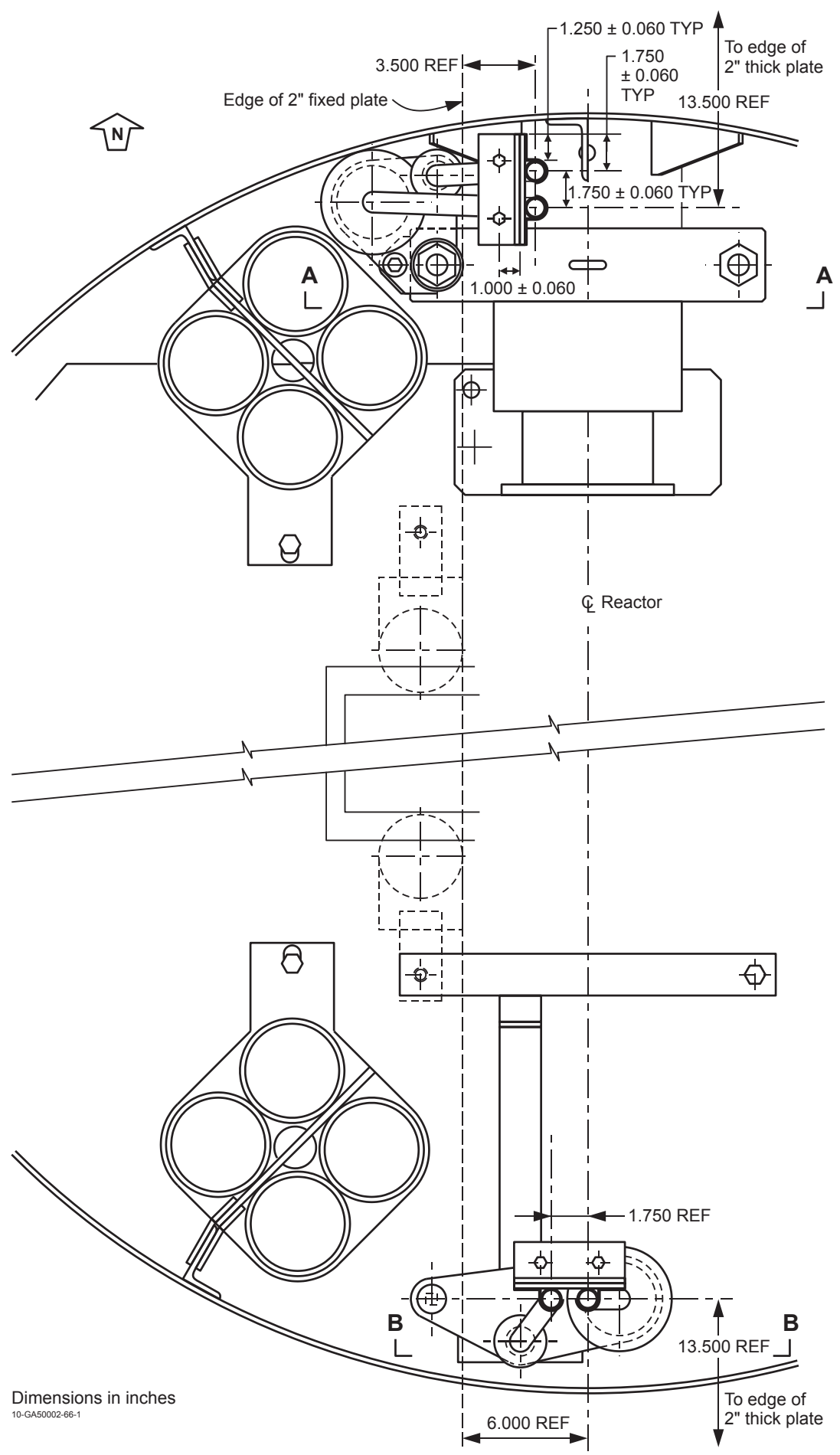

Figure 1.55. Horizontal Detector Placement in NRAD Tank. 
NRAD-FUND-RESR-002

CRIT-REAC-COEF

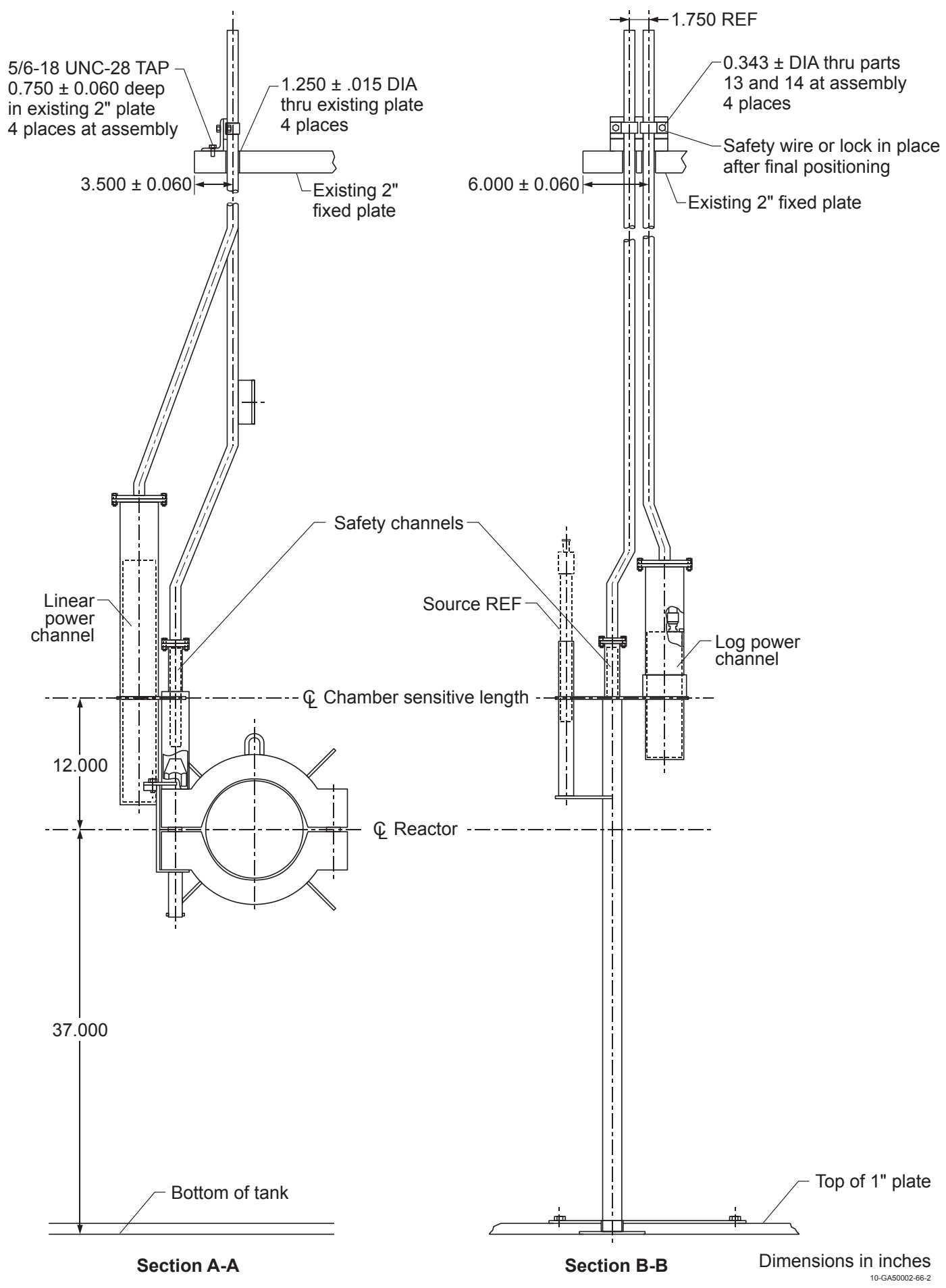

Figure 1.56. Vertical Detector Placement in NRAD Tank. 


\section{Dry Tubes}

Dry tubes can be placed around the periphery of the core to allow for samples to be irradiated without getting them wet. Dry tubes were not installed during the initial critical measurements of the NRAD core. When dry tubes are used, they are typically placed in the corners of the core, as shown in position F-1 NE in Figure 1.6.

Dry tubes are aluminum pipes open at the top with an inside diameter of $1.5625 \mathrm{in} .(3.96875 \mathrm{~cm})$ and a thickness of 0.125 in. $(0.3175 \mathrm{~cm})$. The pipe extends from the grid plate attachment hardware to approximately 4 in. $(10.16 \mathrm{~cm})$ above the tank waterline. When installed in the F-1 NE position, it rests against the $90^{\circ}$ angle formed by the graphite blocks in positions E-1 and F-2, effectively displacing a column of water just outside the reactor core. Experiments are lowered into the tube using a variety of holders. ${ }^{\mathrm{a}}$

The dry tube is stuck to a guide tube fitting to close the bottom of the pipe and attach it into a grid plate adapter. It is slightly cantered against the graphite blocks in the adjacent positions to wedge it into the core; friction counteracts the buoyancy effects. ${ }^{b}$

\section{Graphite Elements}

The graphite elements used the same stainless steel cladding and end fittings as the fuel elements (see Figure 1.57). However, the element internals are a graphite reflector rod with the same density and diameter as the top/bottom axial graphite reflectors in the fuel elements, but with a length of $55.5523 \mathrm{~cm}$ $\left(\sim 21.871\right.$ in. as shown in Figure 1.58). ${ }^{\mathrm{c}}$

Two of these rods were used in the 62-fuel-element core and four in the 64-fuel-element core. Graphite elements were not previously used in any NRAD reactor core configuration.

\footnotetext{
${ }^{a}$ Personal communication with Ken Schreck at HFEF (January 1, 2011).

${ }^{b}$ Personal communication with Ken Schreck at HFEF (January 12, 2011).

${ }^{\mathrm{c}}$ Personal communication with Chris Ellis at GA (September 16, 2010). 


\section{NEA/NSC/DOC(2006)1}

Fundamental - FUND

NRAD-FUND-RESR-002

CRIT-REAC-COEF

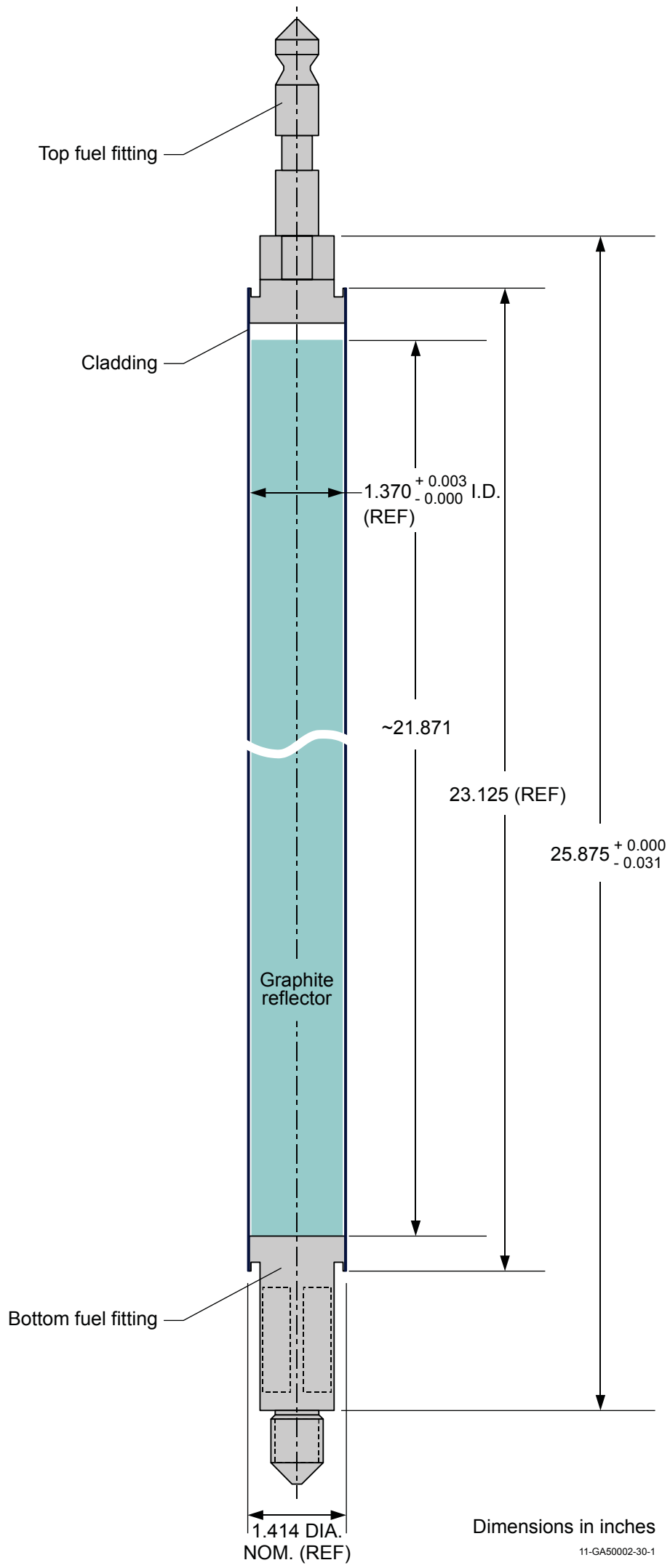

Figure 1.57. Graphite Element. 
NEA/NSC/DOC(2006)1

Fundamental - FUND

NRAD-FUND-RESR-002

CRIT-REAC-COEF

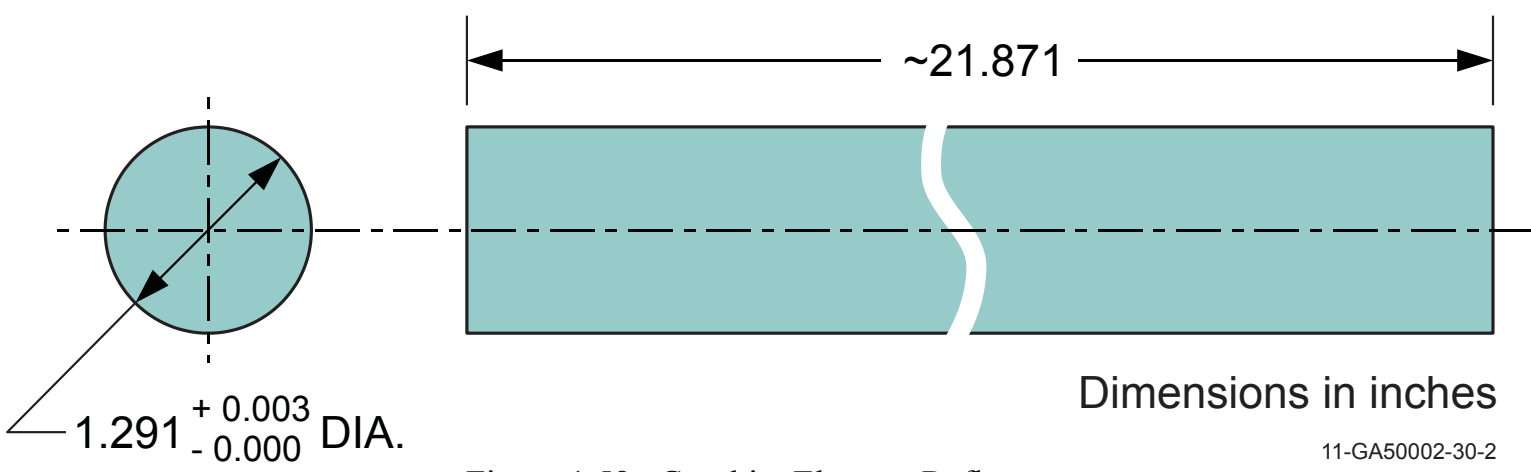

Figure 1.58. Graphite Element Reflector.

\subsubsection{Experimental Procedure}

As-built fuel data, and physical placement of fuel clusters in the core, are found in Appendices D and E, respectively. Measurements taken during the upgrade of the NRAD LEU core are recorded in an INL internal report. ${ }^{\mathrm{a}}$

Fission chamber counts and period measurements were used to monitor for criticality and the power of the core. The NRAD reactor is considered critical when the power level is sustained at $50 \mathrm{~W}$, the regulating rod position is stable, and the period is infinite. The linear power channel also monitors the power level during the measurement of the just-critical state. ${ }^{b}$

Interim criticality with 62 fuel elements (Figure 1.59) was achieved on April 11, 2013. The shim rods were fully withdrawn and the regulating rod was $442 \pm 1$ units $(6.63 \pm 0.015 \mathrm{in}$. or $16.8402 \pm 0.0381 \mathrm{~cm})$. This configuration was attained by moving the graphite block from the F-4 position to the F-6 position and adding an additional cluster containing two fuel and two graphite elements. Control rod measurements, core excess reactivity, and shutdown margin were determined for this configuration (see Section 1.4).

The upgraded core criticality with 64 fuel elements (Figure 1.60) went critical on April 15, 2013. The shim rods were fully withdrawn and the regulating rod was $205 \pm 1$ units $(3.075 \pm 0.015$ in. or $7.8105 \pm$ $0.0381 \mathrm{~cm})$. This configuration was attained by moving the graphite block from the D-1 position to the A-1 position and adding an additional cluster containing two fuel and two graphite elements. Control rod measurements, core excess reactivity, and shutdown margin were determined for this configuration (see Section 1.4). Additional power calorimetric measurements (see Section 1.5) were also performed.

a “NRAD 64 Element Core Upgrade Startup Report,” INL/INT-13-29899 [draft], Idaho National Laboratory (publication date pending). [This reference is not available for public release.]

${ }^{b}$ Personal communication with Ken Schreck at HFEF (September 29, 2010). 
NEA/NSC/DOC(2006)1

Fundamental - FUND

NRAD-FUND-RESR-002

CRIT-REAC-COEF

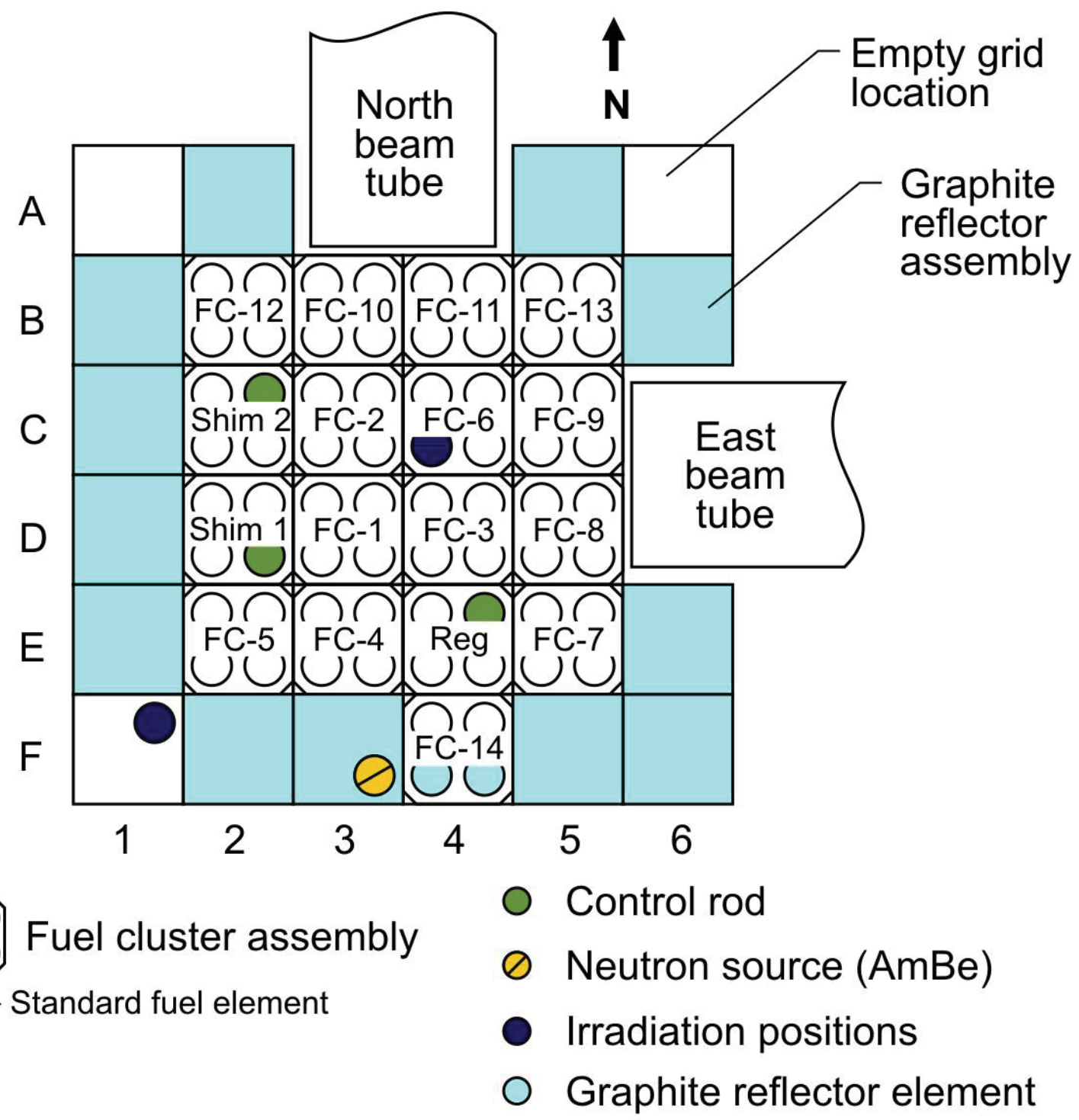

11-GA50002-104.1

Figure 1.59. Intermediary Core Critical Configuration (62 Fuel Elements). 
NEA/NSC/DOC(2006)1

Fundamental - FUND

NRAD-FUND-RESR-002

CRIT-REAC-COEF

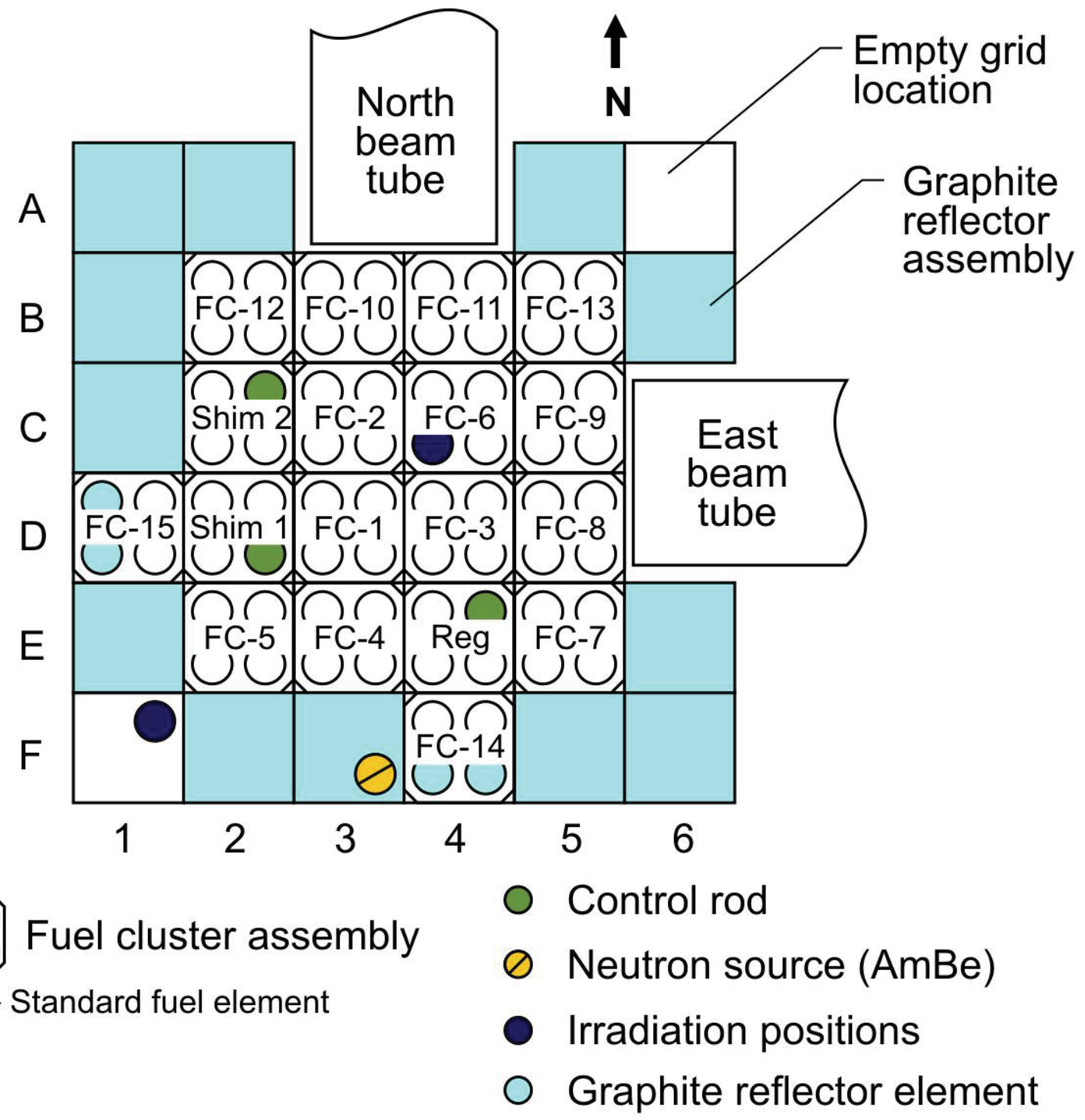

11-GA50002-104-2

Figure 1.60. Upgraded Core Critical Configuration (64 Fuel Elements). 
NEA/NSC/DOC(2006)1

Fundamental - FUND

NRAD-FUND-RESR-002

CRIT-REAC-COEF

\subsubsection{Material Data}

\subsubsection{Facility Description}

\section{Site and Facility}

The rock layer below the HFEF basement is composed of natural lava rock.

The concrete is magnetite aggregate concrete with a density of about $220 \mathrm{lb} / \mathrm{ft}^{3}\left(3524 \mathrm{~kg} / \mathrm{m}^{3}\right)$ with additional steel plates and borated polyethylene to reduce radiation levels in adjacent rooms. ${ }^{\text {a }}$

The concrete surrounding the reactor tank contains $120 \mathrm{lb} / \mathrm{yd}^{3}\left(131 \mathrm{~kg} / \mathrm{m}^{3}\right)$ of boron frit. ${ }^{\mathrm{b}}$

\section{Reactor Containment}

The reactor tank is constructed from welded aluminum $6061-\mathrm{T} 6 .^{\mathrm{c}}$

\section{Non-Nuclear Components}

The overflow and coolant system piping is comprised of aluminum 6061-T6.

\section{Moderator/Coolant}

A single thermistor, located approximately $1 \mathrm{ft}(\sim 30.48 \mathrm{~cm})$ below the surface of the tank water, is used to measure water temperature. It is nonlinear, very accurate, and calibrated to a tenth of a degree Celsius. Two additional thermistors are located before and after the coolant water heat exchanger to measure coolant temperature during power operations. They are calibrated to a hundredth of a degree Celsius. Full power operation is limited to $39{ }^{\circ} \mathrm{C}$. Startup temperatures are typically at $26{ }^{\circ} \mathrm{C}$ and at-power operations are typically performed at $37^{\circ} \mathrm{C}$.

For the critical core with 62 fuel elements the tank water temperature was $30.0^{\circ} \mathrm{C}$. The tank water temperature was $27.8{ }^{\circ} \mathrm{C}$ for the critical with 64 fuel elements.

The water in the NRAD tank goes through several deionizers to remove impurities. The water chemistry is monitored for conductivity and radioactivity content.

\subsubsection{Reactor Core}

\section{Core Support Structure}

The core support structure and core mounting pad are composed of aluminum 6061-T6. They are bolted together with cap screws also composed of aluminum 6061-T6.

\footnotetext{
a "NRAD Safety Analysis Report,” DSA-005-NRAD rev. 5, Idaho National Laboratory (April 2, 2009). [This reference is not available for public release.]

b "HFEF/N Neutron Radiography Facility System Design Description,” W0170-0004-SA rev. 2, Idaho National Laboratory (June 1, 1978). [This reference is not available for public release.]

c "NRAD Reactor Fuel Core Conversion," DSA-005-NRAD-ADD-3 rev. 0, Idaho National Laboratory (April 2, 2009). [This reference is not available for public release.]
} 
NEA/NSC/DOC(2006)1

Fundamental - FUND

NRAD-FUND-RESR-002

CRIT-REAC-COEF

\section{Grid Plate Assembly}

The grid plate assembly is composed of aluminum 1100. It is bolted to the support structure with aluminum 6061-T6 nuts and bolts. The skirt on the four sides of the grid plate is also aluminum 6061T6. The dowel pins used to align the cluster assemblies are stainless steel 304.

\section{Fuel Cluster Assembly}

A cluster of four fuel elements contains approximately $592 \pm 1 \mathrm{~g}$ of ${ }^{235} \mathrm{U}$.

The locking plates and locking bolts for the upper cluster attachments are stainless steel 304 or 304L. The threaded insert used in the top assemblies is either stainless steel 303 or 18-8. The bottom cluster fitting and remaining parts of the top assembly are aluminum 6061-T6.

\section{Fuel Elements}

The TRIGA fuel elements were manufactured in 2009-2010 by TRIGA International, a joint venture between General Atomics in San Diego, California, USA, and CERCA, a subsidiary of AREVA NP in Romans-sur-Isère, France, at the CERCA Fuel Fabrication Plant. A total of 64 low enriched uranium fuel elements were fabricated for the NRAD reactor. A summary of the as-built fuel data (Appendix D) is provided in Table 1.5 .

Table 1.5. Summary of As-Built Fuel Data per Average Fuel Element (Appendix D). ${ }^{\left({ }^{(a)}\right.}$

\begin{tabular}{|c|c|c|c|c||}
\hline $\begin{array}{c}\text { Core Configuration } \\
\text { Number of Fuel Elements }\end{array}$ & Initial Critical & Initial Full Load & Intermediary & All Elements \\
\hline \hline Total Mass (g) & $2506.4 \pm 3.5$ & $2506.5 \pm 3.4$ & $2506.6 \pm 3.4$ & $2506.8 \pm 3.6$ \\
Uranium Mass (g) & $749.6 \pm 2.5$ & $749.9 \pm 2.7$ & $749.9 \pm 2.7$ & $750.2 \pm 3.1$ \\
${ }^{\mathbf{2 3 5} \text { U Mass (g) }}$ & $147.9 \pm 0.5$ & $148.0 \pm 0.6$ & $148.0 \pm 0.6$ & $148.1 \pm 0.7$ \\
${ }^{235}$ U Enrichment (wt.\%) & $19.74 \pm 0.01$ & $19.74 \pm 0.02$ & $19.74 \pm 0.02$ & $19.74 \pm 0.02$ \\
U Mass Content (wt.\%) & $29.91 \pm 0.07$ & $29.92 \pm 0.09$ & $29.92 \pm 0.08$ & $29.23 \pm 0.10$ \\
H/Zr Ratio & $1.58 \pm 0.01$ & $1.58 \pm 0.01$ & $1.58 \pm 0.01$ & $1.58 \pm 0.01$ \\
Er Content (wt.\%) & $0.90 \pm 0.02$ & $0.90 \pm 0.02$ & $0.90 \pm 0.02$ & $0.90 \pm 0.02$ \\
C Content (wt.\%) & $0.30 \pm 0.01$ & $0.30 \pm 0.02$ & $0.30 \pm 0.02$ & $0.30 \pm 0.02$ \\
Fuel Element Length (mm) & $380.2 \pm 0.4$ & $380.2 \pm 0.4$ & $380.2 \pm 0.4$ & $380.2 \pm 0.4$ \\
Fuel Element Diameter (mm) & $34.805 \pm 0.003$ & $34.805 \pm 0.003$ & $34.805 \pm 0.003$ & $34.805 \pm 0.003$ \\
Cladding Inner Diameter (mm) & $34.894 \pm 0.005$ & $34.894 \pm 0.005$ & $34.894 \pm 0.005$ & $34.894 \pm 0.005$ \\
Fuel-Clad Gap (mm) & $0.088 \pm 0.005$ & $0.089 \pm 0.005$ & $0.089 \pm 0.005$ & $0.089 \pm 0.005$ \\
\hline \hline
\end{tabular}

(a) The uncertainty in these values is $1 \sigma$ of the average population and not the average mean.

TRIGA fuel is a uranium-zirconium-hydride $\left(\mathrm{UZrH}_{\mathrm{x}}\right)$ fuel where the uranium is dispersed in a matrix of zirconium-hydride. Typically the $\mathrm{H} / \mathrm{Zr}$ ratio is $\sim 1.6$. The final fuel form is accomplished by hydriding uranium-zirconium alloy fuel sections to provide intrinsic moderation. A hole is drilled through the center of the fuel section to facilitate hydriding; then a zirconium rod is placed in the hole to prevent fuel damage during reactor operations.

Fuel with an $\mathrm{H} / \mathrm{Zr}$ ratio of $\sim 1.6$ is $\delta$-phase, fcc hydride that allows for considerable variation in fuel temperatures without building up high internal gas pressures in the fuel element. This also eliminates the 
NEA/NSC/DOC(2006)1

\section{Fundamental - FUND \\ NRAD-FUND-RESR-002 \\ CRIT-REAC-COEF}

formation of a second phase and the problem of large volume changes at higher temperatures. The absence of significant thermal diffusion of hydrogen also precludes concomitant volume changes and cracking. The dimensional changes of fuel rods due to hydrogen migration are of minor importance. ${ }^{\mathrm{a}}$

The uranium-zirconium alloy is cast in an induction furnace at high temperature under a controlled atmosphere. Prior to casting, all components (uranium, zirconium, erbium, and recycled material cast off from prior fuel fabrication batches) have been carefully weighed and checked. (Erbium is added in small quantities, as a burnable poison, to reduce initial core excess reactivity.) Components are melted in a graphite crucible and poured into a graphite mold to cool down to room temperature. A remelt is performed directly in the mold to improve the homogeneity and structural quality of the alloy. After cooling, the casting is removed from the mold and brought to the desired length and diameter on a lathe. Each fuel meat is then individually identified. After machining, chops (i.e. excess scrap materials that were removed during machining) are washed away to be used as recyclable material and as samples for chemical analysis. The fuel meats are then hydrided in an electrically heated furnace at high temperature under a hydrogen environment. A centerless grinder is used to bring the fuel meat to the final diameter and then the fuel meat is cleaned to remove surface defects. The fuel meat is slid into the cladding with the other fuel element components and the end fittings are welded to the clad and Helium leak tested. ${ }^{\mathrm{b}}$

The addition of erbium to the UZrH introduces no deleterious effects to the fuel and is not believed to segregate as it forms a metallic solution in the uranium-zirconium alloy. Erbium forms a stable hydride, remains dispersed in the alloy, and cannot migrate or segregate because its diffusion rates are very low. ${ }^{\mathrm{a}}$

The fuel elements are clad in stainless steel 304 with end fittings of the same material.

Typical impurities in the fuel agglomerate include carbon and hafnium in the zirconium metal and hydrogen in the erbium. There is $\sim 0.2 \mathrm{wt} . \% \mathrm{Hf}$ in the fuel. The $\mathrm{H}: \mathrm{Zr}$ specification for the fuel only correlates hydrogen to zirconium and does not include the other constituents in the fuel. The raw material feed, uranium fuel from the Y-12 National Security Complex, is typically enriched to $\sim 19.75$ wt. $\%{ }^{235} \mathrm{U}$. The molybdenum poison disc is composed of natural molybdenum and believed to be $\sim 100 \%$ pure. The axial graphite reflectors are comprised of nuclear grade graphite, possibly PGX ${ }^{\mathrm{TM}}$ (low ash, molded graphite) or ECW ${ }^{\mathrm{TM}}$ (highly purified, extruded graphite). ${ }^{\mathrm{C}}$

It is believed that a total of eleven batches of uranium metal were shipped from Y-12 to CERCA to be used in the fabrication of the NRAD fuel elements. ${ }^{d}$ The fuel is assembled under ambient air conditions.

Typically the hafnium content in the zirconium is $60 \mathrm{ppm}$ without a lot of variation. The carbon content in the fuel composition comes from the hydriding process in the graphite crucible. Variations in fuel content typically have very small effects on criticality. The most sensitive composition variations include hydrogen, ${ }^{167} \mathrm{Er}$, and ${ }^{235} \mathrm{U}$. All manufactured fuel was within the required fuel specifications. Variation of the loading pattern for the NRAD reactor core was calculated to have at most a $0.0012 \Delta \mathrm{k}_{\text {eff }}$ difference between the most and least reactive configurations. ${ }^{\mathrm{e}}$

\footnotetext{
${ }^{a}$ M. T. Simnad, F. C. Foushee, and G. B. West, "Fuel Elements for Pulsed TRIGA Research Reactors," Nucl. Technol., 28, 31-56 (1976).

${ }^{\mathrm{b}}$ G. Harbonnier and J-C. Ottone, "TRIGA International: A New TRIGA Fuel Fabrication Facility at CERCA," Proc. Test, Research, and Training Reactors (TRTR) - Annual Meeting 1997, Newport, Oregon (October 21-24, 1997).

${ }^{c}$ Personal communication with John M. Bolin at General Atomics (November 3, 2009).

${ }^{\mathrm{d}}$ Personal communication with John M. Bolin at General Atomics (October 20, 2010).

e Presentation material with subsequent discussion at the American Nuclear Society 2010 Annual Meeting in regards to "Fuel Manufacturing Uncertainty Effect on NRAD Criticality," by H. Choi, J. Bolin, and A. Veca (June $16,2010)$.
} 


\section{Fundamental - FUND \\ NRAD-FUND-RESR-002 \\ CRIT-REAC-COEF}

Casting sprues, rejected meats, and filings are all reprocessed at another AREVA facility and sent back to CERCA for use in new fuel fabrications. Reprocessed material must meet the Y-12 specifications (Table 1.6). ${ }^{\mathrm{a}}$

The nominal density of $\mathrm{UZrH}_{1.6}$ fuel containing $30 \mathrm{wt} . \%$ uranium content is $7.24 \mathrm{~g} / \mathrm{cm}^{3}$.

There is no bonding material between the cladding and fuel meat or other fuel elements components. ${ }^{c}$

A fuel sample $(\sim 15 \mathrm{~g})$ from a spare fuel element that was fabricated and shipped with the fuel elements placed in the NRAD reactor was sent to $\mathrm{Y}-12^{\mathrm{d}}$ for further material analysis. The sample was approximately $29.828 \mathrm{wt} \% \%$ uranium $\left(19.75 \mathrm{wt} . \%{ }^{235} \mathrm{U}\right)$. Various tests were performed during July 7-26, 2010, to determine the complete composition of the fuel. Results from the analyses are given in Table 1.7. Because of the variability in stock material used to fabricate all the TRIGA fuel elements, this sample provides a rough estimate of the fuel composition but does not necessarily represent the exact quantity of material in all fuel elements in the NRAD reactor. Tests to measure the oxygen, nitrogen, and hydrogen content in the sample using Leco methods could not be performed as the quantities exceeded the detection capability of the instrumentation. The fuel in the spare element was prepared in the same fuel batch as the four fuel elements added during the core upgrade.

${ }^{\text {a }}$ Personal communication with Eric C. Woolstenhulme at INL (April 27, 2010).

${ }^{\mathrm{b}}$ N. Comte, B. Thievenaz, M. Doucet, E. Torlini, and T. Pin, "TRIGA A Widely Used Fuel - Assessments, Validation and Application of Criticality Standards," Proc. Nuclear Criticality Safety Division Topical Meeting, Richland, Washington (September 13-17, 2009).

${ }^{c}$ R. E. Smith, “TRIGA Fuel Summary Report,” ICP/INT-05-817, Idaho Cleanup Project, Idaho National Laboratory (March 2005). [This reference is not available for public release.]

${ }^{\mathrm{d}}$ Y-12 National Security Complex, Analytical Chemistry, Oak Ridge, Tennessee. 
NEA/NSC/DOC(2006)1

Fundamental - FUND

NRAD-FUND-RESR-002

CRIT-REAC-COEF

Table 1.6. Y-12 Chemical Specification of Uranium Metal Supplied to Research Reactors. ${ }^{\text {(a) }}$

\begin{tabular}{|c|c|c|c|c|c|c|c|}
\hline Element & Units & LEU & $\begin{array}{c}\text { EBC } \\
\text { Factor }\end{array}$ & Element & Units & LEU & $\begin{array}{c}\text { EBC } \\
\text { Factor }\end{array}$ \\
\hline $\begin{array}{l}\text { Uranium } \\
\text { (Metal) }\end{array}$ & wt. $\%$ & $\geq 99.880$ & & Lead & $\mu \mathrm{g} / \mathrm{gU}$ & $\leq 5.0$ & 0.0000 \\
\hline U-232 & $\mu \mathrm{g} / \mathrm{gU}$ & $\leq 0.002$ & & Lithium & $\mu \mathrm{g} / \mathrm{gU}$ & $\leq 2.0$ & 0.1469 \\
\hline U-234 & wt. $\%$ & $\leq 0.260$ & & Magnesium & $\mu \mathrm{g} / \mathrm{gU}$ & $\leq 50.0$ & 0.0000 \\
\hline $\begin{array}{c}\mathrm{U}-235 \\
( \pm 0.20 \text { wt. } \%)\end{array}$ & wt.\% & 19.75 & & Manganese & $\mu \mathrm{g} / \mathrm{gU}$ & $\leq 24.0$ & 0.0034 \\
\hline U-236 & $\mu \mathrm{g} / \mathrm{gU}$ & $\leq 4600$ & & Molybdenum & $\mu \mathrm{g} / \mathrm{gU}$ & $\leq 100.0$ & 0.0004 \\
\hline $\begin{array}{l}\text { Trans-U } \\
(\text { Alpha) }\end{array}$ & $\mathrm{Bq} / \mathrm{gU}$ & $\leq 100.0$ & & Nickel & $\mu \mathrm{g} / \mathrm{gU}$ & $\leq 100.0$ & 0.0011 \\
\hline $\begin{array}{l}\text { Activation } \\
\text { Products }\end{array}$ & $\mathrm{Bq} / \mathrm{gU}$ & $\leq 100.0$ & & Niobium & $\mu \mathrm{g} / \mathrm{gU}$ & TBR & 0.0002 \\
\hline $\begin{array}{c}\text { Fission } \\
\text { Products }\end{array}$ & $\mathrm{Bq} / \mathrm{gU}$ & $\leq 600.0$ & & Nitrogen & $\mu \mathrm{g} / \mathrm{gU}$ & TBR & 0.0019 \\
\hline Aluminum & $\mu \mathrm{g} / \mathrm{gU}$ & $\leq 150.0$ & 0.0000 & Phosphorus & $\mu \mathrm{g} / \mathrm{gU}$ & $\leq 50.0$ & 0.0000 \\
\hline Arsenic & $\mu \mathrm{g} / \mathrm{gU}$ & $\mathrm{TBR}^{(\mathrm{c})}$ & 0.0008 & Potassium & $\mu \mathrm{g} / \mathrm{gU}$ & TBR & 0.0008 \\
\hline Beryllium & $\mu \mathrm{g} / \mathrm{gU}$ & $\leq 1.0$ & 0.0000 & Samarium & $\mu \mathrm{g} / \mathrm{gU}$ & $\leq 2.0$ & 0.5336 \\
\hline Boron & $\mu \mathrm{g} / \mathrm{gU}$ & $\leq 1.0$ & 1.0000 & Silicon & $\mu \mathrm{g} / \mathrm{gU}$ & $\leq 100.0$ & 0.0000 \\
\hline Cadmium & $\mu \mathrm{g} / \mathrm{gU}$ & $\leq 1.0$ & 0.3172 & Silver & $\mu \mathrm{g} / \mathrm{gU}$ & TBR & 0.0083 \\
\hline Calcium & $\mu \mathrm{g} / \mathrm{gU}$ & $\leq 100.0$ & 0.0002 & Sodium & $\mu \mathrm{g} / \mathrm{gU}$ & $\leq 25.0$ & 0.0003 \\
\hline Carbon & $\mu \mathrm{g} / \mathrm{gU}$ & $\leq 350.0$ & 0.0000 & Tin & $\mu \mathrm{g} / \mathrm{gU}$ & $\leq 100.0$ & 0.0000 \\
\hline Chromium & $\mu \mathrm{g} / \mathrm{gU}$ & $\leq 50.0$ & 0.0008 & Tungsten & $\mu \mathrm{g} / \mathrm{gU}$ & $\leq 100.0$ & 0.0014 \\
\hline Cobalt & $\mu \mathrm{g} / \mathrm{gU}$ & $\leq 5.0$ & 0.0089 & Vanadium & $\mu \mathrm{g} / \mathrm{gU}$ & $\leq 30.0$ & 0.0014 \\
\hline Copper & $\mu \mathrm{g} / \mathrm{gU}$ & $\leq 50.0$ & 0.0008 & Zinc & $\mu \mathrm{g} / \mathrm{gU}$ & TBR & 0.0002 \\
\hline Dysprosium & $\mu \mathrm{g} / \mathrm{gU}$ & $\leq 5.0$ & 0.0818 & Zirconium & $\mu \mathrm{g} / \mathrm{gU}$ & $\leq 25.0$ & 0.0000 \\
\hline Europium & $\mu \mathrm{g} / \mathrm{gU}$ & $\leq 2.0$ & 0.4250 & $\begin{array}{c}\text { Total } \\
\text { Impurities }\end{array}$ & $\mu \mathrm{g} / \mathrm{gU}$ & $\leq 1,200$ & \\
\hline Gadolinium & $\mu \mathrm{g} / \mathrm{gU}$ & $\leq 1.0$ & 4.3991 & \multirow{2}{*}{\multicolumn{2}{|c|}{$\begin{array}{c}\text { Equivalent } \\
\text { Boron Content }^{(\mathrm{d}),(\mathrm{e})}\end{array}$}} & \multirow{2}{*}{$\leq 3.0$} & \\
\hline Iron & $\mu \mathrm{g} / \mathrm{gU}$ & $\leq 250.0$ & 0.0006 & & & & \\
\hline
\end{tabular}

(a) "The Y-12 Standard Specification Low Enriched Uranium Metal Supply to Research and Test Reactors," Y/GNSS/05-05, Rev. 2, BWXT Y-12, Oak Ridge, Tennessee (August 2007).

(b) Alpha activity represents measured transuranium elements: Am-241, Cm-243/-244, Np-237, Pu238, and $\mathrm{Pu}-239 /-240$.

(c) TBR means that the value is "To Be Reported", when material measurements are performed.

(d) Equivalent Boron Content (EBC) factors are taken from ASTM C1233-03, "Standard Practice for Determining Equivalent Boron Contents of Nuclear Materials." EBC calculation will include B, $\mathrm{Cd}, \mathrm{Dy}, \mathrm{Eu}, \mathrm{Gd}, \mathrm{Li}$, and Sm. All other EBC factors are provided for information purposes only.

(e) The limit on EBC may restrict some elements to lower values than shown in the table above. 
NEA/NSC/DOC(2006)1

Fundamental - FUND

NRAD-FUND-RESR-002

CRIT-REAC-COEF

Table 1.7. Y-12 Analysis of U-Er-Zr-H Fuel. ${ }^{(a)}$

\begin{tabular}{|c|c|c|c|c|c|c|c|}
\hline Component & Value & $\begin{array}{c}\text { Unit of } \\
\text { Measure }\end{array}$ & $\begin{array}{c}\text { Test } \\
\text { Method }\end{array}$ & Component & Value & $\begin{array}{c}\text { Unit of } \\
\text { Measure }\end{array}$ & $\begin{array}{c}\text { Test } \\
\text { Method }\end{array}$ \\
\hline $\mathrm{C}$ & 2930 & $\mu \mathrm{g} / \mathrm{g}$ & Carbon Leco & $\mathrm{Er}$ & 4600 & $\mu \mathrm{g} / \mathrm{gU}$ & ICP-MS \\
\hline $\mathrm{U}$ & 296000 & $\mu \mathrm{g} / \mathrm{g}$ & \multirow{5}{*}{$\begin{array}{l}\text { Isotopic } \\
\text { Dilution }^{(\mathfrak{b})}\end{array}$} & $\mathrm{Eu}$ & 0.77 & $\mu \mathrm{g} / \mathrm{gU}$ & ICP-MS \\
\hline U-234 & 0.159 & wt. $\%$ & & $\mathrm{Fe}$ & 194 & $\mu \mathrm{g} / \mathrm{gU}$ & ICP-OES \\
\hline $\mathrm{U}-235$ & 19.726 & wt. $\%$ & & $\mathrm{Ga}$ & $<1$ & $\mu \mathrm{g} / \mathrm{gU}$ & ICP-MS \\
\hline U-236 & 0.144 & wt. $\%$ & & $\mathrm{Gd}$ & $<0.3$ & $\mu \mathrm{g} / \mathrm{gU}$ & ICP-MS \\
\hline $\mathrm{U}-238$ & 79.971 & wt. $\%$ & & $\mathrm{Ge}$ & $<1$ & $\mu \mathrm{g} / \mathrm{gU}$ & ICP-MS \\
\hline Am-241 & -32 & $\mathrm{pCi} / \mathrm{g}$ & \multirow{2}{*}{ CT-AM-5 ${ }^{(\mathrm{c})}$} & $\mathrm{Hf}$ & 34 & $\mu \mathrm{g} / \mathrm{gU}$ & ICP-MS \\
\hline $\mathrm{Cm}-243 / 244$ & 0 & $\mathrm{pCi} / \mathrm{g}$ & & $\mathrm{Hg}$ & $<1$ & $\mu \mathrm{g} / \mathrm{gU}$ & ICP-MS \\
\hline $\mathrm{Np}-237$ & -1.5 & $\mathrm{pCi} / \mathrm{g}$ & CT-NP-5 ${ }^{(\mathrm{c})}$ & Ho & $<1.1$ & $\mu \mathrm{g} / \mathrm{gU}$ & ICP-MS \\
\hline $\mathrm{Pu}-238$ & 35 & $\mathrm{pCi} / \mathrm{g}$ & \multirow{2}{*}{$\begin{array}{c}\text { Alpha } \\
\text { Spectrometry } \\
{ }^{(c)}\end{array}$} & In & $<1$ & $\mu \mathrm{g} / \mathrm{gU}$ & ICP-MS \\
\hline $\mathrm{Pu}-239 / 240$ & 34 & $\mathrm{pCi} / \mathrm{g}$ & & $\mathrm{Ir}$ & $<1$ & $\mu \mathrm{g} / \mathrm{gU}$ & ICP-MS \\
\hline Th-228 & 280 & $\mathrm{pCi} / \mathrm{g}$ & \multirow{3}{*}{$\begin{array}{c}\text { Alpha } \\
\text { Spectrometry }\end{array}$} & $\mathrm{K}$ & 22 & $\mu \mathrm{g} / \mathrm{gU}$ & ICP-MS \\
\hline Th-230 & 42 & $\mathrm{pCi} / \mathrm{g}$ & & $\mathrm{La}$ & $<1$ & $\mu \mathrm{g} / \mathrm{gU}$ & ICP-MS \\
\hline Th-232 & 0 & $\mathrm{pCi} / \mathrm{g}$ & & $\mathrm{Li}$ & $<1$ & $\mu \mathrm{g} / \mathrm{gU}$ & ICP-MS \\
\hline U-234 & 3100000 & $\mathrm{pCi} / \mathrm{g}$ & \multirow{4}{*}{$\begin{array}{c}\text { Alpha } \\
\text { Spectrometry }^{(\mathrm{c})}\end{array}$} & $\mathrm{Lu}$ & $<1.1$ & $\mu \mathrm{g} / \mathrm{gU}$ & ICP-MS \\
\hline U-235 & 150000 & $\mathrm{pCi} / \mathrm{g}$ & & $\mathrm{Mg}$ & $<1$ & $\mu \mathrm{g} / \mathrm{gU}$ & ICP-OES \\
\hline $\mathrm{U}-236$ & 27000 & $\mathrm{pCi} / \mathrm{g}$ & & $\mathrm{Mn}$ & 7.7 & $\mu \mathrm{g} / \mathrm{gU}$ & HR-ICPMS \\
\hline $\mathrm{U}-238$ & 92000 & $\mathrm{pCi} / \mathrm{g}$ & & Mo & 3.4 & $\mu \mathrm{g} / \mathrm{gU}$ & ICP-MS \\
\hline $\mathrm{Ag}$ & $<55$ & $\mu \mathrm{g} / \mathrm{gU}$ & $\mathrm{ICP} \mathrm{MS}^{(\mathrm{d})}$ & $\mathrm{Na}$ & $<5$ & $\mu \mathrm{g} / \mathrm{gU}$ & ICP-OES \\
\hline $\mathrm{Al}$ & $<10$ & $\mu \mathrm{g} / \mathrm{gU}$ & $\mathrm{ICP}-O E S^{(\mathrm{e})}$ & $\mathrm{Nb}$ & 1.3 & $\mu \mathrm{g} / \mathrm{gU}$ & ICP-MS \\
\hline As & $<10$ & $\mu \mathrm{g} / \mathrm{gU}$ & ICP-MS & $\mathrm{Nd}$ & $<1$ & $\mu \mathrm{g} / \mathrm{gU}$ & ICP-MS \\
\hline $\mathrm{Au}$ & $<5$ & $\mu \mathrm{g} / \mathrm{gU}$ & ICP-MS & $\mathrm{Ni}$ & 8.9 & $\mu \mathrm{g} / \mathrm{gU}$ & ICP-OES \\
\hline $\mathrm{B}$ & $<0.5$ & $\mu \mathrm{g} / \mathrm{gU}$ & ICP-MS & Os & $<1$ & $\mu \mathrm{g} / \mathrm{gU}$ & ICP-MS \\
\hline $\mathrm{Ba}$ & $<1$ & $\mu \mathrm{g} / \mathrm{gU}$ & ICP-MS & $\mathrm{P}$ & $<22$ & $\mu \mathrm{g} / \mathrm{gU}$ & ICP-MS \\
\hline $\mathrm{Be}$ & $<0.24$ & $\mu \mathrm{g} / \mathrm{gU}$ & ICP-OES & $\mathrm{Pb}$ & $<1$ & $\mu \mathrm{g} / \mathrm{gU}$ & ICP-MS \\
\hline $\mathrm{Bi}$ & $<1$ & $\mu \mathrm{g} / \mathrm{gU}$ & ICP-MS & $\mathrm{Pd}$ & 2.5 & $\mu \mathrm{g} / \mathrm{gU}$ & ICP-MS \\
\hline $\mathrm{Ca}$ & $<5$ & $\mu \mathrm{g} / \mathrm{gU}$ & ICP-OES & $\operatorname{Pr}$ & $<1$ & $\mu \mathrm{g} / \mathrm{gU}$ & ICP-MS \\
\hline $\mathrm{Cd}$ & $<1$ & $\mu \mathrm{g} / \mathrm{gU}$ & ICP-OES & $\mathrm{Pt}$ & $<1$ & $\mu \mathrm{g} / \mathrm{gU}$ & ICP-MS \\
\hline $\mathrm{Ce}$ & $<1$ & $\mu \mathrm{g} / \mathrm{gU}$ & ICP-MS & $\mathrm{Rb}$ & $<1$ & $\mu \mathrm{g} / \mathrm{gU}$ & ICP-MS \\
\hline $\mathrm{Co}$ & $<1$ & $\mu \mathrm{g} / \mathrm{gU}$ & ICP-OES & $\operatorname{Re}$ & $<1$ & $\mu \mathrm{g} / \mathrm{gU}$ & ICP-MS \\
\hline $\mathrm{Cr}$ & 21.8 & $\mu \mathrm{g} / \mathrm{gU}$ & ICP-OES & $\mathrm{Rh}$ & $<1$ & $\mu \mathrm{g} / \mathrm{gU}$ & ICP-MS \\
\hline Cs & $<1$ & $\mu \mathrm{g} / \mathrm{gU}$ & ICP-MS & $\mathrm{Ru}$ & $<1$ & $\mu \mathrm{g} / \mathrm{gU}$ & ICP-MS \\
\hline $\mathrm{Cu}$ & 3.1 & $\mu \mathrm{g} / \mathrm{gU}$ & ICP-OES & $\mathrm{Sb}$ & $<2$ & $\mu \mathrm{g} / \mathrm{gU}$ & ICP-MS \\
\hline Dy & 0.8 & $\mu \mathrm{g} / \mathrm{gU}$ & ICP-MS & $\mathrm{Sc}$ & $<525$ & $\mu \mathrm{g} / \mathrm{gU}$ & ICP-MS \\
\hline
\end{tabular}


NEA/NSC/DOC(2006)1

Fundamental - FUND

NRAD-FUND-RESR-002

CRIT-REAC-COEF

Table 1.7 (cont'd.). Y-12 Analysis of U-Er-Zr-H Fuel.

\begin{tabular}{|c|c|c|c||}
\hline Component & Value & $\begin{array}{c}\text { Unit of } \\
\text { Measure }\end{array}$ & $\begin{array}{c}\text { Test } \\
\text { Method }\end{array}$ \\
\hline \hline $\mathrm{Se}$ & $<1$ & $\mu \mathrm{g} / \mathrm{gU}$ & ICP-MS \\
\hline $\mathrm{Si}$ & $<15$ & $\mu \mathrm{g} / \mathrm{gU}$ & ICP-OES \\
\hline $\mathrm{Sm}$ & $<0.31$ & $\mu \mathrm{g} / \mathrm{gU}$ & ICP-MS \\
\hline $\mathrm{Sn}$ & $<2$ & $\mu \mathrm{g} / \mathrm{gU}$ & ICP-MS \\
\hline $\mathrm{Sr}$ & $<1$ & $\mu \mathrm{g} / \mathrm{gU}$ & ICP-MS \\
\hline $\mathrm{Ta}$ & $<1$ & $\mu \mathrm{g} / \mathrm{gU}$ & ICP-MS \\
\hline $\mathrm{Tb}$ & $<2.4$ & $\mu \mathrm{g} / \mathrm{gU}$ & ICP-OES \\
\hline $\mathrm{Te}$ & $<60$ & $\mu \mathrm{g} / \mathrm{gU}$ & ICP-MS \\
\hline $\mathrm{Th}$ & $<2.2$ & $\mu \mathrm{g} / \mathrm{gU}$ & ICP-MS \\
\hline \hline
\end{tabular}

\begin{tabular}{|c|c|c|c||}
\hline Component & Value & $\begin{array}{c}\text { Unit of } \\
\text { Measure }\end{array}$ & $\begin{array}{c}\text { Test } \\
\text { Method }\end{array}$ \\
\hline \hline $\mathrm{Ti}$ & 19 & $\mu \mathrm{g} / \mathrm{gU}$ & ICP-OES \\
\hline $\mathrm{Tl}$ & $<2.2$ & $\mu \mathrm{g} / \mathrm{gU}$ & ICP-MS \\
\hline $\mathrm{Tm}$ & $<1.1$ & $\mu \mathrm{g} / \mathrm{gU}$ & ICP-MS \\
\hline $\mathrm{V}$ & $<1$ & $\mu \mathrm{g} / \mathrm{gU}$ & HR-ICPMS \\
\hline $\mathrm{W}$ & $<25$ & $\mu \mathrm{g} / \mathrm{gU}$ & ICP-MS \\
\hline $\mathrm{Y}$ & $<5$ & $\mu \mathrm{g} / \mathrm{gU}$ & ICP-OES \\
\hline $\mathrm{Yb}$ & $<1.1$ & $\mu \mathrm{g} / \mathrm{gU}$ & ICP-MS \\
\hline $\mathrm{Zn}$ & $<1$ & $\mu \mathrm{g} / \mathrm{gU}$ & ICP-OES \\
\hline $\mathrm{Zr}$ & 730000 & $\mu \mathrm{g} / \mathrm{gU}$ & ICP-MS \\
\hline \hline
\end{tabular}

(a) Due to the \% levels of $\mathrm{Zr}$, extreme effort was required to overcome the interferences inherent to each technique in such a complex measurement.

(b) The g/g 2-sigma relative uncertainty is typically within $0.2 \%$ and the absolute difference for ${ }^{235} \mathrm{U}$ wt. $\%$ is typically within $0.025 \%$ for HEU.

(c) The 2-sigma uncertainty for most of the radioisotope measurements is approximately the same as the reported value in the table. The 2-sigma uncertainty in the uranium alpha spectrometer measurements is approximately one order of magnitude less than the value reported in the table.

(d) Quadrupole ICSP-MS.

(e) Three separate analysis runs were performed.

Material samples were sent to Evans Analytical Group ${ }^{\circledR}(E A G)$ Labs for compositional analysis. A total of six samples were evaluated: graphite reflector block (Table 1.14), axial graphite reflector (Table 1.8), plating on molybdenum poison disc (Table 1.9), molybdenum poison disc (Table 1.10), stainless steel end fitting (Table 1.11), and zirconium rod (Table 1.12). These samples, except for the sample from the graphite reflector block, were analyzed from the same spare fuel element that was used for the fuel pellet material analysis. The samples were analyzed from April 16-21, 2010, using glow discharge mass spectrometry (GDMS). This process uses the sample as a cathode in a low pressure $(\sim 100 \mathrm{~Pa})$ gas discharge or plasma (typically argon). Positive gas ions are accelerated towards the sample surface with energies of hundreds to thousands of $\mathrm{eV}$, which results in the erosion and atomization of the upper atomic layers of the sample. The neutral species escape the cathode surface, diffuse into the plasma, and are ionized for mass spectrometry analysis. This method allows for high sensitivity, ease of calibration, and flexibility in sample analysis, and depth profiling for most samples (excludes volatile samples, organic materials, and polymers) with full periodic table coverage. ${ }^{\mathrm{a}}$

The $\mathrm{Zr}$ samples were filed and etched so that no cross-contamination from the stainless steel saw would occur. All samples were analyzed twice with five replicates during each analysis. The data were extremely stable during both analyses. Samples were also plasma-etched during the analysis. ${ }^{\mathrm{b}}$

\footnotetext{
${ }^{a}$ SHIVA Technologies, 6707 Brooklawn Parkway, Syracuse, New York 13211, http://www.eaglabs.com/.

${ }^{\mathrm{b}}$ Personal communication with Timothy Alex West at EAG Labs (April 29, 2010).
} 


\section{NEA/NSC/DOC(2006)1}

Fundamental - FUND

NRAD-FUND-RESR-002

CRIT-REAC-COEF

Table 1.8. GDMS Analysis of Axial Graphite Reflector.

\begin{tabular}{|c|c|c|c|c|c|}
\hline Element & ppm (wt.) & Element & ppm (wt.) & Element & ppm (wt.) \\
\hline $\mathrm{Li}$ & $<0.05$ & $\mathrm{Ga}$ & $<0.01$ & $\mathrm{Nd}$ & $<0.05$ \\
\hline $\mathrm{Be}$ & $<0.05$ & $\mathrm{Ge}$ & $<0.05$ & $\mathrm{Sm}$ & $<0.01$ \\
\hline B & 0.35 & As & $<0.05$ & $\mathrm{Eu}$ & $<0.01$ \\
\hline $\mathrm{C}$ & Matrix & $\mathrm{Se}$ & $<0.05$ & $\mathrm{Gd}$ & $<0.01$ \\
\hline $\mathrm{N}$ & -- & $\mathrm{Br}$ & $<0.1$ & $\mathrm{~Tb}$ & $<0.01$ \\
\hline $\mathrm{O}$ & -- & $\mathrm{Rb}$ & $<0.05$ & Dy & $<0.01$ \\
\hline $\mathrm{F}$ & $<0.1$ & $\mathrm{Sr}$ & $<0.05$ & Ho & $<0.01$ \\
\hline $\mathrm{Na}$ & $<0.05$ & Y & $<0.05$ & $\mathrm{Er}$ & $<0.01$ \\
\hline $\mathrm{Mg}$ & $<0.05$ & $\mathrm{Zr}$ & $<0.05$ & $\mathrm{Tm}$ & $<0.01$ \\
\hline $\mathrm{Al}$ & $<0.05$ & $\mathrm{Nb}$ & $<0.05$ & $\mathrm{Yb}$ & $<0.01$ \\
\hline $\mathrm{Si}$ & 0.75 & Mo & $<0.05$ & $\mathrm{Lu}$ & $<0.01$ \\
\hline $\mathrm{P}$ & $<0.1$ & $\mathrm{Ru}$ & $<0.05$ & $\mathrm{Hf}$ & $<0.01$ \\
\hline S & 0.92 & $\mathrm{Rh}$ & $<0.01$ & $\mathrm{Ta}$ & $<100$ \\
\hline $\mathrm{Cl}$ & 0.24 & $\mathrm{Pd}$ & $<0.05$ & W & $<0.05$ \\
\hline K & $<0.1$ & $\mathrm{Ag}$ & $<0.05$ & $\operatorname{Re}$ & $<0.01$ \\
\hline $\mathrm{Ca}$ & $<0.05$ & $\mathrm{Cd}$ & $<0.05$ & Os & $<0.01$ \\
\hline $\mathrm{Sc}$ & $<0.01$ & In & $<0.05$ & $\mathrm{Ir}$ & $<0.01$ \\
\hline $\mathrm{Ti}$ & $<0.01$ & $\mathrm{Sn}$ & $<0.05$ & $\mathrm{Pt}$ & $<0.01$ \\
\hline $\mathrm{V}$ & $<0.01$ & $\mathrm{Sb}$ & $<0.05$ & $\mathrm{Au}$ & $<0.1$ \\
\hline $\mathrm{Cr}$ & $<0.5$ & $\mathrm{Te}$ & $<0.05$ & $\mathrm{Hg}$ & $<0.1$ \\
\hline $\mathrm{Mn}$ & $<0.01$ & I & $<0.01$ & $\mathrm{Tl}$ & $<0.05$ \\
\hline $\mathrm{Fe}$ & $<0.01$ & Cs & $<0.05$ & $\mathrm{~Pb}$ & $<0.05$ \\
\hline Co & $<0.01$ & $\mathrm{Ba}$ & $<0.05$ & $\mathrm{Bi}$ & $<0.05$ \\
\hline $\mathrm{Ni}$ & $<0.01$ & $\mathrm{La}$ & $<0.05$ & Th & $<0.05$ \\
\hline $\mathrm{Cu}$ & $<0.05$ & $\mathrm{Ce}$ & $<0.05$ & $\mathrm{U}$ & $<0.05$ \\
\hline $\mathrm{Zn}$ & $<0.05$ & $\mathrm{Pr}$ & $<0.05$ & & \\
\hline
\end{tabular}


NEA/NSC/DOC(2006)1

Fundamental - FUND

NRAD-FUND-RESR-002

CRIT-REAC-COEF

Table 1.9. GDMS Analysis of Plating on Molybdenum Disc.

\begin{tabular}{|c|c|c|c|c|c|}
\hline Element & ppm (wt.) & Element & ppm (wt.) & Element & ppm (wt.) \\
\hline $\mathrm{Li}$ & $<0.01$ & $\mathrm{Ga}$ & $<0.05$ & $\mathrm{Nd}$ & $<0.01$ \\
\hline $\mathrm{Be}$ & $<0.01$ & $\mathrm{Ge}$ & $<0.1$ & $\mathrm{Sm}$ & $<0.01$ \\
\hline B & $<0.01$ & As & 0.35 & $\mathrm{Eu}$ & $<0.01$ \\
\hline $\mathrm{C}$ & Binder & $\mathrm{Se}$ & $<0.1$ & $\mathrm{Gd}$ & $<0.01$ \\
\hline $\mathrm{N}$ & -- & $\mathrm{Br}$ & $<0.01$ & $\mathrm{~Tb}$ & $<0.01$ \\
\hline $\mathrm{O}$ & -- & $\mathrm{Rb}$ & $<0.05$ & Dy & $<0.01$ \\
\hline $\mathrm{F}$ & $<0.01$ & $\mathrm{Sr}$ & $<0.5$ & Ho & $<0.01$ \\
\hline $\mathrm{Na}$ & 5 & $\mathrm{Y}$ & $<0.1$ & $\mathrm{Er}$ & $<0.01$ \\
\hline $\mathrm{Mg}$ & 0.45 & $\mathrm{Zr}$ & $<0.1$ & $\mathrm{Tm}$ & $<0.01$ \\
\hline $\mathrm{Al}$ & 0.55 & $\mathrm{Nb}$ & $<0.5$ & $\mathrm{Yb}$ & $<0.01$ \\
\hline $\mathrm{Si}$ & 2.7 & Mo & Matrix & $\mathrm{Lu}$ & $<0.01$ \\
\hline $\mathrm{P}$ & 0.75 & $\mathrm{Ru}$ & $<0.05$ & $\mathrm{Hf}$ & $<0.01$ \\
\hline $\mathrm{S}$ & 3.3 & $\mathrm{Rh}$ & $<0.05$ & $\mathrm{Ta}$ & $<10$ \\
\hline $\mathrm{Cl}$ & 0.2 & $\mathrm{Pd}$ & $<0.1$ & W & 130 \\
\hline K & $\sim 30$ & $\mathrm{Ag}$ & $<0.5$ & $\operatorname{Re}$ & 0.15 \\
\hline $\mathrm{Ca}$ & 2.5 & $\mathrm{Cd}$ & $<10$ & Os & $<0.05$ \\
\hline $\mathrm{Sc}$ & $<0.005$ & In & $<0.05$ & $\mathrm{Ir}$ & $<0.05$ \\
\hline $\mathrm{Ti}$ & $<10$ & $\mathrm{Sn}$ & 0.25 & $\mathrm{Pt}$ & $<0.05$ \\
\hline $\mathrm{V}$ & 1.1 & $\mathrm{Sb}$ & 1.5 & $\mathrm{Au}$ & $<0.05$ \\
\hline $\mathrm{Cr}$ & 4.3 & $\mathrm{Te}$ & $<0.05$ & $\mathrm{Hg}$ & $<0.05$ \\
\hline $\mathrm{Mn}$ & 0.43 & I & $<0.01$ & $\mathrm{Tl}$ & $<0.05$ \\
\hline $\mathrm{Fe}$ & 15 & Cs & $<0.05$ & $\mathrm{~Pb}$ & $<0.05$ \\
\hline $\mathrm{Co}$ & 0.15 & $\mathrm{Ba}$ & 15 & $\mathrm{Bi}$ & $<0.05$ \\
\hline $\mathrm{Ni}$ & 1.3 & $\mathrm{La}$ & 1.1 & Th & $<0.005$ \\
\hline $\mathrm{Cu}$ & 2.5 & $\mathrm{Ce}$ & 0.03 & $\mathrm{U}$ & 0.04 \\
\hline $\mathrm{Zn}$ & $<0.05$ & $\operatorname{Pr}$ & $<0.01$ & & \\
\hline
\end{tabular}


NEA/NSC/DOC(2006)1

Fundamental - FUND

NRAD-FUND-RESR-002

CRIT-REAC-COEF

Table 1.10. GDMS Analysis of Molybdenum Disc.

\begin{tabular}{|c|c|c|c|c|c|}
\hline Element & ppm (wt.) & Element & ppm (wt.) & Element & ppm (wt.) \\
\hline $\mathrm{Li}$ & $<0.01$ & $\mathrm{Ga}$ & $<0.05$ & $\mathrm{Nd}$ & $<0.01$ \\
\hline $\mathrm{Be}$ & $<0.01$ & $\mathrm{Ge}$ & $<0.1$ & $\mathrm{Sm}$ & $<0.01$ \\
\hline B & $<0.01$ & As & 0.35 & $\mathrm{Eu}$ & $<0.01$ \\
\hline $\mathrm{C}$ & -- & $\mathrm{Se}$ & $<0.1$ & Gd & $<0.01$ \\
\hline $\mathrm{N}$ & -- & $\mathrm{Br}$ & $<0.01$ & $\mathrm{~Tb}$ & $<0.01$ \\
\hline $\mathrm{O}$ & -- & $\mathrm{Rb}$ & $<0.05$ & Dy & $<0.01$ \\
\hline $\mathrm{F}$ & $<0.01$ & $\mathrm{Sr}$ & $<0.5$ & Но & $<0.01$ \\
\hline $\mathrm{Na}$ & 0.77 & Y & $<0.1$ & Er & $<0.01$ \\
\hline $\mathrm{Mg}$ & 0.29 & $\mathrm{Zr}$ & $<0.1$ & $\mathrm{Tm}$ & $<0.01$ \\
\hline $\mathrm{Al}$ & 0.33 & $\mathrm{Nb}$ & $<0.5$ & $\mathrm{Yb}$ & $<0.01$ \\
\hline $\mathrm{Si}$ & 1.3 & Mo & Matrix & $\mathrm{Lu}$ & $<0.01$ \\
\hline $\mathrm{P}$ & 0.27 & $\mathrm{Ru}$ & $<0.05$ & $\mathrm{Hf}$ & $<0.01$ \\
\hline S & 0.59 & $\mathrm{Rh}$ & $<0.05$ & $\mathrm{Ta}$ & $<10$ \\
\hline $\mathrm{Cl}$ & $<0.01$ & $\mathrm{Pd}$ & $<0.1$ & W & 120 \\
\hline K & $\sim 20$ & $\mathrm{Ag}$ & $<0.5$ & $\mathrm{Re}$ & 0.11 \\
\hline $\mathrm{Ca}$ & 1.1 & $\mathrm{Cd}$ & $<10$ & Os & $<0.05$ \\
\hline $\mathrm{Sc}$ & $<0.005$ & In & $<0.05$ & Ir & $<0.05$ \\
\hline $\mathrm{Ti}$ & $<10$ & $\mathrm{Sn}$ & 0.13 & $\mathrm{Pt}$ & $<0.05$ \\
\hline $\mathrm{V}$ & 1.1 & $\mathrm{Sb}$ & 1.1 & $\mathrm{Au}$ & $<0.05$ \\
\hline $\mathrm{Cr}$ & 3.3 & $\mathrm{Te}$ & $<0.05$ & $\mathrm{Hg}$ & $<0.05$ \\
\hline $\mathrm{Mn}$ & 0.43 & I & $<0.01$ & $\mathrm{Tl}$ & $<0.05$ \\
\hline $\mathrm{Fe}$ & 8.5 & Cs & $<0.05$ & $\mathrm{~Pb}$ & $<0.05$ \\
\hline $\mathrm{Co}$ & 0.13 & $\mathrm{Ba}$ & 15 & $\mathrm{Bi}$ & $<0.05$ \\
\hline $\mathrm{Ni}$ & 1.1 & $\mathrm{La}$ & 0.79 & Th & $<0.005$ \\
\hline $\mathrm{Cu}$ & 2.5 & $\mathrm{Ce}$ & 0.02 & $\mathrm{U}$ & 0.04 \\
\hline $\mathrm{Zn}$ & $<0.05$ & $\operatorname{Pr}$ & $<0.01$ & & \\
\hline
\end{tabular}


NEA/NSC/DOC(2006)1

Fundamental - FUND

NRAD-FUND-RESR-002

CRIT-REAC-COEF

Table 1.11. GDMS Analysis of Stainless Steel End Fitting.

\begin{tabular}{|cc||}
\hline Element & ppm (wt.) \\
\hline \hline $\mathrm{Li}$ & $<0.01$ \\
$\mathrm{Be}$ & $<0.01$ \\
$\mathrm{~B}$ & 2.5 \\
$\mathrm{C}$ & -- \\
$\mathrm{N}$ & -- \\
$\mathrm{O}$ & -- \\
$\mathrm{F}$ & $<0.01$ \\
$\mathrm{Na}$ & $<0.01$ \\
$\mathrm{Mg}$ & 1.8 \\
$\mathrm{Al}$ & 12 \\
$\mathrm{Si}$ & $\sim 0.4 \mathrm{wt} . \%$ \\
$\mathrm{P}$ & 260 \\
$\mathrm{~S}$ & 22 \\
$\mathrm{Cl}$ & $<0.05$ \\
$\mathrm{~K}$ & $<0.01$ \\
$\mathrm{Ca}$ & 0.5 \\
$\mathrm{Sc}$ & $<0.005$ \\
$\mathrm{Ti}$ & 20 \\
$\mathrm{~V}$ & $\sim 0.1 \mathrm{wt} . \%$ \\
$\mathrm{Cr}$ & Matrix \\
$\mathrm{Mn}$ & Matrix \\
$\mathrm{Fe}$ & Matrix \\
$\mathrm{Co}$ & 800 \\
$\mathrm{Ni}$ & Matrix \\
$\mathrm{Cu}$ & $\sim 0.3$ wt.\% \\
$\mathrm{Zn}$ & 0.5 \\
\hline
\end{tabular}

\begin{tabular}{|cc||}
\hline Element & ppm (wt.) \\
\hline $\mathrm{Ga}$ & 16 \\
$\mathrm{Ge}$ & 20 \\
$\mathrm{As}$ & 35 \\
$\mathrm{Se}$ & $<0.1$ \\
$\mathrm{Br}$ & $<0.1$ \\
$\mathrm{Rb}$ & $<0.5$ \\
$\mathrm{Sr}$ & $<0.2$ \\
$\mathrm{Y}$ & $<0.05$ \\
$\mathrm{Zr}$ & 1.8 \\
$\mathrm{Nb}$ & 110 \\
$\mathrm{Mo}$ & $\sim 0.3 \mathrm{wt} . \%$ \\
$\mathrm{Ru}$ & $<0.1$ \\
$\mathrm{Rh}$ & $<0.05$ \\
$\mathrm{Pd}$ & $<0.05$ \\
$\mathrm{Ag}$ & $<0.5$ \\
$\mathrm{Cd}$ & $<0.1$ \\
$\mathrm{In}$ & $<0.5$ \\
$\mathrm{Sn}$ & 55 \\
$\mathrm{Sb}$ & 8.9 \\
$\mathrm{Te}$ & $<0.05$ \\
$\mathrm{I}$ & $<0.05$ \\
$\mathrm{Cs}$ & $<0.01$ \\
$\mathrm{Ba}$ & $<0.05$ \\
$\mathrm{La}$ & $<0.01$ \\
$\mathrm{Ce}$ & $<0.05$ \\
$\mathrm{Pr}$ & $<0.005$ \\
\hline
\end{tabular}

Element ppm (wt.)

$\mathrm{Nd}<0.005$

$\mathrm{Sm}<0.005$

$\mathrm{Eu}<0.005$

$\mathrm{Gd}<0.005$

$\mathrm{Tb}<0.005$

Dy $<0.005$

Ho $<0.005$

Er $<0.005$

$\mathrm{Tm}<0.005$

$\mathrm{Yb}<0.005$

$\mathrm{Lu}<0.005$

Hf $<0.01$

Ta $<1$

W $\quad 160$

$\operatorname{Re} \quad 0.25$

Os $\quad 0.09$

Ir $\quad 0.09$

Pt $<0.1$

$\mathrm{Au}<0.05$

$\mathrm{Hg}<0.1$

Tl $<0.05$

$\mathrm{Pb} \quad 0.31$

$\mathrm{Bi}<0.01$

Th $<0.005$

$\mathrm{U}$

$<0.005$ 
NEA/NSC/DOC(2006)1

Fundamental - FUND

NRAD-FUND-RESR-002

CRIT-REAC-COEF

Table 1.12. GDMS Analysis of Zirconium Rod.

\begin{tabular}{|c|c|c|c|c|c|}
\hline Element & ppm (wt.) & Element & ppm (wt.) & Element & ppm (wt.) \\
\hline $\mathrm{Li}$ & $<0.005$ & As & 0.04 & $\mathrm{Sm}$ & $<0.005$ \\
\hline $\mathrm{Be}$ & $<0.005$ & $\mathrm{Se}$ & $<0.05$ & $\mathrm{Eu}$ & $<0.005$ \\
\hline B & 0.05 & $\mathrm{Br}$ & $<0.05$ & $\mathrm{Gd}$ & $<0.005$ \\
\hline $\mathrm{F}$ & $<1$ & $\mathrm{Rb}$ & $<0.05$ & $\mathrm{~Tb}$ & $<0.005$ \\
\hline $\mathrm{Na}$ & $<0.01$ & $\mathrm{Sr}$ & $<0.05$ & Dy & $<0.005$ \\
\hline $\mathrm{Mg}$ & $<0.005$ & $\mathrm{Y}$ & $<0.05$ & Ho & $<0.005$ \\
\hline $\mathrm{Al}$ & 40 & $\mathrm{Zr}$ & Matrix & $\mathrm{Er}$ & $<0.005$ \\
\hline $\mathrm{Si}$ & 7.1 & $\mathrm{Nb}$ & 0.61 & $\mathrm{Tm}$ & $<0.005$ \\
\hline $\mathrm{P}$ & 0.79 & Mo & 2.2 & $\mathrm{Yb}$ & $<0.005$ \\
\hline S & 0.25 & $\mathrm{Ru}$ & $<0.05$ & $\mathrm{Lu}$ & $<0.005$ \\
\hline $\mathrm{Cl}$ & 0.23 & $\mathrm{Rh}$ & $<0.05$ & $\mathrm{Hf}$ & 55 \\
\hline K & $<0.1$ & $\mathrm{Pd}$ & $<0.5$ & $\mathrm{Ta}$ & $<5$ \\
\hline $\mathrm{Ca}$ & $<0.05$ & $\mathrm{Ag}$ & $<0.5$ & W & 0.12 \\
\hline $\mathrm{Sc}$ & $<5$ & $\mathrm{Cd}$ & $<0.5$ & $\operatorname{Re}$ & $<0.005$ \\
\hline $\mathrm{Ti}$ & 1.7 & In & $<0.1$ & Os & $<0.005$ \\
\hline V & 0.43 & $\mathrm{Sn}$ & 0.49 & Ir & $<0.005$ \\
\hline $\mathrm{Cr}$ & 120 & $\mathrm{Sb}$ & $<0.05$ & $\mathrm{Pt}$ & $<0.05$ \\
\hline $\mathrm{Mn}$ & 14 & $\mathrm{Te}$ & $<0.05$ & $\mathrm{Au}$ & $<0.05$ \\
\hline $\mathrm{Fe}$ & $\sim 0.15$ wt. $\%$ & I & $<0.1$ & $\mathrm{Hg}$ & $<0.05$ \\
\hline $\mathrm{Co}$ & 1.1 & Cs & $<0.005$ & $\mathrm{Tl}$ & $<0.01$ \\
\hline $\mathrm{Ni}$ & 63 & $\mathrm{Ba}$ & $<0.005$ & $\mathrm{~Pb}$ & 0.36 \\
\hline $\mathrm{Cu}$ & 13 & $\mathrm{La}$ & $<0.005$ & $\mathrm{Bi}$ & 0.16 \\
\hline $\mathrm{Zn}$ & 0.41 & $\mathrm{Ce}$ & $<0.005$ & Th & $<0.001$ \\
\hline $\mathrm{Ga}$ & 2.2 & $\operatorname{Pr}$ & $<0.005$ & $\mathrm{U}$ & 0.07 \\
\hline $\mathrm{Ge}$ & $<0.05$ & $\mathrm{Nd}$ & $<0.005$ & & \\
\hline
\end{tabular}


NEA/NSC/DOC(2006)1

Fundamental - FUND

NRAD-FUND-RESR-002

CRIT-REAC-COEF

\section{Control Rods}

The $\mathrm{B}_{4} \mathrm{C}$ poison material is hot pressed to a minimum density of $2.415 \mathrm{~g} / \mathrm{cm}^{3}$. The tubing material of the control rods is aluminum 6061-T6. ${ }^{\mathrm{a}}$ The extension rod, control rod connection fittings, and dowels are all aluminum 6061-T6. The bottom adapter fitting of the control rod guide tube is built from stainless steel 304 or 304L. The dowel pin used to fix the guide tube to this fitting is stainless steel 18-8. All other material in the control rod guide tube is aluminum 6061-T6.

Design drawings for the $\mathrm{B}_{4} \mathrm{C}$ material specify a minimum density of $2.48 \mathrm{~g} / \mathrm{cm}^{3}$ with a boron content of $78.0 \pm 1.0$ wt.\% with the naturally occurring isotope fraction of ${ }^{10} \mathrm{~B}(18.5 \pm 0.2 \mathrm{wt} . \%)$. The boron to carbon atom ratio in the finished pieces is $4.00 \pm 0.15$.

\section{Graphite Reflector Assembly}

The graphite in the reflector assemblies is considered nuclear/reactor grade. ${ }^{\mathrm{b}}$

Six graphite block samples were sent to IMR Test Labs Material Analysis Services ${ }^{c}$ to analyze the density of the graphite reflector blocks. The samples were measured between May 6-7, 2010, using ASTM C838-96 (2005) ${ }^{\mathrm{d}}$ methods for bulk density determination from mass and dimension measurements at room temperature. A graphite reflector block (similar to the one shown in Figure 1.39) was cut into sections. Pieces from three different axial locations of the block were cut out; at each axial location, a sample was taken from the side and center, such that homogeneity of the graphite density could be established. Results are shown in Table 1.13.

Table 1.13. Density Analysis of Graphite Reflector Block.

\begin{tabular}{|c|c|}
\hline Sample ID & $\begin{array}{c}\text { Density } \\
\left(\mathbf{k g} / \mathbf{m}^{\mathbf{3}}\right)\end{array}$ \\
\hline \hline A-Side & 1,570 \\
\hline A-Center & 1,570 \\
\hline B-Side & 1,560 \\
\hline B-Center & 1,580 \\
\hline C-Side & 1,560 \\
\hline C-Center & 1,580 \\
\hline
\end{tabular}

The results for the GDMS analysis, as described previously for fuel element components, of the graphite reflector block from EAG Labs is in Table 1.14.

The top and bottom assembly adapters are aluminum 6061-T6 and the associated hardware are aluminum 2011-T3 (also known as Toolrite 2011 ${ }^{\mathrm{TM}}$ ).

\footnotetext{
a "HFEF/N Neutron Radiography Facility System Design Description,” W0170-0004-SA rev. 2, Idaho National Laboratory (June 1, 1978). [This reference is not available for public release.]

${ }^{b}$ L. M. Montierth, "Criticality Safety Evaluation for the NRAD Core Conversion," INL/INT-07-13231 rev. 1, Idaho National Laboratory (September 2008). [This reference is not available for public release.]

${ }^{c} 131$ Woodsedge Drive, Lansing Business \& Technology Park, Lansing, New York 14882, http://www.imrtest.com/.

${ }^{\mathrm{d}}$ ASTM C838-96, Standard Test Method for Bulk Density of As-Manufactured Carbon and Graphite Shapes.
} 


\section{NEA/NSC/DOC(2006)1}

Fundamental - FUND

NRAD-FUND-RESR-002

CRIT-REAC-COEF

Table 1.14. GDMS Analysis of Graphite Reflector Block.

\begin{tabular}{|c|c|c|c|c|c|}
\hline Element & ppm (wt.) & Element & ppm (wt.) & Element & ppm (wt.) \\
\hline $\mathrm{Li}$ & $<0.05$ & $\mathrm{Ga}$ & $<0.01$ & $\mathrm{Nd}$ & $<0.05$ \\
\hline $\mathrm{Be}$ & $<0.05$ & $\mathrm{Ge}$ & $<0.05$ & $\mathrm{Sm}$ & $<0.01$ \\
\hline B & 0.75 & As & $<0.05$ & $\mathrm{Eu}$ & $<0.01$ \\
\hline $\mathrm{C}$ & Matrix & $\mathrm{Se}$ & $<0.05$ & $\mathrm{Gd}$ & $<0.01$ \\
\hline $\mathrm{N}$ & -- & $\mathrm{Br}$ & $<0.1$ & $\mathrm{~Tb}$ & $<0.01$ \\
\hline $\mathrm{O}$ & -- & $\mathrm{Rb}$ & $<0.05$ & Dy & $<0.01$ \\
\hline $\mathrm{F}$ & $<0.1$ & $\mathrm{Sr}$ & 0.51 & Но & $<0.01$ \\
\hline $\mathrm{Na}$ & 0.15 & Y & $<0.05$ & Er & $<0.01$ \\
\hline $\mathrm{Mg}$ & 1.4 & $\mathrm{Zr}$ & 0.44 & $\mathrm{Tm}$ & $<0.01$ \\
\hline $\mathrm{Al}$ & 1.3 & $\mathrm{Nb}$ & $<0.05$ & $\mathrm{Yb}$ & $<0.01$ \\
\hline $\mathrm{Si}$ & 81 & Mo & $<0.05$ & $\mathrm{Lu}$ & $<0.01$ \\
\hline $\mathrm{P}$ & 1.8 & $\mathrm{Ru}$ & $<0.05$ & $\mathrm{Hf}$ & $<0.01$ \\
\hline S & 50 & $\mathrm{Rh}$ & $<0.01$ & $\mathrm{Ta}$ & $<100$ \\
\hline $\mathrm{Cl}$ & 2.3 & $\mathrm{Pd}$ & $<0.05$ & W & $<0.05$ \\
\hline K & $<0.1$ & $\mathrm{Ag}$ & $<0.05$ & $\mathrm{Re}$ & $<0.01$ \\
\hline $\mathrm{Ca}$ & 23 & $\mathrm{Cd}$ & $<0.05$ & Os & $<0.01$ \\
\hline $\mathrm{Sc}$ & 0.07 & In & $<0.05$ & Ir & $<0.01$ \\
\hline $\mathrm{Ti}$ & 18 & $\mathrm{Sn}$ & $<0.05$ & $\mathrm{Pt}$ & $<0.01$ \\
\hline V & 29 & $\mathrm{Sb}$ & $<0.05$ & $\mathrm{Au}$ & $<0.1$ \\
\hline $\mathrm{Cr}$ & $<0.5$ & $\mathrm{Te}$ & $<0.05$ & $\mathrm{Hg}$ & $<0.1$ \\
\hline $\mathrm{Mn}$ & 0.12 & I & $<0.01$ & $\mathrm{Tl}$ & $<0.05$ \\
\hline $\mathrm{Fe}$ & 55 & $\mathrm{Cs}$ & $<0.05$ & $\mathrm{~Pb}$ & $<0.05$ \\
\hline Co & $<0.01$ & $\mathrm{Ba}$ & $<0.05$ & $\mathrm{Bi}$ & $<0.05$ \\
\hline $\mathrm{Ni}$ & 3.5 & $\mathrm{La}$ & $<0.05$ & Th & $<0.05$ \\
\hline $\mathrm{Cu}$ & $<0.05$ & $\mathrm{Ce}$ & $<0.05$ & $\mathrm{U}$ & $<0.05$ \\
\hline $\mathrm{Zn}$ & $<0.05$ & $\operatorname{Pr}$ & $<0.05$ & & \\
\hline
\end{tabular}


NEA/NSC/DOC(2006)1

\author{
Fundamental - FUND \\ NRAD-FUND-RESR-002 \\ CRIT-REAC-COEF
}

A dry graphite assembly and two, in-core, wet, graphite assemblies were later weighed to assess the amount of water saturation in the graphite reflectors surrounding the NRAD core. The mass of a dry graphite reflector assembly was $6.8 \mathrm{lbs}(3.0844 \mathrm{~kg})$. The measured weight of graphite block assemblies F-4 and D-1 were respectively $9.5 \mathrm{lbs}(4.3091 \mathrm{~kg})$ and $9.7 \mathrm{lbs}(4.3998 \mathrm{~kg})$. The measurement process is recorded in operating procedures. ${ }^{\mathrm{a}}$ When a graphite block measurement is to be performed, a calibrated scale is utilized to weigh the graphite assembly while it is still under the water level in the tank. This is to reduce personnel exposure to activated metals and impurities, and to prevent water from leaving the graphite, which could reduce the effective worth of the graphite reflector. The scale indicated weights reportable to two decimal places; however, the second decimal place was always zero.

The dummy graphite assembly was prepared using the same graphite as the original graphite reflector blocks (see Figure 1.39) and assembled as shown in Figure 1.36. The only difference between the incore and unirradiated graphite assemblies was the possibility that the in-core assemblies might have had two stainless steel dowels instead of aluminum dowels located in the bottom of the graphite blocks (see Figure 1.36).

Experimenters also noted that when the dry graphite assembly was initially lowered into the NRAD tank to perform a mass measurement, they could watch air bubbles appear along the sides of the graphite block and then rise to the top of the water for quite some time as water filled the void regions of the graphite. The dry graphite assembly was weighed immediately after being lowered underwater.,

\title{
Beam Ports
}

The beam filter tubes are aluminum 6061-T6. The North tube is backpressure filled with helium gas and the East tube contains air. The beam tube support is also constructed from aluminum 6061-T6. The hex head cap screw attached to the top of the beam tube support is aluminum 2024-T4.

The East wet package can contain either air or helium and is currently operated with air. The aperture housings are maintained with a helium overpressure between 75 to 85 inches of water (19 to $21 \mathrm{kPa}$ ), which also includes the beam tube between the tank wall and the aperture housing. Outside the reactor tank on the east side, the beam line is filled with air all the way to the sample tube coming down from the HFEF main cell. The main cell sample tube is filled with Argon. The beam tube outside of the reactor tank up to the north radiography cell is filled with helium. ${ }^{\mathrm{d}}$

The aperture assembly and source tube extending to the tank wall is aluminum 6061-T6. The aperture blocks are Combat Grade A boron nitride from The Carborundum Co., Graphite Products Division. The source tube inner lining is rolled Boral and the tube is filled with helium gas.

\section{Water Hole (Irradiation Position)}

The water hole position (within a control rod guide tube) in the core did not contain any experiments, detectors, or equipment, and thus was only filled with tank water.

\section{Start-Up Source}

The startup source is comprised of AmBe material in a sealed stainless steel container. The source tube and source tube cap are aluminum 6061.

\footnotetext{
a "LEU Core Refueling," NRP-NRAD-005 rev. 6, Idaho National Laboratory (February 2013). [This references is not available for public release.]

${ }^{\mathrm{b}}$ Personal communication with Andrew T. Smolinski (April 11, 2013).

${ }^{c}$ Personal communication with Andrew T. Smolinski (May 6, 2013).

${ }^{d}$ Personal communication with Ken Schreck at HFEF (April 29, 2010). 


\section{Detectors}

The pool detectors are placed in aluminum housings; the specific type of aluminum is not reported.

\section{Dry Tubes}

The aluminum 6061 dry tubes were not installed during the start-up measurements of the NRAD core.

\section{Graphite Elements}

The graphite elements used the same stainless steel cladding and end fittings as the fuel elements. However, the element internals are a graphite reflector rod with the same density and diameter as the top/bottom axial graphite reflectors in the fuel elements, but with a length of $55.5523 \mathrm{~cm}(\sim 21.871 \mathrm{in}.){ }^{\mathrm{a}}$

\subsubsection{Temperature Data}

Startup temperatures are typically at $26^{\circ} \mathrm{C}$ and at-power operations are typically performed at $37^{\circ} \mathrm{C}$. Full power operation is limited to $39^{\circ} \mathrm{C}$.

For the critical core with 62 fuel elements the tank water temperature was $30.0{ }^{\circ} \mathrm{C}$. The tank water temperature was $27.8^{\circ} \mathrm{C}$ for the critical with 64 fuel elements.

\subsubsection{Additional Information Relevant to Critical and Subcritical Measurements}

Additional information is not available.

\subsection{Description of Buckling and Extrapolation Length Measurements}

Buckling and extrapolation length measurements were not performed.

\subsection{Description of Spectral Characteristics Measurements}

Spectral characteristics measurements were not performed.

${ }^{a}$ Personal communication with Chris Ellis at GA (September 16, 2010). 
NEA/NSC/DOC(2006)1

Fundamental - FUND

NRAD-FUND-RESR-002

CRIT-REAC-COEF

\section{$1.4 \quad$ Description of Reactivity Effects Measurements}

\subsubsection{Overview of Experiment}

The core upgrade of the NRAD LEU reactor core began on April 10, 2013, and was completed on April 23,2013 . During this time period, measurements were performed to obtain the worth of two shim rods, one regulating rod, the shutdown margin, and the excess reactivity for both the interim core (62 fuel elements) and the final upgraded core configuration (64 fuel elements). It was during this time period that the mass of the graphite blocks (positions A-1 and F-6 of the 64-fuel-element core) was weighed to estimate the quantity of water saturation in the blocks (see Section 2.1.6.1).

On April 11, 2013, rod worth measurements were performed for the 62 -fuel-element interim core configuration. Rod drops were performed for both shim rods and the partially inserted regulating rod. Positive period measurements were performed to evaluate the remaining worth of the regulating rod and the excess reactivity of the core. The shutdown margin was determined from the difference in the combined worth of the withdrawn portions of the control rods.

On April 15, 2013, the worth measurements were repeated for the 64-fuel-element upgraded core configuration. However, the nuclear instrumentation was recalibrated as part of the power calibration measurements, and the worth measurements were repeated on April 23, 2013.

The linear-power channel was used to measure reactivity changes to measure reactivity effects such as control rod worths. The linear-power channel uses an all-solid-state multirange picoammeter that obtains a current signal from a compensated ion chamber. Depending on the gamma background level, this channel can measure power over most of the operating range of the reactor. ${ }^{\mathrm{a}}$ Figures 1.6, 1.55, and 1.56 provide the only information regarding placement of the linear-power channel in the reactor tank. No additional detector information is available.

Additional kinetics data pertaining to these measurements is unavailable.

\subsubsection{Geometry of the Experiment Configuration and Measurement Procedure}

The geometry of the core configurations and individual reactor components is provided in Section 1.1.2. Changes from the nominal configurations of the 62- and 64-fuel-element cores and a description of the measurement procedure are provided below.

Rod worth measurements are performed according to the procedure NRAD-OI-5140A. ${ }^{\mathrm{b}}$ A summary of the procedure is provided as follows. ${ }^{\mathrm{c}}$

All worth measurements are performed with the reactor critical at either $300 \mathrm{~W}$ for the rod drop measurements or $30 \mathrm{~W}$ for the positive period method. The power level is selected to allow sufficient detector range to gather the necessary information; a power that is high enough so that the instrument noise does not confuse the indication but as low as possible to limit heat generation in the reactor tank.

The reactor is brought to critical with the shim rods fully withdrawn and the regulating rod to a specific height to achieve criticality. The two shim rods are then individually dropped. The decay in the power is timed and a period is derived from the observed power decay; the reactivity necessary to produce the

\footnotetext{
a “HFEF/N Neutron Radiography Facility System Design Description,” W0170-0004-SA rev. 2, Idaho National Laboratory (June 1, 1978). [This reference is not available for public release.]

${ }^{\mathrm{b}}$ R. Bryan and K. Schreck, "Verification of Shutdown Margin and Control-Rod Reactivity Measurement," NRADOI-5140A, Idaho National Laboratory (2006).

${ }^{c}$ Personal communication with Ken Schreck at HFEF (May 26, 2011). 
NEA/NSC/DOC(2006)1

\author{
Fundamental - FUND \\ NRAD-FUND-RESR-002 \\ CRIT-REAC-COEF
}

calculated period is obtained from a data chart in the procedure. Power is marked at three time intervals: 6,10 , and 20 seconds. The calculated three periods are averaged and the average reactivity value is assigned for that rod for the core configuration when the test is performed.

The regulating rod's reactivity is the sum of the rod drop method for that portion of the rod that is withdrawn from the core to establish criticality, and segments that are withdrawn to obtain a positive period. The rod drop portion is identical to that described for the two shim rods.

From exactly critical at $30 \mathrm{~W}$, the regulating rod is withdrawn $\sim 50$ units and the power is allowed to rise. The rise in power is timed for four separate power intervals. When the last time split is obtained, the reactor is returned to critical using the two shim rods as a pair to compensate for the regulating rod in preparation for the next segment. The resulting period is calculated for each of the four timed power intervals and then averaged (the maximum power does not exceed $1 \mathrm{~kW}$ ). The average period is used to obtain a reactivity number associated with that period and assigned to that increment of rod travel. The regulating rod continues out and the shim rods are inserted as a bank in a stepwise manner until the regulating rod is fully withdrawn. Typically, eight measurements are performed for the 60 -fuel-element core. Combination of these eight positive period measurements and the partial rod drop provides the total worth of the regulating rod.

The core excess reactivity is represented by the worth of the regulating rod that remains in the core for a particular core configuration (i.e. the sum of all positive period measurements).

The shutdown margin is represented by the worth of the two shim rods and the portion of the regulating rod that is removed from the core for a given core configuration. The worth of each rod is measured individually and rod shadowing effects are traditionally assumed to be negligible within the experimental uncertainty. In other words, operators at NRAD have not had a need to evaluate or otherwise account for rod shadowing effects because said effects were believed to be nonexistent.

Table 1.15 contains the control rod calibration measurements for the 62 -fuel-element core performed on April 11, 2013. Rod worth measurements for the 64-fuel-element core (April 15, 2013) are provided in Table 1.16. Repeated measurements, after the nuclear instrumentation was recalibrated, were performed on April 23, 2013, and the results are provided in Table 1.17.

Full travel of an NRAD control rod is 15 in. $(38.1 \mathrm{~cm})$. The rod position indication displays $0-1000$ units of travel from a down limit switch to the up limit switch, respectively. Each unit of display is equal to 0.015 in. $(0.0381 \mathrm{~cm})$ of rod travel. A good confidence band $(3 \sigma)$ for knowing the location of the control rod is \pm 4 units $(0.06 \mathrm{in} ., 0.1524 \mathrm{~cm})$. The drive travel in the reactor room was physically measured and validated that the full travel length is $15 \mathrm{in}$. The digital position indication is calibrated at the zero, down limit, and again at 1000 units, or the upper limit, using potentiometers on the back of the reactor console. As much as -3 units to zero units at the lower limit and 999 or 1000 units at the upper limit is allowed. ${ }^{\text {a }}$

No uncertainties are reported with the worth measurements; they are evaluated in Section 2.4.

${ }^{a}$ Personal communication with Ken Schreck at HFEF (April 5-6, 2010). 


\section{NEA/NSC/DOC(2006)1}

Fundamental - FUND

NRAD-FUND-RESR-002

CRIT-REAC-COEF

Table 1.15. Control Rod Calibrations for 62-Fuel-Element Core (April 11, 2013).

\begin{tabular}{|c|c|c|c|c|c|c|c|}
\hline $\begin{array}{c}\text { Initial } \\
\text { Power } \\
(W) \\
\end{array}$ & $\begin{array}{c}\begin{array}{c}\text { Shim } 1 \\
\text { Position } \\
\text { (units) }\end{array} \\
\end{array}$ & $\begin{array}{r}\text { Shim 2 } \\
\text { Position } \\
\text { (units) } \\
\end{array}$ & $\begin{array}{c}\text { Reg } \\
\text { Position } \\
\text { (units) } \\
\end{array}$ & $\begin{array}{c}\text { Reg } \\
\text { Movement } \\
\text { (units) } \\
\end{array}$ & Activity & $\begin{array}{c}\text { Measured } \\
\text { Worth } \\
(\rho \$) \\
\end{array}$ & $\begin{array}{c}\text { Average } \\
\text { Worth } \\
(\rho \$) \\
\end{array}$ \\
\hline \multirow[t]{9}{*}{300} & \multirow[t]{9}{*}{1000} & \multirow[t]{9}{*}{999} & \multirow[t]{9}{*}{442} & \multirow[t]{3}{*}{--} & \multirow[t]{3}{*}{ Shim 1 Drop } & 2.79 & \multirow[t]{3}{*}{2.81} \\
\hline & & & & & & 2.80 & \\
\hline & & & & & & 2.83 & \\
\hline & & & & \multirow[t]{3}{*}{--} & \multirow[t]{3}{*}{ Shim 2 Drop } & 2.79 & \multirow[t]{3}{*}{2.81} \\
\hline & & & & & & 2.80 & \\
\hline & & & & & & 2.83 & \\
\hline & & & & \multirow[t]{3}{*}{0} & \multirow[t]{3}{*}{ Partial Reg Drop } & 0.97 & \multirow[t]{3}{*}{0.98} \\
\hline & & & & & & 0.98 & \\
\hline & & & & & & 1.00 & \\
\hline \multirow[t]{12}{*}{30} & 1000 & 1000 & 440 & 469 & \multirow[t]{9}{*}{ Positive Period } & 0.1121 & \multirow{12}{*}{$\begin{array}{l}1.65 \\
2.63 \\
-6.60\end{array}$} \\
\hline & 945 & 945 & 469 & 515 & & 0.1910 & \\
\hline & 881 & 881 & 515 & 558 & & 0.1786 & \\
\hline & 836 & 836 & 558 & 608 & & 0.2082 & \\
\hline & 789 & 789 & 608 & 668 & & 0.2258 & \\
\hline & 745 & 745 & 668 & 730 & & 0.2113 & \\
\hline & 708 & 708 & 730 & 793 & & 0.1749 & \\
\hline & 679 & 679 & 793 & 889 & & 0.2097 & \\
\hline & 646 & 646 & 889 & 1000 & & 0.1340 & \\
\hline & \multirow[t]{3}{*}{646} & \multirow[t]{3}{*}{646} & \multirow[t]{3}{*}{440} & \multirow[t]{3}{*}{1000} & $\begin{array}{c}\text { Total Positive } \\
\text { Period } \\
\text { (Excess Reactivity) }\end{array}$ & & \\
\hline & & & & & Total Reg Worth & & \\
\hline & & & & & $\begin{array}{c}\text { Shutdown Margin } \\
\text { (Positive Period } \\
\text { Rod) }\end{array}$ & & \\
\hline
\end{tabular}




\section{NEA/NSC/DOC(2006)1}

Fundamental - FUND

NRAD-FUND-RESR-002

CRIT-REAC-COEF

Table 1.16. Control Rod Calibrations for 64-Fuel-Element Core before Nuclear Instrument Recalibration (April 15, 2013).

\begin{tabular}{|c|c|c|c|c|c|c|c|}
\hline $\begin{array}{c}\text { Initial } \\
\text { Power } \\
\text { (W) } \\
\end{array}$ & $\begin{array}{l}\text { Shim } 1 \\
\text { Position } \\
\text { (units) } \\
\end{array}$ & $\begin{array}{c}\text { Shim } 2 \\
\text { Position } \\
\text { (units) } \\
\end{array}$ & $\begin{array}{c}\text { Reg } \\
\text { Position } \\
\text { (units) } \\
\end{array}$ & $\begin{array}{c}\text { Reg } \\
\text { Movement } \\
\text { (units) }\end{array}$ & Activity & $\begin{array}{c}\text { Measured } \\
\text { Worth } \\
(\rho \$) \\
\end{array}$ & $\begin{array}{l}\text { Average } \\
\text { Worth } \\
(\rho \$) \\
\end{array}$ \\
\hline \multirow[t]{9}{*}{300} & \multirow[t]{9}{*}{1000} & \multirow[t]{9}{*}{999} & \multirow[t]{9}{*}{206} & \multirow[t]{3}{*}{--} & \multirow[t]{3}{*}{ Shim 1 Drop } & 2.95 & \multirow[t]{3}{*}{3.02} \\
\hline & & & & & & 3.03 & \\
\hline & & & & & & 3.07 & \\
\hline & & & & \multirow[t]{3}{*}{--} & \multirow[t]{3}{*}{ Shim 2 Drop } & 3.05 & \multirow[t]{3}{*}{3.08} \\
\hline & & & & & & 3.07 & \\
\hline & & & & & & 3.13 & \\
\hline & & & & \multirow[t]{3}{*}{0} & \multirow[t]{3}{*}{ Partial Reg Drop } & 0.22 & \multirow[t]{3}{*}{0.22} \\
\hline & & & & & & 0.22 & \\
\hline & & & & & & 0.22 & \\
\hline \multirow[t]{15}{*}{30} & 1000 & 1000 & 203 & 276 & \multirow[t]{12}{*}{ Positive Period } & 0.1736 & \\
\hline & 927 & 927 & 276 & 335 & & 0.1683 & \\
\hline & 879 & 879 & 335 & 398 & & 0.2218 & \\
\hline & 828 & 828 & 398 & 448 & & 0.1907 & \\
\hline & 789 & 789 & 448 & 508 & & 0.2467 & \\
\hline & 745 & 745 & 508 & 557 & & 0.2125 & \\
\hline & 710 & 710 & 557 & 609 & & 0.1849 & \\
\hline & 682 & 682 & 609 & 675 & & 0.2371 & \\
\hline & 649 & 649 & 675 & 751 & & 0.2519 & \\
\hline & 615 & 615 & 751 & 843 & & 0.2325 & \\
\hline & 584 & 584 & 843 & 901 & & 0.1004 & \\
\hline & 571 & 571 & 901 & 1000 & & 0.1189 & \\
\hline & 571 & 571 & 203 & 1000 & $\begin{array}{c}\text { Total Positive } \\
\text { Period } \\
\text { (Excess Reactivity) }\end{array}$ & & 2.34 \\
\hline & & & & & Total Reg Worth & & 2.56 \\
\hline & & & & & $\begin{array}{c}\text { Shutdown Margin } \\
\text { (Positive Period } \\
\text { Rod) }\end{array}$ & & -6.32 \\
\hline
\end{tabular}




\section{NEA/NSC/DOC(2006)1}

Fundamental - FUND

NRAD-FUND-RESR-002

CRIT-REAC-COEF

Table 1.17. Control Rod Calibrations for 64-Fuel-Element Core after Nuclear Instrument Recalibration (April 23, 2013).

\begin{tabular}{|c|c|c|c|c|c|c|c|}
\hline $\begin{array}{c}\text { Initial } \\
\text { Power } \\
\text { (W) }\end{array}$ & $\begin{array}{c}\text { Shim } 1 \\
\text { Position } \\
\text { (units) }\end{array}$ & $\begin{array}{c}\text { Shim } 2 \\
\text { Position } \\
\text { (units) }\end{array}$ & $\begin{array}{c}\text { Reg } \\
\text { Position } \\
\text { (units) } \\
\end{array}$ & $\begin{array}{c}\text { Reg } \\
\text { Movement } \\
\text { (units) }\end{array}$ & Activity & $\begin{array}{c}\text { Measured } \\
\text { Worth } \\
(\rho \$) \\
\end{array}$ & $\begin{array}{l}\text { Average } \\
\text { Worth } \\
(\rho \$) \\
\end{array}$ \\
\hline \multirow[t]{9}{*}{300} & \multirow[t]{9}{*}{999} & \multirow[t]{9}{*}{999} & \multirow[t]{9}{*}{205} & \multirow[t]{3}{*}{--} & \multirow[t]{3}{*}{ Shim 1 Drop } & 3.04 & \multirow[t]{3}{*}{3.08} \\
\hline & & & & & & 3.07 & \\
\hline & & & & & & 3.13 & \\
\hline & & & & \multirow[t]{3}{*}{--} & \multirow[t]{3}{*}{ Shim 2 Drop } & 3.14 & \multirow[t]{3}{*}{3.11} \\
\hline & & & & & & 3.10 & \\
\hline & & & & & & 3.08 & \\
\hline & & & & \multirow[t]{3}{*}{0} & \multirow[t]{3}{*}{ Partial Reg Drop } & 0.21 & \multirow[t]{3}{*}{0.22} \\
\hline & & & & & & 0.22 & \\
\hline & & & & & & 0.22 & \\
\hline \multirow[t]{13}{*}{30} & 999 & 999 & 203 & 291 & \multirow[t]{10}{*}{ Positive Period } & 0.2196 & \multirow{13}{*}{$\begin{array}{l}2.37 \\
2.59\end{array}$} \\
\hline & 915 & 915 & 291 & 369 & & 0.2473 & \\
\hline & 851 & 851 & 369 & 425 & & 0.2097 & \\
\hline & 807 & 807 & 425 & 490 & & 0.2612 & \\
\hline & 759 & 759 & 490 & 551 & & 0.2508 & \\
\hline & 718 & 718 & 551 & 613 & & 0.2543 & \\
\hline & 679 & 679 & 613 & 685 & & 0.2537 & \\
\hline & 643 & 643 & 685 & 763 & & 0.2479 & \\
\hline & 610 & 610 & 763 & 872 & & 0.2562 & \\
\hline & 576 & 576 & 872 & 999 & & 0.1688 & \\
\hline & \multirow[t]{3}{*}{576} & \multirow[t]{3}{*}{576} & \multirow[t]{3}{*}{203} & \multirow[t]{3}{*}{999} & $\begin{array}{c}\text { Total Positive } \\
\text { Period } \\
\text { (Excess Reactivity) }\end{array}$ & & \\
\hline & & & & & Total Reg Worth & & \\
\hline & & & & & $\begin{array}{c}\text { Shutdown Margin } \\
\text { (Positive Period } \\
\text { Rod) }\end{array}$ & & \\
\hline
\end{tabular}


Fundamental - FUND

NRAD-FUND-RESR-002

CRIT-REAC-COEF

\subsubsection{Material Data}

The materials in the core were those described in Section 1.1.3.

\subsubsection{Temperature Data}

Startup temperatures are typically at $26^{\circ} \mathrm{C}$ and at-power operations are typically performed at $37^{\circ} \mathrm{C}$. Full power operation is limited to $39^{\circ} \mathrm{C}$.

The tank water temperatures for the 62 and 64 fuel element critical configurations were $30.0^{\circ} \mathrm{C}$ and 27.8 ${ }^{\circ} \mathrm{C}$, respectively.

\subsubsection{Additional Information Relevant to Reactivity Effects Measurements}

Additional information is not available. 
NEA/NSC/DOC(2006)1

Fundamental - FUND

NRAD-FUND-RESR-002

CRIT-REAC-COEF

\subsection{Description of Reactivity Coefficient Measurements}

\subsubsection{Overview of Experiment}

The core upgrade of the NRAD LEU reactor core began on April 10, 2013, and was completed on April 23, 2013.During this time period, calorimetric power calibrations were performed up to $250 \mathrm{~kW}$ and the excess reactivity was determined at full power $(250 \mathrm{~kW})$ for the 64 -fuel-element upgraded core.

On April 16 and 17, 2013, power calibrations were performed at powers ranging from 0.1 to $250 \mathrm{~kW}$. The regulating rod position was monitored to assess the reduction in core excess reactivity. The nuclear instrumentation was recalibrated, and this experiment was repeated on April 18, 2013.

The reactivity coefficient measurements due to rising core power have not been evaluated.

\subsubsection{Geometry of the Experiment Configuration and Measurement Procedure}

The geometry of the core configurations and individual reactor components is provided in Section 1.1.2. Changes from the nominal configurations of the 62- and 64-fuel-elements cores described are described below.

Reactor power calibration measurements are performed according to the procedure NRAD-OI-5160A. ${ }^{\mathrm{a}}$ The purpose of these measurements is to calibrate and verify the power channel instrumentation used during operation and for system safety requirements. Typically, the Flow- $\Delta \mathrm{T}$ method is used, where the primary cooling system flow and differential-pressure readings are used to calculate the reactor power.

Calculation of the heating of the tank using measured tank water temperatures is also used, but not required, to verify reactor power and nuclear-instrument calibration. A mixer is used to assist in distribution of the core heat throughout the tank water with the primary cooling system loop is closed.

Results recorded for the rise to power measurements are provided in Table 1.21 for the measurements performed on April 18, 2013, after the nuclear instrumentation used to monitor reactor power was recalibrated. As the core power increased, the position of the regulating rod was withdrawn further from the core. The worth of the regulating rod was used to determine the effective reduction in core excess reactivity. The water temperature was monitored by the thermistor located just before the coolant water heat exchanger and the thermistor located in the reactor tank (see Section 1.1.3.1).

a “Reactor Power Calibration,” NRAD-OI-5160A, Idaho National Laboratory (2009). 
NEA/NSC/DOC(2006)1

Fundamental - FUND

NRAD-FUND-RESR-002

CRIT-REAC-COEF

Table 1.21. Summary of Calorimetric Power Calibration Measurements. ${ }^{(a)}$

\begin{tabular}{|c|c|c|c|c|c|c|c|c|c|}
\hline Date & $\begin{array}{l}\text { Time at } \\
\text { Power }\end{array}$ & $\begin{array}{c}\text { Power } \\
(k W)\end{array}$ & $\begin{array}{c}\text { Reg } \\
\text { Position } \\
\text { (units) }\end{array}$ & $\begin{array}{l}\text { Shim } \\
\text { Position } \\
\text { (units) }\end{array}$ & $\begin{array}{c}\text { Core } \\
\text { ER } \\
\text { (p\$) }\end{array}$ & 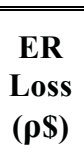 & $\begin{array}{c}\text { Cumulative } \\
\text { ER Loss ( } \$ \text { ) }\end{array}$ & $\begin{array}{c}\text { Hot } \\
\text { Leg } \\
\text { T } \\
\left({ }^{\circ} \mathrm{C}\right)\end{array}$ & $\begin{array}{r}\text { Tank } \\
\text { T }\left({ }^{\circ} \mathbf{C}\right)\end{array}$ \\
\hline \multirow{7}{*}{$\begin{array}{l}\text { 4/16/2013 } \\
\text { through } \\
4 / 18 / 2013\end{array}$} & $\sim 6 \mathrm{~min}$ & 0.1 & 203 & 1000 & 2.38 & 0.00 & 0 & -- & -- \\
\hline & $\sim 6 \mathrm{~min}$ & 1 & 207 & 1000 & 2.37 & 0.01 & 0.01 & -- & -- \\
\hline & $\sim 6 \min$ & 10 & 231 & 1000 & 2.31 & 0.06 & 0.07 & -- & -- \\
\hline & $\sim 6 \mathrm{~min}$ & 50 & 297 & 1000 & 2.12 & 0.19 & 0.26 & -- & -- \\
\hline & $\sim 6 \min$ & 100 & 352 & 1000 & 1.94 & 0.18 & 0.44 & 33.3 & 30.1 \\
\hline & $\sim 6 \mathrm{~min}$ & 200 & 442 & 1000 & 1.61 & 0.33 & 0.77 & 36.4 & 29.9 \\
\hline & $\sim 6 \mathrm{~min}$ & 250 & 477 & 1000 & 1.47 & 0.14 & 0.91 & 37.9 & 29.9 \\
\hline
\end{tabular}

(a) ER is the abbreviation for Excess Reactivity in the core.

The pool detectors are located to the south and north of the reactor core, near the edge of the pool (Figures 1.1 and 1.6). They consist of one linear, one log, and two safety channels. Horizontal and vertical placement of these detectors within the tank is shown with detail in Figures 1.55 and 1.56, respectively.

The wide-range (10 decade) log-power channel is a fission-chamber detector that provides indication of power and period from source level to $120 \%$ of design power. It uses both counting and Campbelling techniques to give an accurate log-power indication with very little gamma background error. Period measurements are from $-30 \mathrm{~s}$ to $+3 \mathrm{~s}$ over the full power range. ${ }^{\mathrm{a}}$

Two power-level-safety channels provide indication of reactor power from $0.001 \%$ to $120 \%$ of design power using uncompensated ion-chamber-type detectors. ${ }^{\text {a }}$

The linear-power channel uses an all-solid-state multirange picoammeter that obtains a current signal from a compensated ion chamber. Depending on the gamma background level, this channel can measure power over most of the operating range of the reactor. ${ }^{\text {a }}$ This channel is used to measure reactivity changes to measure reactivity effects such as control rod worths.

Detector power levels were calibrated on April 16-18, 2013 as part of the NRAD reactor startup procedures. $^{\mathrm{b}}$

\subsubsection{Material Data}

The materials in the core were those described in Section 1.1.3.

\subsubsection{Temperature Data}

Water temperature measurements are reported in Table 1.21. Fuel temperature measurements were not measured.

\footnotetext{
a "HFEF/N Neutron Radiography Facility System Design Description,” W0170-0004-SA rev. 2, Idaho National Laboratory (June 1, 1978). [This reference is not available for public release.]

b "Startup Report for the NRAD Reactor," 911195 rev. 0, GA Project 39296, TRIGA Reactor Division of General Atomics (November 4, 2010). [This reference is not available for public release.]
} 


\subsubsection{Additional Information Relevant to Reactivity Coefficient Measurements}

Additional information is not available.

\subsection{Description of Kinetics Measurements}

Kinetics measurements were not performed.

\subsection{Description of Reaction-Rate Distribution Measurements}

Reaction-rate distribution measurements were not performed.

\subsection{Description of Power Distribution Measurements}

Power distribution measurements were not performed.

\subsection{Description of Isotopic Measurements}

Isotopic measurements were not performed.

\subsection{Description of Other Miscellaneous Types of Measurements}

Other miscellaneous types of measurements were not performed. 
NEA/NSC/DOC(2006)1

Fundamental - FUND

NRAD-FUND-RESR-002

CRIT-REAC-COEF

\subsection{EVALUATION OF EXPERIMENTAL DATA}

Monte Carlo n-Particle (MCNP) version 5-1.60 calculations were utilized to estimate the biases and uncertainties associated with the experimental results in this evaluation for both the 62- and 64-fuelelement core critical configurations. MCNP 5-1.60 calculations were also used for evaluation of the reactivity worth calculations and sample results provided in Section 4. MCNP is a general-purpose, continuous-energy, generalized-geometry, coupled n-particle Monte Carlo transport code. ${ }^{\mathrm{a}}$ The Evaluated Neutron Data File library, ENDF/B-VII.0, ${ }^{\mathrm{b}}$ cross section data were also used in this evaluation. The statistical uncertainty in $\mathrm{k}_{\mathrm{eff}}$ and $\Delta \mathrm{k}_{\mathrm{eff}}$ is 0.00007 and 0.00010 , respectively. Calculations were performed with 1,550 generations with 100,000 neutrons per generation. The $k_{\text {eff }}$ estimates did not include the first 50 generations and are the result of $150,000,000$ neutron histories.

\subsection{Evaluation of Critical and / or Subcritical Configuration Data}

The benchmark models provided in Section 3.1, for the 62- and 64-fuel-element core configurations were utilized with perturbations of the model parameters to estimate uncertainties in $\mathrm{k}_{\mathrm{eff}}$ due to uncertainties in parameter values defining the benchmark configuration. Some perturbations required more detail than that available in the benchmark model. More detailed models (Appendix C) were used to evaluate these uncertainties. Transformation from the detailed model to the benchmark model is described in Section 3.1.1.1. Where applicable, comparison of the upper and lower perturbation $\mathrm{k}_{\text {eff }}$ values to evaluate the uncertainty in the eigenvalue were utilized to minimize correlation effects, if any, induced by comparing all perturbations to the original benchmark model configuration, as discussed elsewhere. ${ }^{\mathrm{c}}$

Unless specifically stated otherwise, all uncertainty values in this section correspond to $1 \sigma$. When the change in $\mathrm{k}_{\mathrm{eff}}$ between the base case and the perturbed model, or between two perturbed models, is less than the statistical uncertainty of the Monte Carlo results, the changes in the variable are amplified, if possible, and the calculations repeated. The resulting calculated change is then scaled back corresponding to the actual uncertainty, assuming that it is linear, which should be adequate for these changes in $k_{\text {eff. }}$

Uncertainties $\leq 0.00010$ are considered negligible because their calculated worth is within the statistical uncertainty of the Monte Carlo approach being utilized.

The total evaluated uncertainty in $\mathrm{k}_{\mathrm{eff}}$ for this experiment is provided in Section 2.1.13. The square root of the sum of the squares of all the individual uncertainties assessed in this section is used to obtain the total uncertainty in the experimental $\mathrm{k}_{\mathrm{eff}}$.

When evaluating parameters such as part diameters, heights, and mass, all parts of a given type are perturbed at the same time: e.g., the uranium mass in all fuel elements is simultaneously increased or decreased. Then the calculated uncertainty is reduced by the square root of the number of components perturbed, representative of a random uncertainty. For many of these uncertainties, there is insufficient information available to evaluate what portion of the total evaluated uncertainty is systematic instead of random. Random uncertainties are treated as $15 \%$ systematic in this evaluation, unless otherwise specified.

\footnotetext{
a X-5 Monte Carlo Team, "MCNP - a General Monte Carlo n-Particle Transport Code, version 5," LA-UR-031987, Los Alamos National Laboratory (2003).

${ }^{\mathrm{b}}$ M. B. Chadwick, et al., "ENDF/B-VII.0: Next Generation Evaluated Nuclear Data Library for Nuclear Science and Technology," Nucl. Data Sheets, 107: 2931-3060 (2006).

c D. Mennerdahl, "Statistical Noise for Nuclear Criticality Safety Specialists," Trans. Am. Nucl. Soc., 101: $465-466$ (2009).
} 


\section{Fundamental - FUND \\ NRAD-FUND-RESR-002 \\ CRIT-REAC-COEF}

This assumption provides a basic prediction of the effect on $\mathrm{k}_{\mathrm{eff}}$ until additional information regarding systematic uncertainties can be better evaluated. Most systematic uncertainties should be below $50 \%$ of the total uncertainty and above the historic approach of ignoring the unknown systematic components (i.e., treat it with a $0 \%$ probability). In actuality, careful experimenters may have an unknown systematic uncertainty that is approximately $10-15 \%$ of their total reported uncertainty. Because significant effort has gone into obtaining and evaluating data for the NRAD reactor, a systematic uncertainty of $15 \%$ is assumed. Evaluated uncertainties are listed as calculated, such that the readers may themselves adjust results according to some desired systematic-to-random uncertainty ratio.

A comprehensive uncertainty analysis was performed for the 60-fuel-element NRAD core configuration (NRAD-FUND-RESR-001). The evaluated uncertainties for many of the perturbed parameters were determined to be negligible $(\leq 0.00010 \Delta \mathrm{k})$, resulting in a much shorter list of uncertainties actually contributing to the total uncertainty, as was evaluated for the 56-fuel-element NRAD core configuration (see Section 2.1.12.2 of NRAD-FUND-RESR-001). A summary of negligible uncertainties pertinent to the current benchmark configurations is provided in Table 2.1; these uncertainties were not evaluated as their contribution to the total uncertainty in the benchmark configurations is judged to be negligible. Table 2.2 contains a list of uncertainties that are individually evaluated in this report for both the 62- and 64-fuel-element core configurations. Evaluation of the core configurations in this benchmark report include uncertainties in the graphite reflector elements, which were not available or utilized in earlier core configurations of the NRAD reactor. Information regarding the complete uncertainty evaluation as performed in NRAD-FUND-RESR-001 is retained in this benchmark report. However, only the uncertainties listed in Table 2.2 were actually evaluated for the core configurations pertaining herein. 
Table 2.1. Summary of Negligible Uncertainties Not Evaluated for 62- and 64-Fuel-Element Cores.

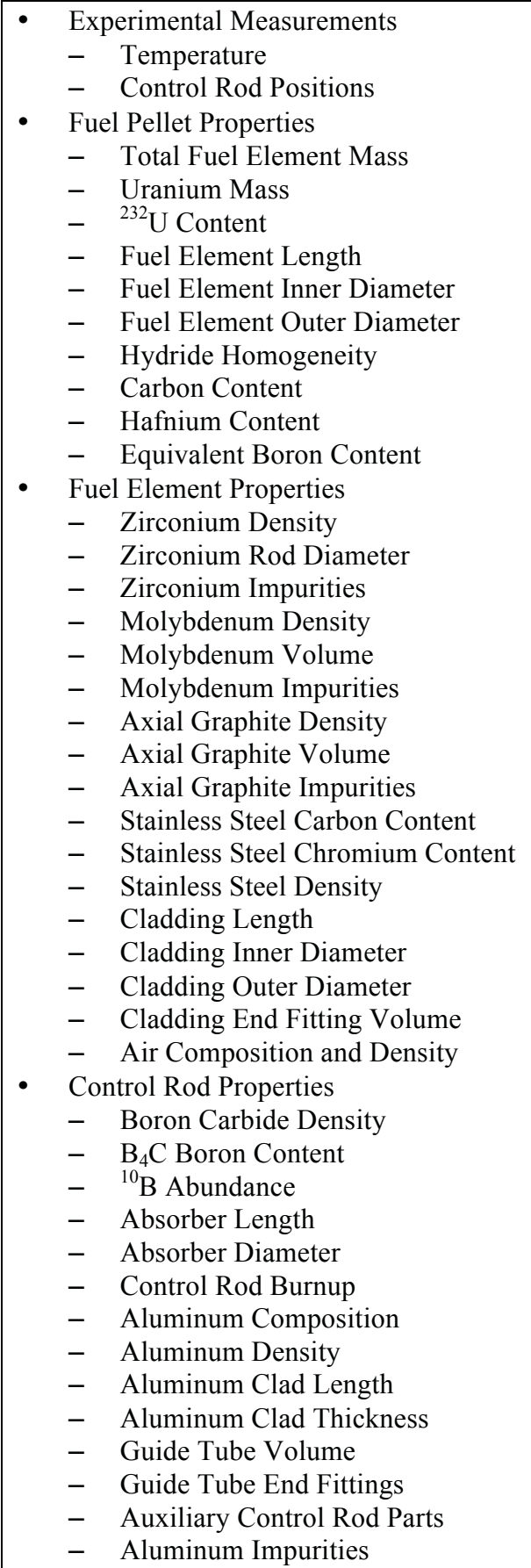

- Fuel Cluster Properties

- Fuel Element Pitch within Assembly

- Fuel Cluster Assembly Parts

- Graphite Reflector Assembly Properties

- Graphite Block Length

- Graphite Block Impurities

- Aluminum Auxiliary Components

- Graphite Assembly Components

- AmBe Source Properties

- Source Tube and Cap Properties

- $\quad$ Grid Plate Properties

- Aluminum Properties

- Location of Holes in Grid Plate

- Bottom Assembly Diameter

- Ex-Core Structural Support Properties

- Grid Plate Support Structure

- Mounting Pad

- Reactor Tank

- $\quad$ Beam Tube Properties

- Aluminum Properties

- Beam Filter Tube Dimensions

- Other Beam Tube Aluminum Components

- Aluminum Impurities

- Gas Content in Beam Tubes

- Boron Nitride Apertures

- Instrumentation and Detector Properties

- All Associated Properties 
NEA/NSC/DOC(2006)1

Fundamental - FUND

NRAD-FUND-RESR-002

CRIT-REAC-COEF

Table 2.2. Summary of Uncertainties Evaluated for 62- and 64-Fuel-Element Cores

\begin{tabular}{|c|c|}
\hline $\begin{array}{ll} & \text { Fuel Pellet Properties } \\
- & { }^{235} \text { U Mass } \\
- & { }^{234} \text { U Content } \\
- & { }^{236} \text { U Content } \\
- & \text { Hydrogen/Uranium Ratio } \\
- & \text { Erbium Content } \\
\text { - } & \text { Fuel Element Properties } \\
- & \text { Stainless Steel Manganese Content } \\
- & \text { Stainless Steel Nickel Content } \\
- & \text { Stainless Steel Impurities } \\
\text { Control Rod Properties } \\
\text { - } \quad \text { B }{ }_{4} \text { Impurities } \\
\text { Graphite Reflector Assembly Properties } \\
\text { - Graphite Block Density } \\
\text { - Graphite Block Cross Section } \\
\text { - Water Saturation of Graphite }\end{array}$ & $\begin{array}{l}\text { - } \text { Grid Plate Properties } \\
\text { - Assembly Pitch in Grid Plate } \\
\text { - } \quad \text { Assembly Hole Diameter } \\
\text { Tank Water Properties } \\
\text { - } \quad \text { Water Impurities } \\
\text { Beam Tube Properties } \\
\text { - } \quad \text { Placement of Beam Lines } \\
\text { Graphite Reflector Element Properties } \\
\text { - Graphite Density } \\
\text { - Graphite Length } \\
\text { - Graphite Diameter } \\
\text { - Graphite Impurities }\end{array}$ \\
\hline
\end{tabular}

\subsubsection{Experimental Measurements}

\subsubsection{Temperature}

The thermistor used to directly measure the bulk tank water temperature has a calibrated accuracy of $0.1{ }^{\circ} \mathrm{C}$. A larger uncertainty of $2{ }^{\circ} \mathrm{C}$ was assumed to represent a $1 \sigma$ uncertainty that includes possible uncertainty in bulk water temperature distribution, calibration standard uncertainty, and accuracy of the thermistor measurement. This value is also ten times the typical variability seen in the tank water temperature.

The temperature of the cold critical system directly impacts the density of the tank water and its effectiveness as a neutron moderator and reflector. Because this is a low power experiment, other temperature effects in neutron cross section data and material properties of reactor fuel, assemblies, and core components are assumed to be negligible compared to the effective change in the water density. This section addresses the effect of the temperature uncertainty on the water density while Section 2.1.9 provides further explanation regarding the physical properties of the tank water, including the correlation of water density with temperature.

This uncertainty was determined to be negligible $(\leq 0.00010)$ in NRAD-FUND-RESR-001.

\subsubsection{Control Rod Positions}

The uncertainty in the measurement of control rod position is \pm 4 units, $\pm 0.1524 \mathrm{~cm},(3 \sigma)$. The critical control rod positions for the shim 1, shim 2, and regulating rods were reported to be withdrawn 1000, 1000 , and 442 units $(38.1,38.1$, and $6.63 \mathrm{~cm})$, respectively, for the 62 -fuel-element core. The respective control rod positions for the 64-fuel-element core were 1000, 1000, and 205 units $(38.1,38.1$, and 3.075 $\mathrm{cm}$ ). The rod position indication displays 0-1000 units of travel from a down limit switch to the up limit switch, respectively. Each unit of display is equal to 0.015 in. $(0.0381 \mathrm{~cm})$ of rod travel.

This uncertainty was determined to be negligible $(\leq 0.00010)$ in NRAD-FUND-RESR-001.

\subsubsection{Measured Value of $k_{\text {eff }}$}

There is no additional information regarding the accuracy of the $k_{\text {eff }}$ measurements for the critical core conditions. Fission counts, linear power, regulating control rod position, and reactor period were all 
NEA/NSC/DOC(2006)1

Fundamental - FUND

NRAD-FUND-RESR-002

CRIT-REAC-COEF

monitored for stability to confirm the critical state of the NRAD reactor. This uncertainty is typically very small and can be considered negligible.

The AmBe source remains in the reactor core during operations. It emits neutrons at the rate of $\sim 1 \times 10^{7}$ neutrons/sec. The fission rate in the core at $50 \mathrm{~W}$ is $\sim 1 \times 10^{12}$ neutrons/sec. Because there are five orders of magnitude difference between the total fission rate and the AmBe source strength, the contribution of the $\mathrm{AmBe}$ source neutrons to the total neutron population is judged to be negligible and no additional bias or uncertainty was evaluated.

\subsubsection{Fuel Pellet - Uranium-Erbium-Zirconium-Hydride Fuel Properties}

The composition of the uranium-erbium-zirconium-hydride fuel is determined using the summary of asbuilt fuel data supplemented with additional information provided by General Atomics, Y-12, or CERCA. The average mass of uranium and ${ }^{235} \mathrm{U}$ can be compared to the total average mass of a single fuel element to obtain the weight fraction of uranium and enrichment (see Table 1.5). The average weight fractions of carbon and erbium are also available in Table 1.5.

The only ${ }^{234} \mathrm{U}$ and ${ }^{236} \mathrm{U}$ content measurements available from the $\mathrm{Y}-12$ data are for the last four NRAD fuel elements added to the core (Table 1.7). They are 0.159 and $0.144 \mathrm{wt.} \%$, respectively, using isotopic dilution measurements, and 0.145 and $0.121 \mathrm{wt} \%$, respectively, calculated from the alpha spectrometry measurement data. Additional data for the ${ }^{232} \mathrm{U},{ }^{234} \mathrm{U}$, and ${ }^{236} \mathrm{U}$ content were obtained regarding samples of Y-12 uranium fuel shipments (reported average values from seven measurements: $0.00004 \mathrm{ppm}, 0.156$ wt.\%, and 0.1289 wt.\%, respectively) to CERCA during this time period. ${ }^{\text {a }}$ Additional fuel measurements obtained from CERCA represent five uranium batches (Appendix $H$ ); the average ${ }^{234} U$ and ${ }^{236} U$ content are 0.192 and $0.252 \mathrm{wt} . \%$, respectively.

The average fuel content of ${ }^{232} \mathrm{U}$ is negligible and is not included in the fuel composition. The average ${ }^{234} \mathrm{U}$ and ${ }^{236} \mathrm{U}$ weight fractions are computed and ${ }^{238} \mathrm{U}$ represents the remaining uranium content in the fuel. The average ${ }^{234} \mathrm{U}$ and ${ }^{246} \mathrm{U}$ content in the uranium was calculated from the two Y-12 fuel sample measurements and the five CERCA fuel measurements: $0.18 \pm 0.02$ and $0.22 \pm 0.09$ wt.\%, respectively. The reported average measurements from the Y-12 shipments were not included in this calculation as the details regarding the average and uncertainty were not provided and there is no direct correlation provided between the shipped uranium and the fabricated fuel meat batches.

It is important to note that there is no correlation between the ${ }^{232} \mathrm{U},{ }^{234} \mathrm{U}$, and ${ }^{236} \mathrm{U}$ content with fuel enrichment due to various enriching and downblending campaigns at $\mathrm{Y}-12$ over time. ${ }^{\mathrm{c}}$

Impurities in the fuel are believed to be quite negligible. The results from the Y-12 analysis (Table 1.7) note that it was difficult to overcome interferences with the high quantities of zirconium. Oxygen and nitrogen levels were also not obtainable. Comparison of the zirconium and erbium measurements in Table 1.7 also does not match well with the reported as-built measurements. The ${ }^{235} \mathrm{U}$, U, and $\mathrm{C}$ measurements do agree with the manufacture data. The as-built data for the fuel pellets are within the manufacturing specifications agreed upon between GA and CERCA. The transactinide measurements of the fuel are at the detection limits and the quantities appear to be negligible. The equivalent boron content (EBC) is computed from the five CERCA fuel measurements (Appendix $\mathrm{H}$ ). The average EBC is $0.96 \pm 0.05 \mathrm{ppm}$. This value is selected to represent the nominal quantity of impurities in the fuel except carbon and hafnium.

\footnotetext{
a Personal communication with Eric C. Woolstenhulme at INL (April 27, 2010).

${ }^{b}$ Personal communication with John M. Bolin at General Atomics (April 11, 2011).

${ }^{c}$ Personal communication with Calvin M. Hopper at ORNL-retired (April 9, 2010). 
NEA/NSC/DOC(2006)1

\section{Fundamental - FUND \\ NRAD-FUND-RESR-002 \\ CRIT-REAC-COEF}

Further discussion with General Atomics has indicated that hafnium content of $0.2 \mathrm{wt} . \%$ represents more of a limit than the actual composition within the fuel of the NRAD reactor. ${ }^{\mathrm{a}}$ The measured value of Hf in the Y-12 fuel sample was $34 \mu \mathrm{g} / \mathrm{gU}$ (Table 1.7), which is equivalent to $\sim 50.2 \mathrm{ppm}$ (wt.\%) in zirconium. The Hf content in the zirconium rod was measured (Table 1.12) to be $55 \mathrm{ppm}$ (wt.\%). A measurement was provided by CERCA for the zirconium sponge material used in the NRAD reactor (Appendix H) with a Hf content of $46 \mathrm{ppm}$ (wt.\%). ${ }^{\mathrm{b}}$ The average $\mathrm{Hf}$ content in the zirconium is $50.4 \pm 4.5 \mathrm{ppm}$ (wt.\%). This is equivalent to a Hf content in the fuel of approximately $34.1 \mathrm{ppm}$ (wt.\%)

The remaining fuel mass is the zirconium hydride material. The $\mathrm{H} / \mathrm{Zr}$ ratio is used to estimate the weight fractions of hydrogen and zirconium in the fuel. The actual quantity is slightly less due to the presence of impurities neglected by assuming hafnium, carbon, and a boron equivalent are the only impurities. However, minor variation in the zirconium hydride content is negligible compared to the variations performed when perturbing other components of the fuel matrix.

The mass density of the fuel can be obtained by dividing the total average fuel mass by the average fuel volume. The outer diameter of the fuel is $3.4805 \mathrm{~cm}$, the inner diameter is $0.635 \mathrm{~cm}$, and the total fuel element length is $38.02 \mathrm{~cm}$. The total computed volume of the fuel in a single fuel element is $\sim 349.69$ $\mathrm{cm}^{3}$; the average fuel mass density is $7.1678 \mathrm{~g} / \mathrm{cm}^{3}$. The average fuel composition is summarized in Table 2.3.

Table 2.3. Average Composition of U-Er-Zr-H Fuel (wt.\%).

\begin{tabular}{|c|c|c|}
\hline Isotope/Element & 62 Fuel Elements & 64 Fuel Elements \\
\hline \hline $\mathrm{B}^{(\mathrm{a})}$ & 0.000096 & 0.000096 \\
$\mathrm{C}$ & 0.3 & 0.3 \\
$\mathrm{Er}$ & 0.9 & 0.9 \\
\hline \hline $\mathrm{H}+\mathrm{Zr}+\mathrm{Hf}$ & 68.8828849 & 68.8733044 \\
\hline $\mathrm{H}$ & 1.1818456 & 1.1816813 \\
$\mathrm{Zr}$ & 67.6976272 & 67.6882114 \\
$\mathrm{Hf}$ & 0.0034121 & 0.0034117 \\
\hline $\mathrm{U}$ & 29.9170191 & 29.9265996 \\
\hline${ }^{232} \mathrm{U} / \mathrm{U}_{\text {tot }}$ & 0.0 & 0.0 \\
${ }^{234} \mathrm{U} / \mathrm{U}_{\text {tot }}$ & 0.18 & 0.18 \\
${ }^{235} \mathrm{U} / \mathrm{U}_{\text {tot }}$ & 19.74 & 19.74 \\
${ }^{236} \mathrm{U} / \mathrm{U}_{\text {tot }}$ & 0.22 & 0.22 \\
${ }^{238} \mathrm{U} / \mathrm{U}_{\text {tot }}$ & 79.86 & 79.86 \\
\hline \hline $\mathrm{Total}$ & 100.0 & 100.0 \\
\hline \hline
\end{tabular}

(a) All impurities, except hafnium and carbon, are treated as equivalent boron content.

\subsubsection{Total Fuel Element Mass}

The average fuel element mass in the 62- and 64-fuel-element cores (Table 1.5), based on the actual measured values of the individual fuel element masses, is $2506.6 \pm 3.4 \mathrm{~g}$ and $2506.8 \pm 3.6 \mathrm{~g}$, respectively.

\footnotetext{
${ }^{a}$ Personal communication with John M. Bolin at General Atomics (April 7, 2011).

${ }^{\mathrm{b}}$ Personal communication with John M. Bolin at General Atomics (April 8, 2011). 
NEA/NSC/DOC(2006)1

\section{Fundamental - FUND \\ NRAD-FUND-RESR-002 \\ CRIT-REAC-COEF}

There is very little information available regarding how the measurements were performed, how accurately they were measured, or what uncertainties were present. As-built mass data appears to be accurate to $\pm 0.01 \mathrm{~g}$, consistent with these data being reported to two decimal places (see Appendix D). While the Y-12 chemical specifications for the uranium fuel wt.\% are indicated to two or three decimal places, actual sample measurements of fuel shipped from Y-12 are reported to three or four decimal places. Reprocessed material at CERCA is reported to one or two decimal places (wt.\%). ${ }^{\mathrm{a}}$ An uncertainty of $\pm 0.1 \mathrm{~g}(1 \sigma)$ seems reasonable for uncertainty in measurements of the $\sim 2.5 \mathrm{~kg}$ fuel element masses.

This uncertainty was determined to be negligible $(\leq 0.00010)$ in NRAD-FUND-RESR-001.

\subsubsection{Uranium Content}

The average uranium mass of the fuel elements in the 62- and 64-fuel-element cores (Table 1.5) is 749.9 $\pm 2.7 \mathrm{~g}$ and $750.2 \pm 3.1 \mathrm{~g}$, respectively, based on the reported measured values of the uranium mass of the individual fuel elements (Appendix D). This results in an average uranium mass content of approximately $29.92 \pm 0.11 \mathrm{wt} \%$. As noted previously, there is very little information available regarding how the measurements were performed, how accurately they were measured, or what uncertainties were present. And as above, an uncertainty of $\pm 0.1 \mathrm{~g}(1 \sigma)$ seems reasonable for the uncertainty in measurements of 1-2 $\mathrm{kg}$ uranium masses in the blending of the uranium alloy.

This uncertainty was determined to be negligible $(\leq 0.00010)$ in NRAD-FUND-RESR-001.

\subsubsection{Uranium Isotopic Distribution}

The average isotopic abundance of ${ }^{235} \mathrm{U}$ for the fuel elements in the 62- and 64-fuel-element cores (Table 1.5 ) is $19.74 \pm 0.02 \mathrm{wt} . \%$, based on reported as-built values for the individual fuel elements (Appendix D). As noted previously, there is very little information available regarding how the measurements were performed, how accurately they were measured, or what uncertainties were present. Fuel specifications from Y-12 indicate an uncertainty of $\pm 0.20 \mathrm{wt} . \%$ (Table 1.6), which appears to represent bounding values for fuel acceptance. The variation in the reported enrichments is much smaller. The entire range of the reported ${ }^{235} \mathrm{U}$ enrichments is $0.07 \mathrm{wt} . \%$. Treating the quoted specification of $\pm 0.20 \mathrm{wt} . \%$ as a tolerance for acceptance, a reasonable estimate of the $1 \sigma$ uncertainty is 0.20 wt. $\% \div 2 \sqrt{3}$, or 0.0577 wt. $\%$; when multiplied by the total mass, this uncertainty in the ${ }^{235} \mathrm{U}$ enrichment is equivalent to approximately \pm 0.43 $\mathrm{g}^{235} \mathrm{U}$.

Typical calibration standards for the evaluation of isotopic measurements of nominally $20 \%$ enriched uranium fuel had an uncertainty in ${ }^{235} \mathrm{U}$ content of approximately $\pm 0.020 \mathrm{wt} . \%(2 \sigma)$, ${ }^{\mathrm{b}}$ which is a $1 \sigma$ uncertainty of approximately $\pm 0.1 \mathrm{~g}$ when perturbing the ${ }^{235} \mathrm{U}$ mass relative to the total uranium mass. This uncertainty is approximately $25 \%$ of the uncertainty in the ${ }^{235} \mathrm{U}$ isotopic content of the fuel elements, and it is used to represent the systematic component of this uncertainty.

To find the effect of the uncertainty of the ${ }^{235} \mathrm{U}$ enrichment on the $\mathrm{k}_{\text {eff }}$ value, the average ${ }^{235} \mathrm{U}$ mass was adjusted by a factor of (1.8/0.43) times the $1 \sigma$ uncertainty of $\pm 0.43 \mathrm{~g}$. An upper perturbation $\mathrm{k}_{\mathrm{eff}}$ value was found by simultaneously increasing the average ${ }^{235} \mathrm{U}$ mass in all fuel elements by $1.8 \mathrm{~g}$ and then simultaneously decreasing by the same amount to find a lower perturbation $k_{\text {eff }}$ value. Half of the difference between the upper and lower perturbation $k_{\text {eff }}$ values was used to represent the variation in $k_{\text {eff }}$ due to perturbing the average ${ }^{235} \mathrm{U}$ mass by $1.8 \mathrm{~g}$. The calculated result was then scaled to obtain the $1 \sigma$ uncertainty. Results are shown in Table 2.4.

\footnotetext{
${ }^{\text {a }}$ Personal communication with Eric C. Woolstenhulme at INL (April 27, 2010).

${ }^{\mathrm{b}}$ National Bureau of Standards Certificate of Analysis Standard Reference Material U-200 (SRM-U200), U.S. Department of Commerce (April 6, 1981).
} 
NEA/NSC/DOC(2006)1

Fundamental - FUND

NRAD-FUND-RESR-002

CRIT-REAC-COEF

Increasing or decreasing the total mass of ${ }^{235} \mathrm{U}$ in the fuel effectively decreases or increases the total mass of ${ }^{238} \mathrm{U}$, changing the enrichment, as the total uranium mass is conserved. The isotopic quantities of the other uranium isotopes remain unchanged. Details of the enrichment batches were not provided for each of the individual fuel elements; it was reported that a total of eleven fuel batches of uranium metal were shipped from Y-12 to CERCA for use in the fabrication of the NRAD fuel elements. It appears that the fuel elements were fabricated from 11 or fewer (most likely 11) enrichment batches; therefore the random component of this uncertainty is divided by $\sqrt{ } 11$.

Table 2.4a. Effect of Uncertainty in Uranium-235 Mass (62-Fuel-Element Core).

\begin{tabular}{|c|c|c|c|c|c|c|c|c|c|}
\hline Deviation & $\Delta \mathbf{k}$ & \pm & $\sigma_{\Delta \mathbf{k}}$ & $\begin{array}{l}\text { Scaling } \\
\text { Factor }\end{array}$ & $\begin{array}{l}\Delta k_{\text {eff }} \\
(1 \sigma)\end{array}$ & \pm & $\sigma_{\text {akeff }}$ & $\begin{array}{c}\Delta \mathbf{k}_{\text {eff }} \\
(25 \% \\
\text { systematic })\end{array}$ & $\begin{array}{c}\Delta \mathbf{k}_{\text {eff }} \\
(75 \% \\
\text { random) }\end{array}$ \\
\hline $\begin{array}{c} \pm 1.8 \mathrm{~g} \\
( \pm 0.24 \\
\text { wt. } \%\end{array}$ & 0.00222 & \pm & 0.00005 & $(1.8 / 0.43)$ & 0.00053 & \pm & 0.00001 & 0.00013 & 0.00012 \\
\hline
\end{tabular}

Table 2.4b. Effect of Uncertainty in Uranium-235 Mass (64-Fuel-Element Core).

\begin{tabular}{||c|ccc|c|ccc|c|c||}
\hline \hline Deviation & $\Delta \mathbf{k}$ & \pm & $\boldsymbol{\sigma}_{\Delta \mathbf{k}}$ & $\begin{array}{c}\text { Scaling } \\
\text { Factor }\end{array}$ & $\begin{array}{c}\Delta \mathbf{k}_{\text {eff }} \\
(\mathbf{1 \sigma})\end{array}$ & \pm & $\boldsymbol{\sigma}_{\Delta \mathrm{keff}}$ & $\begin{array}{c}\Delta \mathbf{k}_{\text {eff }} \\
\mathbf{( 2 5 \%} \\
\text { systematic) }\end{array}$ & $\begin{array}{c}\Delta \mathbf{k}_{\text {eff }} \\
\mathbf{( 7 5 \%} \\
\text { random) }\end{array}$ \\
\hline \hline $\begin{array}{c} \pm 1.8 \mathrm{~g} \\
( \pm 0.24 \\
\text { wt. } \%\end{array}$ & 0.00221 & \pm & 0.00005 & $(1.8 / 0.43)$ & 0.00053 & \pm & 0.00001 & 0.00013 & 0.00012 \\
\hline
\end{tabular}

As discussed in Section 2.1.2, the quantity of ${ }^{232} \mathrm{U}$ in the fuel is negligible. Any uncertainty in the content would also have a negligible effect on $k_{\text {eff. }}$ The ${ }^{234} U$ and ${ }^{236} U$ contents were not typically measured except in some select fuel samples, some of which may not represent uranium used in the NRAD fuel. However, all samples discussed in Section 2.1.2 are from uranium material originating from Y-12. Approximate averages and $1 \sigma$ uncertainties are estimated from these fuel samples because of the ambiguity regarding actual content of these isotopes in the fuel.

The average ${ }^{234} \mathrm{U}$ content in the fuel, based on the discussion of available data in Section 2.1.2, is $0.18 \pm$ $0.02 \mathrm{wt} . \%(1 \sigma)$. This is the average of seven measurements: two from the extra fuel element and five from CERCA measurements.

To find the effect of this uncertainty on the $\mathrm{k}_{\text {eff }}$ value, a ${ }^{234} \mathrm{U}$ content of $0.18 \mathrm{wt} . \%$ was adjusted by a factor of 3 times the $1 \sigma$ uncertainty. An upper perturbation $k_{\text {eff }}$ value was found by simultaneously increasing the ${ }^{234} \mathrm{U}$ content in all fuel elements by $0.06 \mathrm{wt} . \%$ and then simultaneously decreasing by the same amount to find a lower perturbation $\mathrm{k}_{\text {eff }}$ value. Half of the difference between the upper and lower perturbation $k_{\text {eff }}$ values was used to represent the variation in $k_{\text {eff }}$ due to perturbing the ${ }^{234} U$ content by 0.02 wt.\%. The calculated result was then scaled to obtain the $1 \sigma$ uncertainty. Results are shown in Table 2.5.

Table 2.5a. Effect of Uncertainty in Uranium-234 Content (62-Fuel-Element Core).

\begin{tabular}{|c|ccc|c|ccc||}
\hline \hline Deviation & $\Delta \mathbf{k}$ & \pm & $\boldsymbol{\sigma}_{\Delta \mathbf{k}}$ & $\begin{array}{c}\text { Scaling } \\
\text { Factor }\end{array}$ & $\Delta \mathbf{k}_{\text {eff }}(\mathbf{1} \boldsymbol{\sigma})$ & \pm & $\boldsymbol{\sigma}_{\text {akeff }}$ \\
\hline \hline \pm 0.06 wt. $\%( \pm 0.45 \mathrm{~g})$ & -0.00081 & \pm & 0.00005 & 3 & -0.00027 & \pm & 0.00002 \\
\hline
\end{tabular}


NEA/NSC/DOC(2006)1

Fundamental - FUND

NRAD-FUND-RESR-002

CRIT-REAC-COEF

Table 2.5b. Effect of Uncertainty in Uranium-234 Content (64-Fuel-Element Core).

\begin{tabular}{||c|ccc|c|cc||}
\hline \hline Deviation & $\Delta \mathbf{k}$ & \pm & $\boldsymbol{\sigma}_{\Delta \mathbf{k}}$ & $\begin{array}{c}\text { Scaling } \\
\text { Factor }\end{array}$ & $\Delta \mathbf{k}_{\text {eff }}(\mathbf{1 \sigma}) \pm$ & $\boldsymbol{\sigma}_{\Delta \mathbf{k e f f}}$ \\
\hline \hline \pm 0.06 wt. $\%( \pm 0.45 \mathrm{~g})$ & -0.00091 & \pm & 0.00005 & 3 & -0.00030 & \pm 0.00002 \\
\hline \hline
\end{tabular}

The average ${ }^{236} \mathrm{U}$ content is $0.22 \pm 0.09$ wt. $\%(1 \sigma)$. This is the average of seven measurements: two from the extra fuel element and five from CERCA measurements.

To find the effect of this uncertainty on the $\mathrm{k}_{\text {eff }}$ value, a ${ }^{236} \mathrm{U}$ content of $0.22 \mathrm{wt} . \%$ was adjusted by a factor of 2 times the $1 \sigma$ uncertainty. An upper perturbation $k_{\text {eff }}$ value was found by simultaneously increasing the ${ }^{236} \mathrm{U}$ content in all fuel elements by $0.18 \mathrm{wt} . \%$ and then simultaneously decreasing by the same amount to find a lower perturbation $\mathrm{k}_{\mathrm{eff}}$ value. Half of the difference between the upper and lower perturbation $\mathrm{k}_{\text {eff }}$ values was used to represent the variation in $\mathrm{k}_{\text {eff }}$ due to perturbing the ${ }^{236} \mathrm{U}$ content by 0.09 wt.\%. Results are shown in Table 2.6.

Table 2.6a. Effect of Uncertainty in Uranium-236 Content (62-Fuel-Element Core).

\begin{tabular}{||c|ccc|c|ccc||}
\hline \hline Deviation & $\Delta \mathbf{k}$ & \pm & $\boldsymbol{\sigma}_{\Delta \mathbf{k}}$ & $\begin{array}{c}\text { Scaling } \\
\text { Factor }\end{array}$ & $\Delta \mathbf{k}_{\text {eff }}(\mathbf{1} \boldsymbol{\sigma})$ & \pm & $\boldsymbol{\sigma}_{\Delta \mathbf{k e f f}}$ \\
\hline \hline \pm 0.18 wt. $\%( \pm 1.35 \mathrm{~g})$ & -0.00097 & \pm & 0.00005 & 2 & -0.00049 & \pm & 0.00002 \\
\hline \hline
\end{tabular}

Table 2.6b. Effect of Uncertainty in Uranium-236 Content (64-Fuel-Element Core).

\begin{tabular}{|c|ccc|c|ccc||}
\hline \hline Deviation & $\Delta \mathbf{k}$ & \pm & $\boldsymbol{\sigma}_{\mathbf{a k}}$ & $\begin{array}{c}\text { Scaling } \\
\text { Factor }\end{array}$ & $\Delta \mathbf{k}_{\text {eff }}(\mathbf{1} \boldsymbol{\sigma})$ & \pm & $\boldsymbol{\sigma}_{\text {akeff }}$ \\
\hline \hline \pm 0.18 wt.\% $( \pm 1.35 \mathrm{~g})$ & -0.00096 & \pm & 0.00005 & 2 & -0.00048 & \pm & 0.00002 \\
\hline \hline
\end{tabular}

The uncertainty in the ${ }^{234} \mathrm{U}$ and ${ }^{236} \mathrm{U}$ contents is treated as $100 \%$ systematic because the isotopic content of ${ }^{234} \mathrm{U}$ and ${ }^{236} \mathrm{U}$ is not recorded for any of the fuel elements in the NRAD core. Increasing or decreasing the total mass of ${ }^{232} \mathrm{U},{ }^{234} \mathrm{U}$, or ${ }^{236} \mathrm{U}$ in the fuel effectively decreases or increases the total mass of ${ }^{238} \mathrm{U}$. The ${ }^{235} \mathrm{U}$ mass and enrichment remains unchanged. Total uranium mass and total fuel mass are conserved.

\subsubsection{Fuel Element Dimensions}

The average fuel element length and outer diameter in the 62- and 64-fuel-element cores (Table 1.5) are $38.02 \pm 0.04 \mathrm{~cm}(1 \sigma)$ and $3.4805 \pm 0.0003 \mathrm{~cm}(1 \sigma)$, respectively. The inner diameter of the fuel is 0.635 $\mathrm{cm}$, with manufacturing tolerance limits of +0.00 and $-0.0254 \mathrm{~cm}$.

These uncertainties were determined to be negligible $(\leq 0.00010)$ in NRAD-FUND-RESR-001.

\subsubsection{Hydride Ratio}

The average fuel $\mathrm{H} / \mathrm{Zr}$ ratio in the 62- and 64-fuel-element cores (Table 1.5) is $1.58 \pm 0.01(1 \sigma)$.

To find the effect of this uncertainty on the $\mathrm{k}_{\text {eff }}$ value, the average fuel hydride ratio was adjusted by the $3 \sigma$ uncertainty. An upper perturbation $\mathrm{k}_{\mathrm{eff}}$ value was found by simultaneously increasing the hydride ratio in all fuel elements by 0.03 and then simultaneously decreasing by the same amount to find a lower perturbation $\mathrm{k}_{\mathrm{eff}}$ value. Half of the difference between the upper and lower perturbation $\mathrm{k}_{\mathrm{eff}}$ values was 
NEA/NSC/DOC(2006)1

Fundamental - FUND

NRAD-FUND-RESR-002

CRIT-REAC-COEF

used to represent the variation in $k_{\text {eff }}$ due to perturbing the average fuel hydride ratio by 0.03 . The calculated result was then scaled to obtain the $1 \sigma$ uncertainty. Results are shown in Table 2.7.

Increasing or decreasing the hydride ratio does not affect the mass of any other fuel constituents. The total number of fuel elements in this configuration is 62 or 64; therefore the random component of this uncertainty is divided by $\sqrt{6} 62$ or $\sqrt{ } 64$.

Table 2.7a. Effect of Uncertainty in Hydride Ratio (62-Fuel-Element Core).

\begin{tabular}{||c|ccc|c|ccc|c|c||}
\hline \hline Deviation & $\Delta \mathbf{k}$ & \pm & $\boldsymbol{\sigma}_{\Delta \mathbf{k}}$ & $\begin{array}{c}\text { Scaling } \\
\text { Factor }\end{array}$ & $\Delta \mathbf{k}_{\text {eff }}(\mathbf{1 \sigma})$ & \pm & $\boldsymbol{\sigma}_{\Delta \mathbf{k e f f}}$ & $\begin{array}{c}\Delta \mathbf{k}_{\text {eff }} \\
(\mathbf{1 5 \%} \\
\text { systematic) }\end{array}$ & $\begin{array}{c}\Delta \mathbf{k}_{\text {eff }} \\
\mathbf{( 8 5 \%} \\
\text { random) }\end{array}$ \\
\hline \hline $\pm 0.03 \mathrm{H}: \mathrm{Zr}$ & 0.00302 & \pm & 0.00005 & 3 & 0.00101 & \pm 0.00002 & 0.00015 & 0.00011 \\
\hline
\end{tabular}

Table 2.7b. Effect of Uncertainty in Hydride Ratio (64-Fuel-Element Core).

\begin{tabular}{||c|ccc|c|ccc|c|c||}
\hline \hline Deviation & $\Delta \mathbf{k}$ & \pm & $\boldsymbol{\sigma}_{\Delta \mathbf{k}}$ & $\begin{array}{c}\text { Scaling } \\
\text { Factor }\end{array}$ & $\Delta \mathbf{k}_{\text {eff }}(\mathbf{1 \sigma})$ & \pm & $\sigma_{\Delta k \text { keff }}$ & $\begin{array}{c}\Delta \mathbf{k}_{\text {eff }} \\
(\mathbf{1 5 \%} \\
\text { systematic) }\end{array}$ & $\begin{array}{c}\Delta \mathbf{k}_{\text {eff }} \\
\mathbf{8 5 \%} \\
\text { random) }\end{array}$ \\
\hline \hline $\pm 0.03 \mathrm{H}: \mathrm{Zr}$ & 0.00300 & \pm & 0.00005 & 3 & 0.00100 & \pm 0.00002 & 0.00015 & 0.00011 \\
\hline
\end{tabular}

\subsubsection{Hydride Homogeneity}

It is unknown how homogenously throughout the fuel the hydrogen is distributed during the hydriding process. Diffusion of hydrogen in hollow cylinders of zirconium alloy exhibits a fairly flat concentration profile. However, there are slight nonlinear effects due to thermal stresses, such as can be incurred due to impurities in the metal alloy. ${ }^{a}$ Micrographs of fuel samples from the extra fuel element are in Appendix G. Neither carbon nor uranium has any effect on the hydrogen diffusion process for $\mathrm{H} / \mathrm{Zr}$ ratios between 1.5 and 1.8. Erbium and uranium can be uniformly melted into a zirconium alloy; there is no reason to believe that erbium would segregate, as it forms a stable hydride and stays uniformly dispersed. ${ }^{\mathrm{b}}$ There is some indication that the distribution of hydrogen has on average a constant profile throughout a sample of hydride discs being used in thermal migration studies of hydrogen in zirconium-uranium-hydrogen alloys. Two discs nominally containing $\mathrm{ZrH}_{1.6} \mathrm{U}_{0.03}$ exhibited hydrogen-to-zirconium ratios of approximately 1.65, bound between 1.60 and 1.70. Another sample of just $\mathrm{ZrH}_{1.6}$ was sampled five times with the following ratios: $1.68,1.72,1.69,1.69$, and $1.65 .^{\circ}$ The average ratio for the $\mathrm{ZrH}_{1.6}$ sample is $1.69 \pm 0.03(1 \sigma)$. If the bounding limits for the $\mathrm{ZrH}_{1.6} \mathrm{U}_{0.03}$ samples are converted to $1 \sigma$ by dividing the limit by $\sqrt{ } 3$, the average ratio is $\sim 1.65 \pm 0.03(1 \sigma)$. It is concluded that the as-built distribution of hydride throughout the fuel matrix is not completely homogenous and has a $1 \sigma$ uncertainty approximately three times greater than the variation in average ratios between the individual fuel elements. It is unclear how the $\mathrm{H} / \mathrm{Zr}$ ratio is measured for the fuel; therefore, this uncertainty is treated as an additional uncertainty in the hydride composition of the fuel.

This uncertainty was determined to be negligible $(\leq 0.00010)$ in NRAD-FUND-RESR-001.

\footnotetext{
${ }^{a}$ N. M. Vlasov and V. A. Zaznoba, "Thermal Diffusion of Hydrogen in Zirconium with Allowance for Thermal Stresses,” Tech. Phys., 54, 651-655 (2009).

${ }^{\mathrm{b}}$ M. T. Simnad, "The U-ZrH $\mathrm{rH}_{\mathrm{x}}$ Alloy: Its Properties and Use in TRIGA Fuel," E-117-833, GA Project No. 4314, General Atomics (February 1980). [This reference is not available for public release.]

${ }^{\mathrm{c}}$ U. Merten, J. C. Bokros, D. G. Guggisberg, and A. P. Hatcher, "Thermal Migration of Hydrogen in ZirconiumUranium-Hydrogen Alloys,” J. Nucl. Mater., 10, 201-208 (1963).
} 
NEA/NSC/DOC(2006)1

Fundamental - FUND

NRAD-FUND-RESR-002

CRIT-REAC-COEF

\subsubsection{Erbium Content}

The average fuel erbium content in the 62- and 64-fuel-element cores (Table 1.5) is $0.90 \pm 0.02 \mathrm{wt. \%}$ $(1 \sigma)$.

To find the effect of this uncertainty on the $\mathrm{k}_{\mathrm{eff}}$ value, the average fuel erbium content was adjusted by the $3 \sigma$ uncertainty. An upper perturbation $\mathrm{k}_{\mathrm{eff}}$ value was found by simultaneously increasing the average erbium content in all fuel elements by $0.06 \mathrm{wt} . \%$ and then simultaneously decreasing by the same amount to find a lower perturbation $\mathrm{k}_{\text {eff }}$ value. Half of the difference between the upper and lower perturbation $\mathrm{k}_{\text {eff }}$ values was used to represent the variation in $\mathrm{k}_{\text {eff }}$ due to perturbing the average fuel erbium content by 0.06 wt.\%. The calculated result was then scaled to obtain the $1 \sigma$ uncertainty. Results are shown in Table 2.8.

Increasing or decreasing the total erbium content in the fuel effectively decreases or increases the total mass of zirconium hydride in the fuel, changing the U/Zr-H ratio. The total number of fuel elements in this configuration is 62 or 64 ; therefore the random component of this uncertainty is divided by $\sqrt{ } 62$ or $\sqrt{6} 64$.

Table 2.8a. Effect of Uncertainty in Erbium Content (62-Fuel-Element Core).

\begin{tabular}{|c|c|c|c|c|c|c|c|c|c|}
\hline Deviation & $\Delta \mathbf{k}$ & \pm & $\sigma_{\Delta \mathbf{k}}$ & $\begin{array}{l}\text { Scaling } \\
\text { Factor }\end{array}$ & $\Delta k_{\text {eff }}(1 \sigma)$ & \pm & $\sigma_{\text {dkeff }}$ & $\begin{array}{c}\Delta \mathbf{k}_{\text {eff }} \\
(15 \% \\
\text { systematic })\end{array}$ & $\begin{array}{c}\Delta \mathbf{k}_{\text {eff }} \\
(85 \% \\
\text { random })\end{array}$ \\
\hline \pm 0.06 wt. $\%$ & -0.00803 & \pm & 0.00005 & 3 & -0.00268 & \pm & 0.00002 & -0.00040 & -0.00029 \\
\hline
\end{tabular}

Table 2.8b. Effect of Uncertainty in Erbium Content (64-Fuel-Element Core).

\begin{tabular}{||c|ccc|c|ccc|c|c||}
\hline \hline Deviation & $\Delta \mathbf{k}$ & \pm & $\sigma_{\Delta \mathbf{k}}$ & $\begin{array}{c}\text { Scaling } \\
\text { Factor }\end{array}$ & $\Delta \mathbf{k}_{\text {eff }}(\mathbf{1 \sigma})$ & \pm & $\sigma_{\text {akeff }}$ & $\begin{array}{c}\Delta \mathbf{k}_{\text {eff }} \\
\mathbf{1 5 \%} \\
\text { systematic) }\end{array}$ & $\begin{array}{c}\Delta \mathbf{k}_{\text {eff }} \\
\mathbf{8 5 \%} \\
\text { random) }\end{array}$ \\
\hline \hline \pm 0.06 wt.\% & -0.00811 & \pm & 0.00005 & 3 & -0.00270 & \pm & 0.00002 & -0.00041 & -0.00029 \\
\hline
\end{tabular}

\subsubsection{Carbon Content}

The average fuel carbon content in the 62- and 64-fuel-element cores (Table 1.5) is $0.30 \pm 0.02$ wt.\% $(1 \sigma)$.

This uncertainty was determined to be negligible $(\leq 0.00010)$ in NRAD-FUND-RESR-001.

\subsubsection{Additional Impurity Content}

The average Hf content in the zirconium of the fuel, based on the discussion of available data in Section 2.1.2, is $50.4 \pm 4.5 \mathrm{ppm}(\mathrm{wt} . \%, 1 \sigma)$. This is the average of three measurements: one from the extra fuel element, one from the extra zirconium rod and one from a CERCA measurement of the zirconium sponge material used to manufacture the fuel and rod.

The average EBC in the fuel, based on the discussion of available data in Section 2.1.2, is $0.96 \pm 0.05$ ppm $(w t . \%, 1 \sigma)$. This is the average of five CERCA measurements.

These uncertainties were determined to be negligible $(\leq 0.00010)$ in NRAD-FUND-RESR-001. 


\subsubsection{Fuel Element - Non-Fuel Properties}

\subsubsection{Zirconium Rod}

\section{Composition}

The composition of the zirconium rods (Table 2.9) is obtained by reducing the quantity of zirconium to account for the impurities reported in Table 1.12. For elements that are listed only as detection limits, half of the detection limit is assumed to represent the quantity of that impurity in the zirconium material.

Table 2.9. Composition of Zirconium.

\begin{tabular}{|c|c|c|c|}
\hline Element & wt. $\%$ & Element & wt. $\%$ \\
\hline $\mathrm{Li}$ & 0.00000025 & As & 0.000004 \\
\hline $\mathrm{Be}$ & 0.00000025 & $\mathrm{Se}$ & 0.0000025 \\
\hline B & 0.000005 & $\mathrm{Br}$ & 0.0000025 \\
\hline $\mathrm{F}$ & 0.00005 & $\mathrm{Rb}$ & 0.0000025 \\
\hline $\mathrm{Na}$ & 0.0000005 & $\mathrm{Sr}$ & 0.0000025 \\
\hline $\mathrm{Mg}$ & 0.00000025 & $\mathrm{Y}$ & 0.0000025 \\
\hline $\mathrm{Al}$ & 0.004 & $\mathrm{Zr}$ & 99.8169797 \\
\hline $\mathrm{Si}$ & 0.00071 & $\mathrm{Nb}$ & 0.000061 \\
\hline $\mathrm{P}$ & 0.000079 & Mo & 0.00022 \\
\hline $\mathrm{S}$ & 0.000025 & $\mathrm{Ru}$ & 0.0000025 \\
\hline $\mathrm{Cl}$ & 0.000023 & $\mathrm{Rh}$ & 0.0000025 \\
\hline $\mathrm{K}$ & 0.000005 & $\mathrm{Pd}$ & 0.000025 \\
\hline $\mathrm{Ca}$ & 0.0000025 & $\mathrm{Ag}$ & 0.000025 \\
\hline $\mathrm{Sc}$ & 0.00025 & $\mathrm{Cd}$ & 0.000025 \\
\hline $\mathrm{Ti}$ & 0.00017 & In & 0.000005 \\
\hline V & 0.000043 & Sn & 0.000049 \\
\hline $\mathrm{Cr}$ & 0.012 & $\mathrm{Sb}$ & 0.0000025 \\
\hline $\mathrm{Mn}$ & 0.00014 & $\mathrm{Te}$ & 0.0000025 \\
\hline $\mathrm{Fe}$ & 0.15 & I & 0.000005 \\
\hline Co & 0.00011 & Cs & 0.00000025 \\
\hline $\mathrm{Ni}$ & 0.0063 & $\mathrm{Ba}$ & 0.00000025 \\
\hline $\mathrm{Cu}$ & 0.0013 & $\mathrm{La}$ & 0.00000025 \\
\hline $\mathrm{Zn}$ & 0.000041 & $\mathrm{Ce}$ & 0.00000025 \\
\hline $\mathrm{Ga}$ & 0.00022 & $\operatorname{Pr}$ & 0.00000025 \\
\hline $\mathrm{Ge}$ & 0.0000025 & $\mathrm{Nd}$ & 0.00000025 \\
\hline
\end{tabular}

\begin{tabular}{||cl||}
\hline Element & \multicolumn{1}{c|}{ wt.\% } \\
\hline $\mathrm{Sm}$ & 0.00000025 \\
$\mathrm{Eu}$ & 0.00000025 \\
$\mathrm{Gd}$ & 0.00000025 \\
$\mathrm{~Tb}$ & 0.00000025 \\
$\mathrm{Dy}$ & 0.00000025 \\
$\mathrm{Ho}$ & 0.00000025 \\
$\mathrm{Er}$ & 0.00000025 \\
$\mathrm{Tm}$ & 0.00000025 \\
$\mathrm{Yb}$ & 0.00000025 \\
$\mathrm{Lu}$ & 0.00000025 \\
$\mathrm{Hf}$ & 0.0055 \\
$\mathrm{Ta}$ & 0.00025 \\
$\mathrm{~W}$ & 0.000012 \\
$\mathrm{Re}$ & 0.00000025 \\
$\mathrm{Os}$ & 0.00000025 \\
$\mathrm{Ir}$ & 0.00000025 \\
$\mathrm{Pt}$ & 0.00000025 \\
$\mathrm{Au}$ & 0.0000025 \\
$\mathrm{Hg}$ & 0.0000025 \\
$\mathrm{Tl}$ & 0.0000005 \\
$\mathrm{~Pb}$ & 0.000036 \\
$\mathrm{Bi}$ & 0.000016 \\
$\mathrm{Th}$ & 0.00000005 \\
$\mathrm{U}$ & 0.000007 \\
\hline & \\
\hline
\end{tabular}


NEA/NSC/DOC(2006)1

Fundamental - FUND

NRAD-FUND-RESR-002

CRIT-REAC-COEF

\section{Density}

The density of the zirconium rods is not specified. Open literature sources report a density of both 6.506 $\mathrm{g} / \mathrm{cm}^{3}$ (Chart of the Nuclides) ${ }^{\mathrm{a}}$ and $6.52 \mathrm{~g} / \mathrm{cm}^{3}$ (CRC Handbook of Chemistry and Physics). ${ }^{\mathrm{b}}$ A density of $6.51 \pm 0.01 \mathrm{~g} / \mathrm{cm}^{3}(1 \sigma)$ was selected.

This uncertainty was determined to be negligible $(\leq 0.00010)$ in NRAD-FUND-RESR-001.

\section{Dimensions}

The length of the zirconium rod is nominally equal to the average fuel element length (Table 1.5), which is $38.02 \pm 0.04 \mathrm{~cm}(1 \sigma)$. The outer diameter of the zirconium rod (Figure 1.26) is $0.5715 \mathrm{~cm}$ with manufacturing tolerance limits of +0.00 and $-0.0254 \mathrm{~cm}$.

This uncertainty was determined to be negligible $(\leq 0.00010)$ in NRAD-FUND-RESR-001.

\section{Impurities}

The effective bias for removing impurities (Table 2.9) from the zirconium rod was determined to be negligible (Section 3.1.1.1 of NRAD-FUND-RESR-001). Therefore, an uncertainty analysis regarding impurities in the zirconium was judged to be unnecessary as the result would also be negligible.

\subsubsection{Molybdenum Poison Disc}

\section{Composition}

The composition of the molybdenum poison discs (Table 2.10) is obtained by reducing the quantity of molybdenum to account for the impurities reported in Tables 1.9 and 1.10. The average impurity content from these two tables is used to represent the quantity of materials in the entire molybdenum disc as no information is available regarding the amount of molybdenum carbide material coating present. Additionally, the total carbon content of the molybdenum is assumed to be $0.01 \mathrm{wt} . \%$. For elements that are listed only as detection limits, half of the detection limit is assumed to represent the quantity of that impurity in the molybdenum material.

\footnotetext{
${ }^{a}$ E. M. Baum, H. D. Knox, and T. R. Miller, Nuclides and Isotopes: $16^{\text {th }}$ Edition, Knolls Atomic Power Laboratory (2002).

${ }^{\mathrm{b}}$ D. R. Lide, ed., CRC Handbook of Chemistry and Physics, $90^{\text {th }}$ Edition (Internet Version 2010), CRC Press/Taylor and Francis, Boca Raton, FL (2010). 


\section{NEA/NSC/DOC(2006)1}

Fundamental - FUND

NRAD-FUND-RESR-002

CRIT-REAC-COEF

Table 2.10. Composition of Molybdenum.

\begin{tabular}{|c|c|c|c|c|c|}
\hline Element & wt. $\%$ & Element & wt. $\%$ & Element & wt. $\%$ \\
\hline $\mathrm{Li}$ & 0.0000005 & $\mathrm{Ge}$ & 0.000005 & $\mathrm{Nd}$ & 0.0000005 \\
\hline $\mathrm{Be}$ & 0.0000005 & As & 0.000035 & $\mathrm{Sm}$ & 0.0000005 \\
\hline B & 0.0000005 & $\mathrm{Se}$ & 0.000005 & $\mathrm{Eu}$ & 0.0000005 \\
\hline $\mathrm{C}$ & 0.01 & $\mathrm{Br}$ & 0.0000005 & $\mathrm{Gd}$ & 0.0000005 \\
\hline $\mathrm{F}$ & 0.0000005 & $\mathrm{Rb}$ & 0.0000025 & $\mathrm{~Tb}$ & 0.0000005 \\
\hline $\mathrm{Na}$ & 0.0002885 & $\mathrm{Sr}$ & 0.000025 & Dy & 0.0000005 \\
\hline $\mathrm{Mg}$ & 0.000037 & $\mathrm{Y}$ & 0.000005 & Ho & 0.0000005 \\
\hline $\mathrm{Al}$ & 0.000044 & $\mathrm{Zr}$ & 0.000005 & Er & 0.0000005 \\
\hline $\mathrm{Si}$ & 0.0002 & $\mathrm{Nb}$ & 0.000025 & $\mathrm{Tm}$ & 0.0000005 \\
\hline $\mathrm{P}$ & 0.000051 & Mo & 99.968464 & $\mathrm{Yb}$ & 0.0000005 \\
\hline $\mathrm{S}$ & 0.0001945 & $\mathrm{Ru}$ & 0.0000025 & $\mathrm{Lu}$ & 0.0000005 \\
\hline $\mathrm{Cl}$ & 0.000001 & $\mathrm{Rh}$ & 0.0000025 & $\mathrm{Hf}$ & 0.0000005 \\
\hline K & 0.0025 & $\mathrm{Pd}$ & 0.000005 & $\mathrm{Ta}$ & 0.0005 \\
\hline $\mathrm{Ca}$ & 0.00018 & $\mathrm{Ag}$ & 0.000025 & $\mathrm{~W}$ & 0.0125 \\
\hline $\mathrm{Sc}$ & 0.00000025 & $\mathrm{Cd}$ & 0.0005 & $\operatorname{Re}$ & 0.000013 \\
\hline $\mathrm{Ti}$ & 0.0005 & In & 0.0000025 & Os & 0.0000025 \\
\hline V & 0.00011 & $\mathrm{Sn}$ & 0.000019 & $\mathrm{Ir}$ & 0.0000025 \\
\hline $\mathrm{Cr}$ & 0.00038 & $\mathrm{Sb}$ & 0.00013 & $\mathrm{Pt}$ & 0.0000025 \\
\hline $\mathrm{Mn}$ & 0.000043 & $\mathrm{Te}$ & 0.0000025 & $\mathrm{Au}$ & 0.0000025 \\
\hline $\mathrm{Fe}$ & 0.001175 & I & 0.0000005 & $\mathrm{Hg}$ & 0.0000025 \\
\hline $\mathrm{Co}$ & 0.000014 & Cs & 0.0000025 & $\mathrm{Tl}$ & 0.0000025 \\
\hline $\mathrm{Ni}$ & 0.00012 & $\mathrm{Ba}$ & 0.0015 & $\mathrm{~Pb}$ & 0.0000025 \\
\hline $\mathrm{Cu}$ & 0.00025 & $\mathrm{La}$ & 0.0000945 & $\mathrm{Bi}$ & 0.0000025 \\
\hline $\mathrm{Zn}$ & 0.0000025 & $\mathrm{Ce}$ & 0.0000025 & Th & 0.00000025 \\
\hline $\mathrm{Ga}$ & 0.0000025 & $\operatorname{Pr}$ & 0.0000005 & $\mathrm{U}$ & 0.000004 \\
\hline
\end{tabular}

\section{Density}

The density of the molybdenum disc is not specified. Open literature sources report a density of both $10.22 \mathrm{~g} / \mathrm{cm}^{3}$ (Chart of the Nuclides) ${ }^{\mathrm{a}}$ and $10.2 \mathrm{~g} / \mathrm{cm}^{3}$ (CRC Handbook of Chemistry and Physics). ${ }^{\mathrm{b}}$ A density of $10.22 \pm 0.02 \mathrm{~g} / \mathrm{cm}^{3}(1 \sigma)$ was selected.

This uncertainty was determined to be negligible $(\leq 0.00010)$ in NRAD-FUND-RESR-001.

\footnotetext{
${ }^{a}$ E. M. Baum, H. D. Knox, and T. R. Miller, Nuclides and Isotopes: $16^{\text {th }}$ Edition, Knolls Atomic Power Laboratory (2002).

${ }^{\mathrm{b}}$ D. R. Lide, ed., CRC Handbook of Chemistry and Physics, $90^{\text {th }}$ Edition (Internet Version 2010), CRC Press/Taylor and Francis, Boca Raton, FL (2010). 


\section{Dimensions}

The molybdenum poison disc (Figure 1.27) thickness and outer diameter are $0.079375 \mathrm{~cm}$ (no reported uncertainty) and $3.46964 \mathrm{~cm}$ with manufacturing tolerance limits of +0.000 and $-0.0127 \mathrm{~cm}$.

This uncertainty was determined to be negligible $(\leq 0.00010)$ in NRAD-FUND-RESR-001.

\section{Impurities}

The effective bias for removing impurities (Table 2.10) from the molybdenum poison disc was determined to be negligible (Section 3.1.1.1 of NRAD-FUND-RESR-001). Therefore, an uncertainty analysis regarding impurities in the molybdenum was judged to be unnecessary as the result would also be negligible.

\subsubsection{Axial Graphite Reflector}

\section{Composition}

The composition of the axial graphite reflectors (Table 2.11) is obtained by reducing the quantity of graphite to account for the impurities reported in Table 1.8. For elements that are listed only as detection limits, half of the detection limit is assumed to represent the quantity of that impurity in the graphite material. 
NEA/NSC/DOC(2006)1

Fundamental - FUND

NRAD-FUND-RESR-002

CRIT-REAC-COEF

Table 2.11. Composition of Axial Graphite Reflector.

\begin{tabular}{|c|c|c|c|c|c|}
\hline Element & wt.\% & Element & wt.\% & Element & wt.\% \\
\hline $\mathrm{Li}$ & 0.0000025 & Ge & 0.0000025 & $\mathrm{Nd}$ & 0.0000025 \\
\hline $\mathrm{Be}$ & 0.0000025 & As & 0.0000025 & $\mathrm{Sm}$ & 0.0000005 \\
\hline B & 0.000035 & $\mathrm{Se}$ & 0.0000025 & $\mathrm{Eu}$ & 0.0000005 \\
\hline $\mathrm{C}$ & 99.994614 & $\mathrm{Br}$ & 0.000005 & $\mathrm{Gd}$ & 0.0000005 \\
\hline $\mathrm{F}$ & 0.000005 & $\mathrm{Rb}$ & 0.0000025 & $\mathrm{~Tb}$ & 0.0000005 \\
\hline $\mathrm{Na}$ & 0.0000025 & $\mathrm{Sr}$ & 0.0000025 & Dy & 0.0000005 \\
\hline $\mathrm{Mg}$ & 0.0000025 & Y & 0.0000025 & Ho & 0.0000005 \\
\hline $\mathrm{Al}$ & 0.0000025 & $\mathrm{Zr}$ & 0.0000025 & Er & 0.0000005 \\
\hline $\mathrm{Si}$ & 0.000075 & $\mathrm{Nb}$ & 0.0000025 & $\mathrm{Tm}$ & 0.0000005 \\
\hline $\mathrm{P}$ & 0.000005 & Mo & 0.0000025 & $\mathrm{Yb}$ & 0.0000005 \\
\hline S & 0.000092 & $\mathrm{Ru}$ & 0.0000025 & $\mathrm{Lu}$ & 0.0000005 \\
\hline $\mathrm{Cl}$ & 0.000024 & $\mathrm{Rh}$ & 0.0000005 & Hf & 0.0000005 \\
\hline K & 0.00005 & $\mathrm{Pd}$ & 0.0000025 & $\mathrm{Ta}$ & 0.005 \\
\hline $\mathrm{Ca}$ & 0.0000025 & $\mathrm{Ag}$ & 0.0000025 & W & 0.0000025 \\
\hline $\mathrm{Sc}$ & 0.0000005 & $\mathrm{Cd}$ & 0.0000025 & $\mathrm{Re}$ & 0.0000005 \\
\hline $\mathrm{Ti}$ & 0.0000005 & In & 0.0000025 & Os & 0.0000005 \\
\hline V & 0.0000005 & $\mathrm{Sn}$ & 0.0000025 & Ir & 0.0000005 \\
\hline $\mathrm{Cr}$ & 0.000025 & $\mathrm{Sb}$ & 0.0000025 & $\mathrm{Pt}$ & 0.0000005 \\
\hline $\mathrm{Mn}$ & 0.0000005 & $\mathrm{Te}$ & 0.0000025 & $\mathrm{Au}$ & 0.000005 \\
\hline $\mathrm{Fe}$ & 0.0000005 & I & 0.0000005 & $\mathrm{Hg}$ & 0.000005 \\
\hline Co & 0.0000005 & Cs & 0.0000025 & $\mathrm{Tl}$ & 0.0000025 \\
\hline $\mathrm{Ni}$ & 0.0000005 & $\mathrm{Ba}$ & 0.0000025 & $\mathrm{~Pb}$ & 0.0000025 \\
\hline $\mathrm{Cu}$ & 0.0000025 & $\mathrm{La}$ & 0.0000025 & $\mathrm{Bi}$ & 0.0000025 \\
\hline $\mathrm{Zn}$ & 0.0000025 & $\mathrm{Ce}$ & 0.0000025 & Th & 0.0000025 \\
\hline $\mathrm{Ga}$ & 0.0000005 & $\operatorname{Pr}$ & 0.0000025 & U & 0.0000025 \\
\hline
\end{tabular}

\section{Density}

The axial graphite reflectors are nuclear grade graphite, either PGX or ECW. The density of these two graphite types is nominally 1.73 or $1.74 \mathrm{~g} / \mathrm{cm}^{3}$, respectively. ${ }^{\mathrm{a}}$ General Atomics uses a density of 1.73 $\mathrm{g} / \mathrm{cm}^{3}$ to represent the density of the axial graphite reflectors in their TRIGA reactor models. ${ }^{\mathrm{b}}$ A $1 \sigma$ uncertainty of $\pm 0.01 \mathrm{~g} / \mathrm{cm}^{3}$ was selected for the density of the axial graphite reflectors.

This uncertainty was determined to be negligible $(\leq 0.00010)$ in NRAD-FUND-RESR-001.

\footnotetext{
a Personal communication with Victor Leight at GrafTech International (April 5, 2010).

${ }^{\mathrm{b}}$ Personal communication with John M. Bolin at General Atomics (November 3, 2009). 


\section{Dimensions}

The axial graphite reflector (Figure 1.28) length and outer diameter are $8.6868 \pm 0.0254 \mathrm{~cm}$ (manufacturing tolerance) and $3.27914 \mathrm{~cm}$ with manufacturing tolerance limits of +0.00 and $-0.0127 \mathrm{~cm}$.

This uncertainty was determined to be negligible $(\leq 0.00010)$ in NRAD-FUND-RESR-001.

\section{Impurities}

The effective bias for removing impurities (Table 2.11) from the axial graphite reflectors was determined to be negligible (Section 3.1.1.1 of NRAD-FUND-RESR-001). Therefore, an uncertainty analysis regarding impurities in the graphite was judged to be unnecessary as the result would also be negligible.

\subsubsection{Stainless Steel 304 Cladding and End Fittings}

\section{Composition}

The average stainless steel 304 or 304L composition is shown in Table 2.12. However, a sample of stainless steel material used in the fuel cladding provided additional information regarding impurity content. The composition of the stainless steel cladding (Table 2.13) is obtained by reducing the quantity of iron in the average steel composition (Table 2.12) to account for the impurities reported in Table 1.11. For elements that are listed only as detection limits, half of the detection limit is assumed to represent the quantity of that impurity in the graphite material.

This uncertainty was evaluated by individually perturbing the manganese, and nickel constituents between their maximum and minimum value while simultaneously decreasing or increasing, respectively, the iron content in the steel. Half of the difference between the upper and lower perturbation $\mathrm{k}_{\mathrm{eff}}$ values was used to represent the variation in $\mathrm{k}_{\text {eff }}$ due to perturbing the stainless steel composition. The calculated result was then scaled to obtain the $1 \sigma$ uncertainty. Results are provided in Table 2.14.

The uncertainty in the carbon and chromium contents was determined to be negligible $(\leq 0.00010)$ in NRAD-FUND-RESR-001.

Table 2.12. Typical Stainless Steel 304/304L Composition (wt.\%). ${ }^{(a)}$

\begin{tabular}{||c|c|c|c||}
\hline Component & SS304 & SS304L & Average $^{(\mathbf{b})}$ \\
\hline \hline $\mathrm{C}$ & $0.08 \mathrm{Max}$ & $0.03 \mathrm{Max}$ & 0.04 \\
$\mathrm{Cr}$ & $18-20$ & $18-20$ & 19 \\
$\mathrm{Fe}$ & Balance & Balance & 69.4225 \\
$\mathrm{Mn}$ & $2 \mathrm{Max}$ & $2 \mathrm{Max}$ & 1 \\
$\mathrm{Ni}$ & $8-10.5$ & $8-12$ & 10 \\
$\mathrm{P}$ & $0.045 \mathrm{Max}$ & $0.045 \mathrm{Max}$ & 0.0225 \\
$\mathrm{~S}$ & $0.03 \mathrm{Max}$ & $0.03 \mathrm{Max}$ & 0.015 \\
$\mathrm{Si}$ & $1 \mathrm{Max}$ & $1 \mathrm{Max}$ & 0.5 \\
\hline \hline Density (g/cm & 8.00 & 8.00 & 8.00 \\
\hline
\end{tabular}

(a) ASM Aerospace Specification Metals, Inc., http://www.aerospacemetals.com/.

(b) Average based on the maximum range of each component. 
NEA/NSC/DOC(2006)1

Fundamental - FUND

NRAD-FUND-RESR-002

CRIT-REAC-COEF

Table 2.13. Stainless Steel 304/304L Cladding Composition (wt.\%).

\begin{tabular}{||cl||}
\hline \hline Element & \multicolumn{1}{|c|}{ wt.\% } \\
\hline \hline $\mathrm{Li}$ & 0.0000005 \\
$\mathrm{Be}$ & 0.0000005 \\
$\mathrm{~B}$ & 0.00025 \\
$\mathrm{C}$ & 0.04 \\
$\mathrm{~F}$ & 0.0000005 \\
$\mathrm{Na}$ & 0.0000005 \\
$\mathrm{Mg}$ & 0.00018 \\
$\mathrm{Al}$ & 0.0012 \\
$\mathrm{Si}$ & 0.4 \\
$\mathrm{P}$ & 0.026 \\
$\mathrm{~S}$ & 0.0022 \\
$\mathrm{Cl}$ & 0.0000025 \\
$\mathrm{~K}$ & 0.0000005 \\
$\mathrm{Ca}$ & 0.00005 \\
$\mathrm{Sc}$ & 0.00000025 \\
$\mathrm{Ti}$ & 0.002 \\
$\mathrm{~V}$ & 0.1 \\
$\mathrm{Cr}$ & 19 \\
$\mathrm{Mn}$ & 1 \\
$\mathrm{Fe}$ & 68.70712775 \\
$\mathrm{Co}$ & 0.08 \\
$\mathrm{Ni}$ & 10 \\
$\mathrm{Cu}$ & 0.3 \\
$\mathrm{Zn}$ & 0.00005 \\
$\mathrm{Ga}$ & 0.0016 \\
\hline
\end{tabular}

\begin{tabular}{|c|l||}
\hline Element & \multicolumn{1}{c|}{ w. \% } \\
\hline \hline $\mathrm{Ge}$ & 0.002 \\
$\mathrm{As}$ & 0.0035 \\
$\mathrm{Se}$ & 0.000005 \\
$\mathrm{Br}$ & 0.000005 \\
$\mathrm{Rb}$ & 0.000025 \\
$\mathrm{Sr}$ & 0.00001 \\
$\mathrm{Y}$ & 0.0000025 \\
$\mathrm{Zr}$ & 0.00018 \\
$\mathrm{Nb}$ & 0.011 \\
$\mathrm{Mo}$ & 0.3 \\
$\mathrm{Ru}$ & 0.000005 \\
$\mathrm{Rh}$ & 0.0000025 \\
$\mathrm{Pd}$ & 0.0000025 \\
$\mathrm{Ag}$ & 0.000025 \\
$\mathrm{Cd}$ & 0.000005 \\
$\mathrm{In}$ & 0.000025 \\
$\mathrm{Sn}$ & 0.0055 \\
$\mathrm{Sb}$ & 0.00089 \\
$\mathrm{Te}$ & 0.0000025 \\
$\mathrm{I}$ & 0.0000025 \\
$\mathrm{Cs}$ & 0.0000005 \\
$\mathrm{Ba}$ & 0.0000025 \\
$\mathrm{La}$ & 0.0000005 \\
$\mathrm{Ce}$ & 0.00000025 \\
$\mathrm{Pr}$ & 0.00000025 \\
\hline
\end{tabular}

\begin{tabular}{|cl|}
\hline \hline Element & \multicolumn{1}{|c|}{ wt.\% } \\
\hline $\mathrm{Nd}$ & 0.00000025 \\
$\mathrm{Sm}$ & 0.00000025 \\
$\mathrm{Eu}$ & 0.00000025 \\
$\mathrm{Gd}$ & 0.00000025 \\
$\mathrm{~Tb}$ & 0.00000025 \\
$\mathrm{Dy}$ & 0.00000025 \\
$\mathrm{Ho}$ & 0.00000025 \\
$\mathrm{Er}$ & 0.00000025 \\
$\mathrm{Tm}$ & 0.00000025 \\
$\mathrm{Yb}$ & 0.00000025 \\
$\mathrm{Lu}$ & 0.00000025 \\
$\mathrm{Hf}$ & 0.0000005 \\
$\mathrm{Ta}$ & 0.00005 \\
$\mathrm{~W}$ & 0.016 \\
$\mathrm{Re}$ & 0.000025 \\
$\mathrm{Os}$ & 0.000009 \\
$\mathrm{Ir}$ & 0.000009 \\
$\mathrm{Pt}$ & 0.000005 \\
$\mathrm{Au}$ & 0.0000025 \\
$\mathrm{Hg}$ & 0.000005 \\
$\mathrm{Tl}$ & 0.0000025 \\
$\mathrm{~Pb}$ & 0.000031 \\
$\mathrm{Bi}$ & 0.0000005 \\
$\mathrm{Th}$ & 0.00000025 \\
$\mathrm{U}$ & 0.00000025 \\
\hline
\end{tabular}

Table 2.14a. Effect of Uncertainty in Stainless Steel Composition (62-Fuel-Element Core).

\begin{tabular}{||c|ccc|c|ccc||}
\hline Deviation & $\boldsymbol{\Delta}$ & \pm & $\boldsymbol{\sigma}_{\mathbf{a k}}$ & Scaling Factor & $\boldsymbol{\Delta} \mathbf{k}_{\text {eff }}(\mathbf{1 \sigma})$ & \pm & $\boldsymbol{\sigma}_{\text {akeff }}$ \\
\hline \hline Max/Min Manganese Content & -0.00112 & \pm & 0.00005 & $\sqrt{ } 3$ & -0.00065 & \pm & 0.00003 \\
Max/Min Nickel Content & -0.00035 & \pm & 0.00005 & $\sqrt{3}$ & -0.00020 & \pm & 0.00003 \\
\hline
\end{tabular}

Table 2.14b. Effect of Uncertainty in Stainless Steel Composition (64-Fuel-Element Core).

\begin{tabular}{||c|ccc|c|ccc||}
\hline Deviation & $\Delta \mathbf{k}$ & \pm & $\boldsymbol{\sigma}_{\mathbf{a k}}$ & Scaling Factor & \multicolumn{1}{|c|}{$\mathbf{k}_{\text {eff }}(\mathbf{1 \sigma})$} & \pm & $\boldsymbol{\sigma}_{\mathbf{a k e f f}}$ \\
\hline \hline Max/Min Manganese Content & -0.00122 & \pm & 0.00005 & $\sqrt{3}$ & -0.00070 & \pm & 0.00003 \\
Max/Min Nickel Content & -0.00021 & \pm & 0.00005 & $\sqrt{ } 3$ & -0.00012 & \pm & 0.00003 \\
\hline
\end{tabular}


NEA/NSC/DOC(2006)1

Fundamental - FUND

NRAD-FUND-RESR-002

CRIT-REAC-COEF

\section{Density}

As listed in Table 2.12, the density of stainless steel $304 / 304 \mathrm{~L}$ is $8.00 \mathrm{~g} / \mathrm{cm}^{3}$. A $1 \sigma$ uncertainty of 0.01 $\mathrm{g} / \mathrm{cm}^{3}$ is assumed to apply to the stainless steel density.

This uncertainty was determined to be negligible $(\leq 0.00010)$ in NRAD-FUND-RESR-001.

\section{Dimensions - Cladding}

The average fuel clad inner diameter in the 62- and 64-fuel-element cores core is $3.4894 \pm 0.0005 \mathrm{~cm}$ $(1 \sigma)$. The cladding thickness is nominally $0.0508 \mathrm{~cm}$. The clad outer diameter has a nominal reference dimension of $3.59156 \mathrm{~cm}$. The reference clad tube length is $58.7375 \mathrm{~cm}$ (Figure 1.24). No uncertainties are provided for the reference outer diameter and length dimensions.

These uncertainties were determined to be negligible $(\leq 0.00010)$ in NRAD-FUND-RESR-001.

\section{Dimensions - End Fittings}

There is insufficient information regarding all dimensions and their respective manufacturing tolerances for the stainless steel end fittings (Figures 1.29 and 1.30). The few dimensions not specified in the drawings were estimated based on the other available dimensions and the assumption of proportionality of scale between the known and unknown dimensions.

This uncertainty was determined to be negligible $(\leq 0.00010)$ in NRAD-FUND-RESR-001.

\section{Impurities}

There is no additional information regarding the uncertainty in the measured stainless steel impurity values in Table 1.11. The impurity content for elements excluding carbon, chromium, manganese, and nickel (Table 2.13) are assumed to have a bounding uncertainty (with uniform probability distribution) of $\pm 100 \%$. The iron content in the steel is effectively adjusted to conserve mass while the other four elemental weight fractions mentioned above remain unchanged.

To find the effect of this uncertainty on the $\mathrm{k}_{\text {eff }}$ value, the impurity content was adjusted by the assumed bounding limit. An upper perturbation $\mathrm{k}_{\text {eff }}$ value was found by simultaneously increasing the impurity content in all steel cladding by $100 \%$ and then simultaneously decreasing by the same amount to find a lower perturbation $\mathrm{k}_{\mathrm{eff}}$ value. Half of the difference between the upper and lower perturbation $\mathrm{k}_{\mathrm{eff}}$ values was used to represent the variation in $\mathrm{k}_{\text {eff }}$ due to perturbing the impurity content by $100 \%$. The calculated result was then scaled to obtain the $1 \sigma$ uncertainty. Results are shown in Table 2.15.

This uncertainty is treated as $100 \%$ systematic because the actual impurity content is not recorded for any of the fuel elements in the NRAD core and the cladding likely all came from the same lot of steel.

Table 2.15a. Effect of Uncertainty in Stainless Steel Impurities (62-Fuel-Element Core).

\begin{tabular}{|c|ccc|c|ccc||}
\hline \hline Deviation & $\Delta \mathbf{k}$ & \pm & $\boldsymbol{\sigma}_{\Delta \mathbf{k}}$ & $\begin{array}{c}\text { Scaling } \\
\text { Factor }\end{array}$ & $\Delta \mathbf{k}_{\text {eff }}(\mathbf{1 \sigma})$ & \pm & $\boldsymbol{\sigma}_{\Delta \mathbf{k e f f}}$ \\
\hline \hline $\pm 100 \%$ & -0.00063 & \pm & 0.00005 & $\sqrt{ } 3$ & -0.00036 & \pm & 0.00003 \\
\hline
\end{tabular}


NRAD-FUND-RESR-002

CRIT-REAC-COEF

Table 2.15b. Effect of Uncertainty in Stainless Steel Impurities (64-Fuel-Element Core).

\begin{tabular}{||c|ccc|c|ccc||}
\hline \hline Deviation & $\Delta \mathbf{k}$ & \pm & $\boldsymbol{\sigma}_{\Delta \mathbf{k}}$ & $\begin{array}{c}\text { Scaling } \\
\text { Factor }\end{array}$ & $\Delta \mathbf{k}_{\text {eff }}(\mathbf{1 \sigma})$ & \pm & $\boldsymbol{\sigma}_{\Delta \text { skeff }}$ \\
\hline \hline $\pm 100 \%$ & -0.00073 & \pm & 0.00005 & $\sqrt{ } 3$ & -0.00042 & \pm & 0.00003 \\
\hline
\end{tabular}

\subsubsection{Air in Fuel/Cladding Gap}

The reference composition and density of air is shown in Table 2.16. One volume percent of water was added to the composition and the volumetric fractions were renormalized. The computed atomic density of air is provided in Table 2.17.

Table 2.16. Typical Atmospheric Composition ${ }^{(a)}$ by Volume, Dry Air. ${ }^{(b)}$

\begin{tabular}{|c|c||}
\hline Molecular Component & Content (ppm by volume) \\
\hline \hline Nitrogen $\left(\mathrm{N}_{2}\right)$ & 780840 \\
Oxygen $\left(\mathrm{O}_{2}\right)$ & 209460 \\
Argon $(\mathrm{Ar})$ & 9340 \\
Carbon Dioxide $\left(\mathrm{CO}_{2}\right)$ & 380 \\
Neon $(\mathrm{Ne})$ & 18.18 \\
Helium $(\mathrm{He})$ & 5.24 \\
Methane $\left(\mathrm{CH}_{4}\right)$ & 1.7 \\
Krypton $(\mathrm{Kr})$ & 1.14 \\
Hydrogen $\left(\mathrm{H}_{2}\right)$ & 0.55 \\
\hline \hline Surface Density $\left(\mathbf{k g} / \mathbf{m}^{\mathbf{3}}\right)$ & 1.217 \\
\hline \hline
\end{tabular}

(a) "Earth Fact Sheet," National Space Science Data Center, http://nssdc.gsfc.nasa.gov/planetary/factsheet/earthfact. html, (May 20, 2009).

(b) Water typically makes up about $1 \%$ of the composition.

(c) Numbers do not add up to exactly $100 \%$ due to round off error. 
NEA/NSC/DOC(2006)1

Fundamental - FUND

NRAD-FUND-RESR-002

CRIT-REAC-COEF

Table 2.17. Air Composition

and Atomic Density.

\begin{tabular}{|c|c||}
\hline Element & Atoms/b-cm \\
\hline $\mathrm{H}$ & $5.0309 \mathrm{E}-07$ \\
$\mathrm{~N}$ & $3.9268 \mathrm{E}-05$ \\
$\mathrm{O}$ & $1.0804 \mathrm{E}-05$ \\
$\mathrm{Ar}$ & $2.3485 \mathrm{E}-07$ \\
$\mathrm{C}$ & $9.5977 \mathrm{E}-09$ \\
$\mathrm{Ne}$ & $4.5713 \mathrm{E}-10$ \\
$\mathrm{He}$ & $1.3176 \mathrm{E}-10$ \\
$\mathrm{Kr}$ & $2.8665 \mathrm{E}-11$ \\
\hline \hline Total & $5.0820 \mathrm{E}-05$ \\
\hline
\end{tabular}

The effective bias for removing air was determined to be negligible (Section 3.1.1.1 of NRAD-FUND-RESR-001). Therefore, any uncertainty analyses regarding air were judged to be unnecessary as the results would also be negligible.

\subsubsection{Control Rod Properties}

\subsubsection{Boron Carbide Absorber}

\section{Density}

There is conflicting information regarding the density of the boron carbide absorber material in the control rods. The minimum density specification of $2.415 \mathrm{~g} / \mathrm{cm}^{3}$ appears to represent a minimum requirement for NRAD operations $\mathrm{s}^{\mathrm{a}}$ while the specification of $2.48 \mathrm{~g} / \mathrm{cm}^{3}$ represents the manufacturing minimum limit as defined by General Atomics (from design drawings, see Appendix F). The theoretical density of boron carbide is $2.52 \mathrm{~g} / \mathrm{cm}^{3}$. The density of $2.48 \mathrm{~g} / \mathrm{cm}^{3}$ is selected to represent the nominal density of the control rods in the NRAD reactor. The difference between the nominal and theoretical density values, $+0.04 \mathrm{~g} / \mathrm{cm}^{3}$, is selected to represent the uncertainty (bounding with uniform probability distribution) in the density of the boron carbide material.

This uncertainty was determined to be negligible $(\leq 0.00010)$ in NRAD-FUND-RESR-001.

\section{Boron Content}

The manufacturing tolerance specification of boron content in the $\mathrm{B}_{4} \mathrm{C}$ absorber (from design drawings, see Appendix F) is $78.0 \pm 1.0 \mathrm{wt} . \%$ with the natural occurrence of the isotope ${ }^{10} \mathrm{~B}(18.5 \pm 0.2 \mathrm{wt} . \%)$. The $1.0 \mathrm{wt} . \%$ uncertainty in the boron content of the absorber is assumed to be a manufacturing tolerance and will be treated as a bounding uncertainty with uniform probability distribution. A boron content of $\sim 78.3$ wt. $\%$ is selected to represent the experiment, based on the stoichiometric ratio of boron to carbon in $\mathrm{B}_{4} \mathrm{C}$.

This uncertainty was determined to be negligible $(\leq 0.00010)$ in NRAD-FUND-RESR-001.

\footnotetext{
a "HFEF/N Neutron Radiography Facility System Design Description," W0170-0004-SA rev. 2, Idaho National Laboratory (June 1, 1978). [This reference is not available for public release.]
} 


\author{
Fundamental - FUND \\ NRAD-FUND-RESR-002 \\ CRIT-REAC-COEF
}

\title{
Boron-10 Abundance
}

The isotopic abundance of ${ }^{10} \mathrm{~B}$ in natural boron is between 19.1 and 20.3 at.\% with an average value of 19.9 at.\%. ${ }^{\mathrm{a}}$ The manufacturing specification (from design drawings, see Appendix F) of $18.5 \pm 0.2 \mathrm{wt} . \%$ represents a much tighter requirement. The atomic abundance of 19.9 at.\% ( 18.43 wt.\%) is selected to represent the nominal isotopic abundance of ${ }^{10} \mathrm{~B}$. The $\pm 0.2 \mathrm{wt} . \%$ uncertainty in the isotopic abundance of

${ }^{10} \mathrm{~B}$ is assumed to be bounding with uniform probability distribution.

This uncertainty was determined to be negligible $(\leq 0.00010)$ in NRAD-FUND-RESR-001.

\section{Dimensions}

The control rod absorber (Figure 1.31) length and outer diameter are $38.1 \mathrm{~cm}$ (no reported uncertainty) and $3.01498 \mathrm{~cm}$ with manufacturing tolerance limits of +0.000 and $-0.0762 \mathrm{~cm}$.

The effect of varying the nominal length of the control rod absorber is negligible. The manufacturing tolerance is most likely small and any uncertainty is within the uncertainty of the control rod positions (Section 2.1.1.2). No perturbation analysis was performed to evaluate this parameter.

These uncertainties were determined to be negligible $(\leq 0.00010)$ in NRAD-FUND-RESR-001.

\section{Impurities}

No impurities were reported for the boron carbide absorber in the control rods. Impurity quantities in sintered boron carbide material used elsewhere in control rods, which have an equivalent boron content, Table 2.18, were used to evaluate the effective uncertainty due to impurities in the boron carbide.

The impurities reported in Table 2.18 were added to the composition of the absorber material. The difference between the unperturbed and perturbed $\mathrm{k}_{\text {eff }}$ values was used to represent the variation in $\mathrm{k}_{\text {eff }}$ due the inclusion of impurities in the boron carbide material. Results are shown in Table 2.19.

This uncertainty is treated as a $1 \sigma$ uncertainty and $100 \%$ systematic. Because the effect is practically negligible, the statistical uncertainty of 0.00010 is taken to represent the uncertainty in impurity content in the boron carbide absorber.

${ }^{a}$ E. M. Baum, H. D. Knox, and T. R. Miller, Nuclides and Isotopes: $16^{\text {th }}$ Edition, Knolls Atomic Power Laboratory (2002). 
NEA/NSC/DOC(2006)1

Fundamental - FUND

NRAD-FUND-RESR-002

CRIT-REAC-COEF

Table 2.18. Impurity in Sintered $\mathrm{B}_{4} \mathrm{C}$ Pellets. ${ }^{(\mathrm{a})}$

\begin{tabular}{|c|c|}
\hline Boron Content (wt.\%) & 78 \\
\hline \hline Impurity & $\begin{array}{c}\text { Quantity } \\
\text { (ppm wt.\%) }\end{array}$ \\
\hline \hline $\mathrm{Na}$ & $\sim 10$ \\
$\mathrm{Al}$ & $\sim 1000$ \\
$\mathrm{Si}$ & $\sim 1000$ \\
$\mathrm{Ca}$ & $\sim 100$ \\
$\mathrm{Ti}$ & $\sim 1000$ \\
$\mathrm{Mn}$ & $\sim 10$ \\
\hline
\end{tabular}

(a) K. Fujii, S. Nomura, H. Imai, and M. Shindo, "Corrosion Behavior of Sintered Pellet of Graphite and Boron Carbide in Helium Containing Water Vapor," IAEATECDOC-690, International Atomic Energy Agency, Vienna, pp. 169-176 (February 2003).

Table 2.19a. Effect of Uncertainty in Boron Carbide Impurities (62-Fuel-Element Core).

\begin{tabular}{||c|ccc|c|ccc||}
\hline \hline Deviation & $\Delta \mathbf{k}$ & \pm & $\boldsymbol{\sigma}_{\mathrm{\Delta k}}$ & $\begin{array}{c}\text { Scaling } \\
\text { Factor }\end{array}$ & $\boldsymbol{\Delta} \mathbf{k}_{\text {eff }}(\mathbf{1} \boldsymbol{\sigma})$ & \pm & $\boldsymbol{\sigma}_{\text {skeff }}$ \\
\hline \hline Added impurities & 0.00010 & \pm & 0.00010 & 1 & 0.00010 & \pm & 0.00010 \\
\hline
\end{tabular}

Table 2.19b. Effect of Uncertainty in Boron Carbide Impurities (64-Fuel-Element Core).

\begin{tabular}{||c|ccc|c|ccc||}
\hline \hline Deviation & $\boldsymbol{\Delta} \mathbf{k}$ & \pm & $\boldsymbol{\sigma}_{\mathbf{\Delta} \mathbf{k}}$ & $\begin{array}{c}\text { Scaling } \\
\text { Factor }\end{array}$ & $\boldsymbol{\Delta} \mathbf{k}_{\text {eff }}(\mathbf{1} \boldsymbol{\sigma})$ & \pm & $\boldsymbol{\sigma}_{\text {skeff }}$ \\
\hline \hline Added impurities & -0.00002 & \pm & 0.00010 & 1 & -0.00002 & \pm & 0.00010 \\
\hline \hline
\end{tabular}

\section{Burnup}

Evaluation of the effect of the reported burnup on the control rods would require additional information such as operation history, location of the rods within the core, neutron flux, and temperature. Without this information, the next best procedure would be to use rod worth measurements to adjust the rod composition. ${ }^{\mathrm{a}}$ There is no information available to evaluate the burnup history of the control rods during their use at PRNC. Some information is available regarding total core operation of the NRAD reactor, but insufficient to provide a complete evaluation of control rod burnup. Essentially the PRNC core history included $0.5 \mathrm{MW}$-yr on 95 fuel pins and the HEU NRAD core history included $0.25 \mathrm{MW}$-yr on 61 (and later just 60 when the water irradiation position was installed) fuel pins. Because the uncertainty in the boron content and density of the control rods is negligible, it is assumed that changes in absorber composition due to burnup would also be negligible.

\footnotetext{
${ }^{a}$ Personal communication with Javier Ortensi at INL (April 13, 2010).
} 


\subsubsection{Aluminum 6061 Components}

\section{Composition}

The typical composition of aluminum 6061 is reported in Table 2.20. An average value for each element is selected to represent the nominal composition of aluminum, with elemental aluminum representing the balance.

\begin{tabular}{|c|c|c|}
\hline Component & Content & Average $^{(b)}$ \\
\hline $\mathrm{Al}$ & Balance & 97.23 \\
\hline $\mathrm{Cr}$ & $0.04-0.35$ & 0.195 \\
\hline $\mathrm{Cu}$ & $0.15-0.4$ & 0.275 \\
\hline $\mathrm{Fe}$ & 0.7 Max & 0.35 \\
\hline $\mathrm{Mg}$ & $0.8-1.2$ & 1 \\
\hline Mn & $0.15 \mathrm{Max}$ & 0.075 \\
\hline $\mathrm{Si}$ & $0.4-0.8$ & 0.6 \\
\hline $\mathrm{Ti}$ & $0.15 \mathrm{Max}$ & 0.075 \\
\hline $\mathrm{Zn}$ & $0.25 \mathrm{Max}$ & 0.125 \\
\hline $\mathrm{Co}^{(\mathrm{c})}$ & $0.05 \mathrm{Max}$ & 0.025 \\
\hline $\mathrm{Ni}^{(\mathrm{c})}$ & $0.05 \mathrm{Max}$ & 0.025 \\
\hline $\mathrm{Sn}^{(\mathrm{c})}$ & $0.05 \mathrm{Max}$ & 0.025 \\
\hline Density $\left(\mathrm{g} / \mathrm{cm}^{3}\right)$ & 2.70 & 2.70 \\
\hline
\end{tabular}

(a) ASM Aerospace Specification Metals, Inc., http://www.aerospacemetals.com/.

(b) Average based on the maximum range of each component.

(c) Reported "Other" components have a maximum of 0.15 wt. $\%$ total with no more than 0.05 wt. $\%$ per component. $\mathrm{Co}, \mathrm{Ni}$, and $\mathrm{Sn}$ were selected to represent impurities in Al6061.

The effective bias for removing non-aluminum elements (Table 2.20) from aluminum was determined to be negligible (Section 3.1.1.1 of NRAD-FUND-RESR-001). Therefore, any uncertainty analyses regarding the variation in composition of non-aluminum elements were judged to be unnecessary as the results would also be negligible.

\section{Density}

As listed in Table 2.20, the density of aluminum 6061 is $2.70 \mathrm{~g} / \mathrm{cm}^{3}$. A $1 \sigma$ uncertainty of $0.01 \mathrm{~g} / \mathrm{cm}^{3}$ is assumed to apply to the aluminum density.

This uncertainty was determined to be negligible $(\leq 0.00010)$ in NRAD-FUND-RESR-001. 
NEA/NSC/DOC(2006)1

Fundamental - FUND

NRAD-FUND-RESR-002

CRIT-REAC-COEF

\section{Dimensions - Cladding}

The length of the aluminum cladding is between 59.055 and $59.436 \mathrm{~cm}$, with a total control rod reference length that includes end fittings of $60.96 \mathrm{~cm}$. The clad tube has an outer diameter of $3.175 \mathrm{~cm}$ and a wall thickness of $0.07112 \mathrm{~cm}$. No uncertainties are reported for the control rod cladding dimensions.

The effect of varying the nominal length of the control rod cladding is negligible, as any uncertainty is within the uncertainty of the control rod positions (Section 2.1.1.2). No perturbation analysis was performed to evaluate this parameter. The effect of varying the dimensions of the control rod aluminum end fittings would also be negligible.

These uncertainties were determined to be negligible $(\leq 0.00010)$ in NRAD-FUND-RESR-001.

\section{Dimensions - Guide Tubes}

Guide tube dimensions are in Figure 1.35. There is insufficient information regarding manufacturing tolerances in all parts of the guide tube. A 30 vol.\% $(1 \sigma)$ uncertainty was assumed.

This uncertainty was determined to be negligible $(\leq 0.00010)$ in NRAD-FUND-RESR-001.

\section{Dimensions - End Fittings}

The perturbation in the guide tube end fitting parameters was included as part of the uncertainty in the stainless steel end fittings evaluated for the fuel elements (Section 2.1.3.4), as their effective component of uncertainty is negligible.

\section{Dimensions - Other Fittings, Parts, and Fixtures}

The effective bias for removing the control rod extension rods, attachments, and internal rod fittings was determined to be negligible (Section 3.1.1.1 of NRAD-FUND-RESR-001). Therefore, any uncertainty analyses regarding these auxiliary aluminum components were judged to be unnecessary as the results would also be negligible.

\section{Impurities}

The effective bias for removing non-aluminum elements (Table 2.20) from aluminum was determined to be negligible (Section 3.1.1.1 of NRAD-FUND-RESR-001). Therefore, any uncertainty analyses regarding aluminum impurities were judged to be unnecessary as the results would also be negligible.

\subsubsection{Fuel Cluster Properties}

\subsubsection{Fuel Element Pitch in Assembly}

The square pitch between fuel elements within an assembly is $3.8862 \mathrm{~cm}$ (Figure 1.10). No uncertainty is reported for this pitch. However, the manufacturing specifications for the upper assembly components indicate a range for hole placement between 3.87604 and $3.90144 \mathrm{~cm}$. There is no uncertainty reported for the tolerance of the threaded end fitting at the bottom of each fuel element. However, the tolerance should be within the manufacturing specifications provided for the assembly components, as they were designed to accommodate fuel elements with a standard threaded end fitting.

This uncertainty was determined to be negligible $(\leq 0.00010)$ in NRAD-FUND-RESR-001. 


\subsubsection{Fuel Cluster Auxiliary Components}

\section{Steel Components}

The stainless steel 304/304L average composition and density described in Table 2.13 is used to represent the material properties of the steel assembly end fittings that attach the fuel elements and control rods to the fuel cluster assemblies.

The effective bias for removing the steel end fittings was determined to be very small (Section 3.1.1.1 of NRAD-FUND-RESR-001). Therefore, any uncertainty analyses regarding the assembly components were judged to be unnecessary as the results would also be negligible.

\section{Aluminum Components}

The aluminum 6061 composition and density described in Section 2.1.4.2 is used to represent the material properties of the aluminum assembly components of the fuel cluster assemblies.

The effective bias for removing top and bottom assemblies (Figures 1.14 through 1.23) was determined to be negligible (Section 3.1.1.1 of NRAD-FUND-RESR-001). Therefore, any uncertainty analyses regarding the assembly components were judged to be unnecessary as the results would also be negligible.

\subsubsection{Graphite Reflector Assembly Properties}

\subsubsection{Graphite Reflector Blocks}

\section{Composition}

The composition of the graphite block reflectors (Table 2.21) is obtained by reducing the quantity of graphite to account for the impurities reported in Table 1.14. For elements that are listed only as detection limits, half of the detection limit is assumed to represent the quantity of that impurity in the graphite material. 
NEA/NSC/DOC(2006)1

Fundamental - FUND

NRAD-FUND-RESR-002

CRIT-REAC-COEF

Table 2.21. Composition of Graphite Reflector Blocks.

\begin{tabular}{|c|c|c|c|c|c|}
\hline Element & wt. $\%$ & Element & wt. $\%$ & Element & wt. $\%$ \\
\hline $\mathrm{Li}$ & 0.0000025 & $\mathrm{Ge}$ & 0.0000025 & $\mathrm{Nd}$ & 0.0000025 \\
\hline $\mathrm{Be}$ & 0.0000025 & As & 0.0000025 & $\mathrm{Sm}$ & 0.0000005 \\
\hline B & 0.000075 & $\mathrm{Se}$ & 0.0000025 & $\mathrm{Eu}$ & 0.0000005 \\
\hline $\mathrm{C}$ & 99.968029 & $\mathrm{Br}$ & 0.000005 & Gd & 0.0000005 \\
\hline $\mathrm{F}$ & 0.000005 & $\mathrm{Rb}$ & 0.0000025 & $\mathrm{~Tb}$ & 0.0000005 \\
\hline $\mathrm{Na}$ & 0.000015 & $\mathrm{Sr}$ & 0.000051 & Dy & 0.0000005 \\
\hline $\mathrm{Mg}$ & 0.00014 & Y & 0.0000025 & Ho & 0.0000005 \\
\hline $\mathrm{Al}$ & 0.00013 & $\mathrm{Zr}$ & 0.000044 & Er & 0.0000005 \\
\hline $\mathrm{Si}$ & 0.0081 & $\mathrm{Nb}$ & 0.0000025 & $\mathrm{Tm}$ & 0.0000005 \\
\hline $\mathrm{P}$ & 0.00018 & Mo & 0.0000025 & $\mathrm{Yb}$ & 0.0000005 \\
\hline S & 0.005 & $\mathrm{Ru}$ & 0.0000025 & $\mathrm{Lu}$ & 0.0000005 \\
\hline $\mathrm{Cl}$ & 0.00023 & $\mathrm{Rh}$ & 0.0000005 & $\mathrm{Hf}$ & 0.0000005 \\
\hline K & 0.000005 & $\mathrm{Pd}$ & 0.0000025 & $\mathrm{Ta}$ & 0.005 \\
\hline $\mathrm{Ca}$ & 0.0023 & $\mathrm{Ag}$ & 0.0000025 & W & 0.0000025 \\
\hline $\mathrm{Sc}$ & 0.000007 & $\mathrm{Cd}$ & 0.0000025 & $\operatorname{Re}$ & 0.0000005 \\
\hline $\mathrm{Ti}$ & 0.0018 & In & 0.0000025 & Os & 0.0000005 \\
\hline V & 0.0029 & $\mathrm{Sn}$ & 0.0000025 & Ir & 0.0000005 \\
\hline $\mathrm{Cr}$ & 0.000025 & $\mathrm{Sb}$ & 0.0000025 & $\mathrm{Pt}$ & 0.0000005 \\
\hline $\mathrm{Mn}$ & 0.000012 & $\mathrm{Te}$ & 0.0000025 & $\mathrm{Au}$ & 0.000005 \\
\hline $\mathrm{Fe}$ & 0.0055 & I & 0.0000005 & $\mathrm{Hg}$ & 0.000005 \\
\hline Co & 0.0000005 & Cs & 0.0000025 & $\mathrm{Tl}$ & 0.0000025 \\
\hline $\mathrm{Ni}$ & 0.00035 & $\mathrm{Ba}$ & 0.0000025 & $\mathrm{~Pb}$ & 0.0000025 \\
\hline $\mathrm{Cu}$ & 0.0000025 & $\mathrm{La}$ & 0.0000025 & $\mathrm{Bi}$ & 0.0000025 \\
\hline $\mathrm{Zn}$ & 0.0000025 & $\mathrm{Ce}$ & 0.0000025 & Th & 0.0000025 \\
\hline $\mathrm{Ga}$ & 0.0000005 & $\operatorname{Pr}$ & 0.0000025 & $\mathrm{U}$ & 0.0000025 \\
\hline
\end{tabular}

\section{Density}

The average measured density of the graphite reflector blocks (Table 1.13$)$ is $1.570 \pm 0.009 \mathrm{~g} / \mathrm{cm}^{3}(1 \sigma)$. According to ASTM C838-96 (2005), ${ }^{a}$ the within-laboratory variation on density is $0.28 \%$ with a between-laboratory variation of $0.81 \%$, indicating a possible, but unconfirmed, bias for the method used to determine the density of graphite. These percentages represent density uncertainties of \pm 0.004 and $\pm 0.013 \mathrm{~g} / \mathrm{cm}^{3}$, respectively.

To find the effect of this uncertainty on the $\mathrm{k}_{\text {eff }}$ value, the graphite reflector block density was adjusted by the $3 \sigma$ uncertainty. An upper perturbation $\mathrm{k}_{\text {eff }}$ value was found by simultaneously increasing the graphite density by $0.027 \mathrm{~g} / \mathrm{cm}^{3}$ and then simultaneously decreasing by the same amount to find a lower

${ }^{a}$ ASTM C838-96, Standard Test Method for Bulk Density of As-Manufactured Carbon and Graphite Shapes. 


\section{Fundamental - FUND \\ NRAD-FUND-RESR-002 \\ CRIT-REAC-COEF}

perturbation $\mathrm{k}_{\text {eff }}$ value. Half of the difference between the upper and lower perturbation $\mathrm{k}_{\text {eff }}$ values was used to represent the variation in $k_{\text {eff }}$ due to perturbing the graphite density by $0.027 \mathrm{~g} / \mathrm{cm}^{3}$. The calculated result was then scaled to obtain the $1 \sigma$ uncertainty. Results are shown in Table 2.22.

This uncertainty is treated as $100 \%$ systematic instead of $\sim 50 \%$ because it is not completely clear how much of a systematic uncertainty to expect when using this method. Furthermore, six samples were taken from a single block and it is assumed that all graphite blocks have the same density as the sampled block. Variation in density between blocks is unknown.

Table 2.22a. Effect of Uncertainty in Graphite Block Density (62-Fuel-Element Core).

\begin{tabular}{||c|ccc|c|ccc||}
\hline Deviation & $\Delta \mathbf{k}$ & \pm & $\boldsymbol{\sigma}_{\Delta \mathbf{k}}$ & $\begin{array}{c}\text { Scaling } \\
\text { Factor }\end{array}$ & $\Delta \mathbf{k}_{\text {eff }}(\mathbf{1} \boldsymbol{\sigma})$ & \pm & $\boldsymbol{\sigma}_{\text {skeff }}$ \\
\hline \hline $\pm 0.027 \mathrm{~g} / \mathrm{cm}^{3}$ & 0.00042 & \pm & 0.00005 & 3 & 0.00014 & \pm & 0.00002 \\
\hline
\end{tabular}

Table 2.22b. Effect of Uncertainty in Graphite Block Density (64-Fuel-Element Core).

\begin{tabular}{||c|ccc|c|ccc||}
\hline \hline Deviation & $\boldsymbol{\Delta} \mathbf{k}$ & \pm & $\boldsymbol{\sigma}_{\text {ak }}$ & $\begin{array}{c}\text { Scaling } \\
\text { Factor }\end{array}$ & $\Delta \mathbf{k}_{\text {eff }}(\mathbf{1} \mathbf{\sigma})$ & \pm & $\boldsymbol{\sigma}_{\text {akeff }}$ \\
\hline \hline $\pm 0.027 \mathrm{~g} / \mathrm{cm}^{3}$ & 0.00032 & \pm & 0.00005 & 3 & 0.00011 & \pm & 0.00002 \\
\hline
\end{tabular}

\section{Dimensions}

The length of the graphite portion of the graphite reflector blocks (Figure 1.37) is $65.7225 \pm 0.3175 \mathrm{~cm}$ (manufacturing tolerance). The square cross section of the block (Figure 1.37) is $7.366 \mathrm{~cm}$ with manufacturing tolerance limits of +0.000 and $-0.254 \mathrm{~cm}$. The four corners are chamfered: $0.9525 \pm$ $0.0762 \mathrm{~cm} \times 45 \pm 5^{\circ}$.

The uncertainty in the length of the graphite blocks was determined to be negligible $(\leq 0.00010)$ in NRAD-FUND-RESR-001.

The graphite block cross sectional area was adjusted by the manufacturing tolerance. A lower perturbation $k_{\text {eff }}$ value was found by simultaneously decreasing the square area by $0.254 \mathrm{~cm}$ and increasing the chamfer depth by $0.0762 \mathrm{~cm}$ for all graphite blocks. Half of the difference between the unperturbed and lower perturbation $\mathrm{k}_{\text {eff }}$ values was used to represent the variation in $\mathrm{k}_{\text {eff }}$ due to perturbing the graphite block cross sectional area. The calculated result was then scaled to obtain the $1 \sigma$ uncertainty. Results are shown in Table 2.23.

The total number of graphite blocks in this configuration is 12 ; therefore the random component of this uncertainty is divided by $\sqrt{ } 12$. The uncertainty in the cross sectional area of the graphite blocks is divided by $\sqrt{ } 2$ to represent the two main sides of the block as being independently cut. No correction was implemented for the adjustment in chamfer dimensions. The angle of the chamfers was unchanged. 
NEA/NSC/DOC(2006)1

Fundamental - FUND

NRAD-FUND-RESR-002

CRIT-REAC-COEF

Table 2.23a. Effect of Uncertainty in Graphite Block Area (62-Fuel-Element Core).

\begin{tabular}{||c|ccc|c|ccc|c|c||}
\hline \hline Deviation & $\Delta \mathbf{k}$ & \pm & $\boldsymbol{\sigma}_{\mathrm{ak}}$ & $\begin{array}{c}\text { Scaling } \\
\text { Factor }\end{array}$ & $\Delta \mathbf{k}_{\text {eff }}(\mathbf{1} \boldsymbol{\sigma})$ & \pm & $\boldsymbol{\sigma}_{\Delta \mathbf{k e f f}}$ & $\begin{array}{c}\Delta \mathbf{k}_{\text {eff }} \\
(\mathbf{1 5 \%} \\
\text { systematic) }\end{array}$ & $\begin{array}{c}\Delta \mathbf{k}_{\text {eff }} \\
\mathbf{( 8 5 \%} \\
\mathbf{r a n d o m})\end{array}$ \\
\hline \hline$\pm \mathrm{BL}$ & -0.00188 & \pm & 0.00010 & $\sqrt{ } 2 \sqrt{3}$ & -0.00077 & \pm & 0.00004 & -0.00012 & -0.00019 \\
\hline
\end{tabular}

Table 2.23b. Effect of Uncertainty in Graphite Block Area (64-Fuel-Element Core).

\begin{tabular}{|c|ccc|c|ccc|c|c||}
\hline \hline Deviation & $\Delta \mathbf{k}$ & \pm & $\boldsymbol{\sigma}_{\Delta \mathbf{k}}$ & $\begin{array}{c}\text { Scaling } \\
\text { Factor }\end{array}$ & $\Delta \mathbf{k}_{\text {eff }}(\mathbf{1 \sigma})$ & \pm & $\boldsymbol{\sigma}_{\Delta k \text { keff }}$ & $\begin{array}{c}\Delta \mathbf{k}_{\text {eff }} \\
(\mathbf{1 5 \%} \\
\text { systematic) }\end{array}$ & $\begin{array}{c}\Delta \mathbf{k}_{\text {eff }} \\
\mathbf{( 8 5 \%} \\
\text { random) }\end{array}$ \\
\hline \hline$\pm \mathrm{BL}$ & -0.00154 & \pm & 0.00010 & $\sqrt{ } 2 \sqrt{3}$ & -0.00063 & \pm & 0.00004 & -0.00009 & -0.00015 \\
\hline
\end{tabular}

The effective bias for removing aluminum 2011 parts, the AmBe source, and their respective holes was determined to be negligible (Section 3.1.1.1 of NRAD-FUND-RESR-001). Therefore, any uncertainty analyses regarding the holes in the graphite were judged to be unnecessary as the results would also be negligible.

\section{Impurities}

The effective bias for removing impurities from the graphite reflector (Table 1.48) was determined to be negligible (Section 3.1.1.1 of NRAD-FUND-RESR-001). Therefore, any uncertainty analyses regarding the impurities in the graphite were judged to be unnecessary as the results would also be negligible.

\section{Water Saturation Effects}

Many of the graphite blocks have been underwater since the original installation of the NRAD reactor (>30 years) and a few others were added in 1981 and 1989 ( $>20$ years). The blocks were each removed once to exchange the top and bottom assembly adapters with newer components before being placed back into the tank. ${ }^{a}$ It was previously unknown whether any saturation of water within the graphite matrix was present, and initial NRAD models erroneously assumed that no water was contained within the graphite reflector blocks.

The measured weight of a dry graphite block assembly was $6.8 \mathrm{lbs}(3.0844 \mathrm{~kg})$. The measured weight of graphite block assemblies F-4 and D-1 were respectively $9.5 \mathrm{lbs}(4.3091 \mathrm{~kg})$ and $9.7 \mathrm{lbs}(4.3998 \mathrm{~kg})$. The nominal mass for graphite reflector block assemblies in the core is assumed to be $9.6 \mathrm{lbs}$ $(4.35448675 \mathrm{~kg})$ with an uncertainty of $\pm 0.1 \mathrm{lbs}(0.0454 \mathrm{~kg})$. Even though the measurements were indicated to two decimal places, the second decimal place was reported to always be zero; therefore the measurement accuracy uncertainty is assumed to be $\pm 0.1 \mathrm{lbs}(0.0454 \mathrm{~kg})$.

It was unknown whether the two dowels in the bottom section of the graphite reflector assemblies in-core (see Figure 1.36) were aluminum (as used in the dummy reflector assembly) or stainless steel. Basic mass calculations swapping steel for aluminum in the two dowels indicates a difference in mass of approximately 3.0029 ounces $(0.1877 \mathrm{lbs}$, or $85.13 \mathrm{~g})$. Treating this difference as a bounding uncertainty with uniform distribution probability, an additional mass uncertainty of $\pm 0.11 \mathrm{lbs}(0.0499 \mathrm{~kg})$ is estimated to account for not knowing whether the dowels were steel or aluminum.

The square root of the sum of the squares of the uncertainties in the mass measurements, accuracy of the scale, and the dowel weight was utilized to estimate the $1 \sigma$ uncertainty. The difference in mass between

\footnotetext{
${ }^{a}$ Personal communication with Ken Schreck at HFEF (September 2, 2010).
} 


\section{Fundamental - FUND \\ NRAD-FUND-RESR-002 \\ CRIT-REAC-COEF}

a dry assembly and a nominal in-core, wet assembly is $2.8 \mathrm{lbs}(1.2701 \mathrm{~kg})$ with an uncertainty of \pm 0.18 lbs $(0.08 \mathrm{~kg})$, which is assumed to represent the quantity, or mass, of water saturation in the graphite reflector blocks. It is assumed that because the dry graphite block was weighed almost immediately upon entry underwater that water ingress would have had minimal impact on its mass. Any uncertainty due to immediate water ingress is assumed to be negligible and included within the currently estimated $1 \sigma$ uncertainty.

The volume of the graphite in the reflector assembly is approximately $3440 \pm 250 \mathrm{~cm}^{3}$. The volume of the water saturation in the graphite block is approximately $1270 \pm 80 \mathrm{~cm}^{3}$. Taking the ratio of the water to graphite volume yields a nominal water saturation of $37 \pm 4(1 \sigma) \%$.

To find the effect of this uncertainty on the $\mathrm{k}_{\text {eff }}$ value, the water saturation content was adjusted by the $1 \sigma$ uncertainty. An upper perturbation $\mathrm{k}_{\text {eff }}$ value was found by simultaneously increasing the water content by $4 \%$ in all 12 graphite blocks and then simultaneously decreasing by the same amount to find a lower perturbation $k_{\text {eff }}$ value. Half of the difference between the upper and lower perturbation $k_{\text {eff }}$ values was used to represent the variation in $k_{\text {eff }}$ due to perturbing the graphite block water content by $4 \%$. This uncertainty is treated as $100 \%$ systematic because it is believed all graphite blocks would exhibit the same quantity of saturation. The effective uncertainty due to water saturation in the graphite blocks is shown in Table 2.24, and is considered negligible $(\leq 0.00010)$.

Table 2.24a. Effect of Uncertainty in Water Saturation of Graphite (62-Fuel-Element Core).

\begin{tabular}{|c|ccc|c|ccc|}
\hline Deviation & $\Delta \mathbf{k}$ & \pm & $\boldsymbol{\sigma}_{\Delta \mathbf{k}}$ & $\begin{array}{c}\text { Scaling } \\
\text { Factor }\end{array}$ & $\Delta \mathbf{k}_{\text {eff }}(\mathbf{1} \boldsymbol{\sigma})$ & \pm & $\boldsymbol{\sigma}_{\Delta \mathbf{k e f f}}$ \\
\hline \hline $\pm 4 \%$ & 0.00005 & \pm & 0.00005 & 1 & 0.00005 & \pm 0.00005 \\
\hline \hline
\end{tabular}

Table 2.24b. Effect of Uncertainty in Water Saturation of Graphite (64-Fuel-Element Core).

\begin{tabular}{||c|ccc|c|ccc|}
\hline \hline Deviation & $\Delta \mathbf{k}$ & \pm & $\boldsymbol{\sigma}_{\mathrm{ak}}$ & $\begin{array}{c}\text { Scaling } \\
\text { Factor }\end{array}$ & $\Delta \mathbf{k}_{\text {eff }}(\mathbf{1} \boldsymbol{\sigma})$ & \pm & $\boldsymbol{\sigma}_{\text {akeff }}$ \\
\hline \hline $\pm 4 \%$ & 0.00017 & \pm & 0.00005 & 1 & 0.00017 & \pm & 0.00005 \\
\hline
\end{tabular}

\subsubsection{Graphite Reflector Assembly Auxiliary Components}

\section{Aluminum 2011-T3 Components}

The composition and density of aluminum 2011-T3 is reported in Table 2.25. An average composition was selected to represent the tie rod, dowel, and screw components in the graphite reflector block assemblies. 
NEA/NSC/DOC(2006)1

Fundamental - FUND

NRAD-FUND-RESR-002

CRIT-REAC-COEF

Table 2.25. Aluminum 2011-T3 Composition (wt.\%).

\begin{tabular}{|c|c|c|c|}
\hline Component & Content $1^{(a)}$ & 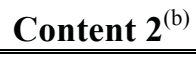 & Average $^{(\mathrm{c})}$ \\
\hline $\mathrm{Al}$ & 93.7 & Balance & 92.925 \\
\hline $\mathrm{Bi}$ & $0.20-0.60$ & $0.2-0.6$ & 0.4 \\
\hline $\mathrm{Cu}$ & $5.0-6.0$ & $5-6$ & 5.5 \\
\hline $\mathrm{Fe}$ & 0.70 Max & 0.7 Max & 0.35 \\
\hline $\mathrm{Si}$ & $0.40 \mathrm{Max}$ & 0.4 Max & 0.2 \\
\hline $\mathrm{Pb}$ & $0.20-0.60$ & $0.2-0.6$ & 0.4 \\
\hline $\mathrm{Zn}$ & 0.30 Max & $0.3 \mathrm{Max}$ & 0.15 \\
\hline $\mathrm{Co}^{(\mathrm{d})}$ & -- & $0.05 \mathrm{Max}$ & 0.025 \\
\hline $\mathrm{Ni}^{(\mathrm{d})}$ & -- & 0.05 Max & 0.025 \\
\hline $\mathrm{Sn}^{(\mathrm{d})}$ & -- & 0.05 Max & 0.025 \\
\hline Density $\left(\mathrm{g} / \mathrm{cm}^{3}\right)$ & 2.82 & 2.83 & 2.82 \\
\hline
\end{tabular}

(a) Alcoa Toolrite 2011®-T3 Aluminum, MatWeb Material Property Data, http://www.matweb.com/.

(b) Metal Suppliers Online, http://www.metalsuppliersonline.com/.

(c) Average based on the maximum range of each component. Values of 0.25 wt. $\%$ are selected for Fe and Si to satisfy the combined maximum requirement of $<0.95 \mathrm{wt} . \%$ and an $\mathrm{Al}$ content of $>99$ wt. $\%$.

(d) Reported "Other" components have a maximum of 0.15 wt.\% total with no more than 0.05 wt.\% per component. $\mathrm{Co}, \mathrm{Ni}$, and Sn were selected to represent impurities in Al6061.

The effective bias for removing aluminum 2011 parts (Figure 1.36) and their respective holes was determined to be negligible (Section 3.1.1.1 of NRAD-FUND-RESR-001). Therefore, any uncertainty analyses regarding the aluminum 2011 parts were judged to be unnecessary as the results would also be negligible.

\section{Aluminum 6061 Components}

The aluminum 6061 composition and density described in Section 2.1.4.2 is used to represent the material properties of the aluminum assembly components of the graphite reflector block assemblies.

The effective bias for removing top and bottom assemblies (Figures 1.14, 1.36, and 1.38) was determined to be negligible (Section 3.1.1.1 of NRAD-FUND-RESR-001). Therefore, any uncertainty analyses regarding the assembly components were judged to be unnecessary as the results would also be negligible.

\subsubsection{Americium-Beryllium Source and Tube}

\section{AmBe Source and Steel Cladding}

The only information available regarding the source (Figure 1.51) is the source strength of $5 \mathrm{Ci}\left(\sim 1 \times 10^{7}\right.$ neutrons $/ \mathrm{sec}$ ) on 5/10/1968 and a stainless steel container that is $3.302 \mathrm{~cm}$ long and $2.032 \mathrm{~cm}$ in outer diameter. In the design drawing for the graphite reflector assembly containing the source, the container is $3.50266 \mathrm{~cm}$ long with an outer diameter of $2.0955 \mathrm{~cm}$. It is assumed that the stainless steel cladding is SS304/304L material with the average composition and density found in Table 2.13. The cladding is assumed to be one-sixteenth inches thick $(0.15875 \mathrm{~cm})$ on all sides and the source container is a right 


\section{Fundamental - FUND \\ NRAD-FUND-RESR-002 \\ CRIT-REAC-COEF}

cylinder with no additional features. Therefore the approximate volume of the source and cladding is $12.08 \mathrm{~cm}^{3}$ and the approximate volume of just the source region within the clad is $7.91 \mathrm{~cm}^{3}$.

The activity of the source was evaluated by decaying the $5 \mathrm{Ci}$ source from the initial date to $3 / 30 / 2010$ (41.92 years) with an americium half-life of 432.7 years. The source had, at the time of the initial experiments, a strength of $\sim 4.7 \mathrm{Ci}\left(1.73 \times 10^{11}\right.$ alphas/s). This is equivalent to a neutron emission rate of approximately $5.2 \times 10^{6}$ neutrons/s assuming 30 neutrons are emitted per one million alpha particles in an AmBe source. ${ }^{a}$

The exact chemical composition of the AmBe source is unknown. A different $5 \mathrm{Ci}$ source of unspecified origin (purchased in 1986) was dismantled, sampled (sub-sampled), and analyzed using inductively coupled plasma mass spectrometry (ICP-MS) at the Idaho National Laboratory. The source was comprised of three separate pellets of varying thickness and mass. Each pellet was sub-sampled to provide 10 samples ranging in size from 6 to $15 \mathrm{mg}$. ${ }^{\mathrm{b}}$ The results of the analyses are in Table 2.26.

Table 2.26. Example AmBe Source Properties. ${ }^{(a)}$

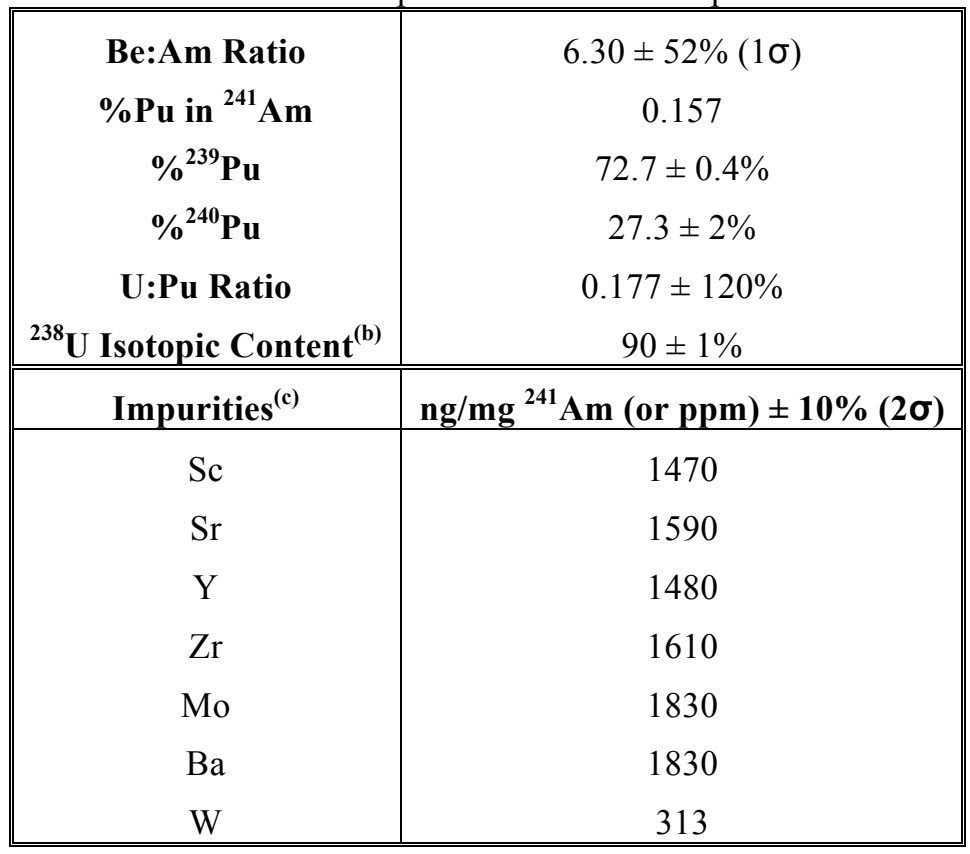

(a) J. Sommers, M. Jimenez, M. Adamic, J. Giglio, and K. Carney, "Characterization of a Sealed AmericiumBeryllium (AmBe) Source by Inductively Coupled Plasma Mass Spectrometry," J. Radioanal. Nucl. Chem., 282, 929932 (2009).

(b) This value represents a variance weighted average of the original data: $98 \pm 2 \%, 84 \pm 3 \%, 95 \pm 3 \%$, and $88 \pm$ $1 \%$.

(c) Only the impurities of significant measurable content were reported.

\footnotetext{
${ }^{a}$ D. R. Lide, ed., CRC Handbook of Chemistry and Physics, $90^{\text {th }}$ Edition (Internet Version 2010), CRC Press/Taylor and Francis, Boca Raton, FL (2010).

b J. Sommers, M. Jimenez, M. Adamic, J. Giglio, and K. Carney, "Characterization of a Sealed AmericiumBeryllium (AmBe) Source by Inductively Coupled Plasma Mass Spectrometry," J. Radioanal. Nucl. Chem., 282, 929-932 (2009).
} 


\section{Fundamental - FUND \\ NRAD-FUND-RESR-002 \\ CRIT-REAC-COEF}

Assuming the AmBe source is homogenously distributed under vacuum conditions within the interior volume of the source cladding, the atomic density of the americium can be calculated directly from the current activity of the source at the time of the experiments. The additional data provided in Table 2.54 can be used to estimate the approximate composition of the AmBe source material. There is assumed to be no ${ }^{237} \mathrm{~Np}$ in the initial source, and that all ${ }^{237} \mathrm{~Np}$ is obtained via the decay of ${ }^{241} \mathrm{Am}$ with no decay of any other radioisotopes in the source. It is assumed that all actinides are in the dioxide form such that an approximate content of oxygen can be included in the material composition. The estimated composition of the AmBe source is shown in Table 2.27. The approximate mass density of this homogenized source is $0.251 \mathrm{~g} / \mathrm{cm}^{3}$.

Table 2.27. Smeared AmBe Source Composition and Atomic Density.

\begin{tabular}{|c|c|}
\hline Isotope/Element & Atoms/b-cm \\
\hline \hline${ }^{241} \mathrm{Am}$ & $4.3062 \mathrm{E}-04$ \\
$\mathrm{Be}$ & $2.7129 \mathrm{E}-03$ \\
${ }^{237} \mathrm{~Np}$ & $2.9906 \mathrm{E}-05$ \\
${ }^{239} \mathrm{Pu}$ & $4.9228 \mathrm{E}-07$ \\
${ }^{240} \mathrm{Pu}$ & $1.8486 \mathrm{E}-07$ \\
${ }^{235} \mathrm{U}$ & $1.1985 \mathrm{E}-08$ \\
${ }^{238} \mathrm{U}$ & $1.0787 \mathrm{E}-07$ \\
$\mathrm{O}$ & $9.2265 \mathrm{E}-04$ \\
$\mathrm{Sc}$ & $3.3943 \mathrm{E}-06$ \\
$\mathrm{Sr}$ & $1.8837 \mathrm{E}-06$ \\
$\mathrm{Y}$ & $1.7280 \mathrm{E}-06$ \\
$\mathrm{Zr}$ & $1.8320 \mathrm{E}-06$ \\
$\mathrm{Mo}$ & $1.9800 \mathrm{E}-06$ \\
$\mathrm{Ba}$ & $1.3833 \mathrm{E}-06$ \\
$\mathrm{~W}$ & $1.7672 \mathrm{E}-07$ \\
\hline \hline Total & $4.1093 \mathrm{E}-03$ \\
\hline
\end{tabular}

The effective bias for removing the encapsulated AmBe source (Figure 1.51), source tube (Figure 1.52), and cap (Figure 1.53) was determined to be negligible (Section 3.1.1.1 of NRAD-FUND-RESR-001). Therefore, any uncertainty analyses regarding the AmBe source were judged to be unnecessary as the results would also be negligible.

\section{Source Tube and Cap}

The composition of the source tube and source tube cap is aluminum 6061 with the composition and density as described in Table 2.20.

The effective bias for removing the encapsulated AmBe source (Figure 1.51), source tube (Figure 1.52), and cap (Figure 1.53) was determined to be negligible (Section 3.1.1.1 of NRAD-FUND-RESR-001). Therefore, any uncertainty analyses regarding the source tube and cap were judged to be unnecessary as the results would also be negligible. 
NEA/NSC/DOC(2006)1

Fundamental - FUND

NRAD-FUND-RESR-002

CRIT-REAC-COEF

\subsubsection{Grid Plate Properties}

\subsubsection{Aluminum 1100}

The composition and density of aluminum 1100 is reported in Table 2.28. An average composition was selected to represent the core grid plate material properties.

Table 2.28. Aluminum 1100 Composition (wt.\%).

\begin{tabular}{|c|c|c|c|}
\hline Component & Content $1^{(\mathrm{a})}$ & Content $2^{(\mathrm{b})}$ & Average $^{(\mathrm{c})}$ \\
\hline $\mathrm{Al}$ & $99.00 \mathrm{Min}$ & 99 Min & 99.225 \\
\hline $\mathrm{Cu}$ & $0.05-0.20$ & $0.05-0.2$ & 0.125 \\
\hline $\mathrm{Fe}$ & 1.0 Max & -- & 0.25 \\
\hline $\mathrm{Mn}$ & $0.05 \mathrm{Max}$ & $0.05 \mathrm{Max}$ & 0.025 \\
\hline $\mathrm{Si}$ & 1.0 Max & -- & 0.25 \\
\hline $\mathrm{Zn}$ & $0.10 \mathrm{Max}$ & $0.1 \mathrm{Max}$ & 0.05 \\
\hline $\mathrm{Fe}+\mathrm{Si}$ & -- & $0.95 \mathrm{Max}$ & 0.5 \\
\hline $\mathrm{Co}^{(\mathrm{d})}$ & 0.05 & 0.05 & 0.025 \\
\hline $\mathrm{Ni}^{(\mathrm{d})}$ & 0.05 & 0.05 & 0.025 \\
\hline $\mathrm{Sn}^{(\mathrm{d})}$ & 0.05 & 0.05 & 0.025 \\
\hline Density $\left(\mathrm{g} / \mathrm{cm}^{3}\right)$ & -- & 2.71 & 2.71 \\
\hline
\end{tabular}

(a) All Metals \& Forge, http://www.steelforge.com/.

(b) Metal Suppliers Online, http://www.metalsuppliersonline.com/.

(c) Average based on the maximum range of each component. Values of 0.25 wt. $\%$ are selected for Fe and Si to satisfy the combined maximum requirement of $<0.95$ wt. $\%$ and an $\mathrm{Al}$ content of $>99$ wt. $\%$.

(d) Reported "Other" components have a maximum of 0.15 wt. \% total with no more than 0.05 wt.\% per component. Co, $\mathrm{Ni}$, and Sn were selected to represent impurities in Al6061.

The effective bias for removing the grid plate (Figure 1.10) was determined to be negligible (Section 3.1.1.1 of NRAD-FUND-RESR-001). Therefore, any uncertainty analyses regarding the grid plate itself were judged to be unnecessary as the results would also be negligible.

\subsubsection{Assembly Pitch in Grid Plate}

The square pitch between fuel elements within an assembly is $8.10006 \mathrm{~cm}$ in the East-West direction and $7.7089 \mathrm{~cm}$ in the North-South direction (Figure 1.11). No uncertainty is reported for this pitch. However, the manufacturing specifications for the grid plate assembly indicate a manufacturing tolerance of $\pm 0.0127 \mathrm{~cm}$ in the location of the center of each hole (Figure 1.10). The assembly hole diameter in the grid plate is $6.1722 \mathrm{~cm}$ with manufacturing tolerance limits of +0.01778 and $-0.00508 \mathrm{~cm}$ (Figure 1.10). The bottom assembly adapters (Figure 1.14) have a diameter of $6.0706 \pm 0.0254 \mathrm{~cm}$ (manufacturing limit). The uncertainty in each of these dimensions impacts the physical location of each assembly placed within the NRAD core; correlation effects between the parameters is unknown, and each contribution to the total pitch uncertainty is addressed individually.

To find the effect of this uncertainty on the $\mathrm{k}_{\text {eff }}$ value, the assembly pitch in the grid plate was adjusted by the bounding limit of $\pm 0.1016 \mathrm{~cm}$, which represents the difference between the nominal diameters of the 
NEA/NSC/DOC(2006)1

\section{Fundamental - FUND \\ NRAD-FUND-RESR-002 \\ CRIT-REAC-COEF}

bottom assembly adapters and the assembly holes in the grid plate. An upper perturbation $\mathrm{k}_{\text {eff }}$ value was found by simultaneously increasing the assembly pitch by $0.1016 \mathrm{~cm}$ and then simultaneously decreasing by the same amount to find a lower perturbation $\mathrm{k}_{\text {eff }}$ value. Half of the difference between the upper and lower perturbation $\mathrm{k}_{\text {eff }}$ values was used to represent the variation in $\mathrm{k}_{\text {eff }}$ due to perturbing the assembly pitch by $0.1016 \mathrm{~cm}$. The calculated result was then scaled to obtain the $1 \sigma$ uncertainty. Results are shown in Table 2.29.

The calculated uncertainty in the nominal pitch is then scaled to account for the uncertainty in the diameter of the assembly holes in the grid plate. The uncertainty related to the assembly pitch is believed to exhibit some randomness. However, the uncertainty in the diameter of the holes in the grid plate is assumed to be $100 \%$ systematic, as a single drill bit would have been used to make them.

The total number of assemblies in this configuration is 29 or 30 (16 fuel clusters, 12 graphite blocks, and 1 or 2 fuel/graphite clusters); therefore the random component of this uncertainty is divided by $\sqrt{ } 29$ or $\sqrt{ } 30$. The calculated uncertainty in the assembly pitch is considered negligible $(\leq 0.00010)$ except for that due to the difference in assembly adapter and hole dimensions and the drilled diameter of the holes in the grid plate.

A single simulation was performed and scaled for all the uncertainties reported in Table 2.29; only the uncertainties in the pitch of the grid plate and hole diameter were retained as others were previously determined to be negligible (see NRAD-FUND-RESR-001).

Table 2.29a. Effect of Uncertainty in Fuel Assembly Pitch (62-Fuel-Element Core).

\begin{tabular}{|c|c|c|c|c|c|c|c|c|c|}
\hline Deviation & $\Delta \mathbf{k}$ & \pm & $\sigma_{\Delta k}$ & $\begin{array}{l}\text { Scaling } \\
\text { Factor }\end{array}$ & $\Delta k_{\text {eff }}(1 \sigma)$ & \pm & $\sigma_{\text {akeff }}$ & $\begin{array}{c}\Delta \mathrm{k}_{\mathrm{eff}} \\
(15 \% \\
\text { systematic) }\end{array}$ & $\begin{array}{c}\Delta \mathbf{k}_{\text {eff }} \\
(85 \% \\
\text { random) } \\
\end{array}$ \\
\hline \multirow[t]{2}{*}{ $\pm 0.1016 \mathrm{~cm}$} & \multirow{2}{*}{0.00232} & & \multirow{2}{*}{0.00005} & $2 \sqrt{ } 3^{(a)}$ & 0.00067 & \pm & 0.00001 & 0.00010 & 0.00011 \\
\hline & & & & $5.7 \times 2 \sqrt{3^{(b)}}$ & 0.00012 & \pm & $<0.00001$ & -- & -- \\
\hline
\end{tabular}

(a) This scaling factor represents adjustment of the perturbed quantity to the uncertainty in assembly placement due to the difference in assembly bottom diameter and grid plate hole diameter.

(b) This scaling factor represents adjustment of the perturbed quantity to the uncertainty in the diameter of assembly holes drilled into the grid plate.

Table 2.29b. Effect of Uncertainty in Fuel Assembly Pitch (64-Fuel-Element Core).

\begin{tabular}{|c|c|c|c|c|c|c|c|c|c|}
\hline Deviation & $\Delta \mathrm{k}$ & \pm & $\sigma_{\Delta \mathbf{k}}$ & $\begin{array}{l}\text { Scaling } \\
\text { Factor }\end{array}$ & $\Delta k_{\text {eff }}(1 \sigma)$ & \pm & $\sigma_{\text {akeff }}$ & $\begin{array}{c}\Delta \mathbf{k}_{\text {eff }} \\
(15 \% \\
\text { systematic })\end{array}$ & $\begin{array}{c}\Delta \mathbf{k}_{\text {eff }} \\
(\mathbf{8 5 \%} \\
\text { random) }\end{array}$ \\
\hline $\pm 0.1016 \mathrm{~cm}$ & 0.00266 & \pm & 0.00005 & $\begin{array}{c}2 \sqrt{3^{(a)}} \\
5.7 \times 2 \sqrt{ } 3^{(b)}\end{array}$ & $\begin{array}{l}0.00077 \\
0.00013\end{array}$ & $\begin{array}{l} \pm \\
\pm\end{array}$ & $\begin{array}{c}0.00001 \\
<0.00001\end{array}$ & $\begin{array}{c}0.00012 \\
--\end{array}$ & $\begin{array}{c}0.00012 \\
--\end{array}$ \\
\hline
\end{tabular}

(a) This scaling factor represents adjustment of the perturbed quantity to the uncertainty in assembly placement due to the difference in assembly bottom diameter and grid plate hole diameter.

(b) This scaling factor represents adjustment of the perturbed quantity to the uncertainty in the diameter of assembly holes drilled into the grid plate.

This uncertainty was previously evaluated using the URAN card in $\mathrm{MCNP}^{\mathrm{a}}$ for the 60 -fuel-element core in NRAD-FUND-RESR-001. This card allows for the stochastic sampling of components with random locations in a lattice. The fuel and graphite assemblies in the core were simulated with random

\footnotetext{
${ }^{a}$ X-5 Monte Carlo Team, "MCNP - A General Monte Carlo N-Particle Transport Code, Version 5, Volume II: User's Guide,” LA-CP-03-0245, Los Alamos National Laboratory (October 3, 2005).
} 
placement within $\pm 0.01016 \mathrm{~cm}$ of their nominal (x,y) placement in the grid plate. The effect calculated using this method were negligible $(\leq 0.00010)$. Analysis using this method indicates that the method employed to obtain the results in Table 2.29 may overestimate the total effective uncertainty in the assembly pitch. However, the calculated uncertainty in the assembly pitch is still quite small compared to other uncertainties in this reactor configuration.

\subsubsection{Ex-Core Structural Support Properties}

\subsubsection{Grid Support Structure}

The aluminum 6061 composition and density described in Section 2.1.4.2 is used to represent the material properties of the aluminum grid support structure.

The effective bias for removing the grid support structure (Figure 1.8) was determined to be negligible (Section 3.1.1.1 of NRAD-FUND-RESR-001). Therefore, any uncertainty analyses regarding the support structure were judged to be unnecessary as the results would also be negligible.

\subsubsection{Mounting Pad}

The aluminum 6061 composition and density described in Section 2.1.4.2 are used to represent the material properties of the aluminum mounting pad.

The effective bias for removing the mounting pad (Figures 1.5 and 1.9) was determined to be negligible (Section 3.1.1.1 of NRAD-FUND-RESR-001). Therefore, any uncertainty analyses regarding the mounting pad were judged to be unnecessary as the results would also be negligible.

\subsubsection{Reactor Tank}

The aluminum 6061 composition and density described in Section 2.1.4.2 is used to represent the material properties of the aluminum reactor tank.

The effective bias for removing the reactor tank (Figures 1.5 and 1.9) was determined to be negligible (Section 3.1.1.1 of NRAD-FUND-RESR-001). Therefore, any uncertainty analyses regarding the mounting pad were judged to be unnecessary as the results would also be negligible.

\subsubsection{Tank Water Properties}

\section{Composition}

The tank water composition is assumed to be pure with the stoichiometric ratio of hydrogen to oxygen. $2: 1$. 


\section{Density}

The density of water, at a given temperature in degrees Celsius, can be obtained by interpolation of data tables provided in the $90^{\text {th }}$ edition of the CRC Handbook of Chemistry and Physics, ${ }^{\text {a }}$ or calculated using an equation provided in the $70^{\text {th }}$ edition of the handbook: ${ }^{\text {b }}$

$$
\rho\left(\frac{\mathrm{kg}}{\mathrm{m}^{3}}\right)=\frac{\left(\begin{array}{c}
999.83952+16.945176 \cdot T-7.9870401 \cdot 10^{-3} \cdot T^{2}-46.170461 \cdot 10^{-6} \cdot T^{3} \\
+105.56302 \cdot 10^{-9} \cdot T^{4}-280.54253 \cdot 10^{-12} \cdot T^{5}
\end{array}\right)}{\left(1+16.879850 \cdot 10^{-3} \cdot T\right)} .
$$

Use of either method provides a density within less than $0.0006 \%$ of the density obtained using the other method. The density of water at the temperature of $27.2^{\circ} \mathrm{C}$ is $0.9965 \mathrm{~g} / \mathrm{cm}^{3}$. The uncertainty in water density is evaluated and discussed as the uncertainty in the experiment temperature (Section 2.1.1.1). Any additional uncertainty incurred through use of the handbook data or equation for water density is assumed to be negligible.

\section{Impurities}

The tank water in the Advanced Test Reactor (ATR, ATR-FUND-RESR-001) is considered "dirtier" than the NRAD tank water. The reported impurity concentration for the ATR is found in Table 2.30.

The impurities reported in Table 2.30 were added to the composition of the tank water. The difference between the unperturbed and perturbed $\mathrm{k}_{\text {eff }}$ values was used to represent the variation in $\mathrm{k}_{\text {eff }}$ due to the inclusion of impurities in the water. Results are shown in Table 2.31.

This uncertainty is treated as a $1 \sigma$ uncertainty and $100 \%$ systematic. Because the effect is practically negligible, the statistical uncertainty of 0.00010 is taken to represent the uncertainty in impurity content in the water.

\footnotetext{
${ }^{a}$ D. R. Lide, ed., CRC Handbook of Chemistry and Physics, $90^{\text {th }}$ Edition (Internet Version 2010), CRC Press/Taylor and Francis, Boca Raton, FL (2010).

${ }^{\mathrm{b}}$ R. C. Weast and D. R. Lide, eds., CRC Handbook of Chemistry and Physics, $70^{\text {th }}$ Edition, CRC Press, Boca Raton, FL (1990).
} 
NEA/NSC/DOC(2006)1

Fundamental - FUND

NRAD-FUND-RESR-002

CRIT-REAC-COEF

Table 2.30. Impurities in ATR Tank Water. ${ }^{(a)}$

\begin{tabular}{|c|c|}
\hline Element & Concentration (ppb) \\
\hline \hline $\mathrm{Fe}$ & 0.84 \\
$\mathrm{Al}$ & 2.02 \\
$\mathrm{Ca}$ & 49.00 \\
$\mathrm{Mg}$ & 5.30 \\
$\mathrm{Mb}$ & 0.37 \\
$\mathrm{Si}$ & 29.40 \\
$\mathrm{Na}$ & 36.10 \\
$\mathrm{Cu}$ & 0.33 \\
$\mathrm{~Pb}$ & 0.20 \\
$\mathrm{Be}$ & 0.23 \\
$\mathrm{Cr}$ & 54.50 \\
$\mathrm{Sr}$ & 0.35 \\
$\mathrm{Ni}$ & 175.00 \\
$\mathrm{Co}$ & 0.30 \\
\hline
\end{tabular}

(a) ATR-FUND-RESR-001.

Table 2.31a. Effect of Uncertainty in Water Impurities (62-Fuel-Element Core).

\begin{tabular}{||c|ccc|c|ccc||}
\hline \hline Deviation & $\boldsymbol{\Delta} \mathbf{k}$ & \pm & $\boldsymbol{\sigma}_{\Delta \mathbf{k}}$ & $\begin{array}{c}\text { Scaling } \\
\text { Factor }\end{array}$ & $\boldsymbol{\Delta} \mathbf{k}_{\text {eff }}(\mathbf{1} \boldsymbol{\sigma})$ & \pm & $\boldsymbol{\sigma}_{\text {skeff }}$ \\
\hline \hline Added impurities & 0.00001 & \pm & 0.00010 & 1 & 0.00001 & \pm & 0.00010 \\
\hline
\end{tabular}

Table 2.31b. Effect of Uncertainty in Water Impurities (64-Fuel-Element Core).

\begin{tabular}{||c|ccc|c|ccc||}
\hline \hline Deviation & $\Delta \mathbf{k}$ & \pm & $\boldsymbol{\sigma}_{\Delta \mathbf{k}}$ & $\begin{array}{c}\text { Scaling } \\
\text { Factor }\end{array}$ & $\boldsymbol{\Delta} \mathbf{k}_{\text {eff }}(\mathbf{1 \sigma})$ & \pm & $\boldsymbol{\sigma}_{\Delta \mathbf{k e f f}}$ \\
\hline \hline Added impurities & 0.00009 & \pm & 0.00010 & 1 & 0.00009 & \pm & 0.00010 \\
\hline \hline
\end{tabular}

\subsubsection{Beam Tube Properties}

\subsubsection{Aluminum 6061}

\section{Composition and Density}

The aluminum 6061 composition and density described in Section 2.1.4.2 is used to represent the material properties of the aluminum reactor tank.

\section{Dimensions - Beam Filter Tube}

The outer height of the East and North beam filter tubes (Figure 1.42) is $16.51 \mathrm{~cm}$ with a manufacturing tolerance for the East tube is +0.000 and $-0.0254 \mathrm{~cm}$, and $\pm 0.0762 \mathrm{~cm}$ for the North tube. The top and bottom aluminum walls are manufactured from $0.635-\mathrm{cm}$-thick stock material. The width of both tubes is $13.97 \mathrm{~cm}$ with a manufacturing tolerance of +0.000 and $-0.0254 \mathrm{~cm}$, with the side aluminum walls 


\section{Fundamental - FUND \\ NRAD-FUND-RESR-002 \\ CRIT-REAC-COEF}

manufactured from $0.3175-\mathrm{cm}$-thick stock material. The front face aluminum plate, placed near the core, is manufactured from 0.2286 -cm-thick stock material. No tolerances are available for the stock material thicknesses. It is assumed that all beam filter tube dimensions are bound, with uniform probability distribution, within a tolerance of $\pm 0.0762 \mathrm{~cm}$, which is the largest manufacturing uncertainty tolerance for the aluminum parts comprising the beam filter tubes.

This uncertainty was determined to be negligible $(\leq 0.00010)$ in NRAD-FUND-RESR-001.

\section{Dimensions - Other Aluminum Beam Tube Components}

The effective bias for removing the beam tube aluminum (Figures 1.40 through 1.49), excluding the beam filter tube, was determined to be negligible (Section 3.1.1.1 of NRAD-FUND-RESR-001). Therefore, any uncertainty analyses regarding aluminum dimensions of the beam tube components (excluding the beam filter tube) were judged to be unnecessary as the results would also be negligible.

\section{Impurities}

The effective bias for removing non-aluminum elements (Table 2.20) from aluminum was determined to be negligible (Section 3.1.1.1 of NRAD-FUND-RESR-001). Therefore, any uncertainty analyses regarding aluminum impurities were judged to be unnecessary as the results would also be negligible.

\subsubsection{Gas Content in Beam Filter Tubes}

The gas content in the East beam filter tube is air with a composition and density as described in Section 2.1.3.5. The gas content in the North beam filter tube and both beam line aperture mechanism housing and beam tubes is helium with a pressure of approximately $0.2 \mathrm{~atm}$ at $300.35 \mathrm{~K}$. The helium is assumed to be pure gas with a calculated atomic density of $1.2209 \times 10^{-6}$ atoms $/ \mathrm{b}-\mathrm{cm}$ (mass density of $8.1149 \times 10^{-6}$ $\mathrm{g} / \mathrm{cm}^{3}$.

$$
\begin{gathered}
\frac{n}{V}=\frac{P \cdot N_{A}}{R \cdot T}=\frac{(0.2 \mathrm{~atm}) \cdot\left(0.60221 \frac{\mathrm{atoms} \cdot \mathrm{cm}^{2}}{\mathrm{~mol} \cdot \mathrm{b}}\right)}{\left(82.05746 \frac{\mathrm{cm} \cdot \mathrm{atm}}{\mathrm{mol} \cdot \mathrm{K}}\right) \cdot(300.35 \mathrm{~K})}=1.2209 \cdot 10^{-6} \frac{\mathrm{atoms}}{\mathrm{b} \cdot \mathrm{cm}} . \\
\rho=\frac{n}{V} \cdot \frac{M}{N_{A}}=1.2209 \cdot 10^{-6} \frac{\mathrm{atoms}}{\mathrm{b} \cdot \mathrm{cm}} \cdot \frac{4.0026 \frac{\mathrm{g}}{\mathrm{mol}}}{\left(0.60221 \frac{\mathrm{atoms} \cdot \mathrm{cm}^{2}}{\mathrm{~mol} \cdot \mathrm{b}}\right)}=8.1149 \cdot 10^{-6} \frac{\mathrm{g}}{\mathrm{cm}^{3}} .
\end{gathered}
$$

The effective bias for removing air and helium was determined to be negligible (Section 3.1.1.1 of NRAD-FUND-RESR-001). Therefore, any uncertainty analyses regarding air were judged to be unnecessary as the results would also be negligible.

\subsubsection{Boron Nitride Apertures}

The aperture blocks are Combat Grade A boron nitride from the graphite products division of The Carborundum Co., which is now Saint-Gobain. ${ }^{a}$ Typical impurities and the physical density for this material is provided in Table 2.32 .

\footnotetext{
${ }^{a}$ Saint-Gobain Advanced Ceramics, Boron Nitride Products, 168 Creekside Drive, Amherst, New York 14228, http://www.bn.saint-gobain.com.
} 
Fundamental - FUND

NRAD-FUND-RESR-002

CRIT-REAC-COEF

Table 2.32. Composition of Combat Grade A Boron Nitride. ${ }^{(a)}$

\begin{tabular}{|c|c|}
\hline Component & Average ppm (wt.\%) \\
\hline $\mathrm{Al}$ & 14.6 \\
\hline $\mathrm{Au}$ & 1 \\
\hline $\mathrm{Be}$ & 1 \\
\hline $\mathrm{Ca}$ & 620.8 \\
\hline $\mathrm{Cr}$ & 22.8 \\
\hline $\mathrm{Cu}$ & 1 \\
\hline $\mathrm{Fe}$ & 1 \\
\hline $\mathrm{K}$ & 23 \\
\hline $\mathrm{Mg}$ & 1 \\
\hline $\mathrm{Mn}$ & 1.4 \\
\hline Mo & 1 \\
\hline $\mathrm{Na}$ & 20 \\
\hline $\mathrm{Ni}$ & 1 \\
\hline $\mathrm{Pb}$ & 1 \\
\hline $\mathrm{Si}$ & 2410.6 \\
\hline $\mathrm{Sn}$ & 1 \\
\hline $\mathrm{Ti}$ & 1 \\
\hline $\mathrm{V}$ & 1 \\
\hline W & 1 \\
\hline $\mathrm{Zn}$ & 1 \\
\hline $\mathrm{Zr}$ & 1 \\
\hline $\mathrm{B}_{2} \mathrm{O}_{3}{ }^{(b)}$ & 4.56 wt. $\%$ \\
\hline $\mathrm{O}_{2}{ }^{(\mathrm{b})}$ & 4.30 wt. $\%$ \\
\hline $\mathrm{BN}$ & Balance \\
\hline Density $\left(\mathrm{g} / \mathrm{cm}^{3}\right)$ & $2.09^{(\mathrm{c})}$ \\
\hline
\end{tabular}

(a) Personal communication with Steve Lyle at Saint-Gobain Boron Nitride (April 21, 2010).

(b) The oxygen quantities overlap some between these two measurements.

(c) Density in a single billet can vary as much as $7-8 \%$ from this average value within the billet.

The effective bias for removing the boron nitride apertures (Figures 1.43 and 1.44) was determined to be negligible (Section 3.1.1.1 of NRAD-FUND-RESR-001). Therefore, any uncertainty analyses regarding boron nitride were judged to be unnecessary as the results would also be negligible. 
NEA/NSC/DOC(2006)1

Fundamental - FUND

NRAD-FUND-RESR-002

CRIT-REAC-COEF

\subsubsection{Placement of Beam Lines Relative to Core Fuel Elements}

The front face of the beam line filter tubes (Figures 1.41 and 1.42) was approximately $2.032 \mathrm{~cm}$ from the outside clad face of the outermost fuel elements in the core. There is no reported uncertainty in this parameter. This distance is a function of core properties such as fuel element pitch within an assembly, fuel assembly pitch, and fuel element outer diameter and beam line properties such is total beam filter tube length, thickness of the beam filter tube attachment region, total thickness of the beam aperture mechanism region, alignment accuracy of the beam mechanism region to the beam tube support stand, and alignment accuracy of the beam line support stand attached to the floor with respect to the location of the core.

The uncertainties due to core parameters are already included with the evaluation of their respective uncertainties in previous sections. The uncertainty in the length of the beam filter tube is $\pm 0.0381 \mathrm{~cm}$. The uncertainty in the thickness of the beam filter tube attachment plate is $\pm 0.00762 \mathrm{~cm}$. The uncertainty in the thickness of the front face aluminum sheet of the aperture mechanism region is assumed to be $\pm 0.0762 \mathrm{~cm}$. The uncertainty in the thickness of the beam aperture mechanism region is assumed to be half of the tolerance value: $\pm 0.0381 / 2(0.01905) \mathrm{cm}$. The uncertainty in the alignment accuracy of the attachment of the aperture mechanism region to the support stand and the support stand to the tank floor, with respect to the core, are both assumed to be $\pm 0.0762 \mathrm{~cm}$. All of these uncertainties are treated as bounding uncertainties with uniform probability distribution. The total maximum position uncertainty for the distance between the core face and the face of the beam filter tube is $\pm 0.29337 \mathrm{~cm}$. Assuming that each aspect of the beam line hardware manufacture and placement is independent, this maximum value is divided by the square-root of the number of components, six (6), and the actual bounding uncertainty in the distance between the core and beam filter tube is approximately $\pm 0.12 \mathrm{~cm}$. This uncertainty is equivalent to assuming a $0.05 \mathrm{in}$. uncertainty in the original $0.8 \mathrm{in}$. approximate distance.

To find the effect of this uncertainty on the $\mathrm{k}_{\mathrm{eff}}$ value, the locations of the beam lines were adjusted by their estimated bounding limit. An upper perturbation $\mathrm{k}_{\mathrm{eff}}$ value was found by simultaneously increasing the distance by $0.12 \mathrm{~cm}$ and then simultaneously decreasing by the same amount to find a lower perturbation $k_{\text {eff }}$ value. Half of the difference between the upper and lower perturbation $k_{\text {eff }}$ values was used to represent the variation in $\mathrm{k}_{\mathrm{eff}}$ due to perturbing the locations of the beam lines. The calculated result was then scaled to obtain the $1 \sigma$ uncertainty. Results are shown in Table 2.33.

The total number of beam tubes in this configuration is 2 ; therefore the random component of this uncertainty is divided by $\sqrt{ } 2$.

Table 2.33a. Effect of Uncertainty in Beam Line Placement (62-Fuel-Element Core).

\begin{tabular}{||c|ccc|c|ccc|c|c||}
\hline Deviation & $\Delta \mathbf{k}$ & \pm & $\boldsymbol{\sigma}_{\Delta \mathbf{k}}$ & $\begin{array}{c}\text { Scaling } \\
\text { Factor }\end{array}$ & $\Delta \mathbf{k}_{\text {eff }}(\mathbf{1 \sigma})$ & \pm & $\boldsymbol{\sigma}_{\Delta \text { keff }}$ & $\begin{array}{c}\Delta \mathbf{k}_{\text {eff }} \\
(\mathbf{1 5 \%} \\
\text { systematic) }\end{array}$ & $\begin{array}{c}\Delta \mathbf{k}_{\text {eff }} \\
\mathbf{8 5 \%} \\
\text { random) }\end{array}$ \\
\hline \hline $\pm 0.12 \mathrm{~cm}$ & 0.00034 & \pm & 0.00005 & $\sqrt{ } 3$ & 0.00020 & \pm & 0.00003 & 0.00003 & 0.00012 \\
\hline \hline
\end{tabular}

Table 2.33b. Effect of Uncertainty in Beam Line Placement (64-Fuel-Element Core).

\begin{tabular}{||c|ccc|c|ccc|c|c||}
\hline Deviation & $\Delta \mathbf{k}$ & \pm & $\boldsymbol{\sigma}_{\mathbf{a k}}$ & $\begin{array}{c}\text { Scaling } \\
\text { Factor }\end{array}$ & $\Delta \mathbf{k}_{\text {eff }}(\mathbf{1} \boldsymbol{\sigma})$ & \pm & $\boldsymbol{\sigma}_{\text {akeff }}$ & $\begin{array}{c}\Delta \mathbf{k}_{\text {eff }} \\
\mathbf{( 1 5 \%} \\
\text { systematic) }\end{array}$ & $\begin{array}{c}\Delta \mathbf{k}_{\text {eff }} \\
\mathbf{( 8 5 \%} \\
\text { random) }\end{array}$ \\
\hline \hline $\pm 0.12 \mathrm{~cm}$ & 0.00028 & \pm & 0.00005 & $\sqrt{ } 3$ & 0.00016 & \pm & 0.00003 & 0.00002 & 0.00010 \\
\hline
\end{tabular}


NEA/NSC/DOC(2006)1

Fundamental - FUND

NRAD-FUND-RESR-002

CRIT-REAC-COEF

Uncertainty in the centerline alignment of the beam line with the core fuel is expected to be small and have a negligible effect on the total $k_{\text {eff }}$ uncertainty. Any uncertainty due to centerline alignment of the beam tube would already be included in the dimensional analysis of the beam filter tube aluminum walls.

\subsubsection{Instrumentation and Detector Properties}

\subsubsection{Dry Tubes, Detectors, etc.}

Dry tubes were not installed during the initial critical measurements of the NRAD core; uncertainty analyses were therefore not performed.

The effective bias for removing the detectors and their housings from the benchmark model was not performed because they are beyond the water reflector boundaries determined in Section 3.1.1.1 of NRAD-FUND-RESR-001. The detectors are sufficiently distanced from the core so as to not directly influence criticality. Therefore, any uncertainty analyses regarding the detectors were judged to be unnecessary as the results would be negligible.

\subsubsection{Graphite Elements}

\section{Composition}

The composition of the graphite element reflectors (Table 2.11) is obtained by reducing the quantity of graphite to account for the impurities reported in Table 1.8. For elements that are listed only as detection limits, half of the detection limit is assumed to represent the quantity of that impurity in the graphite material.

\section{Density}

The graphite element reflectors are nuclear grade graphite, either PGX or ECW. The density of these two graphite types is nominally 1.73 or $1.74 \mathrm{~g} / \mathrm{cm}^{3}$, respectively. ${ }^{\mathrm{a}}$ A $1 \sigma$ uncertainty of $\pm 0.01 \mathrm{~g} / \mathrm{cm}^{3}$ was selected for the density of the graphite element reflectors.

To find the effect of this uncertainty on the $\mathrm{k}_{\text {eff }}$ value, the graphite element reflector density was adjusted by the $3 \sigma$ uncertainty. An upper perturbation $k_{\text {eff }}$ value was found by simultaneously increasing the graphite density by $0.03 \mathrm{~g} / \mathrm{cm}^{3}$ and then simultaneously decreasing by the same amount to find a lower perturbation $k_{\text {eff }}$ value. Half of the difference between the upper and lower perturbation $k_{\text {eff }}$ values was used to represent the variation in $k_{\text {eff }}$ due to perturbing the graphite density by $0.03 \mathrm{~g} / \mathrm{cm}^{3}$. The calculated result was then scaled to obtain the $1 \sigma$ uncertainty. Results are shown in Table 2.34.

This uncertainty is treated as $100 \%$ systematic. The calculated uncertainty in the graphite element reflector density is considered negligible $(\leq 0.00010)$.

Table 2.34a. Effect of Uncertainty in Graphite Element Reflector Density (62-Fuel-Element Core).

\begin{tabular}{||c|ccc|c|ccc||}
\hline \hline Deviation & $\Delta \mathbf{k}$ & \pm & $\boldsymbol{\sigma}_{\Delta \mathbf{k}}$ & $\begin{array}{c}\text { Scaling } \\
\text { Factor }\end{array}$ & $\Delta \mathbf{k}_{\text {eff }}(\mathbf{1} \boldsymbol{\sigma})$ & \pm & $\boldsymbol{\sigma}_{\text {skeff }}$ \\
\hline \hline $\pm 0.03 \mathrm{~g} / \mathrm{cm}^{3}$ & 0.00002 & \pm & 0.00005 & 3 & 0.00001 & \pm & 0.00002 \\
\hline
\end{tabular}

\footnotetext{
${ }^{a}$ Personal communication with Victor Leight at GrafTech International (April 5, 2010).
} 
Table 2.34b. Effect of Uncertainty in Graphite Element Reflector Density (64-Fuel-Element Core).

\begin{tabular}{||c|ccc|c|ccc||}
\hline \hline Deviation & $\Delta \mathbf{k}$ & \pm & $\boldsymbol{\sigma}_{\Delta \mathbf{k}}$ & $\begin{array}{c}\text { Scaling } \\
\text { Factor }\end{array}$ & $\Delta \mathbf{k}_{\text {eff }}(\mathbf{1} \mathbf{)}$ & \pm & $\boldsymbol{\sigma}_{\Delta \mathbf{k e f f}}$ \\
\hline \hline $\pm 0.03 \mathrm{~g} / \mathrm{cm}^{3}$ & 0.00011 & \pm & 0.00005 & 3 & 0.00004 & \pm & 0.00002 \\
\hline
\end{tabular}

\section{Dimensions}

The graphite element reflector length (Figure 1.58) is $55.55234 \mathrm{~cm}$. There is no reported manufacturing tolerance. The reported tolerance for the shorter axial graphite reflectors in the fuel elements (Figure 1.28 ) is $\pm 0.0254 \mathrm{~cm}$. Because the true tolerance is unknown, a larger perturbation was performed in which the graphite rod was extended the full length of the cavity and reduced by a similar amount, i.e. $\pm 0.64521 \mathrm{~cm}$. This uncertainty is treated as at least three times the bounding limit, with uniform probability distribution. The graphite element reflector outer diameter is $3.27914 \mathrm{~cm}$ with manufacturing tolerance limits of +0.00 and $-0.0127 \mathrm{~cm}$.

To find the effect of this uncertainty on the $\mathrm{k}_{\text {eff }}$ value, the graphite element reflector dimensions were adjusted by three times their respective tolerance limits. An upper perturbation $\mathrm{k}_{\mathrm{eff}}$ value was found by simultaneously increasing the graphite volume and then simultaneously decreasing by the same amount to find a lower perturbation $\mathrm{k}_{\mathrm{eff}}$ value. Half of the difference between the upper and lower perturbation $\mathrm{k}_{\mathrm{eff}}$ values was used to represent the variation in $\mathrm{k}_{\mathrm{eff}}$ due to perturbing the graphite reflector dimensions. The calculated result was then scaled to obtain the $1 \sigma$ uncertainty. Results are shown in Tables 2.35 and 2.36 for uncertainties in the reflector length and diameter, respectively.

The graphite element reflector diameter was increased in this perturbation analysis even though there is no positive manufacturing tolerance for this dimension. The total number of graphite elements in this configuration is 2 or 4 ; therefore the random component of this uncertainty is divided by $\sqrt{2}$ or $\sqrt{ } 4$. The calculated uncertainty in the graphite element reflector dimensions is considered negligible $(\leq 0.00010)$.

Table 2.35a. Effect of Uncertainty in Graphite Element Reflector Length (62-Fuel-Element Core).

\begin{tabular}{||c|ccc|c|c|c|c|c|c|}
\hline \hline Deviation & $\Delta \mathbf{k}$ & \pm & $\sigma_{\Delta k}$ & $\begin{array}{c}\text { Scaling } \\
\text { Factor }\end{array}$ & $\Delta \mathbf{k}_{\text {eff }}(\mathbf{1 \sigma})$ & \pm & $\sigma_{\Delta \mathbf{k e f f}}$ & $\begin{array}{c}\Delta \mathbf{k}_{\text {eff }} \\
(\mathbf{1 5 \%} \\
\text { systematic) }\end{array}$ & $\begin{array}{c}\Delta \mathbf{k}_{\text {eff }} \\
\mathbf{( 8 5 \%} \\
\text { random) }\end{array}$ \\
\hline \hline $\pm 0.64521 \mathrm{~cm}$ & -0.00006 & \pm & 0.00005 & $3 \sqrt{3}$ & -0.00001 & \pm & 0.00001 & $<0.00001$ & -0.00001 \\
\hline \hline
\end{tabular}

Table 2.35b. Effect of Uncertainty in Graphite Element Reflector Length (64-Fuel-Element Core).

\begin{tabular}{||c|ccc|c|ccc|c|c||}
\hline \hline Deviation & $\Delta \mathbf{k}$ & \pm & $\sigma_{\Delta \mathbf{k}}$ & $\begin{array}{c}\text { Scaling } \\
\text { Factor }\end{array}$ & $\Delta \mathbf{k}_{\text {eff }} \mathbf{( 1 \sigma )} \pm$ & $\sigma_{\Delta k \text { eff }}$ & $\begin{array}{c}\Delta \mathbf{k}_{\text {eff }} \\
(\mathbf{1 5 \%} \\
\text { systematic) }\end{array}$ & $\begin{array}{c}\Delta \mathbf{k}_{\text {eff }} \\
\mathbf{8 5 \%} \\
\text { random) }\end{array}$ \\
\hline \hline $\pm 0.64521 \mathrm{~cm}$ & 0.00006 & \pm & 0.00005 & $3 \sqrt{3}$ & 0.00001 & \pm & 0.00001 & $<0.00001$ & $<0.00001$ \\
\hline \hline
\end{tabular}

Table 2.36a. Effect of Uncertainty in Graphite Element Reflector Diameter (62-Fuel-Element Core).

\begin{tabular}{||c|ccc|c|ccc|c|c||}
\hline \hline Deviation & $\Delta \mathbf{k}$ & \pm & $\boldsymbol{\sigma}_{\Delta \mathbf{k}}$ & $\begin{array}{c}\text { Scaling } \\
\text { Factor }\end{array}$ & $\Delta \mathbf{k}_{\text {eff }}(\mathbf{1 \sigma})$ & \pm & $\boldsymbol{\sigma}_{\Delta \mathbf{k e f f}}$ & $\begin{array}{c}\Delta \mathbf{k}_{\text {eff }} \\
\mathbf{( 1 5 \%}\end{array}$ & $\begin{array}{c}\Delta \mathbf{k}_{\text {eff }} \\
\mathbf{( 8 5 \%} \\
\mathbf{s y s t e m a t i c )}\end{array}$ \\
\hline \hline $\mathbf{r a n d o m})$
\end{tabular}


NEA/NSC/DOC(2006)1

Fundamental - FUND

NRAD-FUND-RESR-002

CRIT-REAC-COEF

Table 2.36b. Effect of Uncertainty in Graphite Element Reflector Diameter (64-Fuel-Element Core).

\begin{tabular}{||c|ccc|c|ccc|c|c||}
\hline \hline Deviation & $\Delta \mathbf{k}$ & \pm & $\boldsymbol{\sigma}_{\Delta \mathbf{k}}$ & $\begin{array}{c}\text { Scaling } \\
\text { Factor }\end{array}$ & $\Delta \mathbf{k}_{\text {eff }}(\mathbf{1} \boldsymbol{\sigma})$ & \pm & $\boldsymbol{\sigma}_{\text {akeff }}$ & $\begin{array}{c}\Delta \mathbf{k}_{\text {eff }} \\
\mathbf{( 1 5 \%} \\
\text { systematic) }\end{array}$ & $\begin{array}{c}\Delta \mathbf{k}_{\text {eff }} \\
\mathbf{( 8 5 \%} \\
\text { random) }\end{array}$ \\
\hline \hline $\pm 0.0381 \mathrm{~cm}$ & 0.00009 & \pm & 0.00005 & $3 \sqrt{3}$ & 0.00002 & \pm 0.00001 & $<0.00001$ & 0.00001 \\
\hline
\end{tabular}

\section{Impurities}

The effective bias for removing impurities (Table 2.11) from the graphite element reflectors was determined to be negligible. Therefore, an uncertainty analysis regarding impurities in the graphite was judged to be unnecessary as the result would also be negligible.

\section{Stainless Steel Components}

The uncertainties in the parameters relevant to the stainless steel components of the graphite element reflectors were included in their respective evaluation of the uncertainties in the fuel elements because the cladding and end fittings were identical to those utilized in the fuel elements.

\subsubsection{Total Experimental Uncertainty}

A compilation of the total evaluated uncertainty in the 62- and 64-fuel-element core critical configurations of the NRAD reactor is shown in Tables 2.37 and Table 2.38, respectively. As discussed earlier, uncertainties that are not treated as $100 \%$ systematic because perturbation analyses were simultaneously applied to multiple components are treated as $15 \%$ systematic (to preserve some uncertainty due to possible, yet unknown, systematic effects) and $85 \%$ random. In the case of the ${ }^{235} \mathrm{U}$ enrichment, the systematic component of the uncertainty was determined to be $25 \%$. The random portion of the uncertainty is then divided by the square root of the number of perturbed components. The rootmean square of each subcomponent is taken to determine the uncertainty in either the random or systematic components of the total evaluated uncertainty. The total evaluated uncertainty is then the root-mean square of the random and systematic uncertainties.

Uncertainties $\leq 0.00010$ are reported as negligible (neg) and those with no evaluated random component of the total uncertainty are noted with "--". All uncertainties providing at least $0.04 \% \mathrm{Dk}_{\text {eff }}$ are highlighted in gray.

Evaluation of the uncertainty in the 62- and 64-fuel-element core critical configurations was performed after the comprehensive analysis of the 60-fuel-element core (NRAD-FUND-RESR-001). Because most of the uncertainties evaluated for the 60-fuel-element core were negligible only a small selection of uncertainties were evaluated herein. The uncertainties among all evaluated NRAD core configurations are comparable within statistical uncertainties 
Table 2.37. Total Experimental Uncertainty of the 62-Fuel-Element NRAD Core.

\begin{tabular}{|c|c|c|c|c|}
\hline Perturbed Parameter & $\begin{array}{c}\text { Parameter } \\
\text { Value }\end{array}$ & $\begin{array}{c}1 \sigma \\
\text { Uncertainty }\end{array}$ & $\begin{array}{l} \pm \Delta k_{\text {eff }}(1 \sigma) \\
\text { Systematic }\end{array}$ & $\begin{array}{c} \pm \Delta k_{\text {eff }}(1 \sigma) \\
\text { Random }\end{array}$ \\
\hline${ }^{235} \mathrm{U}$ Mass $(\mathrm{g})$ & 148.0 & \pm 0.43 & 0.00013 & 0.00012 \\
\hline${ }^{234} \mathrm{U}$ Content (wt.\%) & 0.18 & \pm 0.02 & 0.00027 & -- \\
\hline${ }^{236} \mathrm{U}$ Content (wt.\%) & 0.22 & \pm 0.09 & 0.00049 & -- \\
\hline Hydrogen/Zirconium Ratio & 1.58 & \pm 0.01 & 0.00015 & 0.00011 \\
\hline Erbium Content in Fuel (wt.\%) & 0.90 & \pm 0.02 & 0.00040 & 0.00029 \\
\hline Stainless Steel Manganese Content & Table 2.12 & Table 2.12 & 0.00065 & -- \\
\hline Stainless Steel Nickel Content & Table 2.12 & Table 2.12 & 0.00020 & -- \\
\hline Stainless Steel Impurities & Table 2.13 & $\pm 100 \%$ & 0.00036 & -- \\
\hline $\mathrm{B}_{4} \mathrm{C}$ Impurities & None & Table 2.18 & 0.00010 & -- \\
\hline Graphite Block Density $\left(\mathrm{g} / \mathrm{cm}^{3}\right)$ & 1.570 & \pm 0.009 & 0.00014 & -- \\
\hline Graphite Block Cross Section $\left(\mathrm{cm}^{2}\right)$ & Figure 1.37 & Figure 1.37 & 0.00012 & 0.00019 \\
\hline Water Saturation of Graphite (vol.\%) & 37 & \pm 4 & neg & -- \\
\hline Assembly Pitch in Grid Plate (cm) & $\begin{array}{c}8.10006 \mathrm{E}-\mathrm{W} \\
7.7089 \mathrm{~N}-\mathrm{S}\end{array}$ & $\pm 0.0508 / \sqrt{ } 3$ & 0.00010 & 0.00011 \\
\hline Assembly Hole Diameter (cm) & 6.1722 & $\begin{array}{l}+0.01778 / \sqrt{ } 3 \\
-0.00508 / \sqrt{ } 3\end{array}$ & 0.00012 & -- \\
\hline Water Impurities & None & Table 2.30 & 0.00010 & -- \\
\hline Placement of Beam Lines $(\mathrm{cm})$ & 2.032 & $\pm 0.12 / \sqrt{ } 3$ & neg & 0.00012 \\
\hline Graphite Element Density $\left(\mathrm{g} / \mathrm{cm}^{3}\right)$ & 1.73 & \pm 0.01 & neg & -- \\
\hline Graphite Element Length $(\mathrm{cm})$ & 55.55234 & $\pm 0.21507 / \sqrt{ } 3$ & neg & neg \\
\hline Graphite Element Diameter $(\mathrm{cm})$ & 3.27914 & $\pm 0.127 / \sqrt{ } 3$ & neg & neg \\
\hline Graphite Element Impurities & Table 2.11 & $\pm 100 \%$ & neg & -- \\
\hline Uncertainty by Type & -- & -- & 0.00109 & 0.00041 \\
\hline Total Experimental Uncertainty & -- & -- & 0.00116 & -- \\
\hline
\end{tabular}


Table 2.38. Total Experimental Uncertainty of the 64-Fuel-Element NRAD Core.

\begin{tabular}{|c|c|c|c|c|}
\hline Perturbed Parameter & $\begin{array}{c}\text { Parameter } \\
\text { Value }\end{array}$ & $\begin{array}{c}1 \sigma \\
\text { Uncertainty }\end{array}$ & $\begin{array}{l} \pm \Delta k_{\text {eff }}(1 \sigma) \\
\text { Systematic }\end{array}$ & $\begin{array}{c} \pm \Delta \mathrm{k}_{\mathrm{eff}}(1 \sigma) \\
\text { Random }\end{array}$ \\
\hline${ }^{235} \mathrm{U}$ Mass $(\mathrm{g})$ & 148.1 & \pm 0.43 & 0.00013 & 0.00012 \\
\hline${ }^{234} \mathrm{U}$ Content (wt.\%) & 0.18 & \pm 0.02 & 0.00030 & -- \\
\hline${ }^{236} \mathrm{U}$ Content (wt.\%) & 0.22 & \pm 0.09 & 0.00048 & -- \\
\hline Hydrogen/Zirconium Ratio & 1.58 & \pm 0.01 & 0.00015 & 0.00011 \\
\hline Erbium Content in Fuel (wt.\%) & 0.90 & \pm 0.02 & 0.00041 & 0.00029 \\
\hline Stainless Steel Manganese Content & Table 2.12 & Table 2.12 & 0.00070 & -- \\
\hline Stainless Steel Nickel Content & Table 2.12 & Table 2.12 & 0.00012 & -- \\
\hline Stainless Steel Impurities & Table 2.13 & $\pm 100 \%$ & 0.00042 & -- \\
\hline $\mathrm{B}_{4} \mathrm{C}$ Impurities & None & Table 2.18 & 0.00010 & -- \\
\hline Graphite Block Density $\left(\mathrm{g} / \mathrm{cm}^{3}\right)$ & 1.570 & \pm 0.009 & 0.00011 & -- \\
\hline Graphite Block Cross Section $\left(\mathrm{cm}^{2}\right)$ & Figure 1.37 & Figure 1.37 & neg & 0.00015 \\
\hline Water Saturation of Graphite (vol.\%) & 37 & \pm 4 & 0.00017 & -- \\
\hline Assembly Pitch in Grid Plate $(\mathrm{cm})$ & $\begin{array}{c}8.10006 \mathrm{E}-\mathrm{W} \\
7.7089 \mathrm{~N}-\mathrm{S}\end{array}$ & $\pm 0.0508 / \sqrt{ } 3$ & 0.00012 & 0.00012 \\
\hline Assembly Hole Diameter (cm) & 6.1722 & $\begin{array}{l}+0.01778 / \sqrt{ } 3 \\
-0.00508 / \sqrt{ } 3\end{array}$ & 0.00013 & -- \\
\hline Water Impurities & None & Table 2.30 & 0.00010 & -- \\
\hline Placement of Beam Lines $(\mathrm{cm})$ & 2.032 & $\pm 0.12 / \sqrt{ } 3$ & neg & neg \\
\hline Graphite Element Density $\left(\mathrm{g} / \mathrm{cm}^{3}\right)$ & 1.73 & \pm 0.01 & neg & -- \\
\hline Graphite Element Length $(\mathrm{cm})$ & 55.55234 & $\pm 0.21507 / \sqrt{ } 3$ & neg & neg \\
\hline Graphite Element Diameter $(\mathrm{cm})$ & 3.27914 & $\pm 0.127 / \sqrt{ } 3$ & neg & neg \\
\hline Graphite Element Impurities & Table 2.11 & $\pm 100 \%$ & neg & -- \\
\hline Uncertainty by Type & -- & -- & 0.00114 & 0.00038 \\
\hline Total Experimental Uncertainty & -- & -- & 0.00120 & -- \\
\hline
\end{tabular}


NEA/NSC/DOC(2006)1

Fundamental - FUND

NRAD-FUND-RESR-002

CRIT-REAC-COEF

\subsection{Evaluation of Buckling and Extrapolation Length Data}

Buckling and extrapolation length measurements were not performed.

\subsection{Evaluation of Spectral Characteristics Data}

Spectral characteristics measurements were not performed.

\subsection{Evaluation of Reactivity Effects Data}

Benchmark models provided in Section 3.1, for the 62- and 64-fuel-element core configurations, were utilized with model perturbations simulating control rod movements, as discussed in Section 3.4, to calculate the worths reported in Section 1.4. Calculations were not performed using the detailed models provided in Appendix $\mathrm{C}$ to evaluate simplification biases. As discussed in Section 3.4.1 of NRAD-FUND-RESR-001, the bias simplifications in the benchmark models (Section 3.1.1.1 of NRAD-FUND-RESR-001) had a negligible impact on the calculated worths.

Reactivity effects measurements evaluated include a total of ten measurements (six control rod worths, two shutdown margins, and two core excess reactivities); all are considered to be acceptable benchmark experiments.

Uncertainties in the measured data were not provided and have been evaluated in this section. Worths measured during the start-up measurements were typically reported in absolute values. The convention taken in this report is the use of negative values for reporting measurements that reduce the neutron population via absorption (control rods and shutdown margins) and positive values for effects that increase the population (positive period measurements and excess reactivities).

\subsubsection{Delayed Neutron Fraction, $\beta_{\text {eff }}$}

Reactivity worths for NRAD measurements are typically reported in $\$$ or $\phi$. Staff historically use a $\beta_{\text {eff }}$ value of 0.0071 to convert reactivity measurements to and from $\Delta \mathrm{k}$. General Atomics utilizes a $\beta_{\text {eff }}$ value of 0.0078 in their design analysis of the NRAD reactor. ${ }^{a}$ Reported values for the delayed neutron fraction in TRIGA-type reactors have been known to range between 0.0070 and $0.0080 .^{\text {b,c,de }}$ The delayed neutron fraction is typically insensitive to reflector material. ${ }^{\circ}$

Calculations were performed to assess the variability in $\beta_{\text {eff }}$ for the NRAD reactor (see Appendix I of NRAD-FUND-RESR-001). A median value of $0.0075 \pm 0.000375$ was selected for all reactivity measurements in both core configurations. Because all reported reactivity measurement worths were reported in units of $\$$ using a $\beta_{\text {eff }}$ value of 0.0071 , they will be adjusted for the selected $\beta_{\text {eff }}$ value of 0.0075 for comparison with calculations and for use as benchmark measurements.

a "LEU Upgrade of the NRAD Reactor, Final Report," 911193 rev. 0, GA Project 39296, TRIGA Reactor Division of General Atomics (August 27, 2010). [This reference is not available for public release.]

${ }^{\mathrm{b}}$ A. Trkov, M. Ravnik, H. Boeck, and B. Glumac, "Reactivity Measurements in a Close-to-Critical TRIGA Reactor Using a Digital Reactivity Meter,” Kerntechnik, 57, 296-300 (1992).

${ }^{c}$ M. T. Simnad, F. C. Foushee, and G. B. West, "Fuel Elements for Pulsed TRIGA ${ }^{\circledR}$ Research Reactors," Nucl. Technol., 28, 31-56 (1976).

d L. Snoj, A. Kavčič, G. Žerovnik, and M. Ravnik, "Calculation of Kinetic Parameters for Mixed TRIGA Cores with Monte Carlo," Ann. Nucl. Energy, 37, 223-229 (2010).

e T. Matsumoto, "Benchmark Analysis of Criticality Experiments in the TRIGA Mark II Using a Continuous Energy Monte Carlo Code MCNP,” J. Nucl. Sci. Technol., 35, 662-670 (1998). 
NEA/NSC/DOC(2006)1

Fundamental - FUND

NRAD-FUND-RESR-002

CRIT-REAC-COEF

\subsubsection{Uncertainties in Rod Worth Measurements}

Typically the uncertainty in the measurement method is much greater than any uncertainties obtained via computational analysis of geometry and composition perturbations in the benchmark models, such as the comprehensive evaluation performed in Section 2.1 for the critical configurations.

As evaluated in Section 2.1.1.2, and discussed elsewhere in a separate analysis of a TRIGA reactor, ${ }^{\mathrm{a}}$ the slight vertical movements and changes in position of the control rods is minor for most worth calculations, $<1 \varnothing$. The uncertainty in the control rod positions is assumed to be included within the uncertainty in the method.

Comparison of Tables 1.17 through 1.19 of NRAD-FUND-RESR-001 for three sets of measurements to determine the regulating rod worth (partial rod drop combined with positive period measurements), core excess reactivity, and shutdown margin of the 60 -fuel-element core, demonstrate that the uncertainty in measurement repeatability in the NRAD reactor is also very small, $<1 \phi$.

As evaluated in Section 2.1.1.2 of NRAD-FUND-RESR-001, the uncertainty in the positioning of each control rod is negligible.

To evaluate the uncertainty in the methods utilized to measure reactivity worth, a literature survey was performed regarding other types of research reactors. While the fundamental physics behind each reactor type is different and impacts typical operations and characteristic uncertainties, the uncertainties in the measurement methods, as discussed below, are relatively similar. Therefore, it is judged to be acceptable to utilize method uncertainties for the measurement of reactivity effects from different research reactors to estimate an uncertainty in the methods utilized to measure the control rod worths in the NRAD reactor.

Insufficient reactivity effects measurements were performed to support assignment of a systematic and random component to each measurement. All evaluated uncertainty components contributing to the total uncertainty in the reactivity effects measurements are assumed to be systematic and combined in quadrature to obtain the total estimated uncertainty in each experimental value.

\subsubsection{Rod Drop Method}

The excitation of a multiplying system, such as a critical reactor, by a rapid change of state, such as a rod drop, will generate short-lived flux modes that are not characteristic of the fundamental mode of the system. However, on the time scales of minutes, the typical period over which rod drop measurements are performed and measured, these harmonics are generally negligible. ${ }^{\mathrm{b}}$

The prompt rod drop method is the easiest way to estimate the reactivity change in a reactor core; this method is based on the prompt flux adjustment that occurs directly after a perturbation, and assumes that the delayed neutron source is constant compared to the initial state. This method is sensitive to spatial effects and less accurate than other methods. Typical uncertainties are on the order of $5-6 \%$ for a TRIGA reactor. ${ }^{\mathrm{c}}$

\footnotetext{
${ }^{a}$ I. Mele, M. Ravnik, and A. Trkov, "TRIGA Mark II Benchmark Experiment, Part I: Steady-State Operation," Nucl. Technol., 105, 37-51 (1994).

${ }^{\mathrm{b}}$ T. Williams, M. Rosselet, and W. Scherer (eds.), "Critical Experiments and Reactor Physics Calculations for LowEnriched High Temperature Gas Cooled Reactors," IAEA-TEC-DOC-1249, International Atomic Energy Agency, Vienna, Austria (2001).

${ }^{c}$ C. Jammes, B. Geslot, R. Rosa, G. Imel, and P. Fougeras, "Comparison of Reactivity Estimations Obtained from Rod-Drop and Pulsed Neutron Source Experiments," Ann. Nucl. Energy, 32, 1131-1145 (2005).
} 
NEA/NSC/DOC(2006)1

\section{Fundamental - FUND \\ NRAD-FUND-RESR-002 \\ CRIT-REAC-COEF}

Uncertainties in the rod drop technique on the order of 5-6\% in the MASURCA reactor ${ }^{\mathrm{a}}$ and HTRPROTEUS critical assembly ${ }^{b}$ have also been reported. The dominant systematic uncertainty is in the kinetic constants and flux perturbations with the statistical component of the uncertainty $<1 \%$.

Common uncertainties for the rod insertion method include uncertainties in the delayed neutron data, which is systematic and common to all measuring methods. Another uncertainty source is in the flux redistribution in the subcritical core. As mentioned previously, the changes in flux is dominated by the long-lived delayed neutron precursors, whose distribution closely resembled that of the critical reactor shortly after the perturbation of the core. The most significant uncertainty source is the flux redistribution in the presence of control rods, i.e., rod shadowing effects. The positions of the control rods in the reactor impact the worth of the rod being measured. The uncertainty in this method is reported to be $3-5 \%$ for individual control rod worths, with a statistical error of $<0.2 \%$. However, the impact of the interference due to the presence of other control rods increases the estimated uncertainty to $\sim 10 \%{ }^{\mathrm{c}}$

The rod insertion method is very similar to the rod drop method, except that the control rods are driven into the core instead of dropped. It has been shown that flux perturbation effects due to control rods present in the core (rod shadowing) can impact the measured worth of a control rod by more than $30 \%$. On average; however, the reported values for this analysis of a TRIGA reactor varied $\sim 8 \%$ and the core operated with most of the control rods partially inserted into the core, ${ }^{\mathrm{d}}$ unlike the NRAD reactor. Comparison of the full regulating rod drop worth with the regulating rod worth obtained from the measured partial drop and partial period measurements gives a difference of $\sim 7 \%$.

Analysis of flux depression factors, similar to the analysis performed on the Slovenian TRIGA reactor, ${ }^{\mathrm{d}}$ was performed using the detailed model of the 60-fuel-element core (see Appendix $\mathrm{C}$ of NRAD-FUND-RESR-001). The position of the linear channel was estimated using Figures 1.55 and 1.56. The active region of the detector was modeled $-26.67 \mathrm{~cm}$ along the $\mathrm{x}$-axis, $+90.17 \mathrm{~cm}$ along the $\mathrm{y}-$ axis, and $+5.08 \mathrm{~cm}$ along the $\mathrm{z}$-axis from the center of the NRAD core along the mid-plane. The active height of the cylindrical detector (simulated as void material) was $55.88 \mathrm{~cm}$ with a radius 0 $4.445 \mathrm{~cm}$. An aluminum 6061 shell was modeled on all sides of the detector with a thickness of $0.3175 \mathrm{~cm}$, with an atom density of $5.9939 \times 10^{-2}$ atoms $/ \mathrm{b}-\mathrm{cm}$. Flux tallies in MCNP were performed on the detector to estimate the neutron flux as it changed due to control rod positions in the simulated core. Two critical configurations were evaluated: (1) Case 2 in Section 3.1 of NRAD-FUND-RESR-001, where both shim rods were fully withdrawn and the reg rod partially inserted, and (2) an alternate critical configuration for the 60-fuel-element core where the reg rod was fully withdrawn and the shim rods partially inserted to maintain criticality (see Full Reg Drop measurement in Table 1.17 of NRAD-FUND-RESR-001). Regulating rod movements were simulated and the fluxes calculating for each change to the models. The flux depression factor is then calculated as the ratio of the flux in the detector for the perturbed configuration divided by the flux in the detector for the critical configuration.

\footnotetext{
${ }^{a}$ G. Perret, C. Jammes, G. Imel, C. Destouches, P. Chaussonnet, J. M. Laurens, R. Soule, G. M. Thomas, W. Assal, P. Fougeras, P. Blaise, J-P. Hudelot, H. Philibert, and G. Bignan, "Determination of Reactivity by a Revised RodDrop Technique in the MUSE-4 Programme - Comparison with Dynamic Measurements," $7^{\text {th }}$ Information Exchange Meeting on Actinide and Fission Product Partitioning and Transmutation, Juja, Korea, October 14-16 (2002).

${ }^{\mathrm{b}}$ M. Rosselet and R. Chawla, "Epithermal Inverse Kinetic Measurements and Their Interpretation Using a TwoGroup Point-Kinetic Model,” Nucl. Sci. Eng., 135, 33-47 (2000).

c I. Mele, M. Ravnik, and A. Trkov, “TRIGA Mark II Benchmark Experiment, Part II: Pulse Operation,” Nucl. Technol., 105, 52-58 (1994).

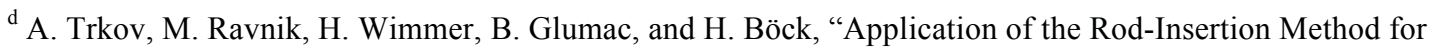
Control Rod Worth Measurements in Research Reactors," Kerntechnik, 60, 255-261 (1995). 
NEA/NSC/DOC(2006)1

\author{
Fundamental - FUND \\ NRAD-FUND-RESR-002 \\ CRIT-REAC-COEF
}

Regulating rod full withdrawal and full insertion from the critical configuration was simulated for configuration (1) and the flux depression factors were calculated for each case. The resultant factors are $0.968 \pm 0.054$ and $1.023 \pm 0.055$, respectively. For configuration (2), only a full insertion of the reg rod was necessary; the computed factor was $0.998 \pm 0.053$. As with other calculations, MCNP5 and ENDF/B-VII.0 nuclear data were used. However, the total number of active particle histories was increased to 650 million in an effort to reduce the uncertainty in the flux tallies. The uncertainty in the neutron flux in the linear channel was $\sim 3.5 \%$, which results in roughly a $5 \%$ uncertainty in the calculated flux depression factors. Unfortunately, this uncertainty is much greater than any observable differences in the flux factor results.

The best approach for further analysis of rod shadowing effects in the NRAD reactor would be to perform additional experiments designed to compare the physical and simulated response of the various core detectors while varying control rod positions within the core. Until further experimentation is possible, an uncertainty of $\sim 8 \%$ due to rod shadowing effects is assumed, based on analyses performed using the Slovenian TRIGA reactor. ${ }^{\mathrm{a}}$

An uncertainty of $10 \%$ is selected to represent the total uncertainty in the rod drop measurement method for this benchmark analysis. This uncertainty includes the uncertainty in the measurement method of $<5 \%$, a statistical uncertainty of $<1 \%$, and the additional uncertainty of $\sim 8 \%$ due to rod shadowing effects.

\title{
2.4.2.2 Positive Period Method
}

The positive period method is also referred to as the rod exchange method, where the rod worth is measured relative to another, calibrated, control rod, or stepwise movements of the rod are measured with a reactivity meter. Calibration curve measurements in a TRIGA reactor have shown that the uncertainty in rod exchange measurements are slightly $<10 \%$. The uncertainty includes uncertainties in control rod positions, interference effects from other control rods during the measurement (rod shadowing), and statistical errors from reactivity calculated by the reactivity meter; the latter of which are negligible. ${ }^{b}$

Due to the severe local flux distribution deformation in rod exchange measurements, simulations need to model the effects correctly for each measurement step. An uncertainty of $10 \%$ is typical for this type of measurement, ${ }^{\mathrm{c}}$ and has become the standard for treating the uncertainty in reactivity measurements in other TRIGA reactors. ${ }^{\mathrm{d}}$

An uncertainty of $10 \%$ is selected to represent the total uncertainty in the positive period measurement method for this benchmark analysis, similar to the uncertainty in the rod drop method as described in the previous subsection.

\subsubsection{Combined Worth Measurements}

The total worth of the regulating control rod is typically obtained by combining the measured worths for a partial rod drop and positive period measurements. Uncertainties in these measured worths were obtained by propagating the uncertainties in the individual measurements used to determine the given

\footnotetext{
${ }^{a}$ A. Trkov, M. Ravnik, H. Wimmer, B. Glumac, and H. Böck, “Application of the Rod-Insertion Method for Control Rod Worth Measurements in Research Reactors," Kerntechnik, 60, 255-261 (1995).

b I. Mele, M. Ravnik, and A. Trkov, "TRIGA Mark II Benchmark Experiment, Part II: Pulse Operation,” Nucl. Technol., 105, 52-58 (1994).

${ }^{\mathrm{c}}$ R. Jeraj, B. Glumac, and M. Maučec, "Monte Carlo Simulation of the TRIGA Mark II Benchmark Experiment," Nucl. Technol., 120, 179-187 (1997).

${ }^{\mathrm{d}}$ T. Matsumoto and N. Hayakawa, "Benchmark Analysis of TRIGA Mark II Reactivity Experiment Using a Continuous Energy Monte Carlo Code MCNP,” J. Nucl. Sci. Technol., 37, 1082-1087 (2000).
} 
NEA/NSC/DOC(2006)1

Fundamental - FUND

NRAD-FUND-RESR-002

CRIT-REAC-COEF

worths. As discussed elsewhere, the exact core configuration, including control rod positions, typically needs to be modeled to reproduce the fission source distribution in the experiment in order to perform calculations that more precisely simulate the measured conditions. ${ }^{c}$ This effectively reduces biases and uncertainties introduced by incorrectly evaluating the measured experimental data.

For reactivity measurements in the NRAD reactor, control rod worths are measured and the excess reactivities and shutdown margins are derived from the measured control rod worths.

\subsubsection{Control Rod Worths}

Control rod withdrawn positions reported in Table 1.15 for the 62 -fuel-element core and Table 1.17 for the 64-fuel-element core are converted from their reported location in units into centimeters, where one "unit" represents $0.0381 \mathrm{~cm}$ (0.015 in.) of rod travel. Rods reported to have been withdrawn 999 or 1000 units are considered fully withdrawn at a position of $38.1 \mathrm{~cm}$. Reported worth values are multiplied by $10 \%$ to obtain their measurement uncertainty, as discussed in Section 2.4.2. As stated in Section 2.4.1, all reported worths are converted from worths obtained with a $\beta_{\text {eff }}$ value of 0.0071 to worths obtained with a value of $0.00750 \pm 0.000375(5 \%, 1 \sigma)$ by multiplying the given values by the ratio $0.0071 / 0.0075$. The uncertainties in the measured worths and $\beta_{\text {eff }}$ are combined (via root-mean square) to obtain the total uncertainty in the adjusted experimental worth data. The adjusted values are provided in the following subsections.

Control rod measurements reported in Table 1.16 were not evaluated as they were repeated in Table 1.17 after the nuclear instrumentation was recalibrated. Any additional uncertainty in the rod worth measurements due to instrumentation calibration uncertainty is assumed to be included in the $10 \%$ measurement uncertainty applied to all worth measurements.

\subsubsection{Rod Drop Measurements}

Partial and full rod worth measurements were performed for the 62-fuel-element core (Table 1.15) and 64-fuel-element core (Table 1.17). The adjusted control rod worths, their positions, and their $1 \sigma$ uncertainties are shown in Table 2.39. The uncertainty in the rod drop measurements includes the standard deviation of the three measured values reported for each rod drop measurements, a $10 \%$ measurement uncertainty, and the $5 \%$ uncertainty in $\beta_{\text {eff. }}$ The uncertainties are propagated and applied to the reported adjusted worth value below.

Table 2.39. Adjusted Control Rod Worths Obtained via Rod Drop Measurements.

\begin{tabular}{|c|c|c|c|c|c|c|c|c|}
\hline \multirow[b]{2}{*}{ Core Description } & \multirow{2}{*}{$\begin{array}{c}\text { Shim 1 } \\
\text { Position } \\
\text { (cm) } \\
\end{array}$} & \multirow{2}{*}{$\begin{array}{c}\text { Shim } 2 \\
\text { Position } \\
(\mathrm{cm}) \\
\end{array}$} & \multirow{2}{*}{$\begin{array}{c}\text { Reg Start } \\
\text { Position } \\
(\mathrm{cm})\end{array}$} & \multirow{2}{*}{$\begin{array}{c}\text { Reg End } \\
\text { Position } \\
\text { (cm) }\end{array}$} & \multirow{2}{*}{$\begin{array}{c}\text { Measurement } \\
\text { Type }\end{array}$} & \multicolumn{3}{|c|}{ Adjusted Worth } \\
\hline & & & & & & $\rho \$$ & \pm & $1 \sigma$ \\
\hline \multirow{3}{*}{62 Fuel Elements } & \multirow{3}{*}{38.1} & \multirow{3}{*}{38.1} & \multirow{3}{*}{16.8402} & -- & Shim 1 Drop & -2.66 & \pm & 0.30 \\
\hline & & & & -- & Shim 2 Drop & -2.66 & \pm & 0.30 \\
\hline & & & & 0.0 & Partial Reg Drop & -0.93 & \pm & 0.11 \\
\hline \multirow{3}{*}{64 Fuel Elements } & \multirow{3}{*}{38.1} & \multirow{3}{*}{38.1} & \multirow{3}{*}{7.8105} & -- & Shim 1 Drop & -2.92 & \pm & 0.33 \\
\hline & & & & -- & Shim 2 Drop & -2.94 & \pm & 0.33 \\
\hline & & & & 0.0 & Partial Reg Drop & -0.21 & \pm & 0.02 \\
\hline
\end{tabular}


NEA/NSC/DOC(2006)1

Fundamental - FUND

NRAD-FUND-RESR-002

CRIT-REAC-COEF

\subsubsection{Positive Period Measurements}

Positive period measurements were performed for the 62-fuel-element core (Table 1.15) and 64-fuelelement core (Table 1.17). Positive period measurements are performed in a series of steps to obtain the total core excess reactivity. Individual steps are reported in Tables 1.15 and 1.17 for the $62-$ and 64 -fuelelement cores, respectively. The sum of the positive period measurements is evaluated as an excess reactivity measurement in Section 2.4.5. The adjusted positive period measurements, their positions, and their $1 \sigma$ uncertainties are shown in Table 2.66. The uncertainty in the positive period measurements includes a $10 \%$ measurement uncertainty and the $5 \%$ uncertainty in $\beta_{\text {eff. }}$. The uncertainties are propagated and applied to the reported adjusted worth value below.

Table 2.66. Adjusted Positive Period Measurements.

\begin{tabular}{|c|c|c|c|c|c|c|c|c|}
\hline \multirow[b]{2}{*}{ Core Description } & \multirow{2}{*}{$\begin{array}{c}\text { Shim 1 } \\
\text { Position } \\
(\mathrm{cm}) \\
\end{array}$} & \multirow{2}{*}{$\begin{array}{c}\text { Shim } 2 \\
\text { Position } \\
(\mathrm{cm}) \\
\end{array}$} & \multirow{2}{*}{$\begin{array}{c}\text { Reg Start } \\
\text { Position } \\
\text { (cm) } \\
\end{array}$} & \multirow{2}{*}{$\begin{array}{c}\text { Reg End } \\
\text { Position } \\
(\mathrm{cm}) \\
\end{array}$} & \multirow{2}{*}{$\begin{array}{c}\text { Measurement } \\
\text { Type }\end{array}$} & \multicolumn{3}{|c|}{ "Adjusted Worth } \\
\hline & & & & & & $\rho \$$ & \pm & $1 \sigma$ \\
\hline \multirow{9}{*}{62 Fuel Elements } & 38.1 & 38.1 & 16.764 & 17.8689 & \multirow{9}{*}{ Positive Period } & 0.11 & \pm & 0.01 \\
\hline & 36.0045 & 36.0045 & 17.8689 & 19.6215 & & 0.18 & \pm & 0.02 \\
\hline & 33.5661 & 33.5661 & 19.6215 & 21.2598 & & 0.17 & \pm & 0.02 \\
\hline & 31.8516 & 31.8516 & 21.2598 & 23.1648 & & 0.20 & \pm & 0.02 \\
\hline & 30.0609 & 30.0609 & 23.1648 & 25.4508 & & 0.21 & \pm & 0.02 \\
\hline & 28.3845 & 28.3845 & 25.4508 & 27.813 & & 0.20 & \pm & 0.02 \\
\hline & 26.9748 & 26.9748 & 27.813 & 30.2133 & & 0.17 & \pm & 0.02 \\
\hline & 25.8699 & 25.8699 & 30.2133 & 33.8709 & & 0.20 & \pm & 0.02 \\
\hline & 24.6126 & 24.6126 & 33.8709 & 38.1 & & 0.13 & \pm & 0.01 \\
\hline \multirow{10}{*}{64 Fuel Elements } & 38.1 & 38.1 & 7.7343 & 11.0871 & \multirow{10}{*}{ Positive Period } & 0.21 & \pm & 0.02 \\
\hline & 34.8615 & 34.8615 & 11.0871 & 14.0589 & & 0.23 & \pm & 0.03 \\
\hline & 32.4231 & 32.4231 & 14.0589 & 16.1925 & & 0.20 & \pm & 0.02 \\
\hline & 30.7467 & 30.7467 & 16.1925 & 18.669 & & 0.25 & \pm & 0.03 \\
\hline & 28.9179 & 28.9179 & 18.669 & 20.9931 & & 0.24 & \pm & 0.03 \\
\hline & 27.3558 & 27.3558 & 20.9931 & 23.3553 & & 0.24 & \pm & 0.03 \\
\hline & 25.8699 & 25.8699 & 23.3553 & 26.0985 & & 0.24 & \pm & 0.03 \\
\hline & 24.4983 & 24.4983 & 26.0985 & 29.0703 & & 0.23 & \pm & 0.03 \\
\hline & 23.241 & 23.241 & 29.0703 & 33.2232 & & 0.24 & \pm & 0.03 \\
\hline & 21.9456 & 21.9456 & 33.2232 & 38.1 & & 0.16 & \pm & 0.02 \\
\hline
\end{tabular}


NEA/NSC/DOC(2006)1

Fundamental - FUND

NRAD-FUND-RESR-002

CRIT-REAC-COEF

\subsubsection{Combined Worth Measurements}

The partial rod drop measurements for the regulating rod are combined with the sum of the positive period measurements (evaluated in the previous two subsections) to obtain the total worth of the regulating control rod. The adjusted regulating rod worths and their $1 \sigma$ uncertainties are shown in Table 2.67. The uncertainty in the total positive period is obtained by taking the square root of the sum of the squares of the individual positive period measurements. The uncertainties from the rod drop and positive period worths are then propagated and applied to the reported adjusted worth value below.

Table 2.67. Adjusted Regulating Rod Combined Worth Measurements.

\begin{tabular}{|c|c|c|c|c|c|c|c|c|c|}
\hline \multirow[t]{2}{*}{ Core Description } & \multicolumn{3}{|c|}{$\begin{array}{l}\text { Partial Rod } \\
\text { Drop Worth }\end{array}$} & \multicolumn{3}{|c|}{$\begin{array}{l}\text { Total Positive } \\
\text { Period Worth }\end{array}$} & \multicolumn{3}{|c|}{ Adjusted Worth } \\
\hline & $\rho \$$ & & & & \pm & $1 \sigma$ & & & \\
\hline & -0.93 & & 0.11 & -1.56 & \pm & 0.06 & -2.49 & \pm & 0.12 \\
\hline 64 Fuel Elen & -0.21 & 工 & 0.02 & -2.24 & \pm & 0.08 & -2.45 & \pm & 0.08 \\
\hline
\end{tabular}

\subsubsection{Shutdown Margin}

The shutdown margin (SDM) is defined as the negative reactivity of the core present when all control elements have been fully inserted to achieve minimum core multiplication. ${ }^{\text {a }}$ It can be simply calculated as the worth of the control rods withdrawn from the core or the total worth of all control rods minus the remaining core excess reactivity. The adjusted shutdown margins and their $1 \sigma$ uncertainties are shown in Table 2.68. The shutdown margin is obtained by summing the worth of the two fully dropped shim rods and the partial worth of the partially drop regulating rod; the worth of each rod was measured separately. The uncertainties from the three adjusted rod drop worths are propagated and applied to the reported SDM value below.

Table 2.68. Adjusted Shutdown Margins $(\rho \$ \pm 1 \sigma)$.

\begin{tabular}{||c|c|ccc|c|ccc||}
\hline Core Description & \multicolumn{3}{|c|}{ 62 Fuel Elements } & \multicolumn{3}{c||}{ 64 Fuel Elements } \\
\hline \multirow{4}{*}{ Method 1 } & Shim 1 & -2.66 & \pm & 0.30 & Shim 1 & -2.92 & \pm & 0.33 \\
\cline { 2 - 8 } & Shim 2 & -2.66 & \pm & 0.30 & Shim 2 & -2.94 & \pm & 0.33 \\
\cline { 2 - 8 } & Partial Reg & -0.93 & \pm & 0.11 & Partial Reg & -0.21 & \pm & 0.02 \\
\cline { 2 - 8 } & SDM & -6.24 & \pm & 0.43 & SDM & -6.06 & \pm & 0.47 \\
\hline
\end{tabular}

a J. J. Duderstadt and L. J. Hamilton, Nuclear Reactor Analysis, John Wiley \& Sons, Ann Arbor, Michigan (1976). 
NEA/NSC/DOC(2006)1

Fundamental - FUND

NRAD-FUND-RESR-002

CRIT-REAC-COEF

\subsubsection{Excess Reactivity}

Excess reactivity (ER) is defined as the core reactivity present with all control elements withdrawn from the core. ${ }^{\text {a }}$ It can be simply calculated as the worth of the control rods remaining in the core when the core is in a critical state or the total worth of all control rods minus the core shutdown margin. Core excess reactivity is obtained by summing the positive period measurements (Section 2.4.3.2); the adjusted excess reactivity values and their $1 \sigma$ uncertainties are shown in Table 2.69. The total uncertainty is obtained by propagating the uncertainties from the individual positive period measurements and not by taking a $10 \%$ uncertainty in the total measured excess reactivity worth, which would overestimate the total uncertainty; the uncertainty in the total positive period is obtained by taking the square root of the sum of the squares of the individual positive period measurements.

Table 2.69. Adjusted Excess Reactivities.

\begin{tabular}{|l|ccc||}
\hline \multirow{2}{*}{ Core Description } & \multicolumn{3}{|c|}{ Excess Reactivity } \\
& $\boldsymbol{\rho} \$$ & \pm & $\mathbf{1 \sigma}$ \\
\hline \hline 62 Fuel Elements & 1.56 & \pm & 0.06 \\
\hline 64 Fuel Elements & 2.24 & \pm & 0.08 \\
\hline
\end{tabular}

\subsubsection{Summary of Reactivity Effects Measurements}

As seen in Sections 1.4 and 2.4, numerous measurements were performed to experimentally determine the worth of various core components in both the 62- and 64-fuel-element cores. Whereas the purpose of the measurements was to obtain specific core parameters, only the desired parameters were evaluated as benchmark experiment measurements. The evaluated worths to be utilized as benchmark measurements include six control rod worths, two shutdown margins and two core excess reactivities; these reactivity effects are summarized in Table 2.70. Case numbers are assigned as follows, X.Y-Z, where X represents the critical core case number, $Y$ indicates the measurement type (in this case 4 for reactivity effect measurement), and $\mathrm{Z}$ represents the ordering of individual measurements for the main core configuration, $\mathrm{X}$.

Table 2.70. Select Reactivity Effects Measurements.

\begin{tabular}{||c|c|c|ccc||}
\hline \multirow{2}{*}{ Case \# } & \multirow{2}{*}{ Core Description } & \multirow{2}{*}{ Measurement } & \multicolumn{3}{|c|}{ Worth } \\
& & $\boldsymbol{\rho} \mathbf{1 0}$ & $\mathbf{1 \sigma}$ \\
\hline \hline $1.4-1$ & 62 Fuel Elements & Shim 1 Worth & -2.66 & \pm & 0.30 \\
\hline $1.4-2$ & 62 Fuel Elements & Shim 2 Worth & -2.66 & \pm & 0.30 \\
\hline $1.4-3$ & 62 Fuel Elements & Reg Worth & -2.49 & \pm & 0.12 \\
\hline $2.4-1$ & 64 Fuel Elements & Shim 1 Worth & -2.92 & \pm & 0.33 \\
\hline $2.4-2$ & 64 Fuel Elements & Shim 2 Worth & -2.94 & \pm & 0.33 \\
\hline $2.4-3$ & 64 Fuel Elements & Reg Worth & -2.45 & \pm & 0.08 \\
\hline $1.4-4$ & 62 Fuel Elements & Shutdown Margin & -6.24 & \pm & 0.43 \\
\hline $2.4-4$ & 64 Fuel Elements & Shutdown Margin & -6.06 & \pm & 0.47 \\
\hline $1.4-5$ & 62 Fuel Elements & Excess Reactivity & 1.56 & \pm & 0.06 \\
\hline $2.4-5$ & 64 Fuel Elements & Excess Reactivity & 2.24 & \pm & 0.08 \\
\hline
\end{tabular}

a J. J. Duderstadt and L. J. Hamilton, Nuclear Reactor Analysis, John Wiley \& Sons, Ann Arbor, Michigan (1976). 


\subsection{Evaluation of Reactivity Coefficient Data}

Reactivity coefficient measurements have not been evaluated. There is insufficient data regarding the fuel temperature distribution within the core to facilitate a neutronics analysis without further evaluation of the thermal balances within the NRAD reactor core and tank. Then evaluation of the excess reactivity could be performed via the evaluation of flux form factors to account for flux redistribution and changes in control rod worth with increased reactor power. ${ }^{\mathrm{a}, \mathrm{b}}$ No benchmark specifications have been developed.

\subsection{Evaluation of Kinetics Measurements Data}

Kinetics measurements were not performed.

\subsection{Evaluation of Reaction-Rate Distributions}

Reaction-rate distribution measurements were not performed.

\subsection{Evaluation of Power Distribution Data}

Power distribution measurements were not performed.

\subsection{Evaluation of Isotopic Measurements}

Isotopic measurements were not performed.

\subsection{Evaluation of Other Miscellaneous Types of Measurements}

Other miscellaneous types of measurements were not performed.

\footnotetext{
${ }^{a}$ A. Trkov, M. Ravnik, H. Wimmer, B. Glumac, and H. Böck, “Application of the Rod-Insertion Method for Control Rod Worth Measurements in Research Reactors," Kerntechnik, 60, 255-261 (1995).

${ }^{\mathrm{b}}$ M. Pdvratnik, L. Snoj, A. Trkov, G. Žerovnik, "Calculations to Support Absolute Thermal Power Calibration of the Slovenian TRIGA Mark II Reactor,” 20 Int. Conf. Nuclear Energy for New Europe 2011, Bovec, Slovenia, September 12-15, 2011.
} 
NEA/NSC/DOC(2006)1

Fundamental - FUND

NRAD-FUND-RESR-002

CRIT-REAC-COEF

\subsection{BENCHMARK SPECIFICATIONS}

\subsection{Benchmark-Model Specifications for Critical and / or Subcritical Measurements}

Both the 62- and 64-fuel-element core configurations of the NRAD reactor have been evaluated as benchmark experiments; they will be noted as Cases 1 and 2, respectively.

\subsubsection{Description of the Benchmark Model Simplifications}

Detailed models (see Appendix C) of the NRAD reactor core configurations were prepared to evaluate biases in the benchmark models. Because the effects of many of the model simplifications produced small or otherwise negligible biases in the benchmark models, a description of detailed benchmark models was unnecessary. Many of the detailed model components, such as assembly fittings, grid plate, and support structures, were homogenized in the detailed model to facilitate computational analyses. Removal of these homogenized components from the model produced negligible bias effects; detailed analysis regarding homogenization effects, biases, and their associated uncertainties was judged to be unnecessary.

\subsubsection{Evaluation of Benchmark Model Biases}

A comprehensive bias analysis was performed using the 60-fuel-element core configuration of NRAD (NRAD-FUND-RESR-001). Only a total simplification bias was computed for the core configurations evaluated herein as the individual biases are expected to be similar to those evaluated previously. A summary of evaluated biases is listed below.

Some possible benchmark biases were evaluated as uncertainties due to a lack of information. They include the following: impurities in the tank water (2.1.9) and impurities in the boron carbide absorber (Section 2.1.4.1).

The AmBe source remains in the reactor core during operations. It emits neutrons at the rate of $\sim 1 \times 10^{7}$ neutrons/sec. The fission rate in the core at $50 \mathrm{~W}$ is $\sim 1 \times 10^{12}$ neutrons $/ \mathrm{sec}$. Because there are five orders of magnitude difference between the total fission rate and the AmBe source strength, the contribution of the AmBe source neutrons to the total neutron population is judged to be negligible and no additional bias or uncertainty was evaluated.

Detailed discussion of the evaluated biases are as follows:

- Full Model

1. All locations in the core (fuel elements and beam lines) containing air were replaced with void.

2. All locations in the core (control rods, assembly attachments, core structure, beam lines, etc.) containing aluminum $(1100,2011$, or 6061$)$ had all non-aluminum elements replaced with void.

- Fuel and Graphite Assemblies

3. All lower fuel assembly adapters were replaced with water.

4. All upper fuel assembly adapters were replaced with water.

5. All bottom fuel end fittings protruding from the fuel clad were replaced with water.

6. All top fuel end fittings protruding from the fuel clad were replaced with water.

7. The impurities in all stainless steel fuel clad and end fittings were replaced with void.

8. Individual fuel compositions were replaced with an average fuel composition for the core.

9. The impurities in all axial graphite reflectors and graphite element reflectors were replaced with void.

10. The impurities in all molybdenum poison discs were replaced with void.

11. The impurities in all zirconium rods were replaced with void. 
NEA/NSC/DOC(2006)1

\author{
Fundamental - FUND \\ NRAD-FUND-RESR-002 \\ CRIT-REAC-COEF
}

- Control Rods

12. All control rod extension rods and associated attachments were replaced with water.

13. All control rod guide tubes, and the guide tube in the empty irradiation position, were replaced with water.

14. All internal aluminum parts in the control rods were replaced with void.

- Graphite Reflector Block Assemblies

15. All lower graphite assembly adapters were replaced with water.

16. All upper graphite assembly adapters were replaced with water.

17. Tie rods, dowels, and screws (Al-2011 parts) in the graphite reflector blocks

A. All Al-2011 parts external to the graphite blocks were replaced with water.

B. All Al-2011 parts internal to the graphite blocks, and their affiliated orifices, were replaced with graphite block material.

18. AmBe source, source tube, and source tube cap

A. The AmBe source and its affiliated hardware external to the graphite block are replaced with water.

B. The AmBe source and its affiliated hardware internal to the graphite block, and the affiliated orifice, were replaced with graphite block material.

19. All impurities in the graphite block reflectors were replaced with void.

- Core/Tank Structure

20. The core grid plate was replaced with water.

21. The core grid support structure was replaced with water.

22. The mounting pad was replaced with water.

23. The reactor tank was replaced with water.

- Neutron Beam Lines

24. All helium in the beam lines was replaced with void.

25. All boron nitride apertures were replaced with void.

26. All beam line supports in the core were replaced with water.

27. Beam line aluminum structure was replaced with void.

- Comprehensive Benchmark Simplification

28. The effective tank water boundary was also reduced radially and axially. The diameter of the tank water in the benchmark model is $90 \mathrm{~cm}$ and the effective water height above and below the axial graphite reflectors in the fuel elements is $25 \mathrm{~cm}$.

A. The effective bias for incorporating all of these simplifications into the benchmark model for Case 1 was calculated to be $0.00105 \pm 0.00010$.

B. The effective bias for incorporating all of these simplifications into the benchmark model for Case 2 was calculated to be $0.00120 \pm 0.00010$.

Individual biases may be positive or negative and many are comparable to the statistical uncertainties. Correlating effects in bias analysis simplifications may also contribute to the difference between the summation of the individual biases and the bias calculated for the benchmark model when all simplifications are performed simultaneously. This difference, however, is within the estimated $1 \sigma$ bias uncertainty. The bias computed with all simplifications included together is the best representative of the true bias. The uncertainty in that bias is obtained from the individual analysis of each simplification. 
NRAD-FUND-RESR-002

CRIT-REAC-COEF

Table 3.1. Evaluated Benchmark Model Simplification Biases. ${ }^{(a)}$

\begin{tabular}{|c|c|c|c|c|c|c|}
\hline \multirow{2}{*}{ Case (Number of Fuel Elements) } & \multicolumn{3}{|c|}{ Calculated Bias } & \multicolumn{3}{|c|}{ Benchmark Bias } \\
\hline & $\Delta \mathbf{k}_{\text {eff }}$ & \pm & $1 \sigma$ & $\Delta \mathbf{k}_{\text {eff }}$ & \pm & $1 \sigma^{(a)}$ \\
\hline $1(62)$ & 0.00105 & \pm & 0.00010 & 0.00105 & \pm & 0.00090 \\
\hline 2 (64) & 0.00120 & \pm & 0.00010 & 0.00120 & \pm & 0.00090 \\
\hline
\end{tabular}

(a) Individual bias simplifications were only evaluated for Case 2 of NRAD-FUND-RESR-001; the evaluated bias uncertainty in that analysis was also applied as the bias uncertainty for the two configurations evaluated herein. The reason that the uncertainty is larger is due to the evaluation of the uncertainties associated with the individually evaluated biases as outlined in the text above.

\subsubsection{Dimensions}

The NRAD reactor is a square-pitched TRIGA conversion reactor with various assemblies. The primary assemblies are four-fuel-element clusters and graphite reflector blocks. A three-fuel-element cluster assembly replaces the empty fuel position with either a control rod or water. Two two-fuel-element cluster assemblies were located on the West and South sides of the core. Empty core positions contain water and two void regions extend from the core on the East and North ends, representative of beam lines used in neutron radiography experiments. 


\section{NEA/NSC/DOC(2006)1}

Fundamental - FUND

\section{NRAD-FUND-RESR-002}

CRIT-REAC-COEF

\subsubsection{Graphite Reflector Block}

The graphite reflector block assembly consists of high purity graphite with overall block dimensions shown in Figure 3.1.
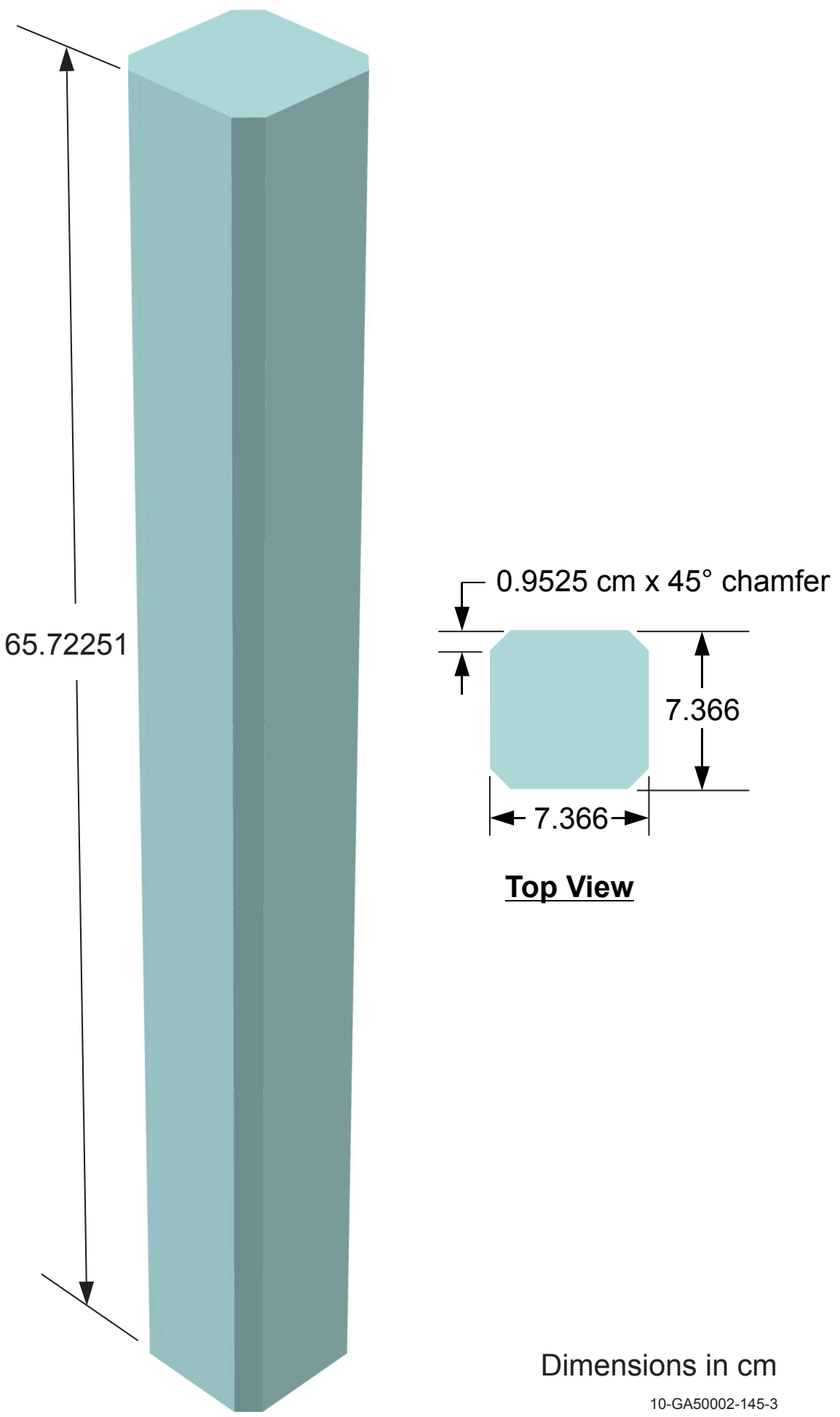

$\underline{\text { Top View }}$

\section{Dimensions in $\mathrm{cm}$}

10-GA50002-145-3

Figure 3.1. Graphite Reflector Block. 


\subsubsection{Fuel Element}

The TRIGA fuel element (Figure 3.2) consists of uranium-erbium-zirconium-hydride fuel with axial high-purity graphite reflectors above and below the fuel. A thin molybdenum poison disc is located between the fuel and the bottom axial reflector. A zirconium rod is located coaxially within the fuel meat. The components are contained within stainless steel cladding with end fixtures. The regions surrounding the fuel element components and within the steel cladding is void.

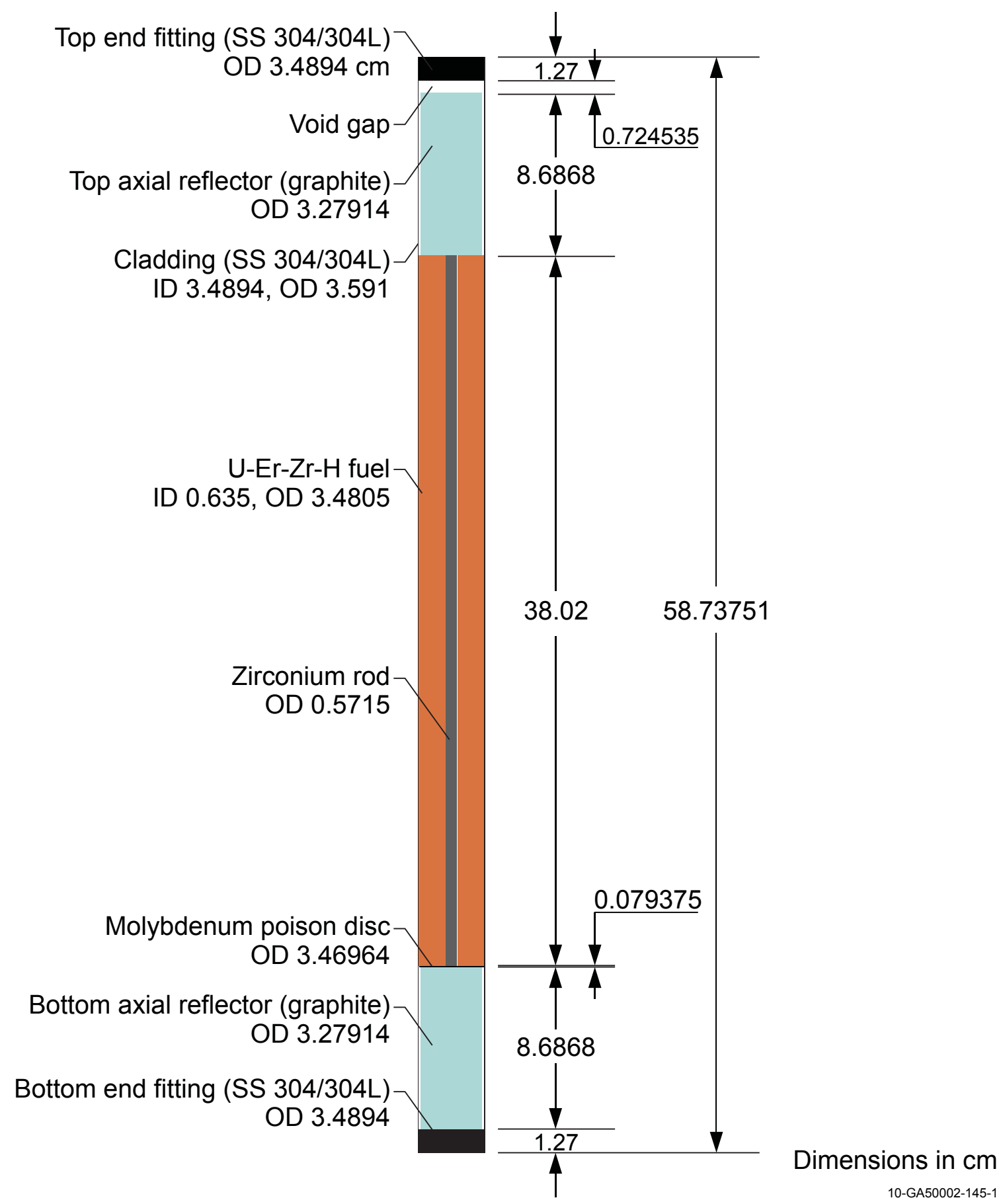

Figure 3.2. TRIGA Fuel Element. 


\subsubsection{Control Rod}

The TRIGA control rod (Figure 3.3) consists of a boron carbide, $\mathrm{B}_{4} \mathrm{C}$, absorber rod contained within aluminum cladding with end fixtures. The region surrounding the absorber rod and within the aluminum cladding is void.

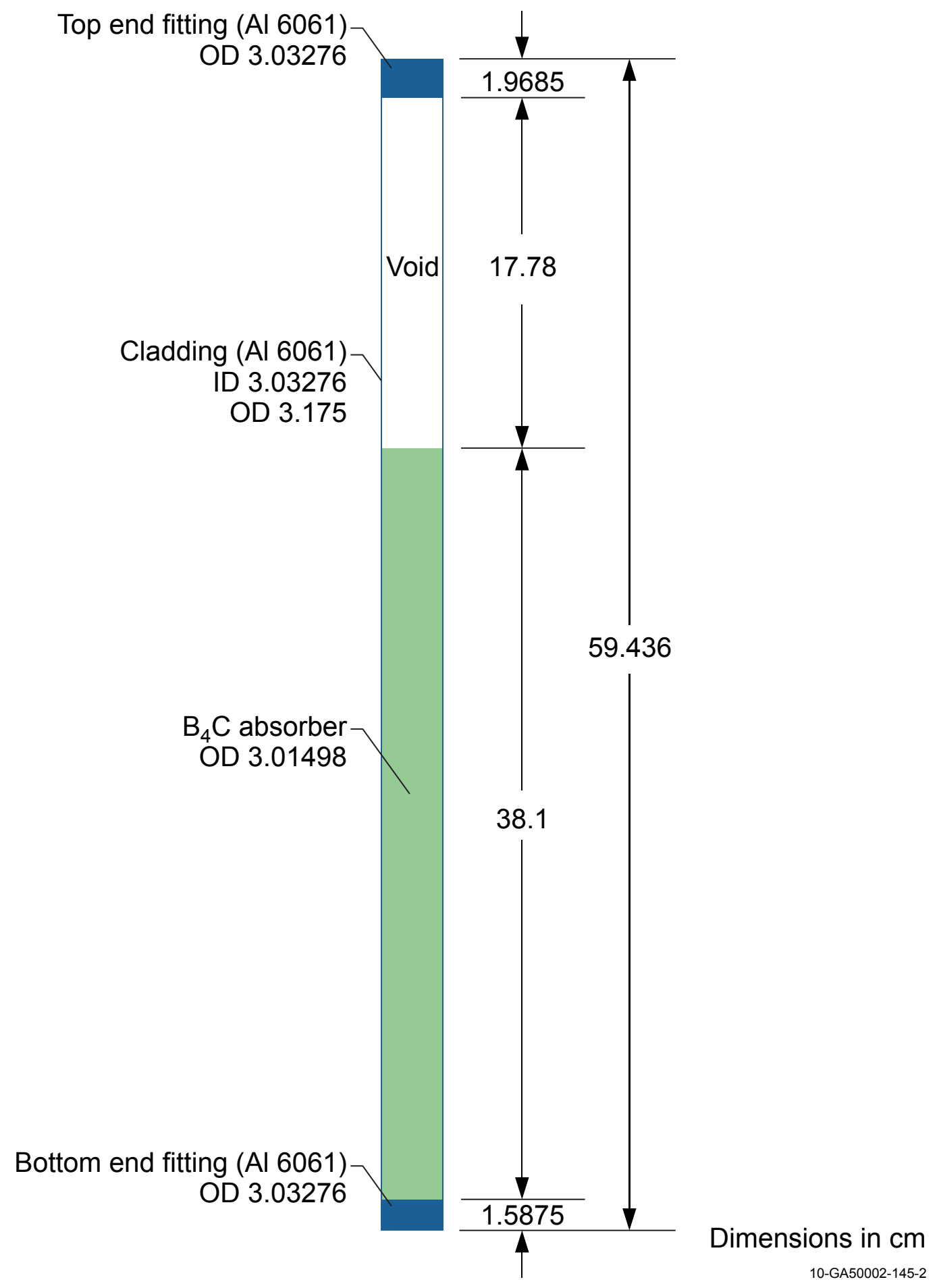

Figure 3.3. TRIGA Control Rod. 


\subsubsection{Graphite Element}

The graphite element (Figure 3.4) consists of a high-purity graphite rod contained within stainless steel cladding with end fixtures. The regions surrounding the graphite element and within the steel cladding is void.

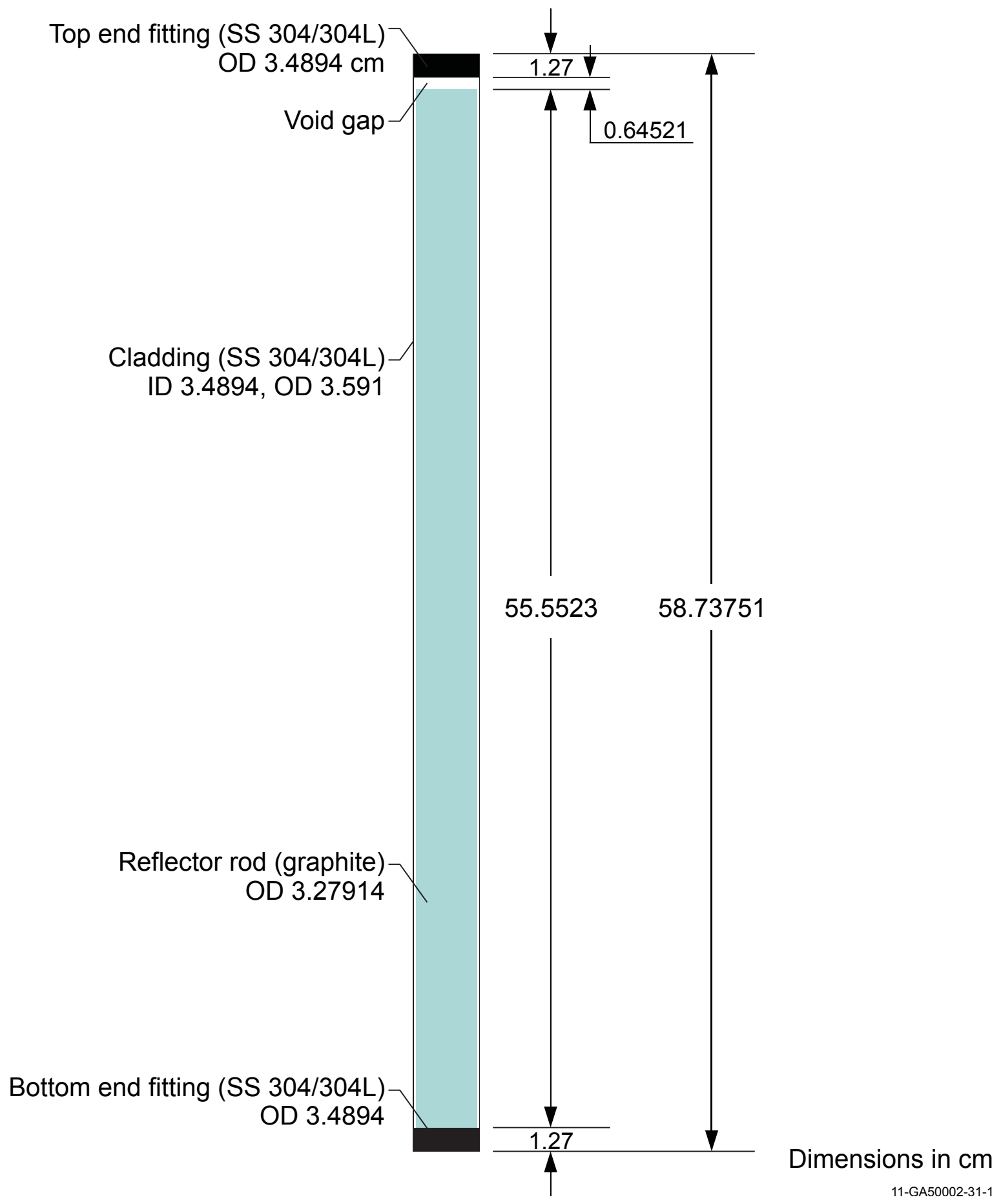

Figure 3.4. Graphite Element. 


\subsubsection{Four-Element Fuel Cluster}

A four-element fuel cluster assembly consists of four fuel elements, as described in Section 3.1.2.2, placed in the configuration shown in Figure 3.5.

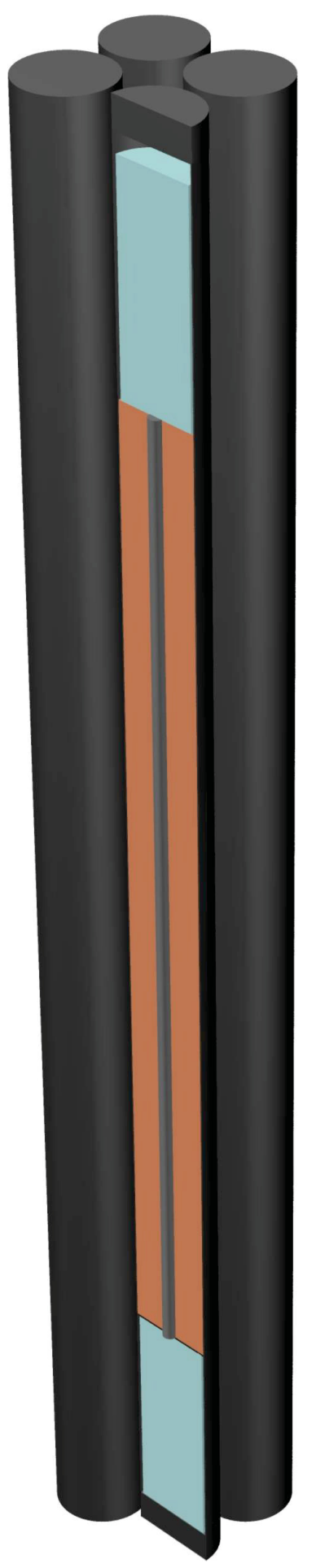

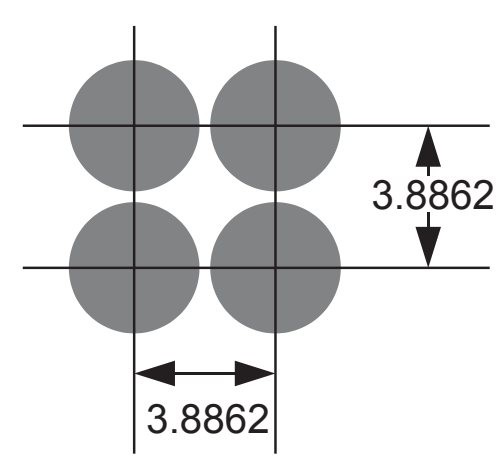

Top View

\section{Dimensions in $\mathrm{cm}$}

10-GA50002-145-4

Figure 3.5. Four-Element Fuel Cluster. 


\subsubsection{Three-Element Fuel Cluster}

A three-element fuel cluster is identical in configuration to the four-element fuel cluster described in Section 3.1.2.5. However, one of the fuel elements is removed and replaced by either a control rod or water (experiment irradiation position). For the locations of three-element fuel clusters in the NRAD reactor core, see Figure 3.7.

\subsubsection{Two-Element Fuel Cluster}

A two-element fuel cluster is identical in configuration to the four-element fuel cluster described in Section 3.1.2.5. However, two of the fuel elements are removed and replaced by two graphite elements. For the locations of two-element fuel clusters in the NRAD reactor core, see Figure 3.7.

\subsubsection{Assembly Pitch}

The pitch between assemblies, whether graphite reflector blocks, four-element fuel clusters, or threeelement fuel clusters, is shown in Figure 3.6. The pitch is shorter in the North-South direction than in the East-West direction.

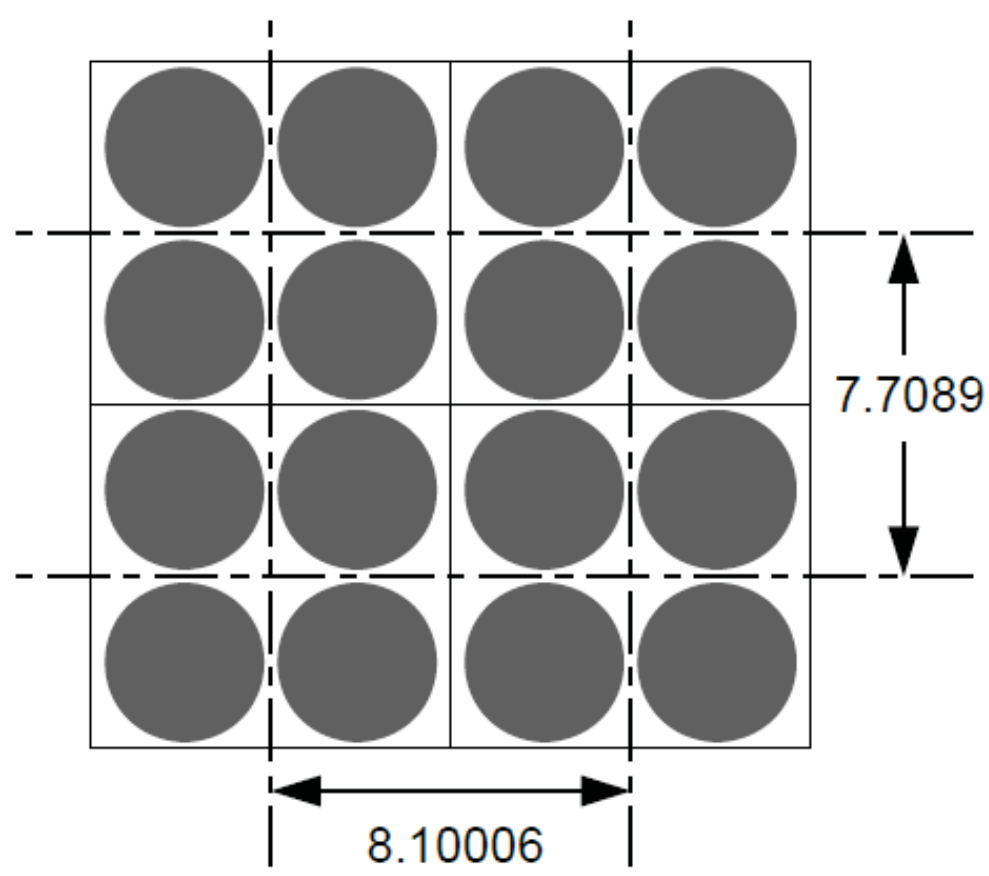

\section{Dimensions in $\mathrm{cm}$}

10-GA50002-145-5

Figure 3.6. NRAD Core Assembly Pitch.

\subsubsection{Core Configuration}

The NRAD reactor core configurations are shown in Figures 3.7 and 3.8. The cores contain three control rods (two shims and a regulating rod), 12 graphite reflector blocks, one empty fuel position, and four empty assembly positions. Cases 1 and 2 have 62 and 64 fuel elements, respectively (see Figures 3.7a 


\section{Fundamental - FUND \\ NRAD-FUND-RESR-002 \\ CRIT-REAC-COEF}

and 3.7b, respectively. Beam lines extend from the East and North faces of the core (Figure 3.9) and are centered along the core fuel midplane. The beams are represented as voids in the benchmark model and extend to the model radial boundary. All model locations not containing fuel elements, control rods, graphite, or void, as previously described in this section, contain water. A comparison of the vertical placement of different reactor components is shown in Figure 3.10.

The shim 1, shim 2, and regulating control rods are withdrawn 38.1,38.1, and $16.8402 \mathrm{~cm}$, respectively (use Figure 3.8 for placement in the core and Figure 3.10 for reference vertical placement), for Case 1.

The shim 1, shim 2, and regulating control rods are withdrawn $38.1,38.1$, and $7.8105 \mathrm{~cm}$, respectively (use Figure 3.8 for placement in the core and Figure 3.10 for reference vertical placement), for Case 2.

The measurement of $2.032 \mathrm{~cm}$ in Figures 3.8 and 3.9 represents the distance between the outer cladding surface of the fuel elements closest to the beam filter tube and the face of the beam filter tube adjacent to the core.

The measurement of $0.123825 \mathrm{~cm}$ in Figure 3.10 represents the difference between the bottom of the fuel meat (top of the molybdenum poison disc) in the fuel elements and the bottom of the control rod absorber material when the control rod is fully inserted into the core. The bottom of the fully-inserted control rod absorber material is positioned slightly above the bottom of the fuel meat. 
Fundamental - FUND

NRAD-FUND-RESR-002

CRIT-REAC-COEF

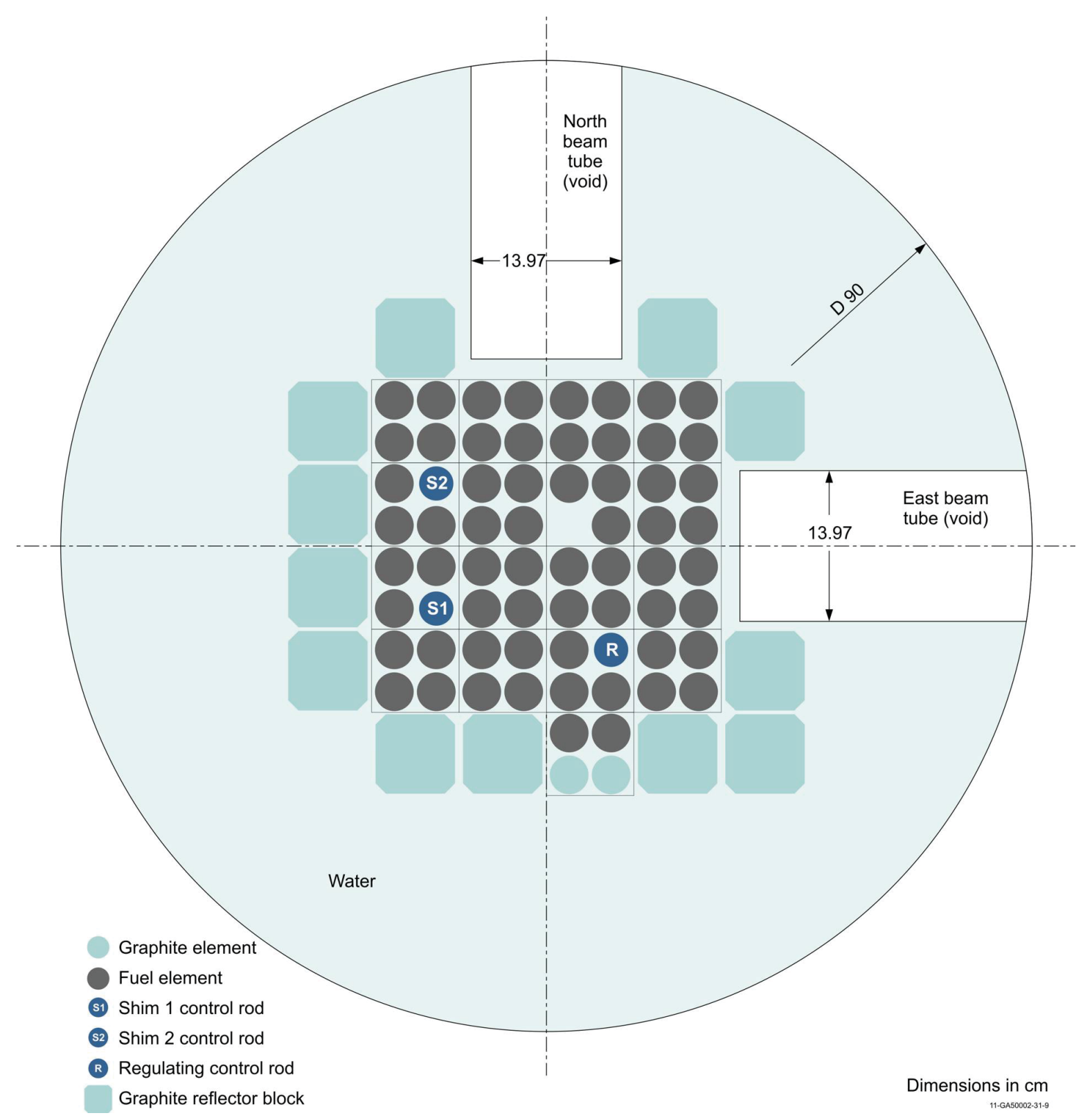

Figure 3.7a. Midplane Cross Section View of NRAD Reactor Core (Case 1). 
Fundamental - FUND

NRAD-FUND-RESR-002

CRIT-REAC-COEF

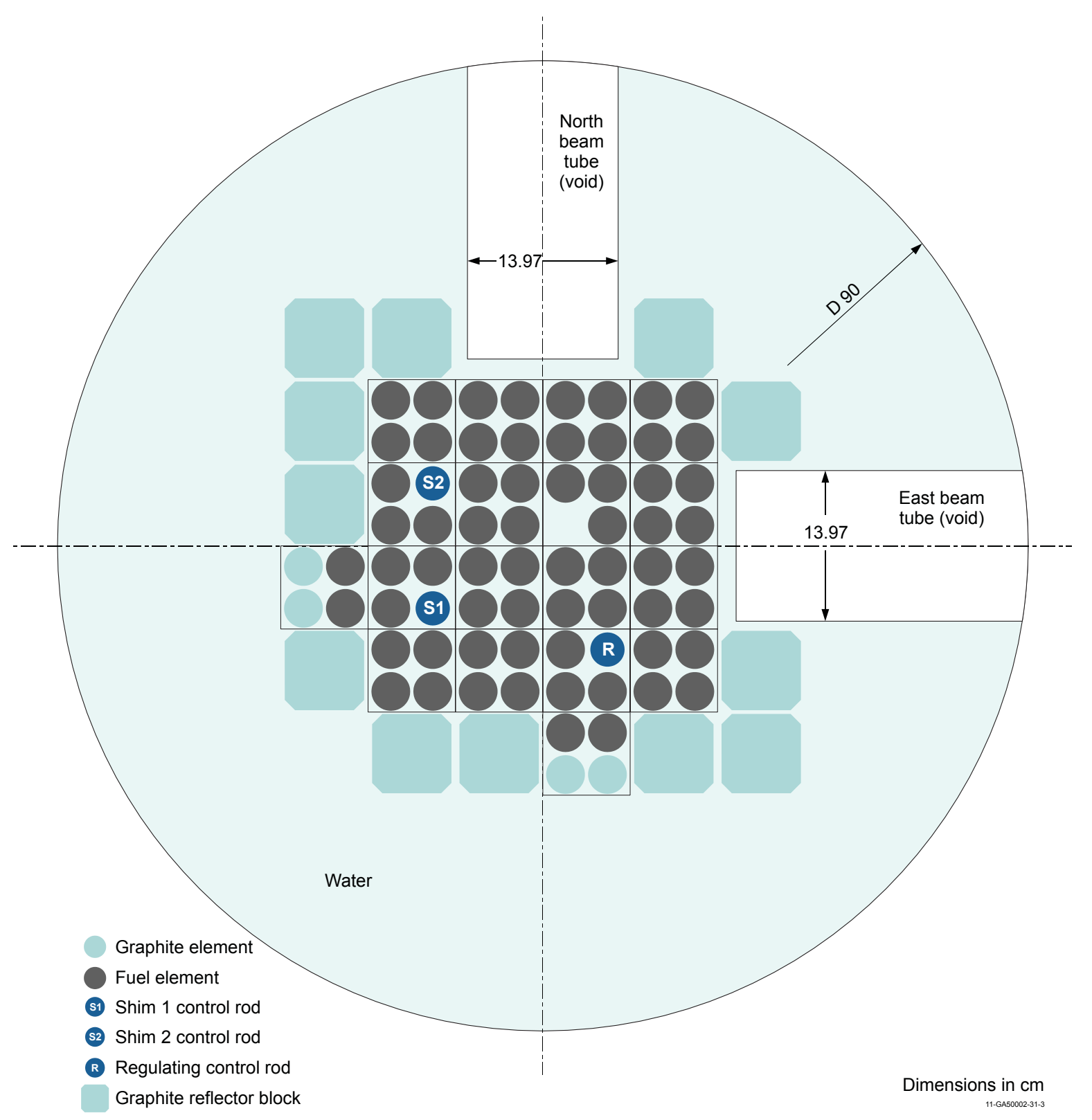

Figure 3.7b. Midplane Cross Section View of NRAD Reactor Core (Case 2). 
Fundamental - FUND

NRAD-FUND-RESR-002

CRIT-REAC-COEF

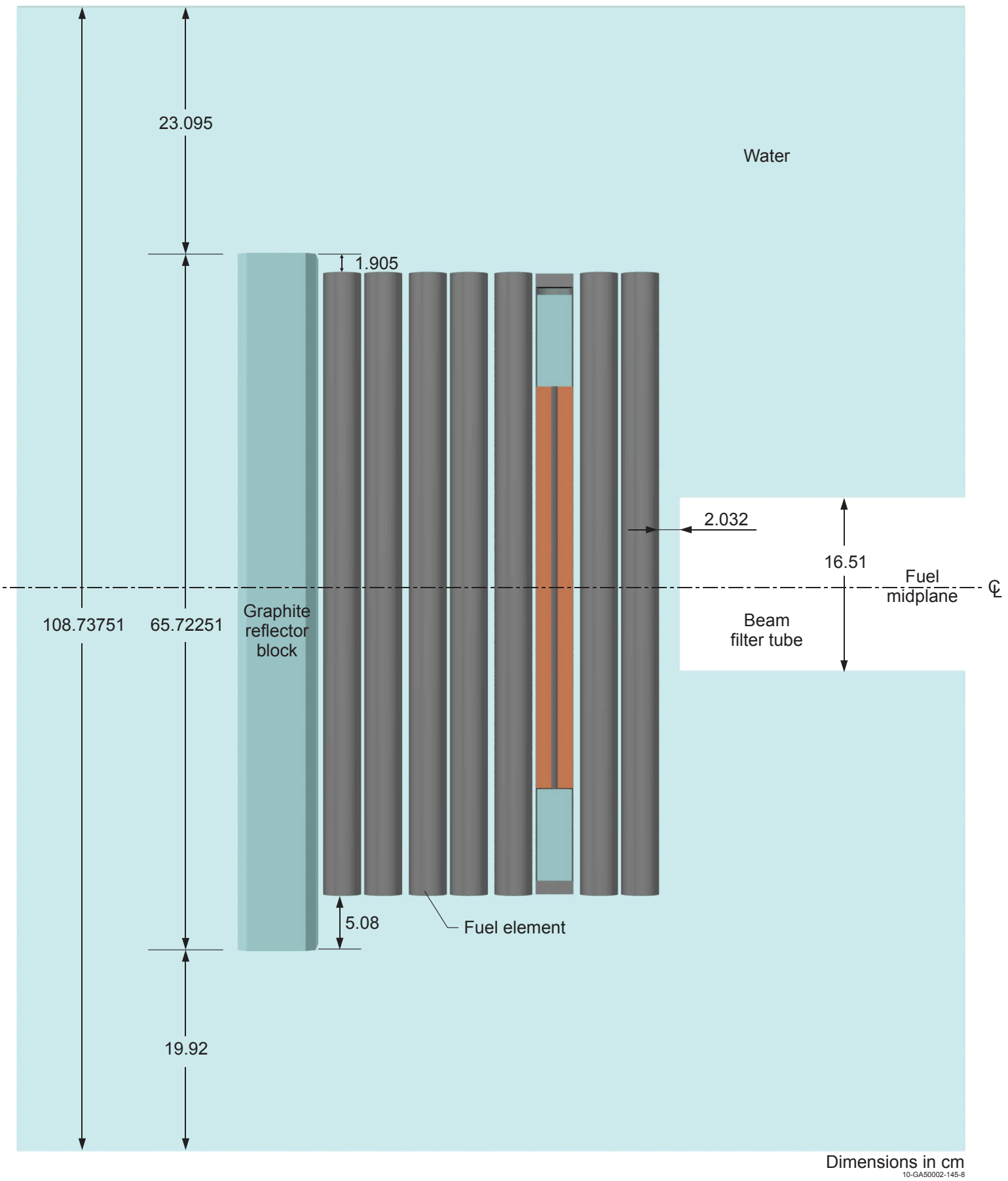

Figure 3.8. Vertical Cross Section View of NRAD Reactor Core through the Centerline of the Fuel Elements Located in the North Half of the Third Row (from the Top) of Fueled Assemblies. 
NEA/NSC/DOC(2006)1

Fundamental - FUND

NRAD-FUND-RESR-002

CRIT-REAC-COEF

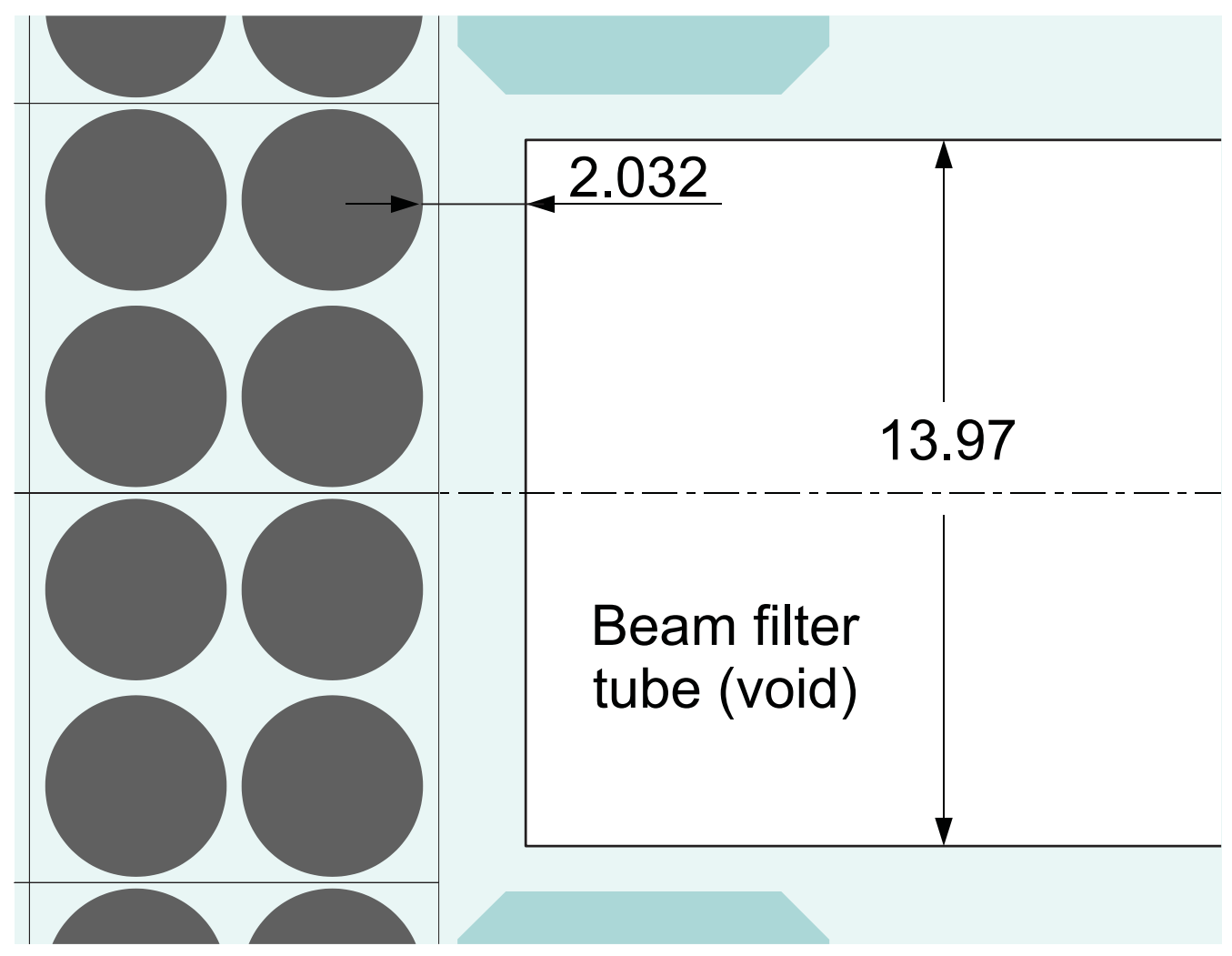

Dimensions in $\mathrm{cm}$

10-GA50002-145-7

Figure 3.9. Beam Filter Tube Placement. 


\section{NEA/NSC/DOC(2006)1}

Fundamental - FUND

NRAD-FUND-RESR-002

CRIT-REAC-COEF

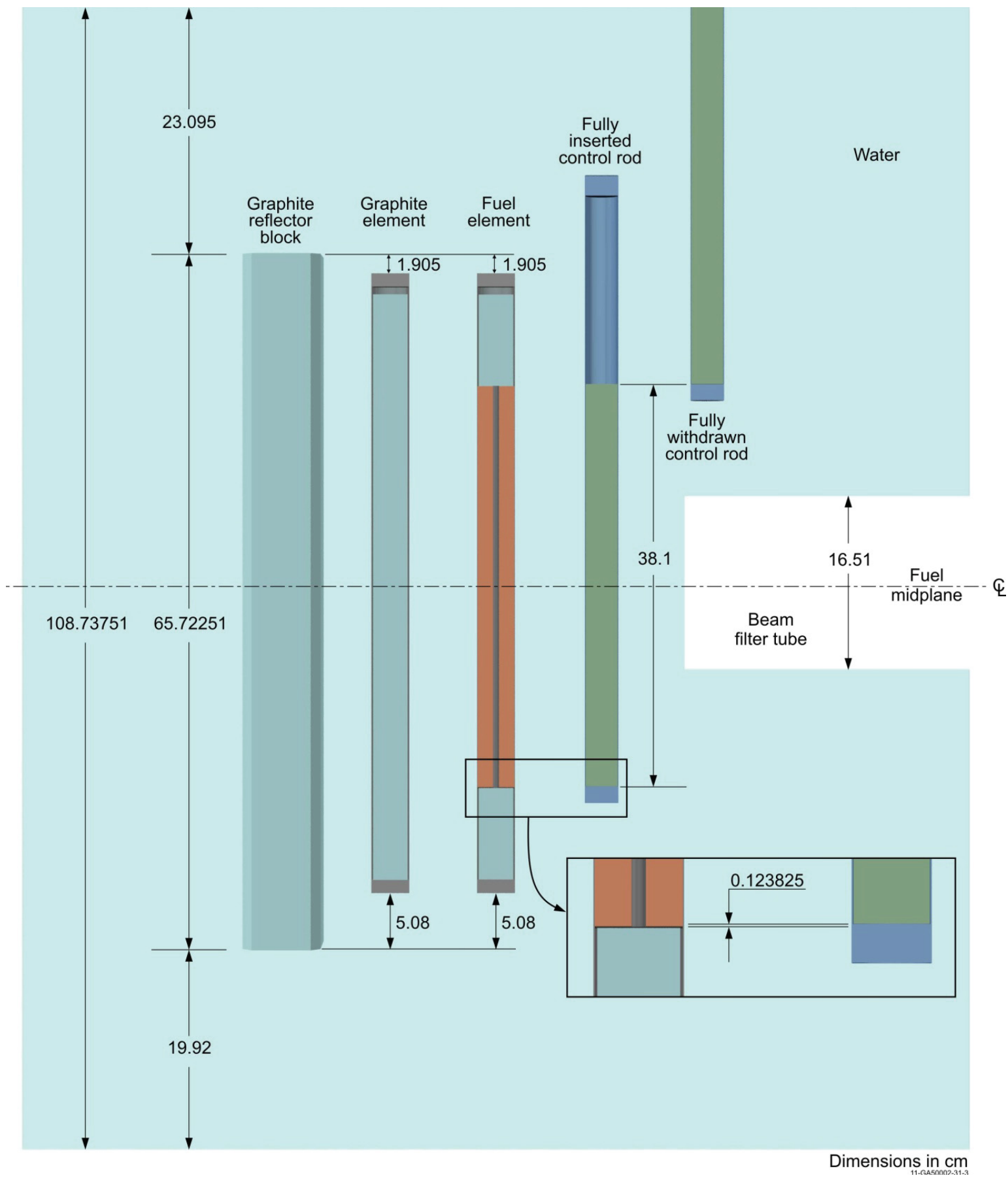

Figure 3.10. NRAD Reactor Core Reference Vertical Placement. 


\author{
Fundamental - FUND \\ NRAD-FUND-RESR-002 \\ CRIT-REAC-COEF
}

\title{
3.1.3 Material Data
}

\subsubsection{Graphite Reflector Block}

The graphite reflector block consists of high purity graphite with a mass density of $1.570 \mathrm{~g} / \mathrm{cm}^{3}$ with an additional water saturation content of 37 vol.\%. Impurities in the graphite have been removed from the benchmark model (Section 2.1.6.1 and 3.1.1.1). The atomic density and composition of the graphite are shown in Table 3.2. Water at a density of $0.99646 \mathrm{~g} / \mathrm{cm}^{3}$ (Table $3.10 \mathrm{~b}$ of NRAD-FUND-RESR-001) is multiplied by $37 \%$ and added to the graphite block atom density for both Case 1 and 2 to account for the water saturation in the graphite.

Table 3.2. Water-Saturated Graphite Reflector Block Atomic Density.

\begin{tabular}{|c|c|c|}
\hline \hline Isotope/Element & Composition (wt.\%) & Atoms/barn-cm \\
\hline \hline H & -- & $2.4649 \mathrm{E}-02$ \\
\hline C & 99.968029 & $7.8692 \mathrm{E}-02$ \\
\hline O & -- & $1.2325 \mathrm{E}-02$ \\
\hline Total & $99.968029^{\text {(a) }}$ & $1.1567 \mathrm{E}-01$ \\
\hline \hline
\end{tabular}

(a) Total weight fraction of the graphite has been reduced due to the removal of material impurities.

\subsubsection{Uranium-Erbium-Zirconium-Hydride Fuel}

The uranium-erbium-zirconium-hydride fuel has a mass density of 7.168064 and $7.168635 \mathrm{~g} / \mathrm{cm}^{3}$ for Cases 1 and 2, respectively Evaluation of the average fuel composition for use in benchmark model is discussed in Section 2.1.2. The atomic density and composition of the fuel are shown in Table 3.3.

Table 3.3a. Uranium-Erbium-Zirconium-Hydride Fuel Atomic Density (Case 1).

\begin{tabular}{|c|c|c||}
\hline Isotope/Element & Composition (wt.\%) & Atoms/barn-cm \\
\hline \hline $\mathrm{H}$ & 1.1818456 & $5.0617 \mathrm{E}-02$ \\
$\mathrm{~B}$ & 0.000096 & $3.8331 \mathrm{E}-07$ \\
$\mathrm{C}$ & 0.3 & $1.0782 \mathrm{E}-03$ \\
$\mathrm{Zr}$ & 67.6976272 & $3.2034 \mathrm{E}-02$ \\
$\mathrm{Er}$ & 0.9 & $2.3227 \mathrm{E}-04$ \\
$\mathrm{Hf}$ & 0.0034121 & $8.2520 \mathrm{E}-07$ \\
${ }^{234} \mathrm{U}$ & 0.0538506 & $9.9323 \mathrm{E}-06$ \\
${ }^{235} \mathrm{U}$ & 5.9044124 & $1.0844 \mathrm{E}-03$ \\
${ }^{236} \mathrm{U}$ & 0.0658174 & $1.2036 \mathrm{E}-05$ \\
${ }^{238} \mathrm{U}$ & 23.8929386 & $4.3326 \mathrm{E}-03$ \\
\hline \hline Total & 100.0 & $8.9401 \mathrm{E}-02$ \\
\hline
\end{tabular}


NEA/NSC/DOC(2006)1

Fundamental - FUND

NRAD-FUND-RESR-002

CRIT-REAC-COEF

Table 3.3b. Uranium-Erbium-Zirconium-Hydride Fuel Atomic Density (Case 2).

\begin{tabular}{|c|c|c|}
\hline Isotope/Element & Composition (wt.\%) & Atoms/barn-cm \\
\hline $\mathrm{H}$ & 1.1816813 & $5.0614 \mathrm{E}-02$ \\
\hline B & 0.000096 & 3.8334E-07 \\
\hline $\mathrm{C}$ & 0.3 & $1.0783 \mathrm{E}-03$ \\
\hline $\mathrm{Zr}$ & 67.6882114 & $3.2032 \mathrm{E}-02$ \\
\hline $\mathrm{Er}$ & 0.9 & 2.3229E-04 \\
\hline $\mathrm{Hf}$ & 0.0034117 & $8.2516 \mathrm{E}-07$ \\
\hline${ }^{234} \mathrm{U}$ & 0.0538679 & $9.9363 \mathrm{E}-06$ \\
\hline${ }^{235} \mathrm{U}$ & 5.9079304 & $1.0851 \mathrm{E}-03$ \\
\hline${ }^{236} \mathrm{U}$ & 0.0658385 & $1.2041 \mathrm{E}-05$ \\
\hline${ }^{238} \mathrm{U}$ & 23.8989628 & $4.3340 \mathrm{E}-03$ \\
\hline Total & 100.0 & 8.9399E-02 \\
\hline
\end{tabular}

\subsubsection{Axial Graphite Reflector}

The axial graphite reflector consists of high purity graphite with a mass density of $1.73 \mathrm{~g} / \mathrm{cm}^{3}$. Impurities in the graphite have been removed from the benchmark model (Section 2.1.3.3 and 3.1.1.1). The atomic density and composition of the graphite are shown in Table 3.4.

Table 3.4. Axial Graphite Reflector Atomic Density.

\begin{tabular}{|c|c|c|}
\hline \hline Isotope/Element & Composition (wt.\%) & Atoms/barn-cm \\
\hline C & 99.994614 & $8.6734 \mathrm{E}-02$ \\
\hline \hline Total & $99.994614^{(\mathrm{a})}$ & $8.6734 \mathrm{E}-02$ \\
\hline
\end{tabular}

(a) Total weight fraction has been reduced due to the removal of material impurities.

\subsubsection{Molybdenum Poison Disc}

The molybdenum poison disc has a mass density of $10.22 \mathrm{~g} / \mathrm{cm}^{3}$. Impurities in the molybdenum have been removed from the benchmark model (Section 2.1.3.2 and 3.1.1.1). The atomic density and composition of the molybdenum are shown in Table 3.5.

Table 3.5. Molybdenum Poison Disc Atomic Density.

\begin{tabular}{|c|c|c|}
\hline Isotope/Element & Composition (wt.\%) & Atoms/barn-cm \\
\hline \hline Mo & 99.968464 & $6.4130 \mathrm{E}-02$ \\
\hline \hline Total & $99.968464^{(\mathrm{a})}$ & $6.4130 \mathrm{E}-02$ \\
\hline
\end{tabular}

(a) Total weight fraction has been reduced due to the removal of material impurities. 


\subsubsection{Zirconium Rod}

The zirconium rod has a mass density of $6.51 \mathrm{~g} / \mathrm{cm}^{3}$. Impurities in the zirconium have been removed from the benchmark model (Section 2.1.3.1 and 3.1.1.1). The atomic density and composition of the zirconium are shown in Table 3.6.

Table 3.6. Zirconium Rod Atomic Density.

\begin{tabular}{|c|c|c|}
\hline \hline Isotope/Element & Composition (wt.\%) & Atoms/barn-cm \\
\hline $\mathrm{Zr}$ & 99.817 & $4.2897 \mathrm{E}-02$ \\
\hline \hline Total & $99.817^{\text {(a) }}$ & $4.2897 \mathrm{E}-02$ \\
\hline
\end{tabular}

(a) Total weight fraction has been reduced due to the removal of material impurities.

\subsubsection{Stainless Steel}

The stainless steel $304 / 304 \mathrm{~L}$ cladding and end fittings have a mass density of $8.00 \mathrm{~g} / \mathrm{cm}^{3}$. Impurities in the stainless steel have been removed from the benchmark model (Section 2.1.3.4 and 3.1.1.1). The atomic density and composition of the stainless steel are shown in Table 3.7.

Table 3.7. Stainless Steel Atomic Density.

\begin{tabular}{|c|c|c|}
\hline Isotope/Element & Composition (wt.\%) & Atoms/barn-cm \\
\hline \hline $\mathrm{C}$ & 0.04 & $1.6044 \mathrm{E}-04$ \\
$\mathrm{Si}$ & 0.4 & $6.8614 \mathrm{E}-04$ \\
$\mathrm{P}$ & 0.026 & $4.0441 \mathrm{E}-05$ \\
$\mathrm{~S}$ & 0.0022 & $3.3049 \mathrm{E}-06$ \\
$\mathrm{Cr}$ & 19 & $1.7604 \mathrm{E}-02$ \\
$\mathrm{Mn}$ & 1 & $8.7693 \mathrm{E}-04$ \\
$\mathrm{Fe}$ & 68.70712775 & $5.9271 \mathrm{E}-02$ \\
$\mathrm{Ni}$ & 10 & $8.2087 \mathrm{E}-03$ \\
\hline \hline Total & $99.17532775^{(\mathrm{a})}$ & $8.6851 \mathrm{E}-02$ \\
\hline
\end{tabular}

(a) Total weight fraction has been reduced due to the removal of material impurities.

\subsubsection{Boron Carbide Absorber}

The boron carbide absorber has a mass density of $2.48 \mathrm{~g} / \mathrm{cm}^{3}$. The atomic density and composition of the boron carbide are shown in Table 3.8. 
Table 3.8. Boron Carbide Absorber Atomic Density.

\begin{tabular}{|c|c|c||}
\hline Isotope/Element & Composition (wt.\%) & Atoms/barn-cm \\
\hline \hline${ }^{10} \mathrm{~B}$ & & $2.1515 \mathrm{E}-02$ \\
${ }^{11} \mathrm{~B}$ & 78.2626 & $8.6601 \mathrm{E}-02$ \\
$\mathrm{C}$ & 21.7374 & $2.7029 \mathrm{E}-02$ \\
\hline \hline Total & 100.0000 & $1.3514 \mathrm{E}-01$ \\
\hline
\end{tabular}

\subsubsection{Aluminum}

The aluminum 6061 cladding and end fittings have a mass density of $2.70 \mathrm{~g} / \mathrm{cm}^{3}$. Non-aluminum elements in the aluminum material have been removed from the benchmark model (Section 2.1.4.2 and 3.1.1.1). The atomic density and composition of the aluminum are shown in Table 3.9.

Table 3.9. Aluminum Atomic Density.

\begin{tabular}{|c|c|c|}
\hline Isotope/Element & Composition (wt.\%) & Atoms/barn-cm \\
\hline \hline $\mathrm{Al}$ & 97.23 & $5.8593 \mathrm{E}-02$ \\
\hline \hline Total & $97.23^{(\mathrm{a})}$ & $5.8593 \mathrm{E}-02$ \\
\hline
\end{tabular}

(a) Total weight fraction has been reduced due to the removal of material impurities.

\subsubsection{Water}

The water has a mass density of 0.99565 and $0.99630 \mathrm{~g} / \mathrm{cm}^{3}$ for Cases 1 and 2, respectively. The atomic density and composition of the water are shown in Table 3.10 .

Table 3.10a. Water Atomic Density (Case 1).

\begin{tabular}{|c|c|c||}
\hline \hline Isotope/Element & Composition (wt.\%) & Atoms/barn-cm \\
\hline $\mathrm{H}$ & 11.1894 & $6.6565 \mathrm{E}-02$ \\
$\mathrm{O}$ & 88.8106 & $3.3282 \mathrm{E}-02$ \\
\hline \hline Total & 100.0000 & $9.9847 \mathrm{E}-02$ \\
\hline
\end{tabular}

Table 3.10b. Water Atomic Density (Case 2).

\begin{tabular}{|c|c|c|}
\hline \hline Isotope/Element & Composition (wt.\%) & Atoms/barn-cm \\
\hline \hline $\mathrm{H}$ & 11.1894 & $6.6608 \mathrm{E}-02$ \\
$\mathrm{O}$ & 88.8106 & $3.3304 \mathrm{E}-02$ \\
\hline \hline Total & 100.0000 & $9.9912 \mathrm{E}-02$ \\
\hline
\end{tabular}

\subsubsection{Graphite Element Reflector}

The graphite element reflector consists of high purity graphite with a mass density of $1.73 \mathrm{~g} / \mathrm{cm}^{3}$. Impurities in the graphite have been removed from the benchmark model (Section 2.1.3.3 and 3.1.1.1). 
The atomic density and composition of the graphite are shown in Table 3.4, as it is the same graphite utilized in the axial graphite reflectors of the fuel elements.

\subsubsection{Temperature Data}

The benchmark model temperature is $300 \mathrm{~K}$.

\subsubsection{Experimental and Benchmark-Model $k_{\text {eff }}$ and / or Subcritical Parameters}

The experimental $k_{\text {eff }}$ values were approximately at unity, made to delayed critical, with respective $1 \sigma$ uncertainties as reported in Section 2.1.13 for each configuration. Simplification biases and uncertainties, as discussed in Section 3.1.1.1 were applied to the benchmark models. The benchmark $\mathrm{k}_{\text {eff }}$ values are shown in Table 3.11 for each case. The uncertainty in the benchmark $k_{\text {eff }}$ values is obtained by summing under quadrature the total experimental uncertainty (Tables 2.65 and 2.64 for Cases 1 and 2, respectively) and the estimated bias uncertainty (Table 3.1).

Table 3.11. Experimental and Benchmark Eigenvalues.

\begin{tabular}{|c|c|c|c|c|c|c|c|c|c|c|}
\hline \multirow{2}{*}{ Case } & \multirow{2}{*}{$\begin{array}{c}\text { \# Fuel } \\
\text { Elements }\end{array}$} & \multicolumn{3}{|c|}{ Experimental } & \multicolumn{3}{|c|}{ Bias } & \multicolumn{3}{|c|}{ Benchmark } \\
\hline & & $\mathbf{k}_{\text {eff }}$ & \pm & $\sigma$ & $\Delta \mathbf{k}$ & \pm & $\sigma$ & $\mathbf{k}_{\text {eff }}$ & \pm & $\sigma$ \\
\hline 1 & 62 & 1.0000 & \pm & 0.0012 & 0.0011 & \pm & 0.0009 & 1.0011 & \pm & 0.0015 \\
\hline 2 & 64 & 1.0000 & \pm & 0.0012 & 0.0012 & \pm & 0.0009 & 1.0012 & \pm & 0.0015 \\
\hline
\end{tabular}

\subsection{Benchmark-Model Specifications for Buckling and Extrapolation-Length Measurements}

Buckling and extrapolation length measurements were not performed.

\subsection{Benchmark-Model Specifications for Spectral Characteristics Measurements}

Spectral characteristics measurements were not performed. 
NEA/NSC/DOC(2006)1

Fundamental - FUND

NRAD-FUND-RESR-002

CRIT-REAC-COEF

\subsection{Benchmark-Model Specifications for Reactivity Effects Measurements}

Reactivity effects measurements evaluated include a total of ten measurements: six control rod worths (Cases 1 through 6), two shutdown margins (Cases 7 and 8), and two core excess reactivities (Cases 9 and 10), as summarized in Table 2.70 .

\subsubsection{Description of the Benchmark Model Simplifications}

Detailed models (see Appendix C) of the NRAD reactor core configurations were prepared to evaluate biases in the benchmark models. Sample calculations performed using the benchmark models provided in Section 3.1 with the model simplifications described in Section 3.1.1.1 yielded results similar to, within the statistical uncertainty, results calculated using the detailed models. Therefore, no bias is applied to the benchmark values.

The reactivity effects measurements were reported in units of $\$$ using a $\beta_{\text {eff }}$ value of 0.0071 ; they have been adjusted for the selected $\beta_{\text {eff }}$ value of 0.0075 for comparison with calculations and for use as benchmark measurements. For further discussion regarding the selection of $\beta_{\text {eff }}$, please see Section 2.4.1.

As discussed in Section 2.4, control rod worths are sensitive to perturbations in the core flux. Therefore, in order to avoid incurring additional biases and bias uncertainties, the benchmark models are developed to reflect the actual measurement methods used to obtain the experimental data.

Control rods originally reported to have been withdrawn 999 or 1000 units are considered fully withdrawn at a position of $38.1 \mathrm{~cm}$. For rods withdrawn only 999 units, this has a negligible impact when computing rod worths.

The benchmark model descriptions and specifications exactly follow the experimental procedure from which the experimental data were obtained for the reactivity effects measurements.

\subsubsection{Dimensions}

The dimensions of the benchmark models for determination of the reactivity effects measurements in the NRAD reactor are identical to those of the critical core configurations described in Section 3.1.2, with exceptions discussed below. The position of the assemblies in the 62- and 64-fuel-element core configurations are shown in Figures 3.7a and 3.7b, respectively.

\subsubsection{Control Rod Worths}

The worth of the shim rods is obtained by comparing the critical configuration of each core with one in which a single shim rod has been fully inserted. A summary of the rod positions is provided in Table 3.12 .

The worth of the regulating rod is obtained by first comparing the critical configuration of each core with one in which the regulating rod has been fully inserted to obtain a partial rod worth. Then a series of rodexchange configurations are performed to obtain the remaining rod worth. The summation of the absolute worth of each pair of rod movements provides the total regulating rod worth. A summary of the rod positions is provided in Table 3.13. 
NEA/NSC/DOC(2006)1

Fundamental - FUND

NRAD-FUND-RESR-002

CRIT-REAC-COEF

Table 3.12. Control Rod Positions to Determine Shim Rod Worths.

\begin{tabular}{|c|c|c|c|c|c|c|}
\hline Case \# & Core Description & $\begin{array}{l}\text { Measurement } \\
\text { (Method) }\end{array}$ & Position \# & $\begin{array}{c}\text { Shim 1 } \\
\text { Position } \\
\text { (cm) }\end{array}$ & $\begin{array}{c}\text { Shim } 2 \\
\text { Position } \\
\text { (cm) }\end{array}$ & $\begin{array}{c}\text { Reg } \\
\text { Position } \\
\text { (cm) }\end{array}$ \\
\hline \multirow{2}{*}{1} & \multirow{2}{*}{62 Fuel Elements } & \multirow{2}{*}{$\begin{array}{l}\text { Shim } 1 \text { Worth } \\
\text { (Rod Drop) }\end{array}$} & a1 & 38.1 & 38.1 & 16.8402 \\
\hline & & & $\mathrm{a} 2$ & 0.0 & 38.1 & 16.8402 \\
\hline \multirow{2}{*}{2} & \multirow{2}{*}{62 Fuel Elements } & \multirow{2}{*}{$\begin{array}{l}\text { Shim } 2 \text { Worth } \\
\text { (Rod Drop) }\end{array}$} & a1 & 38.1 & 38.1 & 16.8402 \\
\hline & & & $\mathrm{a} 2$ & 38.1 & 0.0 & 16.8402 \\
\hline \multirow{2}{*}{4} & \multirow{2}{*}{64 Fuel Elements } & \multirow{2}{*}{$\begin{array}{l}\text { Shim } 1 \text { Worth } \\
\text { (Rod Drop) }\end{array}$} & a1 & 38.1 & 38.1 & 7.8105 \\
\hline & & & $\mathrm{a} 2$ & 0.0 & 38.1 & 7.8105 \\
\hline \multirow[b]{2}{*}{ 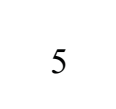 } & \multirow{2}{*}{64 Fuel Elements } & \multirow{2}{*}{$\begin{array}{l}\text { Shim } 2 \text { Worth } \\
\text { (Rod Drop) }\end{array}$} & a1 & 38.1 & 38.1 & 7.8105 \\
\hline & & & $\mathrm{a} 2$ & 38.1 & 0.0 & 7.8105 \\
\hline
\end{tabular}

Table 3.13. Control Rod Positions to Determine Regulating Rod Worths.

\begin{tabular}{|c|c|c|c|c|c|}
\hline Case \# & Core Description & $\begin{array}{l}\text { Measurement } \\
\text { (Method) }\end{array}$ & Position \# & $\begin{array}{c}\text { Shim } \\
\text { Positions } \\
\text { (cm) } \\
\end{array}$ & $\begin{array}{c}\text { Reg } \\
\text { Position } \\
\text { (cm) } \\
\end{array}$ \\
\hline \multirow{20}{*}{3} & \multirow{20}{*}{62 Fuel Elements } & \multirow{2}{*}{$\begin{array}{l}\text { Partial Reg Worth } \\
\text { (Rod Drop) }\end{array}$} & a1 & 38.1 & 16.8402 \\
\hline & & & a2 & 38.1 & 0.0 \\
\hline & & \multirow{18}{*}{$\begin{array}{l}\text { Partial Reg Worth } \\
\text { (Positive Period) }\end{array}$} & b1 & 38.1 & 16.764 \\
\hline & & & $\mathrm{b} 2$ & 38.1 & 17.8689 \\
\hline & & & $\mathrm{c} 1$ & 36.0045 & 17.8689 \\
\hline & & & $\mathrm{c} 2$ & 36.0045 & 19.6215 \\
\hline & & & $\mathrm{d} 1$ & 33.5661 & 19.6215 \\
\hline & & & $\mathrm{d} 2$ & 33.5661 & 21.2598 \\
\hline & & & $\mathrm{e} 1$ & 31.8516 & 21.2598 \\
\hline & & & $\mathrm{e} 2$ & 31.8516 & 23.1648 \\
\hline & & & $\mathrm{f} 1$ & 30.0609 & 23.1648 \\
\hline & & & $\mathrm{f} 2$ & 30.0609 & 25.4508 \\
\hline & & & g1 & 28.3845 & 25.4508 \\
\hline & & & g2 & 28.3845 & 27.813 \\
\hline & & & h1 & 26.9748 & 27.813 \\
\hline & & & $\mathrm{h} 2$ & 26.9748 & 30.2133 \\
\hline & & & i1 & 25.8699 & 30.2133 \\
\hline & & & i2 & 25.8699 & 33.8709 \\
\hline & & & $\mathrm{j} 1$ & 24.6126 & 33.8709 \\
\hline & & & $\mathrm{j} 2$ & 24.6126 & 38.1 \\
\hline
\end{tabular}


NEA/NSC/DOC(2006)1

Fundamental - FUND

NRAD-FUND-RESR-002

CRIT-REAC-COEF

Table 3.13. (cont'd.) Control Rod Positions to Determine Regulating Rod Worths.

\begin{tabular}{|c|c|c|c|c|c|}
\hline Case \# & Core Description & $\begin{array}{l}\text { Measurement } \\
\text { (Method) }\end{array}$ & Position \# & $\begin{array}{c}\text { Shim } \\
\text { Positions } \\
(\mathrm{cm}) \\
\end{array}$ & $\begin{array}{c}\text { Reg } \\
\text { Position } \\
(\mathrm{cm}) \\
\end{array}$ \\
\hline \multirow{22}{*}{6} & \multirow{22}{*}{64 Fuel Elements } & \multirow{2}{*}{$\begin{array}{l}\text { Partial Reg Worth } \\
\text { (Rod Drop) }\end{array}$} & a1 & 38.1 & 7.7343 \\
\hline & & & a2 & 38.1 & 0.0 \\
\hline & & \multirow{20}{*}{$\begin{array}{l}\text { Partial Reg Worth } \\
\text { (Positive Period) }\end{array}$} & b1 & 38.1 & 7.7343 \\
\hline & & & $\mathrm{b} 2$ & 38.1 & 11.0871 \\
\hline & & & $\mathrm{c} 1$ & 34.8615 & 11.0871 \\
\hline & & & $\mathrm{c} 2$ & 34.8615 & 14.0589 \\
\hline & & & $\mathrm{d} 1$ & 32.4231 & 14.0589 \\
\hline & & & $\mathrm{d} 2$ & 32.4231 & 16.1925 \\
\hline & & & $\mathrm{e} 1$ & 30.7467 & 16.1925 \\
\hline & & & e2 & 30.7467 & 18.669 \\
\hline & & & $\mathrm{f} 1$ & 28.9179 & 18.669 \\
\hline & & & $\mathrm{f} 2$ & 28.9179 & 20.9931 \\
\hline & & & g1 & 27.3558 & 20.9931 \\
\hline & & & $\mathrm{g} 2$ & 27.3558 & 23.3553 \\
\hline & & & $\mathrm{h} 1$ & 25.8699 & 23.3553 \\
\hline & & & $\mathrm{h} 2$ & 25.8699 & 26.0985 \\
\hline & & & i1 & 24.4983 & 26.0985 \\
\hline & & & i2 & 24.4983 & 29.0703 \\
\hline & & & $\mathrm{j} 1$ & 23.241 & 29.0703 \\
\hline & & & $\mathrm{j} 2$ & 23.241 & 33.2232 \\
\hline & & & $\mathrm{k} 1$ & 21.9456 & 33.2232 \\
\hline & & & $\mathrm{k} 2$ & 21.9456 & 38.0619 \\
\hline
\end{tabular}


NEA/NSC/DOC(2006)1

Fundamental - FUND

NRAD-FUND-RESR-002

CRIT-REAC-COEF

\subsubsection{Shutdown Margins}

The shutdown margin is represented by the worth of the control rods inserted into the core at critical. For both core configurations, this value is obtained by summing the individual worths obtained for the shim rods using the procedure in Table 3.12 and the regulating rod using the partial rod worth obtained using the rod drop method in Table 3.13. Shutdown margins for the 62- and 64-fuel-element cores are labeled as Cases 7 and 8, respectively (see Table 3.14).

\subsubsection{Excess Reactivities}

The core excess reactivity is represented by the worth of the control rod withdrawn from the core at critical. For both core configurations, this value is obtained by summing the worths obtained for the regulating rod using the positive period method in Table 3.13. Excess reactivities for the 62- and 64fuel-element cores are labeled as Cases 9 and 10, respectively (see Table 3.14).

\subsubsection{Material Data}

The materials of the benchmark models for determination of the reactivity effects measurements in the NRAD reactor are identical to those of the critical core configurations described in Section 3.1.3.

\subsubsection{Temperature Data}

The benchmark model temperature is $300 \mathrm{~K}$.

\subsubsection{Benchmark-Model Specification for Reactivity Effects Parameters}

The experimental measurements are evaluated in Section 2.4 and summarized in Table 2.70. Whereas there was no additional bias determined for model simplifications, these values represent the benchmark experiment worths, and are provided in Table 3.14.

Table 3.14. Benchmark Experiment Reactivity Effects Measurements.

\begin{tabular}{||c|c|c|ccc||}
\hline \hline \multirow{2}{*}{ Case \# } & \multirow{2}{*}{ Core Description } & \multirow{2}{*}{ Measurement } & \multicolumn{3}{|c|}{ Worth } \\
& & & $\mathbf{\rho \$}$ & $\mathbf{1 \sigma}$ \\
\hline \hline $1.4-1$ & 62 Fuel Elements & Shim 1 Worth & -2.66 & \pm & 0.30 \\
\hline $1.4-2$ & 62 Fuel Elements & Shim 2 Worth & -2.66 & \pm & 0.30 \\
\hline $1.4-3$ & 62 Fuel Elements & Reg Worth & -2.49 & \pm & 0.12 \\
\hline $2.4-1$ & 64 Fuel Elements & Shim 1 Worth & -2.92 & \pm & 0.33 \\
\hline $2.4-2$ & 64 Fuel Elements & Shim 2 Worth & -2.94 & \pm & 0.33 \\
\hline $2.4-3$ & 64 Fuel Elements & Reg Worth & -2.45 & \pm & 0.08 \\
\hline $1.4-4$ & 62 Fuel Elements & Shutdown Margin & -6.24 & \pm & 0.43 \\
\hline $2.4-4$ & 64 Fuel Elements & Shutdown Margin & -6.06 & \pm & 0.47 \\
\hline $1.4-5$ & 62 Fuel Elements & Excess Reactivity & 1.56 & \pm & 0.06 \\
\hline $2.4-5$ & 64 Fuel Elements & Excess Reactivity & 2.24 & \pm & 0.08 \\
\hline
\end{tabular}


NEA/NSC/DOC(2006)1

Fundamental - FUND

NRAD-FUND-RESR-002

CRIT-REAC-COEF

\subsection{Benchmark-Model Specifications for Reactivity Coefficient Measurements}

Reactivity coefficient measurements have not been evaluated.

\subsection{Benchmark-Model Specifications for Kinetics Measurements}

Kinetics measurements were not performed.

\subsection{Benchmark-Model Specifications for Reaction-Rate Distribution Measurements}

Reaction-rate distribution measurements were not performed.

\subsection{Benchmark-Model Specifications for Power Distribution Measurements}

Power distribution measurements were not performed.

\subsection{Benchmark-Model Specifications for Isotopic Measurements}

Isotopic measurements were not performed.

\subsection{Benchmark-Model Specifications for Other Miscellaneous Types of Measurements}

Other miscellaneous types of measurements were not performed. 
NEA/NSC/DOC(2006)1

Fundamental - FUND

NRAD-FUND-RESR-002

CRIT-REAC-COEF

\subsection{RESULTS OF SAMPLE CALCULATIONS}

\subsection{Results of Calculations of the Critical or Subcritical Configurations}

The benchmark models described in Section 3.1 were modeled using MCNP5-1.60 (see Appendix A.1 for input decks) and ENDF/B-VII.0 neutron cross section data. Calculations were performed with 1,550 generations with 100,000 neutrons per generation. The $\mathrm{k}_{\text {eff }}$ estimates did not include the first 50 generations and are the result of 150,000,000 neutron histories. Eigenvalues were also computed using JEFF-3.1 and JENDL-3.3 libraries for comparison. The JENDL-3.3 analysis was performed with the inclusion of ENDF/B-VII.0 thermal neutron scattering data because it was not available in the JENDL3.3 library. Thermal neutron scattering, or $\mathrm{S}(\alpha, \beta)$, adjusts the neutron cross sections for neutron upscatter at thermal energies and provides scattering data for elements bound with specific materials. ENDF/BVI.8 results were also provided for comparison against ENDF/B-VII.0 calculations; erbium cross sections were unavailable in ENDF/B-VI.8, so ENDF/B-VII.0 cross sections were used.

Calculations were repeated using both continuous-energy and 238-group ENDF/B-VII.0 neutron cross section data in KENO-VI ${ }^{\mathrm{a}}$ using the same number of cycles and histories as those used in MCNP5. An average pitch of $3.95224 \mathrm{~cm}$ was used with the KENO-VI analysis with the 238-group ENDF/B-VII.0 data.

Calculations were also performed using SERPENT (versions 1.1.17 and 2.1.13), ${ }^{\mathrm{b}}$ another Monte Carlo code similar to MCNP and KENO-VI, but uses the Woodcock delta-tracking method. ${ }^{\mathrm{c}}$ The SERPENT code utilized the same cross section data libraries as MCNP5 and provides comparable results using version 1.1.17. It is currently unknown why calculations performed with version 2.1 .13 calculate closer to the benchmark values. SERPENT calculations were performed with 2,550 generations with 100,000 neutrons per generation. The $\mathrm{k}_{\mathrm{eff}}$ estimates did not include the first 50 generations and are the result of $250,000,000$ neutron histories.

Calculated results are shown in Table 4.1. All calculated eigenvalues are greater than the benchmark values by approximately $1 \%$, with the exception of ENDF/B-VII.0 that is approximately $1.4 \%$, and much greater than the $3 \sigma$ uncertainty for both cases. Additional calculated parameters and neutron spectra that accompany the calculated eigenvalues in Table 4.1 are provided in Appendix B.

The difference between the calculated eigenvalues for continuous energy ENDF/B-VII.0 cross sections in MCNP5 and KENO-VI is due to thermal scattering treatment in the SCALE 6.1 software; updated libraries are currently in development. ${ }^{\mathrm{d}}$

There is a high correlation between the two critical configurations evaluated herein, as demonstrated by the strong similarities in uncertainties, biases, and sample calculations. This correlation also applies with the two critical configurations evaluated in NRAD-FUND-RESR-001.

\footnotetext{
${ }^{a}$ D. F. Hollenbach, L. M. Petrie, S. Goluoglu, N. F. Landers, and M. E. Dunn, "KENO-VI: A General Quadratic Version of the KENO Program,” ORNL/TM-2005/39 Version 6 Vol. II, Sect. F17, Oak Ridge National Laboratory (January 2009).

b J. Leppänen, "Development of a New Monte Carlo Reactor Physics Code," D.C. Thesis, Helsinki University of Technology, VTT Publications 640, VTT Technical Research Centre, Finland, (2007).

${ }^{c}$ E. R. Woodcock, "Techniques Used in the GEM Code for Monte Carlo Neutronics Calculations in Reactors and Other Systems of Complex Geometry," ANL-7050, Argonne National Laboratory (1965).

${ }^{\mathrm{d}}$ Personal communication with B. J. Marshall at ORNL (February 28, 2012). 


\author{
Fundamental - FUND \\ NRAD-FUND-RESR-002 \\ CRIT-REAC-COEF
}

The calculation bias using MCNP5 with ENDF/B-VII and JEFF-3.1 data is comparable to calculations performed $^{\mathrm{a}}$ using the benchmark of the Slovenian TRIGA reactor. ${ }^{\mathrm{b}}$ The calculated experimental uncertainty in the Slovenian reactor is approximately double the uncertainty in this benchmark experiment. The two reactor core designs are fundamentally different and this may have some effect on the calculated results. Monte Carlo analysis of the TRIGA Mark-II reactor at the Musashi Institute of Technology in Japan using MCNP4A and ENDF/B-V data indicated a computational bias in eigenvalue calculations of about $1.0 \% \Delta \mathrm{k} / \mathrm{k}$. Worth calculations, however, were in good agreement with experimental results. ${ }^{\mathrm{c}}$ MCNP modeling of other LEU converted TRIGA reactors also exhibit biases of approximately $\pm 1 \% \Delta \mathrm{k} / \mathrm{k} .{ }^{\mathrm{d}}$ The University of Wisconsin Nuclear Reactor (UWNR) experienced a similar problem as the NRAD reactor in that preliminary computations indicated a higher core excess reactivity than what was later measured in the as-built core. ${ }^{e}$

More recent investigations in Slovenia have been performed to determine that the ENDF/B-VII.0 nuclear data library does not work as well as ENDF/B-VI.8 or JEFF-3.1 for systems containing UZrH fuel. The highest contribution to the overprediction of $\mathrm{k}_{\mathrm{eff}}$ is due to cross section data for ${ }^{91} \mathrm{Zr}$ and the thermal scattering data, $\mathrm{S}(\alpha, \beta)$, for hydrogen and zirconium in the $\mathrm{ZrH}$ lattice. The study concluded that the higher elastic scattering resonance integral in ENDF/B-VII.0 increases thermal neutron flux by improving neutron thermalization, leading to higher fission rates in the thermal region and consequently increasing $\mathrm{k}_{\mathrm{eff}}$. This effect is more pronounced in smaller critical systems. ${ }^{\mathrm{f}}$

\footnotetext{
${ }^{a}$ Personal communications with Luka Snoj at the Jozef Stefan Institute (October 20, 2010).

${ }^{\mathrm{b}}$ R. Jeraj and M. Ravnik, "TRIGA Mark II Reactor: U(20) - Zirconium Hydride Fuel Rods in Water with Graphite Reflector," Rev. 0 (September 30, 1999), IEU-COMP-THERM-003, International Handbook of Evaluated Criticality Safety Benchmark Experiments, NEA/NSC/DOC(95)03, OECD-NEA (2010).

${ }^{c}$ T. Matsumoto and N. Hayakawa, "Benchmark Analysis of TRIGA Mark II Reactivity Experiment Using a Continuous Energy Monte Carlo Code MCNP,” J. Nucl. Sci. Technol., 37, 1082-1087 (2000).

${ }^{\mathrm{d}}$ Personal communications with Chris Ellis at General Atomics and Eric C. Woolstenhulme, Ken Schreck, Randy Damiana, and Ann Marie Philips at INL (August 4, 2010).

e K. T. Austin, "LEU Core Design for the Conversion of University of Wisconsin Nuclear Reactor," Proc. RERTR 2010, Lisbon, Portugal (October 10-13, 2010).

${ }^{\mathrm{f}}$ L. Snoj, G. Žerovnik, and A. Trkov, “Analysis of Cross Section Libraries on Zirconium Benchmarks,” Proc. International Conference on Nuclear Criticality (ICNC) 2011, Edinburgh, Scotland (September 19-23, 2011).
} 
NEA/NSC/DOC(2006)1

Fundamental - FUND

NRAD-FUND-RESR-002

CRIT-REAC-COEF

Table 4.1a. Comparison of Benchmark Eigenvalues (Case 1).

\begin{tabular}{|c|c|c|c|c|c|c|c|c|}
\hline \multirow{2}{*}{$\begin{array}{l}\text { Analysis } \\
\text { Code }\end{array}$} & \multirow{2}{*}{$\begin{array}{l}\text { Neutron Cross } \\
\text { Section Library }\end{array}$} & \multicolumn{3}{|c|}{ Calculated } & \multicolumn{3}{|c|}{ Benchmark } & \multirow{2}{*}{$\frac{C-E}{E}(\%)$} \\
\hline & & $\mathbf{k}_{\text {eff }}$ & \pm & $\sigma$ & $\mathbf{k}_{\text {eff }}$ & \pm & $\sigma$ & \\
\hline \multirow{4}{*}{ MCNP5 } & ENDF/B-VII.0 & 1.01459 & \pm & 0.00007 & \multirow{8}{*}{\multicolumn{3}{|c|}{$1.0011 \pm 0.0015$}} & 1.35 \\
\hline & JEFF-3.1 & 1.01241 & \pm & 0.00007 & & & & 1.13 \\
\hline & JENDL-3.3 $3^{(\mathrm{a})}$ & 1.01183 & \pm & 0.00007 & & & & 1.07 \\
\hline & ENDF/B-VI. $8^{(\mathrm{b})}$ & 1.01009 & \pm & 0.00007 & & & & 0.9 \\
\hline \multirow{2}{*}{ KENO-VI } & $\begin{array}{l}\text { ENDF/B-VII.0 } \\
\text { (238-group) }\end{array}$ & 1.01539 & \pm & 0.00007 & & & & 1.43 \\
\hline & $\begin{array}{c}\text { ENDF/B-VII.0 } \\
\text { (continuous energy) }^{(\mathrm{c})}\end{array}$ & 1.01003 & \pm & 0.00008 & & & & 0.89 \\
\hline \multirow{2}{*}{ SERPENT } & $\begin{array}{l}\text { ENDF/B-VII.0 } \\
\quad(\mathrm{v} .1 .1 .17)\end{array}$ & 1.01437 & \pm & 0.00008 & & & & 1.33 \\
\hline & $\begin{array}{l}\text { ENDF/B-VII.0 } \\
\text { (v. 2.1.13) }\end{array}$ & 1.01323 & \pm & 0.00008 & & & & 1.21 \\
\hline
\end{tabular}

(a) $\mathrm{S}(\alpha, \beta)$ data from the ENDF/B-VII.0 library were used with the JENDL-3.3 cross section data..

(b) ENDF/B-VII.0 cross section data for erbium isotopes were used.

(c) This value is calculated to be $1.01370 \pm 0.00008$ using updated thermal scattering data and treatments currently in the SCALE 6.2 software package (prerelease). Personal communication with B. J. Marshall at ORNL (July 3, 2013).

Table 4.1b. Comparison of Benchmark Eigenvalues (Case 2).

\begin{tabular}{|c|c|c|c|c|c|c|c|}
\hline \multirow{2}{*}{$\begin{array}{l}\text { Analysis } \\
\text { Code }\end{array}$} & \multirow{2}{*}{$\begin{array}{l}\text { Neutron Cross } \\
\text { Section Library }\end{array}$} & \multicolumn{3}{|c|}{ Calculated } & \multicolumn{2}{|c|}{ Benchmark } & \multirow{2}{*}{$\frac{C-E}{E}(\%)$} \\
\hline & & $\mathbf{k}_{\mathrm{eff}}$ & \pm & $\sigma$ & $\mathbf{k}_{\mathrm{eff}}=$ & $\pm \quad \sigma$ & \\
\hline \multirow{4}{*}{ MCNP5 } & ENDF/B-VII.0 & 1.01479 & \pm & 0.00007 & \multirow{8}{*}{\multicolumn{2}{|c|}{$1.0012 \pm 0.0015$}} & 1.36 \\
\hline & JEFF-3.1 & 1.01281 & \pm & 0.00007 & & & 1.16 \\
\hline & JENDL-3.3 $3^{(\mathrm{a})}$ & 1.01191 & \pm & 0.00007 & & & 1.07 \\
\hline & ENDF/B-VI. $8^{(\mathrm{b})}$ & 1.01022 & \pm & 0.00007 & & & 0.90 \\
\hline \multirow{2}{*}{ KENO-VI } & $\begin{array}{l}\text { ENDF/B-VII.0 } \\
\text { (238-group) }\end{array}$ & 1.01528 & \pm & 0.00007 & & & 1.41 \\
\hline & $\begin{array}{c}\text { ENDF/B-VII.0 } \\
(\text { continuous energy) }\end{array}$ & 1.010205 & \pm & 0.0007 & & & 0.90 \\
\hline \multirow{2}{*}{ SERPENT } & $\begin{array}{l}\text { ENDF/B-VII.0 } \\
\quad(\mathrm{v} .1 .1 .17)\end{array}$ & 1.01490 & \pm & 0.00008 & & & 1.37 \\
\hline & $\begin{array}{l}\text { ENDF/B-VII.0 } \\
\text { (v. 2.1.13) }\end{array}$ & 1.01332 & \pm & 0.00008 & & & 1.21 \\
\hline
\end{tabular}

(a) $\mathrm{S}(\alpha, \beta)$ data from the ENDF/B-VII.0 library were used with the JENDL-3.3 cross section data..

(b) ENDF/B-VII.0 cross section data for erbium isotopes were used.

(c) This value is calculated to be $1.01385 \pm 0.00008$ using updated thermal scattering data and treatments currently in the SCALE 6.2 software package (prerelease). Personal communication with B. J. Marshall at ORNL (July 3, 2013). 
NEA/NSC/DOC(2006)1

Fundamental - FUND

NRAD-FUND-RESR-002

CRIT-REAC-COEF

\subsection{Results of Buckling and Extrapolation Length Calculations}

Buckling and extrapolation length measurements were not performed.

\subsection{Results of Spectral-Characteristics Calculations}

Spectral characteristics measurements were not performed.

\subsection{Results of Reactivity-Effects Calculations}

The benchmark specifications described in Section 3.4 were modeled using MCNP5-1.60 (see Appendix A.1 and A.4 for input decks) and ENDF/B-VII.0 neutron cross section data. Calculations were performed with 1,550 generations with 100,000 neutrons per generation. The $\mathrm{k}_{\text {eff }}$ estimates did not include the first 50 generations and are the result of 150,000,000 neutron histories. The difference between various configurations, as described in Section 3.4.2, were simulated to calculate reactivity worths $(\Delta \mathrm{k} / \mathrm{k})$. These worths were then converted into units of $\rho \$$ using a $\beta_{\text {eff }}$ value of $0.00750 \pm$ $0.000375(5 \%, 1 \sigma)$. The Monte Carlo statistical uncertainty is approximately $\$ 0.01$. The uncertainty in the calculated values provided in this section also include the uncertainty in $\beta_{\text {eff }}$ because of the variability in reported and calculated values (see Section 2.4.1); therefore, calculations using additional neutron cross section libraries were not performed.

The worth of a control rod is calculated using the following equation:

$\rho(\$)=\frac{k_{\text {inserted }}-k_{\text {withdrawn }}}{k_{\text {inserted }} \times k_{\text {withdrawn }}} \times \frac{1}{\beta_{\text {eff }}}$.

When evaluating the worth of a partial rod movement, the control rod positions in Section 3.4 were modeled explicitly and the movement simulated as a second static configuration. The difference between the two positions was evaluated as a partial withdrawal, which uses the same equation as for a complete rod drop. The individual partial worths are summed and the uncertainty propagated and applied to the total calculated rod worth.

\subsubsection{Control Rod Worths}

\subsubsection{Shim Rod Worths}

Shim control rod worths were calculated as described in Section 3.4.2.1 and the results are provided in Table 4.2. Calculated and benchmark results are within the $1 \sigma$ uncertainty.

An alternative calculation method was performed using variations of the benchmark models with all three control rods fully withdrawn to estimate the worth of a single dropped shim rod; the difference between the two calculation methods is that the reg rod was partially inserted into the core in the benchmark models. Results are provided in Table 4.3. Calculated and benchmark results are within the $1 \sigma$ uncertainty. The alternative method for calculating the shim rod worths is comparable to the benchmark method except that it calculates the worth of the Shim 2 rod slightly low but within $2 \sigma$. 
NEA/NSC/DOC(2006)1

Fundamental - FUND

NRAD-FUND-RESR-002

CRIT-REAC-COEF

Table 4.2. Comparison of Benchmark Shim Rod Worths.

\begin{tabular}{|c|c|c|c|c|c|c|c|c|c|c|c|}
\hline \multirow{2}{*}{ Case \# } & \multirow{2}{*}{ Core Description } & \multirow{2}{*}{$\begin{array}{l}\text { Measurement } \\
\text { (Method) }\end{array}$} & \multicolumn{3}{|c|}{ Benchmark } & \multicolumn{3}{|c|}{ Calculated } & \multirow{2}{*}{\multicolumn{3}{|c|}{$\mathbf{C} / \mathbf{E} \pm 1 \sigma$}} \\
\hline & & & $\rho \$$ & \pm & $1 \sigma$ & $\rho \$$ & \pm & $1 \sigma$ & & & \\
\hline $1.4-1$ & 62 Fuel Elements & $\begin{array}{l}\text { Shim } 1 \text { Worth } \\
\text { (Rod Drop) }\end{array}$ & -2.66 & \pm & 0.30 & -2.85 & \pm & 0.14 & 1.07 & \pm & 0.13 \\
\hline $1.4-2$ & 62 Fuel Elements & $\begin{array}{l}\text { Shim } 2 \text { Worth } \\
\text { (Rod Drop) }\end{array}$ & -2.66 & \pm & 0.30 & -2.57 & \pm & 0.13 & 0.97 & \pm & 0.12 \\
\hline $2.4-1$ & 64 Fuel Elements & $\begin{array}{l}\text { Shim 1 Worth } \\
\text { (Rod Drop) }\end{array}$ & -2.92 & \pm & 0.33 & -3.13 & \pm & 0.16 & 1.07 & \pm & 0.13 \\
\hline $2.4-2$ & 64 Fuel Elements & $\begin{array}{l}\text { Shim } 2 \text { Worth } \\
\text { (Rod Drop) }\end{array}$ & -2.94 & \pm & 0.33 & -2.87 & \pm & 0.14 & 0.98 & \pm & 0.12 \\
\hline
\end{tabular}

Table 4.3. Alternative Calculation of Shim Rod Worths.

\begin{tabular}{|c|c|c|c|c|c|c|c|c|c|c|c|}
\hline \multirow{2}{*}{ Case \# } & \multirow{2}{*}{ Core Description } & \multirow{2}{*}{$\begin{array}{l}\text { Measurement } \\
\text { (Method) }\end{array}$} & \multicolumn{3}{|c|}{ Benchmark } & \multicolumn{3}{|c|}{ Calculated } & \multirow{2}{*}{\multicolumn{3}{|c|}{$\mathbf{C} / \mathbf{E} \pm 1 \sigma$}} \\
\hline & & & $\rho \$$ & \pm & $1 \sigma$ & $\rho \$$ & \pm & $1 \sigma$ & & & \\
\hline $1.4-1$ & 62 Fuel Elements & $\begin{array}{l}\text { Shim } 1 \text { Worth } \\
\text { (Rod Drop) }\end{array}$ & -2.66 & \pm & 0.30 & -2.63 & \pm & 0.13 & 0.99 & \pm & 0.12 \\
\hline $1.4-2$ & 62 Fuel Elements & $\begin{array}{l}\text { Shim } 2 \text { Worth } \\
\text { (Rod Drop) }\end{array}$ & -2.66 & \pm & 0.30 & -2.20 & \pm & 0.11 & 0.83 & \pm & 0.10 \\
\hline $2.4-1$ & 64 Fuel Elements & $\begin{array}{l}\text { Shim } 1 \text { Worth } \\
\text { (Rod Drop) }\end{array}$ & -2.92 & \pm & 0.33 & -2.79 & \pm & 0.14 & 0.96 & \pm & 0.12 \\
\hline $2.4-2$ & 64 Fuel Elements & $\begin{array}{l}\text { Shim } 2 \text { Worth } \\
\text { (Rod Drop) }\end{array}$ & -2.94 & \pm & 0.33 & -2.30 & \pm & 0.12 & 0.78 & \pm & 0.10 \\
\hline
\end{tabular}




\subsubsection{Regulating Rod Worths}

Regulating control rod worths were calculated as described in Section 3.4.2.1 and the results are provided in Table 4.4; the intermediate steps needed to obtain the final measured value were also calculated and compared against the experimental results. Calculated and benchmark results are within the $1 \sigma$ uncertainty for most positions with the remaining few within the $2 \sigma$ uncertainty.

An alternative calculation method was performed using variations of the benchmark models with all three control rods fully withdrawn to estimate the worth of a single dropped regulating rod; the difference between the two calculation methods is that the reg rod was partially inserted into the core in the benchmark models. Results are provided in Table 4.5. Calculated and benchmark results are within the $1 \sigma$ uncertainty. The alternative method for calculating the regulating rod worths is comparable to the benchmark method.

Table 4.4a. Comparison of Steps to Determine Benchmark Regulating Rod Worths.

\begin{tabular}{|c|c|c|c|c|c|c|c|c|c|}
\hline \multirow{2}{*}{$\begin{array}{c}\text { Case } \\
\#\end{array}$} & \multirow{2}{*}{$\begin{array}{c}\text { Core } \\
\text { Description }\end{array}$} & \multirow{2}{*}{$\begin{array}{l}\text { Measurement } \\
\text { (Method) }\end{array}$} & \multirow{2}{*}{$\begin{array}{c}\text { Position } \\
\#\end{array}$} & \multicolumn{3}{|c|}{ Experiment } & \multicolumn{3}{|c|}{ Calculated } \\
\hline & & & & $\rho \$$ & \pm & $1 \sigma$ & $\rho \$$ & \pm & $1 \sigma$ \\
\hline \multirow{10}{*}{$1.4-3$} & \multirow{10}{*}{$\begin{array}{l}62 \text { Fuel } \\
\text { Elements }\end{array}$} & $\begin{array}{l}\text { Partial Reg Worth } \\
\text { (Rod Drop) }\end{array}$ & $\mathrm{a}$ & -0.93 & \pm & 0.11 & -0.95 & \pm & 0.05 \\
\hline & & \multirow{9}{*}{$\begin{array}{c}\text { Partial Reg Worth } \\
\text { (Positive Period) }\end{array}$} & $\mathrm{b}$ & 0.11 & \pm & 0.01 & 0.12 & \pm & 0.01 \\
\hline & & & $\mathrm{c}$ & 0.18 & \pm & 0.02 & 0.16 & \pm & 0.02 \\
\hline & & & d & 0.17 & \pm & 0.02 & 0.19 & \pm & 0.02 \\
\hline & & & $\mathrm{e}$ & 0.20 & \pm & 0.02 & 0.20 & \pm & 0.02 \\
\hline & & & $\mathrm{f}$ & 0.21 & \pm & 0.02 & 0.21 & \pm & 0.02 \\
\hline & & & $\mathrm{g}$ & 0.20 & \pm & 0.02 & 0.20 & \pm & 0.02 \\
\hline & & & $\mathrm{h}$ & 0.17 & \pm & 0.02 & 0.19 & \pm & 0.02 \\
\hline & & & $\mathrm{i}$ & 0.20 & \pm & 0.02 & 0.22 & \pm & 0.02 \\
\hline & & & $\mathrm{j}$ & 0.13 & \pm & 0.01 & 0.14 & \pm & 0.01 \\
\hline
\end{tabular}


NEA/NSC/DOC(2006)1

Fundamental - FUND

NRAD-FUND-RESR-002

CRIT-REAC-COEF

Table 4.4a. (cont'd.) Comparison of Steps to Determine Benchmark Regulating Rod Worths.

\begin{tabular}{|c|c|c|c|c|c|c|c|c|c|}
\hline \multirow{2}{*}{$\begin{array}{c}\text { Case } \\
\#\end{array}$} & \multirow{2}{*}{$\begin{array}{c}\text { Core } \\
\text { Description }\end{array}$} & \multirow{2}{*}{$\begin{array}{l}\text { Measurement } \\
\text { (Method) }\end{array}$} & \multirow{2}{*}{$\begin{array}{c}\text { Position } \\
\#\end{array}$} & \multicolumn{3}{|c|}{ Experiment } & \multicolumn{3}{|c|}{ Calculated } \\
\hline & & & & $\rho \$$ & \pm & $1 \sigma$ & $\rho \$$ & \pm & $1 \sigma$ \\
\hline \multirow{11}{*}{$2.4-3$} & \multirow{11}{*}{$\begin{array}{l}64 \text { Fuel } \\
\text { Elements }\end{array}$} & $\begin{array}{c}\text { Partial Reg Worth } \\
\text { (Rod Drop) }\end{array}$ & $\mathrm{a}$ & -0.21 & \pm & 0.02 & -0.22 & \pm & 0.02 \\
\hline & & \multirow{10}{*}{$\begin{array}{c}\text { Partial Reg Worth } \\
\text { (Positive Period) }\end{array}$} & $\mathrm{b}$ & 0.21 & \pm & 0.02 & 0.19 & \pm & 0.02 \\
\hline & & & $\mathrm{c}$ & 0.23 & \pm & 0.03 & 0.22 & \pm & 0.02 \\
\hline & & & $\mathrm{d}$ & 0.20 & \pm & 0.02 & 0.21 & \pm & 0.02 \\
\hline & & & $\mathrm{e}$ & 0.25 & \pm & 0.03 & 0.22 & \pm & 0.02 \\
\hline & & & $\mathrm{f}$ & 0.24 & \pm & 0.03 & 0.24 & \pm & 0.02 \\
\hline & & & g & 0.24 & \pm & 0.03 & 0.24 & \pm & 0.02 \\
\hline & & & $\mathrm{h}$ & 0.24 & \pm & 0.03 & 0.28 & \pm & 0.02 \\
\hline & & & $\mathrm{i}$ & 0.23 & \pm & 0.03 & 0.26 & \pm & 0.02 \\
\hline & & & $\mathrm{j}$ & 0.24 & \pm & 0.03 & 0.29 & \pm & 0.02 \\
\hline & & & $\mathrm{k}$ & 0.16 & \pm & 0.02 & 0.16 & \pm & 0.02 \\
\hline
\end{tabular}

Table 4.4b. Comparison of Benchmark Regulating Rod Worths.

\begin{tabular}{|c|c|c|c|c|c|c|c|c|c|c|c|}
\hline \multirow{2}{*}{ Case \# } & \multirow{2}{*}{ Core Description } & \multirow{2}{*}{$\begin{array}{l}\text { Measurement } \\
\text { (Method) }\end{array}$} & \multicolumn{3}{|c|}{ Benchmark } & \multicolumn{3}{|c|}{ Calculated } & \multirow{2}{*}{\multicolumn{3}{|c|}{$\mathbf{C} / \mathbf{E} \pm 1 \sigma$}} \\
\hline & & & $\rho \$$ & \pm & $1 \sigma$ & $\rho \$$ & \pm & $1 \sigma$ & & & \\
\hline $1.4-3$ & 62 Fuel Elements & $\begin{array}{l}\text { Reg Worth } \\
\text { (Sum) }\end{array}$ & -2.49 & \pm & 0.12 & -2.58 & \pm & 0.07 & 1.04 & \pm & 0.06 \\
\hline $2.4-3$ & 64 Fuel Elements & $\begin{array}{l}\text { Reg Worth } \\
\text { (Sum) }\end{array}$ & -2.45 & \pm & 0.08 & -2.54 & \pm & 0.06 & 1.04 & \pm & 0.04 \\
\hline
\end{tabular}

Table 4.5. Alternative Calculation of Regulating Rod Worths.

\begin{tabular}{|c|c|c|c|c|c|c|c|c|c|c|c|}
\hline \multirow{2}{*}{ Case \# } & \multirow{2}{*}{ Core Description } & \multirow{2}{*}{$\begin{array}{c}\text { Measurement } \\
\text { (Method) }\end{array}$} & \multicolumn{3}{|c|}{ Benchmark } & \multicolumn{3}{|c|}{ Calculated } & \multirow{2}{*}{\multicolumn{3}{|c|}{$\mathbf{C} / \mathbf{E} \pm 1 \sigma$}} \\
\hline & & & $\rho \$$ & \pm & $1 \sigma$ & $\rho \$$ & \pm & $1 \sigma$ & & & \\
\hline $1.4-3$ & 62 Fuel Elements & $\begin{array}{l}\text { Reg Worth } \\
\text { (Rod Drop) }\end{array}$ & -2.49 & \pm & 0.12 & -2.60 & \pm & 0.13 & 1.04 & \pm & 0.07 \\
\hline $2.4-3$ & 64 Fuel Elements & $\begin{array}{l}\text { Reg Worth } \\
\text { (Rod Drop) }\end{array}$ & -2.45 & \pm & 0.08 & -2.47 & \pm & 0.12 & 1.01 & \pm & 0.06 \\
\hline
\end{tabular}




\author{
Fundamental - FUND \\ NRAD-FUND-RESR-002 \\ CRIT-REAC-COEF
}

\title{
4.4.2 Shutdown Margins
}

The shutdown margin is represented by the worth of the control rods inserted into the core at critical. The calculated worths of the shims rods is added to the calculated worth of the partially dropped regulating rod (Tables 4.2 and 4.4a, respectively). The results are provided in Table 4.6. Calculated and benchmark results are within the $1 \sigma$ uncertainty.

An alternative calculation method was performed using variations of the benchmark models with all three control rods fully inserted; the computed eigenvalues were subtracted from the eigenvalues calculated for the critical configurations (Table 4.1) to estimate the total worth of inserted control rods. Results are provided in Table 4.7. Calculated and benchmark results are within the $2 \sigma$ uncertainty for Case 7 and $1 \sigma$ uncertainty for Case 8. The alternative method for calculating the shutdown margins appears to calculate values slightly greater than values obtained using the benchmark method.

Table 4.6. Comparison of Benchmark Shutdown Margins.

\begin{tabular}{|c|c|c|c|c|c|c|c|c|c|c|c|}
\hline \multirow{2}{*}{ Case \# } & \multirow{2}{*}{ Core Description } & \multirow{2}{*}{$\begin{array}{l}\text { Measurement } \\
\text { (Method) }\end{array}$} & \multicolumn{3}{|c|}{ Benchmark } & \multicolumn{3}{|c|}{ Calculated } & \multirow{2}{*}{\multicolumn{3}{|c|}{$\mathrm{C} / \mathbf{E} \pm 1 \sigma$}} \\
\hline & & & $\rho \$$ & $I$ & $1 \sigma$ & $\rho \$$ & \pm & $1 \sigma$ & & & \\
\hline $1.4-4$ & 62 Fuel Elements & $\begin{array}{l}\text { Shutdown Margin } \\
\text { (Rod Drops) }\end{array}$ & -6.24 & 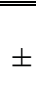 & 0.43 & -6.37 & \pm & 0.20 & 1.02 & \pm & 0.08 \\
\hline $2.4-4$ & 64 Fuel Elements & $\begin{array}{l}\text { Shutdown Margin } \\
\text { (Rod Drops) }\end{array}$ & -6.06 & \pm & 0.47 & -6.21 & \pm & 0.21 & 1.03 & \pm & 0.10 \\
\hline
\end{tabular}

Table 4.7. Alternative Calculation of Shutdown Margins.

\begin{tabular}{|c|c|c|c|c|c|c|c|c|c|c|c|}
\hline \multirow{2}{*}{ Case \# } & \multirow{2}{*}{ Core Description } & \multirow{2}{*}{$\begin{array}{l}\text { Measurement } \\
\text { (Method) }\end{array}$} & \multicolumn{3}{|c|}{ Benchmark } & \multicolumn{3}{|c|}{ Calculated } & \multirow{2}{*}{\multicolumn{3}{|c|}{$\mathbf{C} / \mathbf{E} \pm 1 \sigma$}} \\
\hline & & & $\rho \$$ & \pm & $1 \sigma$ & $\rho \$$ & \pm & $1 \sigma$ & & & \\
\hline $1.4-4$ & 62 Fuel Elements & $\begin{array}{c}\text { Shutdown Margin } \\
\text { (Rod Drops) }\end{array}$ & -6.24 & \pm & 0.43 & -6.72 & \pm & 0.34 & 1.08 & \pm & 0.09 \\
\hline $2.4-4$ & 64 Fuel Elements & $\begin{array}{l}\text { Shutdown Margin } \\
\text { (Rod Drops) }\end{array}$ & -6.06 & \pm & 0.47 & -6.26 & \pm & 0.31 & 1.02 & \pm & 0.09 \\
\hline
\end{tabular}




\author{
Fundamental - FUND \\ NRAD-FUND-RESR-002 \\ CRIT-REAC-COEF
}

\title{
4.4.3 Excess Reactivities
}

The core excess reactivity is represented by the worth of the control rod withdrawn from the core at critical. The worth of the regulating rod removed from the core is obtained by summing the partial period measurements calculated in Table 4.4a. The results are provided in Table 4.8. Calculated and benchmark results are within the $2 \sigma$ uncertainty for Case 9 and $1 \sigma$ uncertainty for Case 10 .

An alternative calculation method was performed using variations of the benchmark models with all three control rods fully withdrawn; the computed eigenvalues were subtracted from the eigenvalue calculated for the critical configurations (Table 4.1) to estimate the total worth of withdrawn regulating control rods. Results are provided in Table 4.9. Calculated and benchmark results are within the $2 \sigma$ uncertainty for Case 9 and $1 \sigma$ uncertainty for Case 10. The alternative method for calculating the core excess reactivities is comparable to the benchmark method, and does not appear to significantly overpredict the excess reactivity.

Table 4.8. Comparison of Benchmark Excess Reactivities.

\begin{tabular}{|c|c|c|c|c|c|c|c|c|c|c|c|}
\hline \multirow{2}{*}{ Case \# } & \multirow{2}{*}{ Core Description } & \multirow{2}{*}{$\begin{array}{c}\text { Measurement } \\
\text { (Method) }\end{array}$} & \multicolumn{3}{|c|}{ Benchmark } & \multicolumn{3}{|c|}{ Calculated } & \multirow{2}{*}{$\mathbf{C} / \mathbf{E}$} & \multirow[b]{2}{*}{ \pm} & \multirow{2}{*}{$1 \sigma$} \\
\hline & & & $\rho \$$ & \pm & $1 \sigma$ & $\rho \$$ & \pm & $1 \sigma$ & & & \\
\hline $1.4-5$ & 62 Fuel Elements & $\begin{array}{l}\text { Excess Reactivity } \\
\text { (Positive Periods) }\end{array}$ & 1.56 & \pm & 0.06 & 1.63 & \pm & 0.05 & 1.04 & \pm & 0.05 \\
\hline $2.4-5$ & 64 Fuel Elements & $\begin{array}{l}\text { Excess Reactivity } \\
\text { (Positive Periods) }\end{array}$ & 2.24 & \pm & 0.08 & 2.32 & \pm & 0.05 & 1.04 & \pm & 0.04 \\
\hline
\end{tabular}

Table 4.9. Alternative Calculation of Excess Reactivities.

\begin{tabular}{|c|c|c|c|c|c|c|c|c|c|c|c|}
\hline \multirow{2}{*}{ Case \# } & \multirow{2}{*}{ Core Description } & \multirow{2}{*}{$\begin{array}{l}\text { Measurement } \\
\text { (Method) }\end{array}$} & \multicolumn{3}{|c|}{ Benchmark } & \multicolumn{3}{|c|}{ Calculated } & \multirow{2}{*}{\multicolumn{3}{|c|}{$\mathbf{C} / \mathbf{E} \pm 1 \sigma$}} \\
\hline & & & & \pm & $1 \sigma$ & $\rho \$$ & \pm & $1 \sigma$ & & & \\
\hline $1.4-5$ & 62 Fuel Elements & $\begin{array}{l}\text { Excess Reactivity } \\
\text { (Positive Period) }\end{array}$ & 1.56 & \pm & 0.06 & 1.65 & \pm & 0.08 & 1.06 & \pm & 0.07 \\
\hline $2.4-5$ & 64 Fuel Elements & $\begin{array}{l}\text { Excess Reactivity } \\
\text { (Positive Period) }\end{array}$ & 2.24 & \pm & 0.08 & 2.25 & \pm & 0.11 & 1.00 & \pm & 0.06 \\
\hline
\end{tabular}




\subsection{Results of Reactivity Coefficient Calculations}

Reactivity coefficient measurements have not been evaluated.

\subsection{Results of Kinetics Parameter Calculations}

Kinetics measurements were not performed.

\subsection{Results of Reaction-Rate Distribution Calculations}

Reaction-rate distribution measurements were not performed.

\subsection{Results of Power Distribution Calculations}

Power distribution measurements were not performed.

\subsection{Results of Isotopic Calculations}

Isotopic measurements were not performed.

\subsection{Results of Calculations for Other Miscellaneous Types of Measurements}

Other miscellaneous types of measurements were not performed. 
NEA/NSC/DOC(2006)1

Fundamental - FUND

NRAD-FUND-RESR-002

CRIT-REAC-COEF

\subsection{REFERENCES}

There are no available public references. 
NEA/NSC/DOC(2006)1

Fundamental - FUND

NRAD-FUND-RESR-002

CRIT-REAC-COEF

\section{APPENDIX A: COMPUTER CODES, CROSS SECTIONS, AND TYPICAL INPUT LISTINGS}

\section{A.1 Critical/Subcritical Configurations}

\section{A.1.1 Name(s) of code system(s) used.}

1. Monte Carlo n-Particle, version 5-1.60 (MCNP5).

2. KENO-VI (SCALE 6.1).

3. SERPENT versions 1.1.17 and 2.1.13.

\section{A.1.2 Bibliographic references for the codes used.}

1. X-5 Monte Carlo Team, "MCNP - a General Monte Carlo n-Particle Transport Code, version 5," LA-UR-03-1987, Los Alamos National Laboratory (2003).

2. D. F. Hollenbach, L. M. Petrie, S. Goluoglu, N. F. Landers, and M. E. Dunn, "KENO-VI: A General Quadratic Version of the KENO Program," ORNL/TM-2005/39 Version 6 Vol. II, Sect. F17, Oak Ridge National Laboratory (January 2009).

3. J. Leppänen, "Development of a New Monte Carlo Reactor Physics Code," D.C. Thesis, Helsinki University of Technology, VTT Publications 640, VTT Technical Research Centre, Finland, (2007).

\section{A.1.3 Origin of cross-section data.}

The Evaluated Neutron Data File library, ENDF/B-VII.0 $0^{\text {a }}$ was utilized in the benchmark model analysis. The European Joint Evaluated Fission and Fusion File, JEFF-3.1, ${ }^{\mathrm{b}}$ the Japanese Evaluated Nuclear Data Library, JENDL-3.3 ${ }^{\mathrm{c}}$ and ENDF/B-VI. $8^{\mathrm{d}}$ were also included for a basic evaluative comparison. The JENDL-3.3 analysis was performed with the inclusion of ENDF/BVII.0 thermal neutron scattering data because it was not available with the JENDL-3.3 library. Thermal neutron scattering, or $S(\alpha, \beta)$, adjusts the neutron cross sections for neutron upscatter at thermal energies and provides scattering data for elements bound within specific materials.

\section{A.1.4 Spectral calculations and data reduction methods used.}

Not applicable.

\section{A.1.5 Number of energy groups or if continuous-energy cross sections are used in the different phases of calculation.}

1. Continuous-energy cross sections (MCNP5 and KENO-VI).

2. 238-group cross sections (KENO-VI).

\footnotetext{
${ }^{a}$ M. B. Chadwick, et al., "ENDF/B-VII.0: Next Generation Evaluated Nuclear Data Library for Nuclear Science and Technology," Nucl. Data Sheets, 107: 2931-3060 (2006).

${ }^{\mathrm{b}}$ A. Koning, R. Forrest, M. Kellett, R. Mills, H. Henriksson, and Y. Rugama, "The JEFF-3.1 Nuclear Data Library," JEFF Report 21, Organisation for Economic Co-operation and Development, Paris (2006).

${ }^{c}$ K. Shibata, et al., “Japanese Evaluated Nuclear Data Library Version 3 Revision3: JENDL-3.3,” J. Nucl. Sci. Tech., 39: 1125-1136 (November 2002).

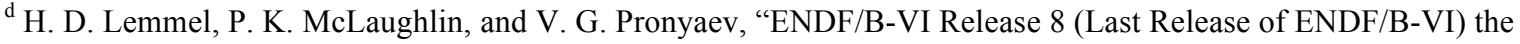
U.S. Evaluated Nuclear Data Library for Neutron Reaction Data," IAEA-NDS-100 Rev. 11, International Atomic Energy Agency, Vienna (November 2001).
} 


\section{A.1.6 Component calculations.}

- Type of cell calculation - Reactor core, reflectors, and moderator

- Geometry - Fuel pin and assembly lattice

- Theory used - Not applicable

- Method used - Monte Carlo

- Calculation characteristics

- MCNP5 and KENO-VI - histories/cycles/cycles skipped $=100,000 / 1,550 / 50$ continuous-energy cross sections

- KENO-VI - histories/cycles/cycles skipped $=100,000 / 1,550 / 50$ 238-group cross sections

- SERPENT - histories/cycles/cycles skipped $=100,000 / 2,550 / 50$ continuous-energy cross sections

\section{A.1.7 Other assumptions and characteristics.}

Not applicable.

\section{A.1.8 Typical input listings for each code system type.}

MCNP5 Input Deck for the 62-fuel-element intermediary core configuration (Case 1):

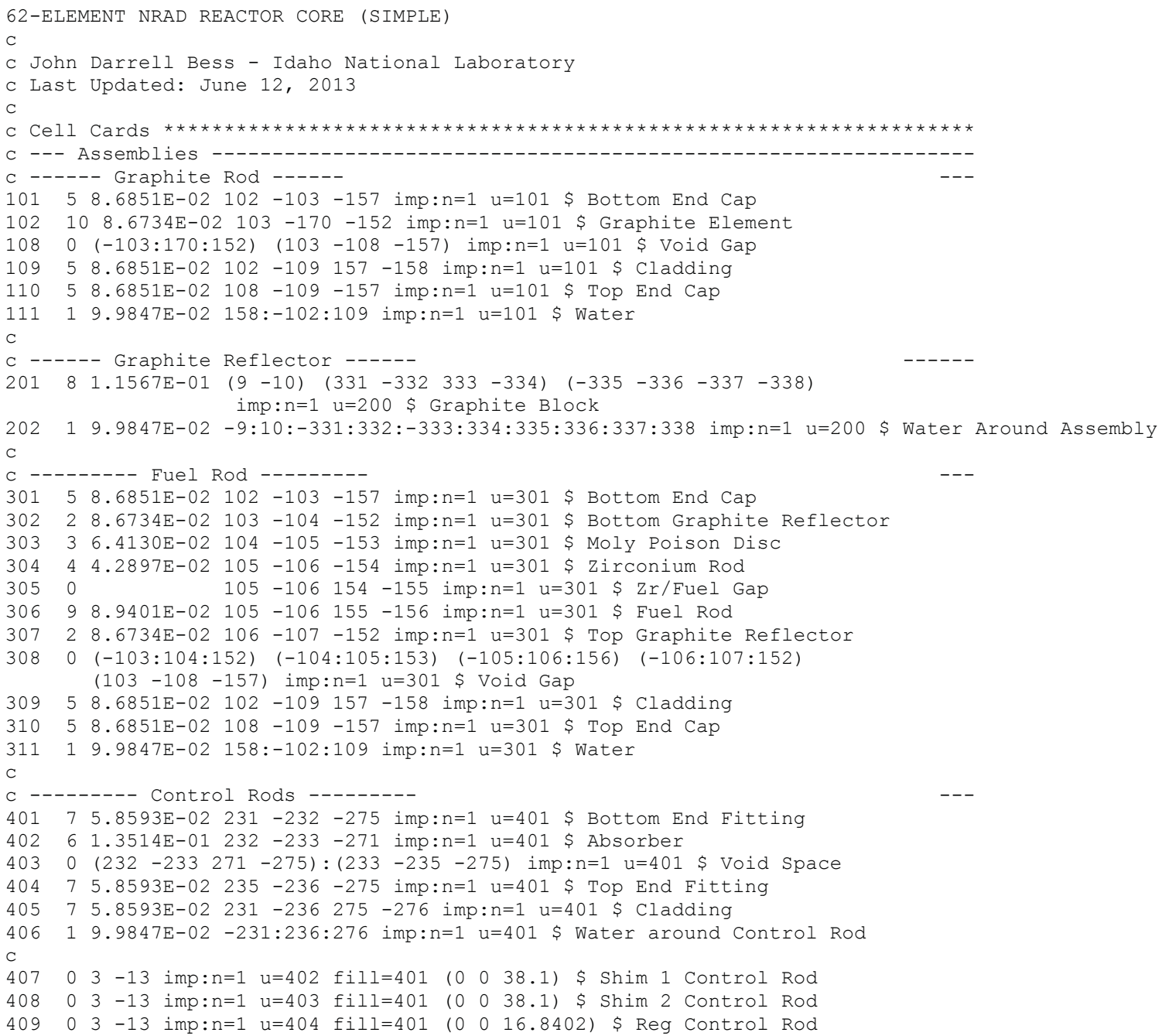




\section{NEA/NSC/DOC(2006)1}

\section{Fundamental - FUND}

\section{NRAD-FUND-RESR-002}

CRIT-REAC-COEF

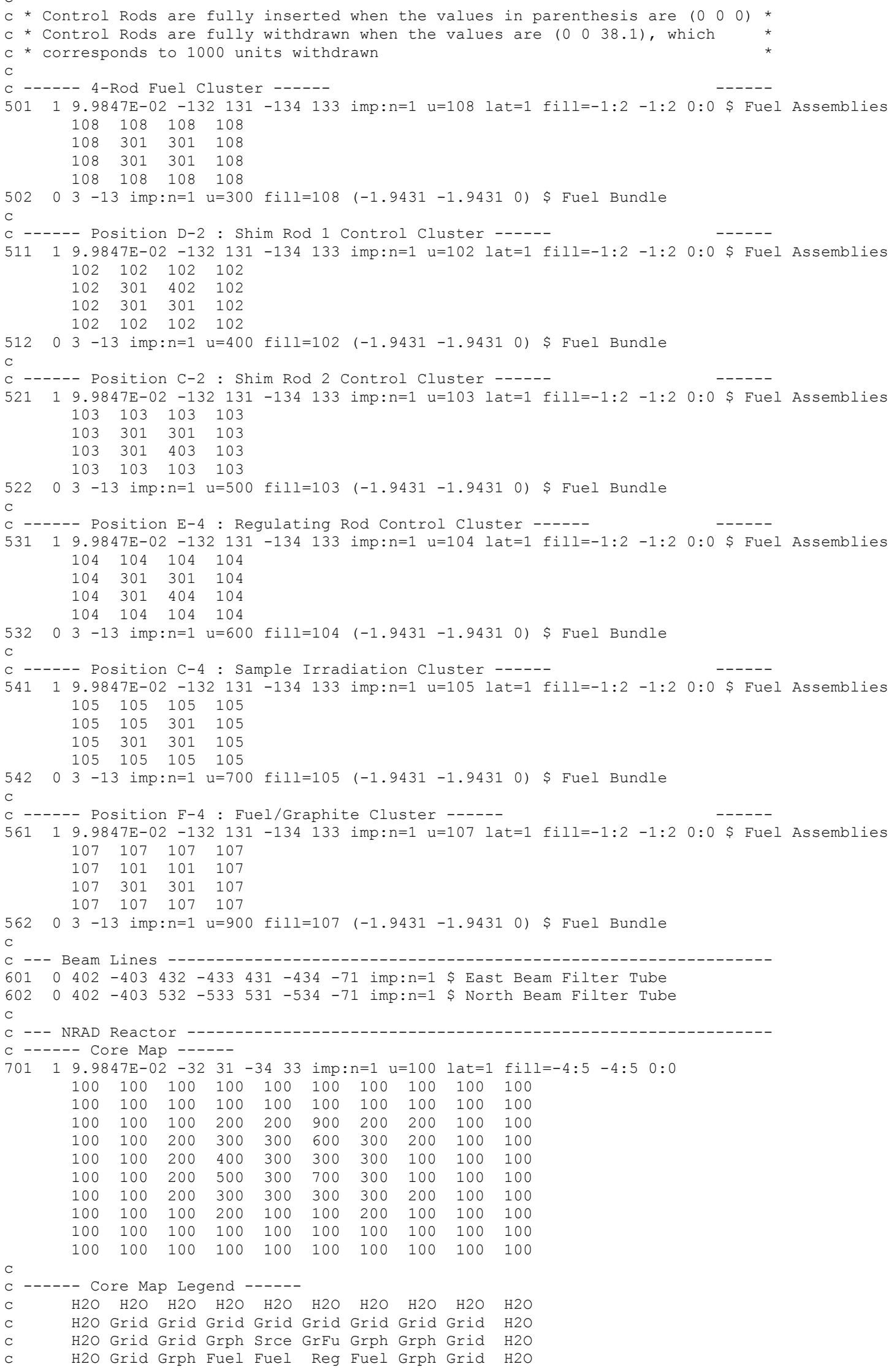


NEA/NSC/DOC(2006)1

\section{Fundamental - FUND}

\section{NRAD-FUND-RESR-002 \\ CRIT-REAC-COEF}

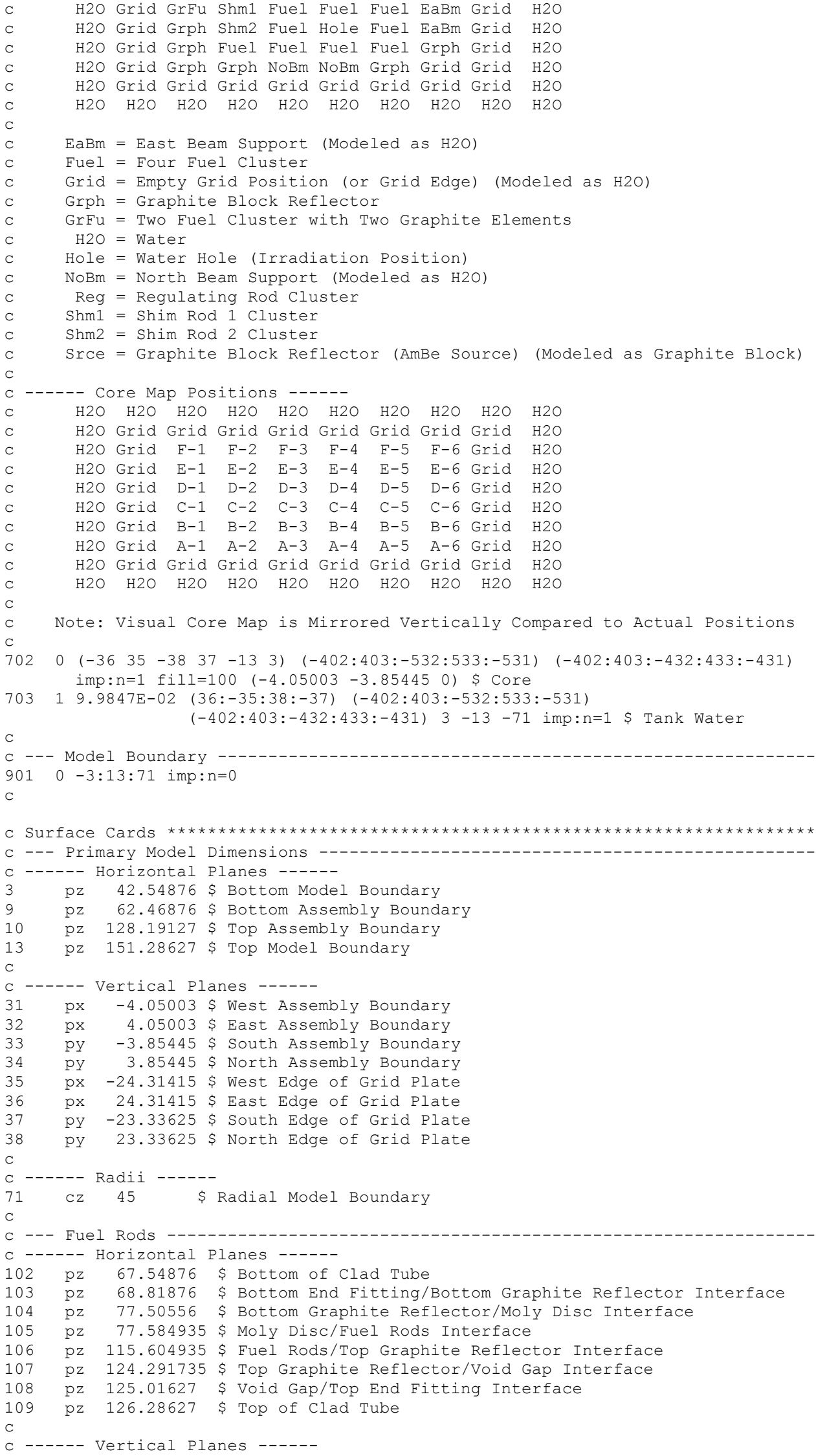


NEA/NSC/DOC(2006)1

\section{Fundamental - FUND}

\section{NRAD-FUND-RESR-002 \\ CRIT-REAC-COEF}

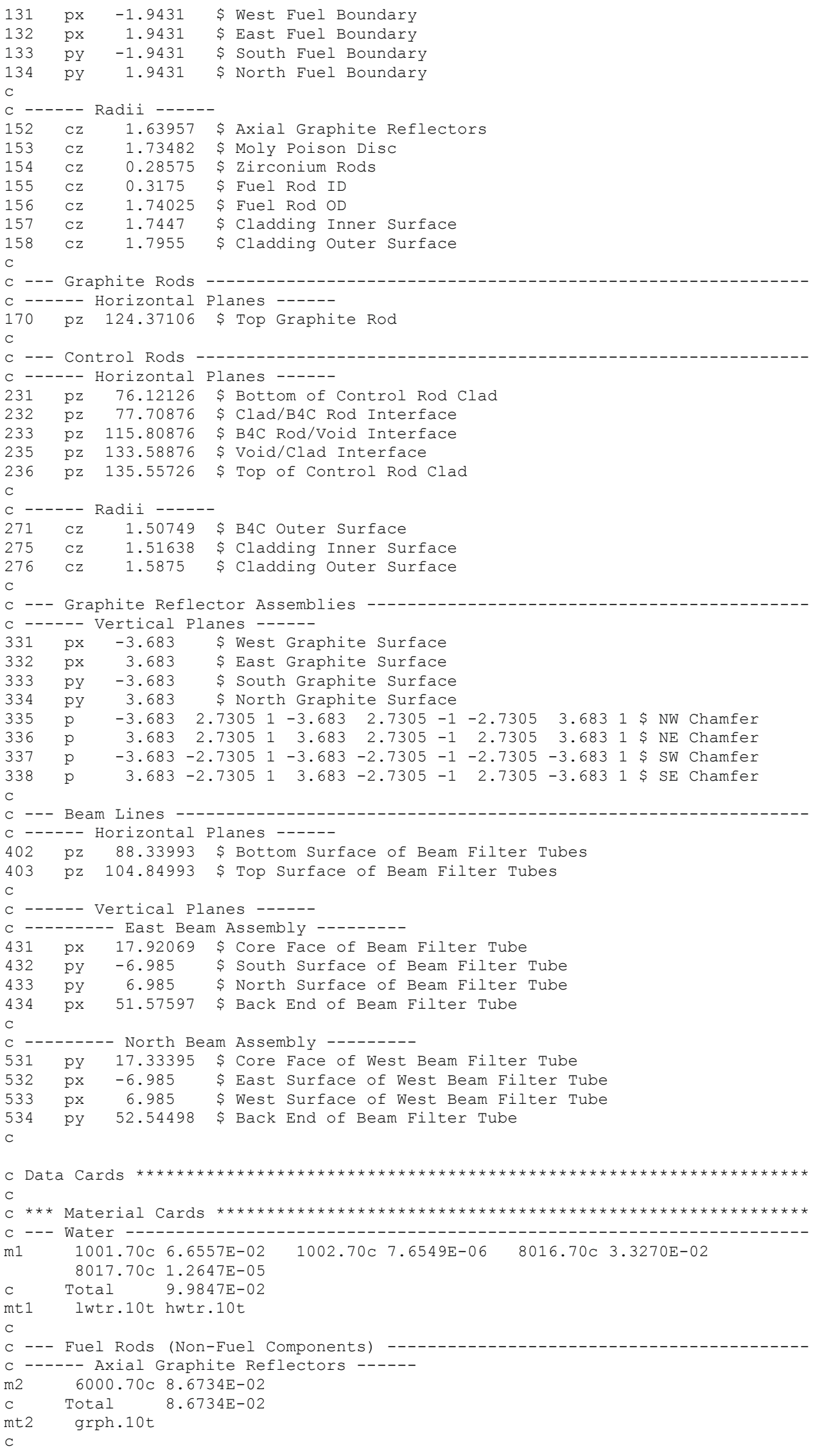


NEA/NSC/DOC(2006)1

\section{Fundamental - FUND}

\section{NRAD-FUND-RESR-002}

CRIT-REAC-COEF

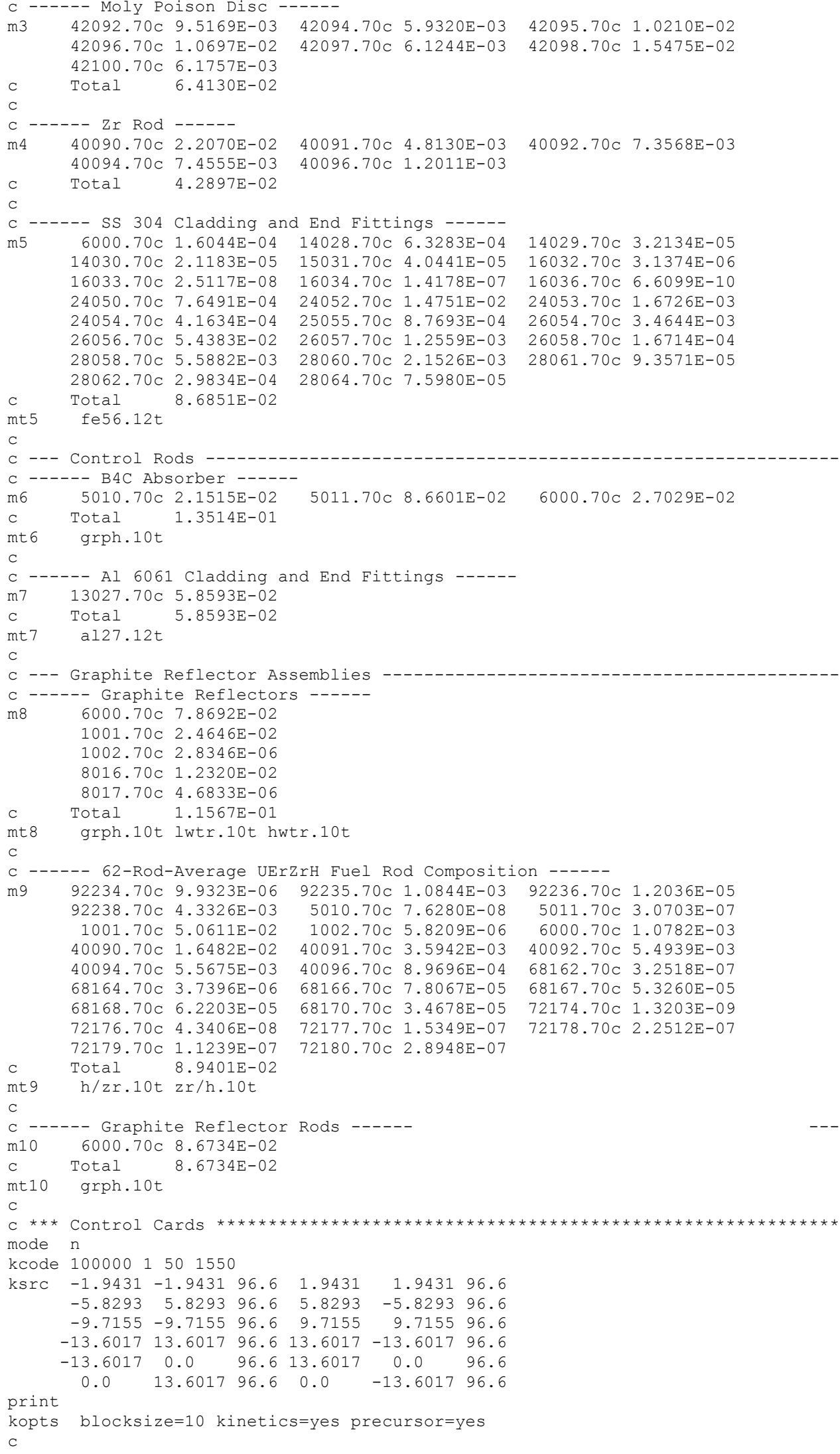


NEA/NSC/DOC(2006)1

Fundamental - FUND

NRAD-FUND-RESR-002

CRIT-REAC-COEF

\section{MCNP5 Input Deck for the 64-fuel-element upgraded core configuration (Case 2):}

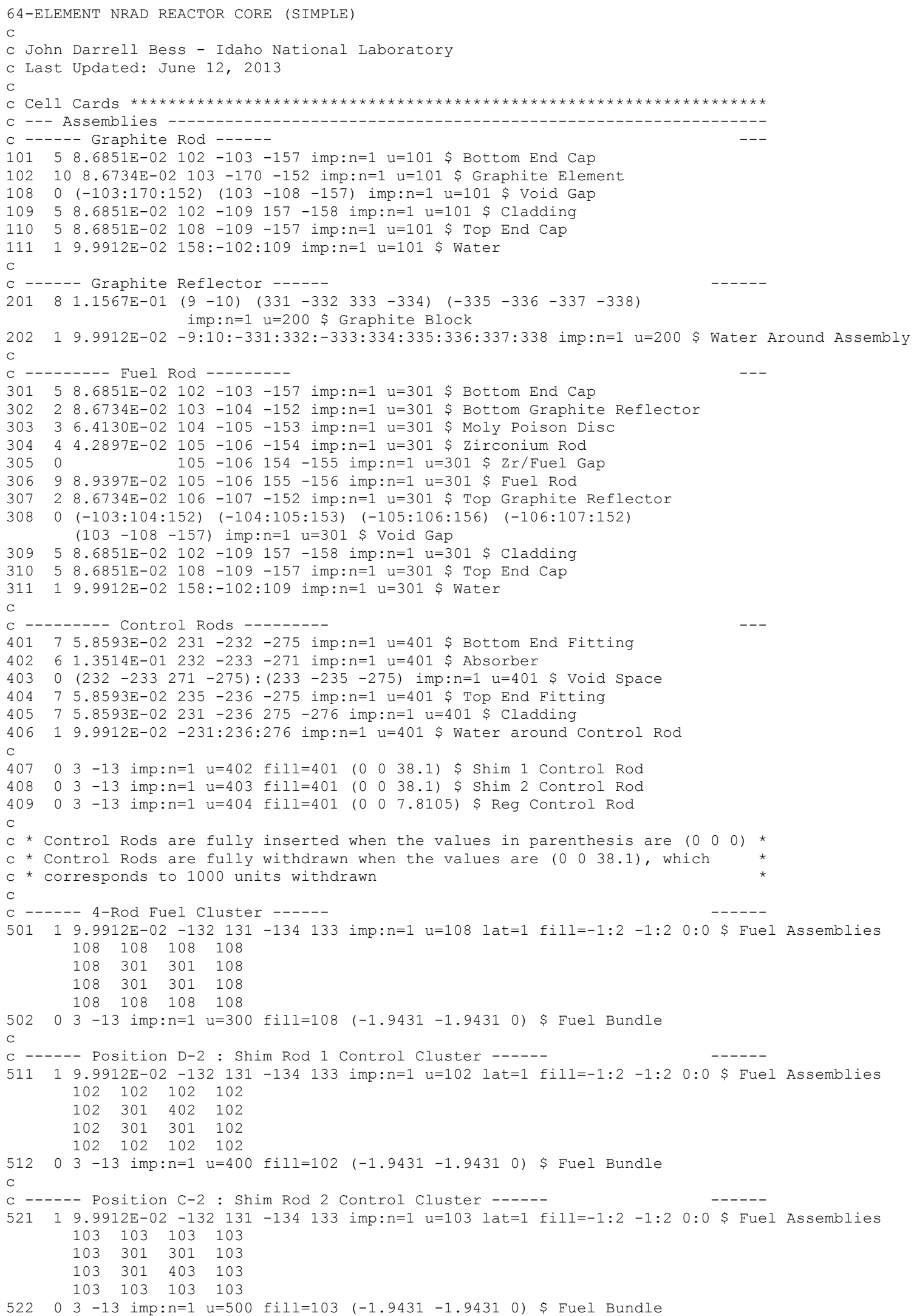




\section{NEA/NSC/DOC(2006)1}

\section{Fundamental - FUND}

\section{NRAD-FUND-RESR-002}

CRIT-REAC-COEF

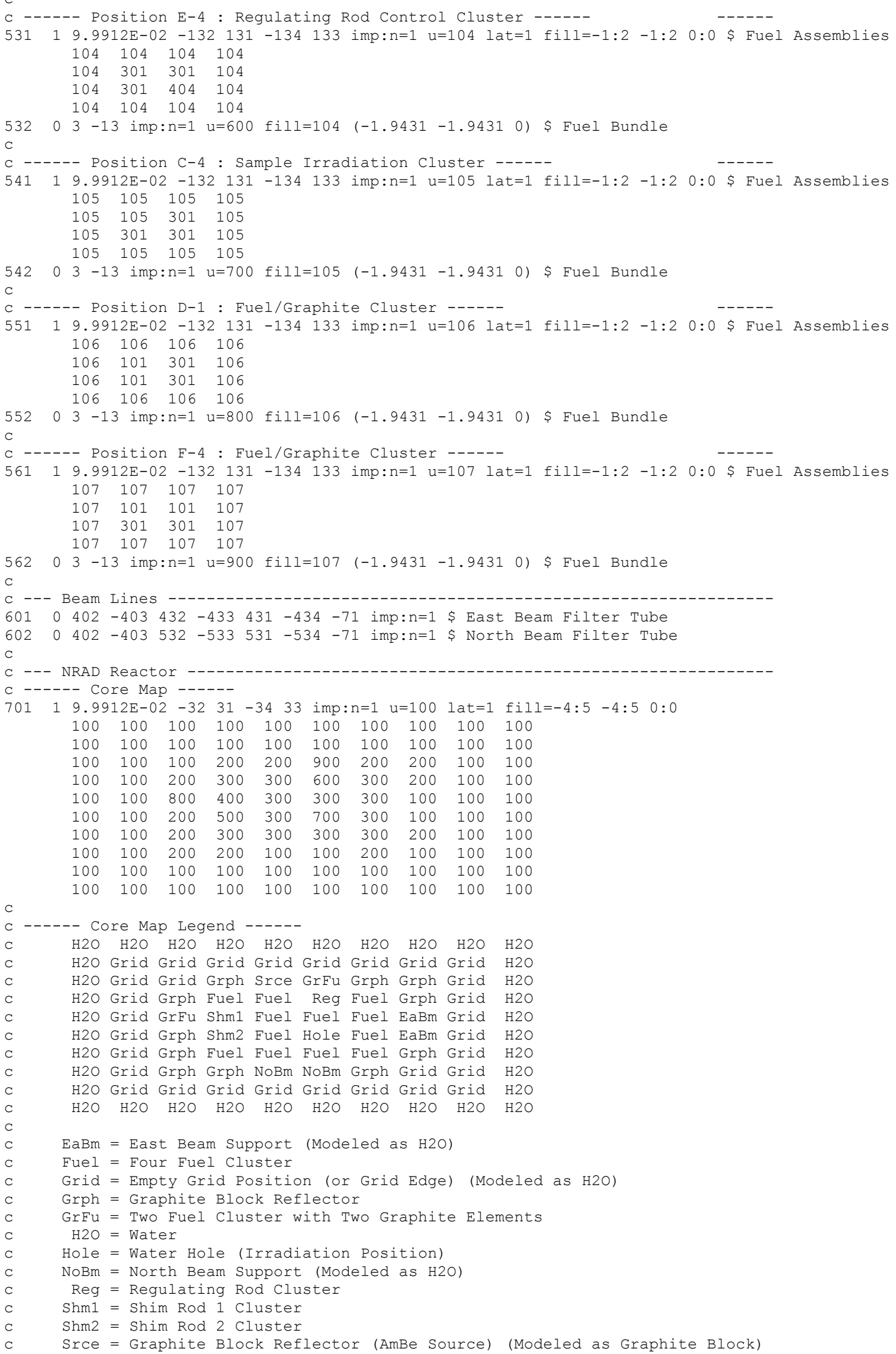


NEA/NSC/DOC(2006)1

\section{Fundamental - FUND}

\section{NRAD-FUND-RESR-002 \\ CRIT-REAC-COEF}

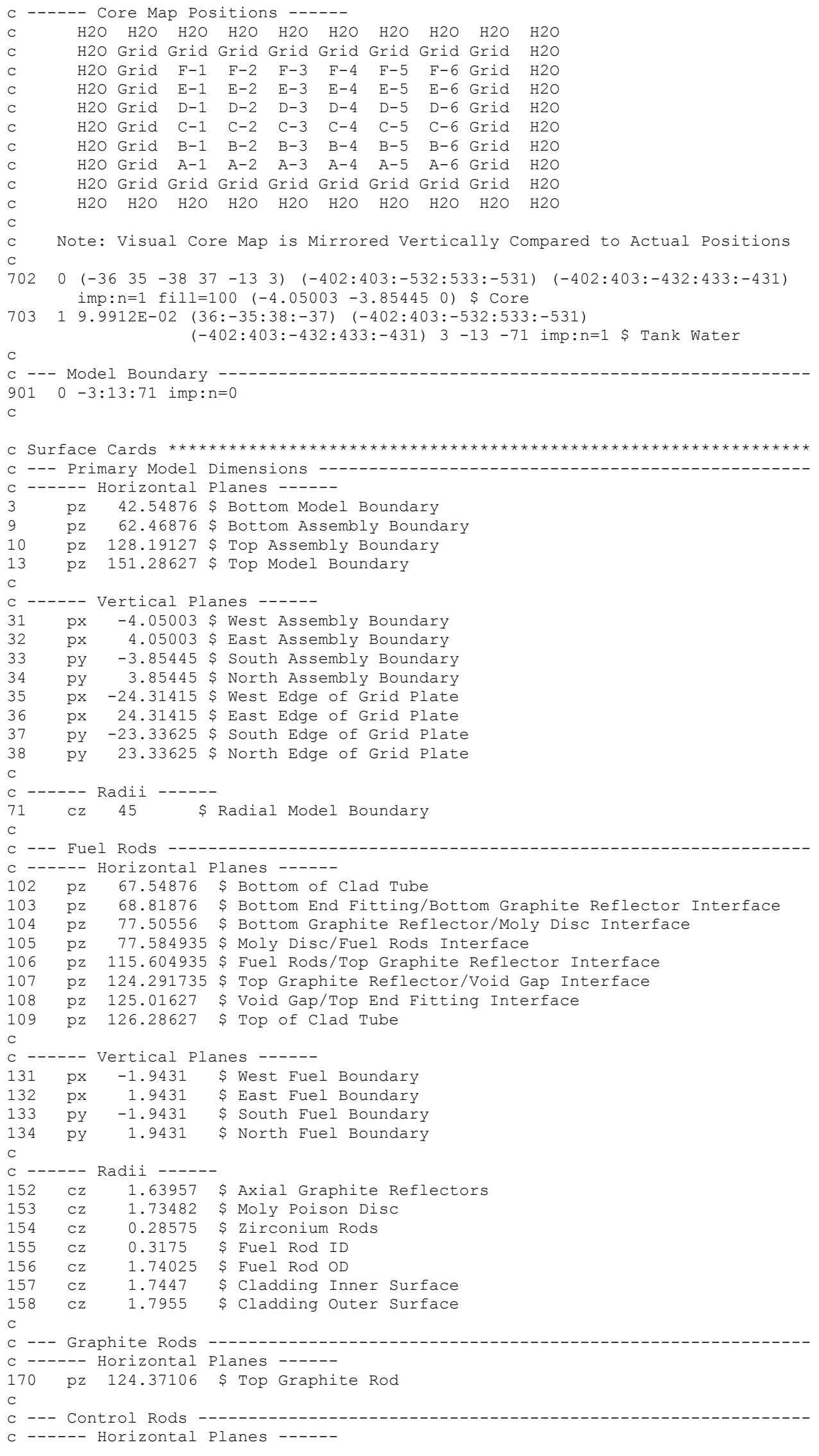


NEA/NSC/DOC(2006)1

\section{Fundamental - FUND}

\section{NRAD-FUND-RESR-002 \\ CRIT-REAC-COEF}

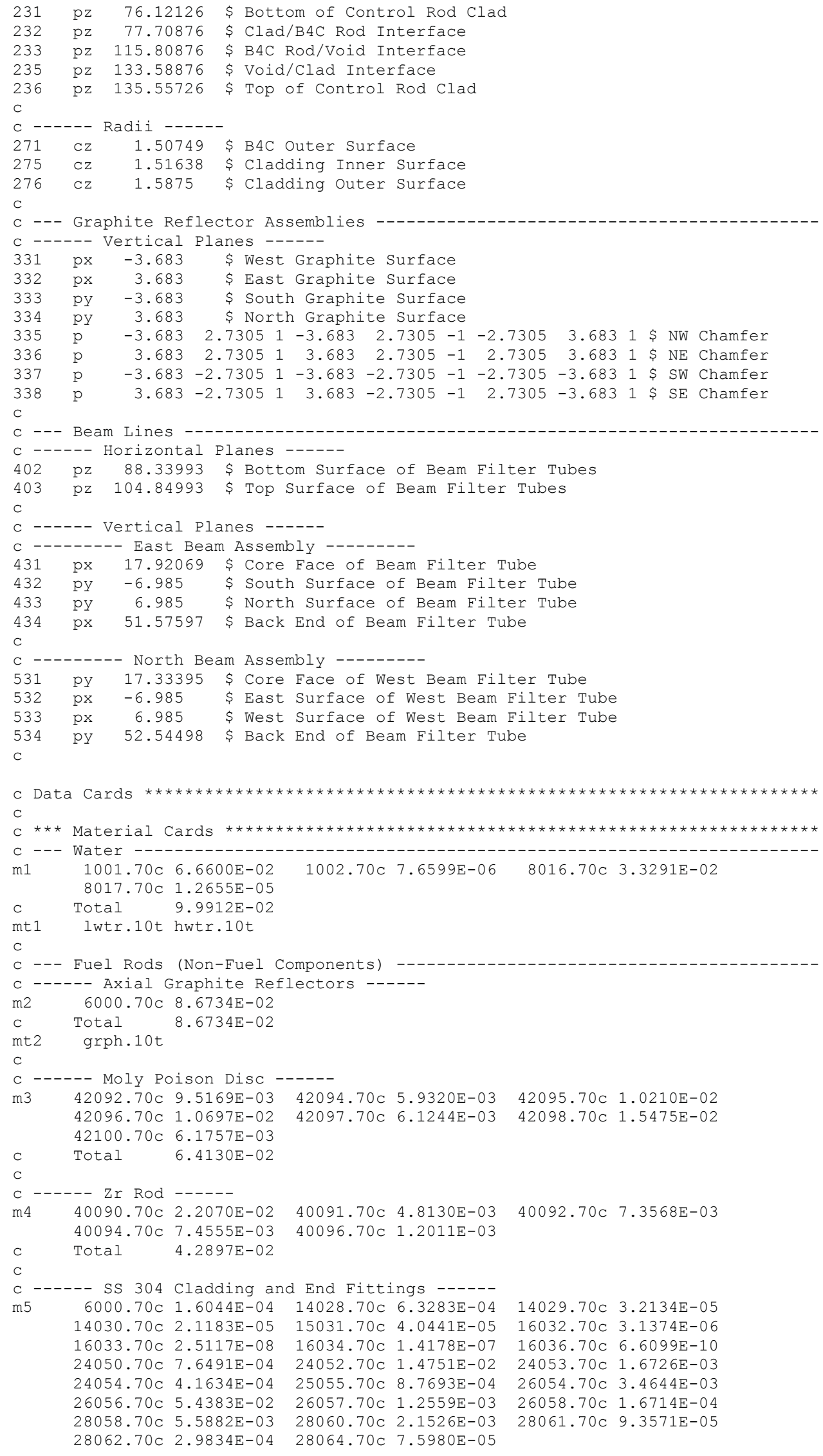


NEA/NSC/DOC(2006)1

Fundamental - FUND

NRAD-FUND-RESR-002

CRIT-REAC-COEF

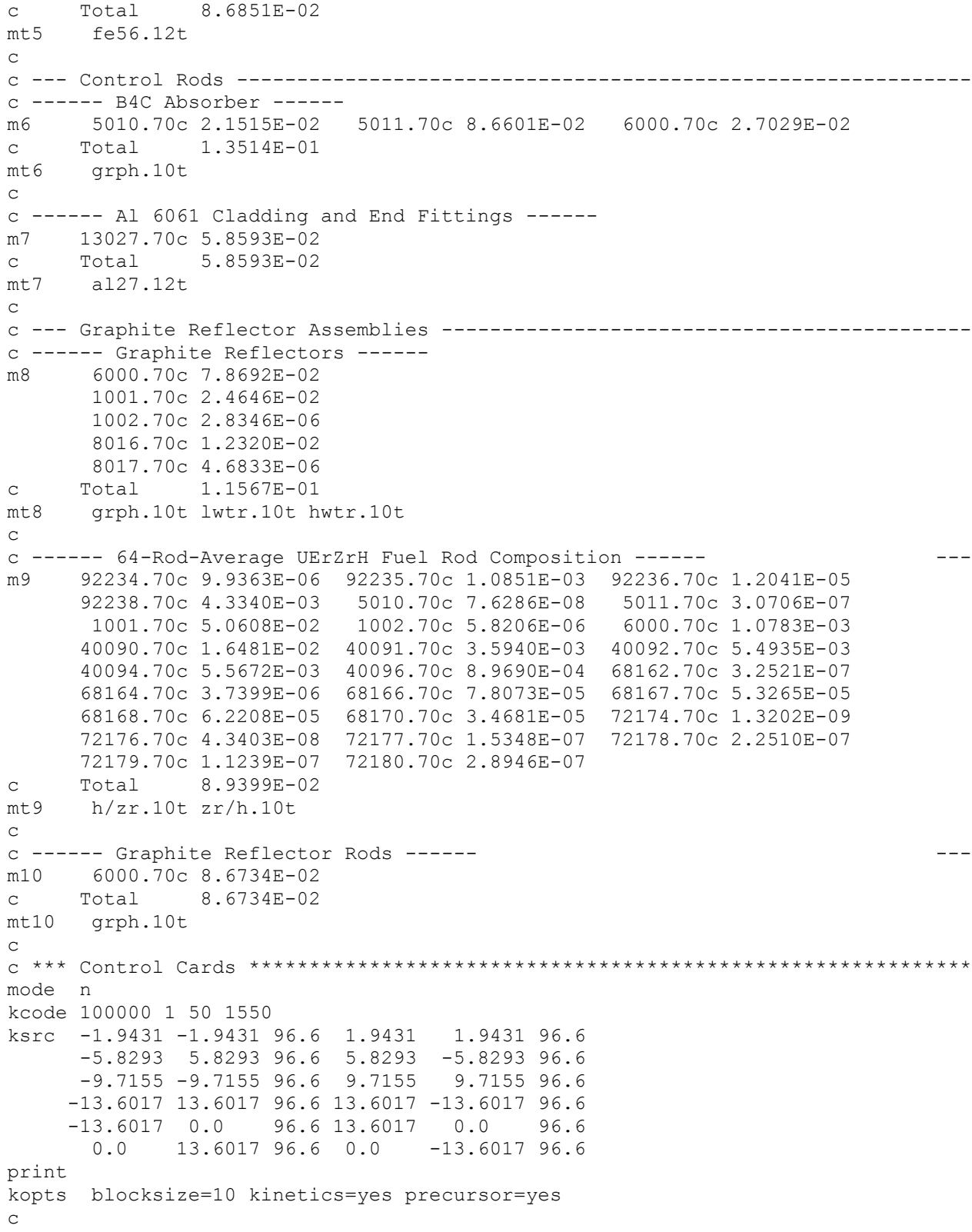




\section{NEA/NSC/DOC(2006)1}

\section{Fundamental - FUND}

\section{NRAD-FUND-RESR-002 \\ CRIT-REAC-COEF}

KENO Input Deck for the 62-fuel-element intermediary core configuration (Case 1):

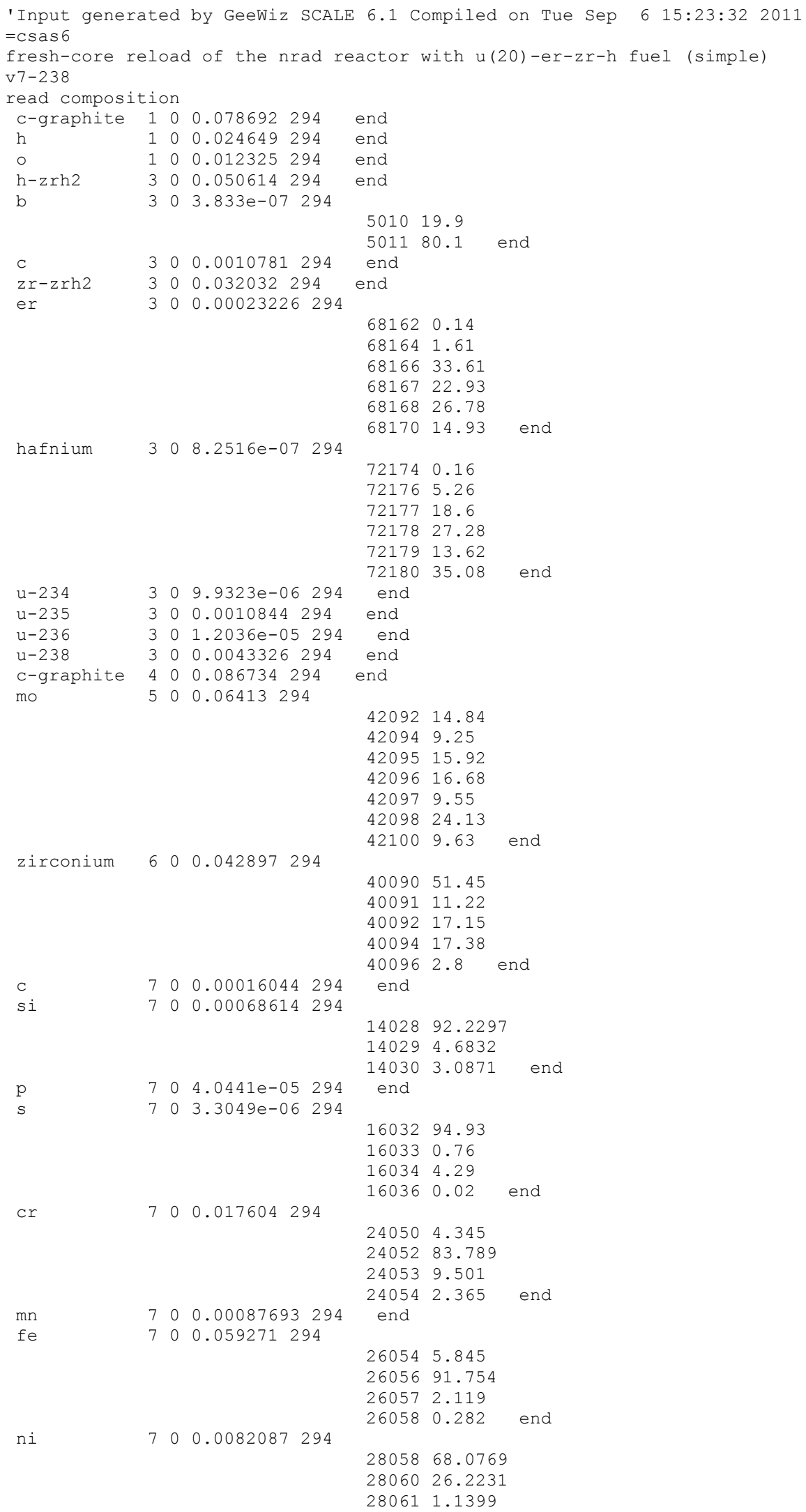


NEA/NSC/DOC(2006)1

\section{Fundamental - FUND}

\section{NRAD-FUND-RESR-002} CRIT-REAC-COEF

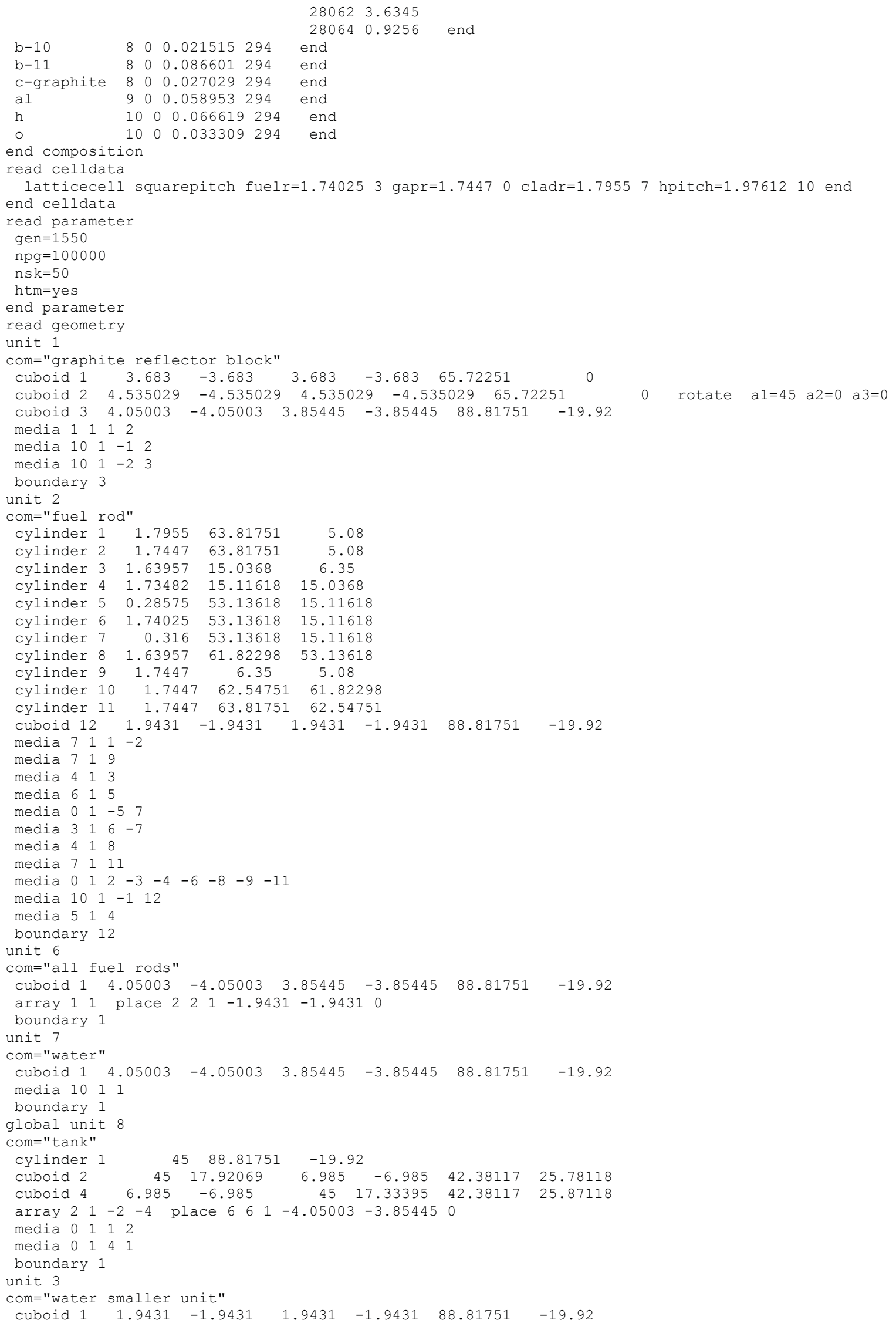


NEA/NSC/DOC(2006)1

Fundamental - FUND

NRAD-FUND-RESR-002

CRIT-REAC-COEF

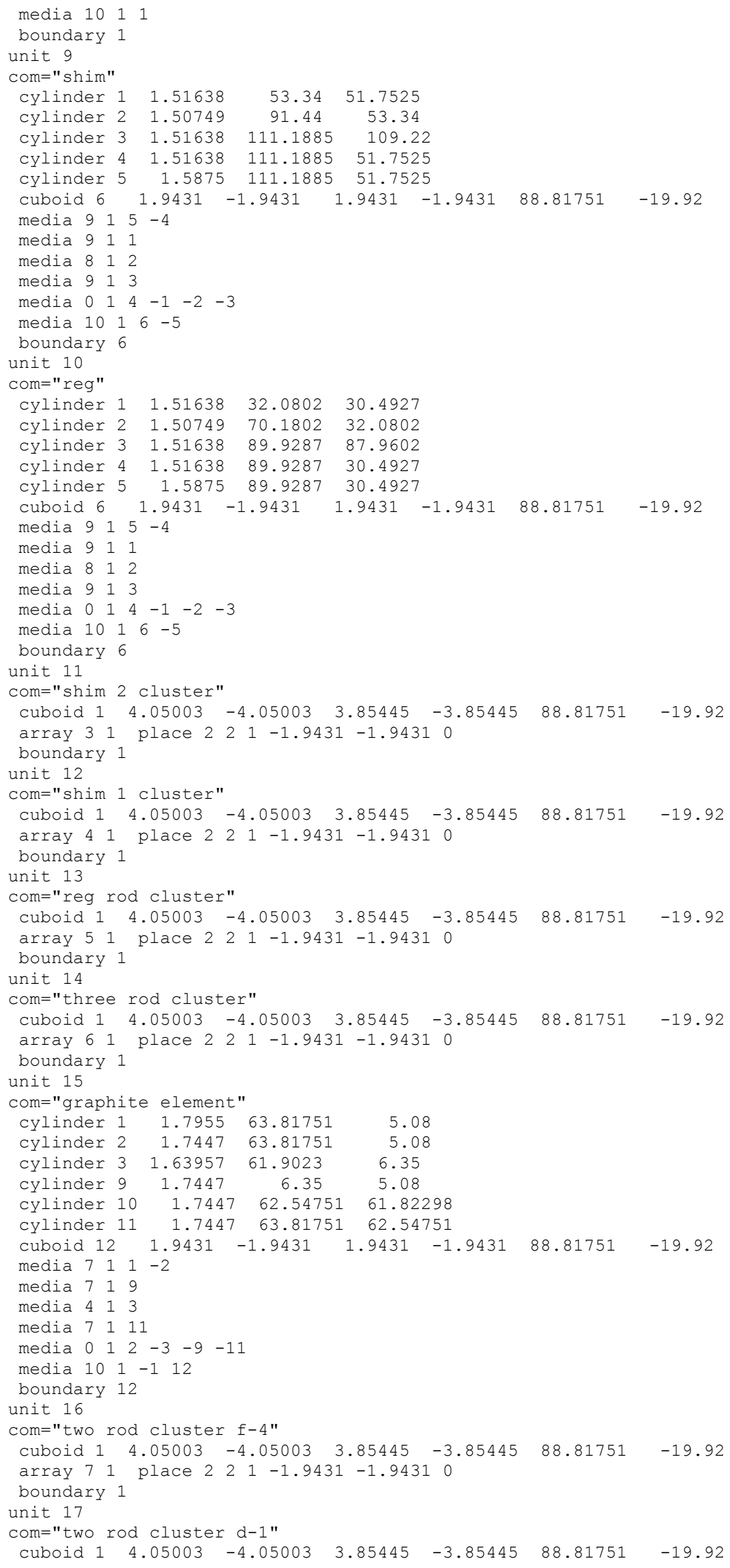


Fundamental - FUND

NRAD-FUND-RESR-002

CRIT-REAC-COEF

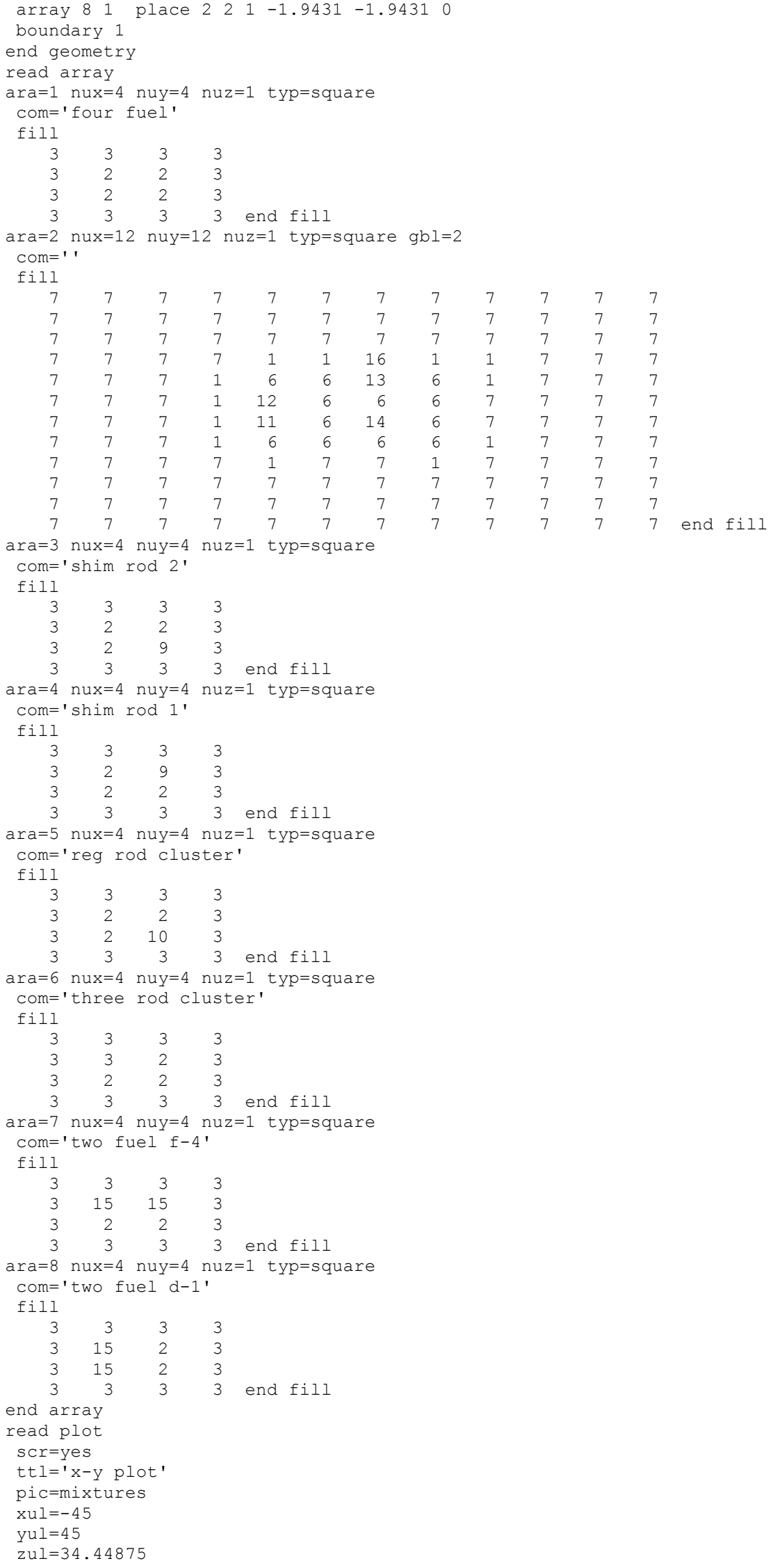


NEA/NSC/DOC(2006)1

Fundamental - FUND

NRAD-FUND-RESR-002

CRIT-REAC-COEF

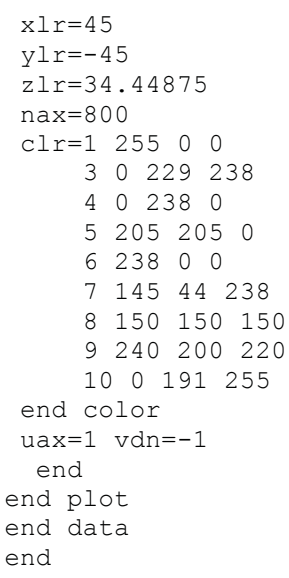




\section{NEA/NSC/DOC(2006)1}

\section{Fundamental - FUND}

\section{NRAD-FUND-RESR-002 \\ CRIT-REAC-COEF}

KENO Input Deck for the 64-fuel-element upgraded core configuration (Case 2):

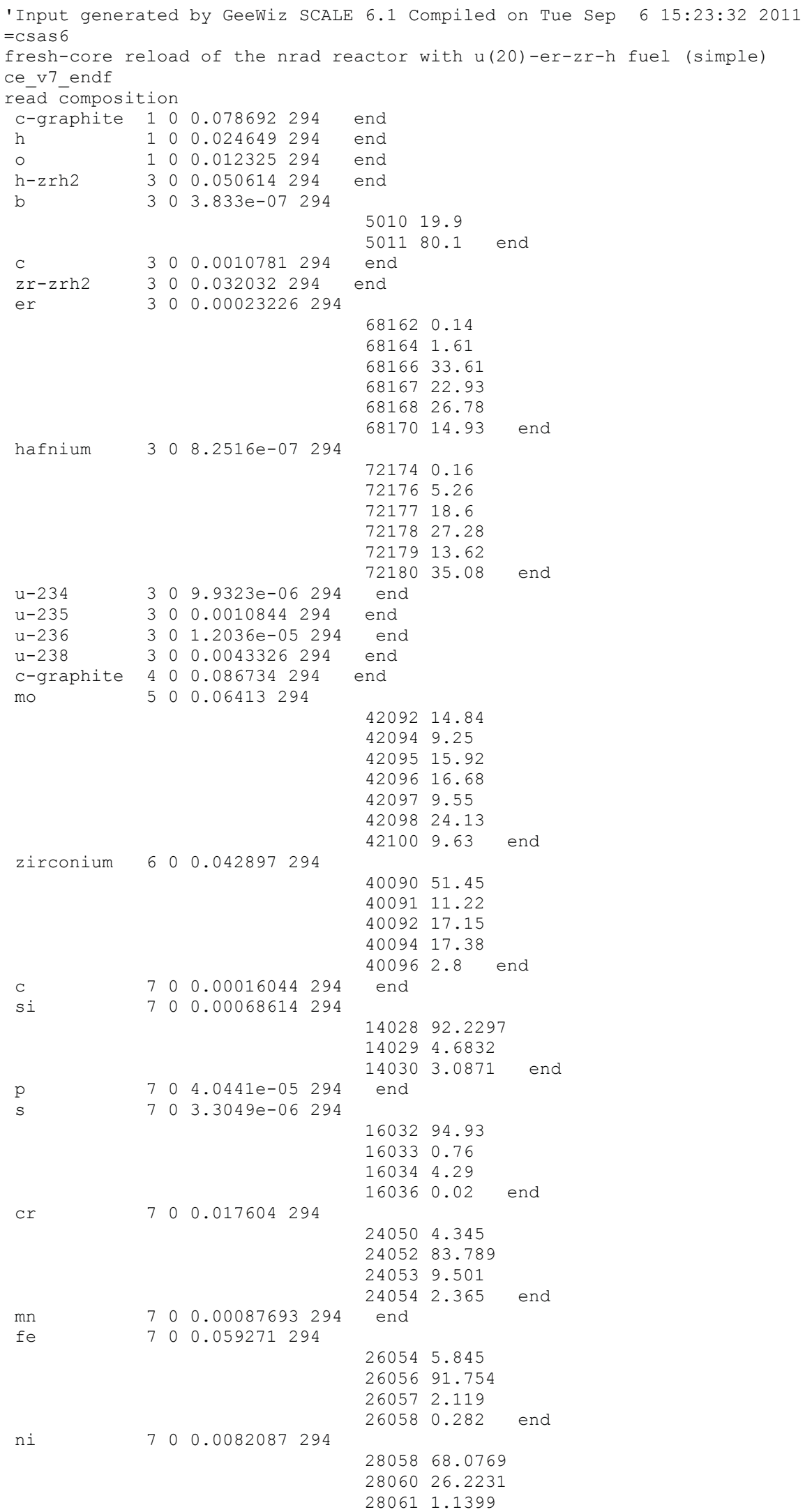


NEA/NSC/DOC(2006)1

\section{Fundamental - FUND}

\section{NRAD-FUND-RESR-002} CRIT-REAC-COEF

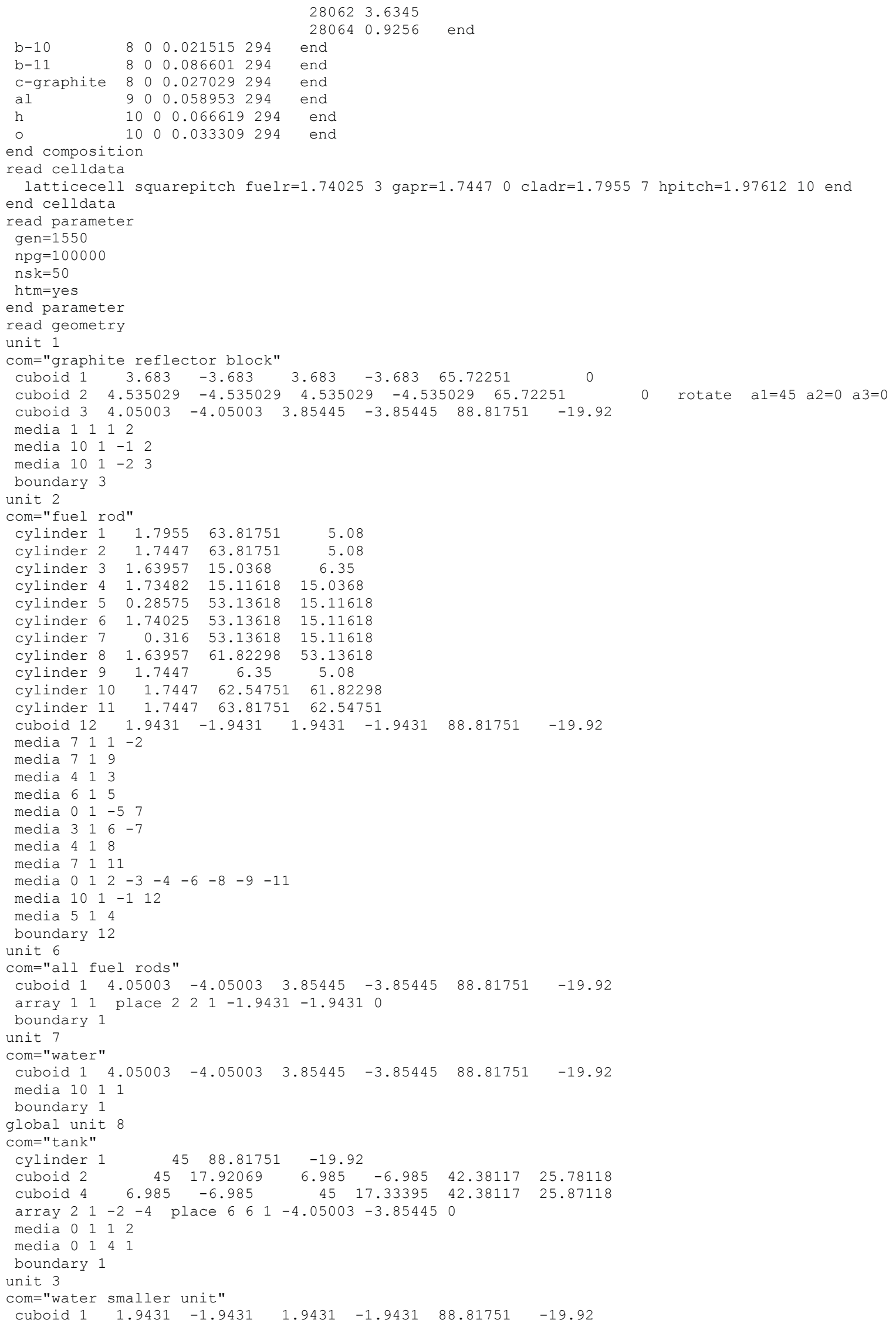


NEA/NSC/DOC(2006)1

Fundamental - FUND

NRAD-FUND-RESR-002

CRIT-REAC-COEF

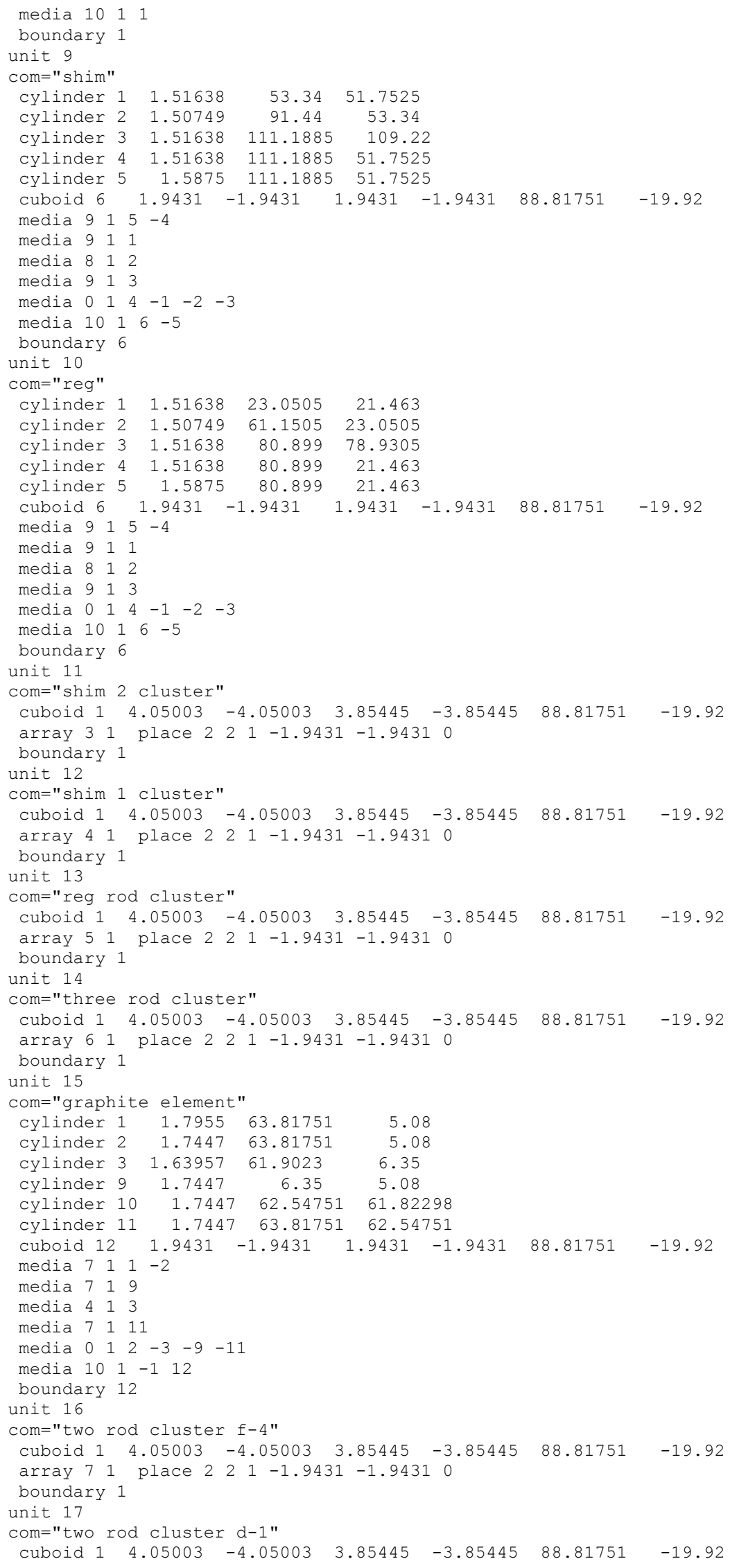


Fundamental - FUND

NRAD-FUND-RESR-002

CRIT-REAC-COEF

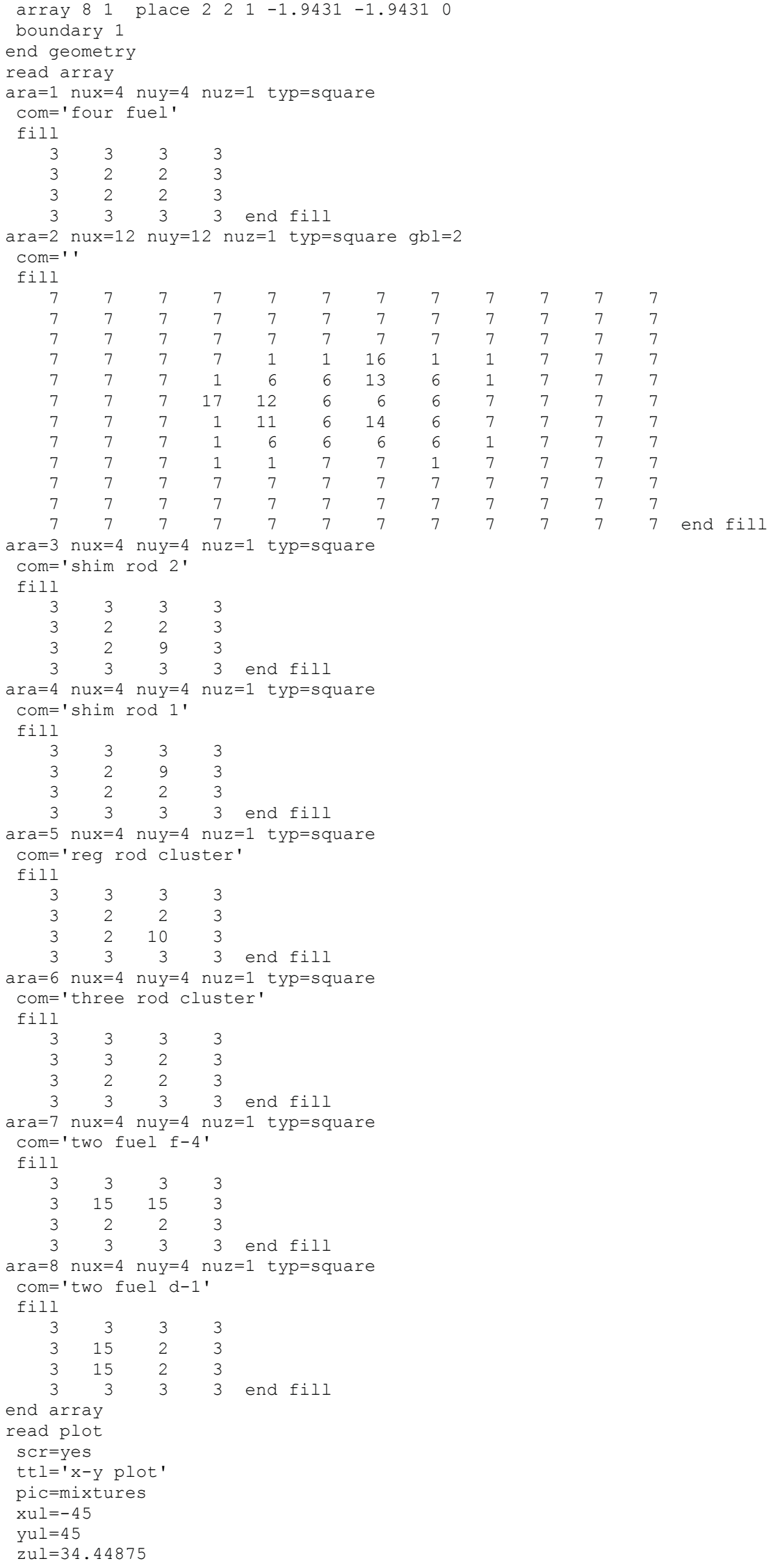


NEA/NSC/DOC(2006)1

Fundamental - FUND

NRAD-FUND-RESR-002

CRIT-REAC-COEF

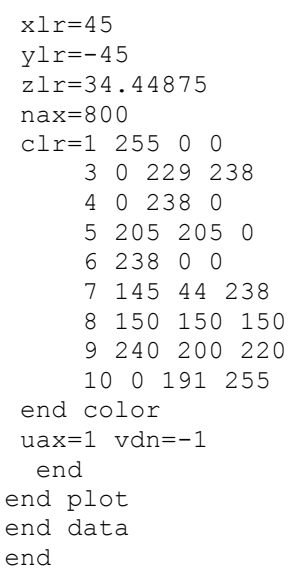


NEA/NSC/DOC(2006)1

Fundamental - FUND

NRAD-FUND-RESR-002

CRIT-REAC-COEF

SERPENT Input Deck for the 62-fuel-element intermediary core configuration (Case 1):

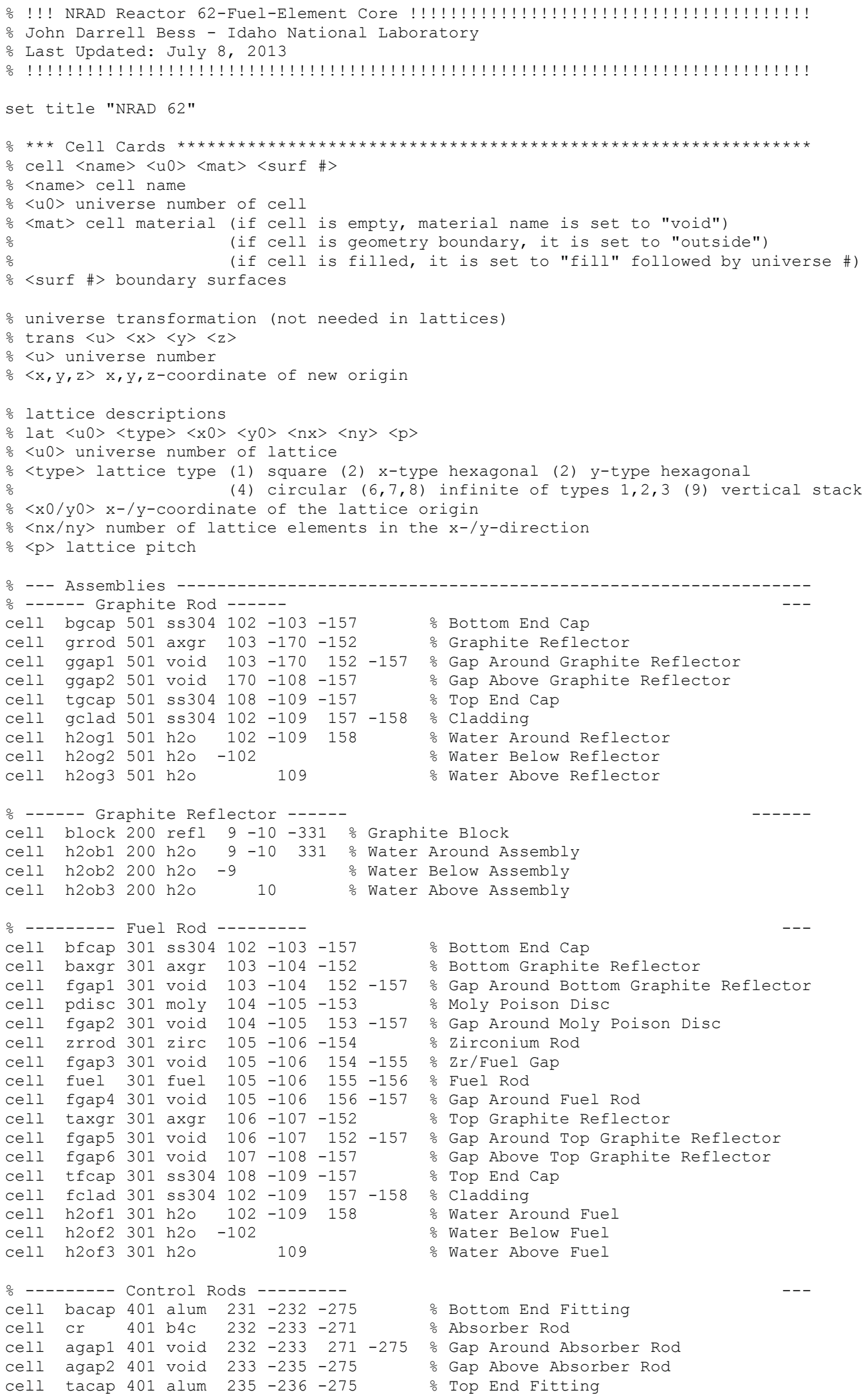


NEA/NSC/DOC(2006)1

\section{Fundamental - FUND}

NRAD-FUND-RESR-002

CRIT-REAC-COEF

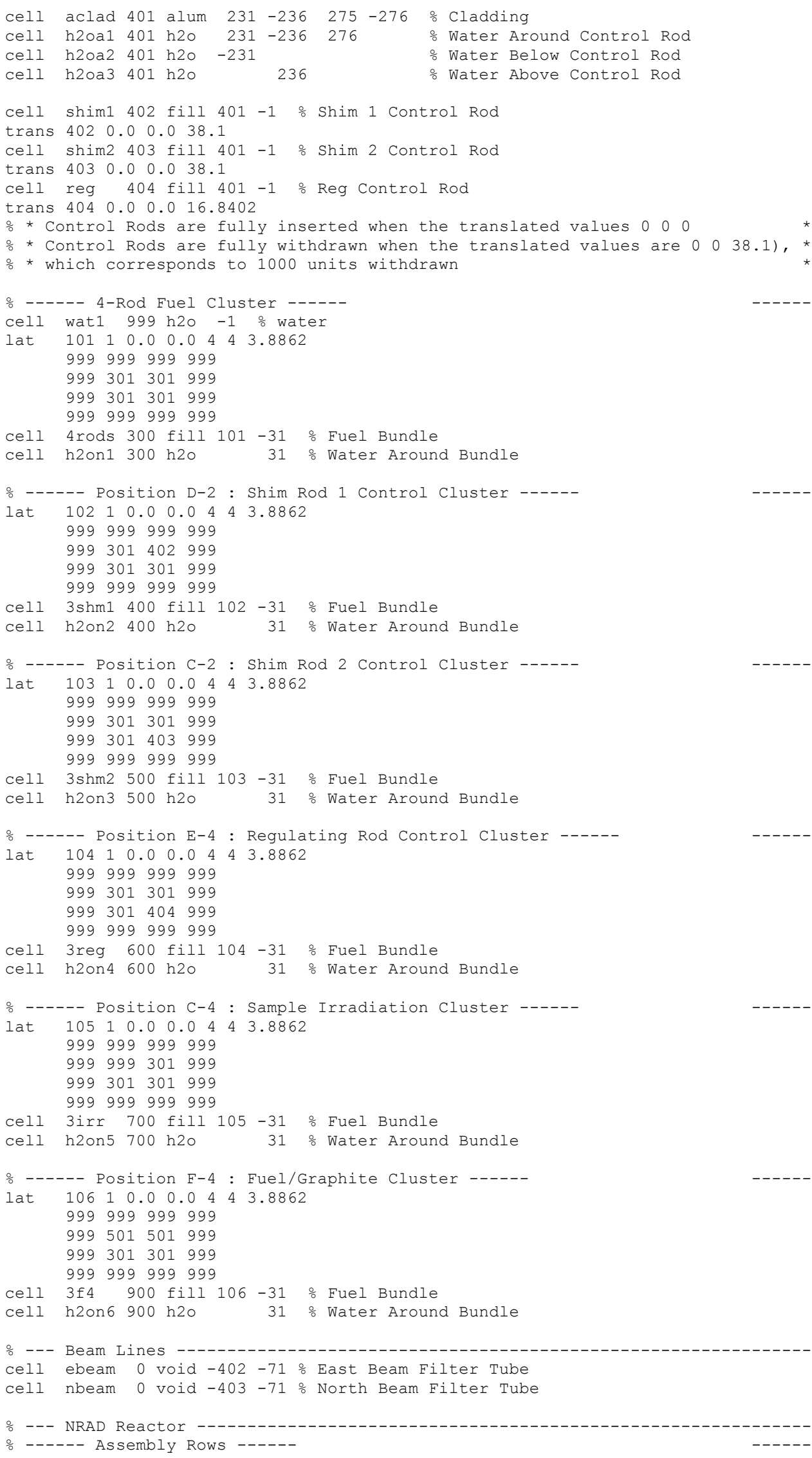


NEA/NSC/DOC(2006)1

Fundamental - FUND

NRAD-FUND-RESR-002

CRIT-REAC-COEF

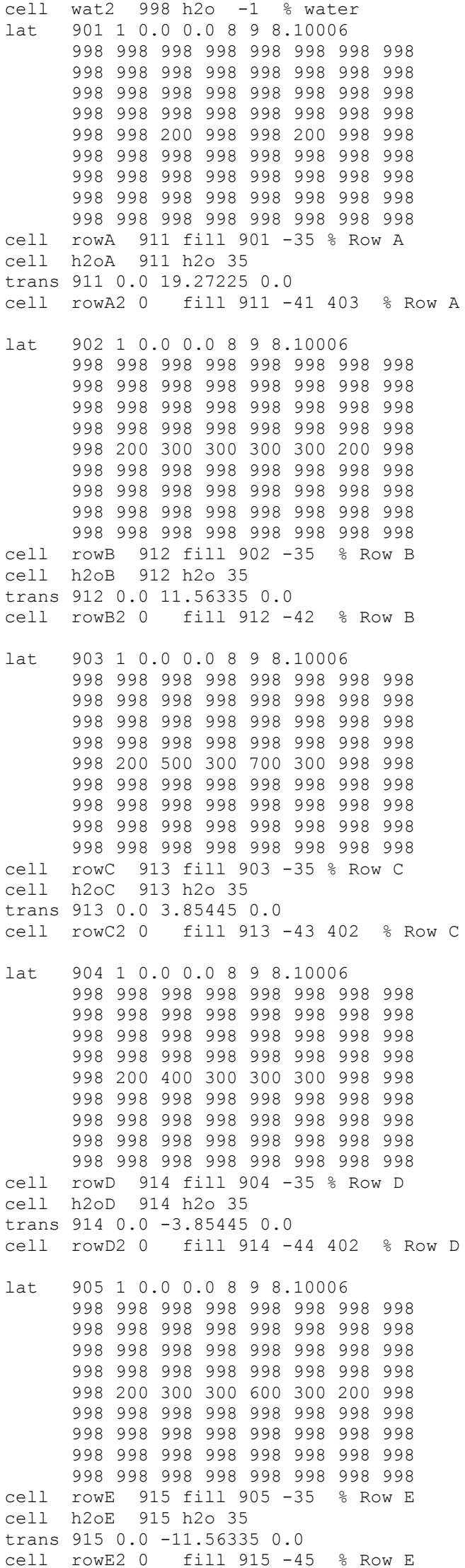


NEA/NSC/DOC(2006)1

Fundamental - FUND

NRAD-FUND-RESR-002

CRIT-REAC-COEF

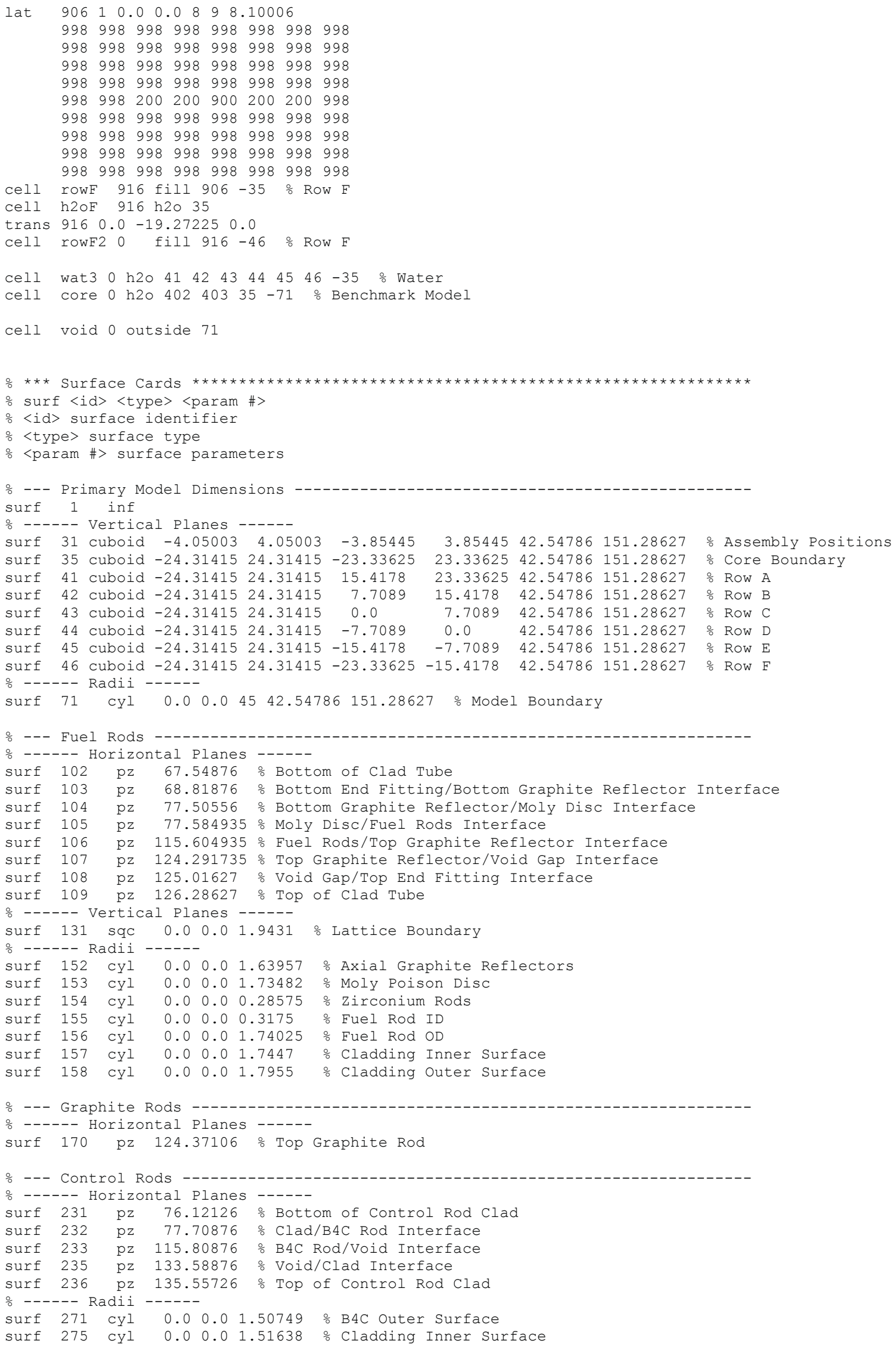


NEA/NSC/DOC(2006)1

\section{Fundamental - FUND}

\section{NRAD-FUND-RESR-002}

CRIT-REAC-COEF

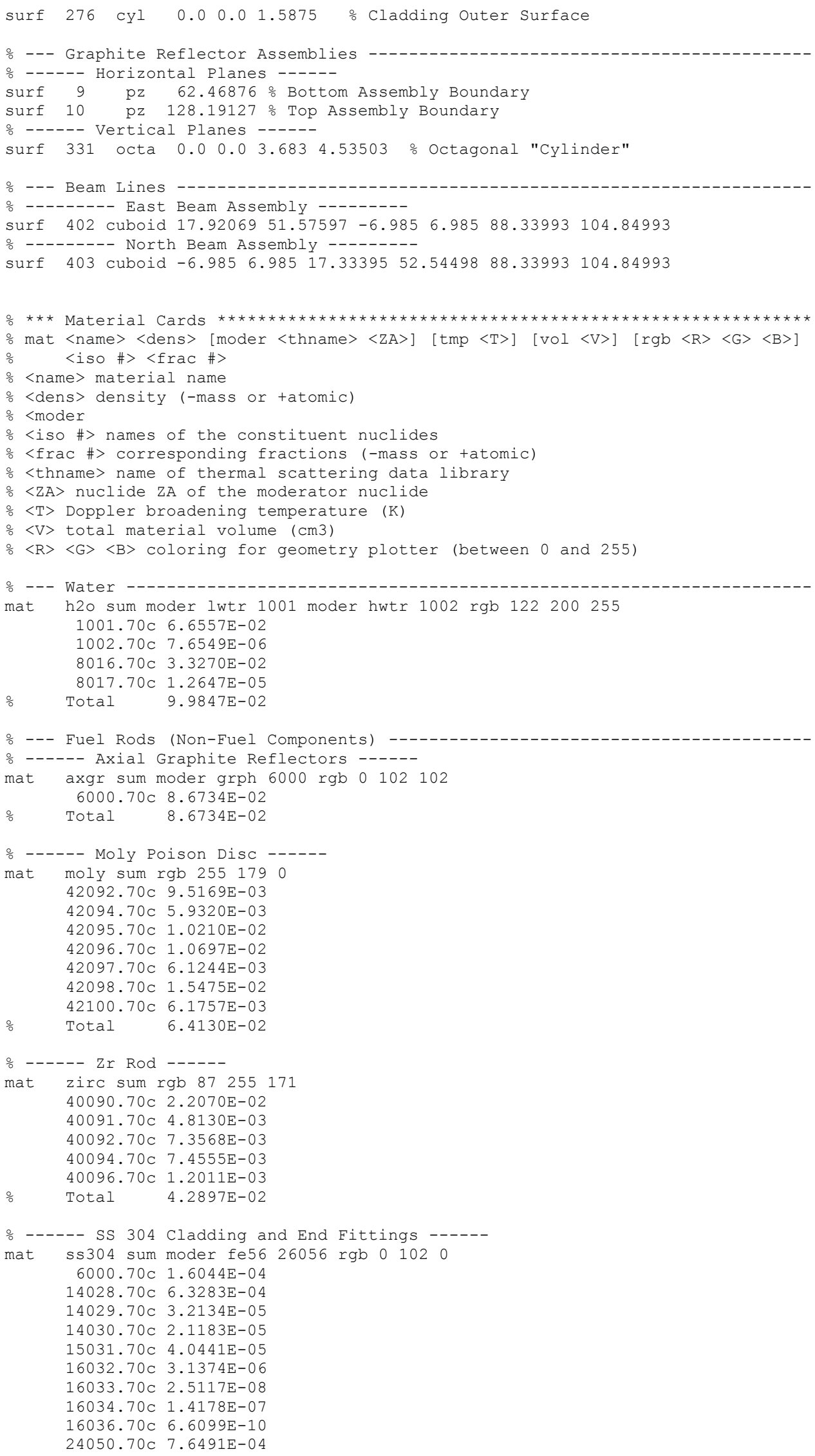


NEA/NSC/DOC(2006)1

Fundamental - FUND

NRAD-FUND-RESR-002

CRIT-REAC-COEF

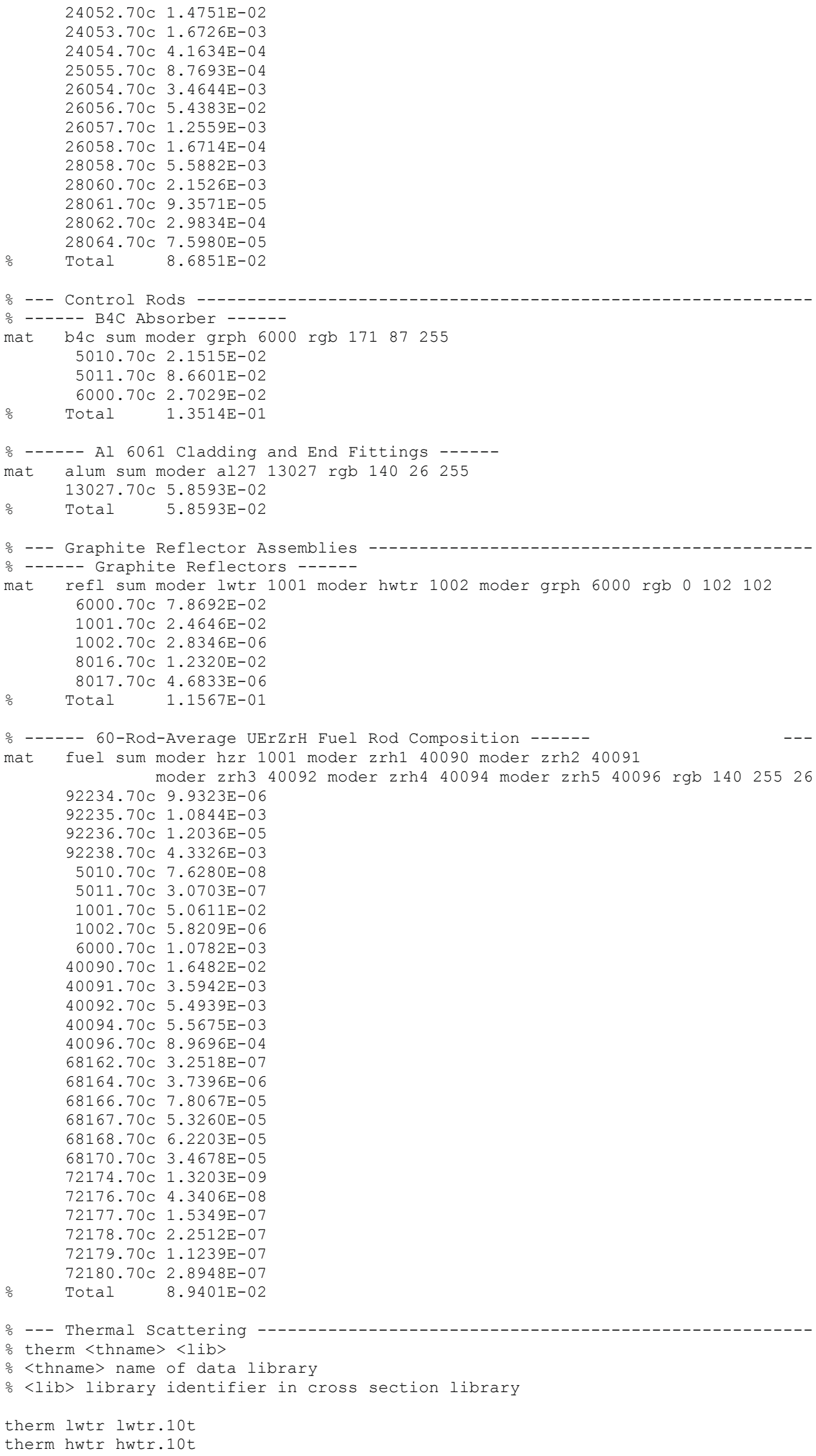


NEA/NSC/DOC(2006)1

Fundamental - FUND

NRAD-FUND-RESR-002

CRIT-REAC-COEF

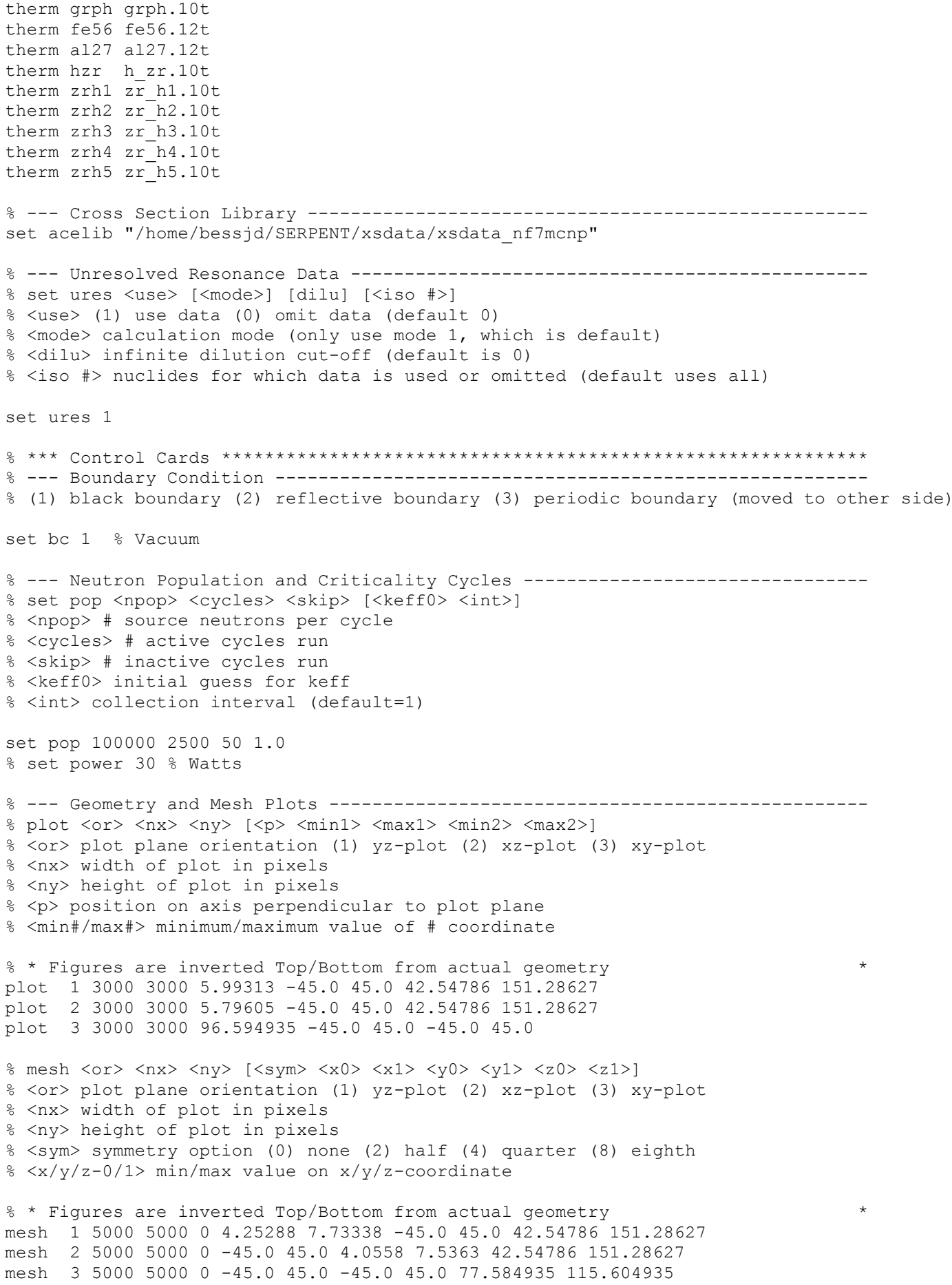


NEA/NSC/DOC(2006)1

\section{Fundamental - FUND}

\section{NRAD-FUND-RESR-002}

CRIT-REAC-COEF

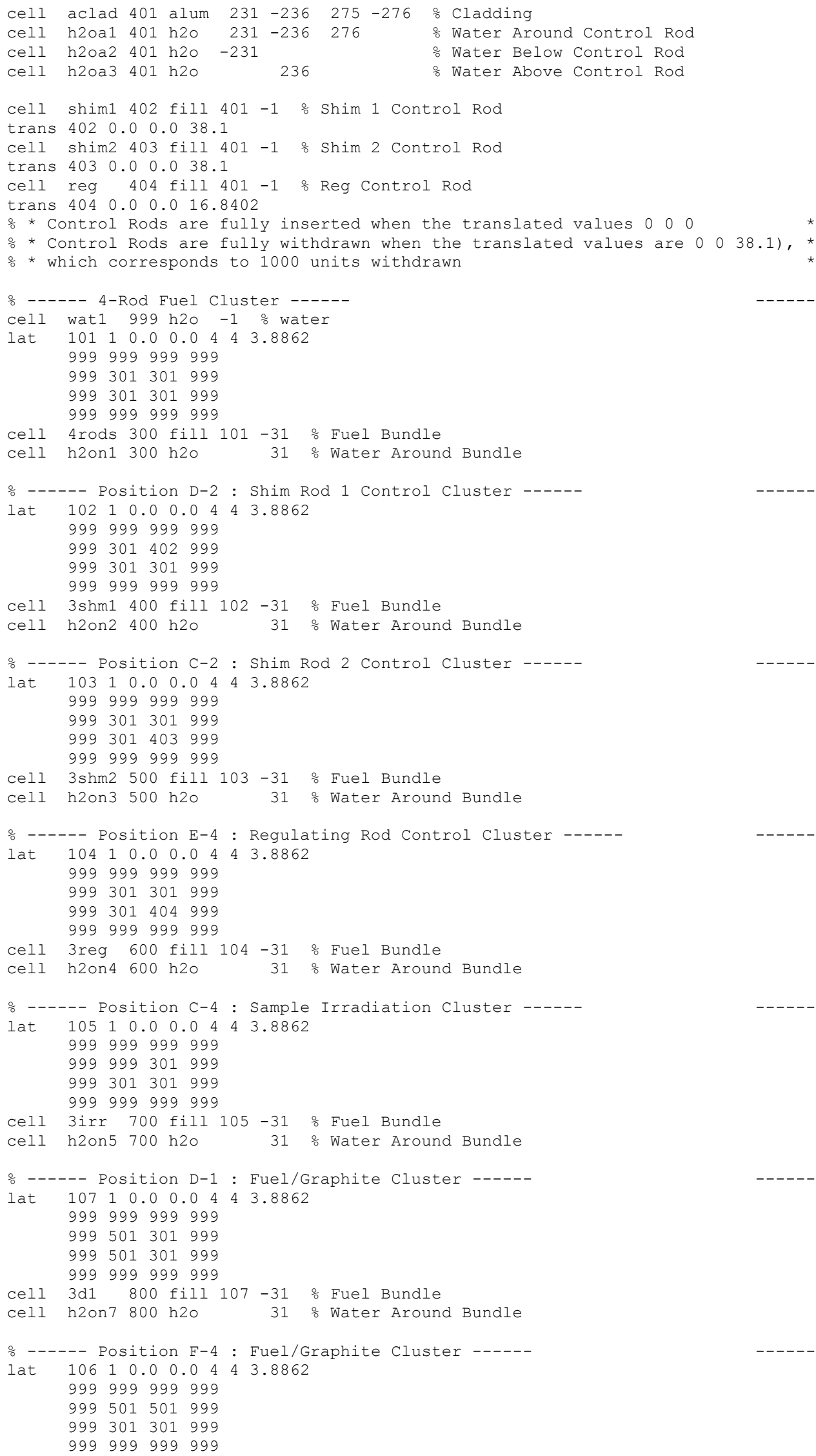


NEA/NSC/DOC(2006)1

Fundamental - FUND

NRAD-FUND-RESR-002

CRIT-REAC-COEF

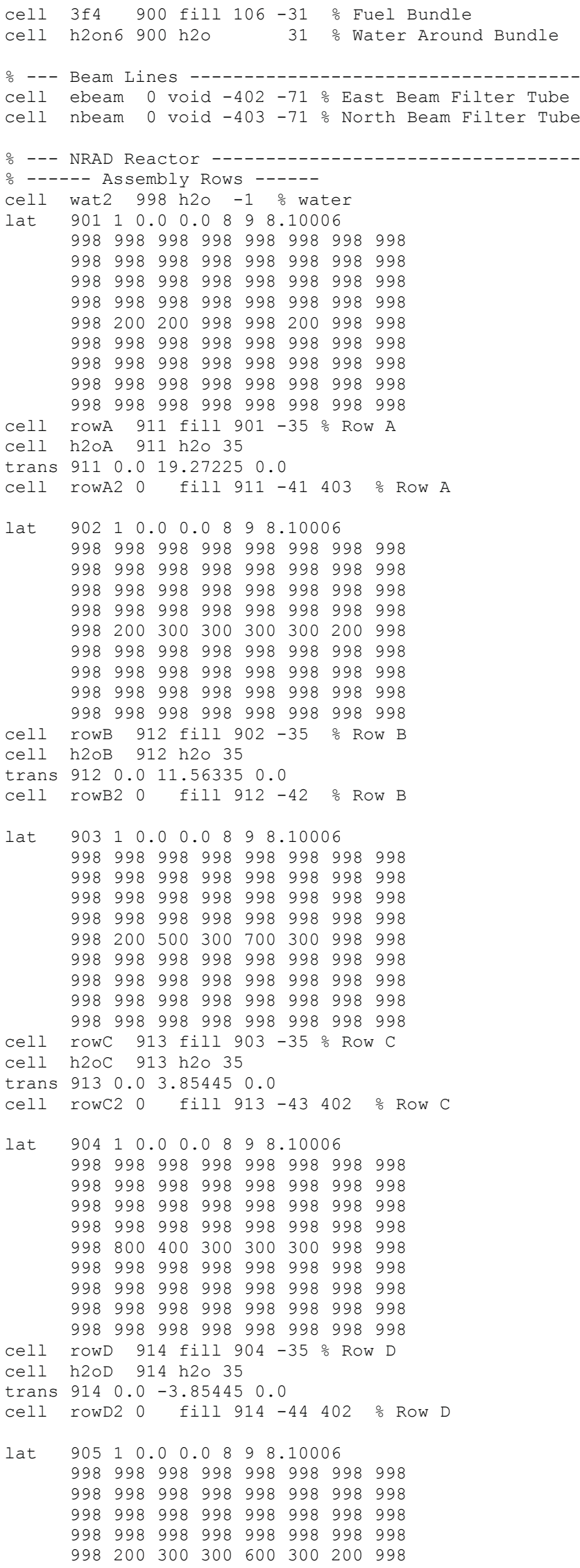


NEA/NSC/DOC(2006)1

Fundamental - FUND

NRAD-FUND-RESR-002

CRIT-REAC-COEF

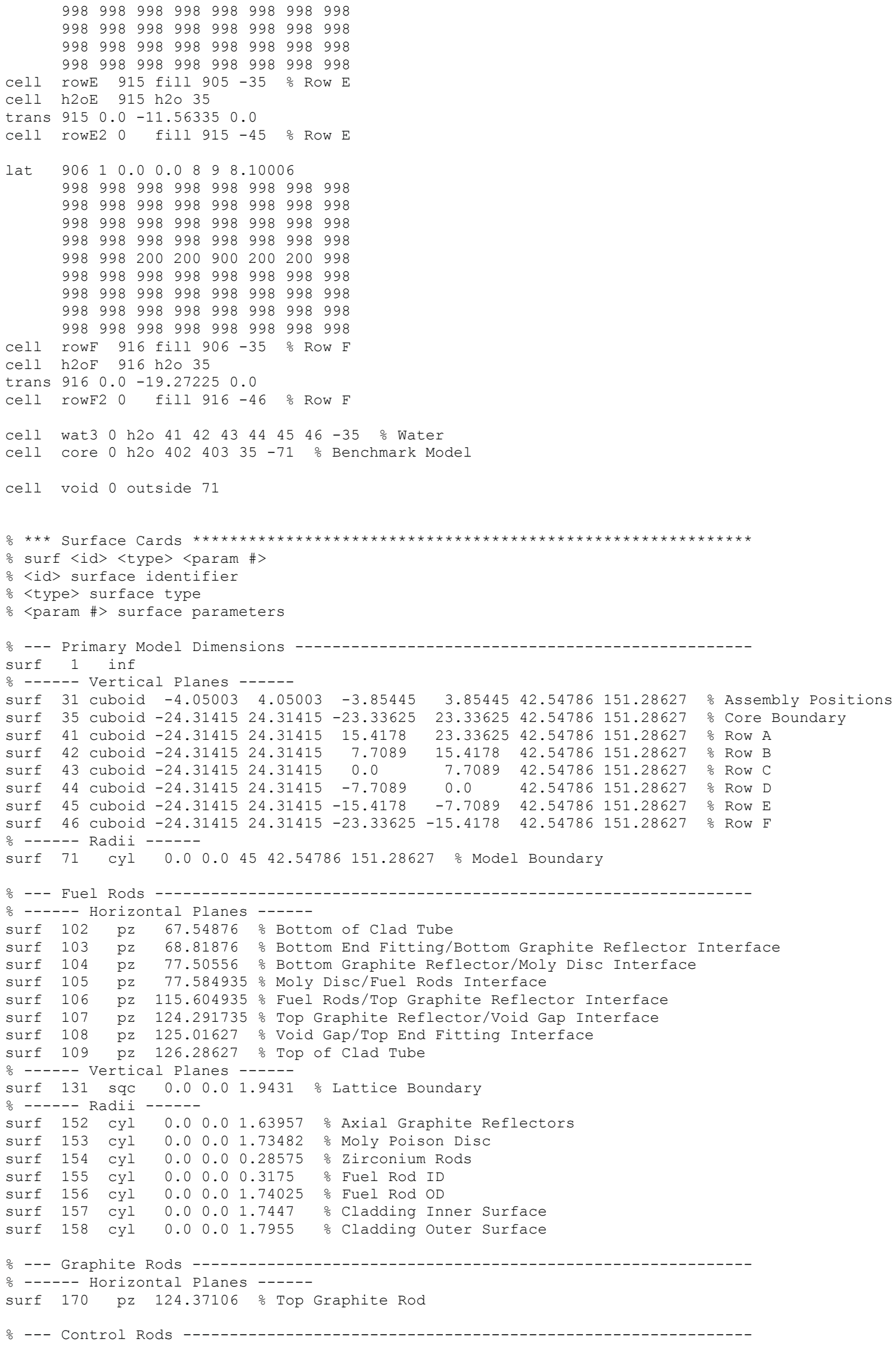


NEA/NSC/DOC(2006)1

\section{Fundamental - FUND}

\section{NRAD-FUND-RESR-002}

CRIT-REAC-COEF

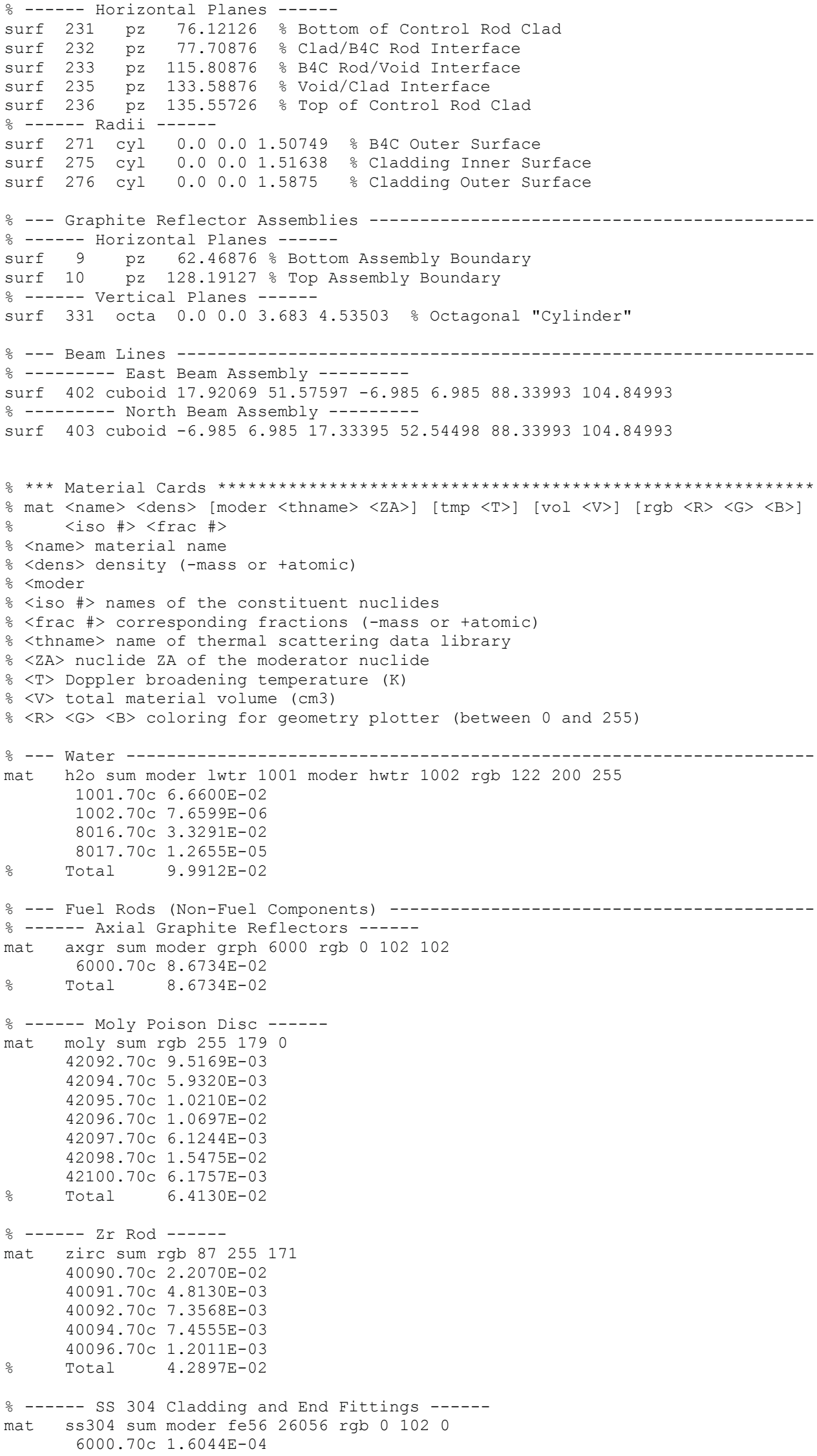


NEA/NSC/DOC(2006)1

Fundamental - FUND

NRAD-FUND-RESR-002

CRIT-REAC-COEF

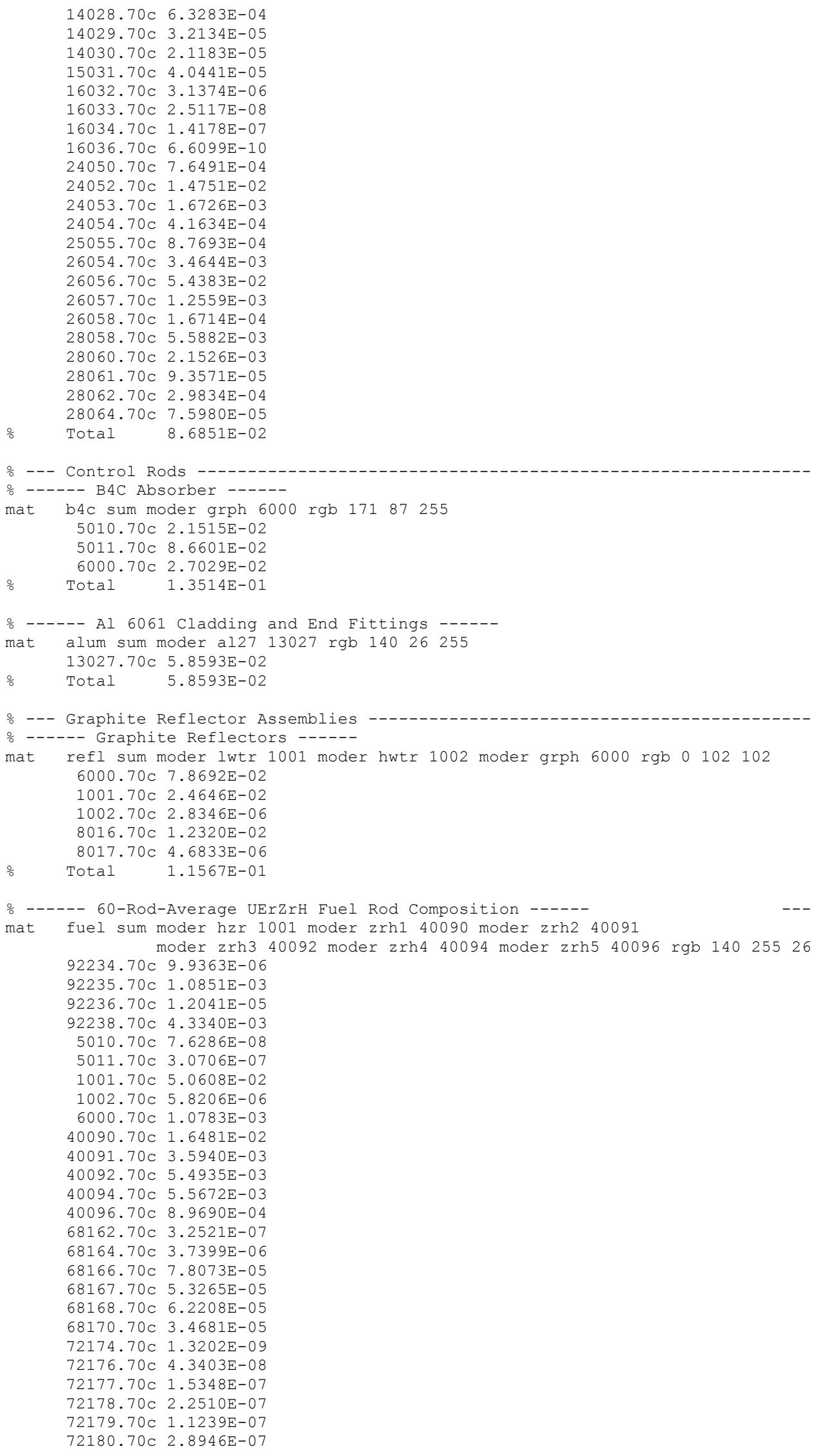


NEA/NSC/DOC(2006)1

Fundamental - FUND

NRAD-FUND-RESR-002

CRIT-REAC-COEF

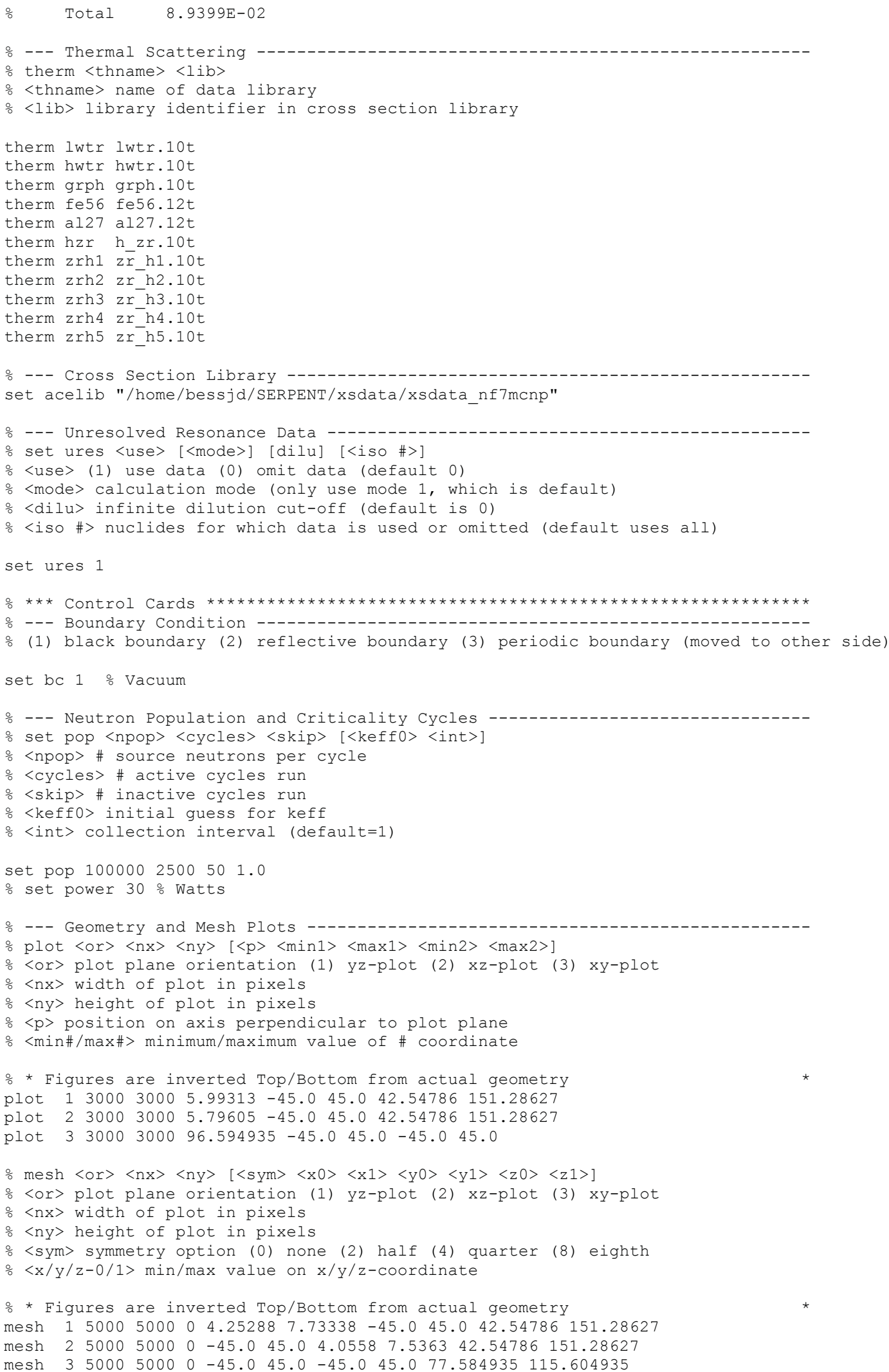




\section{A.2 Buckling and Extrapolation Length Configurations}

Buckling and extrapolation length measurements were not performed.

\section{A.3 Spectral-Characteristics Configurations}

Spectral characteristics measurements were not performed.

\section{A.4 Reactivity-Effects Configurations}

The input decks for analysis of most reactivity effects measurements are those of the critical configurations (Appendix A.1 described in Section 3.1) with adjustments discussed in Section 3.4.2.

\section{A.5 Reactivity Coefficient Configurations}

Reactivity coefficient measurements have not been evaluated.

\section{A.6 Kinetics Parameter Configurations}

Kinetics measurements were not performed.

\section{A.7 Reaction-Rate Configurations}

Reaction-rate distribution measurements were not performed.

\section{A.8 Power Distribution Configurations}

Power distribution measurements were not performed.

\section{A.9 Isotopic Configurations}

Isotopic measurements were not performed.

\section{A.10 Configurations of Other Miscellaneous Types of Measurements}

Other miscellaneous types of measurements were not performed. 
Fundamental - FUND

NRAD-FUND-RESR-002

CRIT-REAC-COEF

\section{APPENDIX B: CALCULATED SPECTRAL DATA}

The neutron spectral calculations provided below were obtained from the output files for the input decks provided in Appendix A.1 and results in Section 4.1. Only spectral data using the ENDF/B-VII.0, JEFF3.1, and JENDL-3.3 neutron cross section libraries are provided here for the MCNP5 analyses and the ENDF/B-VII.0 (238-group and continuous energy) library for the KENO analyses. The cross sections are all continuous in the MCNP5 analyses.

\section{B.1 MCNP-Calculated Spectral Data}

A summary of the computed neutron spectral data using MCNP5 for the benchmark models is provided in Table B.1. 
NEA/NSC/DOC(2006)1

Fundamental - FUND

NRAD-FUND-RESR-002

CRIT-REAC-COEF

Table B.1a. Neutron Spectral Data for Benchmark Model Case 1 (MCNP5).

\begin{tabular}{|c|c|c|c|c|c|}
\hline \multicolumn{2}{|c|}{$\begin{array}{l}\text { Neutron Cross } \\
\text { Section Library } \\
\end{array}$} & ENDF/B-VII.0 & JEFF-3.1 & JENDL-3.3 & ENDF/B-VI.8 \\
\hline \multicolumn{2}{|c|}{$\mathbf{k}_{\text {eff }}$} & 1.01459 & 1.01241 & 1.01183 & 1.01009 \\
\hline \multicolumn{2}{|c|}{$\pm \boldsymbol{\sigma}_{\mathrm{k}}$} & 0.00007 & 0.00007 & 0.00007 & 0.00007 \\
\hline \multicolumn{2}{|r|}{ Leakage } & 2.13 & 2.12 & 2.13 & 2.14 \\
\hline \multirow{3}{*}{$\begin{array}{l}\text { Neutron Balance } \\
(\%)^{(\mathbf{a})}\end{array}$} & Capture & 56.35 & 56.44 & 56.44 & 56.52 \\
\hline & $(\mathbf{x}, \mathbf{x n})$ & 0.05 & 0.05 & 0.04 & 0.05 \\
\hline & Fission & 41.47 & 41.40 & 41.39 & 41.29 \\
\hline \multirow{3}{*}{$\begin{array}{l}\text { Fission Fraction, } \\
\text { by Energy (\%) }\end{array}$} & Thermal $(<0.625 \mathrm{eV})$ & 80.76 & 80.79 & 80.76 & 80.71 \\
\hline & Intermediate & 16.26 & 16.23 & 16.22 & 16.26 \\
\hline & Fast $(>100 \mathrm{keV})$ & 2.98 & 2.98 & 3.02 & 3.04 \\
\hline \multirow{4}{*}{$\begin{array}{c}\text { Fission Fraction, } \\
\text { by Isotope }(\%)\end{array}$} & ${ }^{234} \mathbf{U}$ & 0.01 & 0.01 & 0.01 & 0.01 \\
\hline & ${ }^{235} \mathbf{U}$ & 98.74 & 98.74 & 98.73 & 98.71 \\
\hline & ${ }^{236} U$ & 0.01 & 0.01 & 0.01 & 0.01 \\
\hline & ${ }^{238} \mathbf{U}$ & 1.23 & 1.23 & 1.25 & 1.26 \\
\hline \multicolumn{2}{|c|}{$\begin{array}{l}\text { Average Number of } \\
\text { Neutrons Produced } \\
\text { per Fission }\end{array}$} & 2.444 & 2.443 & 2.443 & 2.444 \\
\hline \multicolumn{2}{|c|}{$\begin{array}{c}\text { Energy of Average } \\
\text { Neutron Lethargy } \\
\text { Causing Fission }(\mathrm{eV})\end{array}$} & 0.26262 & 0.26262 & 0.26339 & 0.27337 \\
\hline \multicolumn{2}{|c|}{$\begin{array}{l}\text { Neutron Generation } \\
\text { Time, } \Lambda \text { (msec) }\end{array}$} & 24.67602 & 24.78155 & 24.87246 & 24.75254 \\
\hline \multicolumn{2}{|c|}{$\pm \sigma_{\Lambda}$} & 0.07362 & 0.07561 & 0.07421 & 0.07354 \\
\hline \multicolumn{2}{|c|}{ Rossi- $\alpha\left(\mathrm{msec}^{-1}\right)$} & $-2.993 \mathrm{E}-04$ & $-2.978 \mathrm{E}-04$ & $-2.987 \mathrm{E}-04$ & $-3.108 \mathrm{E}-04$ \\
\hline \multicolumn{2}{|c|}{$\pm \sigma_{\mathrm{R}}$} & $4.562 \mathrm{E}-06$ & 4.484E-06 & $4.473 \mathrm{E}-06$ & $4.547 \mathrm{E}-06$ \\
\hline \multicolumn{2}{|r|}{$\boldsymbol{\beta}_{\text {eff }}$} & 0.00738 & 0.00738 & 0.00743 & 0.00769 \\
\hline \multicolumn{2}{|c|}{$\pm \boldsymbol{\sigma}_{\beta}$} & 0.00011 & 0.00011 & 0.00011 & 0.00011 \\
\hline
\end{tabular}

(a) The neutron balance is calculated using the neutron balance tables provided in the MCNP output file. The weight fraction of neutrons lost due to a given event are divided by the total neutron loss of those events reported here. 
NEA/NSC/DOC(2006)1

Fundamental - FUND

NRAD-FUND-RESR-002

CRIT-REAC-COEF

Table B.1b. Neutron Spectral Data for Benchmark Model Case 2 (MCNP5).

\begin{tabular}{|c|c|c|c|c|c|}
\hline \multicolumn{2}{|c|}{$\begin{array}{l}\text { Neutron Cross } \\
\text { Section Library } \\
\end{array}$} & ENDF/B-VII.0 & JEFF-3.1 & JENDL-3.3 & ENDF/B-VI.8 \\
\hline \multicolumn{2}{|c|}{$\mathbf{k}_{\text {eff }}$} & 1.01479 & 1.01281 & 1.01191 & 1.01022 \\
\hline \multicolumn{2}{|r|}{$\pm \boldsymbol{\sigma}_{\mathrm{k}}$} & 0.00007 & 0.00007 & 0.00007 & 0.00007 \\
\hline \multicolumn{2}{|r|}{ Leakage } & 2.11 & 2.09 & 2.11 & 2.12 \\
\hline \multirow{3}{*}{$\begin{array}{l}\text { Neutron Balance } \\
(\%)^{(\mathbf{a})}\end{array}$} & Capture & 56.36 & 56.45 & 56.46 & 56.54 \\
\hline & $(\mathbf{x}, \mathbf{x n})$ & 0.05 & 0.05 & 0.04 & 0.05 \\
\hline & Fission & 41.48 & 41.41 & 41.39 & 41.30 \\
\hline \multirow{3}{*}{$\begin{array}{l}\text { Fission Fraction, } \\
\text { by Energy (\%) }\end{array}$} & Thermal $(<0.625 \mathrm{eV})$ & 80.68 & 80.72 & 80.69 & 80.63 \\
\hline & Intermediate & 16.33 & 16.30 & 16.29 & 16.32 \\
\hline & Fast $(>100 \mathrm{keV})$ & 2.99 & 2.98 & 3.02 & 3.04 \\
\hline \multirow{4}{*}{$\begin{array}{c}\text { Fission Fraction, } \\
\text { by Isotope }(\%)\end{array}$} & ${ }^{234} \mathbf{U}$ & 0.01 & 0.01 & 0.01 & 0.01 \\
\hline & ${ }^{235} \mathbf{U}$ & 98.74 & 98.74 & 98.73 & 98.71 \\
\hline & ${ }^{236} U$ & 0.01 & 0.01 & 0.01 & 0.01 \\
\hline & ${ }^{238} \mathbf{U}$ & 1.24 & 1.24 & 1.25 & 1.27 \\
\hline \multicolumn{2}{|c|}{$\begin{array}{c}\text { Average Number of } \\
\text { Neutrons Produced } \\
\text { per Fission }\end{array}$} & 2.444 & 2.443 & 2.443 & 2.444 \\
\hline \multicolumn{2}{|c|}{$\begin{array}{c}\text { Energy of Average } \\
\text { Neutron Lethargy } \\
\text { Causing Fission }(\mathrm{eV})\end{array}$} & 0.26441 & 0.26451 & 0.26521 & 0.27524 \\
\hline \multicolumn{2}{|c|}{$\begin{array}{l}\text { Neutron Generation } \\
\text { Time, } \Lambda \text { (msec) }\end{array}$} & 24.23204 & 24.34086 & 24.38165 & 24.52156 \\
\hline \multicolumn{2}{|c|}{$\pm \boldsymbol{\sigma}_{\Lambda}$} & 0.07148 & 0.07228 & 0.07304 & 0.07298 \\
\hline \multicolumn{2}{|c|}{ Rossi- $\alpha\left(\mathrm{msec}^{-1}\right)$} & $-3.111 \mathrm{E}-04$ & $-3.035 \mathrm{E}-04$ & $-3.037 \mathrm{E}-04$ & $-3.174 \mathrm{E}-04$ \\
\hline \multicolumn{2}{|c|}{$\pm \boldsymbol{\sigma}_{\mathrm{R}}$} & $4.689 \mathrm{E}-06$ & $4.568 \mathrm{E}-06$ & 4.619E-06 & $4.682 \mathrm{E}-06$ \\
\hline \multicolumn{2}{|r|}{$\beta_{\text {eff }}$} & 0.00754 & 0.00739 & 0.00740 & 0.00778 \\
\hline \multicolumn{2}{|c|}{$\pm \boldsymbol{\sigma}_{\beta}$} & 0.00011 & 0.00011 & 0.00011 & 0.00011 \\
\hline
\end{tabular}

(a) The neutron balance is calculated using the neutron balance tables provided in the MCNP output file. The weight fraction of neutrons lost due to a given event are divided by the total neutron loss of those events reported here. 


\section{B.2 KENO-Calculated Spectral Data}

A summary of the computed neutron spectral data using KENO-VI for the benchmark model is provided in Table B.2.

Table B.2a. Neutron Spectral Data for Benchmark Model Case 1 (KENO).

\begin{tabular}{||c||c|c||}
\hline $\begin{array}{c}\text { Neutron Cross } \\
\text { Section Library }\end{array}$ & $\begin{array}{c}\text { ENDF/B-VII.0 } \\
(238 \text {-group) }\end{array}$ & $\begin{array}{c}\text { ENDF/B-VII.0 } \\
\text { (continuous energy) }\end{array}$ \\
\hline $\mathbf{\sigma}_{\mathbf{k}}$ & 1.015389 & 1.010030 \\
\hline $\begin{array}{c}\text { Energy of Average } \\
\text { Neutron Lethargy } \\
\text { Causing Fission (eV) } \\
\pm \boldsymbol{\sigma}_{\mathbf{E A L F}}\end{array}$ & 0.000070 & 0.000080 \\
\hline $\begin{array}{c}\text { Average Number of } \\
\text { Neutrons Produced } \\
\text { per Fission } \\
\pm \sigma_{\mathbf{v}}\end{array}$ & 2.44386 & 0.27032 \\
\hline $\begin{array}{c}\text { Mean Free Path (cm) } \\
\pm \boldsymbol{\sigma}_{\boldsymbol{\lambda}}\end{array}$ & 0.64338 & 0.00007 \\
\hline \hline
\end{tabular}

Table B.2b. Neutron Spectral Data for Benchmark Model Case 2 (KENO).

\begin{tabular}{|c|c|c|}
\hline $\begin{array}{l}\text { Neutron Cross } \\
\text { Section Library }\end{array}$ & $\begin{array}{l}\text { ENDF/B-VII.0 } \\
\text { (238-group) }\end{array}$ & $\begin{array}{c}\text { ENDF/B-VII.0 } \\
\text { (continuous energy) }\end{array}$ \\
\hline $\mathbf{k}_{\text {eff }}$ & 1.015275 & 1.010205 \\
\hline$\pm \sigma_{\mathrm{k}}$ & 0.000070 & 0.000073 \\
\hline $\begin{array}{l}\text { Energy of Average } \\
\text { Neutron Lethargy } \\
\text { Causing Fission (eV) }\end{array}$ & 0.25457 & 0.27193 \\
\hline$\pm \boldsymbol{\sigma}_{\text {EALF }}$ & 0.00004 & 0.00007 \\
\hline $\begin{array}{c}\text { Average Number of } \\
\text { Neutrons Produced } \\
\text { per Fission } \\
\pm \sigma_{v}\end{array}$ & $\begin{array}{r}2.44388 \\
<0.00001\end{array}$ & $\begin{array}{l}2.44392 \\
<0.00001\end{array}$ \\
\hline Mean Free Path $(\mathrm{cm})$ & 0.64717 & 0.64865 \\
\hline$\pm \boldsymbol{\sigma}_{\lambda}$ & 0.00003 & 0.00003 \\
\hline
\end{tabular}


NRAD-FUND-RESR-002

CRIT-REAC-COEF

\section{APPENDIX C: DETAILED MODEL INPUT DECKS}

\section{C.1 Detailed MCNP Models of the NRAD Reactor}

Detailed models of the NRAD reactor core configurations were prepared to evaluate biases in the benchmark models. Because the effects of many of the model simplifications produced small or otherwise negligible biases (in regards to criticality) in the benchmark model, development of a detailed benchmark model was unnecessary. The MCNP5 input decks, using ENDF/B-VII.0 neutron cross section data, is preserved in this appendix for future use. Calculations were performed with 1,550 generations with 100,000 neutrons per generation. The $k_{\text {eff }}$ estimates did not include the first 50 generations and are the result of 150,000,000 neutron histories. Calculated results obtained with this input deck are provided in Table C.1. Figures C.1 through C.5 provide various views of the complexity incorporated into the detailed model. 
NRAD-FUND-RESR-002

CRIT-REAC-COEF

Table C.1. Neutron Spectral Data for Detailed Models.

\begin{tabular}{|c|c|c|c|}
\hline \multicolumn{2}{|r|}{ Case } & 1 & 2 \\
\hline \multicolumn{2}{|c|}{ \# Fuel Elements } & 62 & 64 \\
\hline \multicolumn{2}{|c|}{$\begin{array}{l}\text { Neutron Cross } \\
\text { Section Library } \\
\end{array}$} & ENDF/B-VII.0 & ENDF/B-VII.0 \\
\hline \multicolumn{2}{|r|}{$\mathbf{k}_{\text {eff }}$} & 1.01354 & 1.01359 \\
\hline \multicolumn{2}{|r|}{$\pm \boldsymbol{\sigma}_{\mathrm{k}}$} & 0.00007 & 0.00007 \\
\hline \multirow{4}{*}{$\begin{array}{l}\text { Neutron Balance } \\
\qquad(\%)^{(\mathbf{a})}\end{array}$} & Leakage & 0.03 & 0.03 \\
\hline & Capture & 58.48 & 58.49 \\
\hline & $(\mathbf{x}, \mathbf{x n})$ & 0.05 & 0.05 \\
\hline & Fission & 41.44 & 41.43 \\
\hline \multirow{3}{*}{$\begin{array}{l}\text { Fission Fraction, } \\
\text { by Energy (\%) }\end{array}$} & Thermal $(<0.625 \mathrm{eV})$ & 80.60 & 80.55 \\
\hline & Intermediate & 16.40 & 16.45 \\
\hline & Fast $(>100 \mathrm{keV})$ & 2.99 & 3.00 \\
\hline \multirow{4}{*}{$\begin{array}{l}\text { Fission Fraction, } \\
\text { by Isotope }(\%)\end{array}$} & ${ }^{234} \mathbf{U}$ & 0.01 & 0.01 \\
\hline & ${ }^{235} \mathbf{U}$ & 98.74 & 98.74 \\
\hline & ${ }^{236} \mathbf{U}$ & 0.01 & 0.01 \\
\hline & ${ }^{238} \mathbf{U}$ & 1.24 & 1.24 \\
\hline \multicolumn{2}{|c|}{$\begin{array}{c}\text { Average Number of } \\
\text { Neutrons Produced } \\
\text { per Fission }\end{array}$} & 2.443 & 2.444 \\
\hline \multicolumn{2}{|c|}{$\begin{array}{l}\text { Energy of Average } \\
\text { Neutron Lethargy } \\
\text { Causing Fission (eV) }\end{array}$} & 0.26644 & 0.26781 \\
\hline \multicolumn{2}{|c|}{$\begin{array}{l}\text { Neutron Generation } \\
\text { Time, } \Lambda \text { (msec) }\end{array}$} & 24.37219 & 23.92873 \\
\hline \multicolumn{2}{|c|}{$\pm \boldsymbol{\sigma}_{\Lambda}$} & 0.07393 & 0.07158 \\
\hline \multicolumn{2}{|c|}{ Rossi- $\alpha\left(\mathrm{msec}^{-1}\right)$} & $-3.098 \mathrm{E}-04$ & $-3.025 \mathrm{E}-04$ \\
\hline \multicolumn{2}{|r|}{$\pm \boldsymbol{\sigma}_{\mathbf{R}}$} & 4.702E-06 & 4.629E-06 \\
\hline \multicolumn{2}{|r|}{$\boldsymbol{\beta}_{\text {eff }}$} & 0.00755 & 0.00724 \\
\hline \multicolumn{2}{|r|}{$\pm \boldsymbol{\sigma}_{\beta}$} & 0.00011 & 0.00011 \\
\hline
\end{tabular}

(a) The neutron balance is calculated using the neutron balance tables provided in the MCNP output file. The weight fraction of neutrons lost due to a given event are divided by the total neutron loss of those events reported here. 
NEA/NSC/DOC(2006)1

Fundamental - FUND

NRAD-FUND-RESR-002

CRIT-REAC-COEF

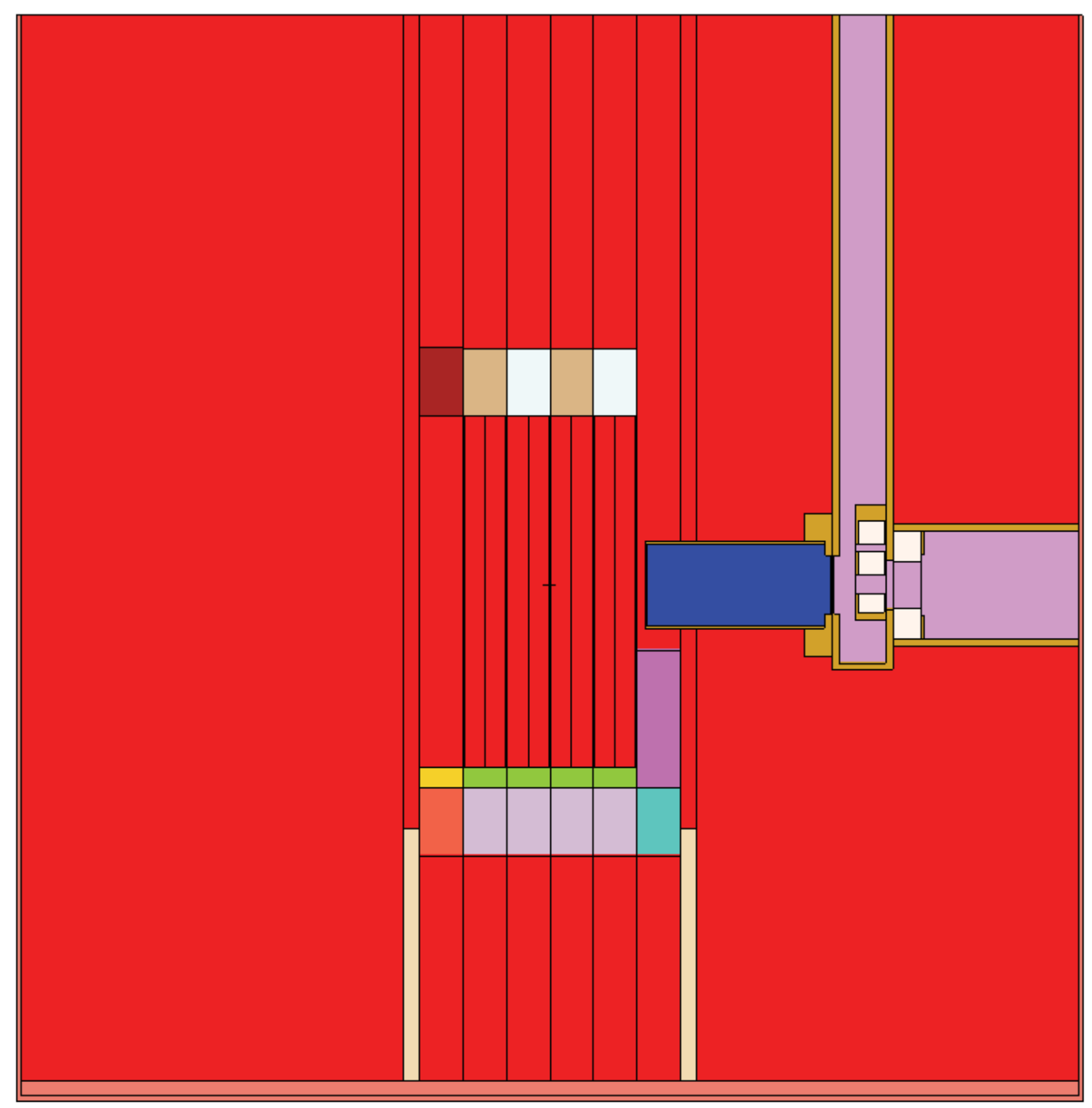

Figure C.1. Vertical Cross Section of Detailed NRAD Model. 
NEA/NSC/DOC(2006)1

Fundamental - FUND

NRAD-FUND-RESR-002

CRIT-REAC-COEF

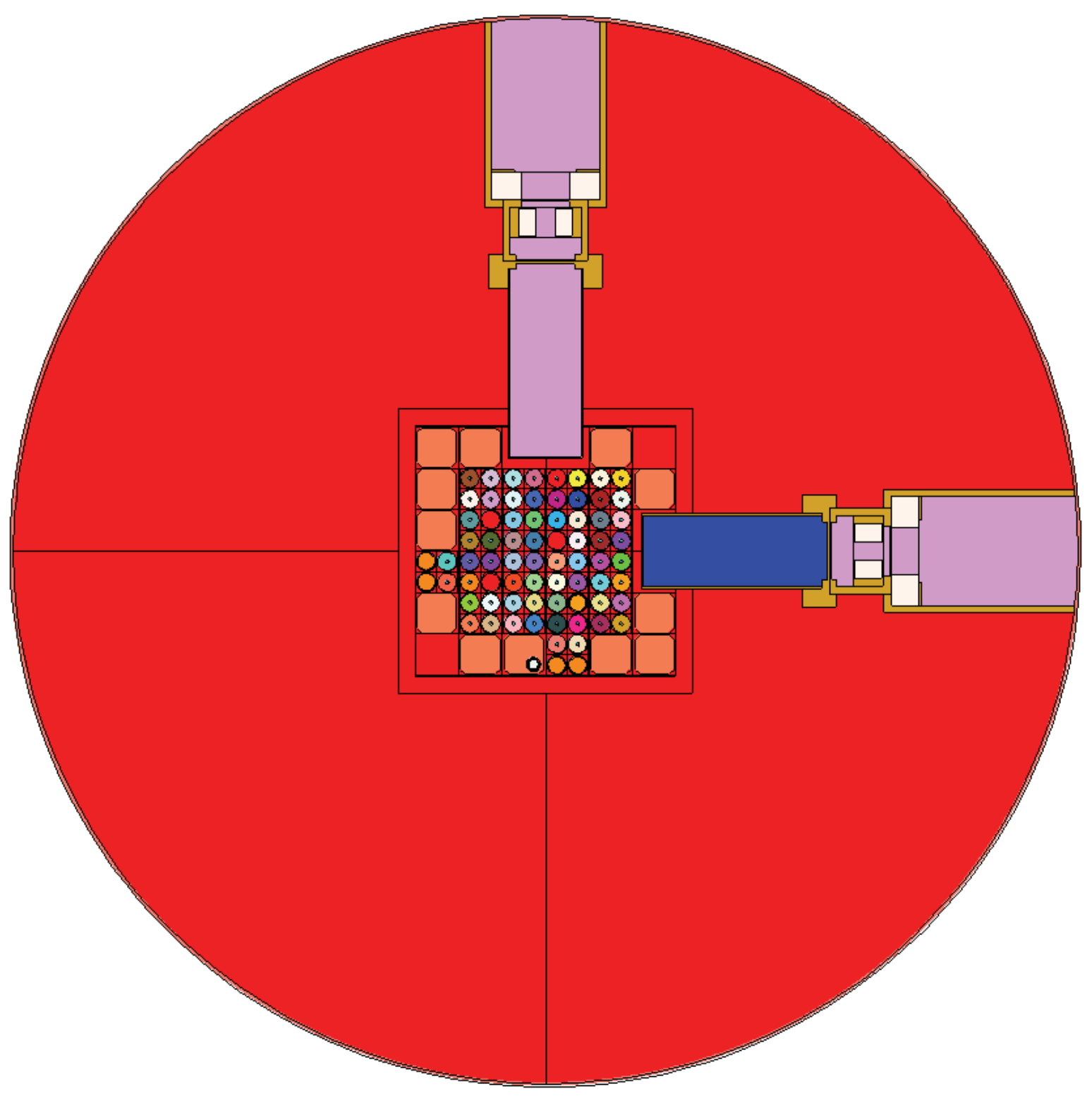

Figure C.2. Horizontal Cross Section of Detailed NRAD Model at Fuel Midplane (64-Fuel-Element Core). 
NEA/NSC/DOC(2006)1

Fundamental - FUND

NRAD-FUND-RESR-002

CRIT-REAC-COEF

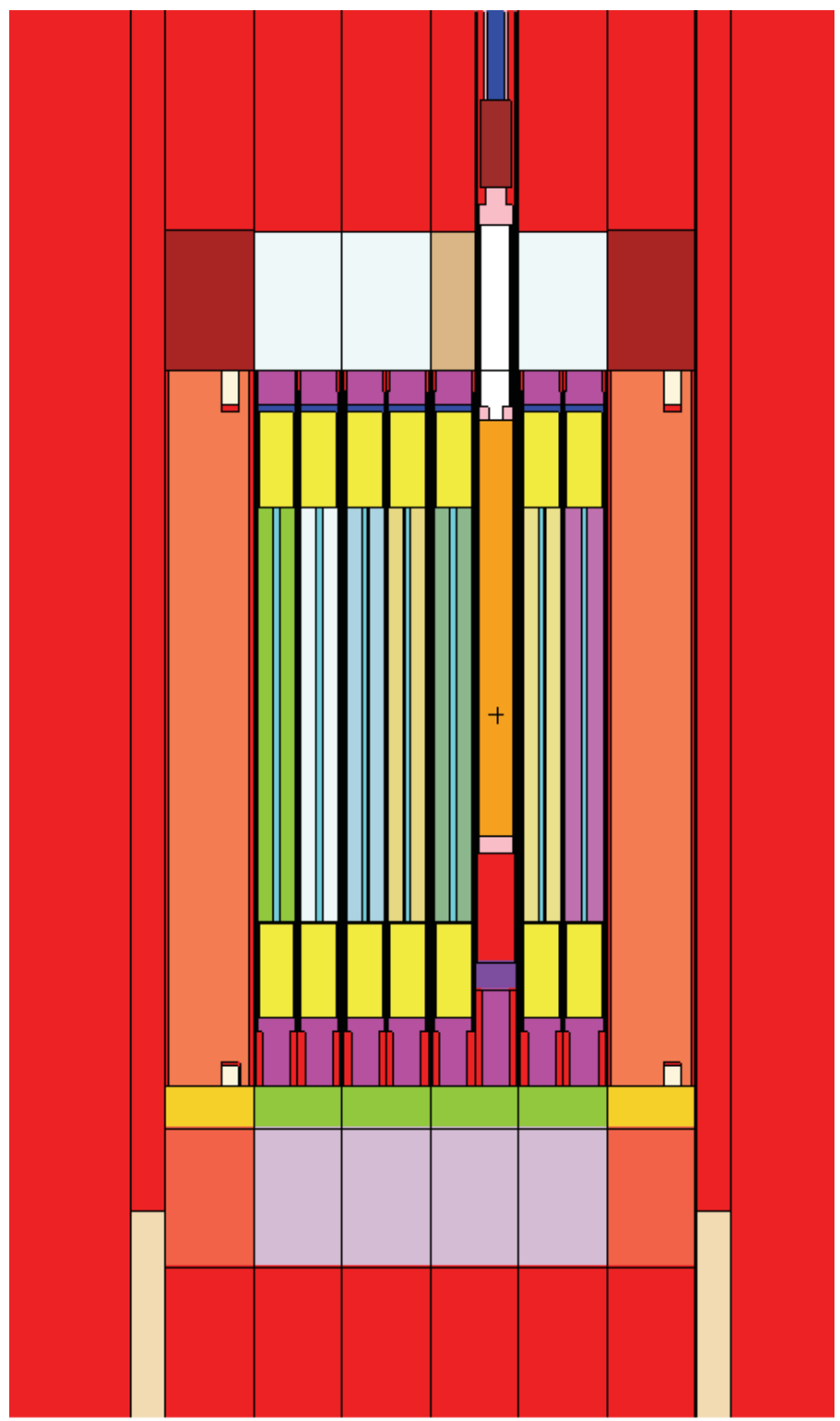

Figure C.3. Fuel Element and Reg Rod View of Detailed NRAD Model. 
NEA/NSC/DOC(2006)1

Fundamental - FUND

NRAD-FUND-RESR-002

CRIT-REAC-COEF

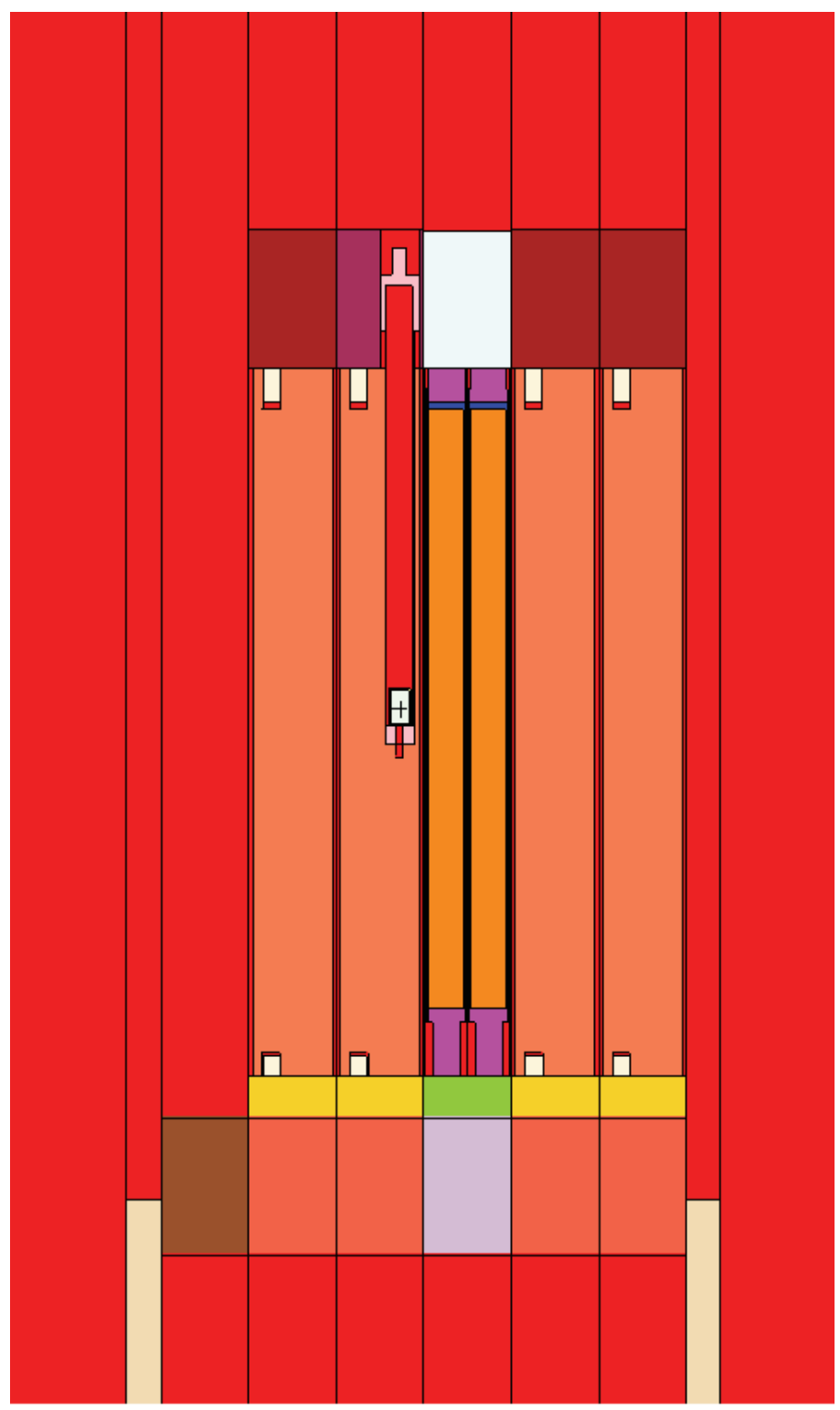

Figure C.4. Graphite Block and AmBe Source View of Detailed NRAD Model. 
Fundamental - FUND

NRAD-FUND-RESR-002

CRIT-REAC-COEF

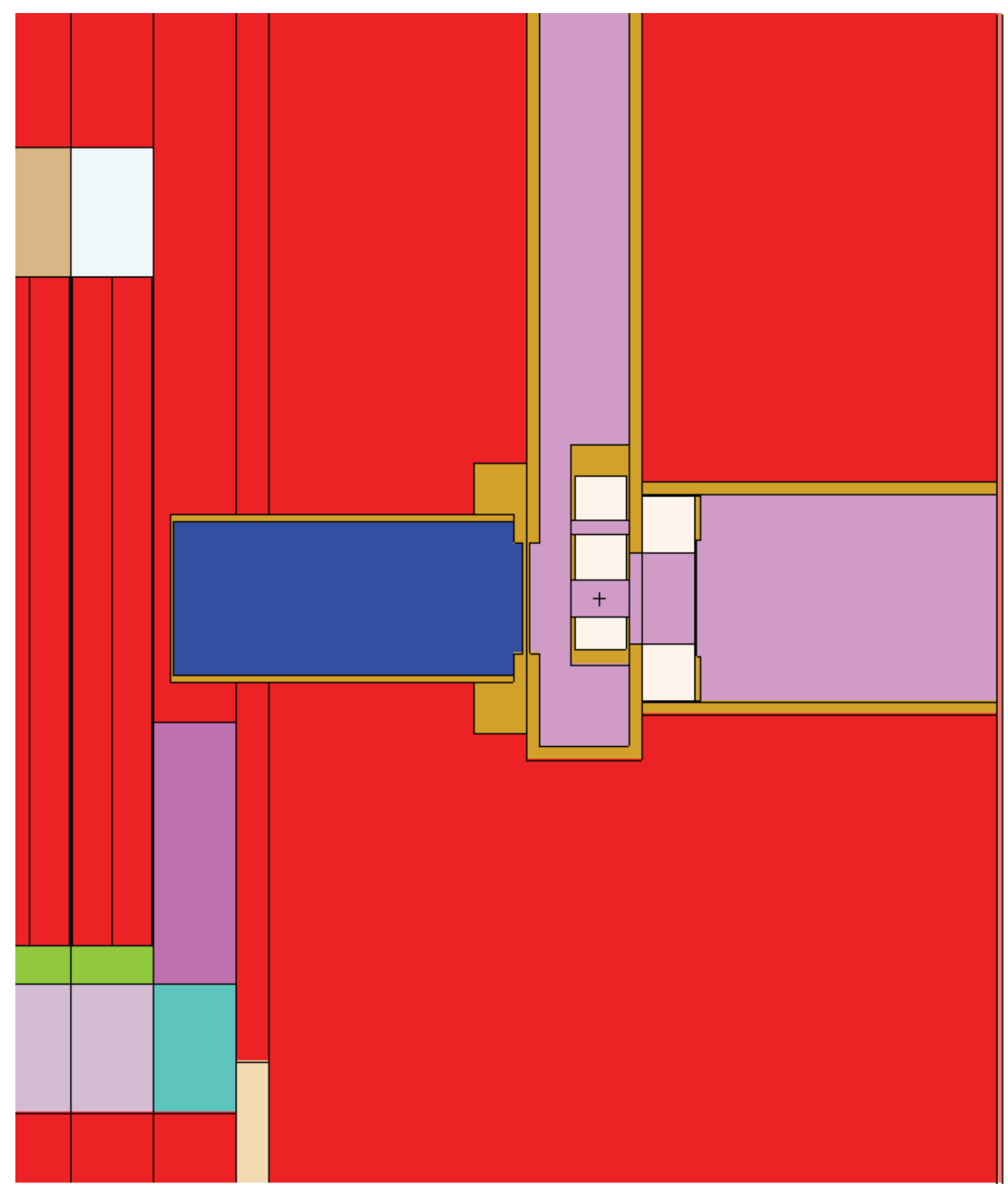

Figure C.5. East Beam Line View of Detailed NRAD Model. 
NEA/NSC/DOC(2006)1

Fundamental - FUND

NRAD-FUND-RESR-002

CRIT-REAC-COEF

\section{C.2 Input Listing for Detailed Models}

\section{MCNP5 Input Deck for the 62-fuel-element intermediary core configuration (Case 1):}

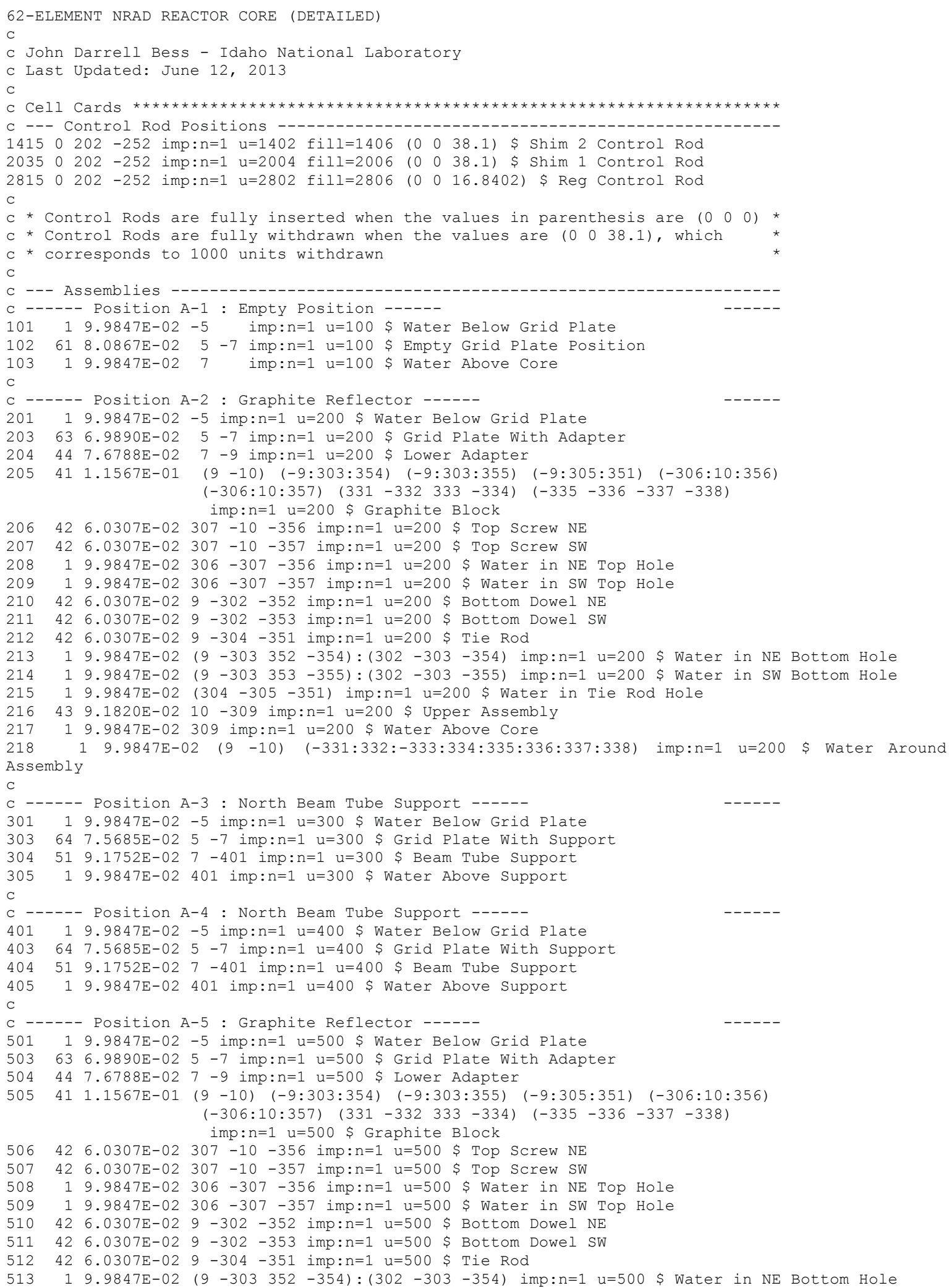




\section{NEA/NSC/DOC(2006)1}

\section{Fundamental - FUND}

\section{NRAD-FUND-RESR-002 CRIT-REAC-COEF}

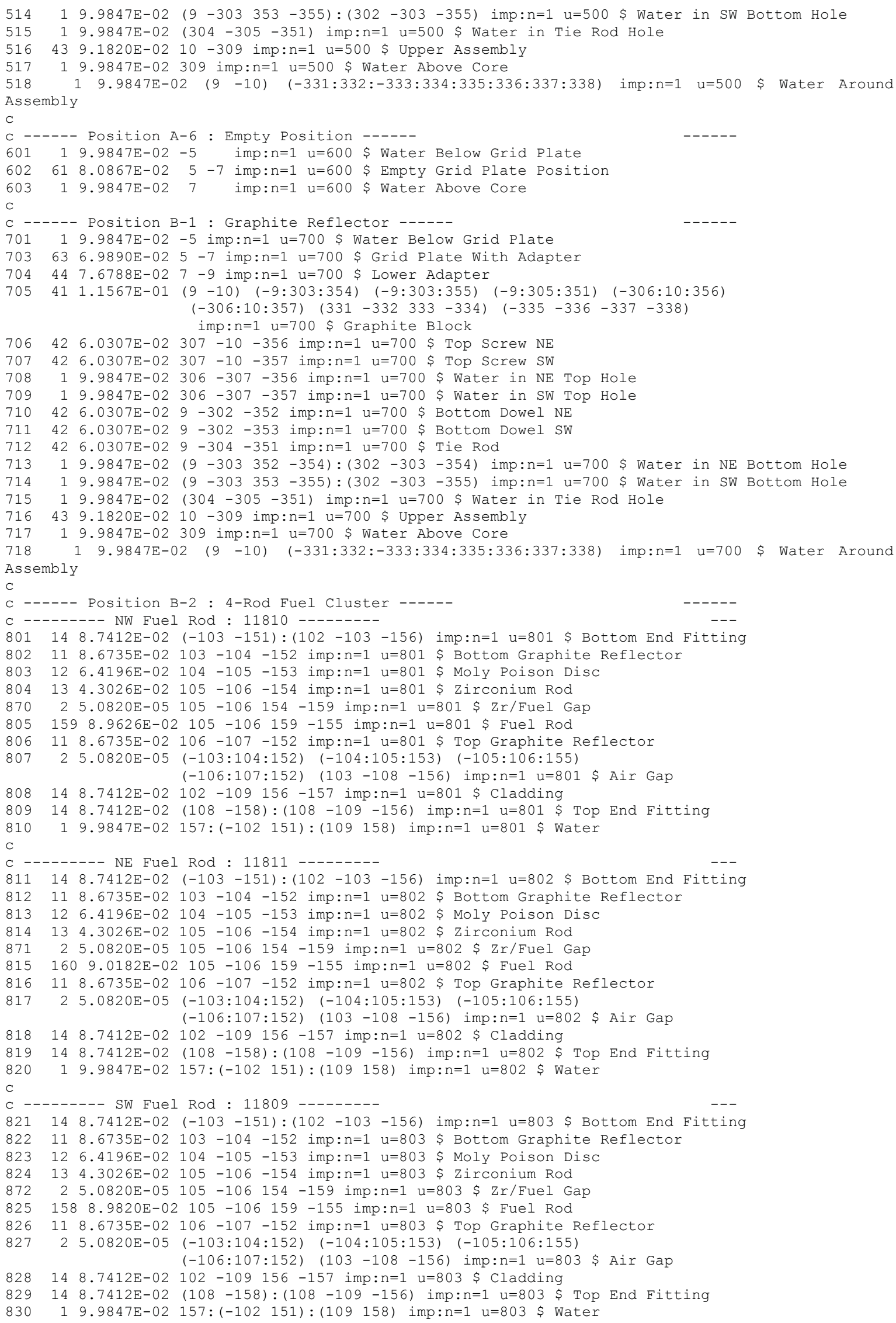




\section{NEA/NSC/DOC(2006)1}

\section{Fundamental - FUND}

\section{NRAD-FUND-RESR-002 CRIT-REAC-COEF}

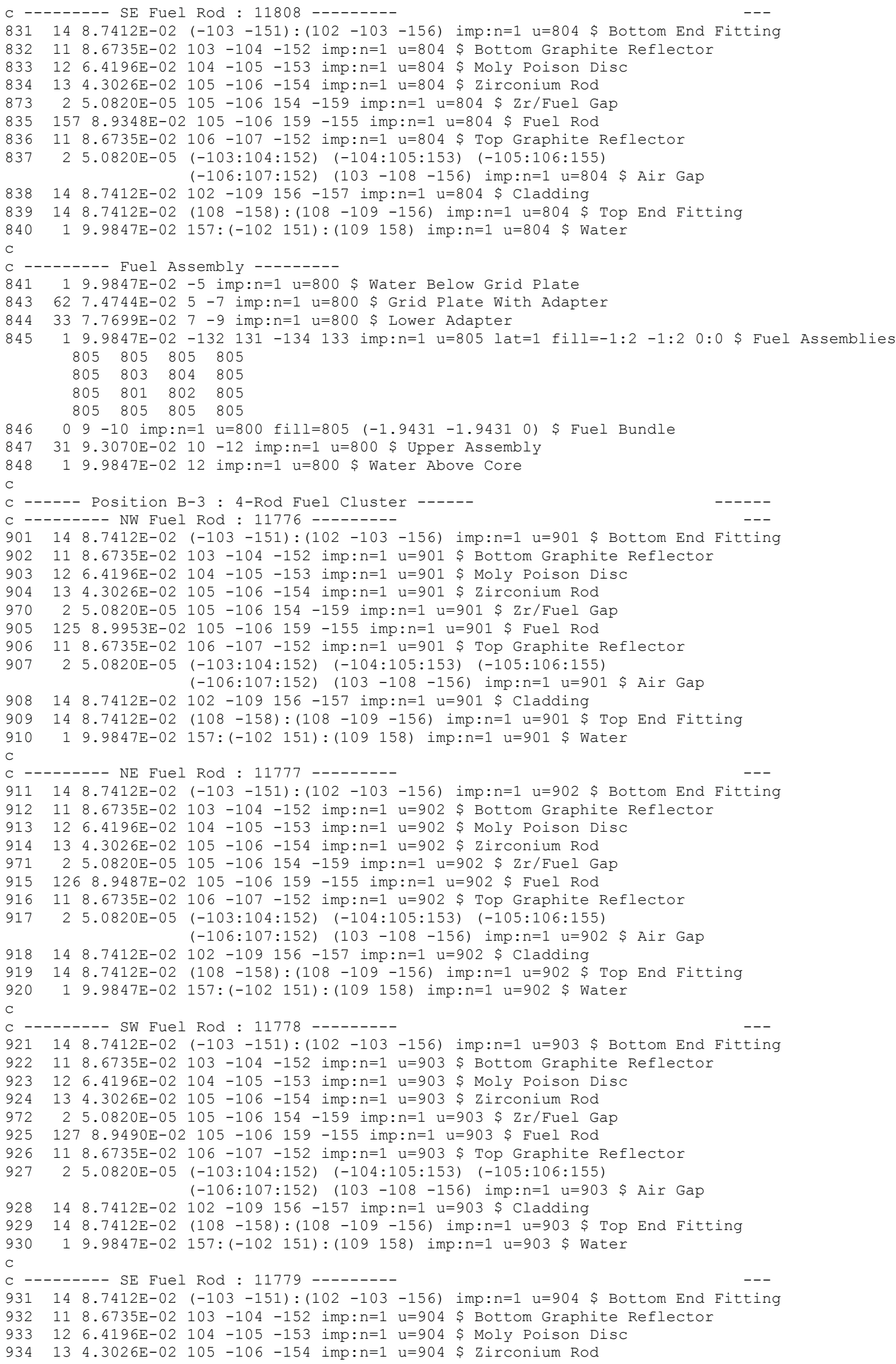




\section{NEA/NSC/DOC(2006)1}

\section{Fundamental - FUND}

\section{NRAD-FUND-RESR-002 CRIT-REAC-COEF}

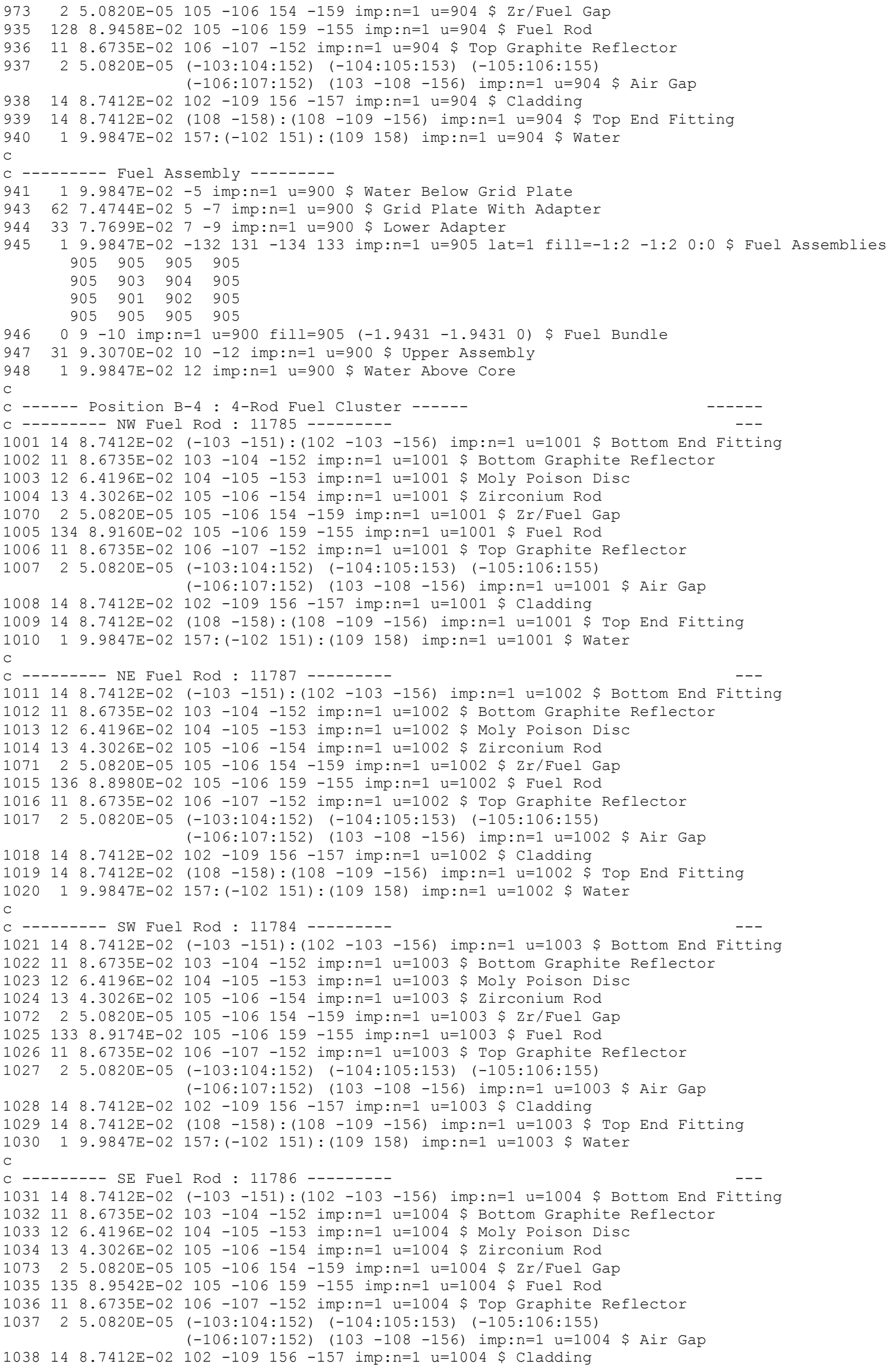




\section{NEA/NSC/DOC(2006)1}

\section{Fundamental - FUND}

\section{NRAD-FUND-RESR-002 CRIT-REAC-COEF}

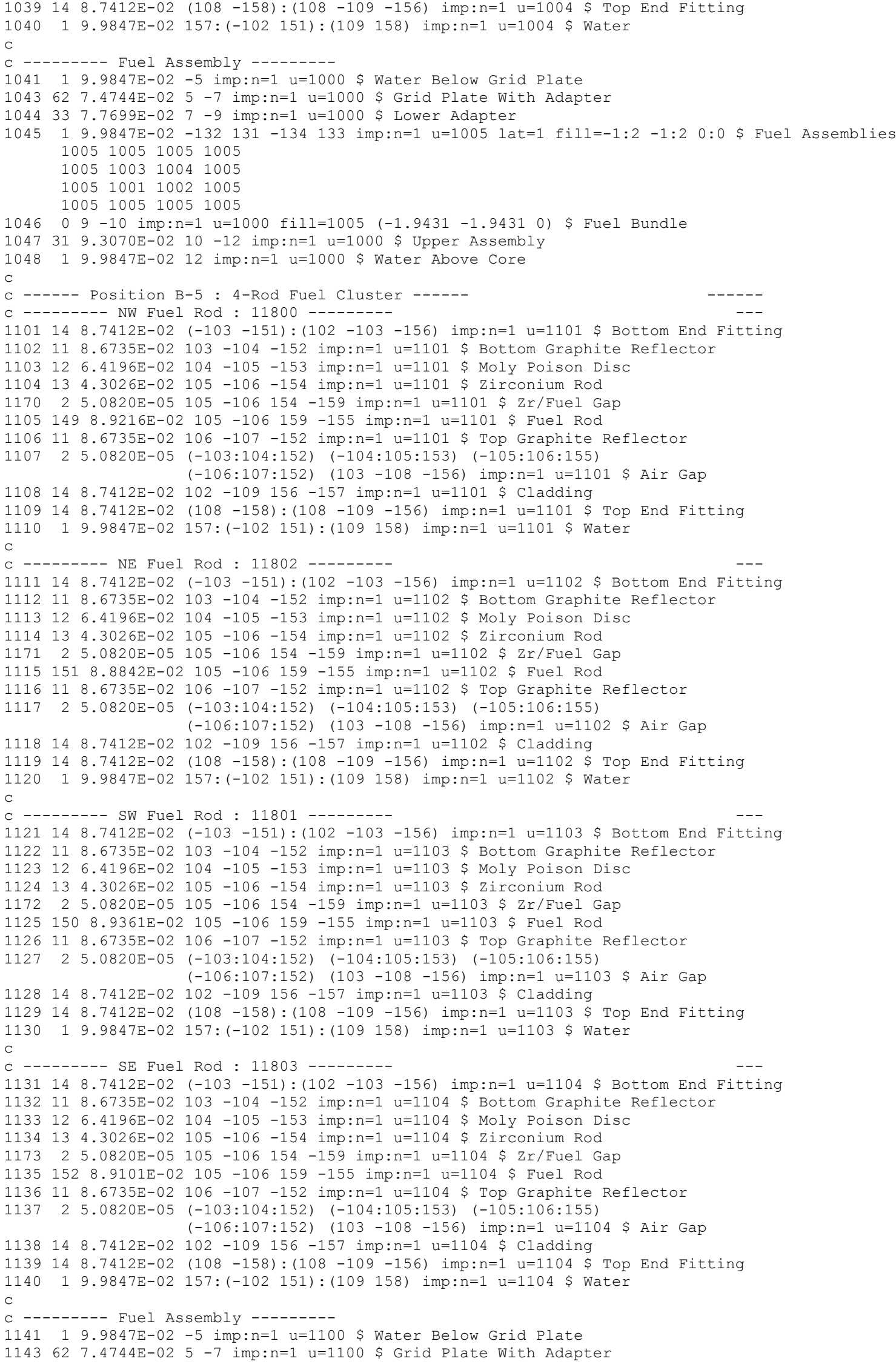




\section{NEA/NSC/DOC(2006)1}

\section{Fundamental - FUND}

\section{NRAD-FUND-RESR-002}

CRIT-REAC-COEF

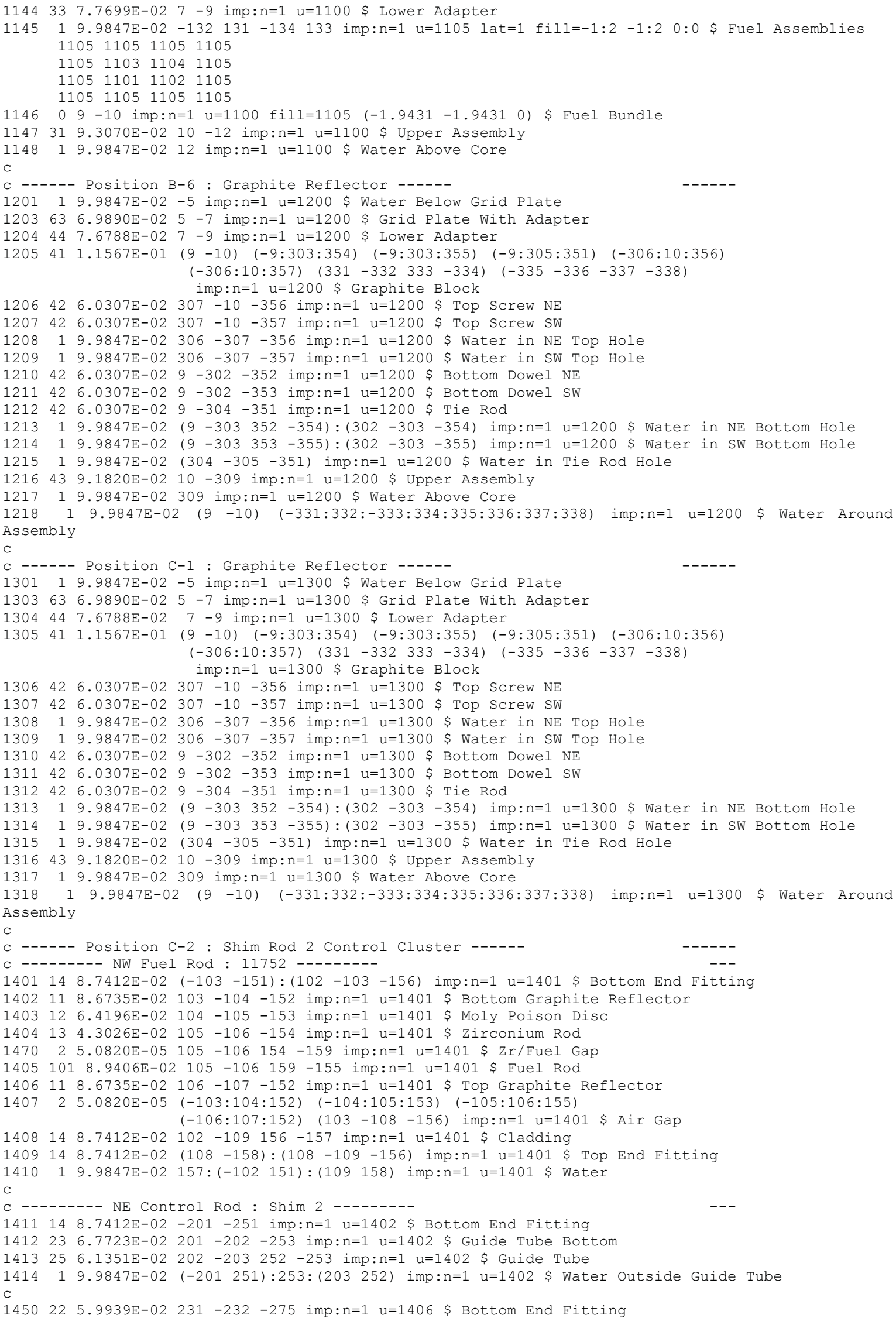




\section{NEA/NSC/DOC(2006)1}

\section{Fundamental - FUND}

\section{NRAD-FUND-RESR-002 CRIT-REAC-COEF}

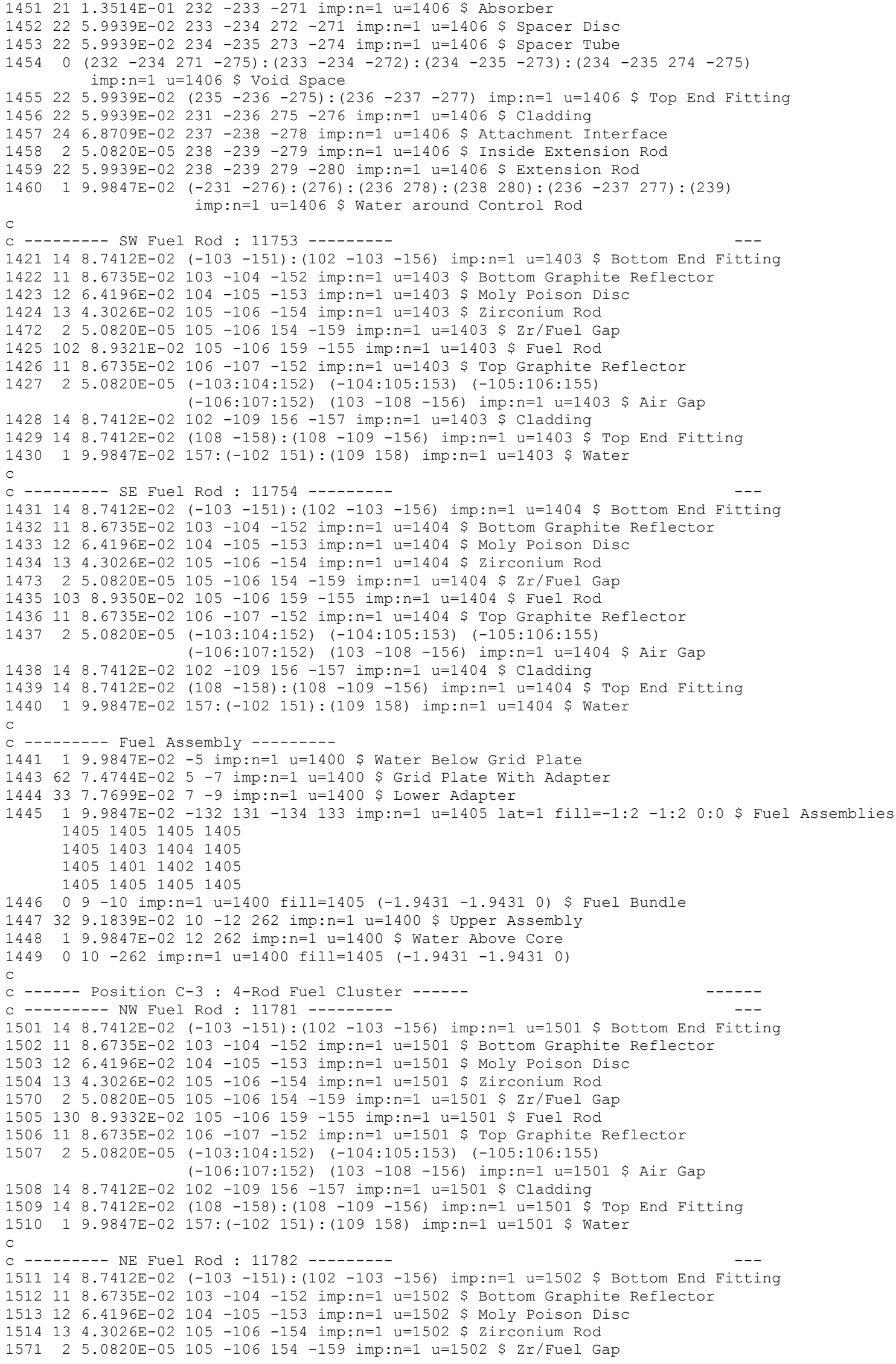




\section{NEA/NSC/DOC(2006)1}

\section{Fundamental - FUND}

\section{NRAD-FUND-RESR-002 CRIT-REAC-COEF}

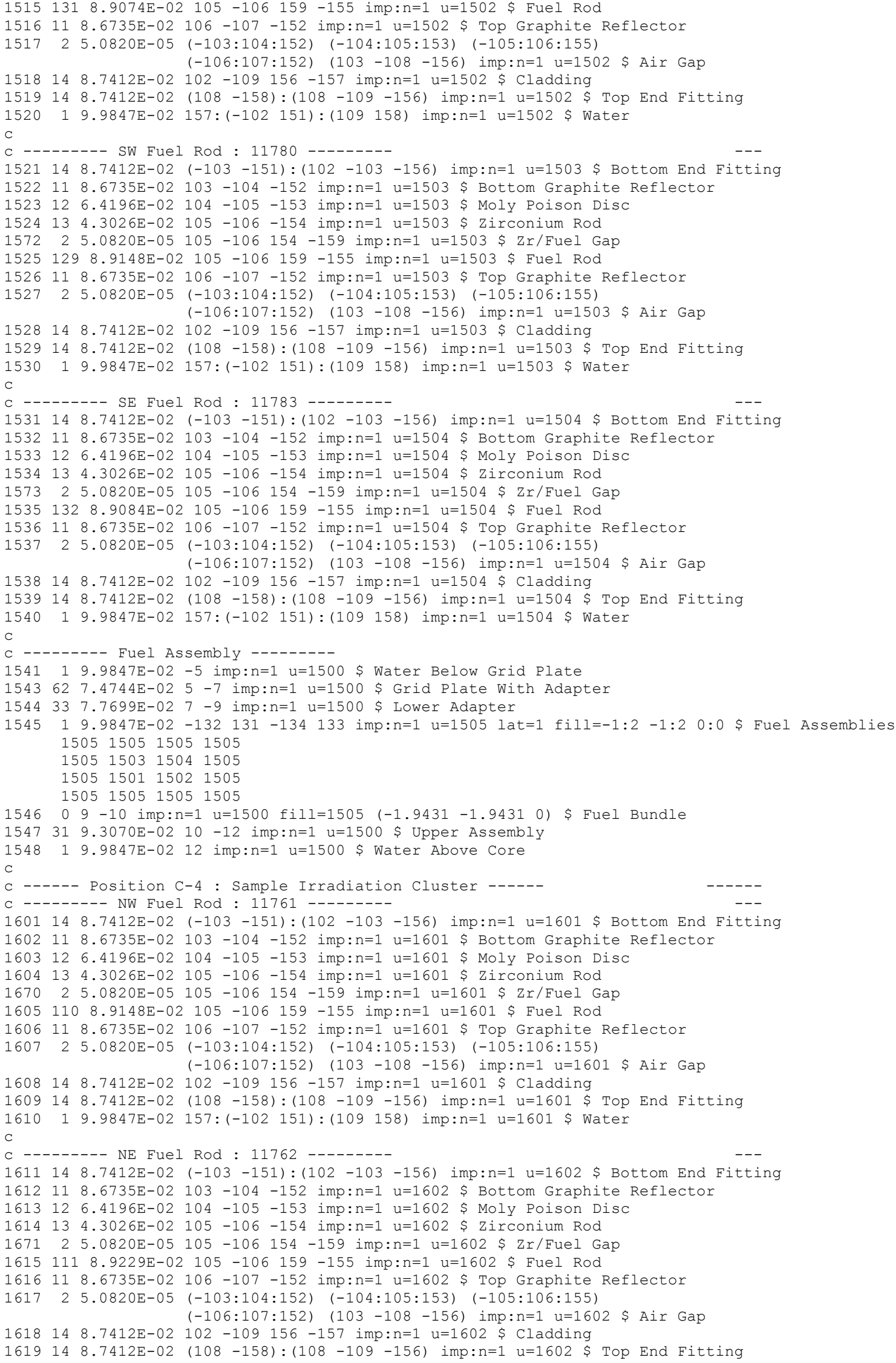




\section{NEA/NSC/DOC(2006)1}

\section{Fundamental - FUND}

\section{NRAD-FUND-RESR-002}

CRIT-REAC-COEF

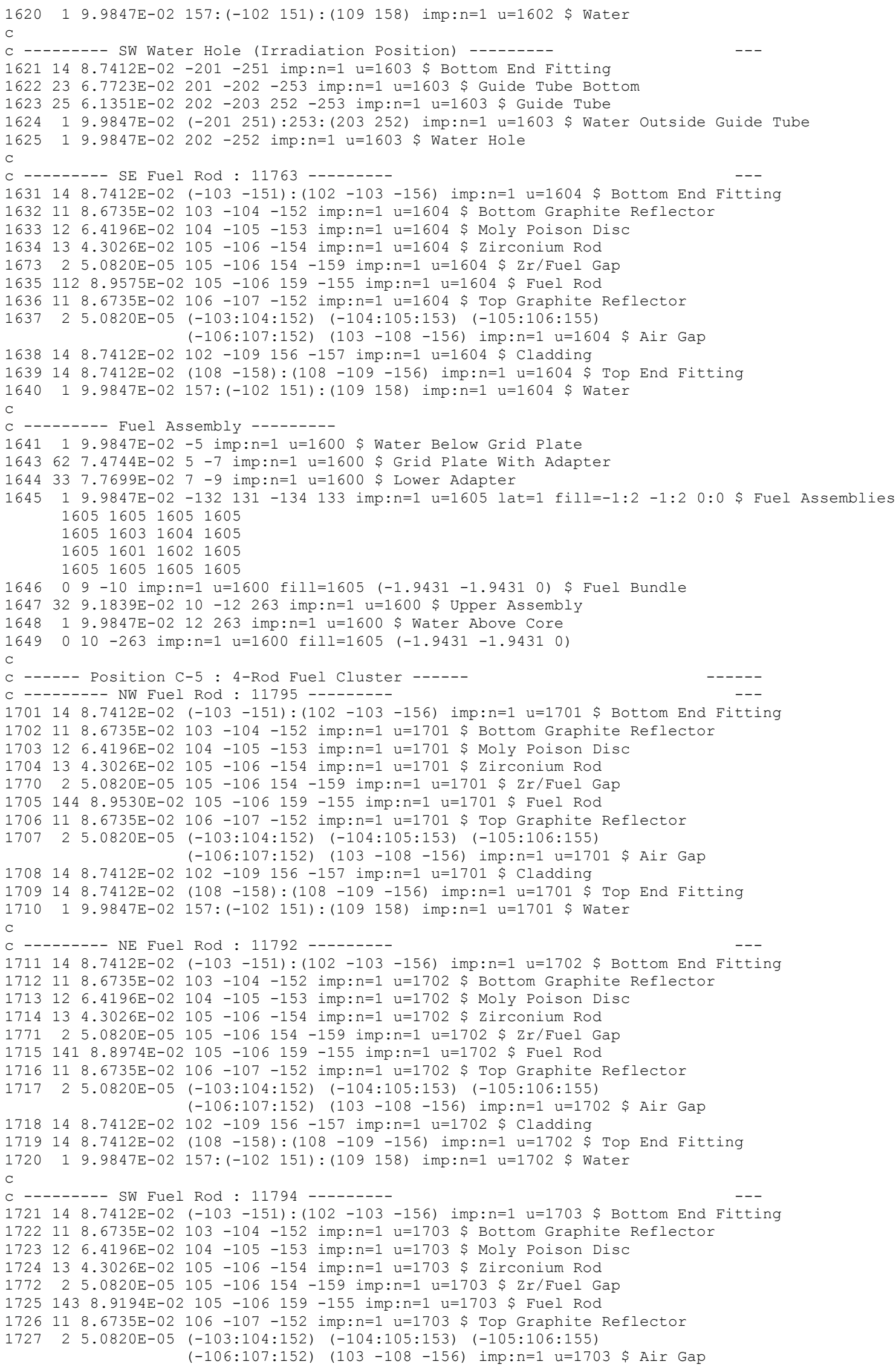




\section{NEA/NSC/DOC(2006)1}

\section{Fundamental - FUND}

\section{NRAD-FUND-RESR-002 CRIT-REAC-COEF}

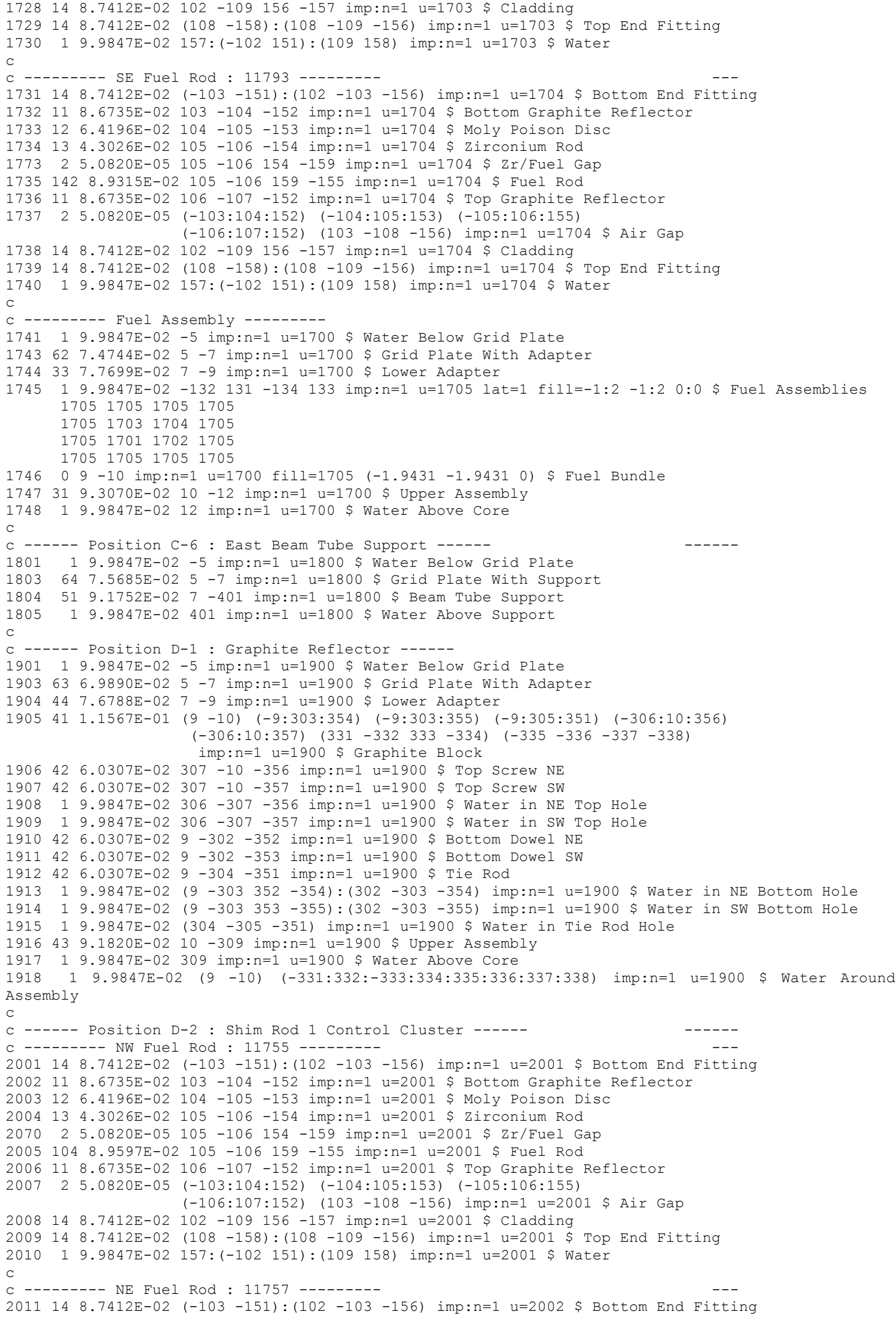




\section{NEA/NSC/DOC(2006)1}

\section{Fundamental - FUND}

\section{NRAD-FUND-RESR-002 CRIT-REAC-COEF}

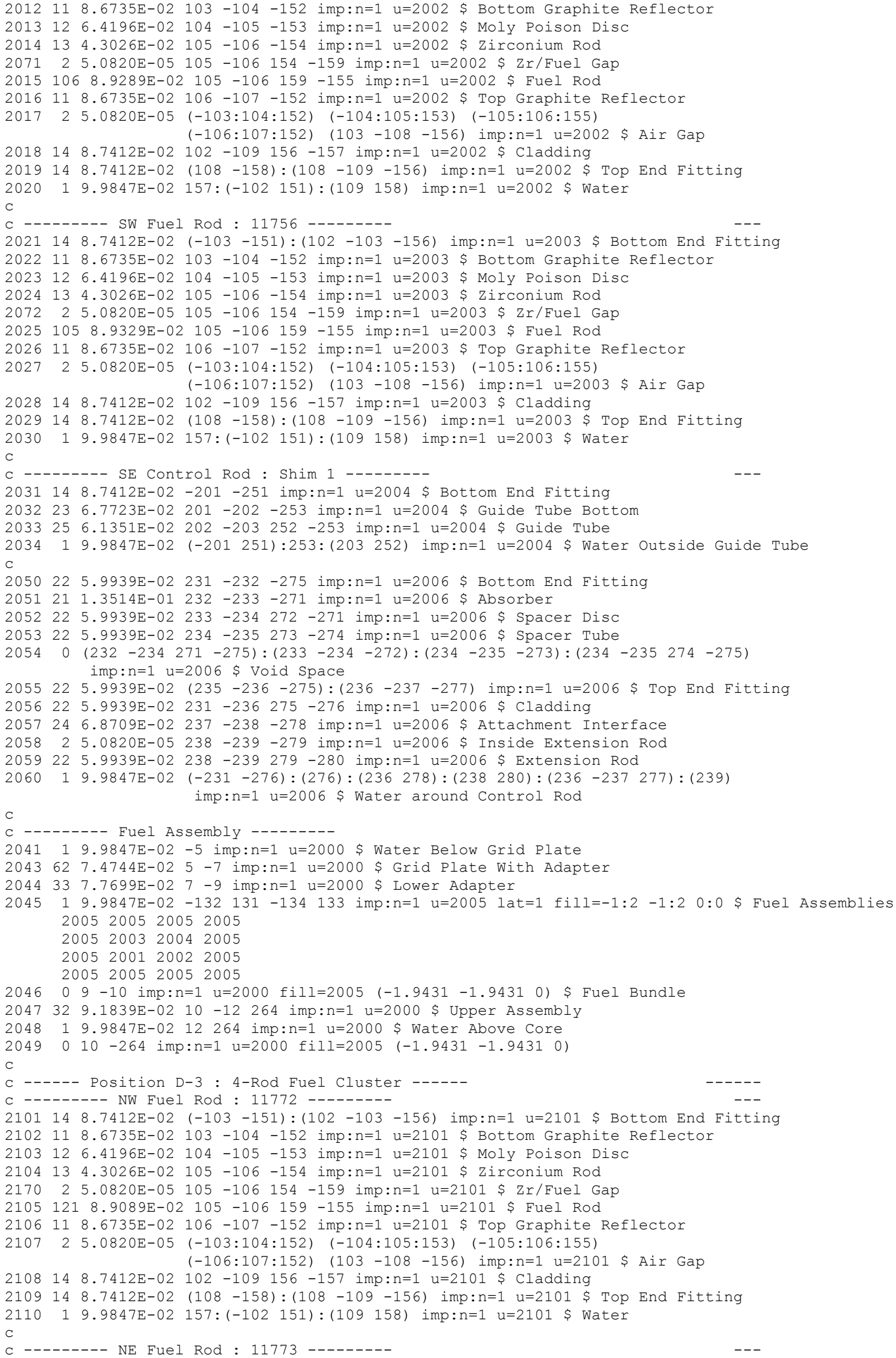




\section{NEA/NSC/DOC(2006)1}

\section{Fundamental - FUND}

\section{NRAD-FUND-RESR-002 CRIT-REAC-COEF}

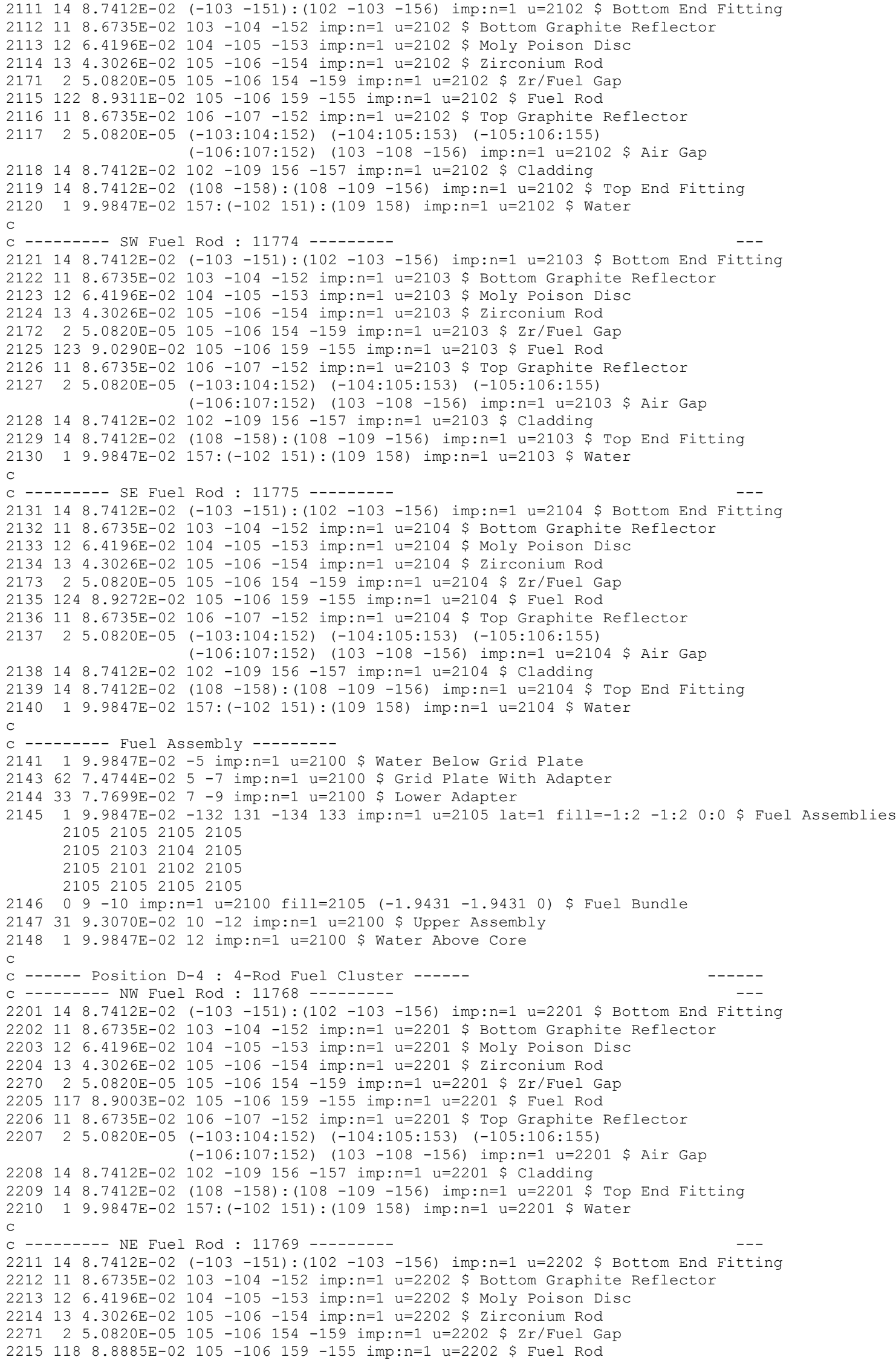




\section{NEA/NSC/DOC(2006)1}

\section{Fundamental - FUND}

\section{NRAD-FUND-RESR-002 CRIT-REAC-COEF}

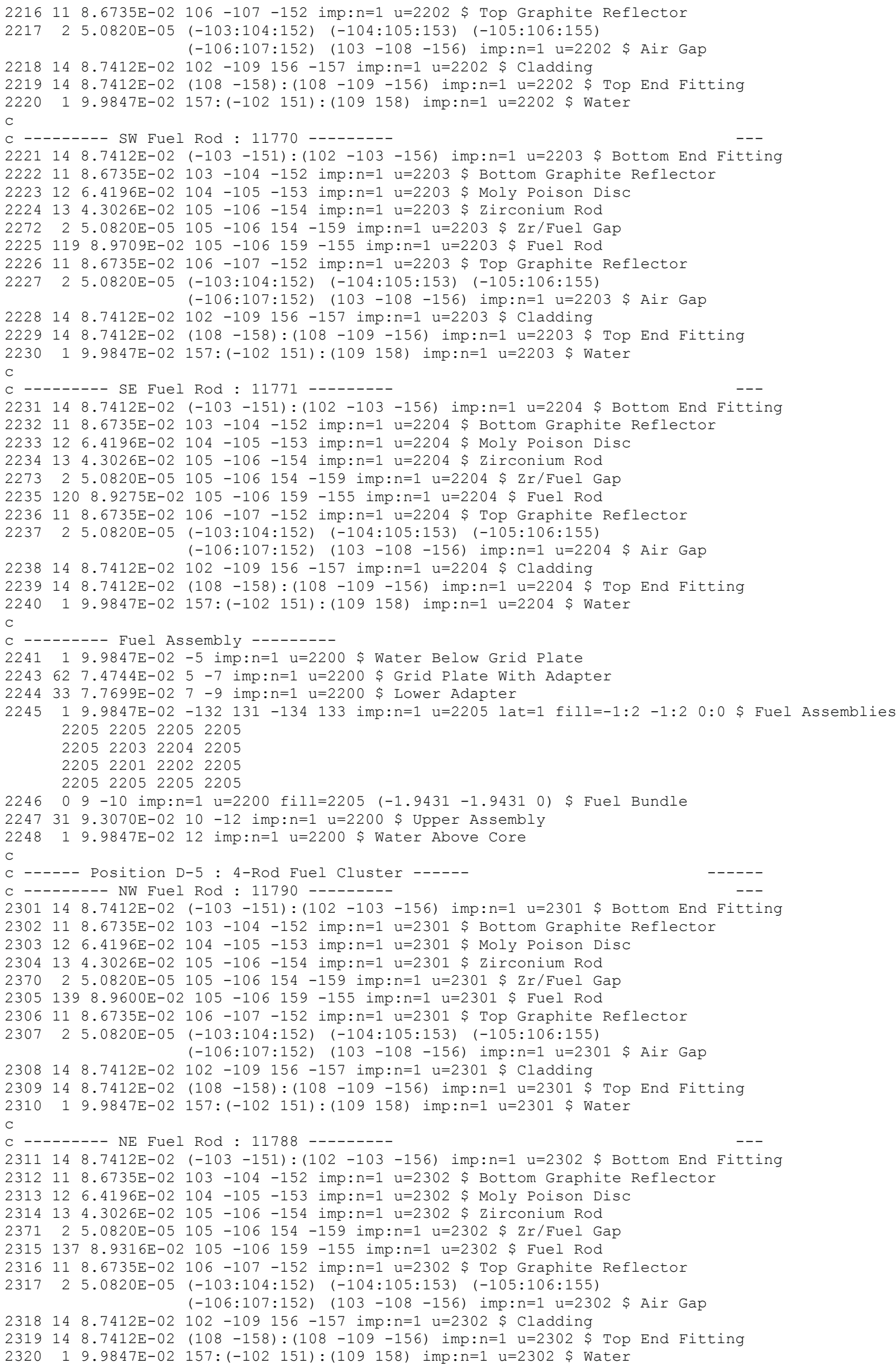




\section{NEA/NSC/DOC(2006)1}

\section{Fundamental - FUND}

\section{NRAD-FUND-RESR-002 CRIT-REAC-COEF}

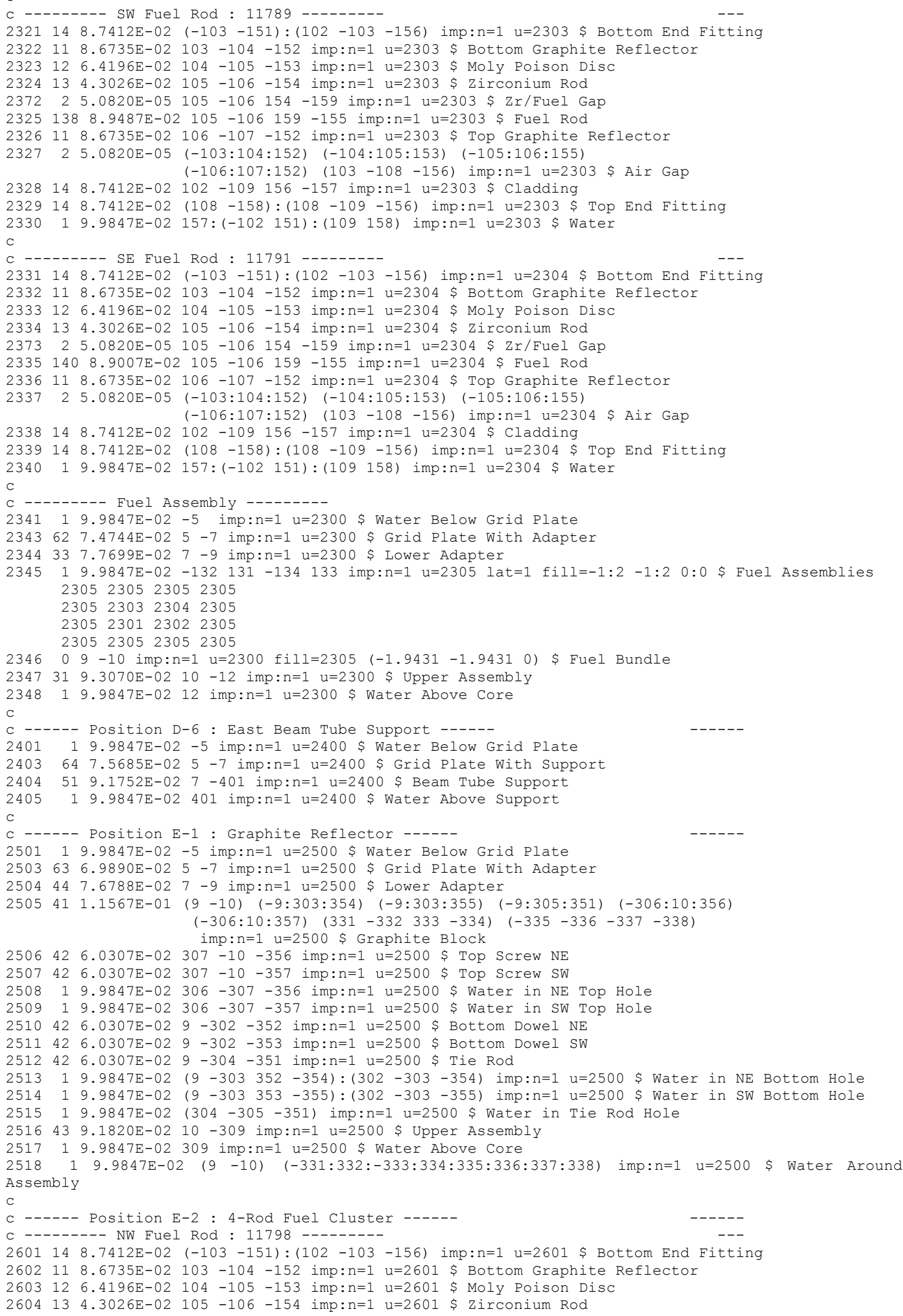




\section{NEA/NSC/DOC(2006)1}

\section{Fundamental - FUND}

\section{NRAD-FUND-RESR-002 CRIT-REAC-COEF}

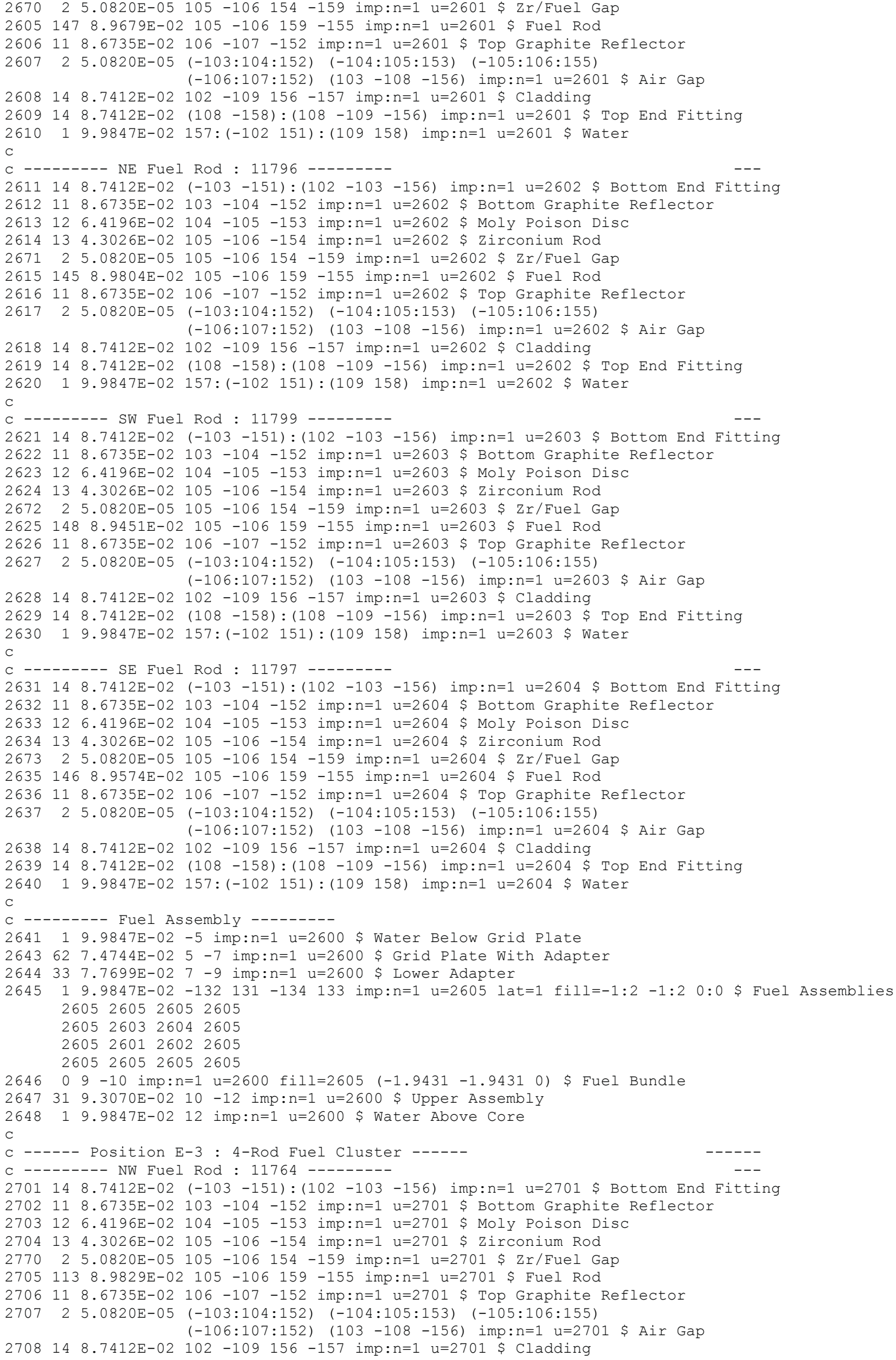




\section{NEA/NSC/DOC(2006)1}

\section{Fundamental - FUND}

\section{NRAD-FUND-RESR-002 CRIT-REAC-COEF}

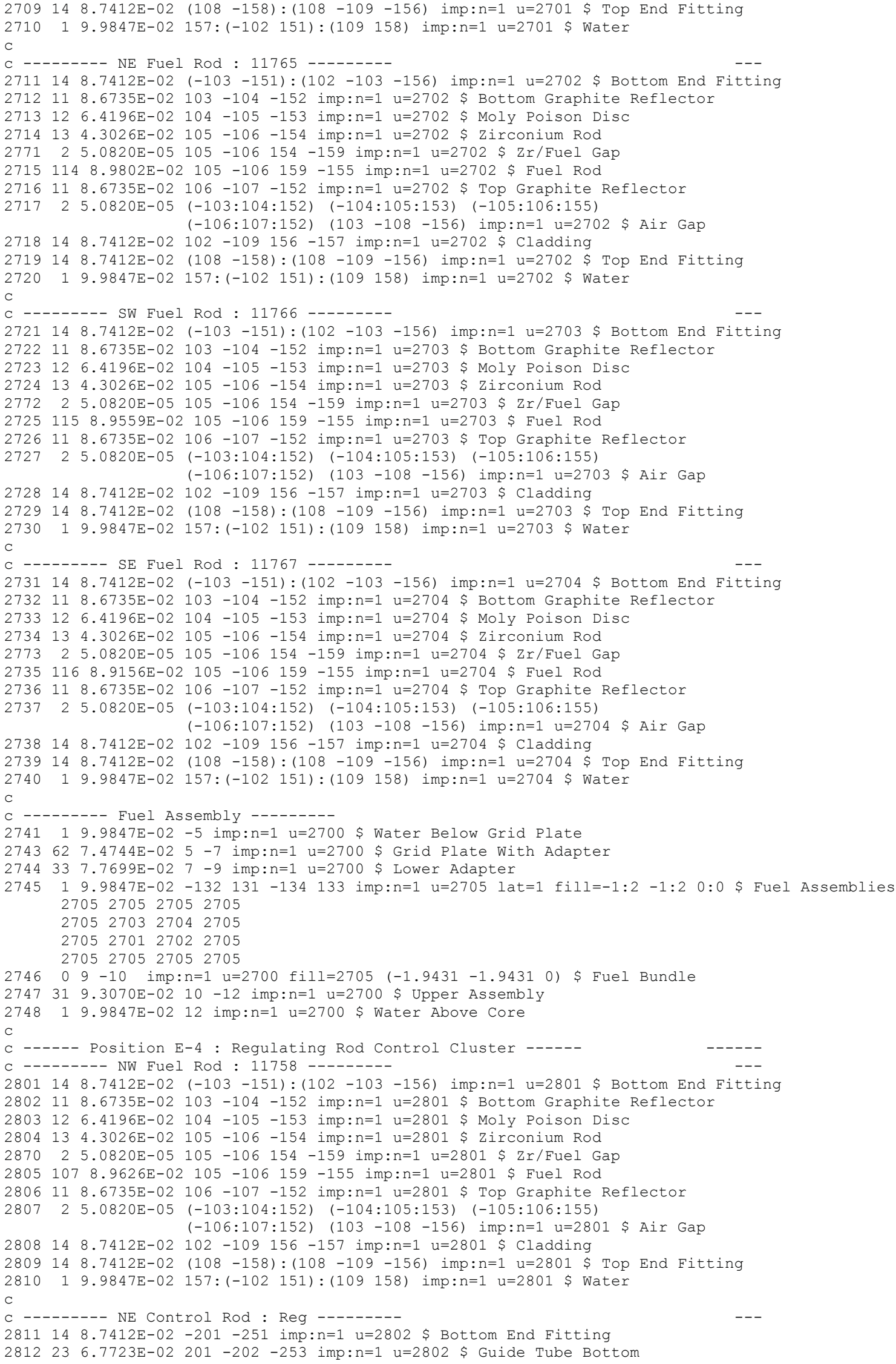




\section{NEA/NSC/DOC(2006)1}

\section{Fundamental - FUND}

\section{NRAD-FUND-RESR-002 CRIT-REAC-COEF}

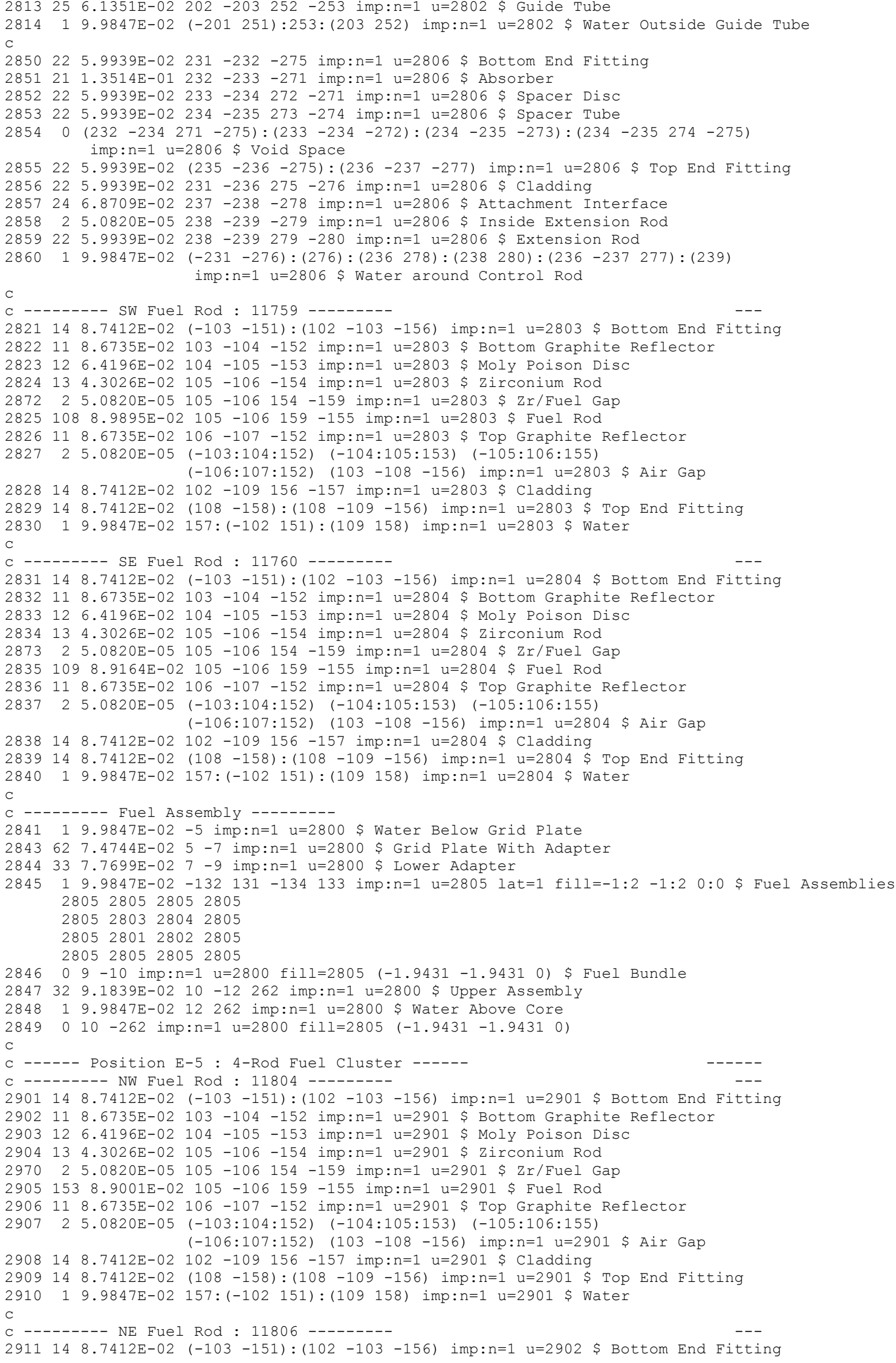




\section{NEA/NSC/DOC(2006)1}

\section{Fundamental - FUND}

\section{NRAD-FUND-RESR-002 CRIT-REAC-COEF}

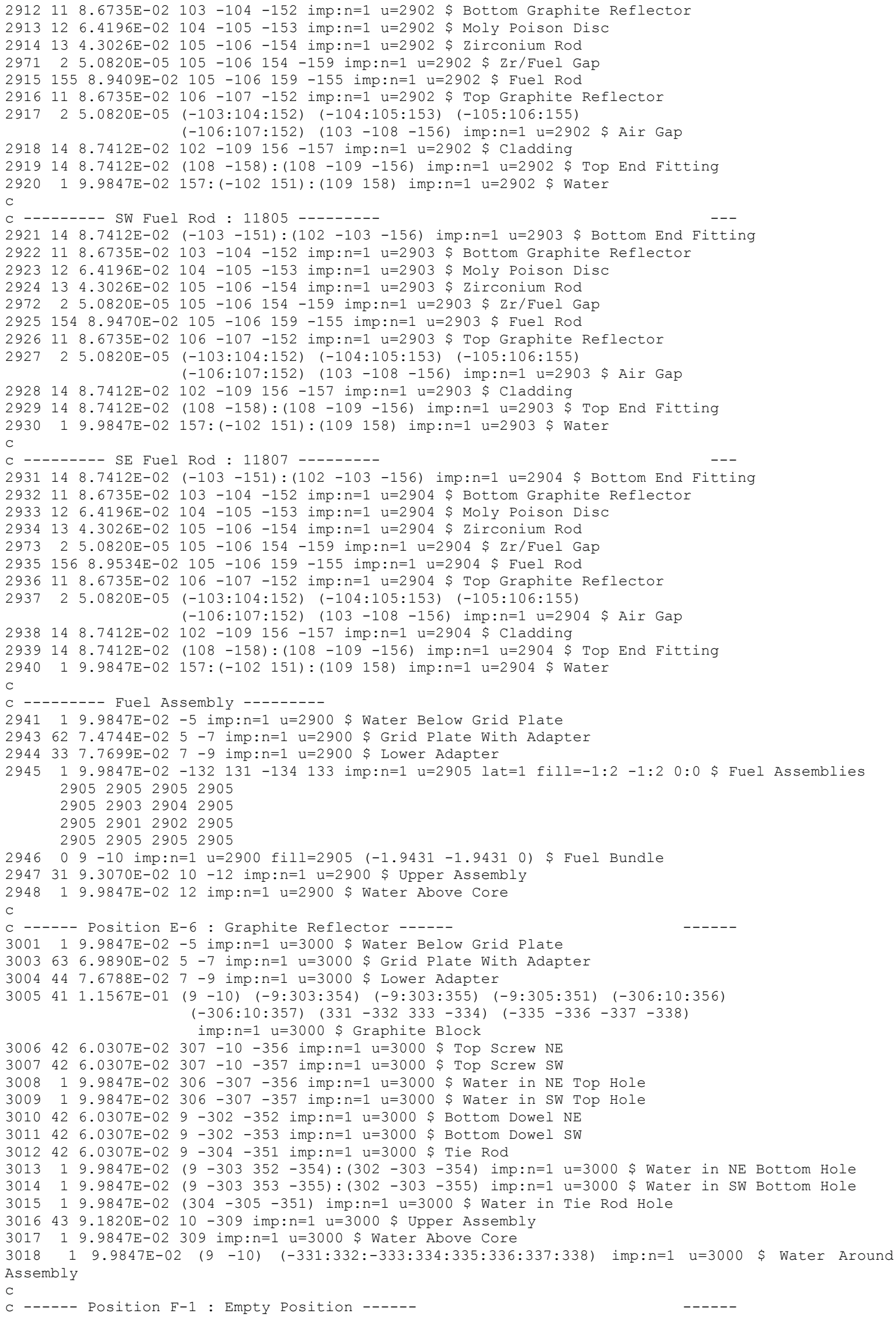




\section{NEA/NSC/DOC(2006)1}

\section{Fundamental - FUND}

\section{NRAD-FUND-RESR-002 CRIT-REAC-COEF}

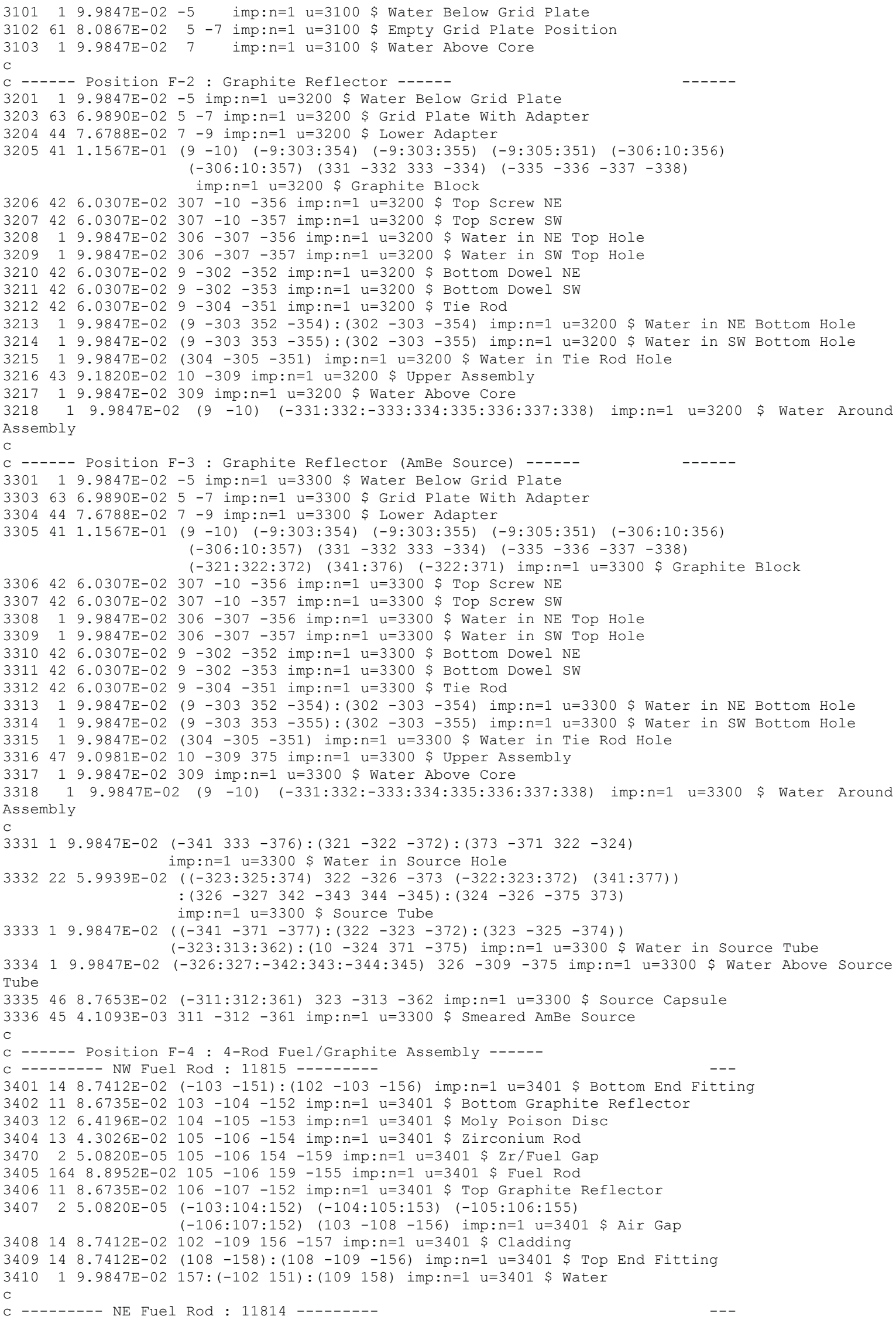




\section{NEA/NSC/DOC(2006)1}

\section{Fundamental - FUND}

\section{NRAD-FUND-RESR-002 CRIT-REAC-COEF}

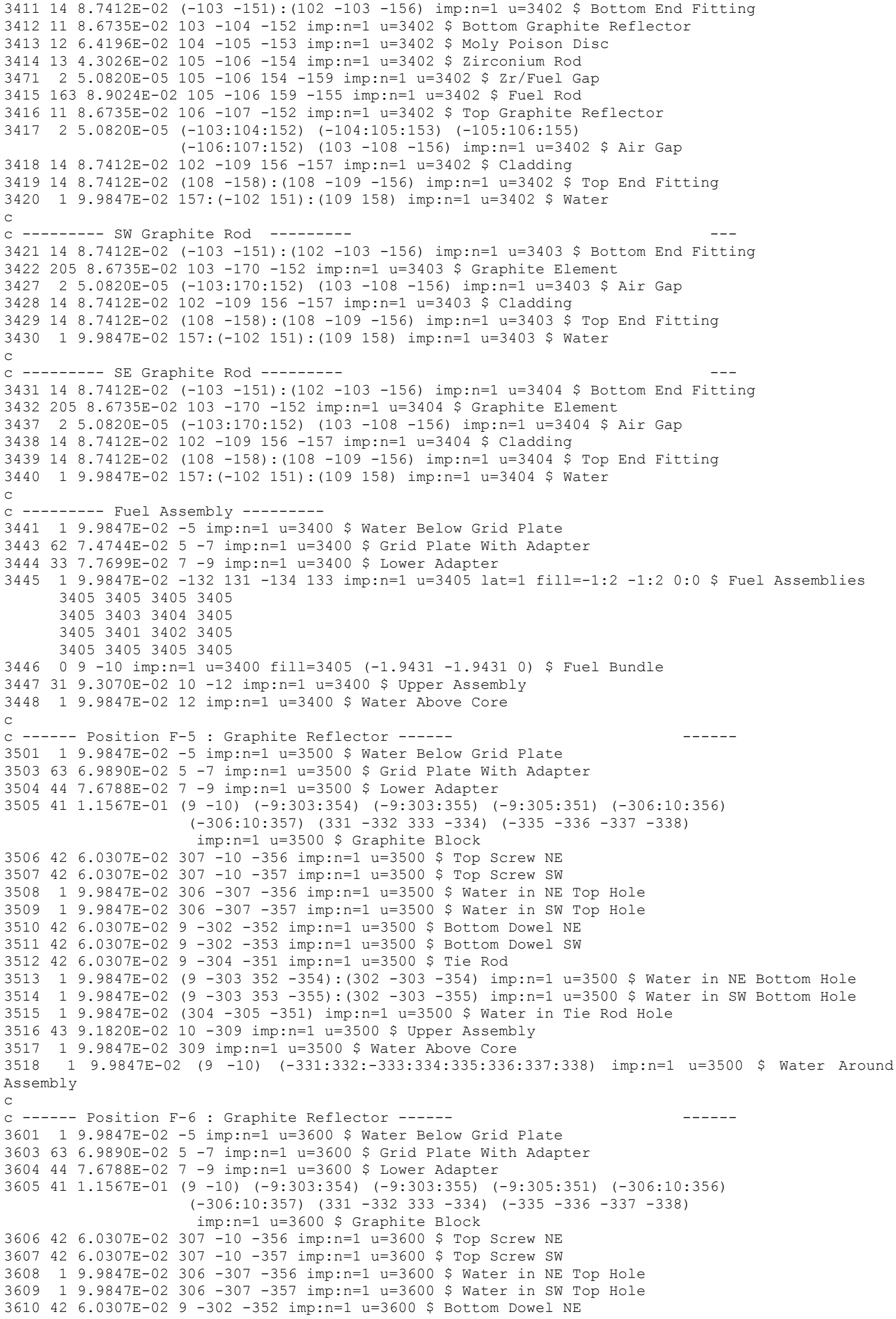




\section{NEA/NSC/DOC(2006)1}

\section{Fundamental - FUND \\ NRAD-FUND-RESR-002 \\ CRIT-REAC-COEF}

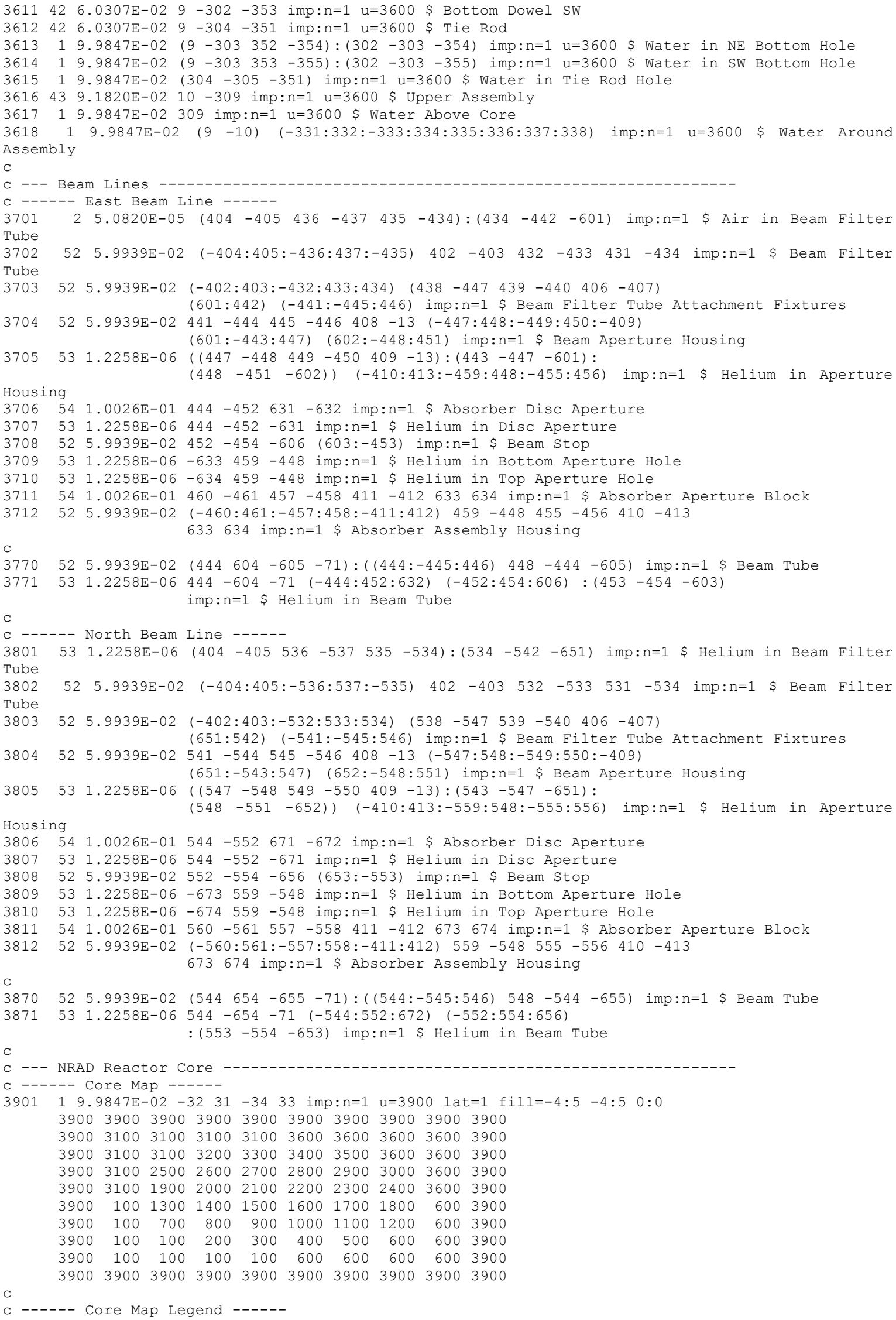




\section{NEA/NSC/DOC(2006)1}

\section{Fundamental - FUND}

\section{NRAD-FUND-RESR-002 \\ CRIT-REAC-COEF}

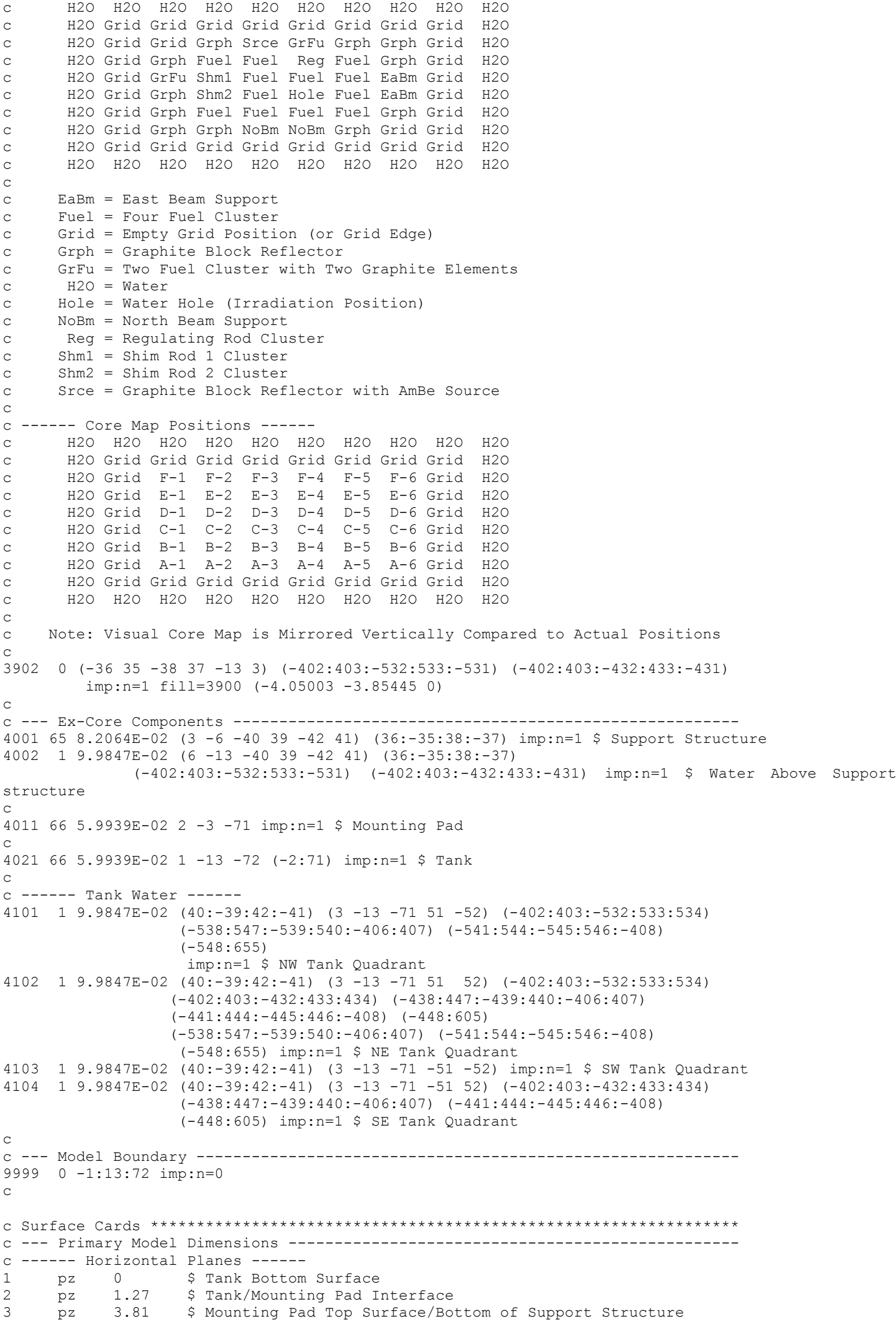


NEA/NSC/DOC(2006)1

\section{Fundamental - FUND}

\section{NRAD-FUND-RESR-002 \\ CRIT-REAC-COEF}

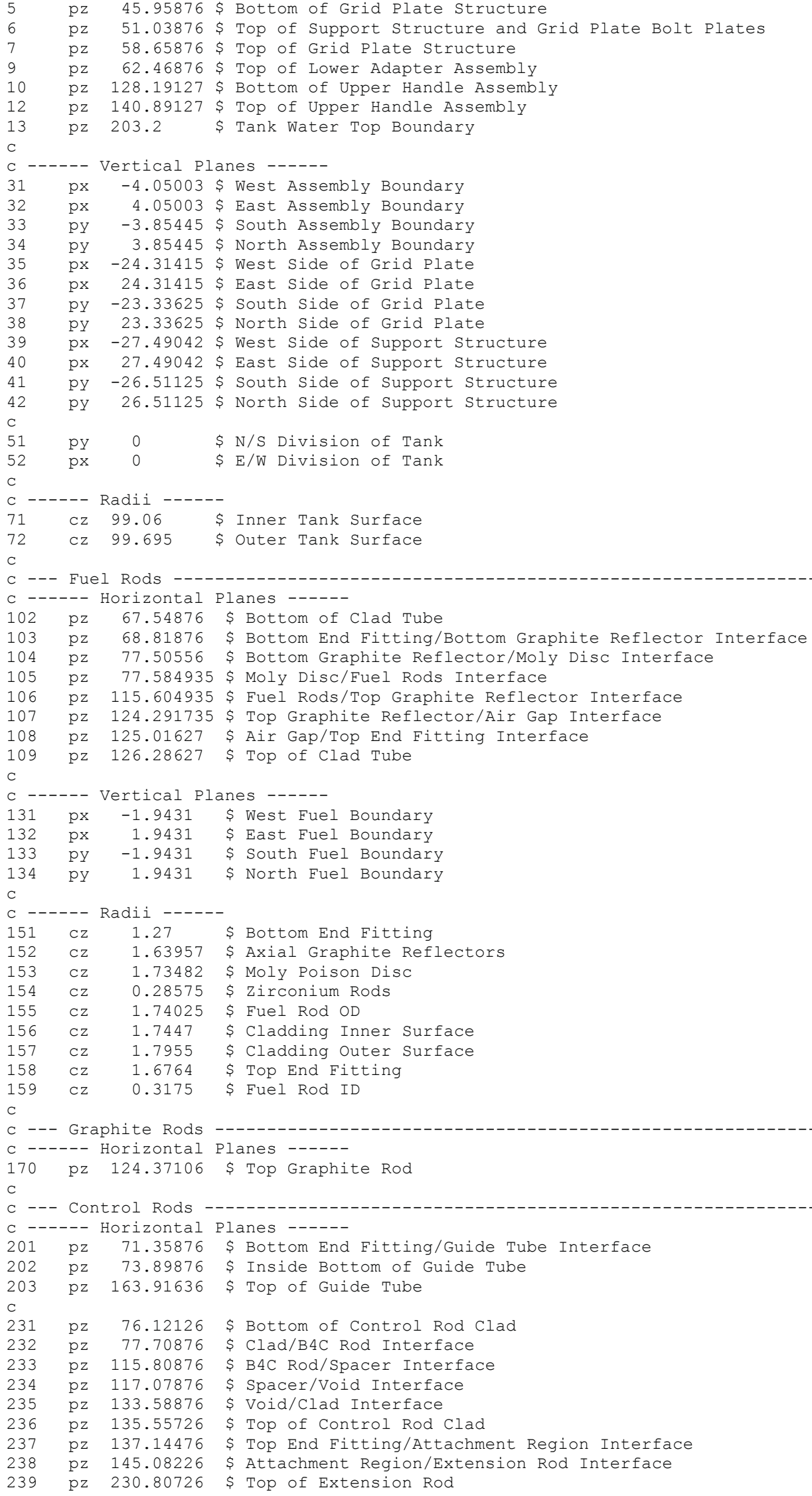


NEA/NSC/DOC(2006)1

Fundamental - FUND

NRAD-FUND-RESR-002

CRIT-REAC-COEF

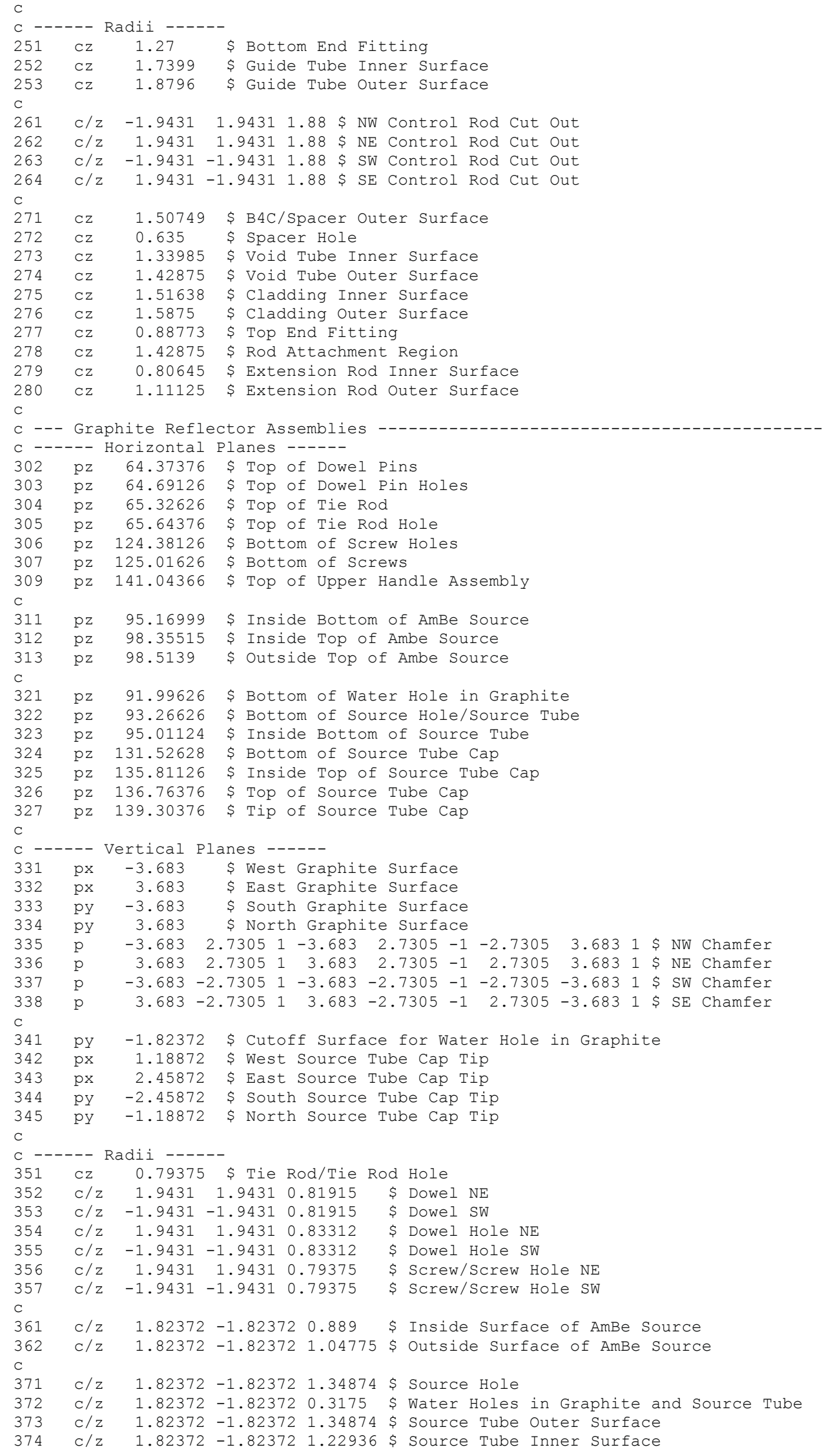


NEA/NSC/DOC(2006)1

\section{Fundamental - FUND}

\section{NRAD-FUND-RESR-002 CRIT-REAC-COEF}

\begin{tabular}{|c|c|c|c|}
\hline 375 & $\mathrm{C} / \mathrm{z}$ & 1.82372 & -1.823721 .82499 \$ Source Tube Cap Outer Surface \\
\hline 376 & $\mathrm{c} / \mathrm{y}$ & 1.82372 & 92.313760 .3175 \$ Water Interconnect Hole in Graphite \\
\hline 377 & $\mathrm{c} / \mathrm{y}$ & 1.82372 & 94.138750 .23749 \$ Water Interconnect Hole in Source Tube \\
\hline \\
\hline \multicolumn{4}{|c|}{$---\mathrm{Be}$} \\
\hline \multicolumn{4}{|c|}{ :----- Horizontal Planes ------ } \\
\hline 401 & $\mathrm{pz}$ & 84.455 & \$ Top of Beam Tube Support \\
\hline 402 & $\mathrm{pz}$ & 88.33993 & \$ Bottom Surface of Beam Filter Tubes \\
\hline 403 & $\mathrm{pz}$ & 104.84993 & \$ Top Surface of Beam Filter Tubes \\
\hline 404 & $\mathrm{pz}$ & 88.97493 & \$ Inside Bottom Surface of Beam Filter Tubes \\
\hline 405 & $\mathrm{pz}$ & 104.21493 & \$ Inside Top Surface of Beam Filter Tubes \\
\hline 406 & $\mathrm{pz}$ & 83.25993 & \$ Bottom Surface of Tube Attachment Fixtures \\
\hline 407 & $\mathrm{pz}$ & 109.92993 & \$ Top Surface of Tube Attachment Fixtures \\
\hline 408 & $\mathrm{pz}$ & 80.71993 & \$ Outside Bottom Surface of Aperture Housing \\
\hline 409 & $\mathrm{pz}$ & 81.98993 & \$ Inside Bottom Surface of Aperture Housing \\
\hline 410 & $\mathrm{pz}$ & 90.08618 & \$ Bottom of Absorber Assembly \\
\hline 411 & $\mathrm{pz}$ & 91.51493 & \$ Bottom of Absorber Block \\
\hline 412 & $\mathrm{pz}$ & 108.65993 & \$ Top of Absorber Block \\
\hline 413 & $\mathrm{pz}$ & 111.67618 & \$ Top of Absorber Assembly \\
\hline \multicolumn{4}{|r|}{$e^{1}$} \\
\hline \multirow{2}{*}{\multicolumn{4}{|c|}{$\begin{array}{l}\text { C }----- \text { Vertical Planes }------ \\
\text { c }------- \text { East Beam Assembly }--------\end{array}$}} \\
\hline & & & \\
\hline 431 & $\mathrm{px}$ & 17.92069 & \$ Core Face of Beam Filter Tube \\
\hline 432 & py & -6.985 & \$ South Surface of Beam Filter Tube \\
\hline 433 & py & 6.985 & \$ North Surface of Beam Filter Tube \\
\hline 434 & $\mathrm{px}$ & 51.57569 & \$ Back End of Beam Filter Tube \\
\hline 435 & $\mathrm{px}$ & 18.14929 & \$ Inside Core Face of Beam Filter Tube \\
\hline 436 & py & -6.6675 & \$ Inside South Surface of Beam Filter Tube \\
\hline 437 & py & 6.6675 & \$ Inside North Surface of Beam Filter Tube \\
\hline 438 & $\mathrm{px}$ & 47.76569 & \$ Beam Filter Tube Attachment Fixtures \\
\hline 439 & py & -10.4775 & \$ South Surface of Tube Attachment Fixtures \\
\hline 440 & py & 10.4775 & \$ North Surface of Tube Attachment Fixtures \\
\hline 441 & $\mathrm{px}$ & 52.84569 & \$ Core-Side Face of Beam Aperture Housing \\
\hline 442 & $\mathrm{px}$ & 52.52819 & \$ Beam Window Surface on Filter Tube \\
\hline 443 & $\mathrm{px}$ & 53.16319 & \$ Beam Window Surface on Aperture Housing \\
\hline 444 & $\mathrm{px}$ & 64.27569 & \$ Tank-Side Face of Beam Aperture Housing \\
\hline 445 & py & -7.9375 & \$ South Surface of Aperture Housing \\
\hline 446 & py & 7.9375 & \$ North Surface of Aperture Housing \\
\hline 447 & $\mathrm{px}$ & 54.11569 & \$ Inside Core-Side Face of Aperture Housing \\
\hline 448 & $\mathrm{px}$ & 63.00569 & \$ Inside Tank-Side Face of Aperture Housing \\
\hline 449 & py & -6.6675 & \$ Inside South Surface of Aperture Housing \\
\hline 450 & py & 6.6675 & \$ Inside North Surface of Aperture Housing \\
\hline 451 & $\mathrm{px}$ & 64.19949 & \$ Beam Window Surface on Aperture Housing \\
\hline 452 & $\mathrm{px}$ & 69.35569 & \$ Disc Absorber/Stop Interface \\
\hline 453 & $\mathrm{px}$ & 69.51317 & \$ Beam Window Surface in Absorber stop \\
\hline 454 & $\mathrm{px}$ & 69.99069 & \$ Tank-Side Face of Absorber Stop \\
\hline 455 & py & -6.62686 & \$ South Surface of Absorber Assembly \\
\hline 456 & py & 6.62686 & \$ North Surface of Absorber Assembly \\
\hline 457 & py & -5.08 & \$ South Surface of Absorber Block \\
\hline 458 & py & 5.08 & \$ North Surface of Absorber Block \\
\hline 459 & $\mathrm{px}$ & 57.29069 & \$ Core-Side Face of Absorber Assembly \\
\hline 460 & $\mathrm{px}$ & 57.60819 & \$ Core-Side Face of Absorber Block \\
\hline 461 & $\mathrm{px}$ & 62.68819 & \$ Tank-Side Face of Absorber Block \\
\hline \multicolumn{4}{|r|}{ 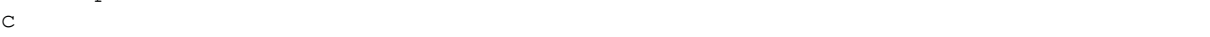 } \\
\hline & --- & -- North $B \epsilon$ & eam Assembly --------- \\
\hline 531 & py & 17.33395 & \$ Core Face of West Beam Filter Tube \\
\hline 532 & $\mathrm{px}$ & -6.985 & \$ East Surface of West Beam Filter Tube \\
\hline 533 & $\mathrm{px}$ & 6.985 & \$ West Surface of West Beam Filter Tube \\
\hline 534 & py & 52.57645 & \$ Back End of Beam Filter Tube \\
\hline 535 & py & 17.56255 & \$ Inside Core Face of Beam Filter Tube \\
\hline 536 & $\mathrm{px}$ & -6.6675 & \$ Inside East Surface of Beam Filter Tube \\
\hline 537 & $\mathrm{px}$ & 6.6675 & \$ Inside West Surface of Beam Filter Tube \\
\hline 538 & py & 48.76645 & \$ Beam Filter Tube Attachment Fixtures \\
\hline 539 & $\mathrm{px}$ & -10.4775 & \$ East Surface of Tube Attachment Fixtures \\
\hline 540 & $\mathrm{px}$ & 10.4775 & \$ West Surface of Tube Attachment Fixtures \\
\hline 541 & py & 53.84645 & \$ Core-Side Face of Beam Aperture Housing \\
\hline 542 & py & 53.52895 & \$ Beam Window Surface on Filter Tube \\
\hline 543 & py & 54.16395 & \$ Beam Window Surface on Aperture Housing \\
\hline 544 & py & 65.27645 & \$ Tank-Side Face of Beam Aperture Housing \\
\hline 545 & $\mathrm{px}$ & -7.9375 & \$ East Surface of Aperture Housing \\
\hline 546 & $\mathrm{px}$ & 7.9375 & \$ West Surface of Aperture Housing \\
\hline 547 & py & 55.11645 & \$ Inside Core-Side Face of Aperture Housing \\
\hline 548 & py & 64.00645 & \$ Inside Tank-Side Face of Aperture Housing \\
\hline 549 & $\mathrm{px}$ & -6.6675 & \$ Inside East Surface of Aperture Housing \\
\hline 550 & $\mathrm{px}$ & 6.6675 & \$ Inside West Surface of Aperture Housing \\
\hline 551 & py & 65.20025 & \$ Beam Window Surface on Aperture Housing \\
\hline
\end{tabular}


NEA/NSC/DOC(2006)1

\section{Fundamental - FUND}

\section{NRAD-FUND-RESR-002 CRIT-REAC-COEF}

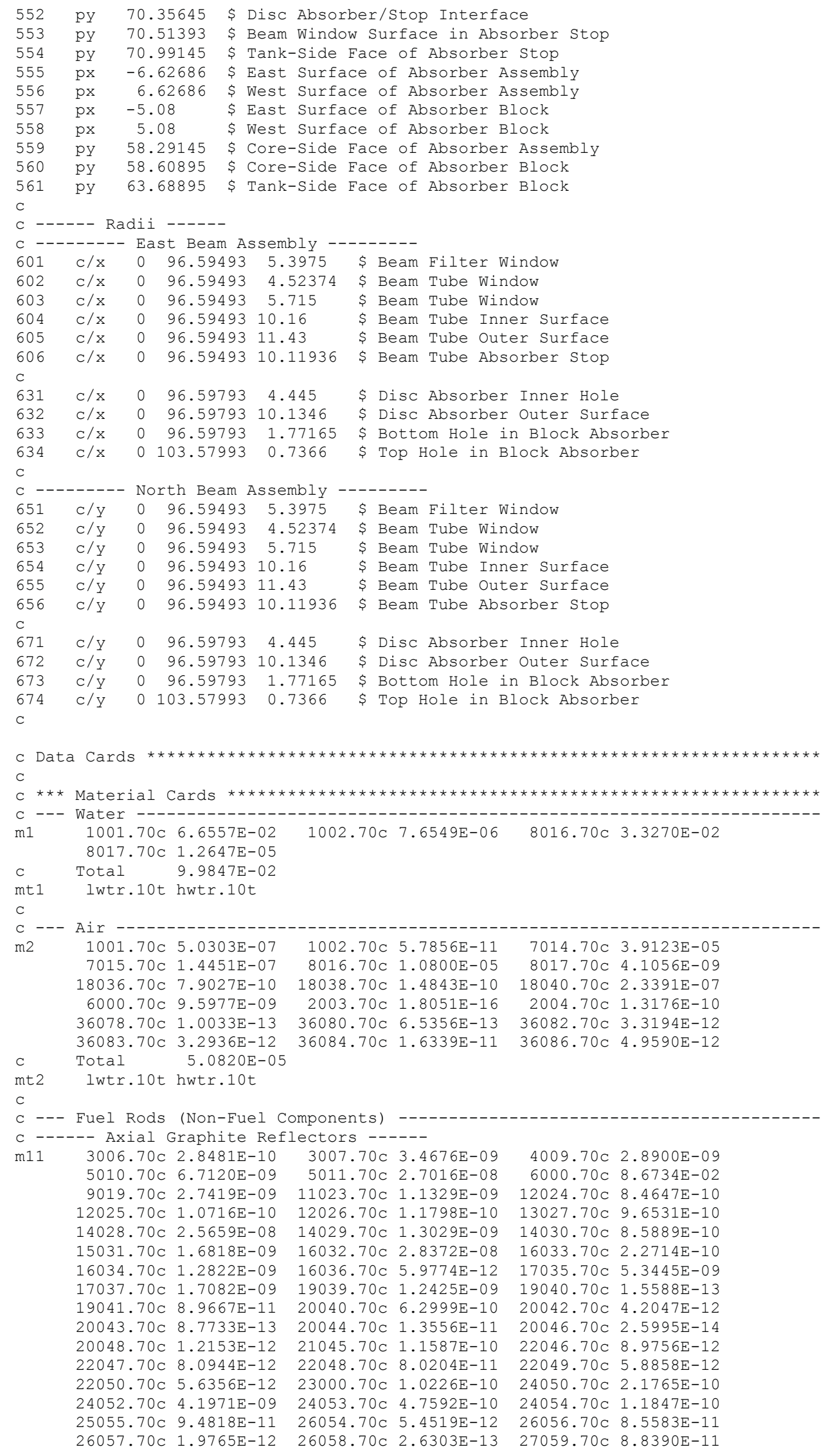


NEA/NSC/DOC(2006)1

\section{Fundamental - FUND}

\section{NRAD-FUND-RESR-002 \\ CRIT-REAC-COEF}

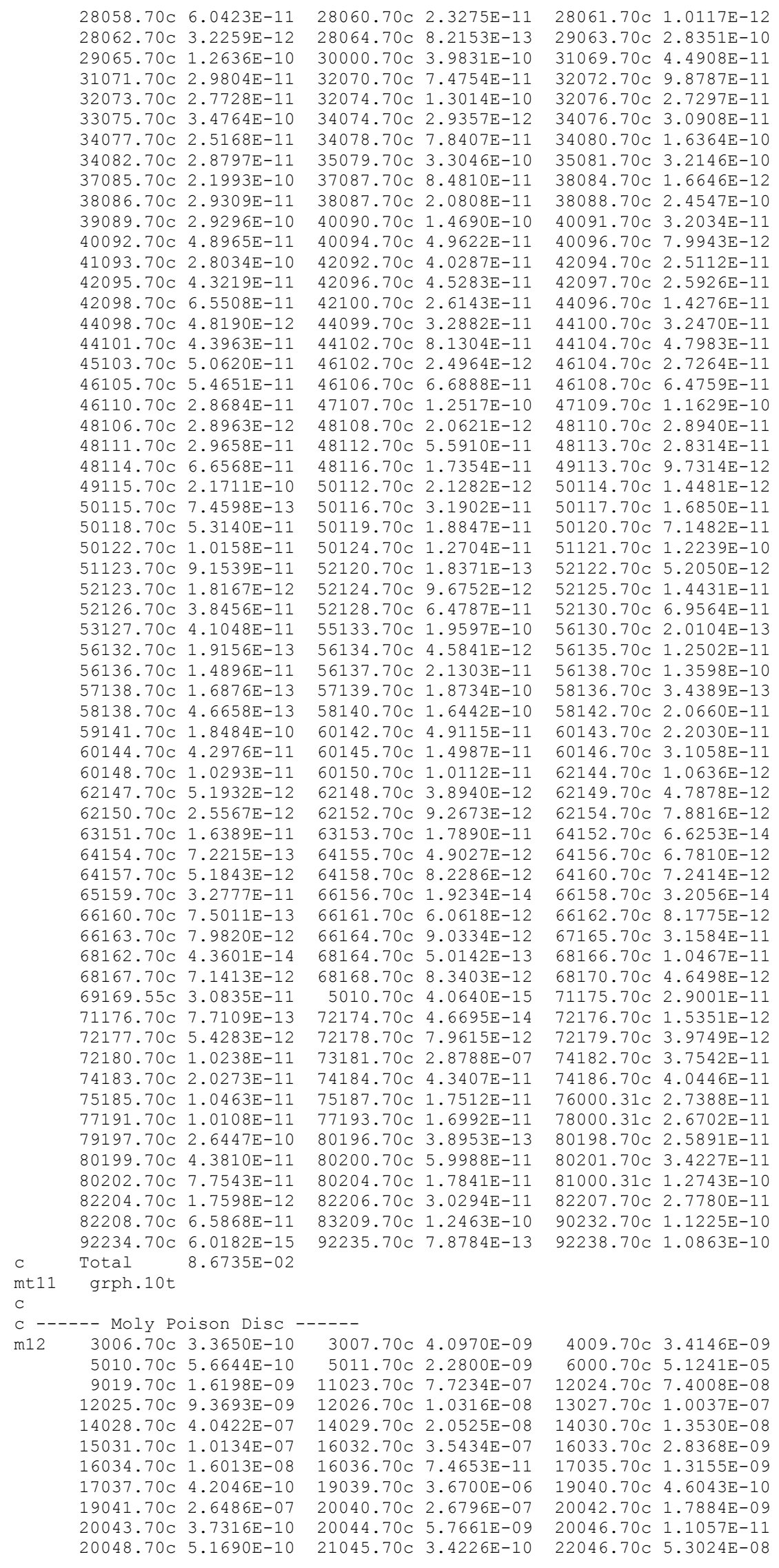


NEA/NSC/DOC(2006)1

\section{Fundamental - FUND}

\section{NRAD-FUND-RESR-002 \\ CRIT-REAC-COEF}

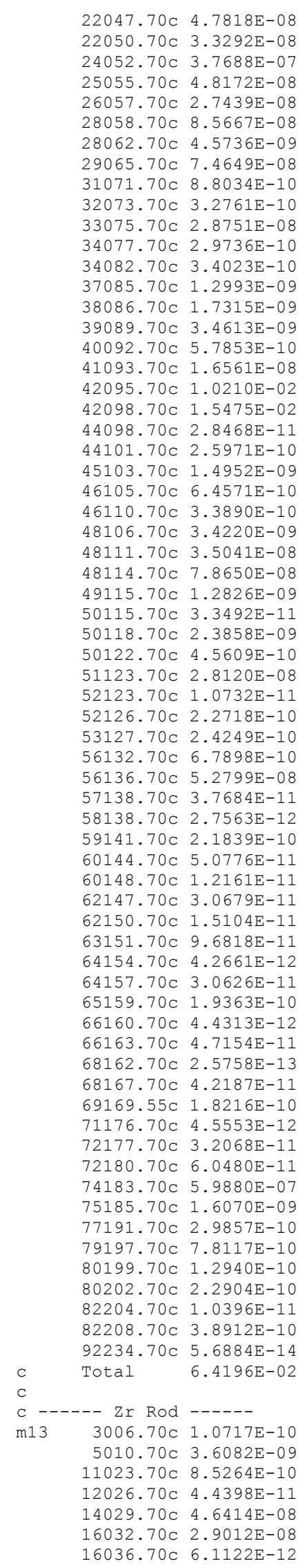

$22047.70 \mathrm{C} \quad 4.7818 \mathrm{E}-08$ $22050.70 \mathrm{C} 3.3292 \mathrm{E}-08$ $70 \mathrm{c} .7688 \mathrm{E}-07$ $26057.70 \mathrm{C} 2.7439 \mathrm{E}-08$ $28058.70 \mathrm{C} \quad 8.5667 \mathrm{E}-08$ $28062.70 \mathrm{C} 4.5736 \mathrm{E}-09$ $29065.70 \mathrm{C} 7.4649 \mathrm{E}-08$ 1.70 $8.8034 \mathrm{E}-10$ $61 \mathrm{E}-10$ $34082.70 \mathrm{C} 3.4023 \mathrm{E}-10$ $.70 \mathrm{C} 1.2993 \mathrm{E}-09$ $39089.70 \mathrm{C} 3.4613 \mathrm{E}-09$ $40092.70 \mathrm{C} 5.7853 \mathrm{E}-10$ . $1093.70 \mathrm{C} 1.6561 \mathrm{E}-08$ $475 \mathrm{E}-02$ $44098.70 \mathrm{C} 2.8468 \mathrm{E}-11$ $44101.70 \mathrm{C} 2.5971 \mathrm{E}-10$ $03.70 \mathrm{C} 1.4952 \mathrm{E}-09$ $46105.70 \mathrm{C} 6.4571 \mathrm{E}-10$ $.70 \mathrm{C} 3.3890 \mathrm{E}-10$ $48111.70 \mathrm{C} 3.5041 \mathrm{E}-08$ $48114.70 \mathrm{C} 7.8650 \mathrm{E}-08$ $59115.70 \mathrm{C} 1.2826 \mathrm{E}-09$ $50118.70 \mathrm{C} 2.3858 \mathrm{E}-09$ $50122.70 \mathrm{C} \quad 4.5609 \mathrm{E}-10$ $51123.70 \mathrm{C} 2.8120 \mathrm{E}-08$ $3.70 \mathrm{C} 1.0732 \mathrm{E}-11$ $5126.70 \mathrm{C} 2.2718 \mathrm{E}-10$ $.70 \mathrm{C} 2.4249 \mathrm{E}-10$ $56136.70 \mathrm{C} \quad 5.2799 \mathrm{E}-08$ $38.70 \mathrm{C} 3.7684 \mathrm{E}-11$ $3 \mathrm{E}-12$ $60148.70 \mathrm{C} 1.2161 \mathrm{E}-11$ . $63151.70 \mathrm{C} 9.6818 \mathrm{E}-11$ $64154.70 \mathrm{C} 4.2661 \mathrm{E}-12$ $6157.70 \mathrm{C} 3.0626 \mathrm{E}-11$ $313 \mathrm{E}-12$ $66163.70 \mathrm{C} 4.7154 \mathrm{E}-11$ $68162.70 \mathrm{C} \quad 2.5758 \mathrm{E}-13$ $8167.70 \mathrm{C} 4.2187 \mathrm{E}-11$ $169.55 \mathrm{c} 1.8216 \mathrm{E}-10$ $72180.70 \mathrm{C} \quad 6.0480 \mathrm{E}-11$ $74183.70 \mathrm{C} \quad 5.9880 \mathrm{E}-07$ 75185.70 C $1.6070 \mathrm{E}-09$ $79197.70 \mathrm{C} 7.8117 \mathrm{E}-10$ $80199.70 \mathrm{C} 1.2940 \mathrm{E}-10$ $4 \mathrm{E}-10$ $82208.70 \mathrm{C} 3.8912 \mathrm{E}-10$ $92234.70 \mathrm{C} 5.6884 \mathrm{E}-14$ - Zr Rod -----5006.70 c $1.0717 \mathrm{E}-10$ $264 \mathrm{E}-10$ $12026.70 \mathrm{C} \quad 4.4398 \mathrm{E}-11$ $16032.70 \mathrm{C} 2.9012 \mathrm{E}-08$ $16036.70 \mathrm{C} 6.1122 \mathrm{E}-12$
$22048.70 \mathrm{C} 4.7381 \mathrm{E}-07$ $23000.70 \mathrm{C} 1.3290 \mathrm{E}-07$ $24053.70 \mathrm{C} \quad 4.2735 \mathrm{E}-08$ $26054.70 \mathrm{C} 7.5687 \mathrm{E}-08$ $26058.70 \mathrm{C} 3.6516 \mathrm{E}-09$ $28060.70 \mathrm{C} 3.2999 \mathrm{E}-08$ $28064.70 \mathrm{C} 1.1648 \mathrm{E}-09$ $30000.70 \mathrm{C} 2.3530 \mathrm{E}-09$ $32070.70 \mathrm{C} 8.8322 \mathrm{E}-10$ $32074.70 \mathrm{C} 1.5376 \mathrm{E}-09$ $34074.70 \mathrm{C} 3.4686 \mathrm{E}-11$ $34078.70 \mathrm{C} 9.2638 \mathrm{E}-10$ $35079.70 \mathrm{C} 1.9522 \mathrm{E}-10$ $37087.70 \mathrm{C} 5.0101 \mathrm{E}-10$ $38087.70 \mathrm{C} 1.2292 \mathrm{E}-09$ $40090.70 \mathrm{C} 1.7356 \mathrm{E}-09$ $40094.70 \mathrm{C} 5.8629 \mathrm{E}-10$ $42092.70 \mathrm{C} 9.5169 \mathrm{E}-03$ $42096.70 \mathrm{C} 1.0697 \mathrm{E}-02$ $42100.70 \mathrm{C} \quad 6.1757 \mathrm{E}-03$ $44099.70 \mathrm{C} 1.9425 \mathrm{E}-10$ $44102.70 \mathrm{C} \quad 4.8030 \mathrm{E}-10$ $46102.70 \mathrm{C} 2.9495 \mathrm{E}-11$ $46106.70 \mathrm{C} 7.9029 \mathrm{E}-10$ $47107.70 \mathrm{C} \quad 7.3944 \mathrm{E}-09$ $48108.70 \mathrm{C} 2.4364 \mathrm{E}-09$ $48112.70 \mathrm{C} \quad 6.6057 \mathrm{E}-08$ $48116.70 \mathrm{C} 2.0504 \mathrm{E}-08$ $50112.70 \mathrm{C} 9.5551 \mathrm{E}-11$ $50116.70 \mathrm{C} 1.4323 \mathrm{E}-09$ $50119.70 \mathrm{C} 8.4617 \mathrm{E}-10$ $50124.70 \mathrm{C}$ 5.7035E-10 $52120.70 \mathrm{C} 1.0853 \mathrm{E}-12$ $52124.70 \mathrm{C} 5.7157 \mathrm{E}-11$ $52128.70 \mathrm{C} 3.8273 \mathrm{E}-10$ $55133.70 \mathrm{C} 1.1577 \mathrm{E}-09$ $56134.70 \mathrm{C} 1.6248 \mathrm{E}-08$ $56137.70 \mathrm{C} 7.5508 \mathrm{E}-08$ $57139.70 \mathrm{C} 4.1833 \mathrm{E}-08$ $58140.70 \mathrm{C} 9.7130 \mathrm{E}-10$ $60142.70 \mathrm{C} 5.8030 \mathrm{E}-11$ $60145.70 \mathrm{C} 1.7708 \mathrm{E}-11$ $60150.70 \mathrm{C} 1.1947 \mathrm{E}-11$ $62148.70 \mathrm{C} 2.3004 \mathrm{E}-11$ $62152.70 \mathrm{C} 5.4747 \mathrm{E}-11$ $63153.70 \mathrm{C} 1.0569 \mathrm{E}-10$ $64155.70 \mathrm{C} 2.8963 \mathrm{E}-11$ $64158.70 \mathrm{C} \quad 4.8610 \mathrm{E}-11$ $66156.70 \mathrm{C} 1.1362 \mathrm{E}-13$ $66161.70 \mathrm{C} 3.5810 \mathrm{E}-11$ $66164.70 \mathrm{C} \quad 5.3365 \mathrm{E}-11$ $68164.70 \mathrm{C} 2.9621 \mathrm{E}-12$ $68168.70 \mathrm{C} 4.9271 \mathrm{E}-11$ $5010.70 \mathrm{C} 2.4008 \mathrm{E}-14$ $72174.70 \mathrm{C} \quad 2.7585 \mathrm{E}-13$ $72178.70 \mathrm{C} 4.7033 \mathrm{E}-11$ $73181.70 \mathrm{C} 1.7007 \mathrm{E}-07$ $74184.70 \mathrm{C} \quad 1.2821 \mathrm{E}-06$ $75187.70 \mathrm{C} 2.6898 \mathrm{E}-09$ $77193.70 \mathrm{C} 5.0189 \mathrm{E}-10$ $80196.70 \mathrm{C} 1.1506 \mathrm{E}-12$ $80200.70 \mathrm{C} 1.7719 \mathrm{E}-10$ $80204.70 \mathrm{C} \quad 5.2697 \mathrm{E}-11$ $82206.70 \mathrm{C} 1.7896 \mathrm{E}-10$ $83209.70 \mathrm{C} 7.3626 \mathrm{E}-10$ $92235.70 \mathrm{C} 7.4467 \mathrm{E}-12$

$3007.70 \mathrm{C} \quad 1.3049 \mathrm{E}-09$ $5011.70 \mathrm{C} 1.4523 \mathrm{E}-08$ $12024.70 \mathrm{C} 3.1853 \mathrm{E}-10$ $13027.70 \mathrm{C} 5.8120 \mathrm{E}-06$ $14030.70 \mathrm{C} 3.0596 \mathrm{E}-08$ $16033.70 \mathrm{C} 2.3226 \mathrm{E}-10$ $17035.70 \mathrm{C} 1.9273 \mathrm{E}-08$
$22049.70 \mathrm{C} \quad 3.4771 \mathrm{E}-08$ $24050.70 \mathrm{C} 1.9543 \mathrm{E}-08$ $24054.70 \mathrm{C} 1.0638 \mathrm{E}-08$ $26056.70 \mathrm{C} 1.1881 \mathrm{E}-06$ $27059.70 \mathrm{C} 1.4621 \mathrm{E}-08$ $28061.70 \mathrm{C} 1.4344 \mathrm{E}-09$ $29063.70 \mathrm{C} \quad 1.6748 \mathrm{E}-07$ $31069.70 \mathrm{C} 1.3265 \mathrm{E}-09$ $32072.70 \mathrm{C} 1.1672 \mathrm{E}-09$ $32076.70 \mathrm{C} 3.2252 \mathrm{E}-10$ $34076.70 \mathrm{C} 3.6518 \mathrm{E}-10$ $34080.70 \mathrm{C} 1.9334 \mathrm{E}-09$ $35081.70 \mathrm{C} 1.8990 \mathrm{E}-10$ $38084.70 \mathrm{C} 9.8339 \mathrm{E}-11$ $38088.70 \mathrm{C} 1.4501 \mathrm{E}-08$ $40091.70 \mathrm{C} 3.7849 \mathrm{E}-10$ $40096.70 \mathrm{C} 9.4453 \mathrm{E}-11$ $42094.70 \mathrm{C} 5.9320 \mathrm{E}-03$ $42097.70 \mathrm{C} \quad 6.1244 \mathrm{E}-03$ $44096.70 \mathrm{C} 8.4339 \mathrm{E}-11$ $44100.70 \mathrm{C} 1.9182 \mathrm{E}-10$ $44104.70 \mathrm{C} 2.8346 \mathrm{E}-10$ $46104.70 \mathrm{C} 3.2213 \mathrm{E}-10$ $46108.70 \mathrm{C} 7.6513 \mathrm{E}-10$ $47109.70 \mathrm{C} \quad 6.8697 \mathrm{E}-09$ $48110.70 \mathrm{C} 3.4192 \mathrm{E}-08$ $48113.70 \mathrm{C} 3.3453 \mathrm{E}-08$ $49113.70 \mathrm{C} 5.7488 \mathrm{E}-11$ $50114.70 \mathrm{C} \quad 6.5014 \mathrm{E}-11$ $50117.70 \mathrm{C} 7.5653 \mathrm{E}-10$ $50120.70 \mathrm{C} 3.2093 \mathrm{E}-09$ $51121.70 \mathrm{C} 3.7596 \mathrm{E}-08$ $52122.70 \mathrm{C} 3.0749 \mathrm{E}-11$ $52125.70 \mathrm{C} 8.5253 \mathrm{E}-11$ $52130.70 \mathrm{C} 4.1095 \mathrm{E}-10$ $56130.70 \mathrm{C} 7.1259 \mathrm{E}-10$ $56135.70 \mathrm{C} 4.4315 \mathrm{E}-08$ $56138.70 \mathrm{C} \quad 4.8199 \mathrm{E}-07$ $58136.70 \mathrm{C} 2.0315 \mathrm{E}-12$ $58142.70 \mathrm{C} 1.2205 \mathrm{E}-10$ $60143.70 \mathrm{C} 2.6028 \mathrm{E}-11$ $60146.70 \mathrm{C} 3.6695 \mathrm{E}-11$ $62144.70 \mathrm{C} \quad 6.2831 \mathrm{E}-12$ $62149.70 \mathrm{C} 2.8284 \mathrm{E}-11$ $62154.70 \mathrm{C} 4.6561 \mathrm{E}-11$ $64152.70 \mathrm{C} 3.9139 \mathrm{E}-13$ $64156.70 \mathrm{C} 4.0059 \mathrm{E}-11$ $64160.70 \mathrm{C} \quad 4.2779 \mathrm{E}-11$ $66158.70 \mathrm{C} 1.8937 \mathrm{E}-13$ $66162.70 \mathrm{C} \quad 4.8309 \mathrm{E}-11$ $67165.70 \mathrm{c} 1.8658 \mathrm{E}-10$ $68166.70 \mathrm{C} \quad 6.1837 \mathrm{E}-11$ $68170.70 \mathrm{C} 2.7469 \mathrm{E}-11$ $71175.70 \mathrm{C} 1.7132 \mathrm{E}-10$ $72176.70 \mathrm{C} 9.0686 \mathrm{E}-12$ $72179.70 \mathrm{C} 2.3482 \mathrm{E}-11$ $74182.70 \mathrm{C} 1.1089 \mathrm{E}-06$ $74186.70 \mathrm{C} 1.1947 \mathrm{E}-06$ $76000.31 \mathrm{C} 8.0896 \mathrm{E}-10$ $78000.31 \mathrm{C} 7.8873 \mathrm{E}-10$ $80198.70 \mathrm{C} 7.6476 \mathrm{E}-11$ $80201.70 \mathrm{C} 1.0110 \mathrm{E}-10$ $81000.31 \mathrm{C} 7.5282 \mathrm{E}-10$ $82207.70 \mathrm{C} 1.6411 \mathrm{E}-10$ $90232.70 \mathrm{C}$ 6.6310E-11 $92238.70 \mathrm{C} 1.0268 \mathrm{E}-09$

$4009.70 \mathrm{C} 1.0875 \mathrm{E}-09$ $9019.70 \mathrm{C} 1.0318 \mathrm{E}-07$ $12025.70 \mathrm{C} 4.0325 \mathrm{E}-11$ $14028.70 \mathrm{C} 9.1406 \mathrm{E}-07$ $15031.70 \mathrm{C} 9.9991 \mathrm{E}-08$ $16034.70 \mathrm{C} 1.3111 \mathrm{E}-09$ $17037.70 \mathrm{C} \quad 6.1600 \mathrm{E}-09$ 
NEA/NSC/DOC(2006)1

\section{Fundamental - FUND}

\section{NRAD-FUND-RESR-002 \\ CRIT-REAC-COEF}

$19039.70 \mathrm{c} 4.6755 \mathrm{E}-09$ $20040.70 \mathrm{C} 2.3707 \mathrm{E}-09$ $20044.70 \mathrm{C} 5.1013 \mathrm{E}-11$ $21045.70 \mathrm{C} 2.1801 \mathrm{E}-07$ $22048.70 \mathrm{C} 1.0261 \mathrm{E}-07$ $23000.70 \mathrm{C} 3.3092 \mathrm{E}-08$ $24053.70 \mathrm{C} 8.5963 \mathrm{E}-07$ $26054.70 \mathrm{C} \quad 6.1547 \mathrm{E}-06$ $26058.70 \mathrm{C} 2.9694 \mathrm{E}-07$ $28060.70 \mathrm{C} 1.1035 \mathrm{E}-06$ $28064.70 \mathrm{C} \quad 3.8952 \mathrm{E}-08$ $30000.70 \mathrm{C} 2.4581 \mathrm{E}-08$ $32070.70 \mathrm{C} 2.8130 \mathrm{E}-10$ $32074.70 \mathrm{C} \quad 4.8971 \mathrm{E}-10$ $34074.70 \mathrm{C} 1.1047 \mathrm{E}-11$ $34078.70 \mathrm{C} 2.9505 \mathrm{E}-10$ $35079.70 \mathrm{c} 6.2176 \mathrm{E}-10$ $37087.70 \mathrm{C} 3.1914 \mathrm{E}-10$ $38087.70 \mathrm{C} 7.8300 \mathrm{E}-11$ $40090.70 \mathrm{C} 2.2070 \mathrm{E}-02$ $40094.70 \mathrm{C} 7.4555 \mathrm{E}-03$ $42092.70 \mathrm{C} 1.3341 \mathrm{E}-08$ $42096.70 \mathrm{C} 1.4995 \mathrm{E}-08$ $42100.70 \mathrm{C} \quad 8.6572 \mathrm{E}-09$ $44099.70 \mathrm{C} \quad 1.2374 \mathrm{E}-10$ $44102.70 \mathrm{c} 3.0595 \mathrm{E}-10$ $46102.70 \mathrm{C} \quad 9.3939 \mathrm{E}-11$ $46106.70 \mathrm{C} \quad 2.5170 \mathrm{E}-09$ $47107.70 \mathrm{C} \quad 4.7101 \mathrm{E}-09$ $48108.70 \mathrm{C} \quad 7.7599 \mathrm{E}-11$ $48112.70 \mathrm{C} 2.1039 \mathrm{E}-09$ $48116.70 \mathrm{C} \quad 6.5305 \mathrm{E}-10$ $50112.70 \mathrm{C} 1.5697 \mathrm{E}-10$ $50116.70 \mathrm{c} 2.3529 \mathrm{E}-09$ $50119.70 \mathrm{C} 1.3901 \mathrm{E}-09$ $50124.70 \mathrm{c} 9.3695 \mathrm{E}-10$ $52120.70 \mathrm{c} 6.9129 \mathrm{E}-13$ $52124.70 \mathrm{C} 3.6408 \mathrm{E}-11$ $52128.70 \mathrm{C} 2.4380 \mathrm{E}-10$ $55133.70 \mathrm{C} 7.3744 \mathrm{E}-11$ $56134.70 \mathrm{C} 1.7250 \mathrm{E}-12$ $56137.70 \mathrm{C} 8.0162 \mathrm{E}-12$ $57139.70 \mathrm{C} 7.0495 \mathrm{E}-11$ $58140.70 \mathrm{C} \quad 6.1870 \mathrm{E}-11$ $60142.70 \mathrm{C} 1.8482 \mathrm{E}-11$ $60145.70 \mathrm{C} 5.6398 \mathrm{E}-12$ $60150.70 \mathrm{C} 3.8051 \mathrm{E}-12$ $62148.70 \mathrm{C} 7.3266 \mathrm{E}-12$ $62152.70 \mathrm{C} 1.7437 \mathrm{E}-11$ $63153.70 \mathrm{c} 3.3661 \mathrm{E}-11$ $64155.70 \mathrm{C} 9.2244 \mathrm{E}-12$ $64158.70 \mathrm{C} 1.5482 \mathrm{E}-11$ $66156.70 \mathrm{c} 3.6188 \mathrm{E}-14$ $66161.70 \mathrm{c} 1.1405 \mathrm{E}-11$ $66164.70 \mathrm{C} 1.6996 \mathrm{E}-11$ $68164.70 \mathrm{C} 9.4341 \mathrm{E}-13$ $68168.70 \mathrm{C} 1.5692 \mathrm{E}-11$ $5010.70 \mathrm{c} \quad 7.6464 \mathrm{E}-15$ $72174.70 \mathrm{c} 1.9328 \mathrm{E}-09$ $72178.70 \mathrm{C} 3.2955 \mathrm{E}-07$ $73181.70 \mathrm{c} 5.4165 \mathrm{E}-08$ $74184.70 \mathrm{C} 7.8403 \mathrm{E}-10$ $75187.70 \mathrm{C} 3.2949 \mathrm{E}-11$ $77193.70 \mathrm{c} 3.1970 \mathrm{E}-11$ $80196.70 \mathrm{C} 7.3291 \mathrm{E}-13$ $80200.70 \mathrm{C} 1.1287 \mathrm{E}-10$ $80204.70 \mathrm{C} 3.3567 \mathrm{E}-11$ $82206.70 \mathrm{C} 1.6416 \mathrm{E}-09$ $83209.70 \mathrm{c} 3.0015 \mathrm{E}-09$ $92235.70 \mathrm{C} 8.3010 \mathrm{E}-12$ C ------ SS 304 Cladding and End Fittings --.--m14 3006.70c 2.6341E-10 3007.70c 3.2070E-09 $5010.70 \mathrm{c} 2.2170 \mathrm{E}-07 \quad 5011.70 \mathrm{c} 8.9237 \mathrm{E}-07$ 9019.70c 1.2679E-09 11023.70c $1.0478 \mathrm{E}-09$
$19041.70 \mathrm{C} 3.3742 \mathrm{E}-10$ $20043.70 \mathrm{C} 3.3014 \mathrm{E}-12$ $20048.70 \mathrm{C} \quad 4.5730 \mathrm{E}-12$ $22047.70 \mathrm{C} 1.0356 \mathrm{E}-08$ $22050.70 \mathrm{C} 7.2103 \mathrm{E}-09$ $24052.70 \mathrm{C} 7.5810 \mathrm{E}-06$ $25055.70 \mathrm{C} 9.9904 \mathrm{E}-07$ $26057.70 \mathrm{C} 2.2313 \mathrm{E}-06$ $28058.70 \mathrm{C} 2.8649 \mathrm{E}-06$ $28062.70 \mathrm{c} 1.5295 \mathrm{E}-07$ $29065.70 \mathrm{C} 2.4726 \mathrm{E}-07$ $31071.70 \mathrm{C} 4.9347 \mathrm{E}-08$ $32073.70 \mathrm{C} 1.0434 \mathrm{E}-10$ $33075.70 \mathrm{C} 2.0931 \mathrm{E}-09$ $34077.70 \mathrm{C} 9.4708 \mathrm{E}-11$ $34082.70 \mathrm{C} 1.0836 \mathrm{E}-10$ $37085.70 \mathrm{C} 8.2761 \mathrm{E}-10$ $38086.70 \mathrm{C} 1.1029 \mathrm{E}-10$ $39089.70 \mathrm{C} 1.1024 \mathrm{E}-09$ $40092.70 \mathrm{C} 7.3568 \mathrm{E}-03$ $41093.70 \mathrm{C} 2.5740 \mathrm{E}-08$ $42095.70 \mathrm{C} 1.4312 \mathrm{E}-08$ $42098.70 \mathrm{C} 2.1692 \mathrm{E}-08$ $44098.70 \mathrm{C} 1.8134 \mathrm{E}-11$ $44101.70 \mathrm{C} 1.6543 \mathrm{E}-10$ $45103.70 \mathrm{C} 9.5242 \mathrm{E}-10$ $46105.70 \mathrm{C} 2.0565 \mathrm{E}-09$ $46110.70 \mathrm{C} 1.0794 \mathrm{E}-09$ $48106.70 \mathrm{C} 1.0899 \mathrm{E}-10$ $48111.70 \mathrm{C} 1.1160 \mathrm{E}-09$ $48114.70 \mathrm{C} 2.5050 \mathrm{E}-09$ $49115.70 \mathrm{c} 1.6339 \mathrm{E}-09$ $50115.70 \mathrm{C} 5.5020 \mathrm{E}-11$ $50118.70 \mathrm{C} 3.9193 \mathrm{E}-09$ $50122.70 \mathrm{C} 7.4924 \mathrm{E}-10$ $51123.70 \mathrm{c} 3.4446 \mathrm{E}-10$ $52123.70 \mathrm{c} \quad 6.8361 \mathrm{E}-12$ $52126.70 \mathrm{C} 1.4471 \mathrm{E}-10$ $53127.70 \mathrm{C} 1.5446 \mathrm{E}-09$ $56132.70 \mathrm{C} 7.2083 \mathrm{E}-14$ $56136.70 \mathrm{C} \quad 5.6054 \mathrm{E}-12$ $57138.70 \mathrm{c} 6.3503 \mathrm{E}-14$ $58138.70 \mathrm{c} 1.7557 \mathrm{E}-13$ $59141.70 \mathrm{C} 6.9556 \mathrm{E}-11$ $60144.70 \mathrm{C} 1.6172 \mathrm{E}-11$ $60148.70 \mathrm{c} 3.8731 \mathrm{E}-12$ $62147.70 \mathrm{C} 9.7710 \mathrm{E}-12$ $62150.70 \mathrm{c} 4.8105 \mathrm{E}-12$ $63151.70 \mathrm{c} 3.0836 \mathrm{E}-11$ $64154.70 \mathrm{c} 1.3587 \mathrm{E}-12$ $64157.70 \mathrm{C} \quad 9.7542 \mathrm{E}-12$ $65159.70 \mathrm{C}$ 6.1670E-11 $66160.70 \mathrm{c} 1.4113 \mathrm{E}-12$ $66163.70 \mathrm{c} 1.5018 \mathrm{E}-11$ $68162.70 \mathrm{C} 8.2036 \mathrm{E}-14$ $68167.70 \mathrm{c} 1.3436 \mathrm{E}-11$ $69169.55 \mathrm{c} 5.8016 \mathrm{E}-11$ $71176.70 \mathrm{c} 1.4508 \mathrm{E}-12$ $72177.70 \mathrm{C} 2.2469 \mathrm{E}-07$ $72180.70 \mathrm{C} \quad 4.2378 \mathrm{E}-07$ $74183.70 \mathrm{c} 3.6617 \mathrm{E}-10$ $75185.70 \mathrm{c} 1.9685 \mathrm{E}-11$ $77191.70 \mathrm{C} 1.9019 \mathrm{E}-11$ $79197.70 \mathrm{C} 4.9760 \mathrm{E}-10$ $80199.70 \mathrm{C} 8.2428 \mathrm{E}-11$ $80202.70 \mathrm{C} 1.4590 \mathrm{E}-10$ $82204.70 \mathrm{C} 9.5361 \mathrm{E}-11$ $82208.70 \mathrm{C} 3.5692 \mathrm{E}-09$ $92234.70 \mathrm{C} \quad 6.3410 \mathrm{E}-14$

$4009.70 \mathrm{C} \quad 2.6729 \mathrm{E}-09$ $6000.70 \mathrm{C} \quad 1.6044 \mathrm{E}-04$ $12024.70 \mathrm{C} 2.8183 \mathrm{E}-07$ 
NEA/NSC/DOC(2006)1

\section{Fundamental - FUND}

\section{NRAD-FUND-RESR-002 \\ CRIT-REAC-COEF}

$12025.70 \mathrm{c} 3.5679 \mathrm{E}-08$ $14028.70 \mathrm{C} \quad 6.3283 \mathrm{E}-04$ $15031.70 \mathrm{C} \quad 4.0441 \mathrm{E}-05$ $16034.70 \mathrm{c} 1.4178 \mathrm{E}-07$ $17037.70 \mathrm{C} 8.2281 \mathrm{E}-10$ $19041.70 \mathrm{C} \quad 4.1465 \mathrm{E}-11$ $20043.70 \mathrm{C} 8.1140 \mathrm{E}-11$ $20048.70 \mathrm{C} 1.1239 \mathrm{E}-10$ $22047.70 \mathrm{C} 1.4972 \mathrm{E}-07$ $22050.70 \mathrm{C} 1.0424 \mathrm{E}-07$ $24052.70 \mathrm{C} 1.4751 \mathrm{E}-02$ $25055.70 \mathrm{c} 8.7693 \mathrm{E}-04$ $26057.70 \mathrm{C} 1.2559 \mathrm{E}-03$ $28058.70 \mathrm{C} 5.5882 \mathrm{E}-03$ $28062.70 \mathrm{C} 2.9834 \mathrm{E}-04$ $29065.70 \mathrm{C} 7.0120 \mathrm{E}-05$ $31071.70 \mathrm{C} 4.4103 \mathrm{E}-07$ $32073.70 \mathrm{C} 1.0258 \mathrm{E}-07$ $33075.70 \mathrm{C} 2.2506 \mathrm{E}-06$ $34077.70 \mathrm{C} 2.3277 \mathrm{E}-10$ $34082.70 \mathrm{C} 2.6633 \mathrm{E}-10$ $37085.70 \mathrm{C} 1.0170 \mathrm{E}-08$ $38086.70 \mathrm{C} \quad 5.4214 \mathrm{E}-10$ $39089.70 \mathrm{C} 1.3547 \mathrm{E}-09$ $40092.70 \mathrm{C} 1.6303 \mathrm{E}-08$ $41093.70 \mathrm{c} 5.7041 \mathrm{E}-06$ $42095.70 \mathrm{C} 2.3983 \mathrm{E}-05$ $42098.70 \mathrm{c} 3.6351 \mathrm{E}-05$ $44098.70 \mathrm{C} \quad 4.4568 \mathrm{E}-11$ $44101.70 \mathrm{C} \quad 4.0660 \mathrm{E}-10$ $45103.70 \mathrm{C} 1.1704 \mathrm{E}-09$ $46105.70 \mathrm{C} 2.5272 \mathrm{E}-10$ $46110.70 \mathrm{C} 1.3264 \mathrm{E}-10$ $48106.70 \mathrm{c} 2.6786 \mathrm{E}-11$ $48111.70 \mathrm{C} \quad 2.7429 \mathrm{E}-10$ $48114.70 \mathrm{C} \quad 6.1566 \mathrm{E}-10$ $49115.70 \mathrm{C} 1.0040 \mathrm{E}-08$ 50115.70 $7.5891 \mathrm{E}-09$ $50118.70 \mathrm{C} 5.4061 \mathrm{E}-07$ $50122.70 \mathrm{C} 1.0335 \mathrm{E}-07$ $51123.70 \mathrm{C} 1.5070 \mathrm{E}-07$ $52123.70 \mathrm{C} 8.4007 \mathrm{E}-12$ $52126.70 \mathrm{C} \quad 1.7783 \mathrm{E}-10$ $53127.70 \mathrm{C} \quad 9.4908 \mathrm{E}-10$ $56132.70 \mathrm{C} 8.8582 \mathrm{E}-13$ $56136.70 \mathrm{c} \quad 6.8883 \mathrm{E}-11$ $57138.70 \mathrm{C} 1.5607 \mathrm{E}-13$ $58138.70 \mathrm{c} 2.1576 \mathrm{E}-12$ $59141.70 \mathrm{C} 8.5476 \mathrm{E}-11$ $60144.70 \mathrm{C} 1.9873 \mathrm{E}-11$ $60148.70 \mathrm{c} 4.7596 \mathrm{E}-12$ $62147.70 \mathrm{C} 1.2007 \mathrm{E}-11$ $62150.70 \mathrm{c} 5.9116 \mathrm{E}-12$ $63151.70 \mathrm{c} 3.7894 \mathrm{E}-11$ $64154.70 \mathrm{C} 1.6697 \mathrm{E}-12$ $64157.70 \mathrm{c} 1.1987 \mathrm{E}-11$ $65159.70 \mathrm{C} 7.5785 \mathrm{E}-11$ $66160.70 \mathrm{c} 1.7344 \mathrm{E}-12$ $66163.70 \mathrm{c} 1.8455 \mathrm{E}-11$ $68162.70 \mathrm{c} 1.0081 \mathrm{E}-13$ $68167.70 \mathrm{C} 1.6512 \mathrm{E}-11$ $69169.55 \mathrm{C} 7.1295 \mathrm{E}-11$ $71176.70 \mathrm{C} \quad 1.7829 \mathrm{E}-12$ $72177.70 \mathrm{c} 2.5102 \mathrm{E}-11$ $72180.70 \mathrm{C} \quad 4.7343 \mathrm{E}-11$ $74183.70 \mathrm{c} 5.9998 \mathrm{E}-07$ $75185.70 \mathrm{c} 2.4191 \mathrm{E}-09$ $77191.70 \mathrm{C} \quad 8.4138 \mathrm{E}-10$ $79197.70 \mathrm{C} \quad 6.1148 \mathrm{E}-10$ $80199.70 \mathrm{C} 2.0259 \mathrm{E}-10$ $80202.70 \mathrm{C} 3.5858 \mathrm{E}-10$ $82204.70 \mathrm{C} 1.0091 \mathrm{E}-10$ $82208.70 \mathrm{C} 3.7769 \mathrm{E}-09$ $92234.70 \mathrm{C} 2.7830 \mathrm{E}-15$ C Total mt14 fe56.12t
$12026.70 \mathrm{C} \quad 3.9283 \mathrm{E}-08$ $14029.70 \mathrm{C} 3.2134 \mathrm{E}-05$ $16032.70 \mathrm{C} 3.1374 \mathrm{E}-06$ $16036.70 \mathrm{c} \quad 6.6099 \mathrm{E}-10$ $19039.70 \mathrm{C} \quad 5.7456 \mathrm{E}-10$ $20040.70 \mathrm{C} 5.8265 \mathrm{E}-08$ $20044.70 \mathrm{C} 1.2538 \mathrm{E}-09$ $21045.70 \mathrm{C} 2.6791 \mathrm{E}-10$ $22048.70 \mathrm{c} 1.4835 \mathrm{E}-06$ $23000.70 \mathrm{C} 9.4573 \mathrm{E}-05$ $24053.70 \mathrm{C} 1.6726 \mathrm{E}-03$ $26054.70 \mathrm{C} 3.4644 \mathrm{E}-03$ $26058.70 \mathrm{C} \quad 1.6714 \mathrm{E}-04$ $28060.70 \mathrm{C} 2.1526 \mathrm{E}-03$ $28064.70 \mathrm{C} 7.5980 \mathrm{E}-05$ $30000.70 \mathrm{C} 3.6838 \mathrm{E}-08$ $32070.70 \mathrm{c} 2.7655 \mathrm{E}-07$ $32074.70 \mathrm{C} 4.8144 \mathrm{E}-07$ $34074.70 \mathrm{C} \quad 2.7151 \mathrm{E}-11$ $34078.70 \mathrm{C} 7.2515 \mathrm{E}-10$ $35079.70 \mathrm{C} 1.5281 \mathrm{E}-09$ $37087.70 \mathrm{C} 3.9218 \mathrm{E}-09$ $38087.70 \mathrm{C} \quad 3.8489 \mathrm{E}-10$ $40090.70 \mathrm{C} \quad 4.8909 \mathrm{E}-08$ $40094.70 \mathrm{C} 1.6522 \mathrm{E}-08$ $42092.70 \mathrm{C} 2.2356 \mathrm{E}-05$ $42096.70 \mathrm{C} 2.5128 \mathrm{E}-05$ $42100.70 \mathrm{C} 1.4507 \mathrm{E}-05$ $44099.70 \mathrm{C} 3.0411 \mathrm{E}-10$ $44102.70 \mathrm{C} 7.5194 \mathrm{E}-10$ $46102.70 \mathrm{C} 1.1544 \mathrm{E}-11$ $46106.70 \mathrm{c} 3.0931 \mathrm{E}-10$ $47107.70 \mathrm{C} \quad 5.7882 \mathrm{E}-09$ $48108.70 \mathrm{C} \quad 1.9072 \mathrm{E}-11$ $48112.70 \mathrm{C} \quad 5.1708 \mathrm{E}-10$ $48116.70 \mathrm{C} 1.6050 \mathrm{E}-10$ $50112.70 \mathrm{C} 2.1651 \mathrm{E}-08$ $50116.70 \mathrm{c} 3.2455 \mathrm{E}-07$ $50119.70 \mathrm{C} 1.9174 \mathrm{E}-07$ $50124.70 \mathrm{C} 1.2924 \mathrm{E}-07$ $52120.70 \mathrm{C} \quad 8.4951 \mathrm{E}-13$ $52124.70 \mathrm{C} \quad 4.4741 \mathrm{E}-11$ $52128.70 \mathrm{C} 2.9959 \mathrm{E}-10$ $55133.70 \mathrm{C} 1.8124 \mathrm{E}-10$ $56134.70 \mathrm{C} 2.1198 \mathrm{E}-11$ $56137.70 \mathrm{C} 9.8510 \mathrm{E}-11$ $57139.70 \mathrm{C} 1.7326 \mathrm{E}-10$ $58140.70 \mathrm{C} 7.6031 \mathrm{E}-10$ $60142.70 \mathrm{C} 2.2712 \mathrm{E}-11$ $60145.70 \mathrm{c} 6.9306 \mathrm{E}-12$ $60150.70 \mathrm{C} \quad 4.6761 \mathrm{E}-12$ $62148.70 \mathrm{c} 9.0035 \mathrm{E}-12$ $62152.70 \mathrm{c} 2.1427 \mathrm{E}-11$ $63153.70 \mathrm{c}$ 4.1365E-11 $64155.70 \mathrm{C} 1.1336 \mathrm{E}-11$ $64158.70 \mathrm{c} 1.9026 \mathrm{E}-11$ 66156.70 C $4.4471 \mathrm{E}-14$ $66161.70 \mathrm{c} 1.4016 \mathrm{E}-11$ $66164.70 \mathrm{C} 2.0886 \mathrm{E}-11$ $68164.70 \mathrm{C} 1.1593 \mathrm{E}-12$ $68168.70 \mathrm{C} 1.9284 \mathrm{E}-11$ $5010.70 \mathrm{c} 9.3965 \mathrm{E}-15$ $72174.70 \mathrm{C} 2.1593 \mathrm{E}-13$ $72178.70 \mathrm{c} 3.6816 \mathrm{E}-11$ $73181.70 \mathrm{C} 1.3312 \mathrm{E}-08$ $74184.70 \mathrm{C} 1.2846 \mathrm{E}-06$ $75187.70 \mathrm{C} \quad 4.0491 \mathrm{E}-09$ $77193.70 \mathrm{C} 1.4143 \mathrm{E}-09$ $80196.70 \mathrm{C} 1.8013 \mathrm{E}-12$ $80200.70 \mathrm{C} 2.7740 \mathrm{E}-10$ $80204.70 \mathrm{C} 8.2500 \mathrm{E}-11$ $82206.70 \mathrm{C} 1.7371 \mathrm{E}-09$ $83209.70 \mathrm{C} 1.1527 \mathrm{E}-10$ $92235.70 \mathrm{C} 3.6432 \mathrm{E}-13$
$13027.70 \mathrm{c} 2.1427 \mathrm{E}-06$ $14030.70 \mathrm{c} 2.1183 \mathrm{E}-05$ $16033.70 \mathrm{C} 2.5117 \mathrm{E}-08$ $17035.70 \mathrm{C} 2.5744 \mathrm{E}-09$ $19040.70 \mathrm{C} \quad 7.2084 \mathrm{E}-14$ $20042.70 \mathrm{C} 3.8887 \mathrm{E}-10$ $20046.70 \mathrm{C} 2.4042 \mathrm{E}-12$ $22046.70 \mathrm{C} 1.6602 \mathrm{E}-07$ $22049.70 \mathrm{C} 1.0887 \mathrm{E}-07$ $24050.70 \mathrm{C} \quad 7.6491 \mathrm{E}-04$ $24054.70 \mathrm{C} \quad 4.1634 \mathrm{E}-04$ $26056.70 \mathrm{C} 5.4383 \mathrm{E}-02$ $27059.70 \mathrm{c} \quad 6.5399 \mathrm{E}-05$ $28061.70 \mathrm{C} 9.3571 \mathrm{E}-05$ $29063.70 \mathrm{C} 1.5732 \mathrm{E}-04$ $31069.70 \mathrm{c} \quad 6.6453 \mathrm{E}-07$ $32072.70 \mathrm{C} 3.6546 \mathrm{E}-07$ $32076.70 \mathrm{C} 1.0098 \mathrm{E}-07$ $34076.70 \mathrm{C} 2.8585 \mathrm{E}-10$ $34080.70 \mathrm{c} 1.5135 \mathrm{E}-09$ $35081.70 \mathrm{C} 1.4865 \mathrm{E}-09$ $38084.70 \mathrm{C} 3.0791 \mathrm{E}-11$ $38088.70 \mathrm{C} 4.5406 \mathrm{E}-09$ $40091.70 \mathrm{C} 1.0666 \mathrm{E}-08$ $40096.70 \mathrm{C} 2.6617 \mathrm{E}-09$ $42094.70 \mathrm{c} 1.3935 \mathrm{E}-05$ $42097.70 \mathrm{C} 1.4387 \mathrm{E}-05$ $44096.70 \mathrm{C} 1.3204 \mathrm{E}-10$ $44100.70 \mathrm{C} \quad 3.0030 \mathrm{E}-10$ $44104.70 \mathrm{C} 4.4378 \mathrm{E}-10$ $46104.70 \mathrm{c} 1.2608 \mathrm{E}-10$ $46108.70 \mathrm{C} 2.9946 \mathrm{E}-10$ $47109.70 \mathrm{C} \quad 5.3775 \mathrm{E}-09$ $48110.70 \mathrm{C} 2.6765 \mathrm{E}-10$ $48113.70 \mathrm{C} 2.6186 \mathrm{E}-10$ $49113.70 \mathrm{C} 4.5001 \mathrm{E}-10$ $50114.70 \mathrm{C} 1.4732 \mathrm{E}-08$ $50117.70 \mathrm{C} \quad 1.7143 \mathrm{E}-07$ $50120.70 \mathrm{C} 7.2722 \mathrm{E}-07$ $51121.70 \mathrm{C} 2.0148 \mathrm{E}-07$ $52122.70 \mathrm{C} \quad 2.4070 \mathrm{E}-11$ $52125.70 \mathrm{c} \quad 6.6734 \mathrm{E}-11$ $52130.70 \mathrm{c} 3.2168 \mathrm{E}-10$ $56130.70 \mathrm{C} \quad 9.2967 \mathrm{E}-13$ $56135.70 \mathrm{C} 5.7815 \mathrm{E}-11$ $56138.70 \mathrm{c} \quad 6.2882 \mathrm{E}-10$ $58136.70 \mathrm{C} \quad 1.5902 \mathrm{E}-12$ $58142.70 \mathrm{c} 9.5535 \mathrm{E}-11$ $60143.70 \mathrm{C} 1.0187 \mathrm{E}-11$ $60146.70 \mathrm{c} 1.4362 \mathrm{E}-11$ $62144.70 \mathrm{c} 2.4591 \mathrm{E}-12$ $62149.70 \mathrm{C} 1.1070 \mathrm{E}-11$ $62154.70 \mathrm{c} 1.8223 \mathrm{E}-11$ $64152.70 \mathrm{C} 1.5319 \mathrm{E}-13$ $64156.70 \mathrm{c} 1.5679 \mathrm{E}-11$ $64160.70 \mathrm{C} 1.6743 \mathrm{E}-11$ $66158.70 \mathrm{C} 7.4118 \mathrm{E}-14$ $66162.70 \mathrm{c} 1.8908 \mathrm{E}-11$ $67165.70 \mathrm{c} 7.3026 \mathrm{E}-11$ $68166.70 \mathrm{C} 2.4202 \mathrm{E}-11$ $68170.70 \mathrm{c} 1.0751 \mathrm{E}-11$ $71175.70 \mathrm{c} \quad 6.7054 \mathrm{E}-11$ $72176.70 \mathrm{C} 7.0987 \mathrm{E}-12$ $72179.70 \mathrm{c} 1.8381 \mathrm{E}-11$ $74182.70 \mathrm{C} 1.1111 \mathrm{E}-06$ $74186.70 \mathrm{C} 1.1970 \mathrm{E}-06$ $76000.31 \mathrm{C} 2.2797 \mathrm{E}-09$ $78000.31 \mathrm{C} 1.2348 \mathrm{E}-09$ $80198.70 \mathrm{C} 1.1973 \mathrm{E}-10$ $80201.70 \mathrm{C} 1.5828 \mathrm{E}-10$ $81000.31 \mathrm{C} 5.8929 \mathrm{E}-10$ $82207.70 \mathrm{C} 1.5930 \mathrm{E}-09$ $90232.70 \mathrm{C} 5.1906 \mathrm{E}-11$ $92238.70 \mathrm{C} 5.0233 \mathrm{E}-11$ 
NEA/NSC/DOC(2006)1

Fundamental - FUND

NRAD-FUND-RESR-002

CRIT-REAC-COEF

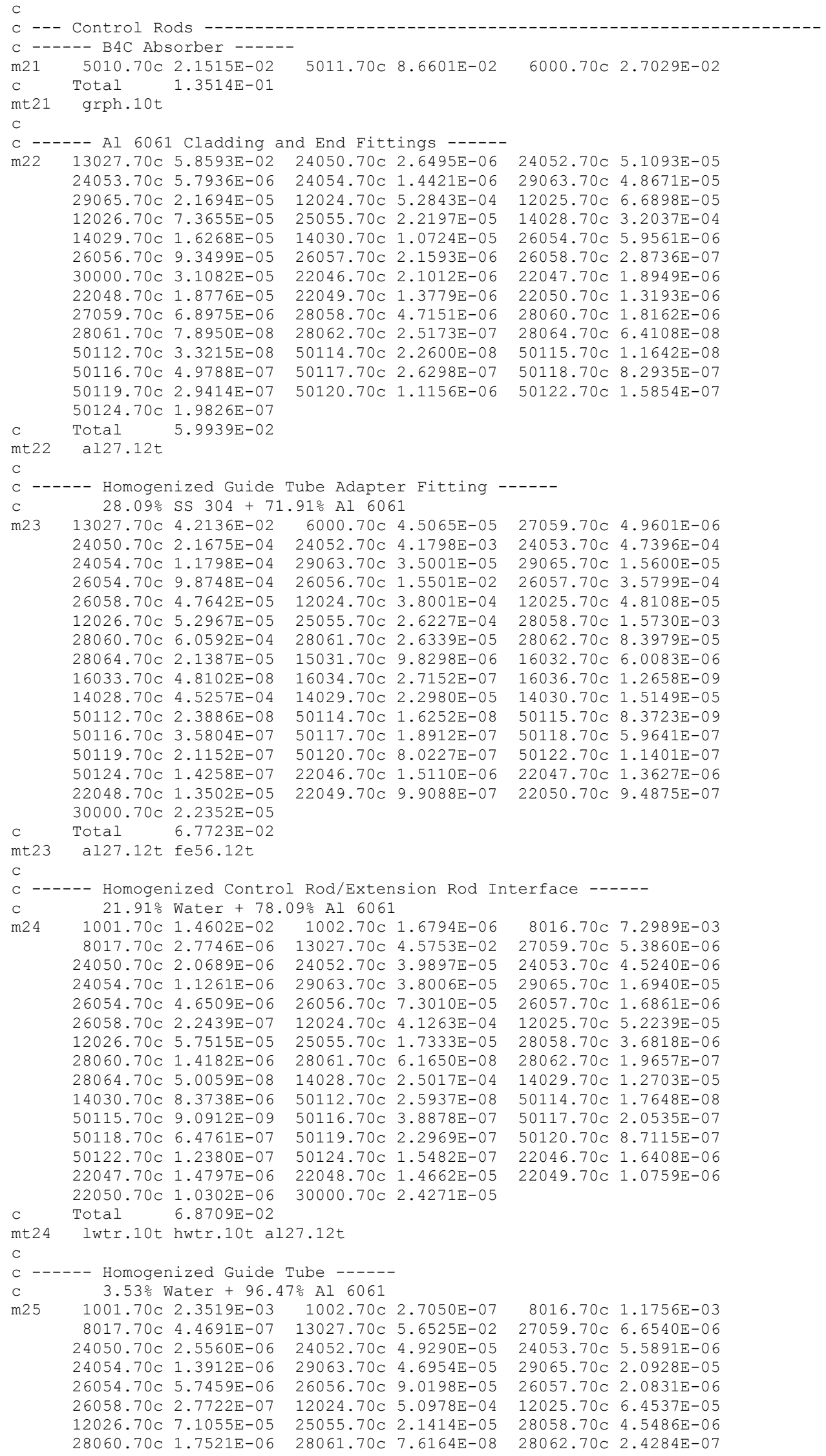

$8016.70 \mathrm{C} 7.2989 \mathrm{E}-03$ $27059.70 \mathrm{C} 5.3860 \mathrm{E}-06$ $24053.70 \mathrm{C} \quad 4.5240 \mathrm{E}-06$ $29065.70 \mathrm{C} \quad 1.6940 \mathrm{E}-05$ $26057.70 \mathrm{C} 1.6861 \mathrm{E}-06$ $12025.70 \mathrm{C} 5.2239 \mathrm{E}-05$ $28058.70 \mathrm{C} \quad 3.6818 \mathrm{E}-06$ $28062.70 \mathrm{C} \quad 1.9657 \mathrm{E}-07$ $14029.70 \mathrm{C} 1.2703 \mathrm{E}-05$ $50114.70 \mathrm{c} 1.7648 \mathrm{E}-08$ $50117.70 \mathrm{C} \quad 2.0535 \mathrm{E}-07$ $50120.70 \mathrm{C} 8.7115 \mathrm{E}-07$ $22046.70 \mathrm{C} 1.6408 \mathrm{E}-06$ $22049.70 \mathrm{C} 1.0759 \mathrm{E}-06$

$8016.70 \mathrm{C} 1.1756 \mathrm{E}-03$ $27059.70 \mathrm{C} \quad 6.6540 \mathrm{E}-06$ $24053.70 \mathrm{C} 5.5891 \mathrm{E}-06$ $29065.70 \mathrm{C} 2.0928 \mathrm{E}-05$ $26057.70 \mathrm{C} 2.0831 \mathrm{E}-06$ $12025.70 \mathrm{C} \quad 6.4537 \mathrm{E}-05$ $28058.70 \mathrm{C} \quad 4.5486 \mathrm{E}-06$ $28062.70 \mathrm{C} 2.4284 \mathrm{E}-07$ 


\section{NEA/NSC/DOC(2006)1}

\section{Fundamental - FUND}

\section{NRAD-FUND-RESR-002 CRIT-REAC-COEF}

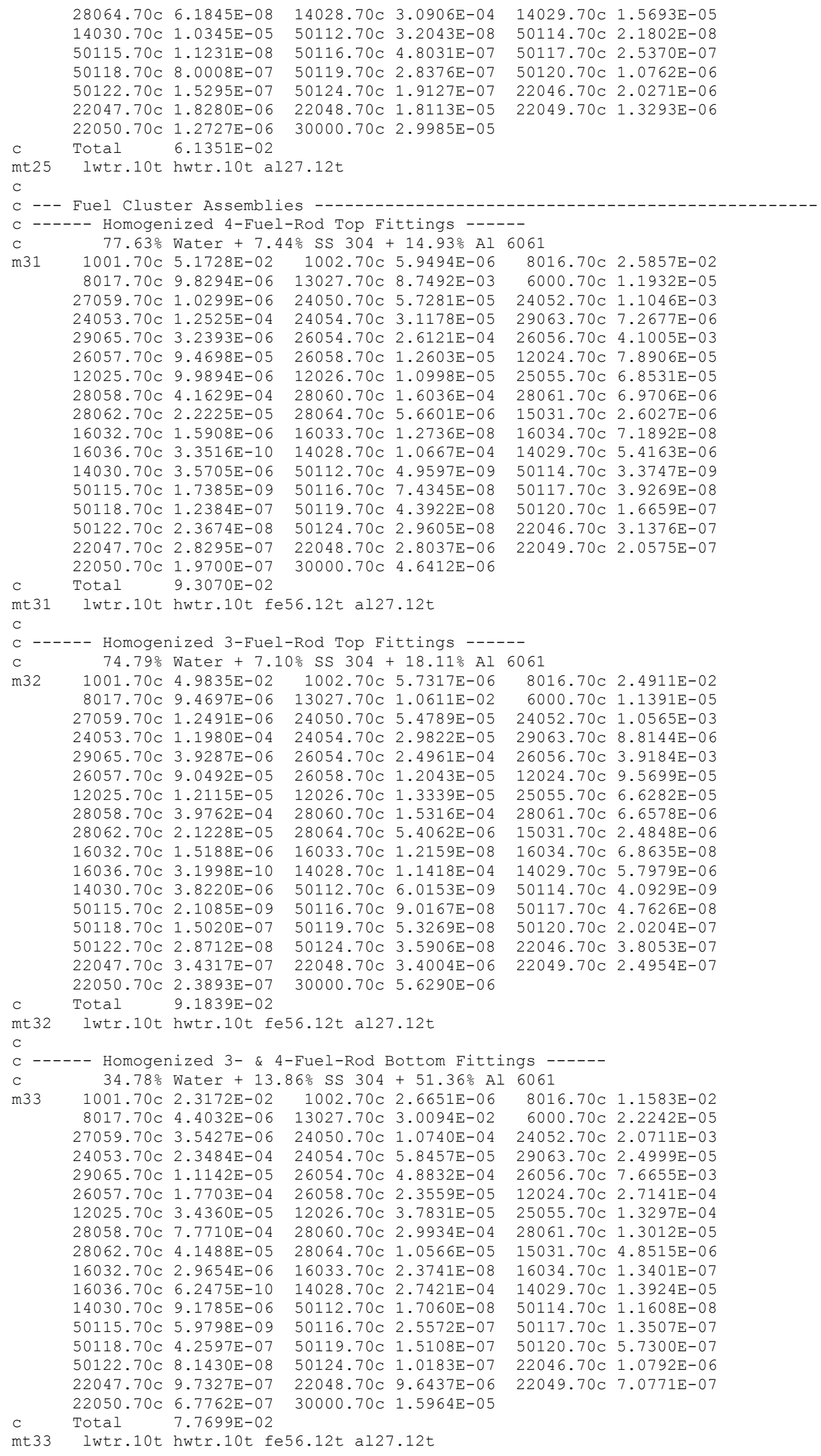


NEA/NSC/DOC(2006)1

\section{Fundamental - FUND}

\section{NRAD-FUND-RESR-002 \\ CRIT-REAC-COEF}

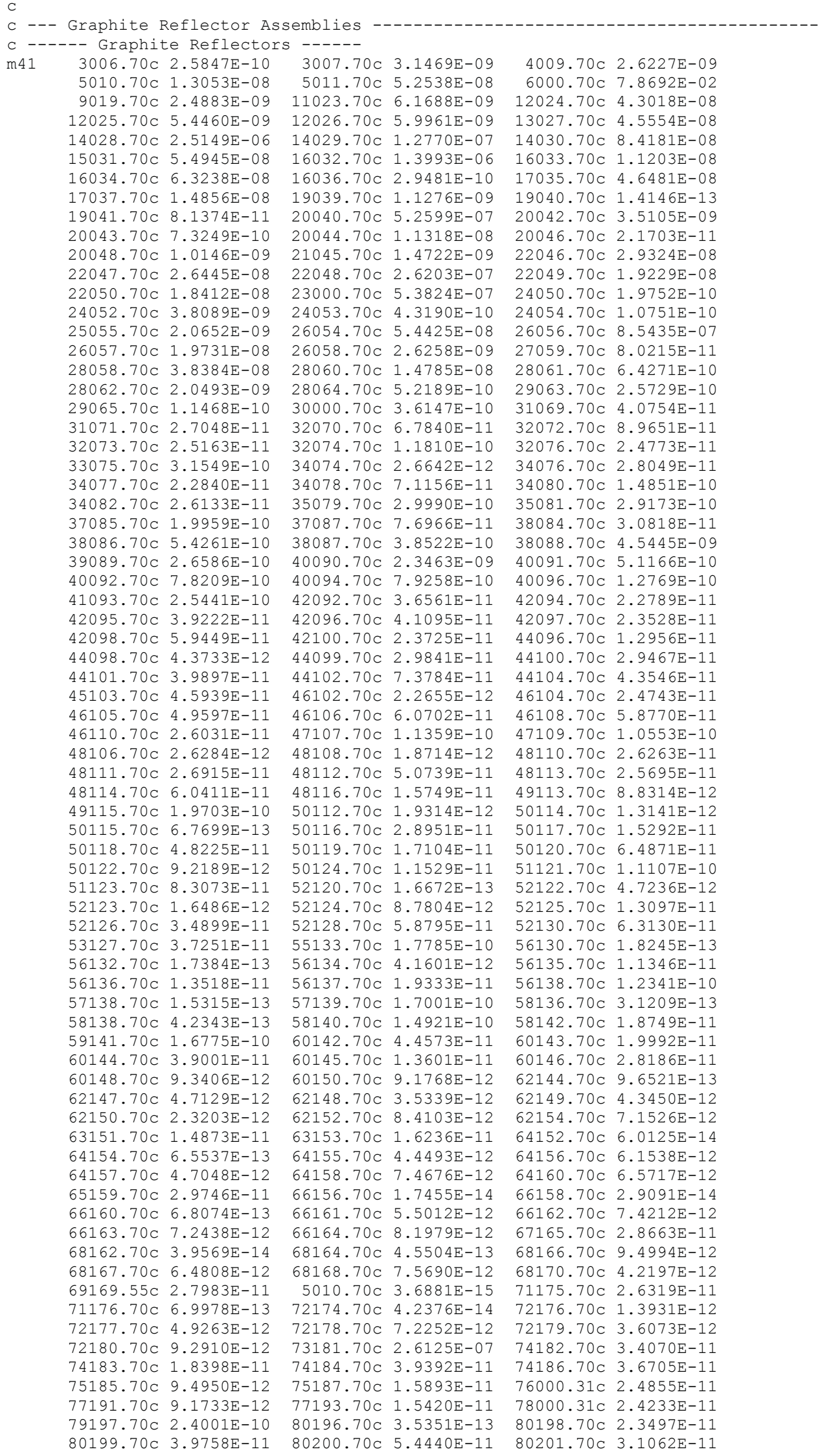




\section{NEA/NSC/DOC(2006)1}

\section{Fundamental - FUND}

\section{NRAD-FUND-RESR-002 CRIT-REAC-COEF}

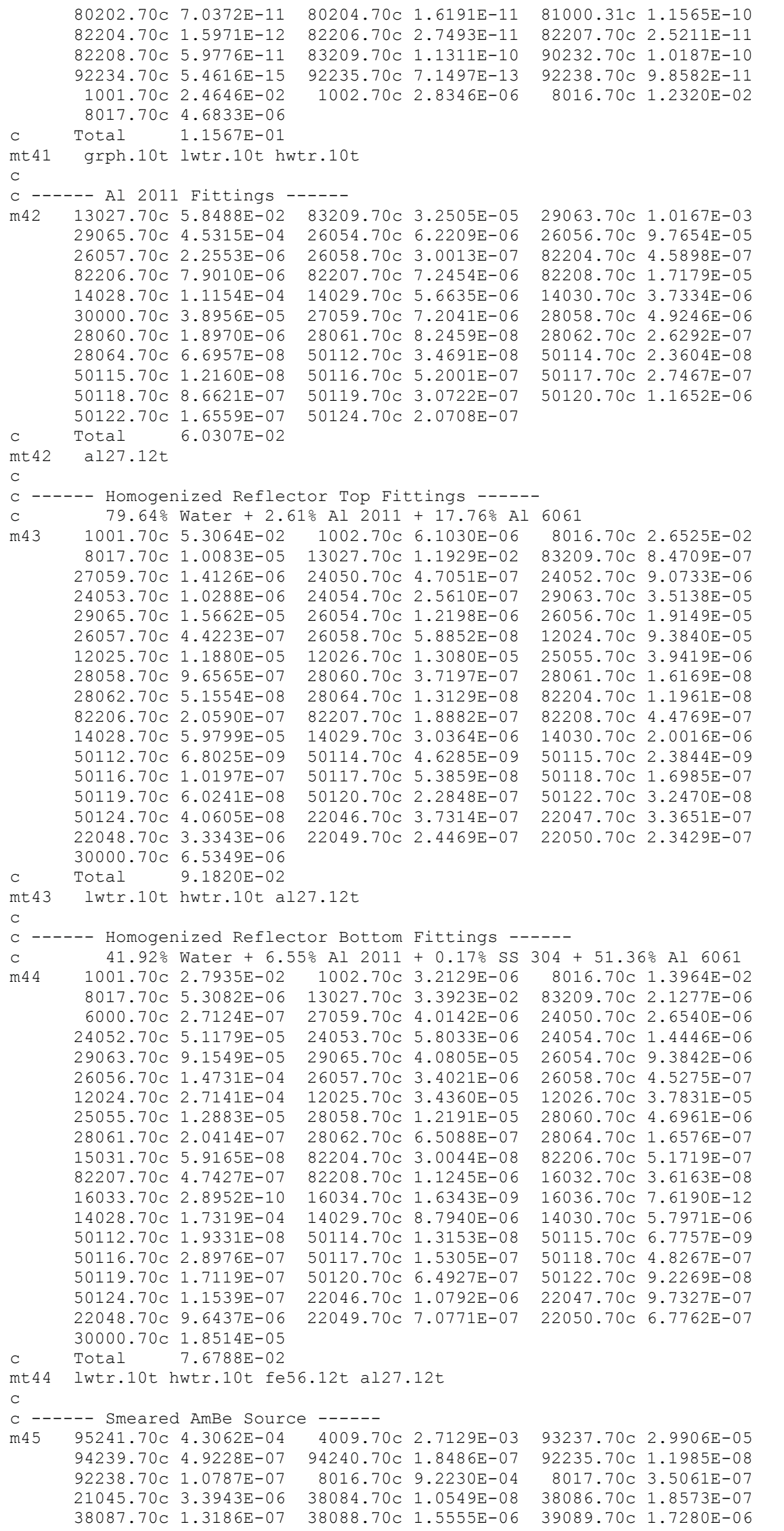

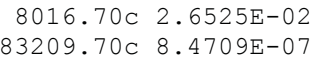

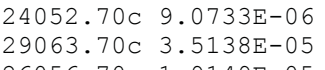
$\begin{array}{ll}26056.70 \mathrm{C} & 1.9149 \mathrm{E}-05 \\ 12024.70 \mathrm{C} & 9.3840 \mathrm{E}-05 \\ 25055.70 \mathrm{C} & 3.9419 \mathrm{E}-06\end{array}$

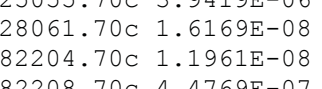
$\begin{array}{ll}82208.70 \mathrm{C} & 4.4769 \mathrm{E}-07 \\ 14030.70 \mathrm{C} & 2.0016 \mathrm{E}-06 \\ 50115.70 \mathrm{C} & 2.3844 \mathrm{E}-09\end{array}$ $\begin{array}{ll}50115.70 \mathrm{C} & 2.3844 \mathrm{E}-09 \\ 50118.70 \mathrm{C} & 1.6985 \mathrm{E}-07\end{array}$ $50122.70 \mathrm{C} \quad 3.2470 \mathrm{E}-08$
$22047.70 \mathrm{C} \quad 3.3651 \mathrm{E}-07$ $22050.70 \mathrm{C} 2.3429 \mathrm{E}-07$ $81000.31 \mathrm{C} 1.1565 \mathrm{E}-10$ 9232.70 $1.0187 \mathrm{E}-10$

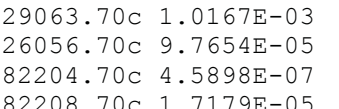
$82208.70 \mathrm{C} 1.7179 \mathrm{E}-05$ $28058.70 \mathrm{C} \quad 4.9246 \mathrm{E}-06$ $28062.70 \mathrm{C} 2.6292 \mathrm{E}-07$

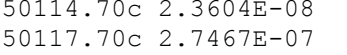
$50120.70 \mathrm{C} 1.1652 \mathrm{E}-06$

7

3 


\section{NEA/NSC/DOC(2006)1}

\section{Fundamental - FUND}

\section{NRAD-FUND-RESR-002 CRIT-REAC-COEF}

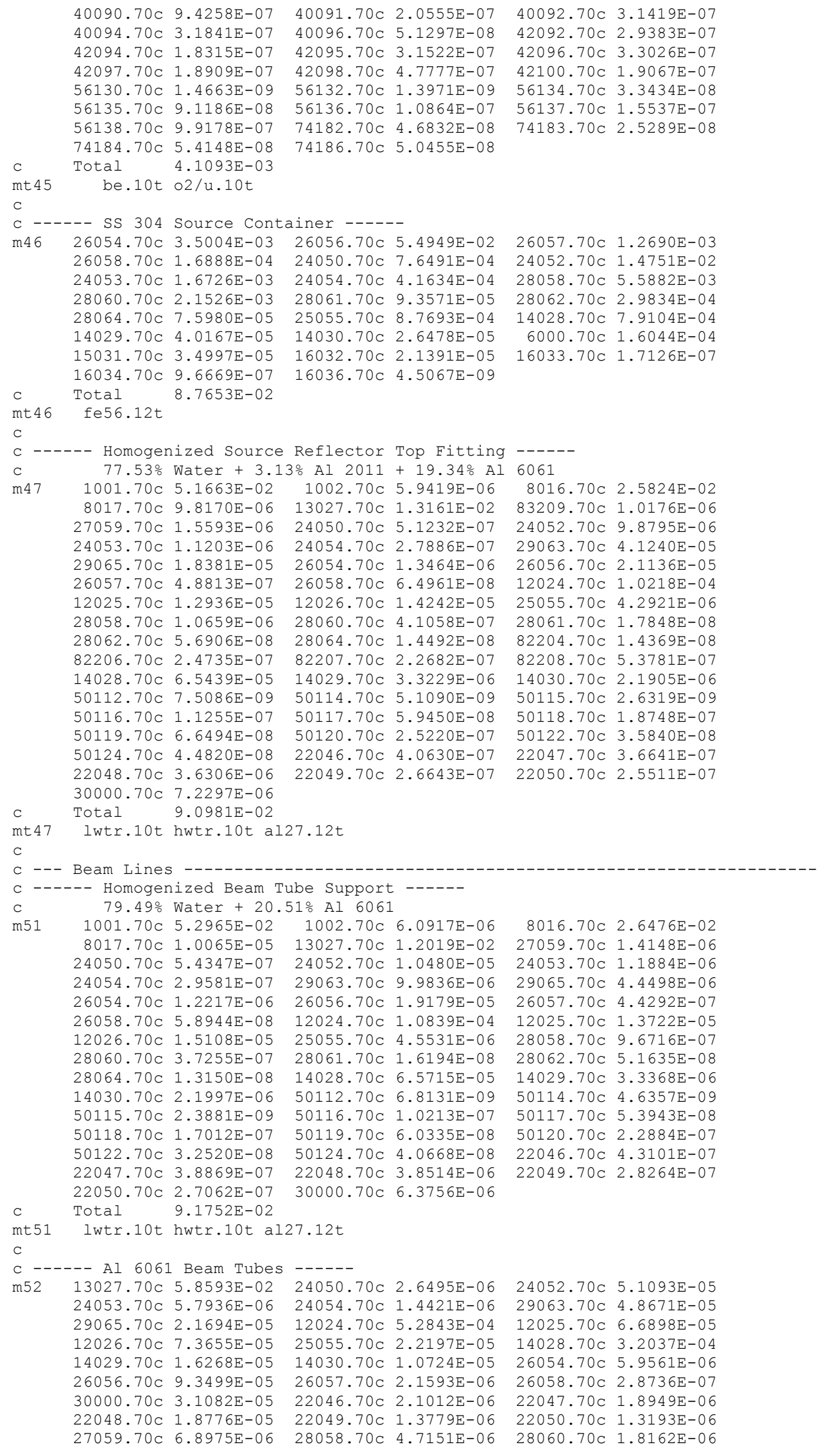


NEA/NSC/DOC(2006)1

\section{Fundamental - FUND}

\section{NRAD-FUND-RESR-002 CRIT-REAC-COEF}

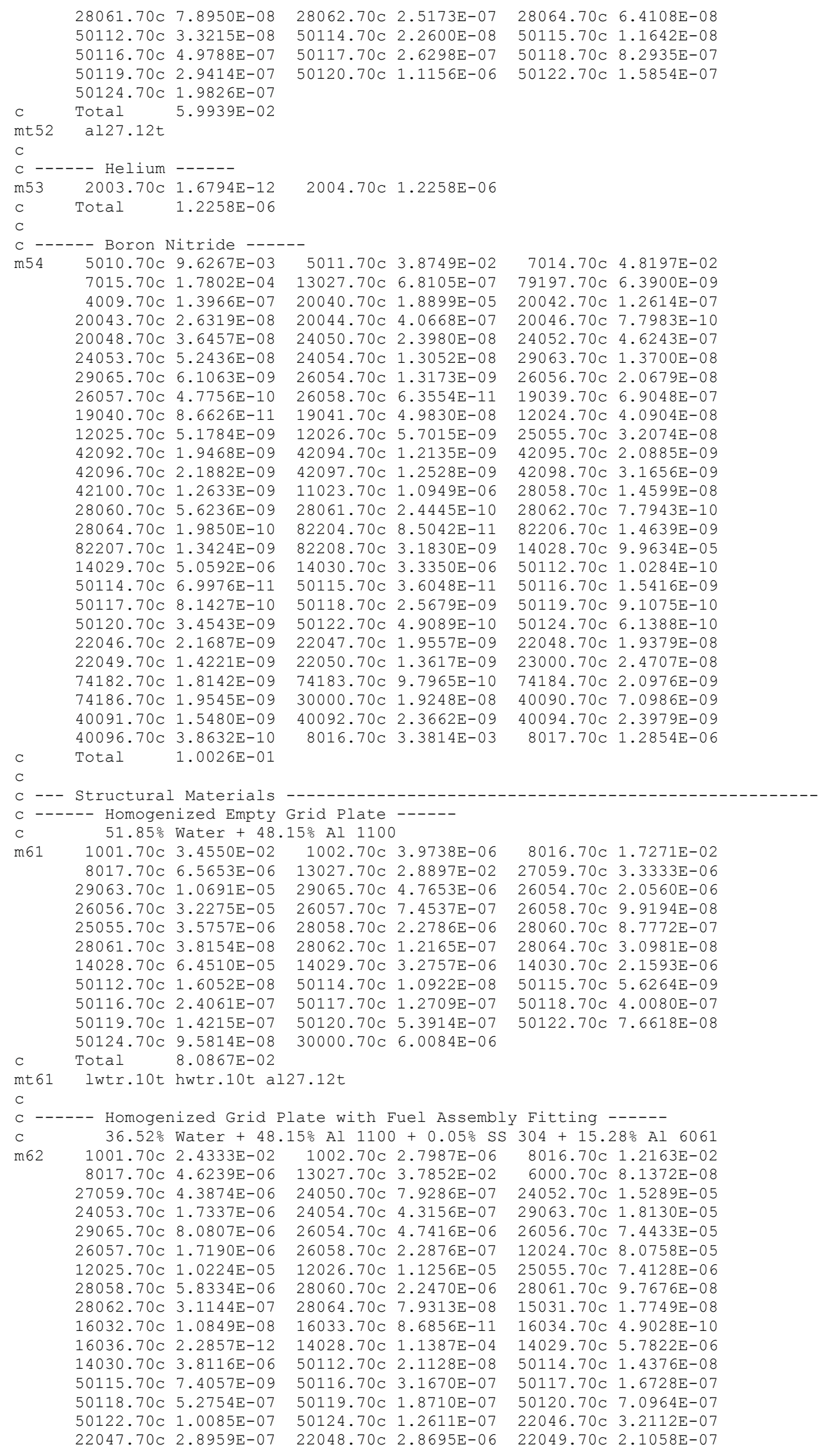




\section{NEA/NSC/DOC(2006)1}

\section{Fundamental - FUND}

\section{NRAD-FUND-RESR-002 \\ CRIT-REAC-COEF}

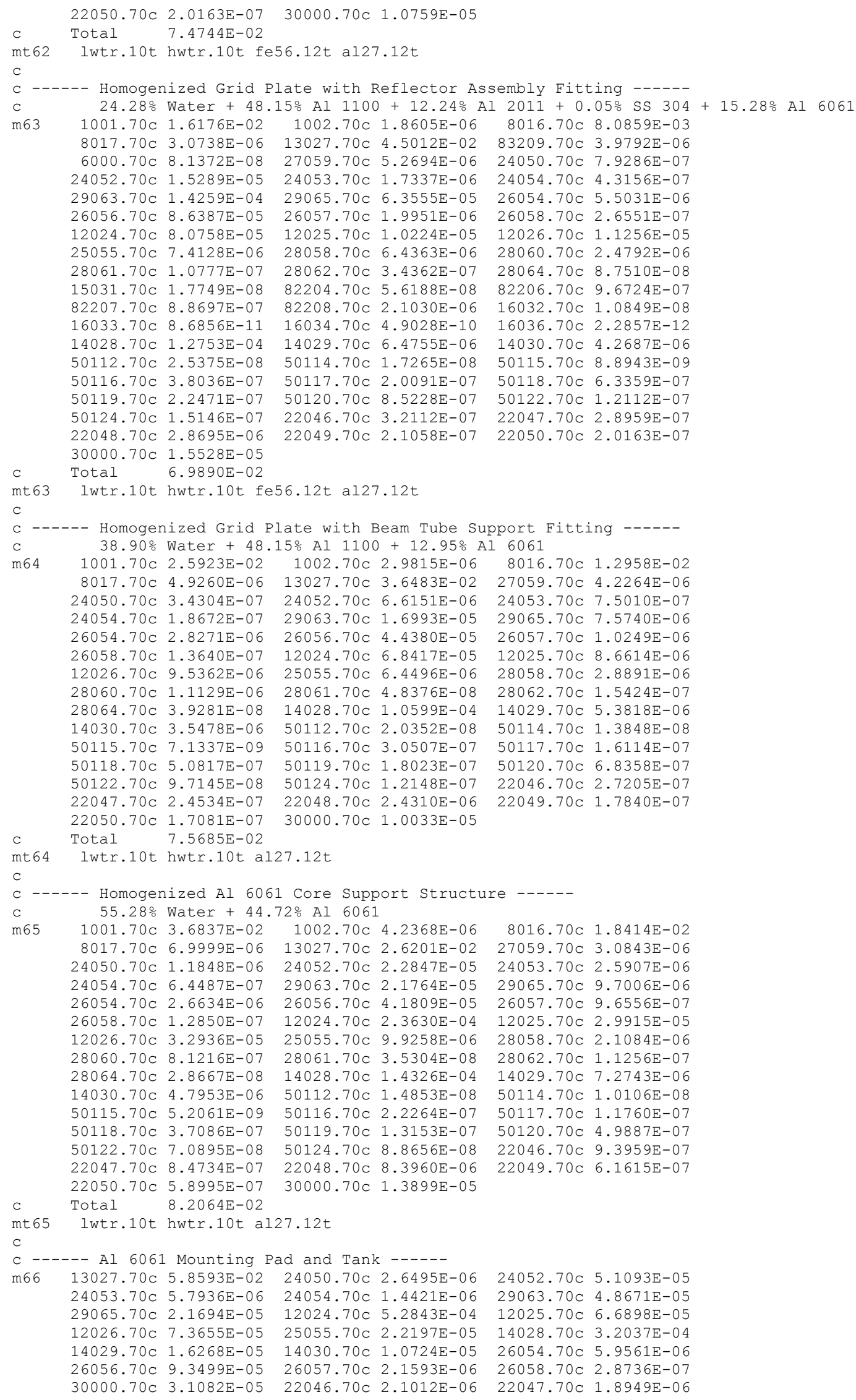




\section{NEA/NSC/DOC(2006)1}

\section{Fundamental - FUND}

\section{NRAD-FUND-RESR-002 CRIT-REAC-COEF}

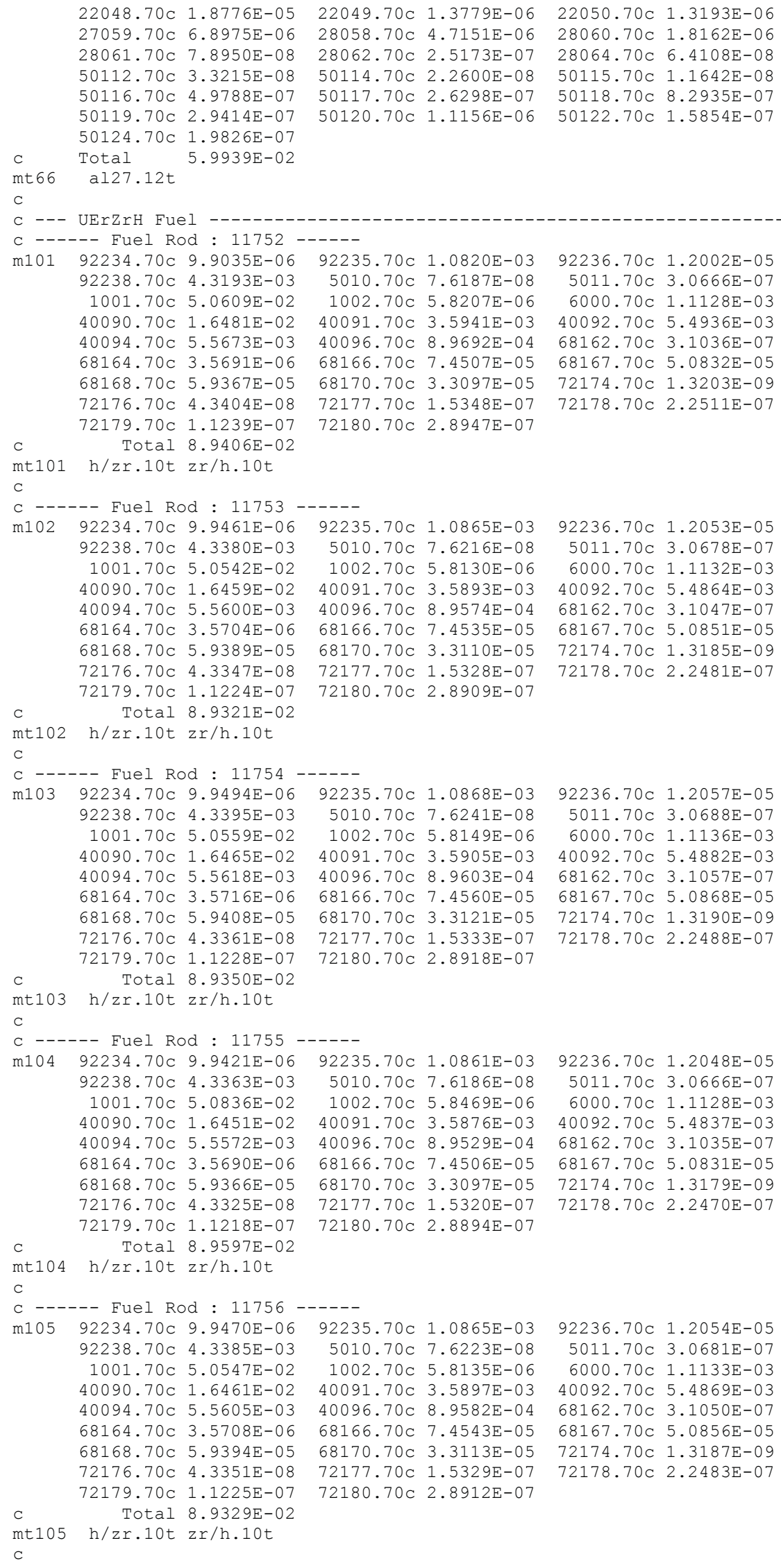




\section{NEA/NSC/DOC(2006)1}

\section{Fundamental - FUND}

\section{NRAD-FUND-RESR-002}

CRIT-REAC-COEF

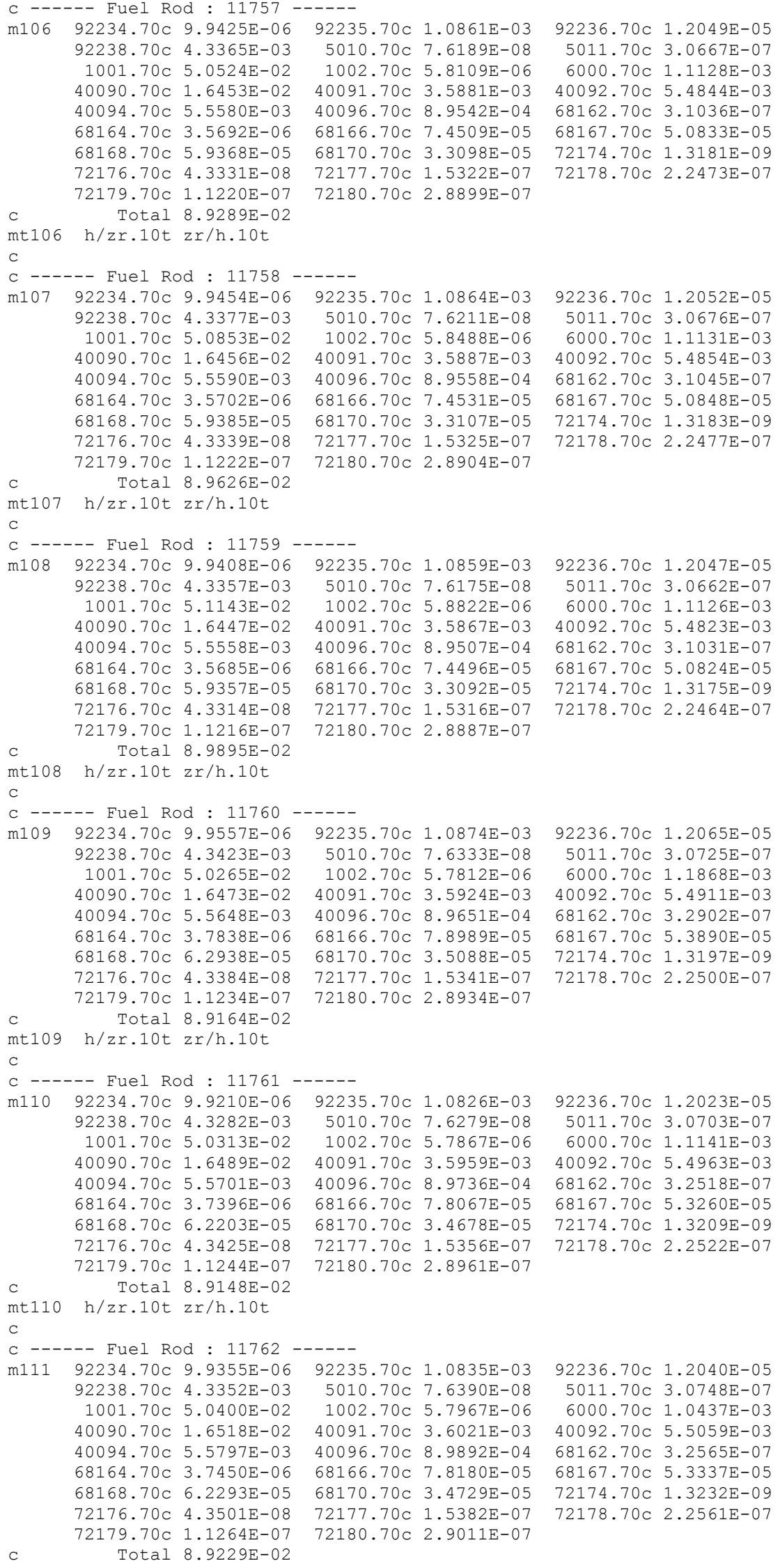

$92236.70 \mathrm{C} \quad 1.2049 \mathrm{E}-05$ $5011.70 \mathrm{C} 3.0667 \mathrm{E}-07$ $6000.70 \mathrm{C} 1.1128 \mathrm{E}-03$ $40092.70 \mathrm{C} \quad 5.4844 \mathrm{E}-03$ $68162.70 \mathrm{C} \quad 3.1036 \mathrm{E}-07$ $68167.70 \mathrm{C} \quad 5.0833 \mathrm{E}-05$ $72174.70 \mathrm{C} 1.3181 \mathrm{E}-09$ $72178.70 \mathrm{C} 2.2473 \mathrm{E}-07$

$92236.70 \mathrm{C} \quad 1.2052 \mathrm{E}-05$ $5011.70 \mathrm{C} 3.0676 \mathrm{E}-07$ $6000.70 \mathrm{C} 1.1131 \mathrm{E}-03$ $40092.70 \mathrm{C} \quad 5.4854 \mathrm{E}-03$ $68162.70 \mathrm{C} 3.1045 \mathrm{E}-07$ $68167.70 \mathrm{C} 5.0848 \mathrm{E}-05$ $72174.70 \mathrm{C} \quad 1.3183 \mathrm{E}-09$ $72178.70 \mathrm{C} 2.2477 \mathrm{E}-07$

$92236.70 \mathrm{C} \quad 1.2047 \mathrm{E}-05$ $5011.70 \mathrm{C} 3.0662 \mathrm{E}-07$ $6000.70 \mathrm{C} 1.1126 \mathrm{E}-03$ $40092.70 \mathrm{C} 5.4823 \mathrm{E}-03$ $68162.70 \mathrm{C} 3.1031 \mathrm{E}-07$ $68167.70 \mathrm{C} 5.0824 \mathrm{E}-05$ $72174.70 \mathrm{C} 1.3175 \mathrm{E}-09$ $72178.70 \mathrm{C} \quad 2.2464 \mathrm{E}-07$

$92236.70 \mathrm{C} \quad 1.2065 \mathrm{E}-05$ $5011.70 \mathrm{C} 3.0725 \mathrm{E}-07$ $6000.70 \mathrm{C} 1.1868 \mathrm{E}-03$ $40092.70 \mathrm{C} 5.4911 \mathrm{E}-03$ $68162.70 \mathrm{C} 3.2902 \mathrm{E}-07$ $68167.70 \mathrm{C} 5.3890 \mathrm{E}-05$ $72174.70 \mathrm{C} 1.3197 \mathrm{E}-09$ $72178.70 \mathrm{C} 2.2500 \mathrm{E}-07$

$92236.70 \mathrm{C} \quad 1.2023 \mathrm{E}-05$ $5011.70 \mathrm{C} 3.0703 \mathrm{E}-07$ $6000.70 \mathrm{C} 1.1141 \mathrm{E}-03$ $40092.70 \mathrm{C} 5.4963 \mathrm{E}-03$ $68162.70 \mathrm{C} 3.2518 \mathrm{E}-07$ $68167.70 \mathrm{C} 5.3260 \mathrm{E}-05$ $72174.70 \mathrm{C} \quad 1.3209 \mathrm{E}-09$ $72178.70 \mathrm{C} 2.2522 \mathrm{E}-07$

$92236.70 \mathrm{C} 1.2040 \mathrm{E}-05$ $5011.70 \mathrm{C} 3.0748 \mathrm{E}-07$ $6000.70 \mathrm{C} 1.0437 \mathrm{E}-03$ $40092.70 \mathrm{C} 5.5059 \mathrm{E}-03$ $68162.70 \mathrm{C} \quad 3.2565 \mathrm{E}-07$ $68167.70 \mathrm{C} 5.3337 \mathrm{E}-05$ $72174.70 \mathrm{C} \quad 1.3232 \mathrm{E}-09$ $72178.70 \mathrm{C} 2.2561 \mathrm{E}-07$ 


\section{NEA/NSC/DOC(2006)1}

\section{Fundamental - FUND}

\section{NRAD-FUND-RESR-002 \\ CRIT-REAC-COEF}

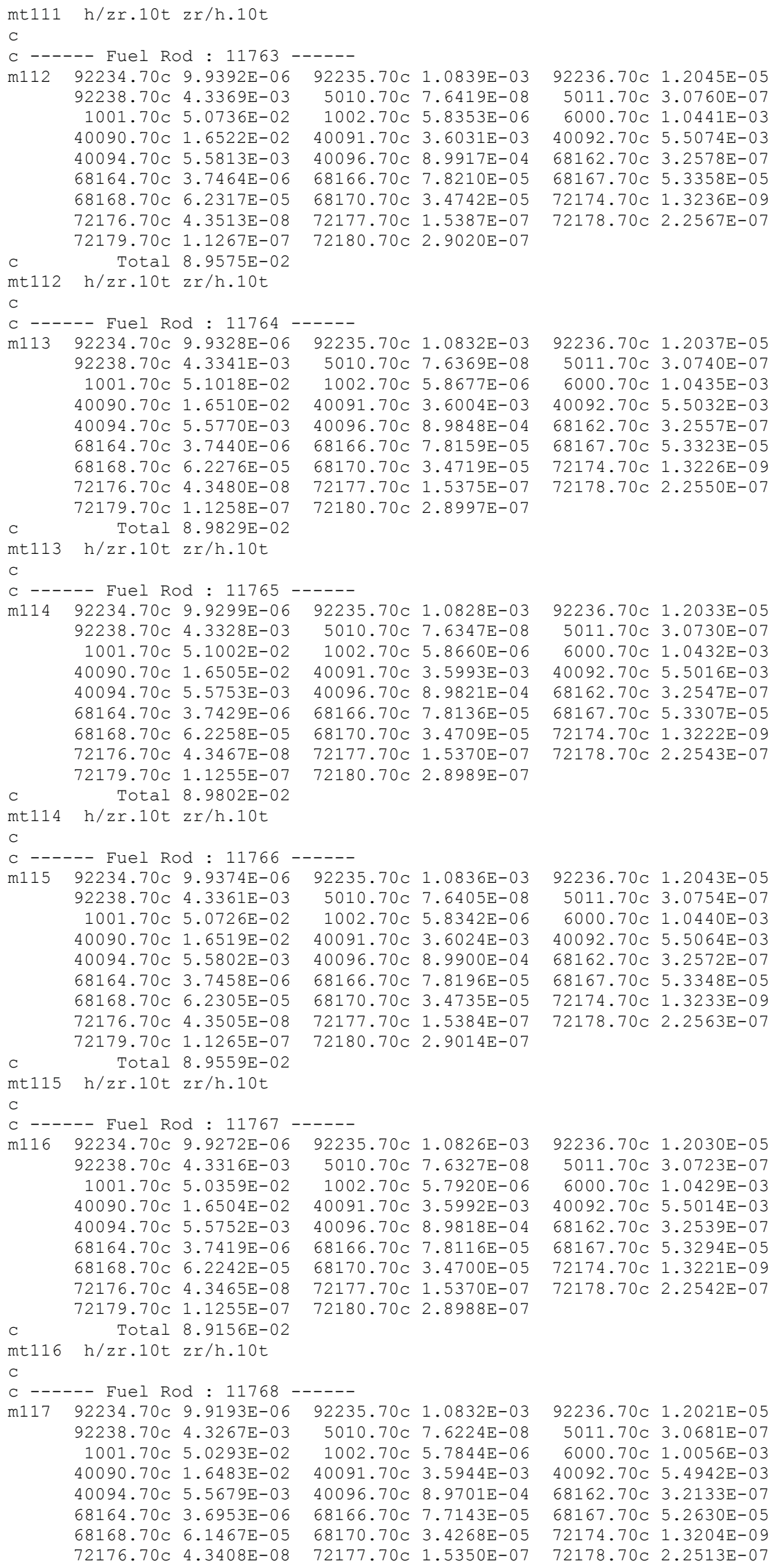

$92236.70 \mathrm{C} 1.2030 \mathrm{E}-05$ $5011.70 \mathrm{C} 3.0723 \mathrm{E}-07$ $6000.70 \mathrm{C} 1.0429 \mathrm{E}-03$ $40092.70 \mathrm{C} 5.5014 \mathrm{E}-03$ $68162.70 \mathrm{C} \quad 3.2539 \mathrm{E}-07$ $68167.70 \mathrm{C} 5.3294 \mathrm{E}-05$ $72174.70 \mathrm{C} 1.3221 \mathrm{E}-09$ $72178.70 \mathrm{C} 2.2542 \mathrm{E}-07$

$92236.70 \mathrm{C} \quad 1.2021 \mathrm{E}-05$ $5011.70 \mathrm{C} 3.0681 \mathrm{E}-07$ $6000.70 \mathrm{C} 1.0056 \mathrm{E}-03$ $40092.70 \mathrm{C} 5.4942 \mathrm{E}-03$ $68162.70 \mathrm{C} 3.2133 \mathrm{E}-07$ $68167.70 \mathrm{C} 5.2630 \mathrm{E}-05$ $72174.70 \mathrm{C} 1.3204 \mathrm{E}-09$ $72178.70 \mathrm{C} \quad 2.2513 \mathrm{E}-07$ 


\section{NEA/NSC/DOC(2006)1}

\section{Fundamental - FUND}

\section{NRAD-FUND-RESR-002 \\ CRIT-REAC-COEF}

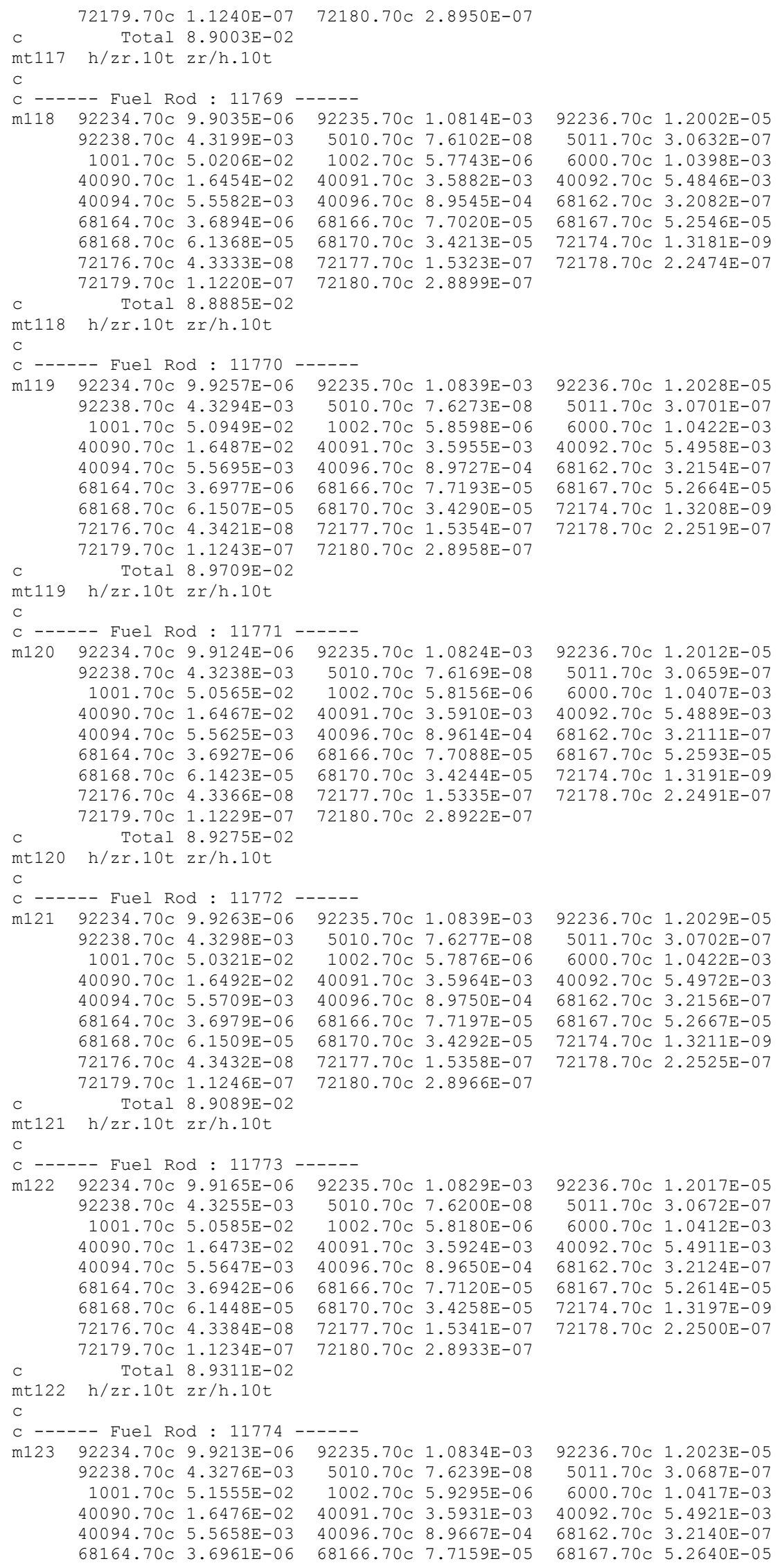

$92236.70 \mathrm{C} 1.2029 \mathrm{E}-05$ $5011.70 \mathrm{c} 3.0702 \mathrm{E}-07$ $6000.70 \mathrm{C} 1.0422 \mathrm{E}-03$ $40092.70 \mathrm{C} 5.4972 \mathrm{E}-03$ $68162.70 \mathrm{C} 3.2156 \mathrm{E}-07$ $68167.70 \mathrm{C} 5.2667 \mathrm{E}-05$ $72174.70 \mathrm{C}$ 1.3211E-09 $72178.70 \mathrm{C} \quad 2.2525 \mathrm{E}-07$

$92236.70 \mathrm{C} \quad 1.2017 \mathrm{E}-05$ $5011.70 \mathrm{C} 3.0672 \mathrm{E}-07$ $6000.70 \mathrm{C} 1.0412 \mathrm{E}-03$ $40092.70 \mathrm{C} 5.4911 \mathrm{E}-03$ $68162.70 \mathrm{C} \quad 3.2124 \mathrm{E}-07$ $68167.70 \mathrm{C} \quad 5.2614 \mathrm{E}-05$ $72174.70 \mathrm{C} 1.3197 \mathrm{E}-09$ $72178.70 \mathrm{C} 2.2500 \mathrm{E}-07$

$92236.70 \mathrm{C} \quad 1.2023 \mathrm{E}-05$ $5011.70 \mathrm{C} 3.0687 \mathrm{E}-07$ $6000.70 \mathrm{C} 1.0417 \mathrm{E}-03$ $40092.70 \mathrm{C} 5.4921 \mathrm{E}-03$ $68162.70 \mathrm{C} 3.2140 \mathrm{E}-07$ $68167.70 \mathrm{C} 5.2640 \mathrm{E}-05$ 


\section{NEA/NSC/DOC(2006)1}

\section{Fundamental - FUND}

\section{NRAD-FUND-RESR-002 \\ CRIT-REAC-COEF}

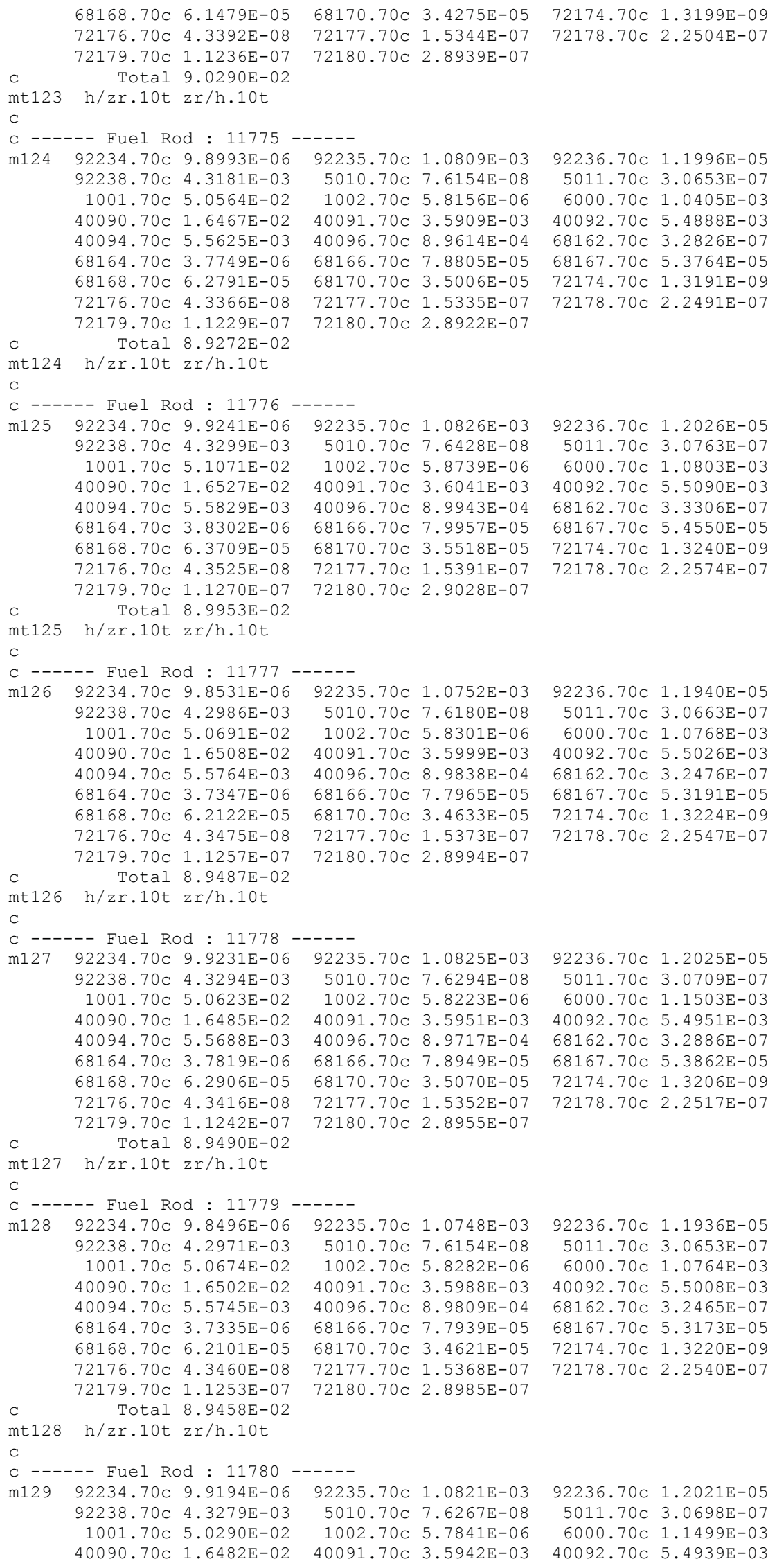

$72174.70 \mathrm{C} 1.3199 \mathrm{E}-09$ $72178.70 \mathrm{C} 2.2504 \mathrm{E}-07$

$92236.70 \mathrm{C} 1.1996 \mathrm{E}-05$ $5011.70 \mathrm{c} \quad 3.0653 \mathrm{E}-07$ $6000.70 \mathrm{c} 1.0405 \mathrm{E}-03$ $40092.70 \mathrm{C} \quad 5.4888 \mathrm{E}-03$ $68162.70 \mathrm{c} 3.2826 \mathrm{E}-07$ $68167.70 \mathrm{C} \quad 5.3764 \mathrm{E}-05$ $72174.70 \mathrm{C} 1.3191 \mathrm{E}-09$ $72178.70 \mathrm{C} 2.2491 \mathrm{E}-07$

$92236.70 \mathrm{C} \quad 1.2026 \mathrm{E}-05$ $5011.70 \mathrm{C} 3.0763 \mathrm{E}-07$ $6000.70 \mathrm{c} 1.0803 \mathrm{E}-03$ $40092.70 \mathrm{C} \quad 5.5090 \mathrm{E}-03$ $68162.70 \mathrm{C} 3.3306 \mathrm{E}-07$ $68167.70 \mathrm{c} 5.4550 \mathrm{E}-05$ $72174.70 \mathrm{C} \quad 1.3240 \mathrm{E}-09$ $72178.70 \mathrm{C} \quad 2.2574 \mathrm{E}-07$

$92236.70 \mathrm{C} 1.1940 \mathrm{E}-05$ $5011.70 \mathrm{c} 3.0663 \mathrm{E}-07$ $6000.70 \mathrm{C} 1.0768 \mathrm{E}-03$ $40092.70 \mathrm{C} 5.5026 \mathrm{E}-03$ $68162.70 \mathrm{C} 3.2476 \mathrm{E}-07$ $68167.70 \mathrm{C} 5.3191 \mathrm{E}-05$ $72174.70 \mathrm{C} 1.3224 \mathrm{E}-09$ $72178.70 \mathrm{C} 2.2547 \mathrm{E}-07$

$92236.70 \mathrm{C} \quad 1.2025 \mathrm{E}-05$ $5011.70 \mathrm{c} 3.0709 \mathrm{E}-07$ $6000.70 \mathrm{C} \quad 1.1503 \mathrm{E}-03$ $40092.70 \mathrm{C} 5.4951 \mathrm{E}-03$ $68162.70 \mathrm{c} 3.2886 \mathrm{E}-07$ $68167.70 \mathrm{C} 5.3862 \mathrm{E}-05$ $72174.70 \mathrm{c} 1.3206 \mathrm{E}-09$ $72178.70 \mathrm{C} 2.2517 \mathrm{E}-07$

$92236.70 \mathrm{C} \quad 1.1936 \mathrm{E}-05$ $5011.70 \mathrm{c} 3.0653 \mathrm{E}-07$ $6000.70 \mathrm{C} \quad 1.0764 \mathrm{E}-03$ $40092.70 \mathrm{C} \quad 5.5008 \mathrm{E}-03$ $68162.70 \mathrm{c} 3.2465 \mathrm{E}-07$ $68167.70 \mathrm{c} \quad 5.3173 \mathrm{E}-05$ $72174.70 \mathrm{C} 1.3220 \mathrm{E}-09$ $72178.70 \mathrm{C} 2.2540 \mathrm{E}-07$

$92236.70 \mathrm{C} 1.2021 \mathrm{E}-05$ $5011.70 \mathrm{c} 3.0698 \mathrm{E}-07$ $6000.70 \mathrm{c} 1.1499 \mathrm{E}-03$ $40092.70 \mathrm{C} \quad 5.4939 \mathrm{E}-03$ 


\section{NEA/NSC/DOC(2006)1}

\section{Fundamental - FUND}

\section{NRAD-FUND-RESR-002 CRIT-REAC-COEF}

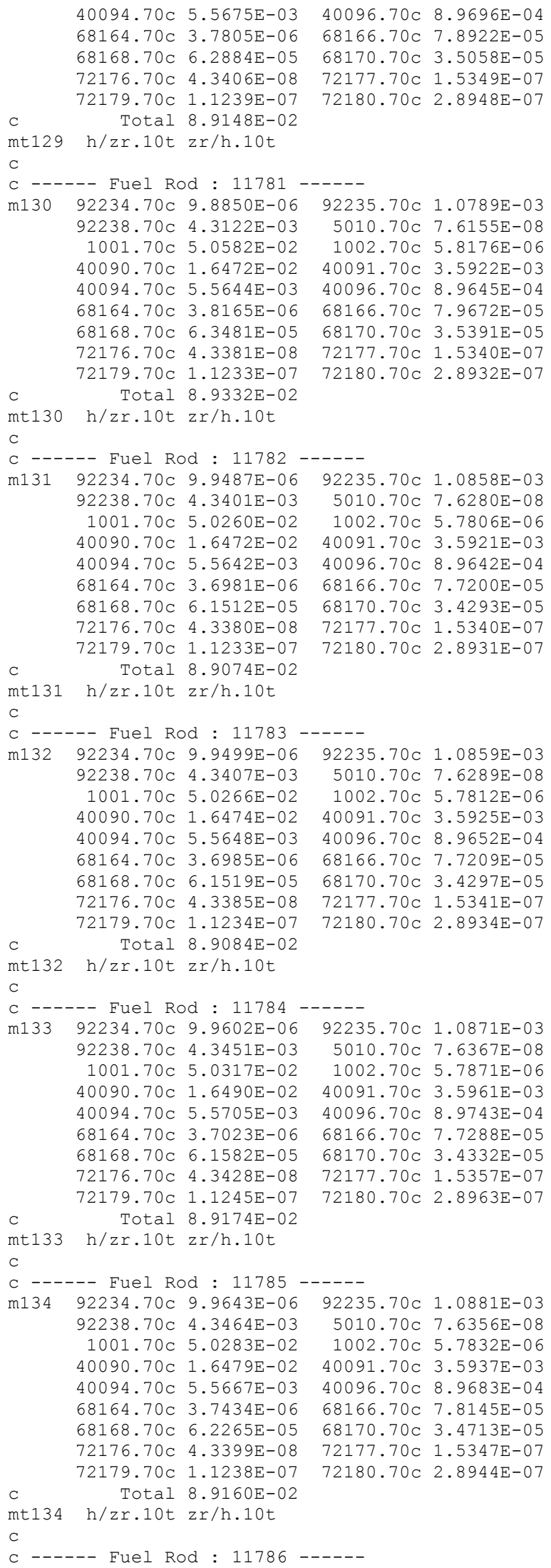

$40094.70 \mathrm{C} 5.5675 \mathrm{E}-03$ $68164.70 \mathrm{C} 3.7805 \mathrm{E}-06$ $68168.70 \mathrm{C} \quad 6.2884 \mathrm{E}-05$ $72176.70 \mathrm{C} 4.3406 \mathrm{E}-08$ $72179.70 \mathrm{C} \quad 1.1239 \mathrm{E}-07$ mt129 h/zr.10t zr/h.10t

$68162.70 \mathrm{C} \quad 3.2874 \mathrm{E}-07$

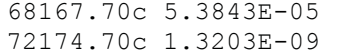
$72178.70 \mathrm{C} 2.2512 \mathrm{E}-07$

$92236.70 \mathrm{C}-1.1979 \mathrm{E}-05$ $5011.70 \mathrm{C} 3.0653 \mathrm{E}-07$ $6000.70 \mathrm{C} 1.0764 \mathrm{E}-03$

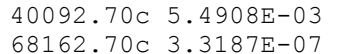
$68167.70 \mathrm{C} 5.4355 \mathrm{E}-05$ $72174.70 \mathrm{C} 1.3196 \mathrm{E}-09$ 92236.70 $1.2056 \mathrm{E}-05$ $5011.70 \mathrm{C} 3.0704 \mathrm{E}-07$ $40092.70 \mathrm{C} 5.4906 \mathrm{E}-03$ $68162.70 \mathrm{C} \quad 3.2157 \mathrm{E}-07$ $68167.70 \mathrm{C} 5.2669 \mathrm{E}-05$ $\begin{array}{ll}72178.70 \mathrm{C} & 2.2498 \mathrm{E}-07\end{array}$

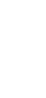

9




\section{NEA/NSC/DOC(2006)1}

\section{Fundamental - FUND}

\section{NRAD-FUND-RESR-002 \\ CRIT-REAC-COEF}

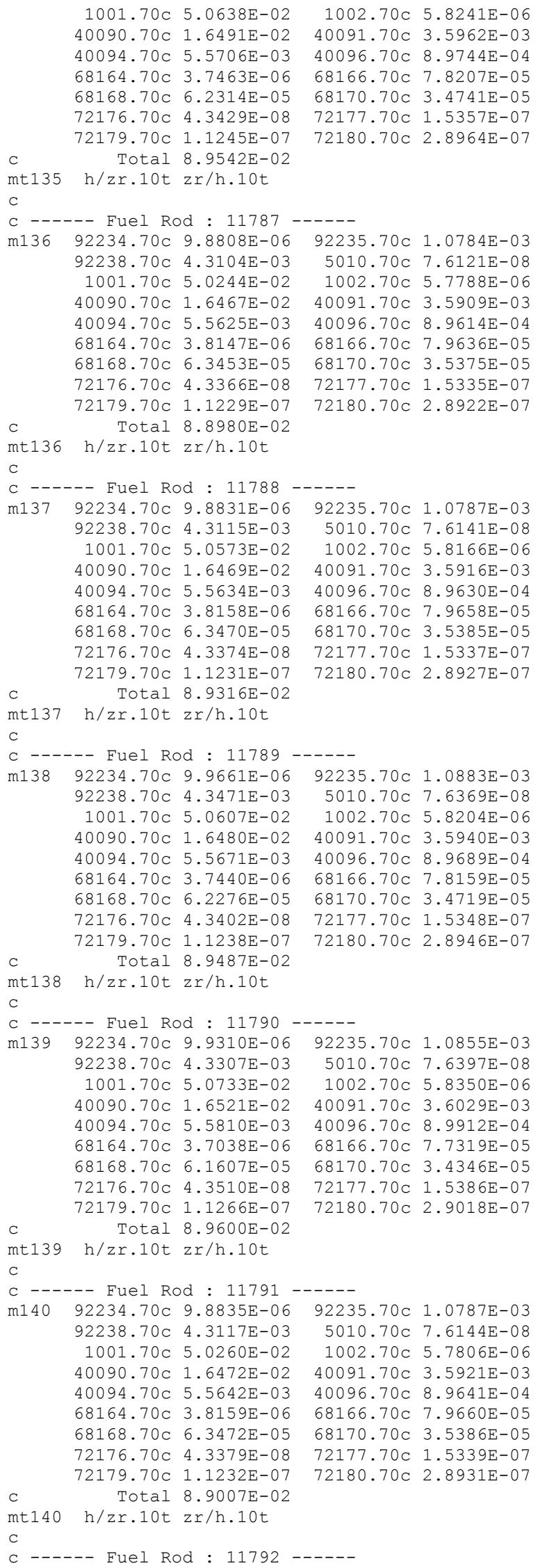

$92236.70 \mathrm{C} \quad 1.1977 \mathrm{E}-05$ $5011.70 \mathrm{c} 3.0649 \mathrm{E}-07$ $6000.70 \mathrm{C} 1.0763 \mathrm{E}-03$ $40092.70 \mathrm{C} 5.4905 \mathrm{E}-03$ $68162.70 \mathrm{C} \quad 3.3182 \mathrm{E}-07$ $68167.70 \mathrm{C} 5.4347 \mathrm{E}-05$ $72174.70 \mathrm{C} 1.3195 \mathrm{E}-09$ $72178.70 \mathrm{C} 2.2498 \mathrm{E}-07$

$5011.70 \mathrm{C} 3.0740 \mathrm{E}-07$ $6000.70 \mathrm{C} \quad 1.1514 \mathrm{E}-03$ $52.70 \mathrm{C} 5.4934 \mathrm{E}-03$

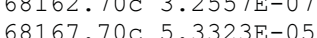
$72174.70 \mathrm{C} 1.3202 \mathrm{E}-09$ $72178.70 \mathrm{C} 2.2510 \mathrm{E}-07$

$92236.70 \mathrm{C} \quad 1.2035 \mathrm{E}-05$ $5011.70 \mathrm{C} 3.0751 \mathrm{E}-07$ $6000.70 \mathrm{C} 1.0798 \mathrm{E}-03$ $68162.70 \mathrm{C} \quad 3.2207 \mathrm{E}-07$ $6167.70 \mathrm{C} 5.2750 \mathrm{E}-05$ $72174.70 \mathrm{C} 1.3235 \mathrm{E}-09$ $72178.70 \mathrm{C} \quad 2.2566 \mathrm{E}-07$ $40092.70 \mathrm{C} 5.5071 \mathrm{E}-03$ 


\section{NEA/NSC/DOC(2006)1}

\section{Fundamental - FUND}

\section{NRAD-FUND-RESR-002 CRIT-REAC-COEF}

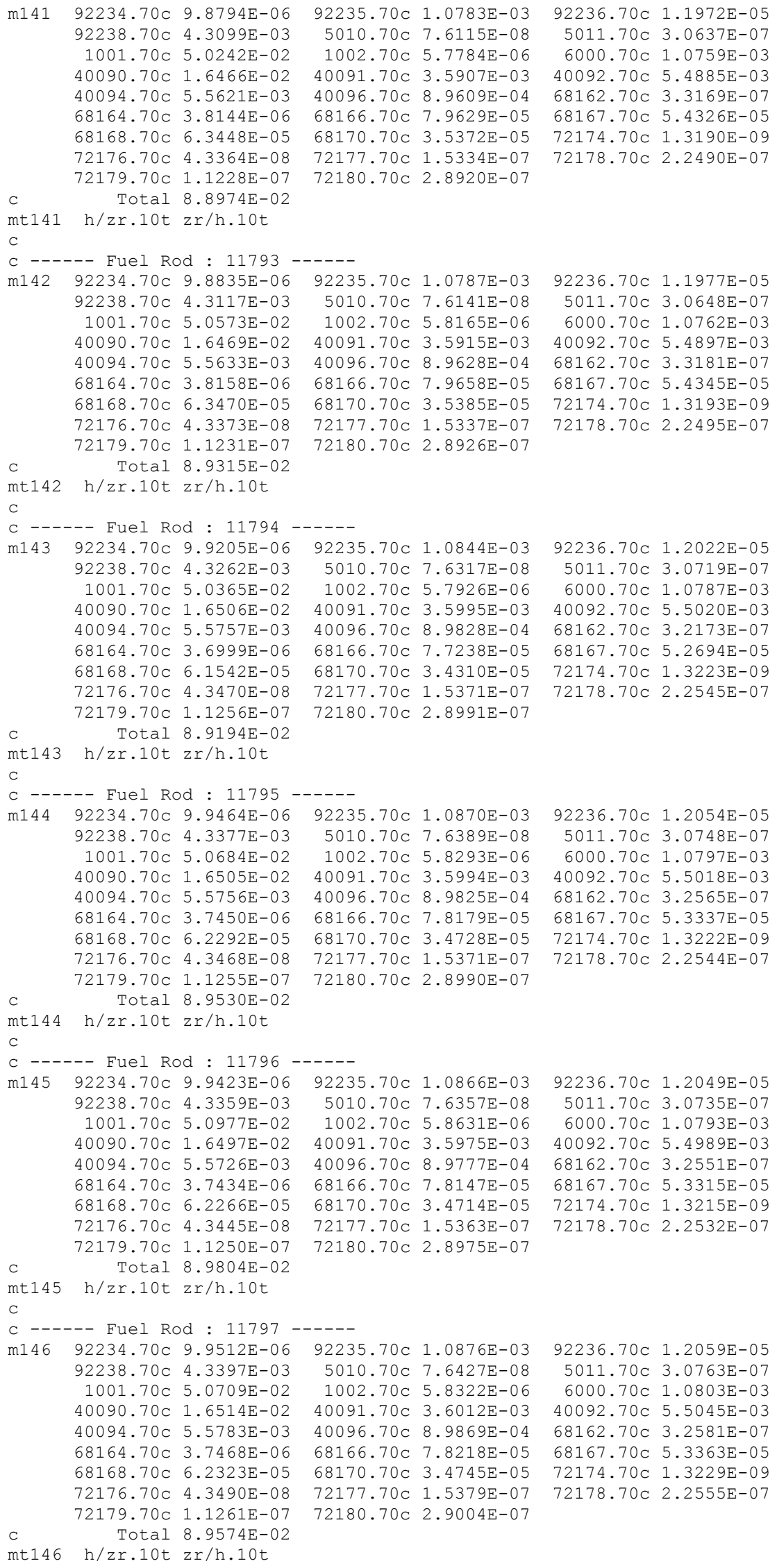
$5011.70 \mathrm{C} 3.0735 \mathrm{E}-07$ $6000.70 \mathrm{C} 1.0793 \mathrm{E}-03$ $40092.70 \mathrm{C} 5.4989 \mathrm{E}-03$ $68162.70 \mathrm{C} 3.2551 \mathrm{E}-07$ $68167.70 \mathrm{C} 5.3315 \mathrm{E}-05$ $72174.70 \mathrm{C} 1.3215 \mathrm{E}-09$ $72178.70 \mathrm{C} \quad 2.2532 \mathrm{E}-07$

$92236.70 \mathrm{C} \quad 1.2059 \mathrm{E}-05$ $5011.70 \mathrm{c} 3.0763 \mathrm{E}-07$ $6000.70 \mathrm{C} \quad 1.0803 \mathrm{E}-03$ $40092.70 \mathrm{C} 5.5045 \mathrm{E}-03$ $68162.70 \mathrm{C} 3.2581 \mathrm{E}-07$ $68167.70 \mathrm{C} 5.3363 \mathrm{E}-05$ $72174.70 \mathrm{C} 1.3229 \mathrm{E}-09$ $72178.70 \mathrm{C} 2.2555 \mathrm{E}-07$ 


\section{NEA/NSC/DOC(2006)1}

\section{Fundamental - FUND}

\section{NRAD-FUND-RESR-002 \\ CRIT-REAC-COEF}

C

$\begin{array}{lll}\text { C }----- \text { Fuel Rod : } 11798 & ------ \\ \text { m147 92234.70C 9.9348E-06 } 9223\end{array}$ $92238.70 \mathrm{C} 4.3326 \mathrm{E}-03$ $1001.70 \mathrm{C} 5.0946 \mathrm{E}-02$ $40090.70 \mathrm{C} \quad 1.6487 \mathrm{E}-02$ $40094.70 \mathrm{C} 5.5692 \mathrm{E}-03$ $68164.70 \mathrm{C} 3.7821 \mathrm{E}-06$ $68168.70 \mathrm{C} \quad 6.2910 \mathrm{E}-05$ $72176.70 \mathrm{C} \quad 4.3419 \mathrm{E}-08$ $72179.70 \mathrm{C} \quad 1.1243 \mathrm{E}-07$ C Total 8.9679E-02 mt147 h/zr.10t zr/h.10t c c ----- Fuel Rod : 11799 m148 92234.70c 9.8641E-06 $92238.70 \mathrm{C} \quad 4.3032 \mathrm{E}-03$ $1001.70 \mathrm{C} 5.0788 \mathrm{E}-02$ $40090.70 \mathrm{C} \quad 1.6435 \mathrm{E}-02$ $40094.70 \mathrm{C} 5.5519 \mathrm{E}-03$ $68164.70 \mathrm{C} 3.8083 \mathrm{E}-06$ $68168.70 \mathrm{C} \quad 6.3346 \mathrm{E}-05$ $72176.70 \mathrm{C} \quad 4.3284 \mathrm{E}-08$ $72179.70 \mathrm{C} \quad 1.1208 \mathrm{E}-07$ C Total $8.9451 \mathrm{E}-02$ mt148 h/zr.10t zr/h.10t

$$
\text { C }
$$
$92238.70 \mathrm{C} \quad 4.3707 \mathrm{E}-03 \quad 5010.70 \mathrm{C} 7.6345 \mathrm{E}-08$ $1001.70 \mathrm{C} 5.0490 \mathrm{E}-02 \quad 1002.70 \mathrm{C} 5.8070 \mathrm{E}-06$ $40090.70 \mathrm{C} \quad 1.6442 \mathrm{E}-02 \quad 40091.70 \mathrm{C} \quad 3.5856 \mathrm{E}-03$ $40094.70 \mathrm{C} 5.5542 \mathrm{E}-03 \quad 40096.70 \mathrm{C} \quad 8.9481 \mathrm{E}-04$ $68164.70 \mathrm{c} \quad 3.7428 \mathrm{E}-06 \quad 68166.70 \mathrm{c} \quad 7.8134 \mathrm{E}-05$ $68168.70 \mathrm{C} \quad 6.2257 \mathrm{E}-05 \quad 68170.70 \mathrm{C} \quad 3.4708 \mathrm{E}-05$ $72176.70 \mathrm{C} \quad 4.3302 \mathrm{E}-08 \quad 72177.70 \mathrm{C} \quad 1.5312 \mathrm{E}-07$ $72179.70 \mathrm{C} \quad 1.1212 \mathrm{E}-07 \quad 72180.70 \mathrm{C} \quad 2.8879 \mathrm{E}-07$ C Total $8.9216 \mathrm{E}-02$ mt149 h/zr.10t zr/h.10t

$$
\text { c }
$$
C ------ Fuel Rod : 11801 m150 92234.70c 9.9357E-06 $92238.70 \mathrm{C} \quad 4.3325 \mathrm{E}-03$ $1001.70 \mathrm{C} 5.0651 \mathrm{E}-02$ $40090.70 \mathrm{C} 1.6495 \mathrm{E}-02$ $40094.70 \mathrm{C} 5.5719 \mathrm{E}-03$ $68164.70 \mathrm{C} 3.7409 \mathrm{E}-06$ $68168.70 \mathrm{C} \quad 6.2225 \mathrm{E}-05$ $72176.70 \mathrm{C} \quad 4.3440 \mathrm{E}-08$ $72179.70 \mathrm{C} 1.1248 \mathrm{E}-07$ C Total 8.9361E-02 mt150 h/zr.10t $\mathrm{zr} / \mathrm{h} .10 \mathrm{t}$ C ----- Fuel Rod : 11802 m15192234.70c 1.0000E-05 $92238.70 \mathrm{C} 4.3598 \mathrm{E}-03$ $1001.70 \mathrm{C} 5.0204 \mathrm{E}-02$ $40090.70 \mathrm{C} 1.6453 \mathrm{E}-02$ $40094.70 \mathrm{C} 5.5580 \mathrm{E}-03$ $68164.70 \mathrm{C} \quad 3.8670 \mathrm{E}-06$ $68168.70 \mathrm{C} \quad 6.4321 \mathrm{E}-05$ $72176.70 \mathrm{C} \quad 4.3332 \mathrm{E}-08$ $72179.70 \mathrm{C} \quad 1.1220 \mathrm{E}-07$ C Total 8.8842E-02 mt151 h/zr.10t zr/h.10t c C ----- Fuel Rod : 11803 m152 92234.70C 9.9943E-06 $92238.70 \mathrm{C} 4.3572 \mathrm{E}-03$ $1001.70 \mathrm{C} 5.0489 \mathrm{E}-02$ $40090.70 \mathrm{C} \quad 1.6442 \mathrm{E}-02$ $40094.70 \mathrm{C} 5.5542 \mathrm{E}-03$ $68164.70 \mathrm{c} 3.8647 \mathrm{E}-06$ $68168.70 \mathrm{C} \quad 6.4284 \mathrm{E}-05$ $72176.70 \mathrm{C} 4.3301 \mathrm{E}-08$ $72179.70 \mathrm{C} 1.1212 \mathrm{E}-07$
$5010.70 \mathrm{C} 7.6299 \mathrm{E}-08$ $1002.70 \mathrm{C} 5.8595 \mathrm{E}-06$ $40091.70 \mathrm{C} 3.5953 \mathrm{E}-03$

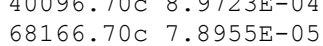
$68170.70 \mathrm{C} 3.5073 \mathrm{E}-05$ $72177.70 \mathrm{C} \quad 1.5353 \mathrm{E}-07$ $72180.70 \mathrm{C} \quad 2.8957 \mathrm{E}-07$

$92235.70 \mathrm{C} 1.0765 \mathrm{E}-03$ $5010.70 \mathrm{C} 7.5993 \mathrm{E}-08$

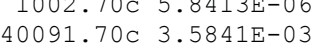
$40096.70 \mathrm{C} 8.9444 \mathrm{E}-04$ $68166.70 \mathrm{C} 7.9502 \mathrm{E}-05$ $68170.70 \mathrm{C} \quad 3.5316 \mathrm{E}-05$ $72177.70 \mathrm{C} 1.5306 \mathrm{E}-07$ $72180.70 \mathrm{C} 2.8867 \mathrm{E}-07$

$92235.70 \mathrm{C} 1.0864 \mathrm{E}-03$ $5010.70 \mathrm{C} 7.6306 \mathrm{E}-08$ $1002.70 \mathrm{C} \quad 5.8255 \mathrm{E}-06$ $40091.70 \mathrm{C} 3.5971 \mathrm{E}-03$ $40096.70 \mathrm{C} \quad 8.9767 \mathrm{E}-04$ $68170.70 \mathrm{C} 3.4691 \mathrm{E}-05$ $72177.70 \mathrm{C} \quad 1.5361 \mathrm{E}-07$ $72180.70 \mathrm{C} 2.8971 \mathrm{E}-07$

$92235.70 \mathrm{C} 1.0942 \mathrm{E}-03$ $5010.70 \mathrm{C} 7.6333 \mathrm{E}-08$ $1002.70 \mathrm{C} \quad 5.7742 \mathrm{E}-06$ $40091.70 \mathrm{c} 3.5881 \mathrm{E}-03$ $40096.70 \mathrm{C} 8.9542 \mathrm{E}-04$ $68166.70 \mathrm{C} 8.0726 \mathrm{E}-05$ $68170.70 \mathrm{C} 3.5859 \mathrm{E}-05$ $72177.70 \mathrm{C} 1.5323 \mathrm{E}-07$ $72180.70 \mathrm{C} 2.8899 \mathrm{E}-07$

$92235.70 \mathrm{C} \quad 1.0936 \mathrm{E}-03$ $5010.70 \mathrm{C} 7.6288 \mathrm{E}-08$ $1002.70 \mathrm{C} \quad 5.8069 \mathrm{E}-06$ $40091.70 \mathrm{C} 3.5856 \mathrm{E}-03$ $40096.70 \mathrm{C} 8.9480 \mathrm{E}-04$ $68166.70 \mathrm{C} 8.0678 \mathrm{E}-05$ $68170.70 \mathrm{C} \quad 3.5838 \mathrm{E}-05$ $72177.70 \mathrm{C} \quad 1.5312 \mathrm{E}-07$ $72180.70 \mathrm{C} 2.8879 \mathrm{E}-07$ $68166.70 \mathrm{C} 7.8095 \mathrm{E}-05$
$92236.70 \mathrm{C} 1.2039 \mathrm{E}-05$ $5011.70 \mathrm{c} 3.0711 \mathrm{E}-07$ $6000.70 \mathrm{c} 1.0066 \mathrm{E}-03$ $40092.70 \mathrm{C} 5.4955 \mathrm{E}-03$ $68162.70 \mathrm{C} 3.2888 \mathrm{E}-07$ $68167.70 \mathrm{C} 5.3866 \mathrm{E}-05$ $72174.70 \mathrm{C} 1.3207 \mathrm{E}-09$ $72178.70 \mathrm{C} 2.2518 \mathrm{E}-07$

$92236.70 \mathrm{C} \quad 1.1954 \mathrm{E}-05$ $5011.70 \mathrm{C} 3.0588 \mathrm{E}-07$ $6000.70 \mathrm{C} 1.0741 \mathrm{E}-03$ $40092.70 \mathrm{C} 5.4784 \mathrm{E}-03$ $68162.70 \mathrm{C} 3.3116 \mathrm{E}-07$ $68167.70 \mathrm{C} 5.4239 \mathrm{E}-05$ $72174.70 \mathrm{C} 1.3166 \mathrm{E}-09$ $72178.70 \mathrm{C} \quad 2.2448 \mathrm{E}-07$

$92236.70 \mathrm{C} 1.2141 \mathrm{E}-05$ $5011.70 \mathrm{C} 3.0730 \mathrm{E}-07$ $6000.70 \mathrm{C} 1.0431 \mathrm{E}-03$ $40092.70 \mathrm{C} 5.4807 \mathrm{E}-03$ $68162.70 \mathrm{C} \quad 3.2546 \mathrm{E}-07$ $68167.70 \mathrm{C} 5.3306 \mathrm{E}-05$ $72174.70 \mathrm{C} 1.3172 \mathrm{E}-09$ $72178.70 \mathrm{C} \quad 2.2458 \mathrm{E}-07$

$92236.70 \mathrm{C} 1.2041 \mathrm{E}-05$ $5011.70 \mathrm{C} 3.0714 \mathrm{E}-07$ $6000.70 \mathrm{C} 9.7070 \mathrm{E}-04$ $40092.70 \mathrm{C} 5.4982 \mathrm{E}-03$ $68162.70 \mathrm{C} \quad 3.2530 \mathrm{E}-07$ $68167.70 \mathrm{C} 5.3279 \mathrm{E}-05$ $72174.70 \mathrm{C} 1.3214 \mathrm{E}-09$ $72178.70 \mathrm{C} \quad 2.2529 \mathrm{E}-07$

$92236.70 \mathrm{C} \quad 1.2119 \mathrm{E}-05$ $5011.70 \mathrm{C} 3.0725 \mathrm{E}-07$ $6000.70 \mathrm{C} 9.3508 \mathrm{E}-04$ $40092.70 \mathrm{C} 5.4845 \mathrm{E}-03$ $68162.70 \mathrm{C} 3.3626 \mathrm{E}-07$ $68167.70 \mathrm{C} 5.5074 \mathrm{E}-05$ $72174.70 \mathrm{C} 1.3181 \mathrm{E}-09$ $72178.70 \mathrm{C} \quad 2.2473 \mathrm{E}-07$

$92236.70 \mathrm{C} \quad 1.2111 \mathrm{E}-05$ $5011.70 \mathrm{C} 3.0707 \mathrm{E}-07$ $6000.70 \mathrm{C} 9.3453 \mathrm{E}-04$ $40092.70 \mathrm{C} 5.4807 \mathrm{E}-03$ $68162.70 \mathrm{C} 3.3606 \mathrm{E}-07$ $68167.70 \mathrm{C} 5.5042 \mathrm{E}-05$ $72174.70 \mathrm{C} 1.3172 \mathrm{E}-09$ $72178.70 \mathrm{C} 2.2457 \mathrm{E}-07$ 
NEA/NSC/DOC(2006)1

\section{Fundamental - FUND}

\section{NRAD-FUND-RESR-002 CRIT-REAC-COEF}

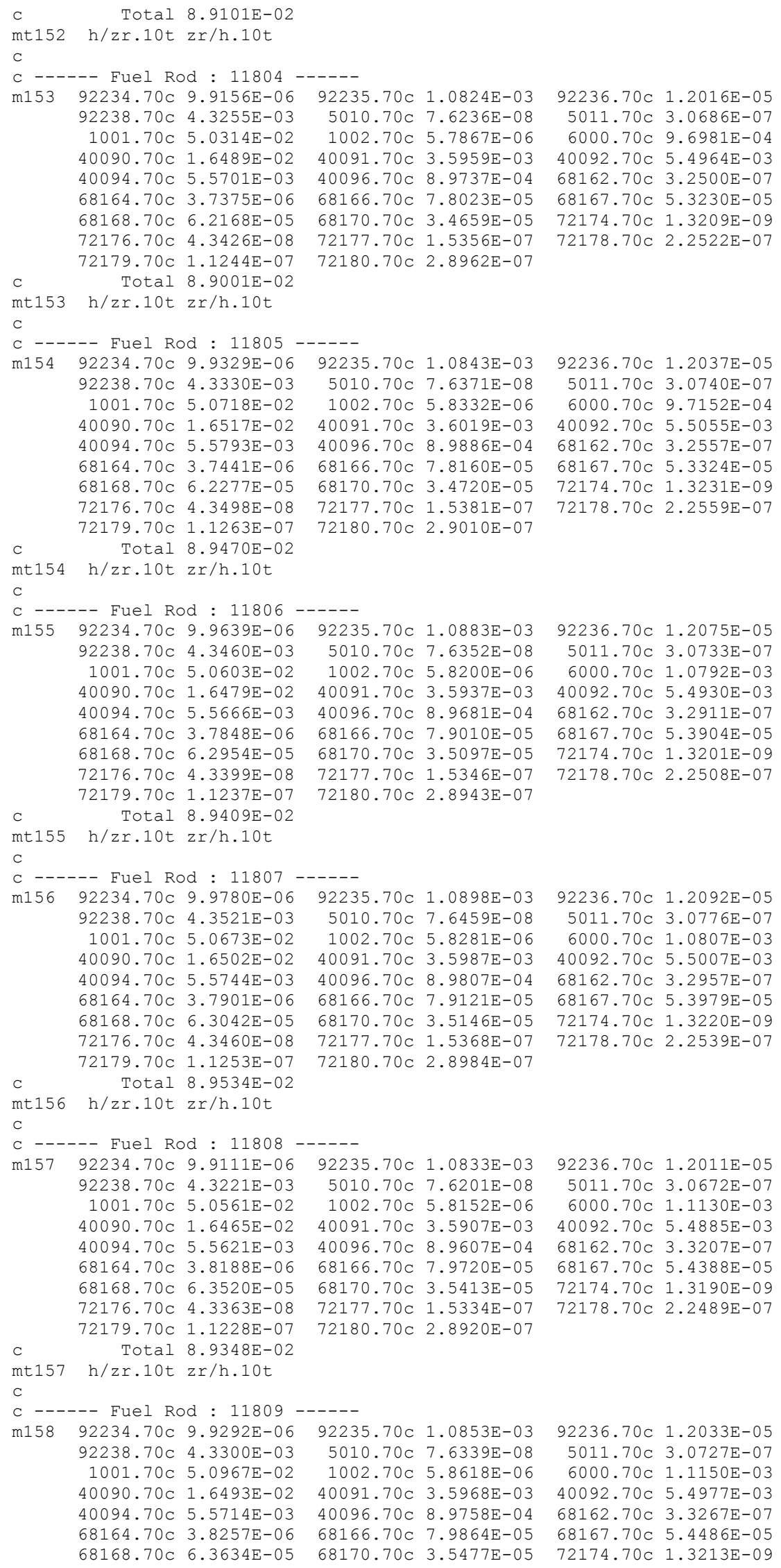

$92236.70 \mathrm{C} \quad 1.2016 \mathrm{E}-05$ $5011.70 \mathrm{C} 3.0686 \mathrm{E}-07$ $6000.70 \mathrm{C} 9.6981 \mathrm{E}-04$ $40092.70 \mathrm{C} 5.4964 \mathrm{E}-03$ $68162.70 \mathrm{C} 3.2500 \mathrm{E}-07$ $68167.70 \mathrm{C} 5.3230 \mathrm{E}-05$ $72174.70 \mathrm{C} \quad 1.3209 \mathrm{E}-09$ $72178.70 \mathrm{C} 2.2522 \mathrm{E}-07$

$92236.70 \mathrm{C} \quad 1.2037 \mathrm{E}-05$ $5011.70 \mathrm{C} \quad 3.0740 \mathrm{E}-07$ $6000.70 \mathrm{C} 9.7152 \mathrm{E}-04$ $40092.70 \mathrm{C} 5.5055 \mathrm{E}-03$ $68162.70 \mathrm{C} 3.2557 \mathrm{E}-07$ $68167.70 \mathrm{C} 5.3324 \mathrm{E}-05$ $72174.70 \mathrm{C} 1.3231 \mathrm{E}-09$ $72178.70 \mathrm{C} \quad 2.2559 \mathrm{E}-07$

$92236.70 \mathrm{C} \quad 1.2075 \mathrm{E}-05$ $5011.70 \mathrm{C} 3.0733 \mathrm{E}-07$ $6000.70 \mathrm{C} 1.0792 \mathrm{E}-03$ $40092.70 \mathrm{C} 5.4930 \mathrm{E}-03$ $68162.70 \mathrm{C} 3.2911 \mathrm{E}-07$ $68167.70 \mathrm{C} 5.3904 \mathrm{E}-05$ $72174.70 \mathrm{C} 1.3201 \mathrm{E}-09$ $72178.70 \mathrm{C} 2.2508 \mathrm{E}-07$

$92236.70 \mathrm{C} \quad 1.2092 \mathrm{E}-05$ $5011.70 \mathrm{C} 3.0776 \mathrm{E}-07$ $6000.70 \mathrm{C} 1.0807 \mathrm{E}-03$ $40092.70 \mathrm{C} 5.5007 \mathrm{E}-03$ $68162.70 \mathrm{C} 3.2957 \mathrm{E}-07$ $68167.70 \mathrm{C} 5.3979 \mathrm{E}-05$ $72174.70 \mathrm{C} 1.3220 \mathrm{E}-09$ $72178.70 \mathrm{C} \quad 2.2539 \mathrm{E}-07$

$92236.70 \mathrm{C} \quad 1.2011 \mathrm{E}-05$ $5011.70 \mathrm{C} 3.0672 \mathrm{E}-07$ $6000.70 \mathrm{C} 1.1130 \mathrm{E}-03$ $40092.70 \mathrm{C} 5.4885 \mathrm{E}-03$ $68162.70 \mathrm{C} 3.3207 \mathrm{E}-07$ $68167.70 \mathrm{C} 5.4388 \mathrm{E}-05$ $72174.70 \mathrm{C} 1.3190 \mathrm{E}-09$ $72178.70 \mathrm{C} 2.2489 \mathrm{E}-07$

$92236.70 \mathrm{C} 1.2033 \mathrm{E}-05$ $5011.70 \mathrm{C} 3.0727 \mathrm{E}-07$ $6000.70 \mathrm{C} 1.1150 \mathrm{E}-03$ $40092.70 \mathrm{C} 5.4977 \mathrm{E}-03$ $68162.70 \mathrm{C} 3.3267 \mathrm{E}-07$ $68167.70 \mathrm{C} 5.4486 \mathrm{E}-05$ $72174.70 \mathrm{C} 1.3213 \mathrm{E}-09$ 
NEA/NSC/DOC(2006)1

\section{Fundamental - FUND}

\section{NRAD-FUND-RESR-002 CRIT-REAC-COEF}

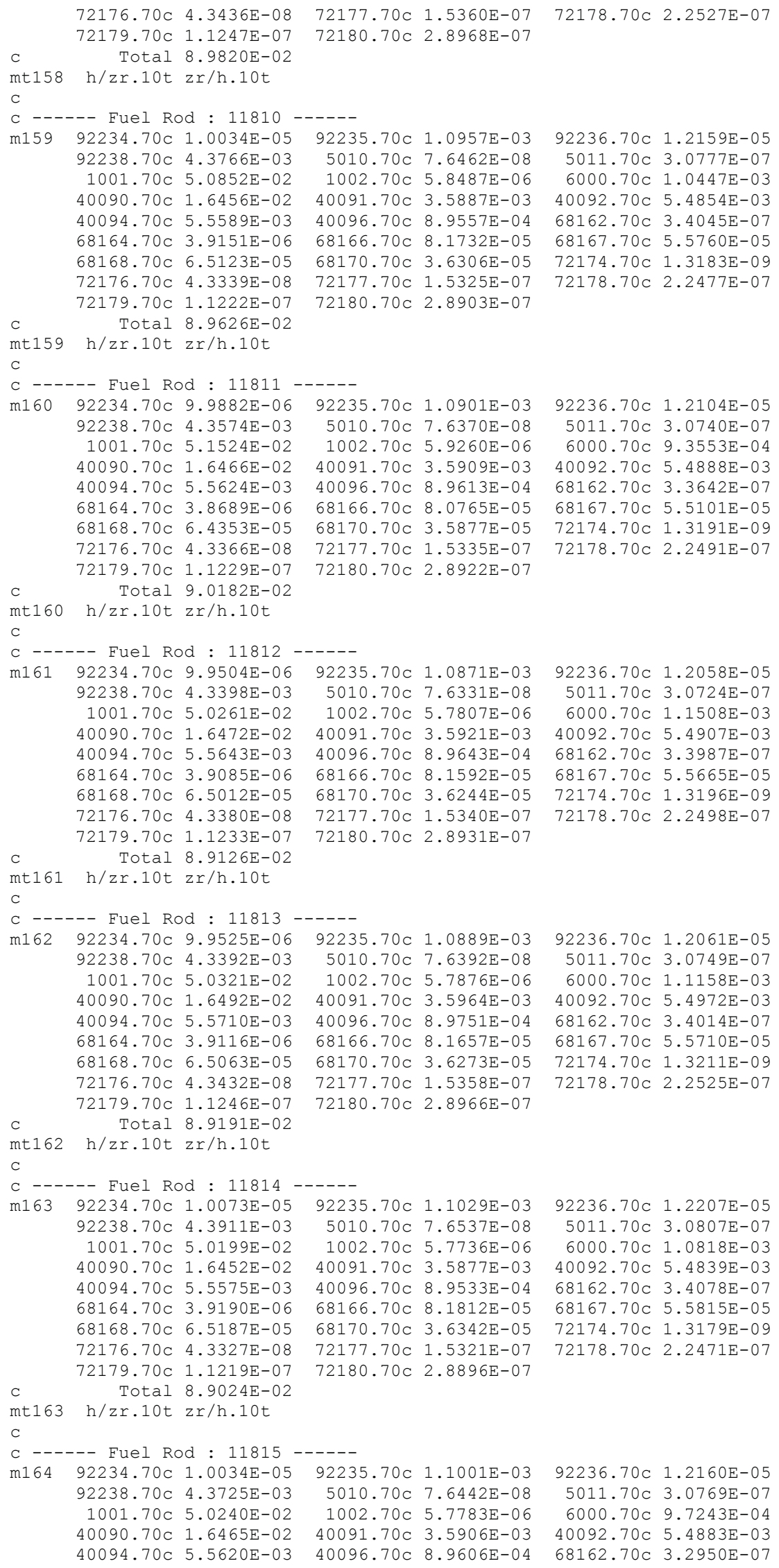

$72178.70 \mathrm{C} \quad 2.2527 \mathrm{E}-07$

$92236.70 \mathrm{C} \quad 1.2159 \mathrm{E}-05$ $5011.70 \mathrm{C} \quad 3.0777 \mathrm{E}-07$ $6000.70 \mathrm{C} 1.0447 \mathrm{E}-03$ $40092.70 \mathrm{C} \quad 5.4854 \mathrm{E}-03$ $68162.70 \mathrm{C} 3.4045 \mathrm{E}-07$ $68167.70 \mathrm{C} 5.5760 \mathrm{E}-05$ $72174.70 \mathrm{C} 1.3183 \mathrm{E}-09$ $72178.70 \mathrm{C} \quad 2.2477 \mathrm{E}-07$

$92236.70 \mathrm{C} \quad 1.2104 \mathrm{E}-05$ $5011.70 \mathrm{C} 3.0740 \mathrm{E}-07$ $6000.70 \mathrm{C} 9.3553 \mathrm{E}-04$ $40092.70 \mathrm{C} 5.4888 \mathrm{E}-03$ $68162.70 \mathrm{C} 3.3642 \mathrm{E}-07$ $68167.70 \mathrm{C} 5.5101 \mathrm{E}-05$ $72174.70 \mathrm{C} 1.3191 \mathrm{E}-09$ $72178.70 \mathrm{C} \quad 2.2491 \mathrm{E}-07$

$92236.70 \mathrm{C} \quad 1.2058 \mathrm{E}-05$ $5011.70 \mathrm{C} 3.0724 \mathrm{E}-07$ $6000.70 \mathrm{C} 1.1508 \mathrm{E}-03$ $40092.70 \mathrm{C} 5.4907 \mathrm{E}-03$ $68162.70 \mathrm{C} 3.3987 \mathrm{E}-07$ $68167.70 \mathrm{C} 5.5665 \mathrm{E}-05$ $72174.70 \mathrm{C} 1.3196 \mathrm{E}-09$ $72178.70 \mathrm{C} \quad 2.2498 \mathrm{E}-07$

$92236.70 \mathrm{C} \quad 1.2061 \mathrm{E}-05$ $5011.70 \mathrm{C} 3.0749 \mathrm{E}-07$ $6000.70 \mathrm{C} 1.1158 \mathrm{E}-03$ $40092.70 \mathrm{C} 5.4972 \mathrm{E}-03$ $68162.70 \mathrm{C} 3.4014 \mathrm{E}-07$ $68167.70 \mathrm{C} \quad 5.5710 \mathrm{E}-05$ $72174.70 \mathrm{C} 1.3211 \mathrm{E}-09$ $72178.70 \mathrm{C} 2.2525 \mathrm{E}-07$

$92236.70 \mathrm{C} \quad 1.2207 \mathrm{E}-05$ $5011.70 \mathrm{C} 3.0807 \mathrm{E}-07$ $6000.70 \mathrm{C} 1.0818 \mathrm{E}-03$ $40092.70 \mathrm{C} 5.4839 \mathrm{E}-03$ $68162.70 \mathrm{C} \quad 3.4078 \mathrm{E}-07$ $68167.70 \mathrm{C} 5.5815 \mathrm{E}-05$ $72174.70 \mathrm{C} \quad 1.3179 \mathrm{E}-09$ $72178.70 \mathrm{C} 2.2471 \mathrm{E}-07$

$92236.70 \mathrm{C} \quad 1.2160 \mathrm{E}-05$ $5011.70 \mathrm{C} 3.0769 \mathrm{E}-07$ $6000.70 \mathrm{C} 9.7243 \mathrm{E}-04$ $40092.70 \mathrm{C} 5.4883 \mathrm{E}-03$ $68162.70 \mathrm{C} 3.2950 \mathrm{E}-07$ 


\section{NEA/NSC/DOC(2006)1}

\section{Fundamental - FUND}

\section{NRAD-FUND-RESR-002 \\ CRIT-REAC-COEF}

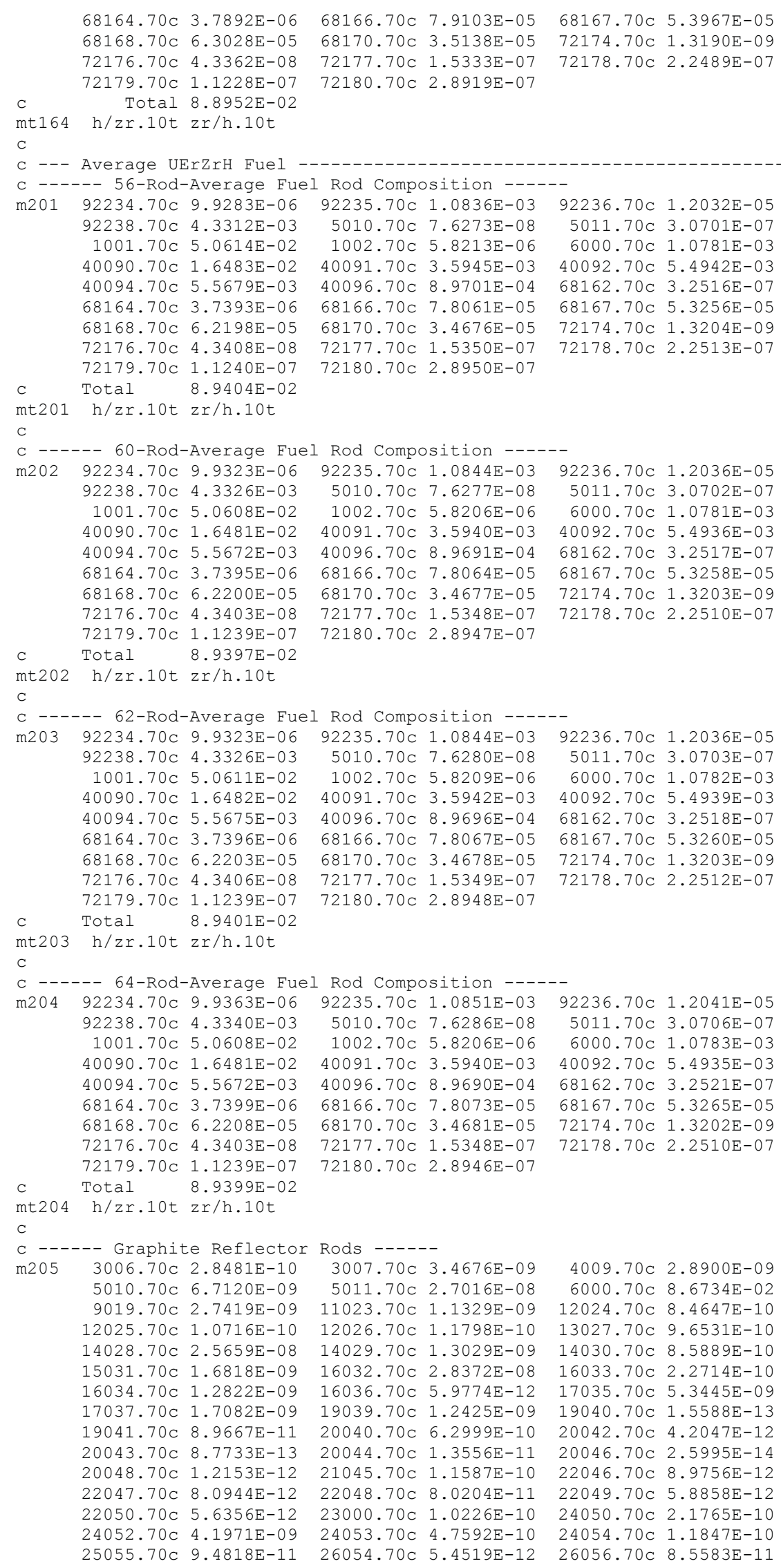


NEA/NSC/DOC(2006)1

\section{Fundamental - FUND}

\section{NRAD-FUND-RESR-002 \\ CRIT-REAC-COEF}

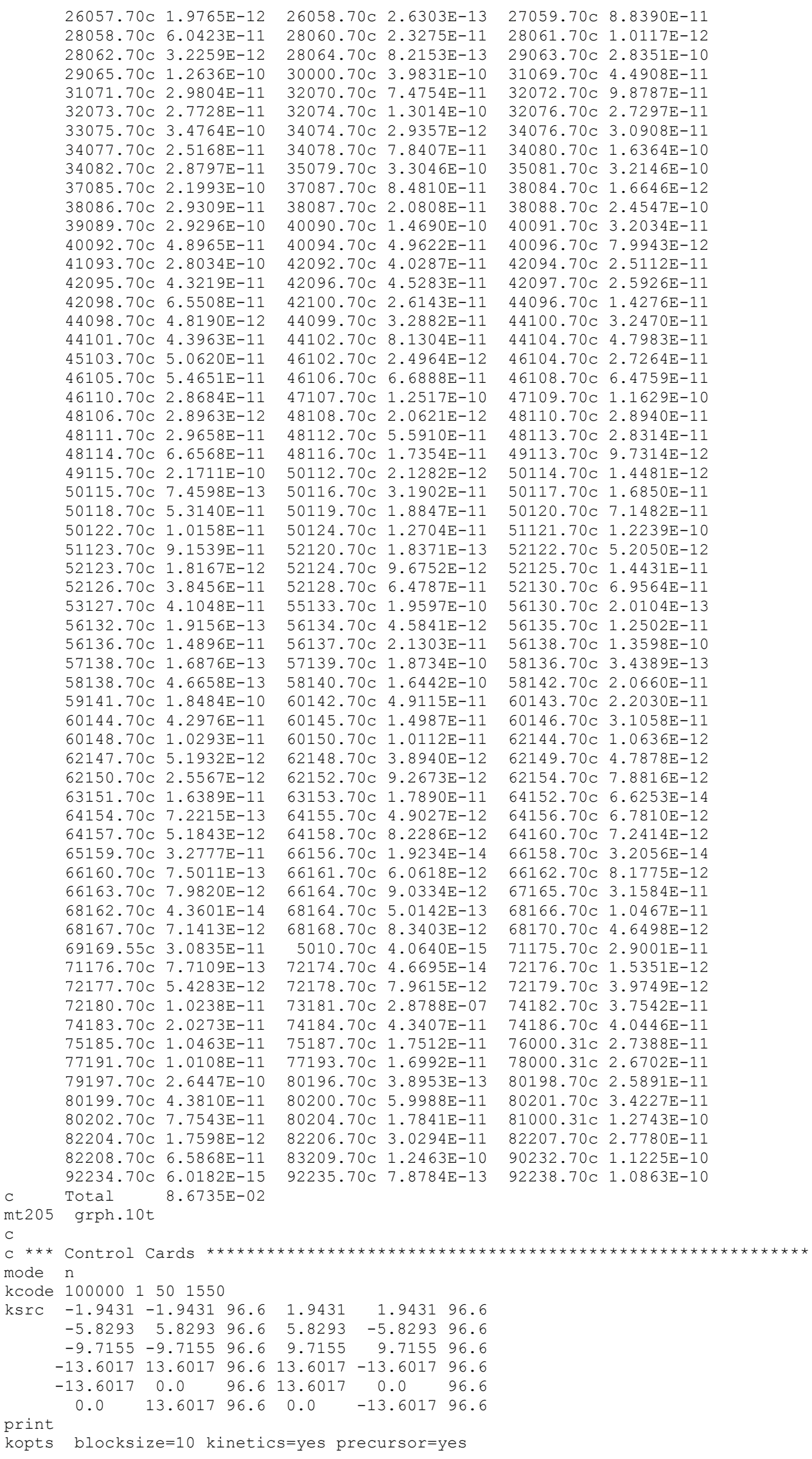


NEA/NSC/DOC(2006)1

Fundamental - FUND

NRAD-FUND-RESR-002

CRIT-REAC-COEF 
NEA/NSC/DOC(2006)1

Fundamental - FUND

NRAD-FUND-RESR-002

CRIT-REAC-COEF

\section{MCNP5 Input Deck for the 64-fuel-element upgraded core configuration (Case 2):}

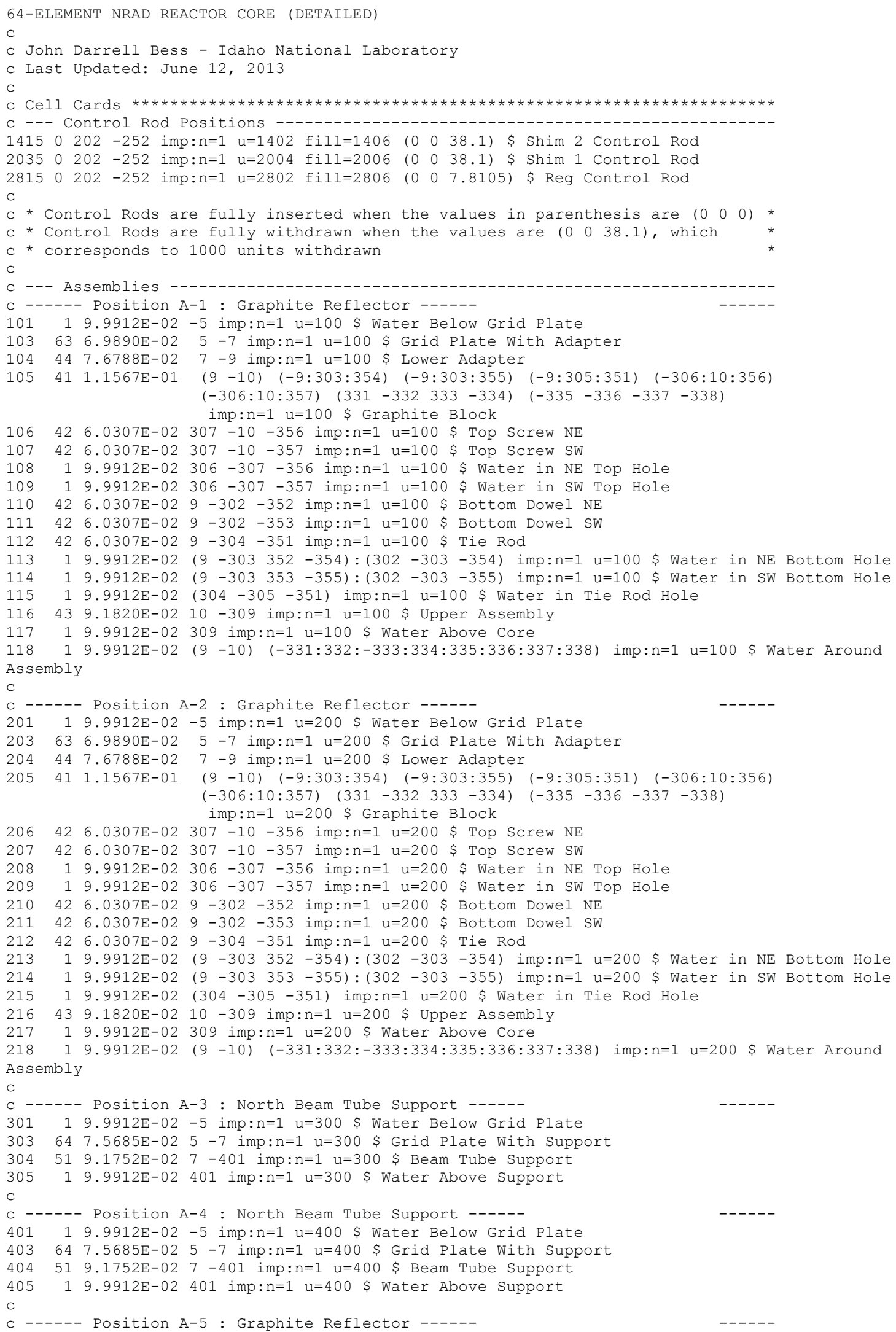




\section{NEA/NSC/DOC(2006)1}

\section{Fundamental - FUND}

\section{NRAD-FUND-RESR-002 CRIT-REAC-COEF}

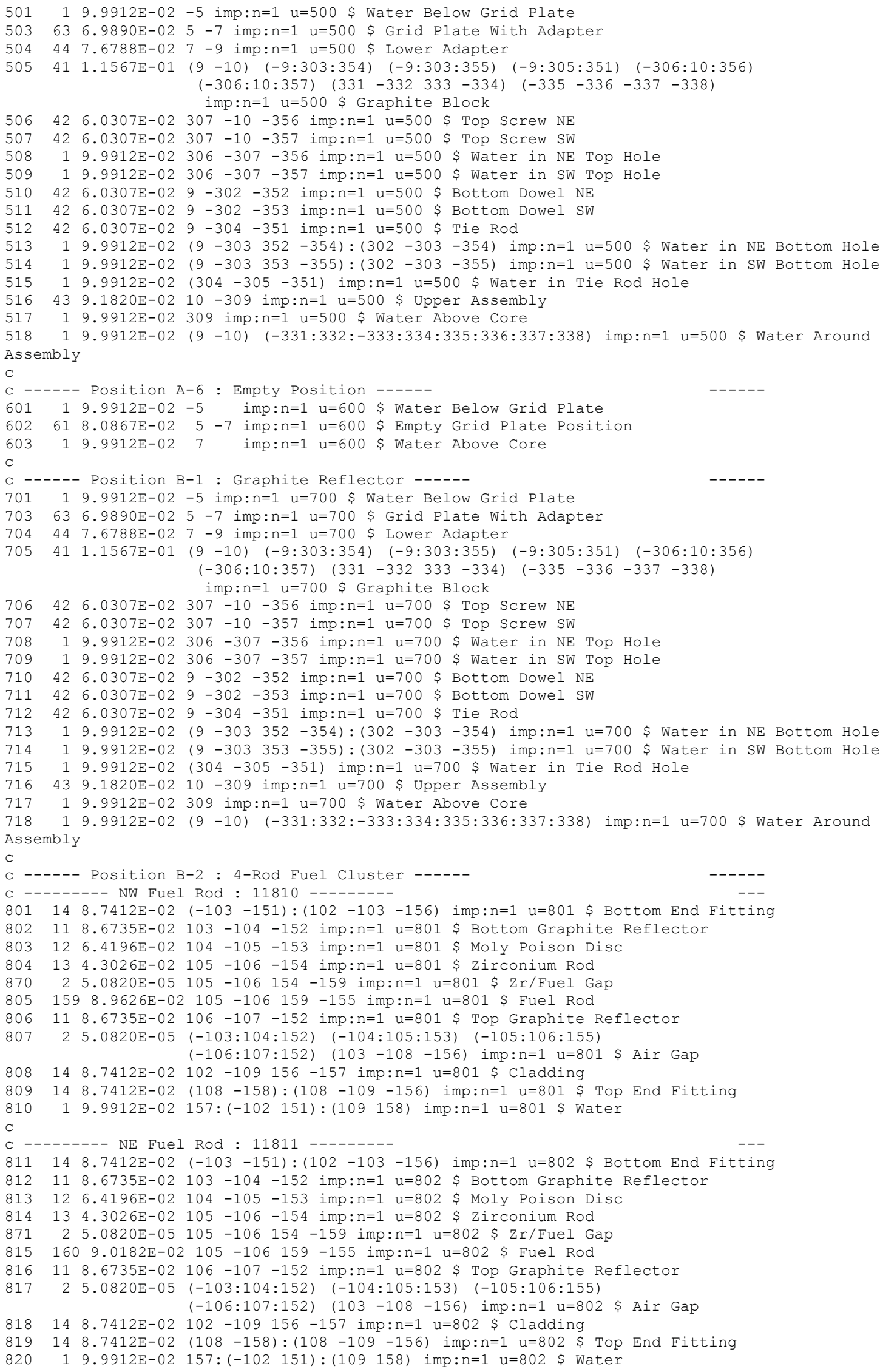




\section{NEA/NSC/DOC(2006)1}

\section{Fundamental - FUND}

\section{NRAD-FUND-RESR-002 CRIT-REAC-COEF}

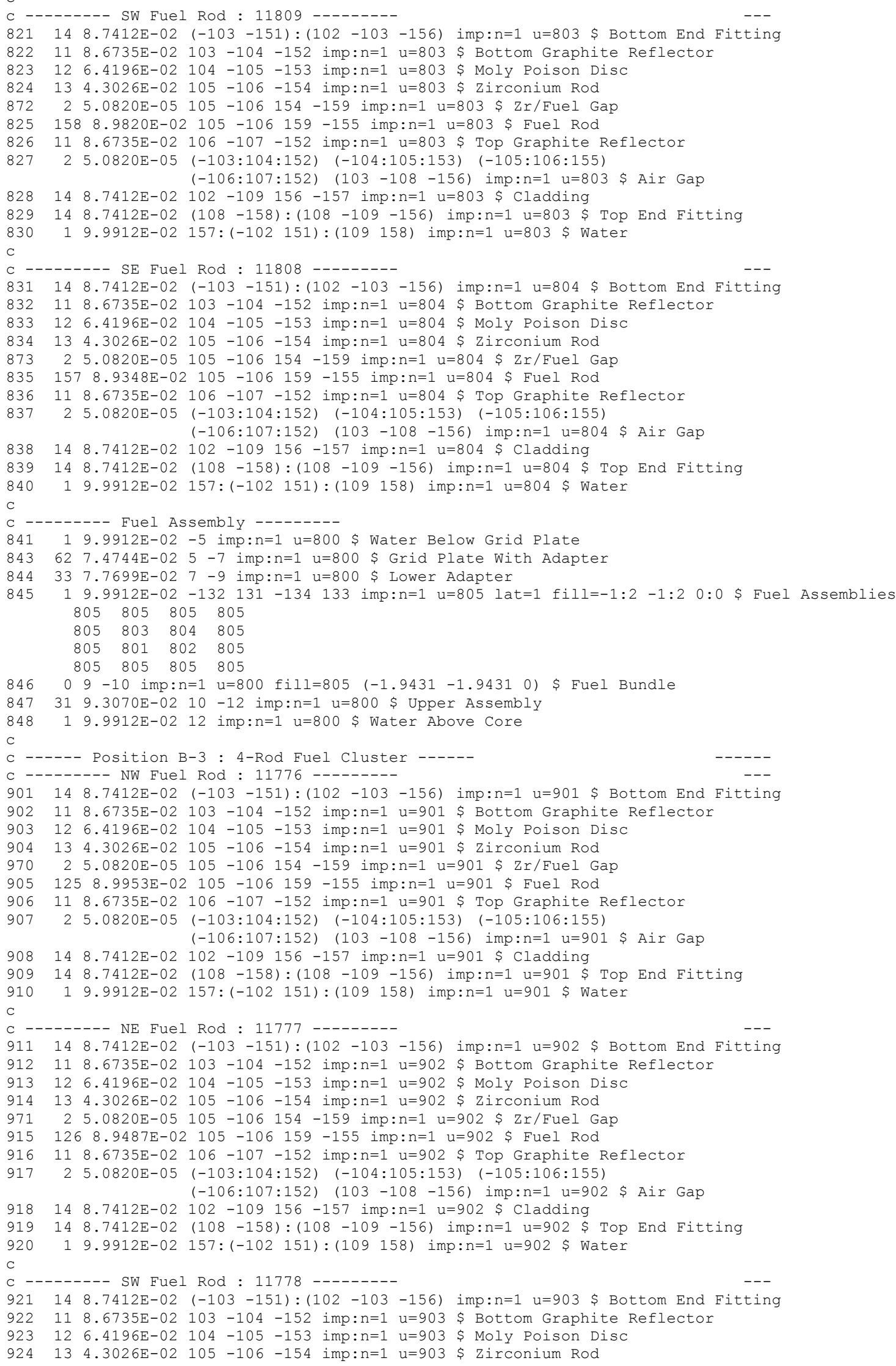




\section{NEA/NSC/DOC(2006)1}

\section{Fundamental - FUND}

\section{NRAD-FUND-RESR-002 CRIT-REAC-COEF}

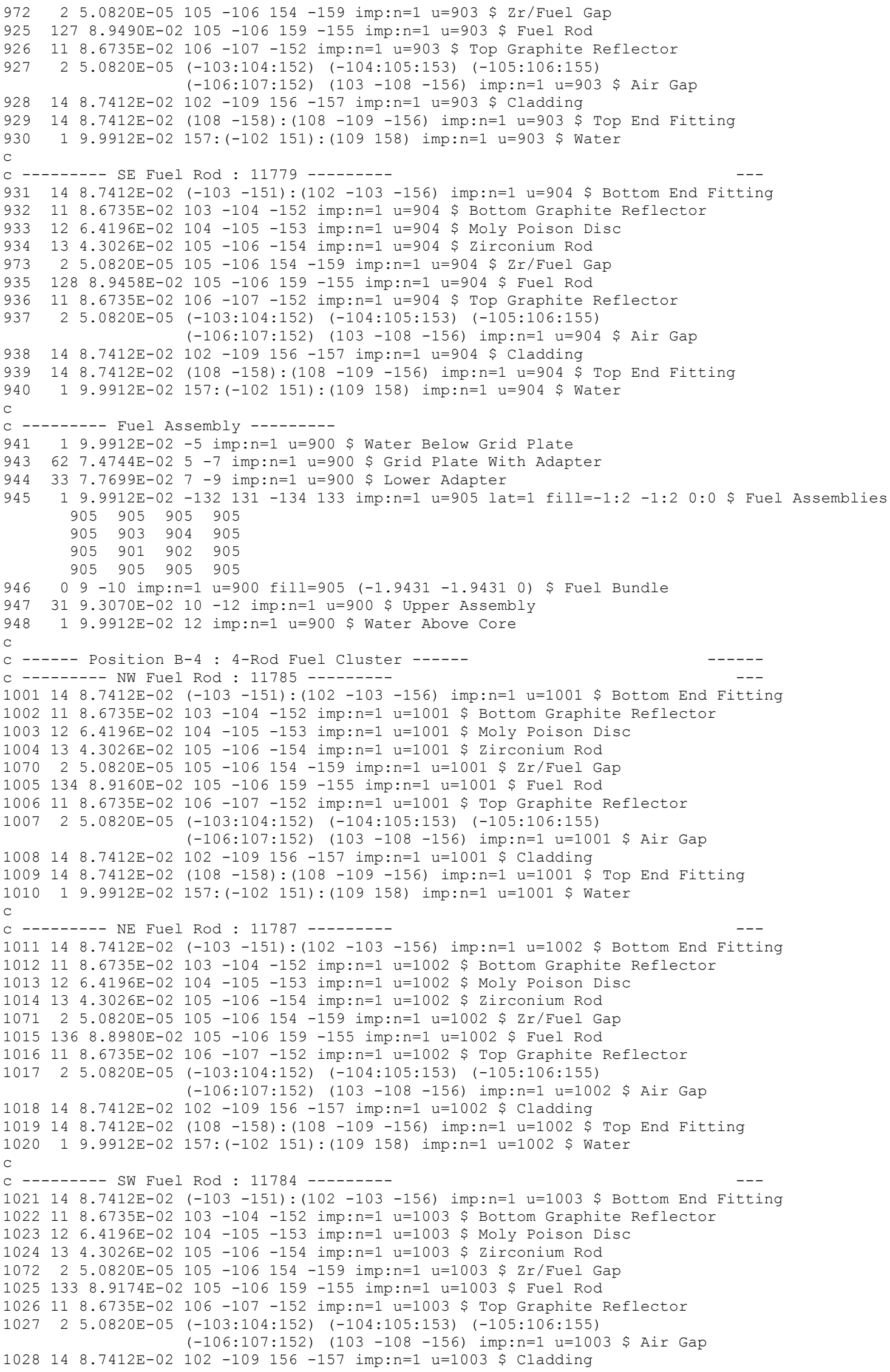




\section{NEA/NSC/DOC(2006)1}

\section{Fundamental - FUND}

\section{NRAD-FUND-RESR-002 CRIT-REAC-COEF}

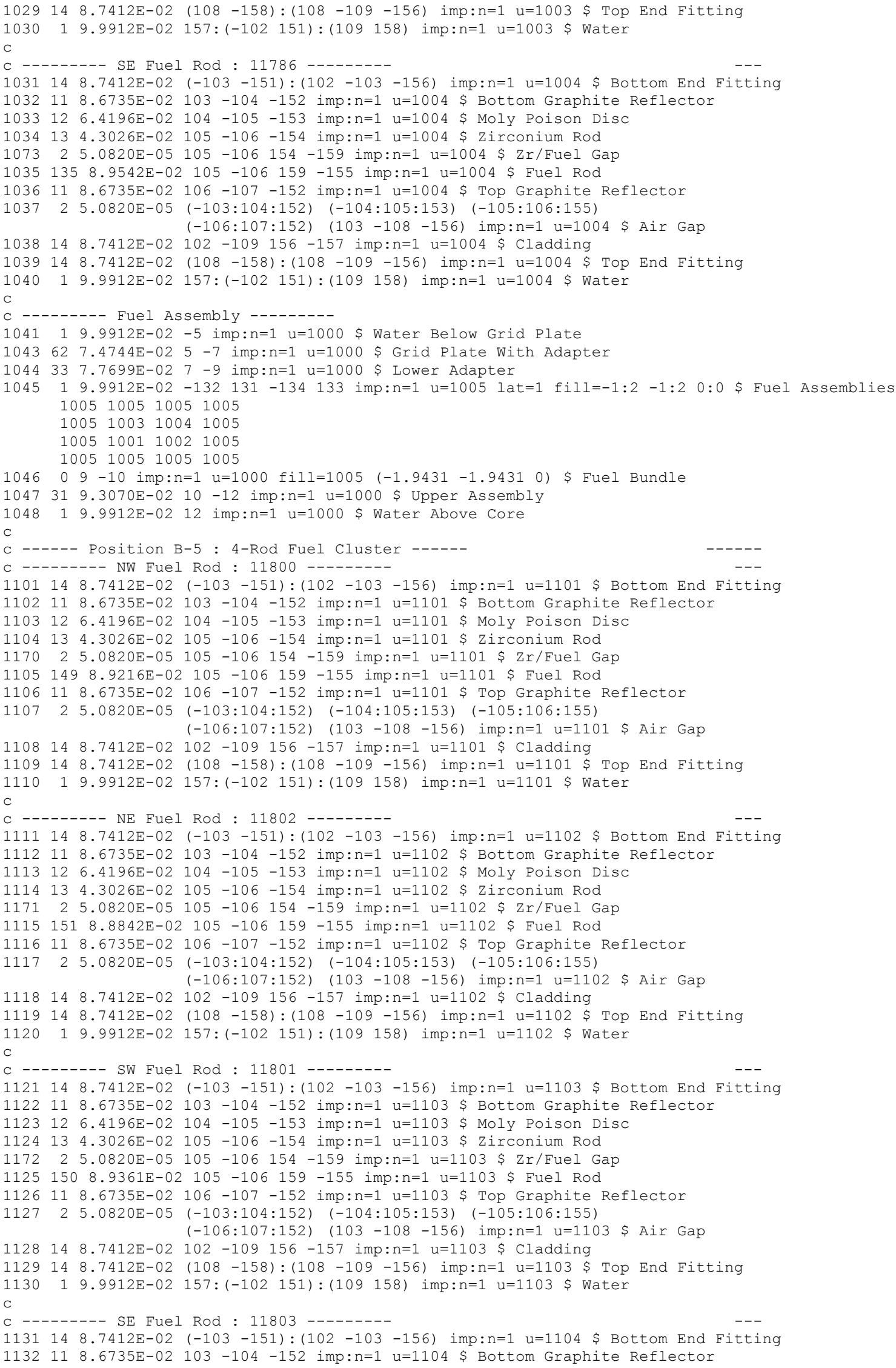




\section{NEA/NSC/DOC(2006)1}

\section{Fundamental - FUND}

\section{NRAD-FUND-RESR-002 CRIT-REAC-COEF}

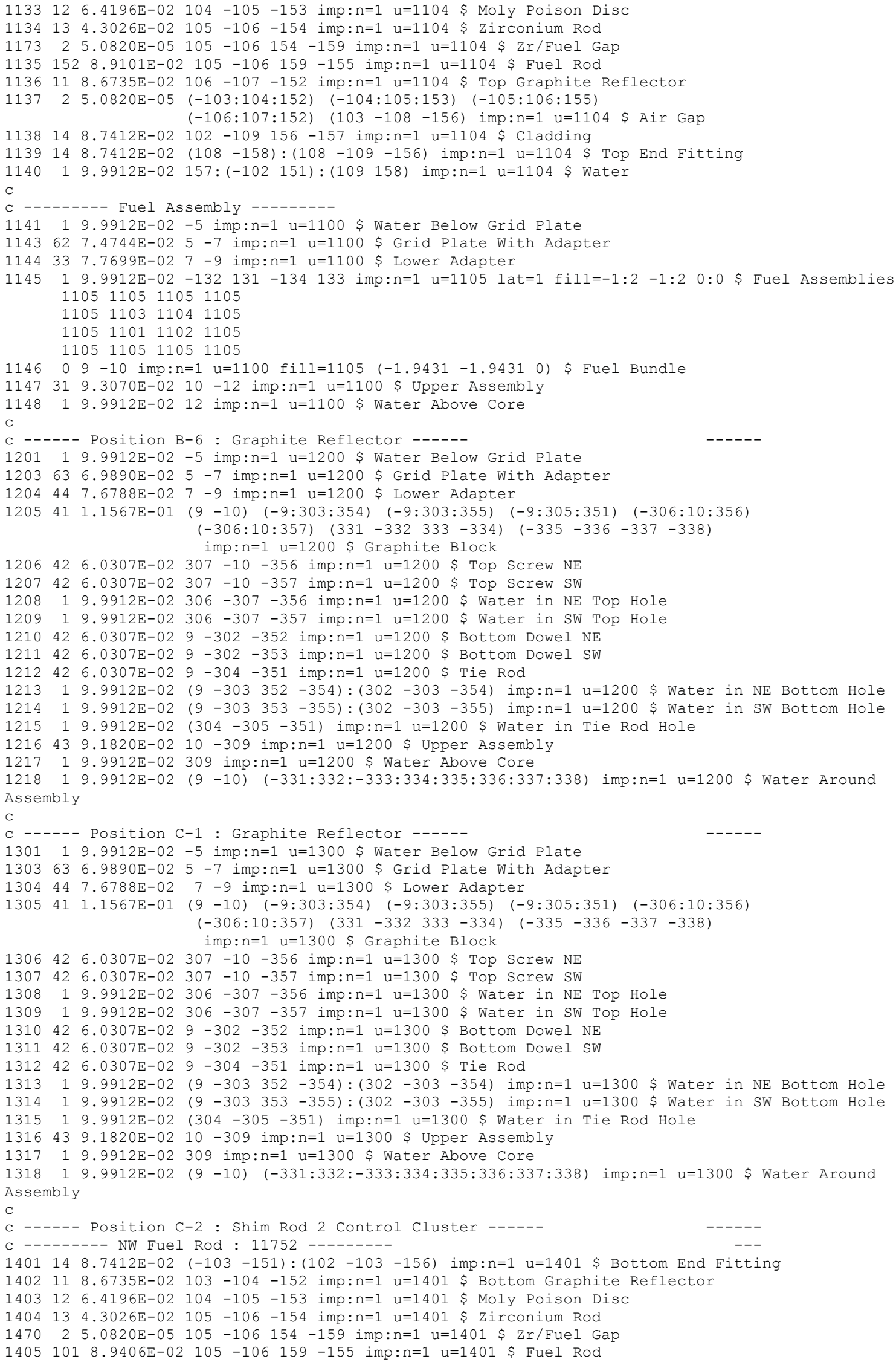




\section{NEA/NSC/DOC(2006)1}

\section{Fundamental - FUND}

\section{NRAD-FUND-RESR-002 CRIT-REAC-COEF}

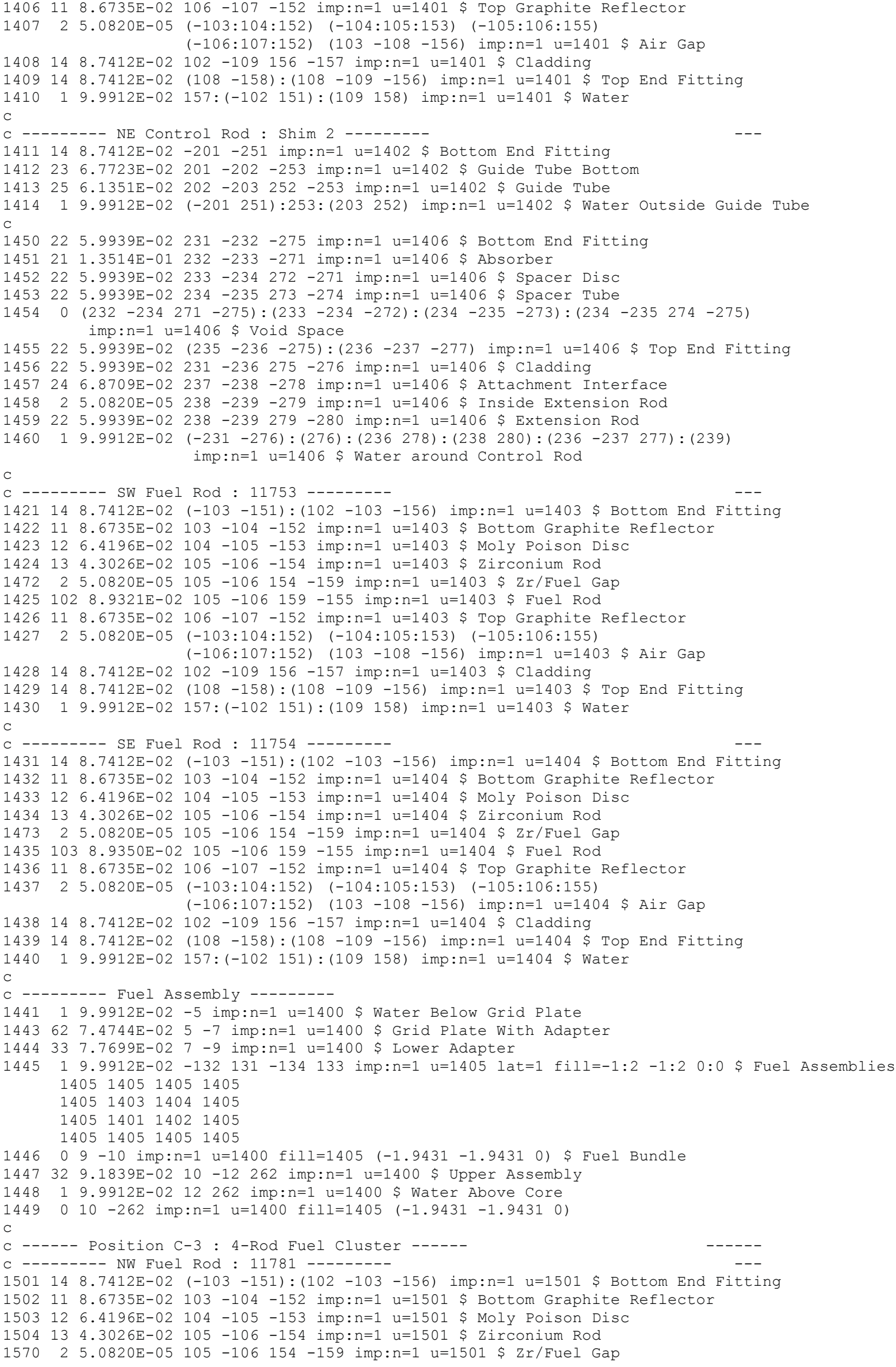




\section{NEA/NSC/DOC(2006)1}

\section{Fundamental - FUND}

\section{NRAD-FUND-RESR-002 CRIT-REAC-COEF}

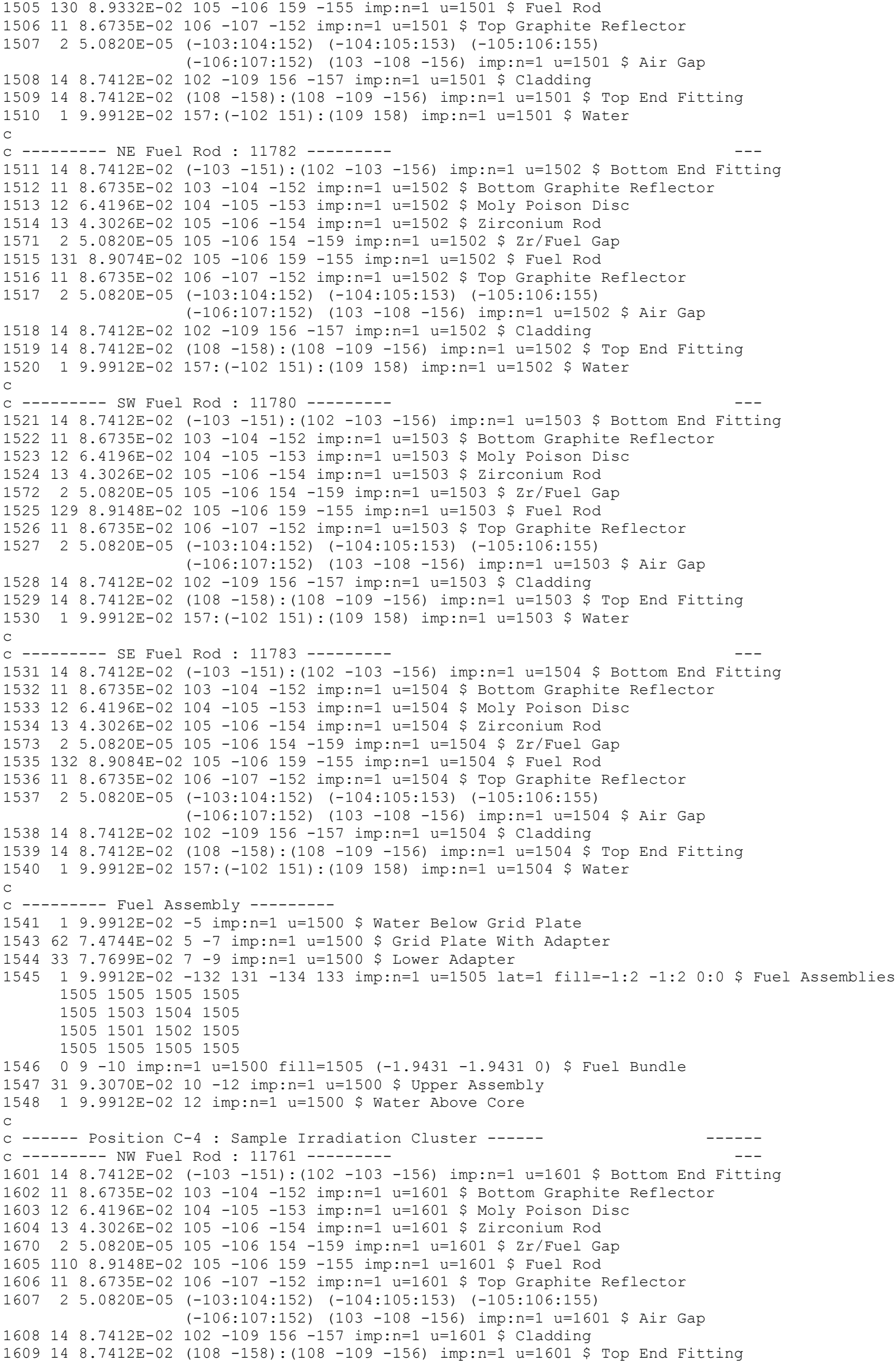




\section{NEA/NSC/DOC(2006)1}

\section{Fundamental - FUND}

\section{NRAD-FUND-RESR-002} CRIT-REAC-COEF

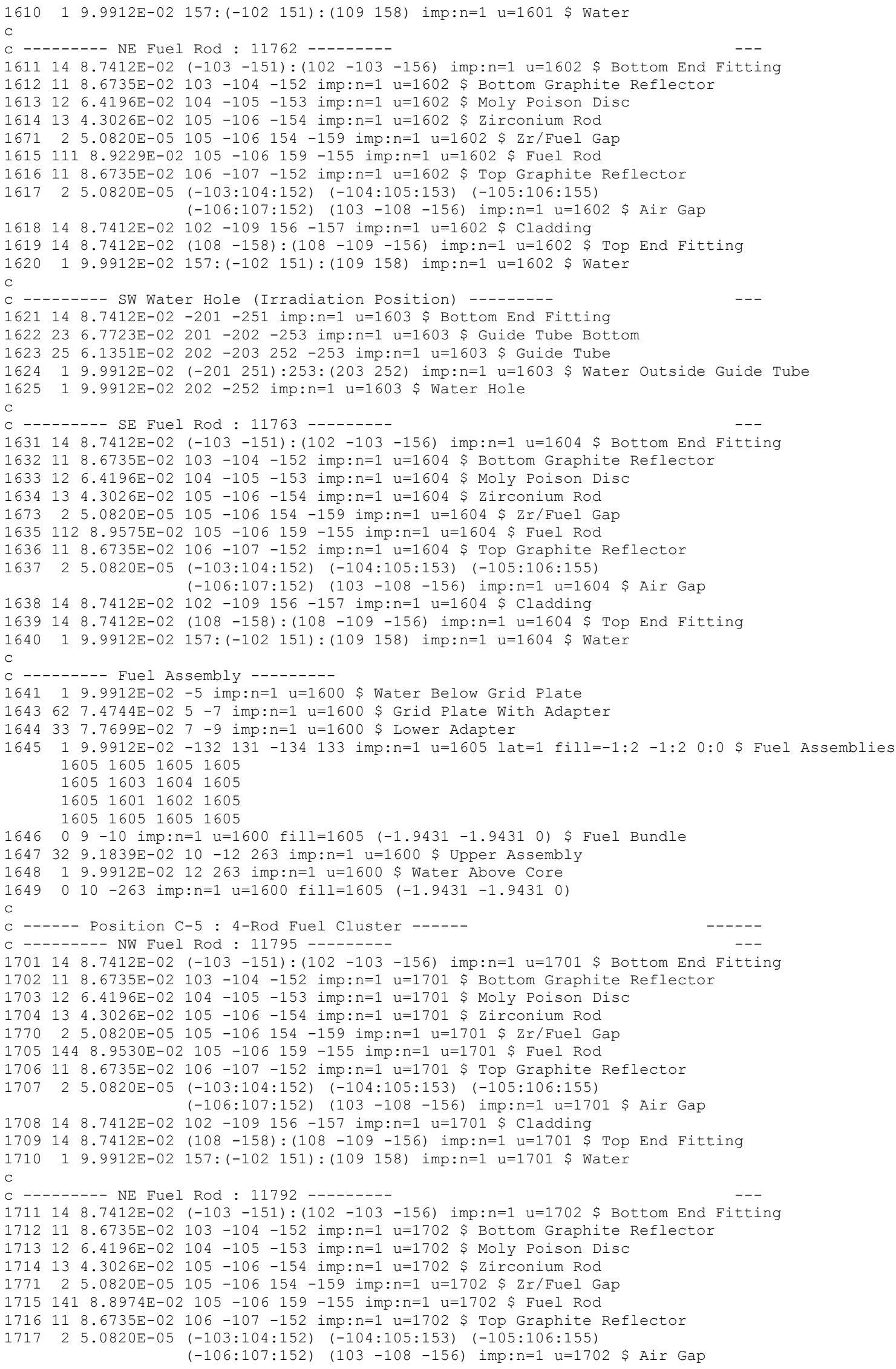




\section{NEA/NSC/DOC(2006)1}

\section{Fundamental - FUND}

\section{NRAD-FUND-RESR-002 CRIT-REAC-COEF}

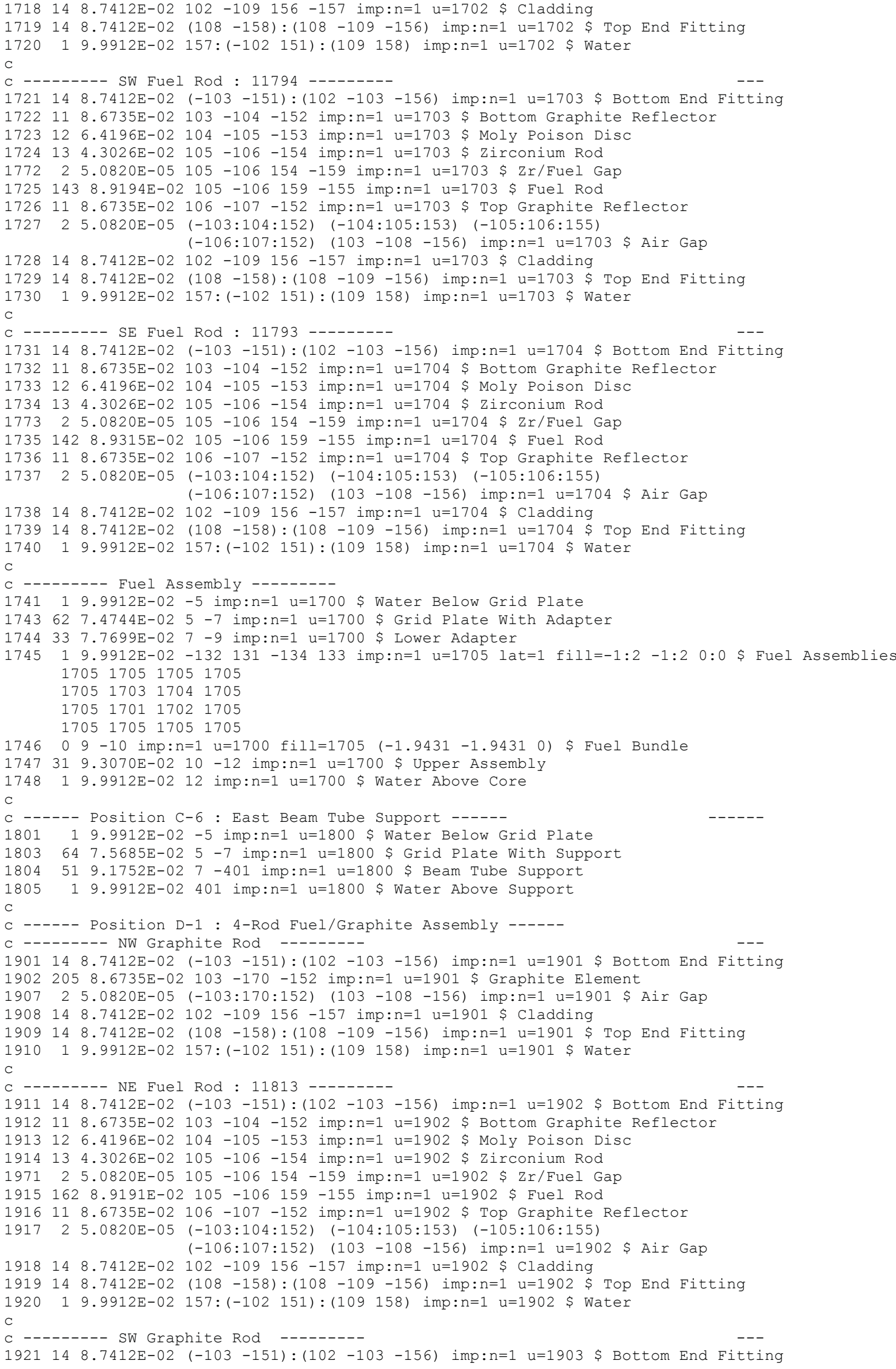




\section{NEA/NSC/DOC(2006)1}

\section{Fundamental - FUND}

\section{NRAD-FUND-RESR-002 CRIT-REAC-COEF}

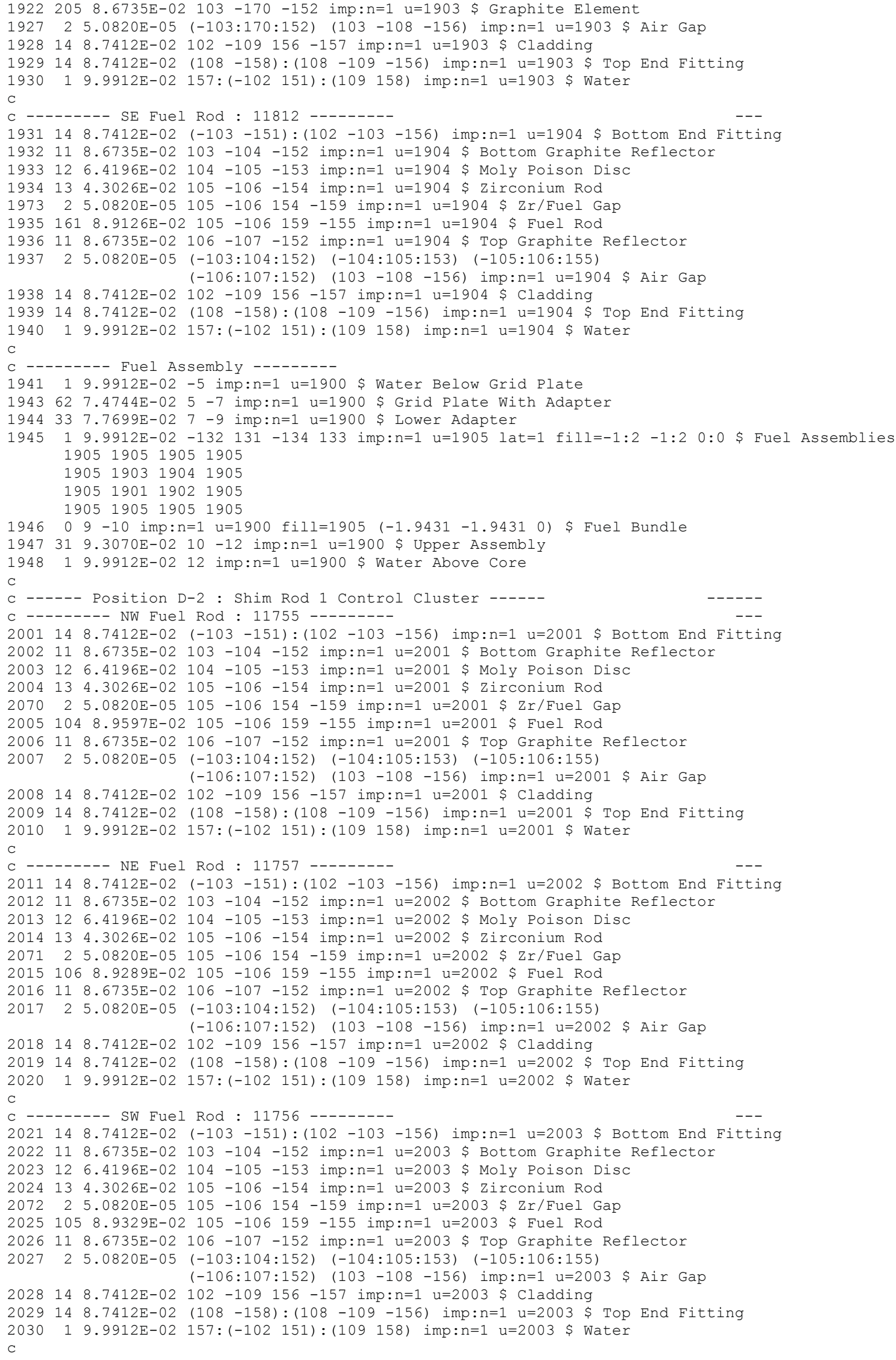




\section{NEA/NSC/DOC(2006)1}

\section{Fundamental - FUND}

\section{NRAD-FUND-RESR-002 CRIT-REAC-COEF}

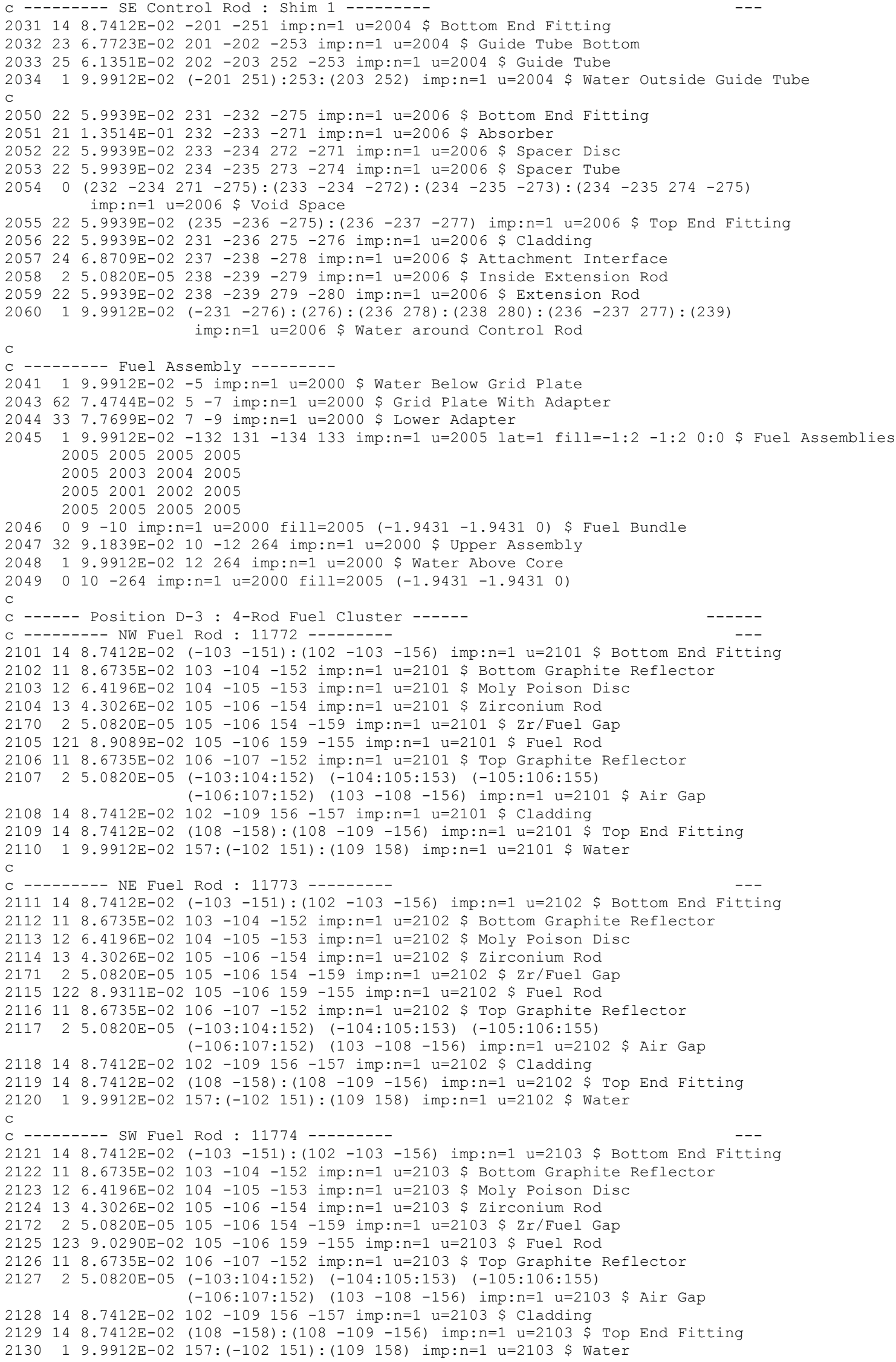




\section{NEA/NSC/DOC(2006)1}

\section{Fundamental - FUND}

\section{NRAD-FUND-RESR-002 CRIT-REAC-COEF}

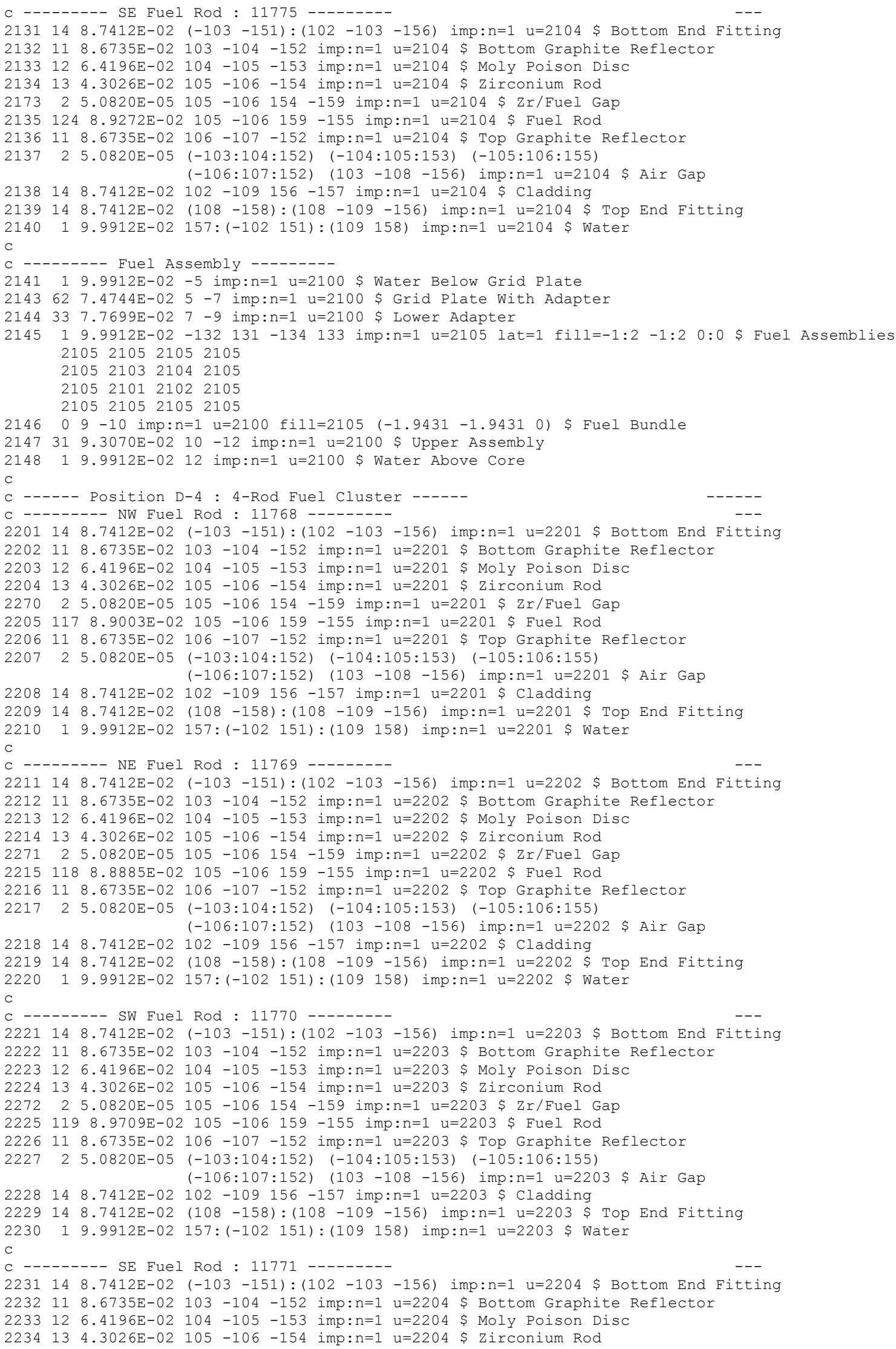




\section{NEA/NSC/DOC(2006)1}

\section{Fundamental - FUND}

\section{NRAD-FUND-RESR-002 CRIT-REAC-COEF}

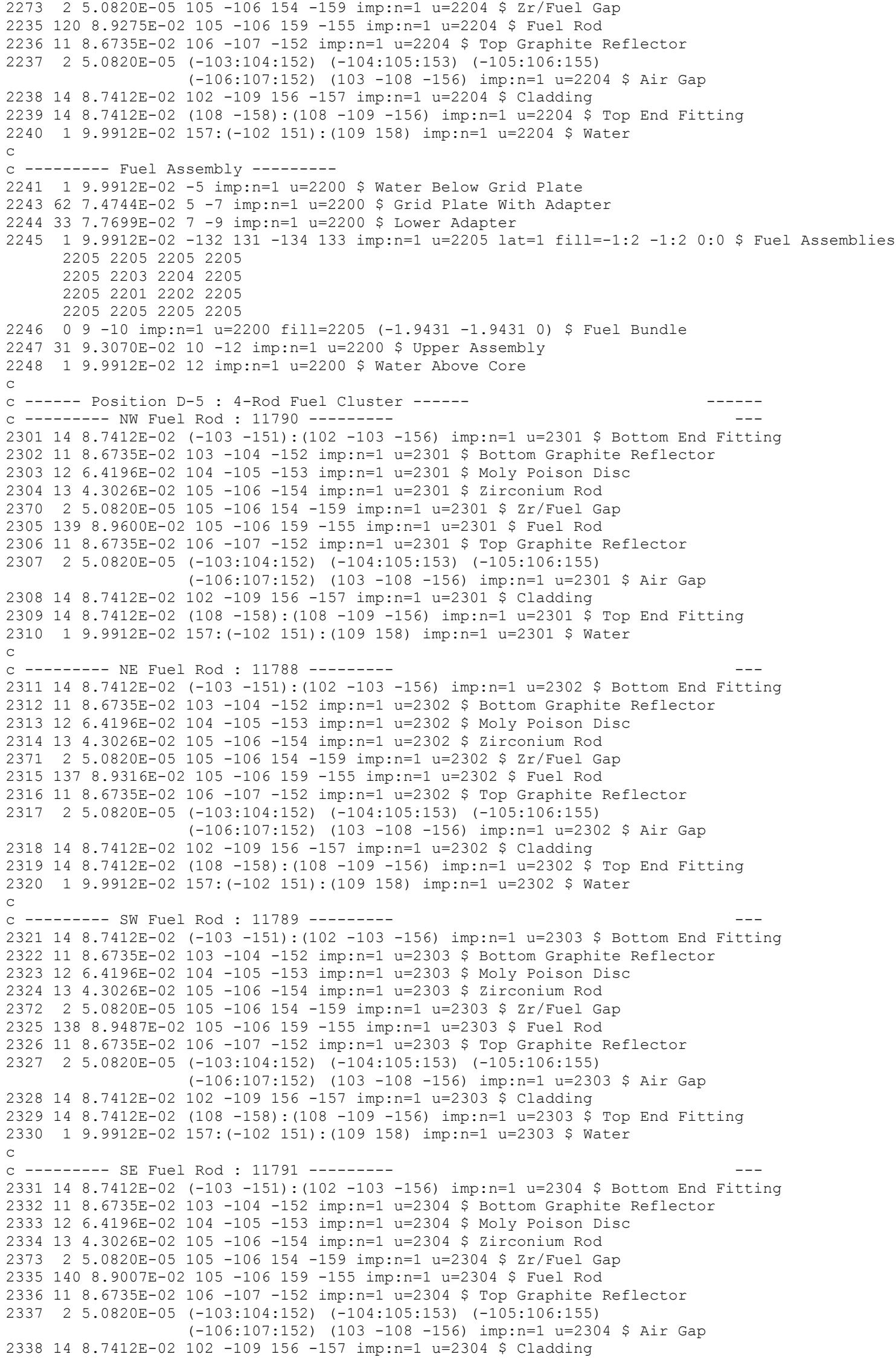




\section{NEA/NSC/DOC(2006)1}

\section{Fundamental - FUND}

\section{NRAD-FUND-RESR-002 CRIT-REAC-COEF}

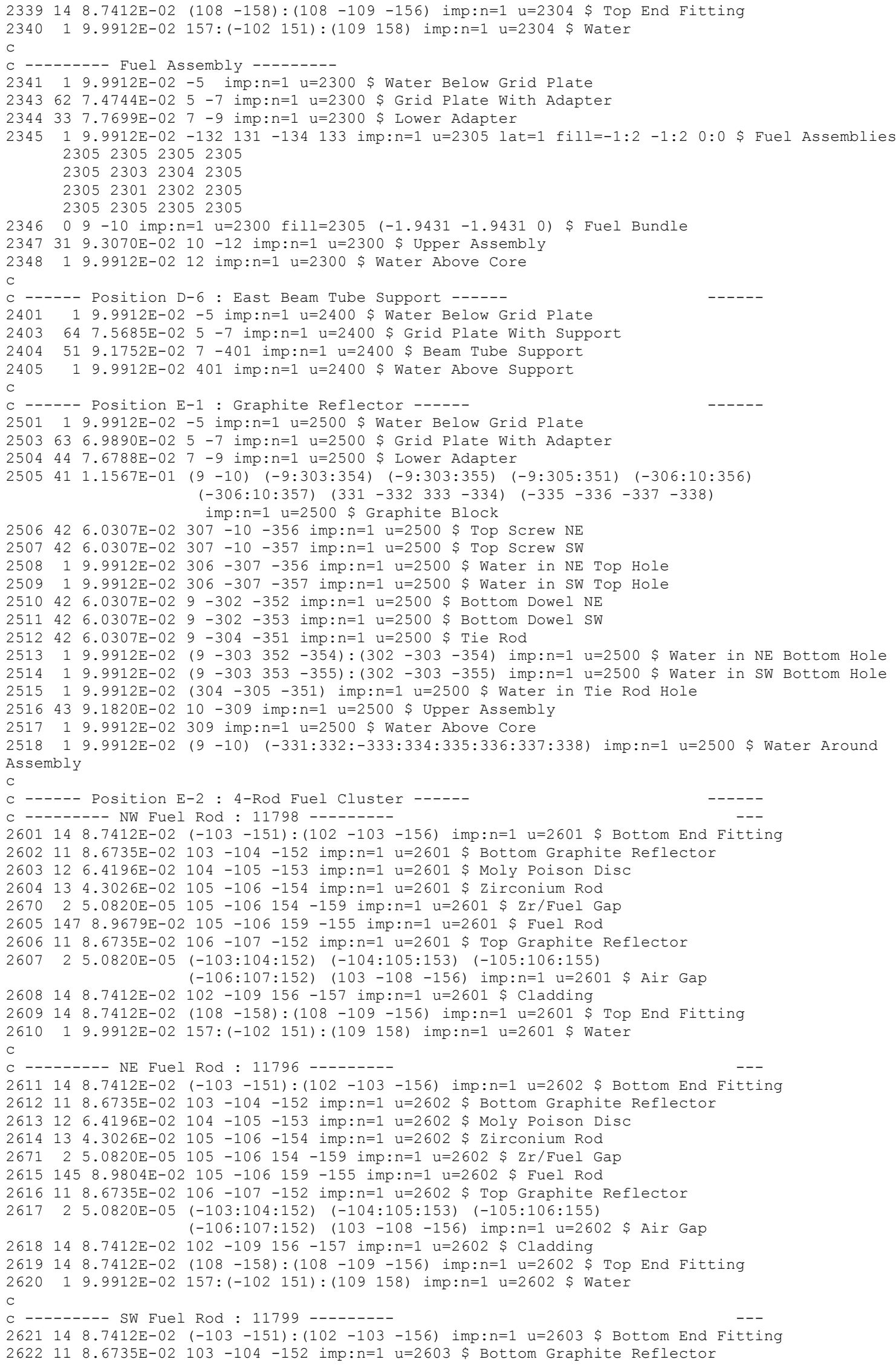




\section{NEA/NSC/DOC(2006)1}

\section{Fundamental - FUND}

\section{NRAD-FUND-RESR-002 CRIT-REAC-COEF}

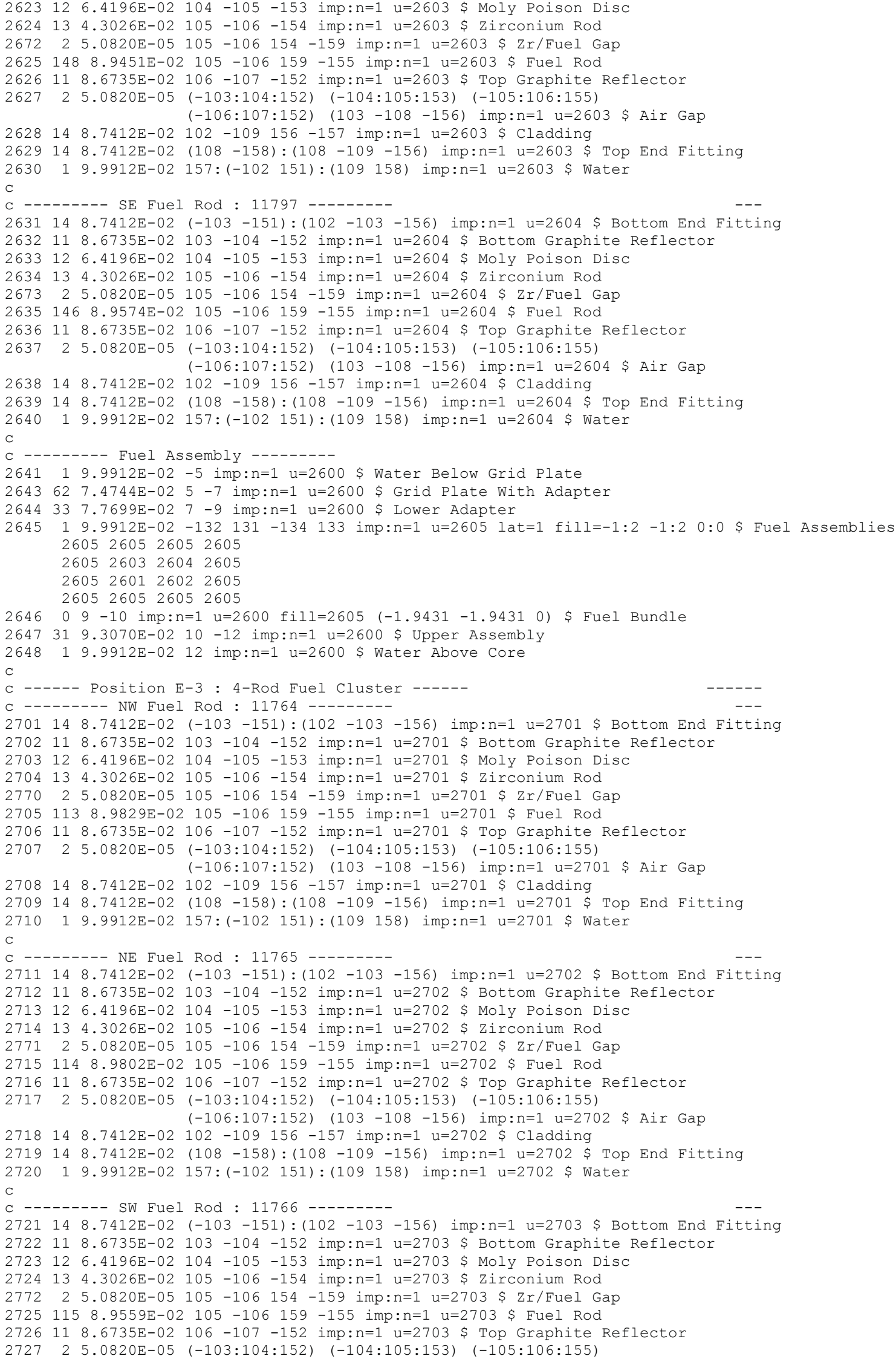




\section{NEA/NSC/DOC(2006)1}

\section{Fundamental - FUND}

\section{NRAD-FUND-RESR-002 CRIT-REAC-COEF}

$(-106: 107: 152) \quad(103-108-156)$ imp:n=1 $u=2703$ \$ Air Gap $2728148.7412 \mathrm{E}-02102-109156-157$ imp:n=1 u=2703 \$ Cladding $2729148.7412 \mathrm{E}-02(108-158):(108-109-156)$ imp:n=1 u=2703 \$ Top End Fitting 27301 9.9912E-02 157:(-102 151):(109 158) imp:n=1 u=2703 \$ Water

$\mathrm{C}$ SE Fuel Rod : $11767-$

$2731148.7412 \mathrm{E}-02$ (-103 -151):(102 -103 -156) imp:n=1 u=2704 \$ Bottom End Fitting

$2732118.6735 \mathrm{E}-02103-104-152$ imp:n=1 u=2704 \$ Bottom Graphite Reflector

$2733126.4196 \mathrm{E}-02104-105-153$ imp: $\mathrm{n}=1 \mathrm{u}=2704$ \$ Moly Poison Disc

273413 4.3026E-02 105 -106 -154 imp:n=1 u=2704 \$ Zirconium Rod

$277325.0820 \mathrm{E}-05105-106154-159$ imp:n=1 u=2704 $\mathrm{Zr} / \mathrm{Fuel}$ Gap

$27351168.9156 \mathrm{E}-02105-106159-155$ imp:n=1 u=2704 \$ Fuel Rod

273611 8.6735E-02 $106-107$-152 imp:n=1 u=2704 \$ Top Graphite Reflector

$273725.0820 \mathrm{E}-05 \quad(-103: 104: 152) \quad(-104: 105: 153) \quad(-105: 106: 155)$

$(-106: 107: 152) \quad(103-108-156)$ imp: $n=1 \quad u=2704$ \$ Air Gap

$2738148.7412 \mathrm{E}-02102-109156-157$ imp:n=1 u=2704 \$ Cladding

$2739148.7412 \mathrm{E}-02(108-158):(108-109-156)$ imp:n=1 u=2704 \$ Top End Fitting

27401 9.9912E-02 157:(-102 151):(109 158) imp:n=1 u=2704 \$ Water

$\mathrm{C}$

C ------- Fuel Assembly

$274119.9912 \mathrm{E}-02-5$ imp:n=1 u=2700 \$ Water Below Grid Plate

$2743627.4744 \mathrm{E}-025-7$ imp:n=1 u=2700 \$ Grid Plate With Adapter

$2744337.7699 \mathrm{E}-027-9$ imp:n=1 u=2700 \$ Lower Adapter

$274519.9912 \mathrm{E}-02-132131-134133$ imp:n=1 u=2705 lat=1 fill=-1:2 -1:2 0:0 \$ Fuel Assemblies $27052705 \quad 2705 \quad 2705$

$27052703 \quad 2704 \quad 2705$

$270527012702 \quad 2705$

$270527052705 \quad 2705$

$274609-10$ imp: $n=1$ u=2700 fill=2705 (-1.9431 -1.9431 0) \$ Fuel Bundle

$2747319.3070 \mathrm{E}-02 \quad 10-12 \mathrm{imp}: \mathrm{n}=1 \mathrm{u}=2700$ S Upper Assembly

$274819.9912 \mathrm{E}-0212$ imp:n=1 u=2700 \$ Water Above Core

C ----- Position E-4 : Regulating Rod Control Cluster ------

C -------- NW Fuel Rod : 11758 -.-------

$2801148.7412 \mathrm{E}-02(-103-151):(102-103-156)$ imp:n=1 u=2801 \$ Bottom End Fitting

$2802118.6735 \mathrm{E}-02103-104-152 \mathrm{imp}: \mathrm{n}=1 \mathrm{u}=2801$ \$ Bottom Graphite Reflector

280312 6.4196E-02 $104-105$-153 imp:n=1 u=2801 \$ Moly Poison Disc

$2804134.3026 \mathrm{E}-02105-106-154$ imp:n=1 u=2801 \$ Zirconium Rod

$287025.0820 \mathrm{E}-05105-106154-159$ imp:n=1 u=2801 \$ Zr/Fuel Gap

$28051078.9626 \mathrm{E}-02105-106159-155$ imp:n=1 u=2801 \$ Fuel Rod

$2806118.6735 \mathrm{E}-02106-107-152$ imp:n=1 u=2801 \$ Top Graphite Reflector

$280725.0820 \mathrm{E}-05(-103: 104: 152) \quad(-104: 105: 153) \quad(-105: 106: 155)$

$(-106: 107: 152) \quad(103-108-156)$ imp:n=1 u=2801 \$ Air Gap

$2808148.7412 \mathrm{E}-02 \quad 102-109156-157$ imp:n=1 u=2801 \$ Cladding

$2809148.7412 \mathrm{E}-02(108-158):(108-109-156)$ imp:n=1 u=2801 \$ Top End Fitting

$281019.9912 \mathrm{E}-02$ 157:(-102 151):(109 158) imp:n=1 u=2801 \$ Water C

C ------- NE Control Rod : Reg

$2811148.7412 \mathrm{E}-02-201-251$ imp:n=1 u=2802 \$ Bottom End Fitting

$2812236.7723 \mathrm{E}-02201-202-253$ imp:n=1 u=2802 \$ Guide Tube Bottom

$2813256.1351 \mathrm{E}-02202-203252$-253 imp:n=1 u=2802 \$ Guide Tube

$281419.9912 \mathrm{E}-02$ (-201 251):253:(203 252) imp:n=1 u=2802 \$ Water Outside Guide Tube

285022 5.9939E-02 231 -232 -275 imp:n=1 u=2806 \$ Bottom End Fitting

285121 1.3514E-01 $232-233-271$ imp:n=1 u=2806 \$ Absorber

285222 5.9939E-02 $233-234272-271$ imp:n=1 u=2806 \$ Spacer Disc

$2853225.9939 \mathrm{E}-02234-235273-274$ imp:n=1 u=2806 \$ Spacer Tube

$28540(232-234 \quad 271-275):\left(\begin{array}{llllll}233 & -234 & -272\end{array}\right):\left(\begin{array}{lllll}234 & -235 & -273\end{array}\right):\left(\begin{array}{lllll}234 & -235 & 274 & -275\end{array}\right)$

imp: $n=1 \quad u=2806$ \$ Void Space

$2855225.9939 \mathrm{E}-02(235-236-275):(236-237-277)$ imp:n=1 u=2806 \$ Top End Fitting

$2856225.9939 \mathrm{E}-02231-236275$-276 imp:n=1 u=2806 \$ Cladding

$2857246.8709 \mathrm{E}-02237-238-278$ imp:n=1 u=2806 \$ Attachment Interface

$285825.0820 \mathrm{E}-05238-239-279$ imp:n=1 u=2806 \$ Inside Extension Rod

285922 5.9939E-02 238 -239 279 -280 imp:n=1 u=2806 \$ Extension Rod

$286019.9912 \mathrm{E}-02(-231-276):(276):(236278):(238$ 280):(236 -237 277):(239)

imp:n=1 $u=2806$ \$ Water around Control Rod

C -------- SW Fuel Rod : 11759 --------

$2821148.7412 \mathrm{E}-02(-103-151):(102-103-156)$ imp:n=1 u=2803 \$ Bottom End Fitting

$2822118.6735 \mathrm{E}-02103-104-152$ imp:n=1 u=2803 \$ Bottom Graphite Reflector

$2823126.4196 \mathrm{E}-02104-105-153$ imp:n=1 u=2803 \$ Moly Poison Disc

$2824134.3026 \mathrm{E}-02105-106$-154 imp:n=1 u=2803 \$ Zirconium Rod

$287225.0820 \mathrm{E}-05105-106154-159$ imp:n=1 u=2803 $\$ \mathrm{Zr} / \mathrm{Fuel}$ Gap

2825108 8.9895E-02 $105-106159$-155 imp:n=1 u=2803 \$ Fuel Rod

282611 8.6735E-02 $106-107-152$ imp:n=1 u=2803 \$ Top Graphite Reflector

$282725.0820 \mathrm{E}-05 \quad(-103: 104: 152) \quad(-104: 105: 153) \quad(-105: 106: 155)$ 


\section{NEA/NSC/DOC(2006)1}

\section{Fundamental - FUND}

\section{NRAD-FUND-RESR-002 CRIT-REAC-COEF}

$(-106: 107: 152) \quad(103-108-156)$ imp: $n=1 \quad u=2803$ \$ Air Gap $2828148.7412 \mathrm{E}-02102-109156-157$ imp:n=1 u=2803 \$ Cladding $2829148.7412 \mathrm{E}-02(108-158):(108-109-156)$ imp:n=1 u=2803 \$ Top End Fitting 28301 9.9912E-02 157:(-102 151):(109 158) imp:n=1 u=2803 \$ Water

$\mathrm{C}$

$2831148.7412 \mathrm{E}-02$ (-103 -151):(102 -103 -156) imp:n=1 u=2804 \$ Bottom End Fitting

$2832118.6735 \mathrm{E}-02103-104-152$ imp:n=1 u=2804 \$ Bottom Graphite Reflector

$2833126.4196 \mathrm{E}-02104-105-153$ imp: $n=1 \mathrm{u}=2804$ \$ Moly Poison Disc

$2834134.3026 \mathrm{E}-02105-106-154$ imp:n=1 u=2804 \$ Zirconium Rod

$287325.0820 \mathrm{E}-05105-106154-159$ imp:n=1 u=2804 $\mathrm{Zr} / \mathrm{Fuel}$ Gap

$28351098.9164 \mathrm{E}-02105-106159-155$ imp:n=1 u=2804 \$ Fuel Rod

$2836118.6735 \mathrm{E}-02106-107-152$ imp:n=1 u=2804 \$ Top Graphite Reflector

$283725.0820 \mathrm{E}-05 \quad(-103: 104: 152) \quad(-104: 105: 153) \quad(-105: 106: 155)$

$(-106: 107: 152) \quad(103-108-156)$ imp: $n=1 \quad u=2804$ \$ Air Gap

$2838148.7412 \mathrm{E}-02102-109156-157$ imp:n=1 u=2804 \$ Cladding

$2839148.7412 \mathrm{E}-02(108-158):(108-109-156)$ imp:n=1 u=2804 \$ Top End Fitting

$284019.9912 \mathrm{E}-02$ 157:(-102 151):(109 158) imp:n=1 u=2804 \$ Water

$\mathrm{C}$

C ------- Fuel Assembly

$284119.9912 \mathrm{E}-02-5$ imp:n=1 u=2800 \$ Water Below Grid Plate

$2843627.4744 \mathrm{E}-025-7$ imp:n=1 u=2800 \$ Grid Plate With Adapter

$2844337.7699 \mathrm{E}-027-9$ imp: $\mathrm{n}=1 \mathrm{u}=2800$ \$ Lower Adapter

$284519.9912 \mathrm{E}-02-132131-134133 \mathrm{imp}: \mathrm{n}=1 \mathrm{u}=2805$ lat=1 fill=-1:2 -1:2 0:0 \$ Fuel Assemblies 2805280528052805

$280528032804 \quad 2805$

$280528012802 \quad 2805$

2805280528052805

$284609-10$ imp: $n=1 \quad u=2800$ fill=2805 (-1.9431 -1.9431 0) \$ Fuel Bundle

$2847329.1839 \mathrm{E}-0210-12262 \mathrm{imp}: \mathrm{n}=1 \mathrm{u}=2800$ \$pper Assembly

$284819.9912 \mathrm{E}-0212262$ imp:n=1 u=2800 \$ Water Above Core

$2849010-262$ imp:n=1 u=2800 fill=2805 (-1.9431 -1.94310$)$ C

C ----- Position E-5 : 4-Rod Fuel Cluster ------

C -------- NW Fuel Rod : 11804 --------

$2901148.7412 \mathrm{E}-02(-103-151):(102-103-156)$ imp:n=1 u=2901 \$ Bottom End Fitting

$2902118.6735 \mathrm{E}-02103-104-152$ imp:n=1 u=2901 \$ Bottom Graphite Reflector

290312 6.4196E-02 $104-105$-153 imp:n=1 u=2901 \$ Moly Poison Disc

290413 4.3026E-02 $105-106$-154 imp:n=1 u=2901 \$ Zirconium Rod

$297025.0820 \mathrm{E}-05105-106154-159$ imp:n=1 u=2901 \$ Zr/Fuel Gap

$29051538.9001 \mathrm{E}-02105-106159-155$ imp:n=1 u=2901 \$ Fuel Rod

290611 8.6735E-02 $106-107$-152 imp:n=1 u=2901 \$ Top Graphite Reflector

$290725.0820 \mathrm{E}-05 \quad(-103: 104: 152) \quad(-104: 105: 153) \quad(-105: 106: 155)$

$(-106: 107: 152) \quad(103-108-156)$ imp:n=1 u=2901 \$ Air Gap

$2908148.7412 \mathrm{E}-02102-109156-157$ imp:n=1 u=2901 \$ Cladding

290914 8.7412E-02 (108-158):(108-109-156) imp:n=1 u=2901 \$ Top End Fitting

$291019.9912 \mathrm{E}-02$ 157:(-102 151):(109 158) imp:n=1 u=2901 \$ Water

C -------- NE Fuel Rod : $11806--------$

$2911148.7412 \mathrm{E}-02$ (-103 -151):(102 -103 -156) imp:n=1 u=2902 \$ Bottom End Fitting

$2912118.6735 \mathrm{E}-02103-104-152$ imp:n=1 u=2902 \$ Bottom Graphite Reflector

291312 6.4196E-02 $104-105$-153 imp:n=1 u=2902 \$ Moly Poison Disc

291413 4.3026E-02 $105-106$-154 imp: $n=1$ u=2902 \$ Zirconium Rod

$297125.0820 \mathrm{E}-05105-106154-159$ imp:n=1 u=2902 \$ Zr/Fuel Gap

$29151558.9409 \mathrm{E}-02105-106159-155$ imp:n=1 u=2902 \$ Fuel Rod

$2916118.6735 \mathrm{E}-02106-107$-152 imp:n=1 u=2902 \$ Top Graphite Reflector

$291725.0820 \mathrm{E}-05 \quad(-103: 104: 152) \quad(-104: 105: 153) \quad(-105: 106: 155)$

$(-106: 107: 152) \quad(103-108-156)$ imp:n=1 u=2902 \$ Air Gap

$2918148.7412 \mathrm{E}-02102-109156-157$ imp:n=1 u=2902 \$ Cladding

291914 8.7412E-02 (108-158):(108-109-156) imp:n=1 u=2902 \$ Top End Fitting

29201 9.9912E-02 157:(-102 151):(109 158) imp:n=1 u=2902 \$ Water C

C -------- SW Fuel Rod : $11805--------$

$2921148.7412 \mathrm{E}-02$ (-103 -151): (102 -103 -156) imp:n=1 u=2903 \$ Bottom End Fitting

$2922118.6735 \mathrm{E}-02103-104-152$ imp:n=1 u=2903 \$ Bottom Graphite Reflector

$2923126.4196 \mathrm{E}-02104-105-153$ imp:n=1 u=2903 \$ Moly Poison Disc

292413 4.3026E-02 105 -106 -154 imp: $=1$ u=2903 \$ Zirconium Rod

$297225.0820 \mathrm{E}-05105-106154-159$ imp:n=1 u=2903 \$ Zr/Fuel Gap

$29251548.9470 \mathrm{E}-02105-106159-155$ imp:n=1 u=2903 \$ Fuel Rod

292611 8.6735E-02 $106-107-152$ imp:n=1 u=2903 \$ Top Graphite Reflector

$292725.0820 \mathrm{E}-05 \quad(-103: 104: 152) \quad(-104: 105: 153) \quad(-105: 106: 155)$

$(-106: 107: 152) \quad(103-108-156)$ imp: $n=1$ u=2903 \$ Air Gap

$2928148.7412 \mathrm{E}-02102-109156-157$ imp:n=1 u=2903 \$ Cladding

$2929148.7412 \mathrm{E}-02(108-158):(108-109-156)$ imp:n=1 u=2903 \$ Top End Fitting

29301 9.9912E-02 157:(-102 151):(109 158) imp:n=1 u=2903 \$ Water

C 


\section{NEA/NSC/DOC(2006)1}

\section{Fundamental - FUND}

\section{NRAD-FUND-RESR-002 CRIT-REAC-COEF}

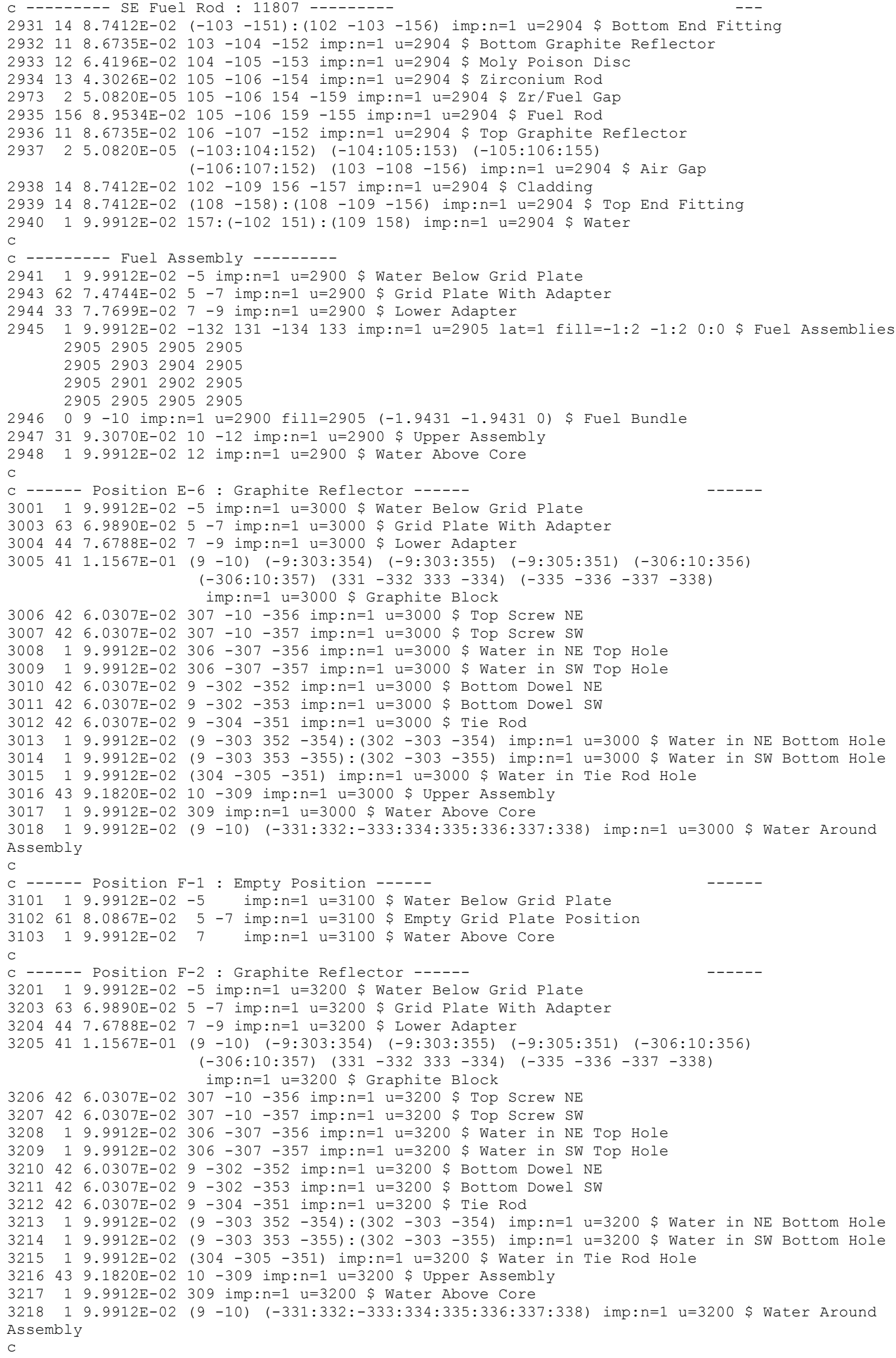




\section{NEA/NSC/DOC(2006)1}

\section{Fundamental - FUND}

\section{NRAD-FUND-RESR-002 CRIT-REAC-COEF}

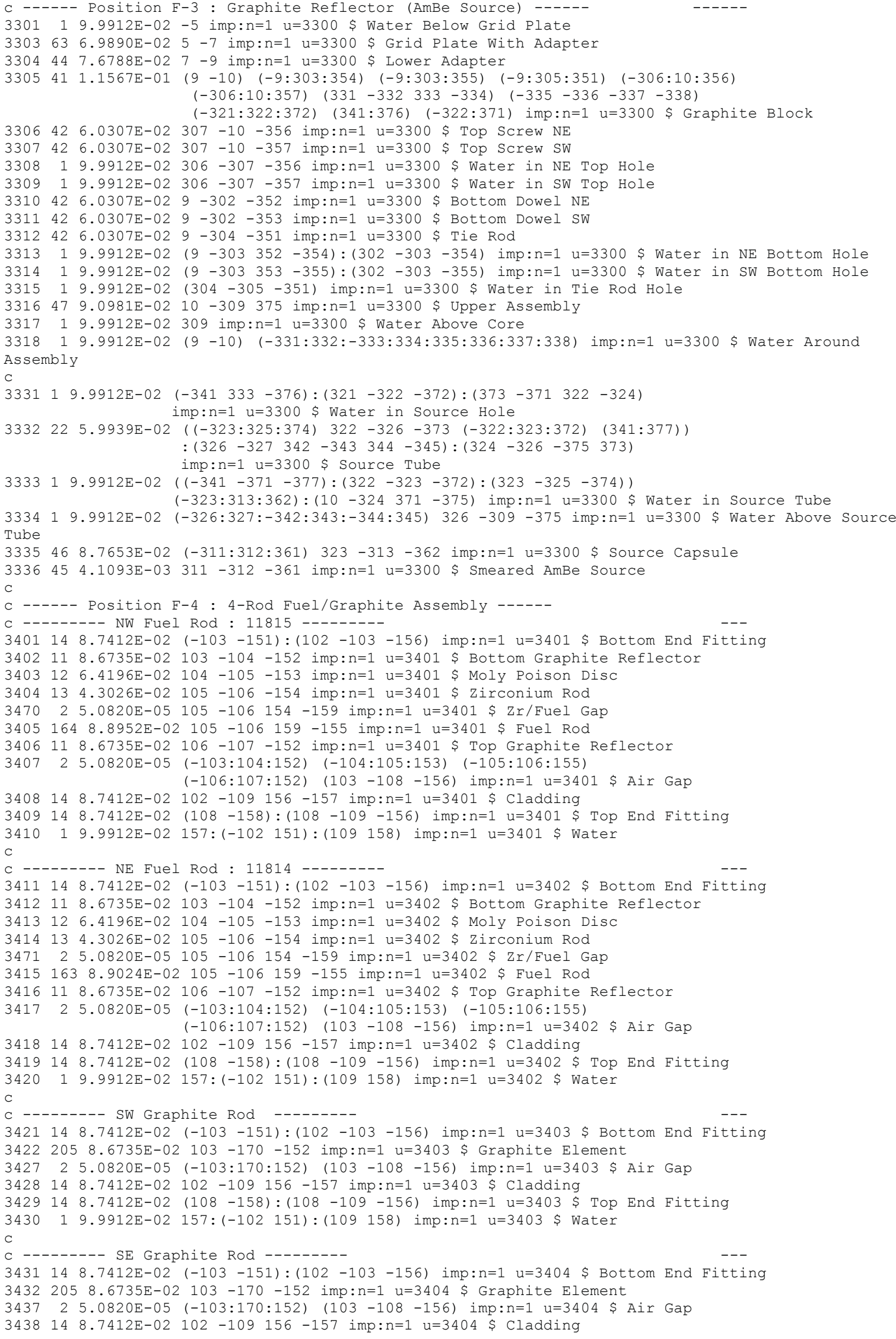




\section{NEA/NSC/DOC(2006)1}

\section{Fundamental - FUND}

\section{NRAD-FUND-RESR-002 CRIT-REAC-COEF}

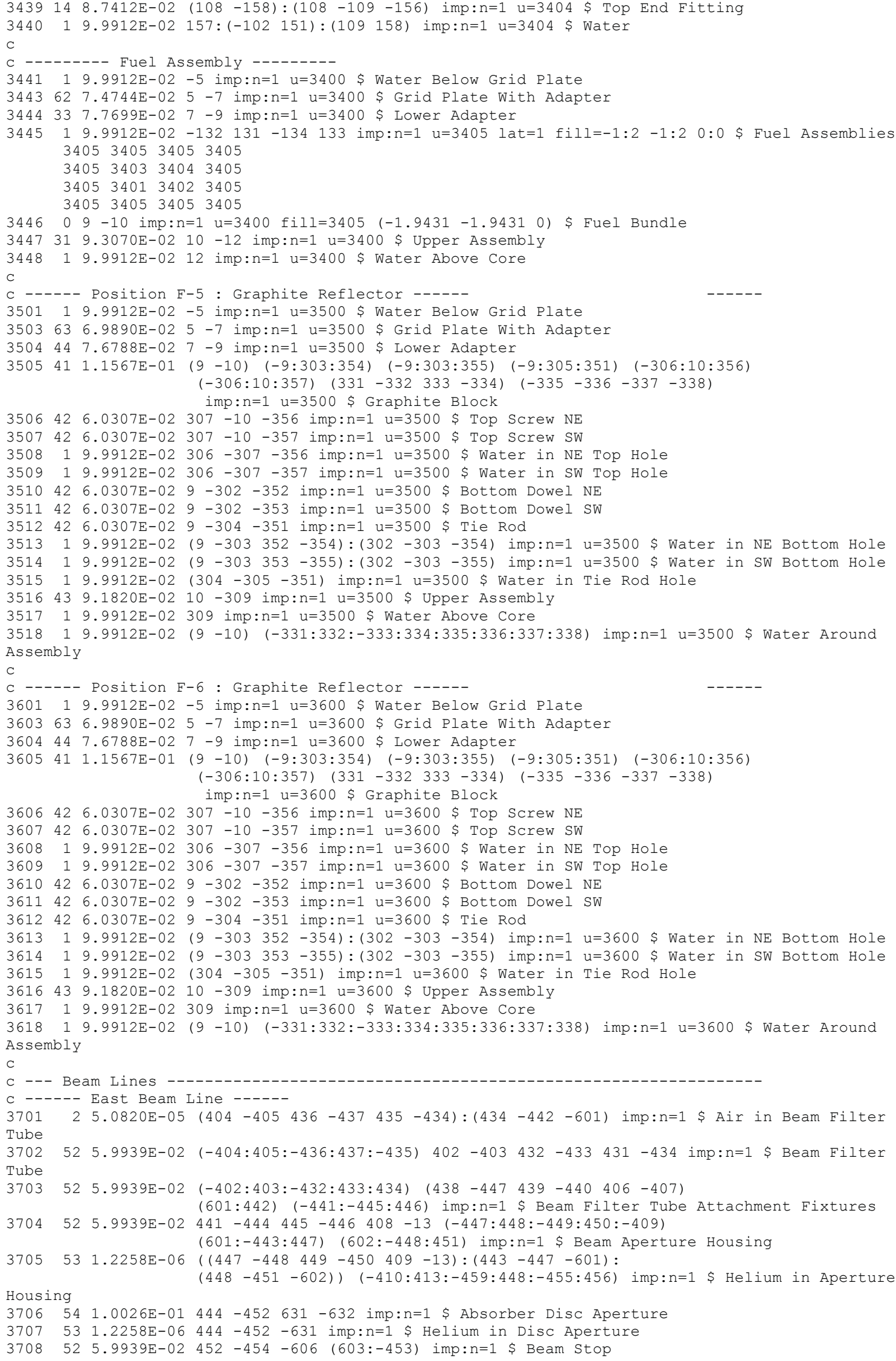




\section{NEA/NSC/DOC(2006)1}

\section{Fundamental - FUND}

\section{NRAD-FUND-RESR-002 \\ CRIT-REAC-COEF}

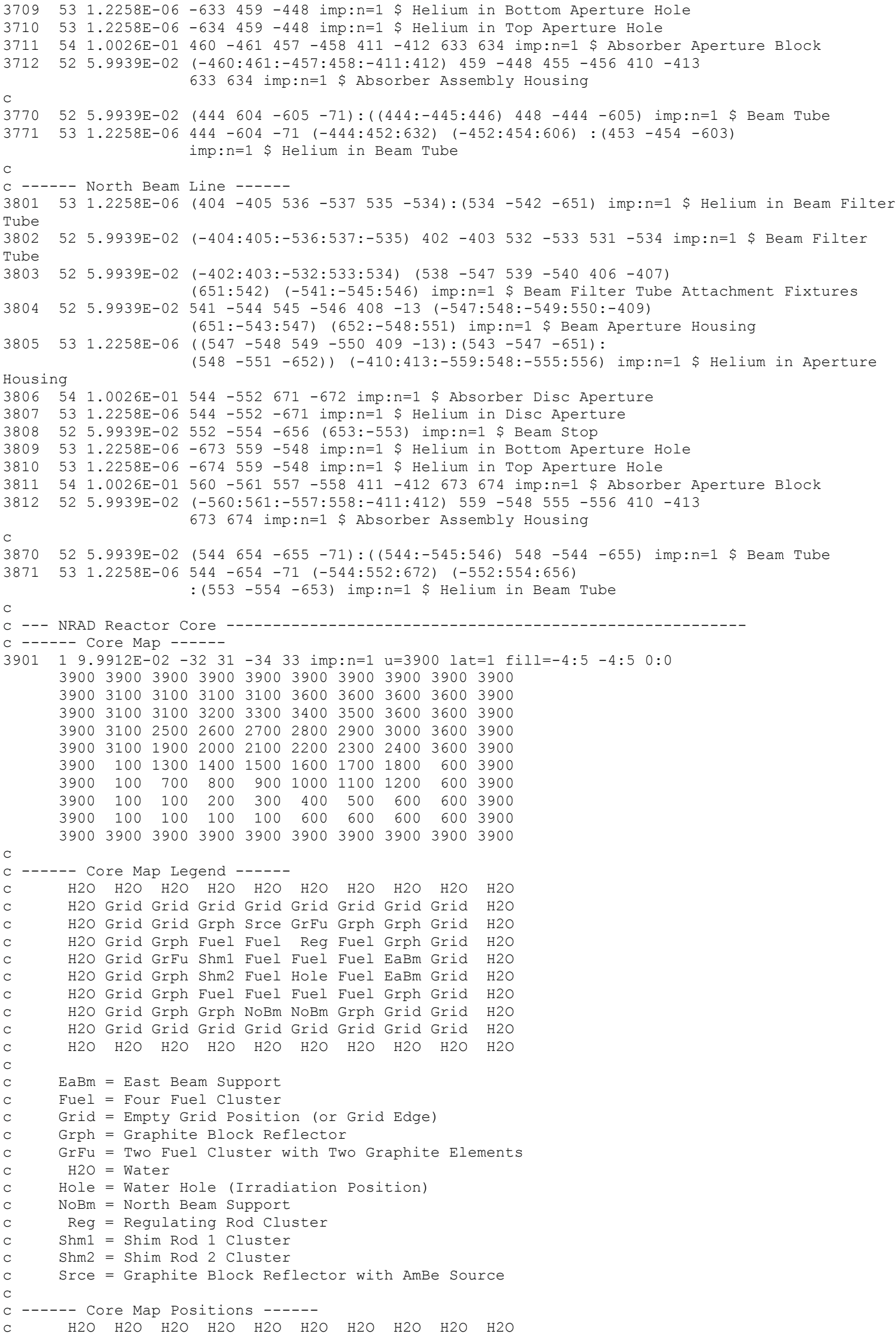




\section{NEA/NSC/DOC(2006)1}

\section{Fundamental - FUND}

\section{NRAD-FUND-RESR-002 \\ CRIT-REAC-COEF}

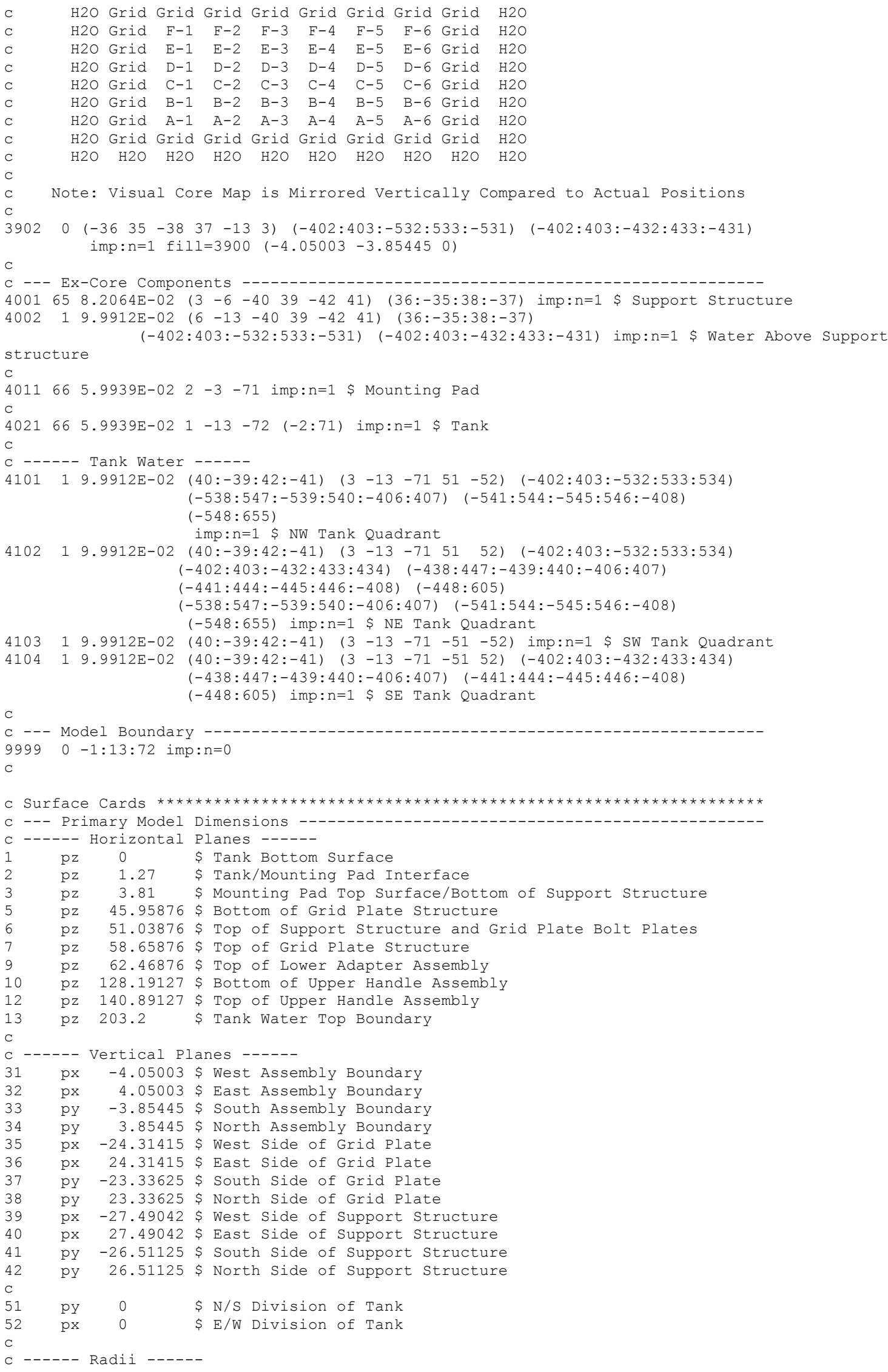


NEA/NSC/DOC(2006)1

Fundamental - FUND

NRAD-FUND-RESR-002

CRIT-REAC-COEF

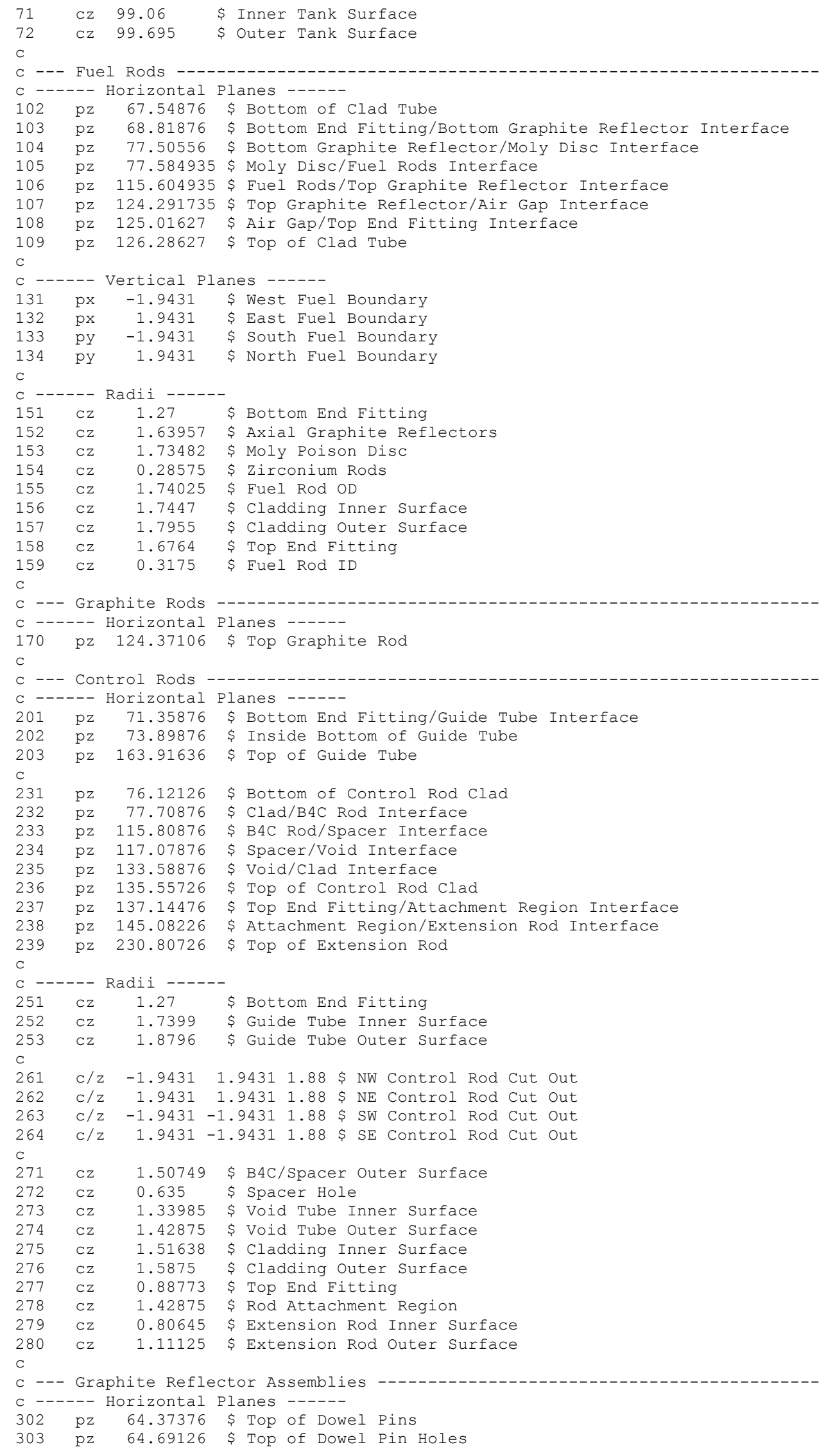


NEA/NSC/DOC(2006)1

Fundamental - FUND

NRAD-FUND-RESR-002

CRIT-REAC-COEF

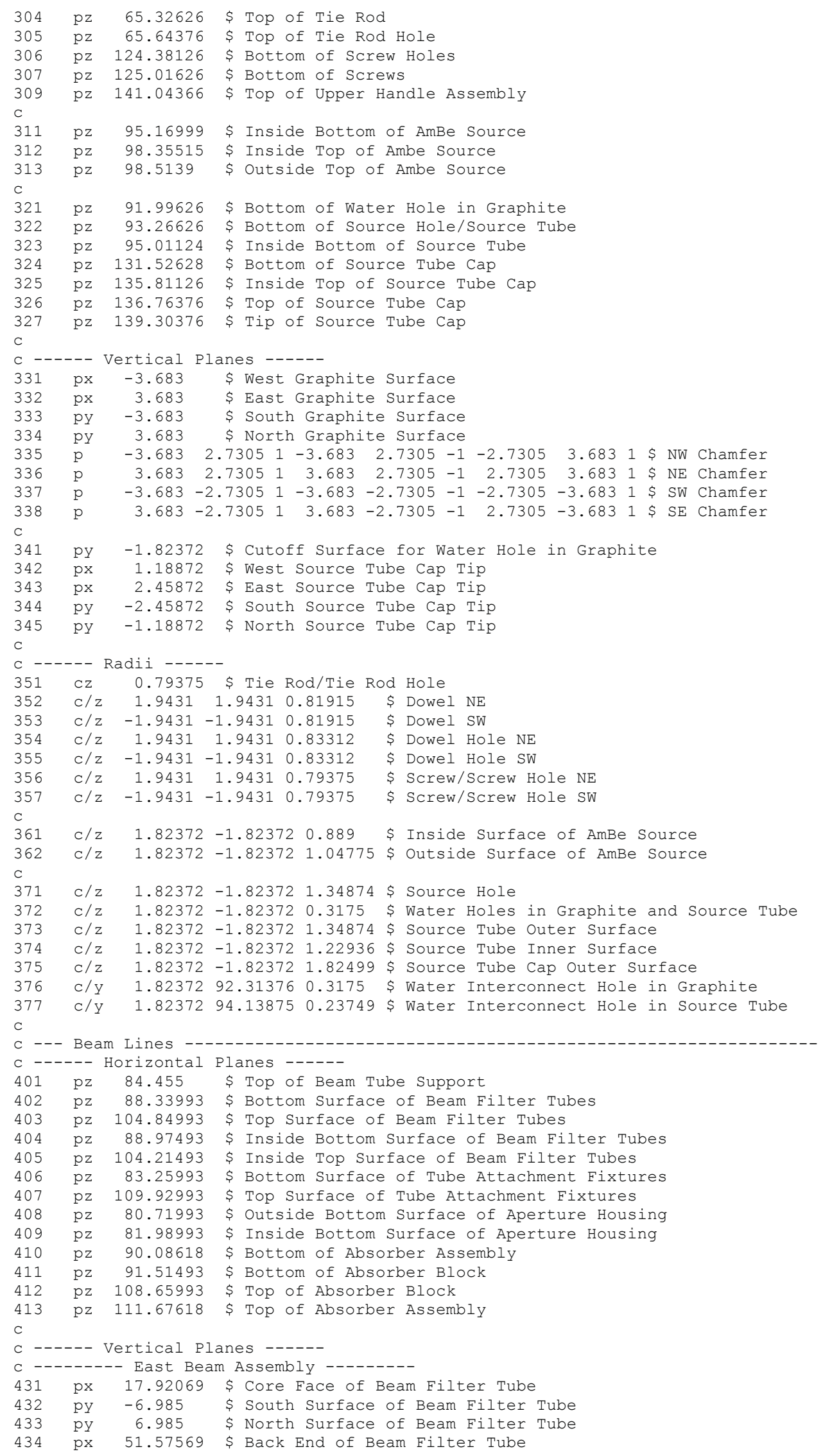


NEA/NSC/DOC(2006)1

\section{Fundamental - FUND}

\section{NRAD-FUND-RESR-002} CRIT-REAC-COEF

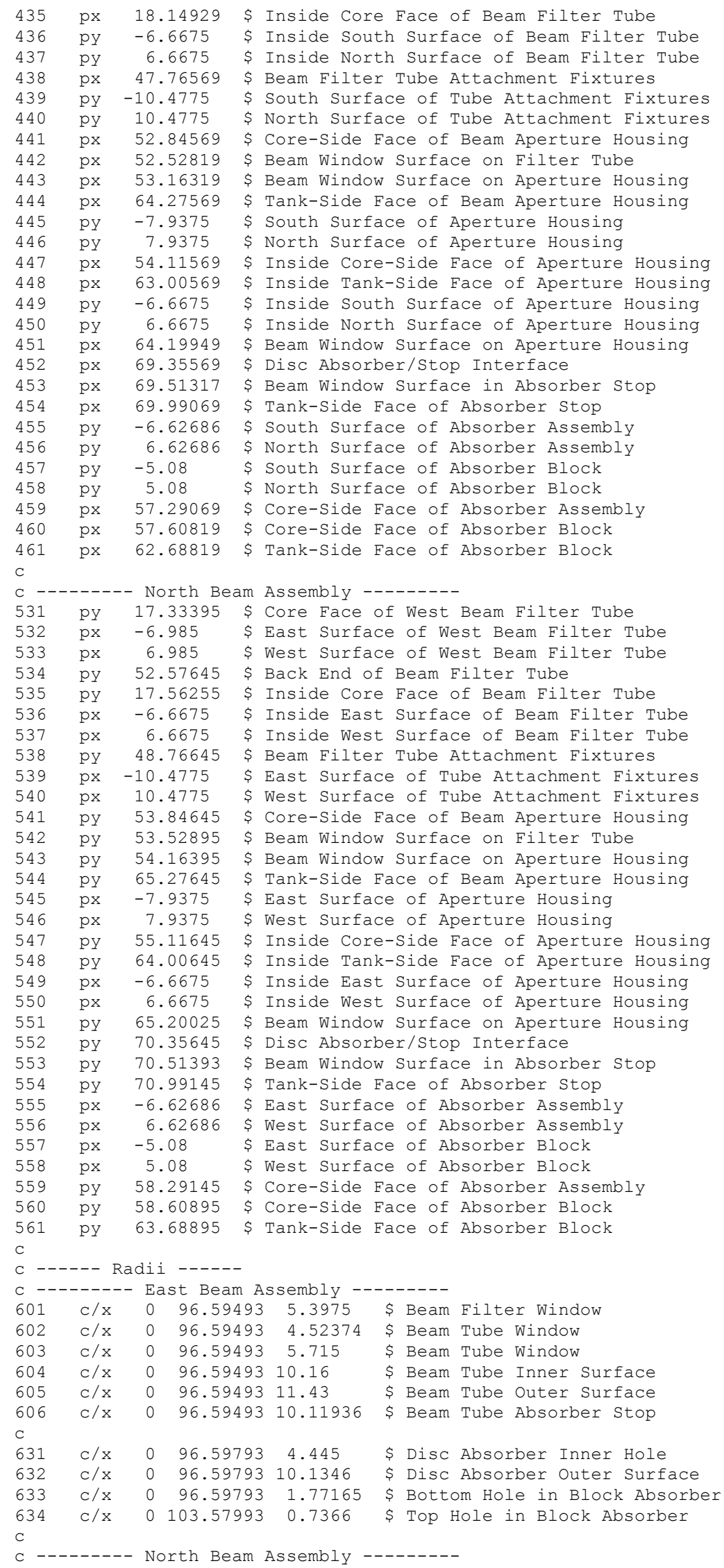


NEA/NSC/DOC(2006)1

\section{Fundamental - FUND}

\section{NRAD-FUND-RESR-002 \\ CRIT-REAC-COEF}

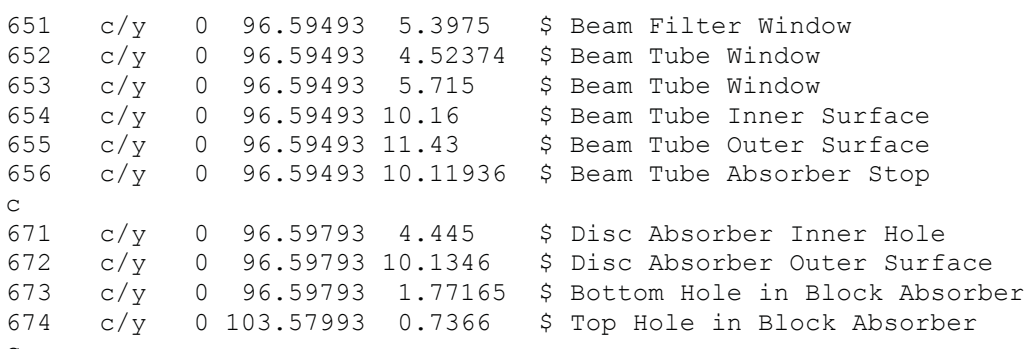

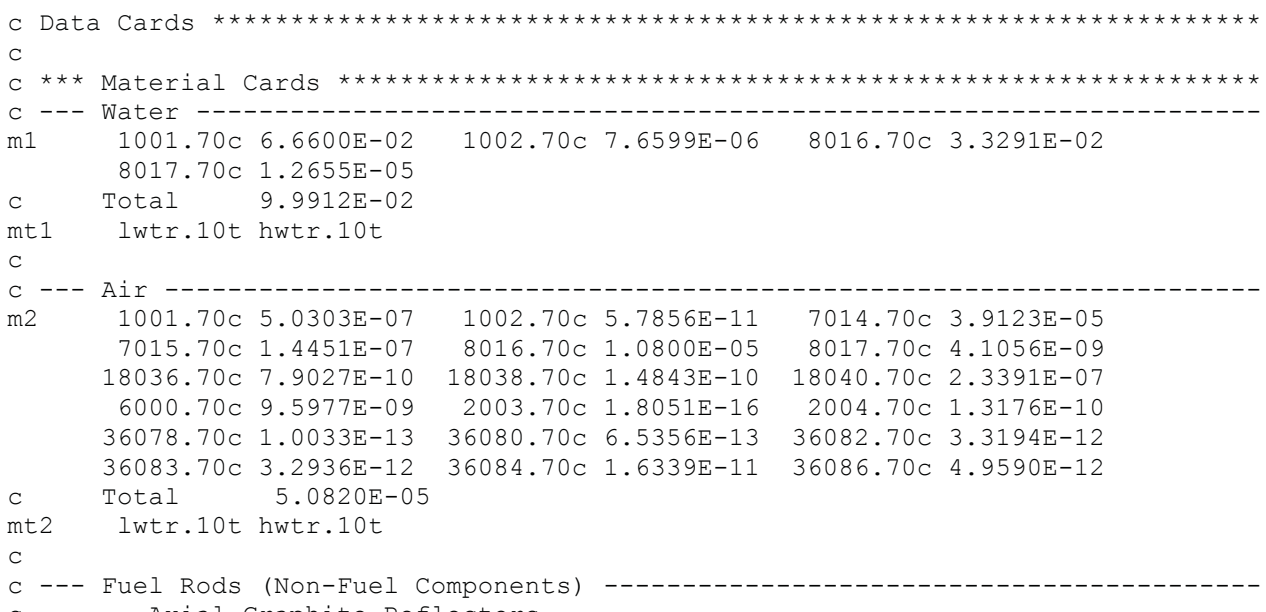

m11 3006.70c 2.8481E-10 3007.70 3.4676E-09 $5010.70 \mathrm{C} \quad 6.7120 \mathrm{E}-09 \quad 5011.70 \mathrm{C} \quad 2.7016 \mathrm{E}-08 \quad 6000.70 \mathrm{C} \quad 8.6734 \mathrm{E}-02$ $9019.70 \mathrm{C} 2.7419 \mathrm{E}-09 \quad 11023.70 \mathrm{C} \quad 1.1329 \mathrm{E}-09 \quad 12024.70 \mathrm{C} \quad 8.4647 \mathrm{E}-10$ $12025.70 \mathrm{C} \quad 1.0716 \mathrm{E}-10 \quad 12026.70 \mathrm{C} \quad 1.1798 \mathrm{E}-10 \quad 13027.70 \mathrm{C} \quad 9.6531 \mathrm{E}-10$ $14028.70 \mathrm{C} 2.5659 \mathrm{E}-08 \quad 14029.70 \mathrm{C} \quad 1.3029 \mathrm{E}-09 \quad 14030.70 \mathrm{c} \quad 8.5889 \mathrm{E}-10$ $15031.70 \mathrm{C} \quad 1.6818 \mathrm{E}-09 \quad 16032.70 \mathrm{C} \quad 2.8372 \mathrm{E}-08 \quad 16033.70 \mathrm{C} \quad 2.2714 \mathrm{E}-10$ $16034.70 \mathrm{C} \quad 1.2822 \mathrm{E}-09 \quad 16036.70 \mathrm{C} \quad 5.9774 \mathrm{E}-12 \quad 17035.70 \mathrm{C} \quad 5.3445 \mathrm{E}-09$ $17037.70 \mathrm{C} 1.7082 \mathrm{E}-09 \quad 19039.70 \mathrm{C} \quad 1.2425 \mathrm{E}-09 \quad 19040.70 \mathrm{C} \quad 1.5588 \mathrm{E}-13$ $19041.70 \mathrm{C} \quad 8.9667 \mathrm{E}-11 \quad 20040.70 \mathrm{C} \quad 6.2999 \mathrm{E}-10 \quad 20042.70 \mathrm{C} \quad 4.2047 \mathrm{E}-12$ $20043.70 \mathrm{C} \quad 8.7733 \mathrm{E}-13 \quad 20044.70 \mathrm{C} \quad 1.3556 \mathrm{E}-11 \quad 20046.70 \mathrm{C} \quad 2.5995 \mathrm{E}-14$ $20048.70 \mathrm{C} 1.2153 \mathrm{E}-12 \quad 21045.70 \mathrm{C} \quad 1.1587 \mathrm{E}-10 \quad 22046.70 \mathrm{C} \quad 8.9756 \mathrm{E}-12$ $22047.70 \mathrm{C} 8.0944 \mathrm{E}-12 \quad 22048.70 \mathrm{C} \quad 8.0204 \mathrm{E}-11 \quad 22049.70 \mathrm{C} \quad 5.8858 \mathrm{E}-12$ $22050.70 \mathrm{C} \quad 5.6356 \mathrm{E}-12 \quad 23000.70 \mathrm{C} \quad 1.0226 \mathrm{E}-10 \quad 24050.70 \mathrm{C} \quad 2.1765 \mathrm{E}-10$ $24052.70 \mathrm{C} \quad 4.1971 \mathrm{E}-09 \quad 24053.70 \mathrm{C} \quad 4.7592 \mathrm{E}-10 \quad 24054.70 \mathrm{C} \quad 1.1847 \mathrm{E}-10$ $25055.70 \mathrm{C} \quad 9.4818 \mathrm{E}-11 \quad 26054.70 \mathrm{C} \quad 5.4519 \mathrm{E}-12 \quad 26056.70 \mathrm{C} \quad 8.5583 \mathrm{E}-11$ $26057.70 \mathrm{C} \quad 1.9765 \mathrm{E}-12 \quad 26058.70 \mathrm{C} \quad 2.6303 \mathrm{E}-13 \quad 27059.70 \mathrm{C} \quad 8.8390 \mathrm{E}-11$ $28058.70 \mathrm{C} \quad 6.0423 \mathrm{E}-11 \quad 28060.70 \mathrm{C} \quad 2.3275 \mathrm{E}-11 \quad 28061.70 \mathrm{C} \quad 1.0117 \mathrm{E}-12$ $28062.70 \mathrm{C} \quad 3.2259 \mathrm{E}-12 \quad 28064.70 \mathrm{C} \quad 8.2153 \mathrm{E}-13 \quad 29063.70 \mathrm{C} \quad 2.8351 \mathrm{E}-10$ $29065.70 \mathrm{C} 1.2636 \mathrm{E}-10 \quad 30000.70 \mathrm{C} \quad 3.9831 \mathrm{E}-10 \quad 31069.70 \mathrm{c} \quad 4.4908 \mathrm{E}-11$

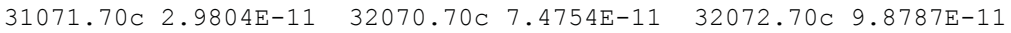
$32073.70 \mathrm{C} 2.7728 \mathrm{E}-11 \quad 32074.70 \mathrm{C} \quad 1.3014 \mathrm{E}-10 \quad 32076.70 \mathrm{C} \quad 2.7297 \mathrm{E}-11$ $33075.70 \mathrm{C} \quad 3.4764 \mathrm{E}-10 \quad 34074.70 \mathrm{C} \quad 2.9357 \mathrm{E}-12 \quad 34076.70 \mathrm{C} \quad 3.0908 \mathrm{E}-11$ $34077.70 \mathrm{C} 2.5168 \mathrm{E}-11 \quad 34078.70 \mathrm{C} \quad 7.8407 \mathrm{E}-11 \quad 34080.70 \mathrm{C} \quad 1.6364 \mathrm{E}-10$ $34082.70 \mathrm{C} \quad 2.8797 \mathrm{E}-11 \quad 35079.70 \mathrm{C} \quad 3.3046 \mathrm{E}-10 \quad 35081.70 \mathrm{c} \quad 3.2146 \mathrm{E}-10$ $37085.70 \mathrm{C} 2.1993 \mathrm{E}-10 \quad 37087.70 \mathrm{C} \quad 8.4810 \mathrm{E}-11 \quad 38084.70 \mathrm{C} \quad 1.6646 \mathrm{E}-12$ $38086.70 \mathrm{C} 2.9309 \mathrm{E}-11 \quad 38087.70 \mathrm{C} \quad 2.0808 \mathrm{E}-11 \quad 38088.70 \mathrm{C} \quad 2.4547 \mathrm{E}-10$ $39089.70 \mathrm{C} \quad 2.9296 \mathrm{E}-10 \quad 40090.70 \mathrm{C} \quad 1.4690 \mathrm{E}-10 \quad 40091.70 \mathrm{C} \quad 3.2034 \mathrm{E}-11$ $40092.70 \mathrm{C} \quad 4.8965 \mathrm{E}-11 \quad 40094.70 \mathrm{C} \quad 4.9622 \mathrm{E}-11$ $41093.70 \mathrm{C} \quad 2.8034 \mathrm{E}-10 \quad 42092.70 \mathrm{C} \quad 4.0287 \mathrm{E}-11$ $42095.70 \mathrm{C} \quad 4.3219 \mathrm{E}-11 \quad 42096.70 \mathrm{C} \quad 4.5283 \mathrm{E}-11$ $42098.70 \mathrm{C} \quad 6.5508 \mathrm{E}-11 \quad 42100.70 \mathrm{C} \quad 2.6143 \mathrm{E}-11$ $44098.70 \mathrm{C} \quad 4.8190 \mathrm{E}-12 \quad 44099.70 \mathrm{C} \quad 3.2882 \mathrm{E}-11$ $44101.70 \mathrm{C} 4.3963 \mathrm{E}-11 \quad 44102.70 \mathrm{C} 8.1304 \mathrm{E}-11$ $45103.70 \mathrm{C} \quad 5.0620 \mathrm{E}-11 \quad 46102.70 \mathrm{C} \quad 2.4964 \mathrm{E}-12$ $46105.70 \mathrm{C} \quad 5.4651 \mathrm{E}-11 \quad 46106.70 \mathrm{C} \quad 6.6888 \mathrm{E}-11$ $46110.70 \mathrm{C} 2.8684 \mathrm{E}-11 \quad 47107.70 \mathrm{C} \quad 1.2517 \mathrm{E}-10$ $48106.70 \mathrm{C} 2.8963 \mathrm{E}-12 \quad 48108.70 \mathrm{C} 2.0621 \mathrm{E}-12$ $48111.70 \mathrm{C} \quad 2.9658 \mathrm{E}-11 \quad 48112.70 \mathrm{C}$ 5.5910E-11 $48114.70 \mathrm{C} \quad 6.6568 \mathrm{E}-11 \quad 48116.70 \mathrm{C} \quad 1.7354 \mathrm{E}-11$ $49115.70 \mathrm{C} \quad 2.1711 \mathrm{E}-10 \quad 50112.70 \mathrm{C} \quad 2.1282 \mathrm{E}-12$ $50115.70 \mathrm{C} \quad 7.4598 \mathrm{E}-13 \quad 50116.70 \mathrm{C} \quad 3.1902 \mathrm{E}-11$ $50118.70 \mathrm{C} 5.3140 \mathrm{E}-11$ $50119.70 \mathrm{C} 1.8847 \mathrm{E}-11$ $40096.70 \mathrm{C} 7.9943 \mathrm{E}-12$ $42094.70 \mathrm{C} 2.5112 \mathrm{E}-11$ $42097.70 \mathrm{C} 2.5926 \mathrm{E}-11$ $44096.70 \mathrm{C} 1.4276 \mathrm{E}-11$ $44100.70 \mathrm{C} 3.2470 \mathrm{E}-11$ $44104.70 \mathrm{C} 4.7983 \mathrm{E}-11$ $46104.70 \mathrm{C} \quad 2.7264 \mathrm{E}-11$ $46108.70 \mathrm{C} \quad 6.4759 \mathrm{E}-11$ $47109.70 \mathrm{C} 1.1629 \mathrm{E}-10$ $48110.70 \mathrm{C} 2.8940 \mathrm{E}-11$ $48113.70 \mathrm{C} 2.8314 \mathrm{E}-11$ $49113.70 \mathrm{C} 9.7314 \mathrm{E}-12$ $50114.70 \mathrm{C} 1.4481 \mathrm{E}-12$ $50117.70 \mathrm{C} 1.6850 \mathrm{E}-11$ $50120.70 \mathrm{C} 7.1482 \mathrm{E}-11$ 
NEA/NSC/DOC(2006)1

\section{Fundamental - FUND}

\section{NRAD-FUND-RESR-002 \\ CRIT-REAC-COEF}

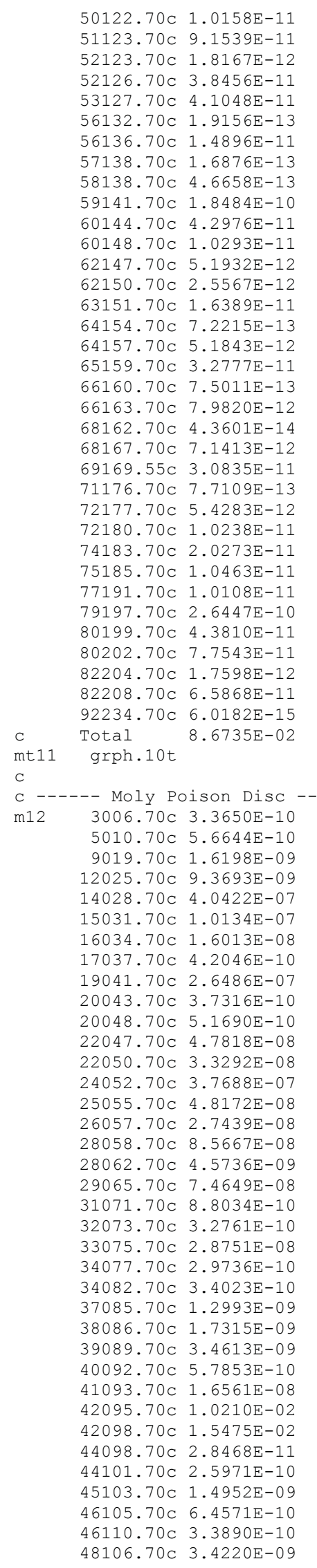

$50122.70 \mathrm{C} \quad 1.0158 \mathrm{E}-11$

$50124.70 \mathrm{C} \quad 1.2704 \mathrm{E}-11$ $52120.70 \mathrm{C} 1.8371 \mathrm{E}-13$ $52124.70 \mathrm{C} 9.6752 \mathrm{E}-12$ $52128.70 \mathrm{C} \quad 6.4787 \mathrm{E}-11$ $55133.70 \mathrm{C} 1.9597 \mathrm{E}-10$ $56134.70 \mathrm{C} \quad 4.5841 \mathrm{E}-12$ $56137.70 \mathrm{C} 2.1303 \mathrm{E}-11$ $57139.70 \mathrm{C} 1.8734 \mathrm{E}-10$ $58140.70 \mathrm{C} 1.6442 \mathrm{E}-10$ $60142.70 \mathrm{C} \quad 4.9115 \mathrm{E}-11$ $60145.70 \mathrm{C} 1.4987 \mathrm{E}-11$ $60150.70 \mathrm{C} 1.0112 \mathrm{E}-11$ $62148.70 \mathrm{C} \quad 3.8940 \mathrm{E}-12$ $62152.70 \mathrm{C} \quad 9.2673 \mathrm{E}-12$ $63153.70 \mathrm{C} 1.7890 \mathrm{E}-11$ $64155.70 \mathrm{C} \quad 4.9027 \mathrm{E}-12$ $64158.70 \mathrm{C} 8.2286 \mathrm{E}-12$ $66156.70 \mathrm{C} 1.9234 \mathrm{E}-14$ $66161.70 \mathrm{C} \quad 6.0618 \mathrm{E}-12$ $66164.70 \mathrm{C} 9.0334 \mathrm{E}-12$ $68164.70 \mathrm{C} 5.0142 \mathrm{E}-13$ $68168.70 \mathrm{C} 8.3403 \mathrm{E}-12$ $5010.70 \mathrm{C} 4.0640 \mathrm{E}-15$ $72174.70 \mathrm{C} \quad 4.6695 \mathrm{E}-14$ $72178.70 \mathrm{C} \quad 7.9615 \mathrm{E}-12$ $73181.70 \mathrm{C} 2.8788 \mathrm{E}-07$ $74184.70 \mathrm{C} \quad 4.3407 \mathrm{E}-11$ $75187.70 \mathrm{C} \quad 1.7512 \mathrm{E}-11$ $77193.70 \mathrm{C} 1.6992 \mathrm{E}-11$ $80196.70 \mathrm{C} 3.8953 \mathrm{E}-13$ $80200.70 \mathrm{C} 5.9988 \mathrm{E}-11$ $80204.70 \mathrm{C} 1.7841 \mathrm{E}-11$ $82206.70 \mathrm{C} 3.0294 \mathrm{E}-11$ $83209.70 \mathrm{C} 1.2463 \mathrm{E}-10$ $92235.70 \mathrm{C} \quad 7.8784 \mathrm{E}-13$
$3007.70 \mathrm{C} \quad 4.0970 \mathrm{E}-09$ $5011.70 \mathrm{C} 2.2800 \mathrm{E}-09$ $11023.70 \mathrm{C} 7.7234 \mathrm{E}-07$ $12026.70 \mathrm{C} 1.0316 \mathrm{E}-08$ $14029.70 \mathrm{C} 2.0525 \mathrm{E}-08$ $16032.70 \mathrm{C} \quad 3.5434 \mathrm{E}-07$ $16036.70 \mathrm{C} 7.4653 \mathrm{E}-11$ $19039.70 \mathrm{C} 3.6700 \mathrm{E}-06$ $20040.70 \mathrm{C} 2.6796 \mathrm{E}-07$ $20044.70 \mathrm{C} 5.7661 \mathrm{E}-09$ $21045.70 \mathrm{C} \quad 3.4226 \mathrm{E}-10$ $22048.70 \mathrm{C} \quad 4.7381 \mathrm{E}-07$ $23000.70 \mathrm{C} 1.3290 \mathrm{E}-07$ $24053.70 \mathrm{C} 4.2735 \mathrm{E}-08$ $26054.70 \mathrm{C} \quad 7.5687 \mathrm{E}-08$ $26058.70 \mathrm{C} 3.6516 \mathrm{E}-09$ $28060.70 \mathrm{C} 3.2999 \mathrm{E}-08$ $28064.70 \mathrm{C} 1.1648 \mathrm{E}-09$ $32070.70 \mathrm{C} 8.8322 \mathrm{E}-10$ $32074.70 \mathrm{C} 1.5376 \mathrm{E}-09$ $34074.70 \mathrm{C} 3.4686 \mathrm{E}-11$ $34078.70 \mathrm{C} \quad 9.2638 \mathrm{E}-10$ $35079.70 \mathrm{C} 1.9522 \mathrm{E}-10$ $37087.70 \mathrm{C} 5.0101 \mathrm{E}-10$ $38087.70 \mathrm{C} \quad 1.2292 \mathrm{E}-09$ $40090.70 \mathrm{C} 1.7356 \mathrm{E}-09$ $40094.70 \mathrm{C} 5.8629 \mathrm{E}-10$ $42092.70 \mathrm{C} 9.5169 \mathrm{E}-03$ $42096.70 \mathrm{C} \quad 1.0697 \mathrm{E}-02$ $42100.70 \mathrm{C} \quad 6.1757 \mathrm{E}-03$ $44099.70 \mathrm{C} 1.9425 \mathrm{E}-10$ $44102.70 \mathrm{C} \quad 4.8030 \mathrm{E}-10$ $46102.70 \mathrm{C} \quad 2.9495 \mathrm{E}-11$ $46106.70 \mathrm{C} 7.9029 \mathrm{E}-10$ $47107.70 \mathrm{C} 7.3944 \mathrm{E}-09$ $48108.70 \mathrm{C} 2.4364 \mathrm{E}-09$ $30000.70 \mathrm{C} 2.3530 \mathrm{E}-09$
$51121.70 \mathrm{C} 1.2239 \mathrm{E}-10$ $52122.70 \mathrm{C} \quad 5.2050 \mathrm{E}-12$ $52125.70 \mathrm{C} 1.4431 \mathrm{E}-11$ $52130.70 \mathrm{C} \quad 6.9564 \mathrm{E}-11$ $56130.70 \mathrm{C} 2.0104 \mathrm{E}-13$ $56135.70 \mathrm{C} 1.2502 \mathrm{E}-11$ $56138.70 \mathrm{C} 1.3598 \mathrm{E}-10$ $58136.70 \mathrm{C} 3.4389 \mathrm{E}-13$ $58142.70 \mathrm{C} 2.0660 \mathrm{E}-11$ $60143.70 \mathrm{C} \quad 2.2030 \mathrm{E}-11$ $60146.70 \mathrm{C} 3.1058 \mathrm{E}-11$ $62144.70 \mathrm{C} 1.0636 \mathrm{E}-12$ $62149.70 \mathrm{C} \quad 4.7878 \mathrm{E}-12$ $62154.70 \mathrm{C} 7.8816 \mathrm{E}-12$ $64152.70 \mathrm{C} \quad 6.6253 \mathrm{E}-14$ $64156.70 \mathrm{C} \quad 6.7810 \mathrm{E}-12$ $64160.70 \mathrm{C} 7.2414 \mathrm{E}-12$ $66158.70 \mathrm{C} 3.2056 \mathrm{E}-14$ $66162.70 \mathrm{C} \quad 8.1775 \mathrm{E}-12$ $67165.70 \mathrm{C} 3.1584 \mathrm{E}-11$ $68166.70 \mathrm{C} \quad 1.0467 \mathrm{E}-11$ $68170.70 \mathrm{C} 4.6498 \mathrm{E}-12$ $71175.70 \mathrm{C} 2.9001 \mathrm{E}-11$ $72176.70 \mathrm{C} 1.5351 \mathrm{E}-12$ $72179.70 \mathrm{C} \quad 3.9749 \mathrm{E}-12$ $74182.70 \mathrm{C} 3.7542 \mathrm{E}-11$ $74186.70 \mathrm{C} \quad 4.0446 \mathrm{E}-11$ $76000.31 \mathrm{C} 2.7388 \mathrm{E}-11$ $78000.31 \mathrm{C} 2.6702 \mathrm{E}-11$ $80198.70 \mathrm{C} 2.5891 \mathrm{E}-11$ $80201.70 \mathrm{C} 3.4227 \mathrm{E}-11$ $81000.31 \mathrm{C} 1.2743 \mathrm{E}-10$ $82207.70 \mathrm{C} 2.7780 \mathrm{E}-11$ $90232.70 \mathrm{C} 1.1225 \mathrm{E}-10$ $92238.70 \mathrm{C} 1.0863 \mathrm{E}-10$
$4009.70 \mathrm{C} \quad 3.4146 \mathrm{E}-09$ $6000.70 \mathrm{C} 5.1241 \mathrm{E}-05$ $12024.70 \mathrm{C} 7.4008 \mathrm{E}-08$ $13027.70 \mathrm{C} 1.0037 \mathrm{E}-07$ $14030.70 \mathrm{C} 1.3530 \mathrm{E}-08$ $16033.70 \mathrm{C} 2.8368 \mathrm{E}-09$ $17035.70 \mathrm{C} 1.3155 \mathrm{E}-09$ $19040.70 \mathrm{C} 4.6043 \mathrm{E}-10$ $20042.70 \mathrm{C} 1.7884 \mathrm{E}-09$ $20046.70 \mathrm{C} 1.1057 \mathrm{E}-11$ $22046.70 \mathrm{C} 5.3024 \mathrm{E}-08$ $22049.70 \mathrm{C} \quad 3.4771 \mathrm{E}-08$ $24050.70 \mathrm{C} 1.9543 \mathrm{E}-08$ $24054.70 \mathrm{C} 1.0638 \mathrm{E}-08$ $26056.70 \mathrm{C} 1.1881 \mathrm{E}-06$ $27059.70 \mathrm{C} 1.4621 \mathrm{E}-08$ $28061.70 \mathrm{C} 1.4344 \mathrm{E}-09$ $29063.70 \mathrm{C} \quad 1.6748 \mathrm{E}-07$ $31069.70 \mathrm{C} 1.3265 \mathrm{E}-09$ $32072.70 \mathrm{C} \quad 1.1672 \mathrm{E}-09$ $32076.70 \mathrm{C} \quad 3.2252 \mathrm{E}-10$ $34076.70 \mathrm{C} 3.6518 \mathrm{E}-10$ $34080.70 \mathrm{C} \quad 1.9334 \mathrm{E}-09$ $35081.70 \mathrm{C} 1.8990 \mathrm{E}-10$ $38084.70 \mathrm{C} 9.8339 \mathrm{E}-11$ $38088.70 \mathrm{C} \quad 1.4501 \mathrm{E}-08$ $40091.70 \mathrm{C} 3.7849 \mathrm{E}-10$ $40096.70 \mathrm{C} 9.4453 \mathrm{E}-11$ $42094.70 \mathrm{C} 5.9320 \mathrm{E}-03$ $42097.70 \mathrm{C} \quad 6.1244 \mathrm{E}-03$ $44096.70 \mathrm{C} \quad 8.4339 \mathrm{E}-11$ $44100.70 \mathrm{C} 1.9182 \mathrm{E}-10$ $44104.70 \mathrm{C} 2.8346 \mathrm{E}-10$ $46104.70 \mathrm{C} \quad 3.2213 \mathrm{E}-10$ $46108.70 \mathrm{C} 7.6513 \mathrm{E}-10$ $47109.70 \mathrm{C} \quad 6.8697 \mathrm{E}-09$ $48110.70 \mathrm{C} 3.4192 \mathrm{E}-08$ 
NEA/NSC/DOC(2006)1

\section{Fundamental - FUND}

\section{NRAD-FUND-RESR-002 \\ CRIT-REAC-COEF}

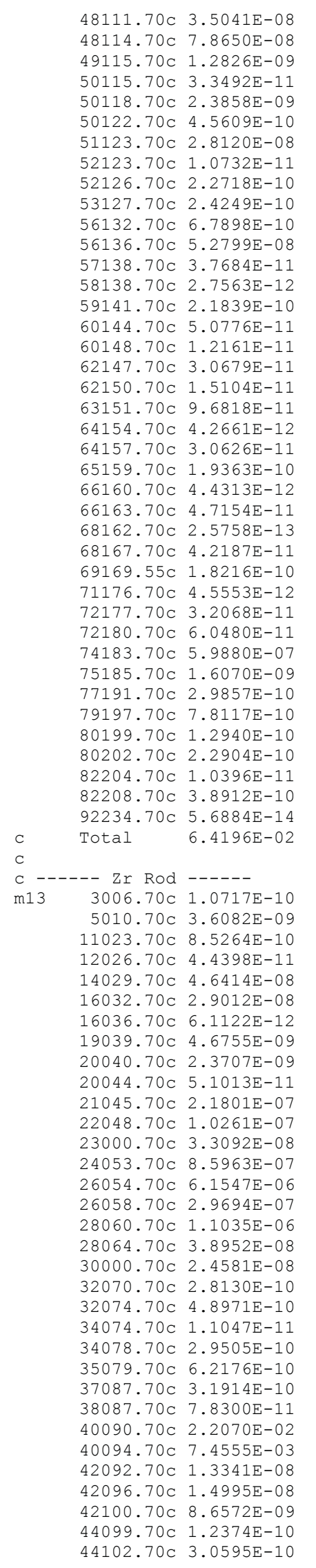

$48112.70 \mathrm{C} \quad 6.6057 \mathrm{E}-08$ $48116.70 \mathrm{C} 2.0504 \mathrm{E}-08$ $50112.70 \mathrm{C}$ 9.5551E-11 $50116.70 \mathrm{C} 1.4323 \mathrm{E}-09$ $50119.70 \mathrm{C} 8.4617 \mathrm{E}-10$ $50124.70 \mathrm{C} 5.7035 \mathrm{E}-10$ $52120.70 \mathrm{c} 1.0853 \mathrm{E}-12$ $52124.70 \mathrm{C} 5.7157 \mathrm{E}-11$ $52128.70 \mathrm{C} 3.8273 \mathrm{E}-10$ $55133.70 \mathrm{C} 1.1577 \mathrm{E}-09$ $56134.70 \mathrm{C} \quad 1.6248 \mathrm{E}-08$ $56137.70 \mathrm{C} 7.5508 \mathrm{E}-08$ $57139.70 \mathrm{C} 4.1833 \mathrm{E}-08$ $58140.70 \mathrm{C} \quad 9.7130 \mathrm{E}-10$ $60142.70 \mathrm{C} 5.8030 \mathrm{E}-11$ $60145.70 \mathrm{C} 1.7708 \mathrm{E}-11$ $60150.70 \mathrm{C} 1.1947 \mathrm{E}-11$ $62148.70 \mathrm{C} 2.3004 \mathrm{E}-11$ $62152.70 \mathrm{C} \quad 5.4747 \mathrm{E}-11$ $63153.70 \mathrm{C} \quad 1.0569 \mathrm{E}-10$ $64155.70 \mathrm{C} 2.8963 \mathrm{E}-11$ $64158.70 \mathrm{C} 4.8610 \mathrm{E}-11$ $66156.70 \mathrm{C} 1.1362 \mathrm{E}-13$ $66161.70 \mathrm{C} 3.5810 \mathrm{E}-11$ $66164.70 \mathrm{c} 5.3365 \mathrm{E}-11$ $68164.70 \mathrm{C} 2.9621 \mathrm{E}-12$ $68168.70 \mathrm{C} 4.9271 \mathrm{E}-11$ $5010.70 \mathrm{c} 2.4008 \mathrm{E}-14$ $72174.70 \mathrm{c} 2.7585 \mathrm{E}-13$ $72178.70 \mathrm{C} \quad 4.7033 \mathrm{E}-11$ $73181.70 \mathrm{C} 1.7007 \mathrm{E}-07$ $74184.70 \mathrm{C} 1.2821 \mathrm{E}-06$ $75187.70 \mathrm{C} 2.6898 \mathrm{E}-09$ $77193.70 \mathrm{C} 5.0189 \mathrm{E}-10$ $80196.70 \mathrm{C} 1.1506 \mathrm{E}-12$ $80200.70 \mathrm{C} 1.7719 \mathrm{E}-10$ $80204.70 \mathrm{C} 5.2697 \mathrm{E}-11$ $82206.70 \mathrm{C} 1.7896 \mathrm{E}-10$ $83209.70 \mathrm{C} 7.3626 \mathrm{E}-10$ $92235.70 \mathrm{C} 7.4467 \mathrm{E}-12$

$3007.70 \mathrm{c} 1.3049 \mathrm{E}-09$ $5011.70 \mathrm{C} 1.4523 \mathrm{E}-08$ $12024.70 \mathrm{C} 3.1853 \mathrm{E}-10$ $13027.70 \mathrm{C} 5.8120 \mathrm{E}-06$ $14030.70 \mathrm{c} 3.0596 \mathrm{E}-08$ $16033.70 \mathrm{C} 2.3226 \mathrm{E}-10$ $17035.70 \mathrm{C} 1.9273 \mathrm{E}-08$ $19040.70 \mathrm{C} \quad 5.8658 \mathrm{E}-13$ $20042.70 \mathrm{C} 1.5822 \mathrm{E}-11$ $20046.70 \mathrm{C} 9.7819 \mathrm{E}-14$ $22046.70 \mathrm{C} 1.1484 \mathrm{E}-08$ $22049.70 \mathrm{C} 7.5305 \mathrm{E}-09$ $24050.70 \mathrm{C} 3.9312 \mathrm{E}-07$ $24054.70 \mathrm{C} 2.1398 \mathrm{E}-07$ $26056.70 \mathrm{c} 9.6615 \mathrm{E}-05$ $27059.70 \mathrm{C} 7.3175 \mathrm{E}-08$ $28061.70 \mathrm{C} 4.7970 \mathrm{E}-08$ $29063.70 \mathrm{C} \quad 5.5476 \mathrm{E}-07$ $31069.70 \mathrm{C} \quad 7.4355 \mathrm{E}-08$ $32072.70 \mathrm{C} \quad 3.7174 \mathrm{E}-10$ $32076.70 \mathrm{C} 1.0272 \mathrm{E}-10$ $34076.70 \mathrm{C} 1.1631 \mathrm{E}-10$ $34080.70 \mathrm{c} 6.1579 \mathrm{E}-10$ $35081.70 \mathrm{c} 6.0483 \mathrm{E}-10$ $38084.70 \mathrm{C} \quad 6.2640 \mathrm{E}-12$ $38088.70 \mathrm{C} \quad 9.2372 \mathrm{E}-10$ $40091.70 \mathrm{C} 4.8130 \mathrm{E}-03$ $40096.70 \mathrm{C} 1.2011 \mathrm{E}-03$ $42094.70 \mathrm{C} 8.3156 \mathrm{E}-09$ $42097.70 \mathrm{C} \quad 8.5853 \mathrm{E}-09$ $44096.70 \mathrm{C} 5.3723 \mathrm{E}-11$ $44100.70 \mathrm{C} 1.2218 \mathrm{E}-10$ $44104.70 \mathrm{C} 1.8056 \mathrm{E}-10$
$48113.70 \mathrm{C} \quad 3.3453 \mathrm{E}-08$ $49113.70 \mathrm{c} 5.7488 \mathrm{E}-11$ $50114.70 \mathrm{c} \quad 6.5014 \mathrm{E}-11$ $50117.70 \mathrm{c} 7.5653 \mathrm{E}-10$ $50120.70 \mathrm{C} 3.2093 \mathrm{E}-09$ $51121.70 \mathrm{C} 3.7596 \mathrm{E}-08$ $52122.70 \mathrm{c} 3.0749 \mathrm{E}-11$ $52125.70 \mathrm{C}$ 8.5253E-11 $52130.70 \mathrm{c} 4.1095 \mathrm{E}-10$ $56130.70 \mathrm{C} 7.1259 \mathrm{E}-10$ $56135.70 \mathrm{C} 4.4315 \mathrm{E}-08$ $56138.70 \mathrm{C} 4.8199 \mathrm{E}-07$ $58136.70 \mathrm{c} 2.0315 \mathrm{E}-12$ $58142.70 \mathrm{C} 1.2205 \mathrm{E}-10$ $60143.70 \mathrm{c} 2.6028 \mathrm{E}-11$ $60146.70 \mathrm{c} 3.6695 \mathrm{E}-11$ $62144.70 \mathrm{C} \quad 6.2831 \mathrm{E}-12$ $62149.70 \mathrm{C} 2.8284 \mathrm{E}-11$ $62154.70 \mathrm{c} 4.6561 \mathrm{E}-11$ $64152.70 \mathrm{C} 3.9139 \mathrm{E}-13$ $64156.70 \mathrm{C} \quad 4.0059 \mathrm{E}-11$ $64160.70 \mathrm{C} \quad 4.2779 \mathrm{E}-11$ $66158.70 \mathrm{c} 1.8937 \mathrm{E}-13$ $66162.70 \mathrm{C} \quad 4.8309 \mathrm{E}-11$ $67165.70 \mathrm{C} 1.8658 \mathrm{E}-10$ $68166.70 \mathrm{c} \quad 6.1837 \mathrm{E}-11$ $68170.70 \mathrm{C} 2.7469 \mathrm{E}-11$ $71175.70 \mathrm{C} 1.7132 \mathrm{E}-10$ $72176.70 \mathrm{C} \quad 9.0686 \mathrm{E}-12$ $72179.70 \mathrm{C} 2.3482 \mathrm{E}-11$ $74182.70 \mathrm{C} 1.1089 \mathrm{E}-06$ $74186.70 \mathrm{C} 1.1947 \mathrm{E}-06$ $76000.31 \mathrm{C} 8.0896 \mathrm{E}-10$ $78000.31 \mathrm{C} 7.8873 \mathrm{E}-10$ $80198.70 \mathrm{c} 7.6476 \mathrm{E}-11$ $80201.70 \mathrm{C} 1.0110 \mathrm{E}-10$ $81000.31 \mathrm{C} 7.5282 \mathrm{E}-10$ $82207.70 \mathrm{C} 1.6411 \mathrm{E}-10$ $90232.70 \mathrm{c} 6.6310 \mathrm{E}-11$ $92238.70 \mathrm{C} 1.0268 \mathrm{E}-09$

$4009.70 \mathrm{C} \quad 1.0875 \mathrm{E}-09$ $9019.70 \mathrm{C} \quad 1.0318 \mathrm{E}-07$ $12025.70 \mathrm{C} 4.0325 \mathrm{E}-11$ $14028.70 \mathrm{C} 9.1406 \mathrm{E}-07$ $15031.70 \mathrm{C} 9.9991 \mathrm{E}-08$ $16034.70 \mathrm{C} 1.3111 \mathrm{E}-09$ $17037.70 \mathrm{C} 6.1600 \mathrm{E}-09$ $19041.70 \mathrm{C} 3.3742 \mathrm{E}-10$ $20043.70 \mathrm{C} 3.3014 \mathrm{E}-12$ $20048.70 \mathrm{c} 4.5730 \mathrm{E}-12$ $22047.70 \mathrm{C} 1.0356 \mathrm{E}-08$ $22050.70 \mathrm{C} 7.2103 \mathrm{E}-09$ $24052.70 \mathrm{c} 7.5810 \mathrm{E}-06$ $25055.70 \mathrm{C} \quad 9.9904 \mathrm{E}-07$ $26057.70 \mathrm{C} 2.2313 \mathrm{E}-06$ $28058.70 \mathrm{C} 2.8649 \mathrm{E}-06$ $28062.70 \mathrm{C} 1.5295 \mathrm{E}-07$ $29065.70 \mathrm{C} 2.4726 \mathrm{E}-07$ $31071.70 \mathrm{C} \quad 4.9347 \mathrm{E}-08$ $32073.70 \mathrm{C} 1.0434 \mathrm{E}-10$ $33075.70 \mathrm{C} 2.0931 \mathrm{E}-09$ $34077.70 \mathrm{C} 9.4708 \mathrm{E}-11$ $34082.70 \mathrm{C} 1.0836 \mathrm{E}-10$ $37085.70 \mathrm{c} 8.2761 \mathrm{E}-10$ $38086.70 \mathrm{C} 1.1029 \mathrm{E}-10$ $39089.70 \mathrm{C} 1.1024 \mathrm{E}-09$ $40092.70 \mathrm{C} 7.3568 \mathrm{E}-03$ $41093.70 \mathrm{C} 2.5740 \mathrm{E}-08$ $42095.70 \mathrm{C} 1.4312 \mathrm{E}-08$ $42098.70 \mathrm{C} \quad 2.1692 \mathrm{E}-08$ $44098.70 \mathrm{C} 1.8134 \mathrm{E}-11$ $44101.70 \mathrm{C} 1.6543 \mathrm{E}-10$ $45103.70 \mathrm{C} \quad 9.5242 \mathrm{E}-10$ 
NEA/NSC/DOC(2006)1

\section{Fundamental - FUND}

\section{NRAD-FUND-RESR-002 \\ CRIT-REAC-COEF}

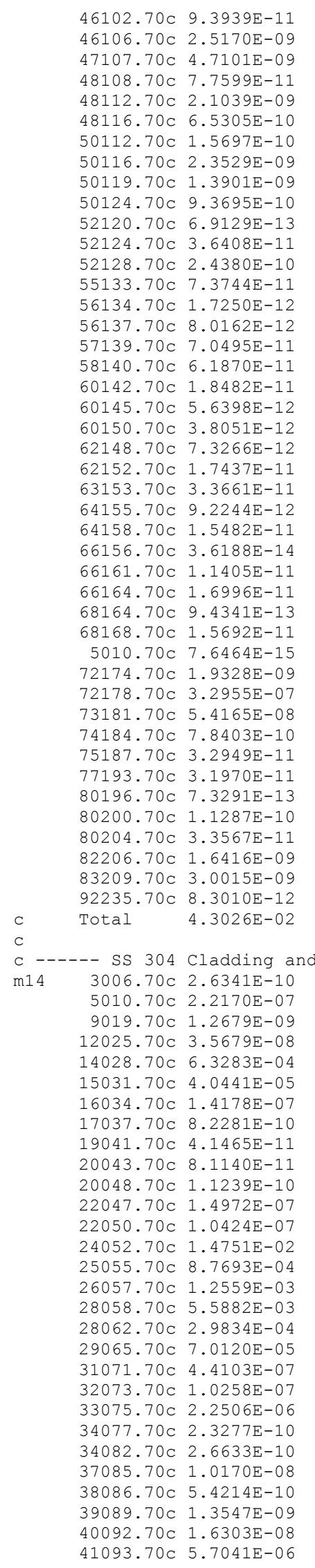

$46102.70 \mathrm{C} \quad 9.3939 \mathrm{E}-11$

$46104.70 \mathrm{C} \quad 1.0260 \mathrm{E}-09$ $46108.70 \mathrm{C} 2.4369 \mathrm{E}-09$ $47109.70 \mathrm{C} \quad 4.3759 \mathrm{E}-09$ $48110.70 \mathrm{C} 1.0890 \mathrm{E}-09$ $48113.70 \mathrm{C} 1.0655 \mathrm{E}-09$ $49113.70 \mathrm{C} 7.3238 \mathrm{E}-11$ $50114.70 \mathrm{C} 1.0680 \mathrm{E}-10$ $50117.70 \mathrm{C} 1.2428 \mathrm{E}-09$ $50120.70 \mathrm{C} 5.2722 \mathrm{E}-09$ $51121.70 \mathrm{C} \quad 4.6054 \mathrm{E}-10$ $52122.70 \mathrm{C} \quad 1.9587 \mathrm{E}-11$ $52125.70 \mathrm{C} 5.4305 \mathrm{E}-11$ $52130.70 \mathrm{C} \quad 2.6177 \mathrm{E}-10$ $56130.70 \mathrm{C} \quad 7.5652 \mathrm{E}-14$ $56135.70 \mathrm{C} 4.7047 \mathrm{E}-12$ $56138.70 \mathrm{C} \quad 5.1171 \mathrm{E}-11$ $58136.70 \mathrm{C} 1.2941 \mathrm{E}-13$ $58142.70 \mathrm{C} 7.7742 \mathrm{E}-12$ $60143.70 \mathrm{C} 8.2898 \mathrm{E}-12$ $60146.70 \mathrm{C} 1.1687 \mathrm{E}-11$ $62144.70 \mathrm{C} 2.0011 \mathrm{E}-12$ $62149.70 \mathrm{C} 9.0083 \mathrm{E}-12$ $62154.70 \mathrm{C} 1.4829 \mathrm{E}-11$ $64152.70 \mathrm{C} 1.2465 \mathrm{E}-13$ $64156.70 \mathrm{C} 1.2758 \mathrm{E}-11$ $64160.70 \mathrm{C} 1.3625 \mathrm{E}-11$ $66158.70 \mathrm{C} \quad 6.0314 \mathrm{E}-14$ $66162.70 \mathrm{C} 1.5386 \mathrm{E}-11$ $67165.70 \mathrm{C}$ 5.9425E-11 $68166.70 \mathrm{C} 1.9695 \mathrm{E}-11$ $68170.70 \mathrm{C} 8.7486 \mathrm{E}-12$ $71175.70 \mathrm{C} \quad 5.4565 \mathrm{E}-11$ $72176.70 \mathrm{C} \quad 6.3542 \mathrm{E}-08$ $72179.70 \mathrm{C} 1.6453 \mathrm{E}-07$ $74182.70 \mathrm{C} \quad 6.7810 \mathrm{E}-10$ $74186.70 \mathrm{C} 7.3055 \mathrm{E}-10$ $76000.31 \mathrm{C} 5.1530 \mathrm{E}-11$ $78000.31 \mathrm{C} 5.0241 \mathrm{E}-11$ $80198.70 \mathrm{C} \quad 4.8714 \mathrm{E}-11$ $80201.70 \mathrm{C}$ 6.4398E-11 $81000.31 \mathrm{C} 9.5908 \mathrm{E}-11$ $82207.70 \mathrm{C} 1.5053 \mathrm{E}-09$ $90232.70 \mathrm{C} 8.4477 \mathrm{E}-12$ $92238.70 \mathrm{C} 1.1446 \mathrm{E}-09$ End Fittings -----$3007.70 \mathrm{C} 3.2070 \mathrm{E}-09$ $5011.70 \mathrm{C} 8.9237 \mathrm{E}-07$ $11023.70 \mathrm{C} 1.0478 \mathrm{E}-09$ $12026.70 \mathrm{C} 3.9283 \mathrm{E}-08$ $14029.70 \mathrm{C} \quad 3.2134 \mathrm{E}-05$ $16032.70 \mathrm{C} \quad 3.1374 \mathrm{E}-06$ $16036.70 \mathrm{c} 6.6099 \mathrm{E}-10$ $19039.70 \mathrm{C} 5.7456 \mathrm{E}-10$ $20040.70 \mathrm{C} 5.8265 \mathrm{E}-08$ $20044.70 \mathrm{C} 1.2538 \mathrm{E}-09$ $21045.70 \mathrm{C} 2.6791 \mathrm{E}-10$ $22048.70 \mathrm{C} 1.4835 \mathrm{E}-06$ $23000.70 \mathrm{C} 9.4573 \mathrm{E}-05$ $24053.70 \mathrm{C} 1.6726 \mathrm{E}-03$ $26054.70 \mathrm{C} 3.4644 \mathrm{E}-03$ $26058.70 \mathrm{C} 1.6714 \mathrm{E}-04$ $28060.70 \mathrm{C} 2.1526 \mathrm{E}-03$ $28064.70 \mathrm{C} 7.5980 \mathrm{E}-05$ $30000.70 \mathrm{C} 3.6838 \mathrm{E}-08$ $32070.70 \mathrm{C} 2.7655 \mathrm{E}-07$ $32074.70 \mathrm{C} \quad 4.8144 \mathrm{E}-07$ $34074.70 \mathrm{C} 2.7151 \mathrm{E}-11$ $34078.70 \mathrm{C} 7.2515 \mathrm{E}-10$ $35079.70 \mathrm{C} 1.5281 \mathrm{E}-09$ $37087.70 \mathrm{C} 3.9218 \mathrm{E}-09$ $38087.70 \mathrm{C} 3.8489 \mathrm{E}-10$ $40090.70 \mathrm{C} \quad 4.8909 \mathrm{E}-08$ $40094.70 \mathrm{C} 1.6522 \mathrm{E}-08$ $42092.70 \mathrm{C} 2.2356 \mathrm{E}-05$
$46105.70 \mathrm{C} 2.0565 \mathrm{E}-09$ $46110.70 \mathrm{C} 1.0794 \mathrm{E}-09$ $48106.70 \mathrm{C} 1.0899 \mathrm{E}-10$ $48111.70 \mathrm{C} 1.1160 \mathrm{E}-09$ $48114.70 \mathrm{C} 2.5050 \mathrm{E}-09$ $49115.70 \mathrm{C} 1.6339 \mathrm{E}-09$ $50115.70 \mathrm{C} 5.5020 \mathrm{E}-11$ $50118.70 \mathrm{C} 3.9193 \mathrm{E}-09$ $50122.70 \mathrm{C} 7.4924 \mathrm{E}-10$ $51123.70 \mathrm{C} \quad 3.4446 \mathrm{E}-10$ $52123.70 \mathrm{C} \quad 6.8361 \mathrm{E}-12$ $52126.70 \mathrm{C} 1.4471 \mathrm{E}-10$ $53127.70 \mathrm{C} 1.5446 \mathrm{E}-09$ $56132.70 \mathrm{C} 7.2083 \mathrm{E}-14$ $56136.70 \mathrm{C} 5.6054 \mathrm{E}-12$ $57138.70 \mathrm{C} \quad 6.3503 \mathrm{E}-14$ $58138.70 \mathrm{C} 1.7557 \mathrm{E}-13$ $59141.70 \mathrm{C} \quad 6.9556 \mathrm{E}-11$ $60144.70 \mathrm{C} 1.6172 \mathrm{E}-11$ $60148.70 \mathrm{C} 3.8731 \mathrm{E}-12$ $62147.70 \mathrm{C} \quad 9.7710 \mathrm{E}-12$ $62150.70 \mathrm{C} 4.8105 \mathrm{E}-12$ $63151.70 \mathrm{C} 3.0836 \mathrm{E}-11$ $64154.70 \mathrm{C} 1.3587 \mathrm{E}-12$ $64157.70 \mathrm{C} \quad 9.7542 \mathrm{E}-12$ $65159.70 \mathrm{C} \quad 6.1670 \mathrm{E}-11$ $66160.70 \mathrm{C} 1.4113 \mathrm{E}-12$ $66163.70 \mathrm{c} 1.5018 \mathrm{E}-11$ $68162.70 \mathrm{C} 8.2036 \mathrm{E}-14$ $68167.70 \mathrm{C} 1.3436 \mathrm{E}-11$ $69169.55 \mathrm{C} 5.8016 \mathrm{E}-11$ $71176.70 \mathrm{C} 1.4508 \mathrm{E}-12$ $72177.70 \mathrm{C} 2.2469 \mathrm{E}-07$ $72180.70 \mathrm{C} \quad 4.2378 \mathrm{E}-07$ $74183.70 \mathrm{C} \quad 3.6617 \mathrm{E}-10$ $75185.70 \mathrm{C} 1.9685 \mathrm{E}-11$ $77191.70 \mathrm{C}$ 1.9019E-11 $79197.70 \mathrm{C} 4.9760 \mathrm{E}-10$ $80199.70 \mathrm{C} 8.2428 \mathrm{E}-11$ $80202.70 \mathrm{C} 1.4590 \mathrm{E}-10$ $82204.70 \mathrm{C} 9.5361 \mathrm{E}-11$ $82208.70 \mathrm{C} 3.5692 \mathrm{E}-09$ $92234.70 \mathrm{C} \quad 6.3410 \mathrm{E}-14$

$4009.70 \mathrm{C} 2.6729 \mathrm{E}-09$ $6000.70 \mathrm{C} 1.6044 \mathrm{E}-04$ $12024.70 \mathrm{C} 2.8183 \mathrm{E}-07$ $13027.70 \mathrm{C} \quad 2.1427 \mathrm{E}-06$ $14030.70 \mathrm{C} 2.1183 \mathrm{E}-05$ $16033.70 \mathrm{C} 2.5117 \mathrm{E}-08$ $17035.70 \mathrm{C} \quad 2.5744 \mathrm{E}-09$ $19040.70 \mathrm{C} 7.2084 \mathrm{E}-14$ $20042.70 \mathrm{C} 3.8887 \mathrm{E}-10$ $20046.70 \mathrm{C} 2.4042 \mathrm{E}-12$ $22046.70 \mathrm{C} 1.6602 \mathrm{E}-07$ $22049.70 \mathrm{C} 1.0887 \mathrm{E}-07$ $24050.70 \mathrm{C} 7.6491 \mathrm{E}-04$ $24054.70 \mathrm{C} \quad 4.1634 \mathrm{E}-04$ $26056.70 \mathrm{C}$ 5.4383E-02 $27059.70 \mathrm{C} \quad 6.5399 \mathrm{E}-05$ $28061.70 \mathrm{C} 9.3571 \mathrm{E}-05$ $29063.70 \mathrm{C} \quad 1.5732 \mathrm{E}-04$ $31069.70 \mathrm{C} \quad 6.6453 \mathrm{E}-07$ $32072.70 \mathrm{C} 3.6546 \mathrm{E}-07$ $32076.70 \mathrm{C} \quad 1.0098 \mathrm{E}-07$ $34076.70 \mathrm{C} 2.8585 \mathrm{E}-10$ $34080.70 \mathrm{C} \quad 1.5135 \mathrm{E}-09$ $35081.70 \mathrm{C} 1.4865 \mathrm{E}-09$ $38084.70 \mathrm{C} 3.0791 \mathrm{E}-11$ $38088.70 \mathrm{C} \quad 4.5406 \mathrm{E}-09$ $40091.70 \mathrm{C} 1.0666 \mathrm{E}-08$ $40096.70 \mathrm{C} 2.6617 \mathrm{E}-09$ 42094.70C 1.3935E-05 
NEA/NSC/DOC(2006)1

\section{Fundamental - FUND}

\section{NRAD-FUND-RESR-002 CRIT-REAC-COEF}

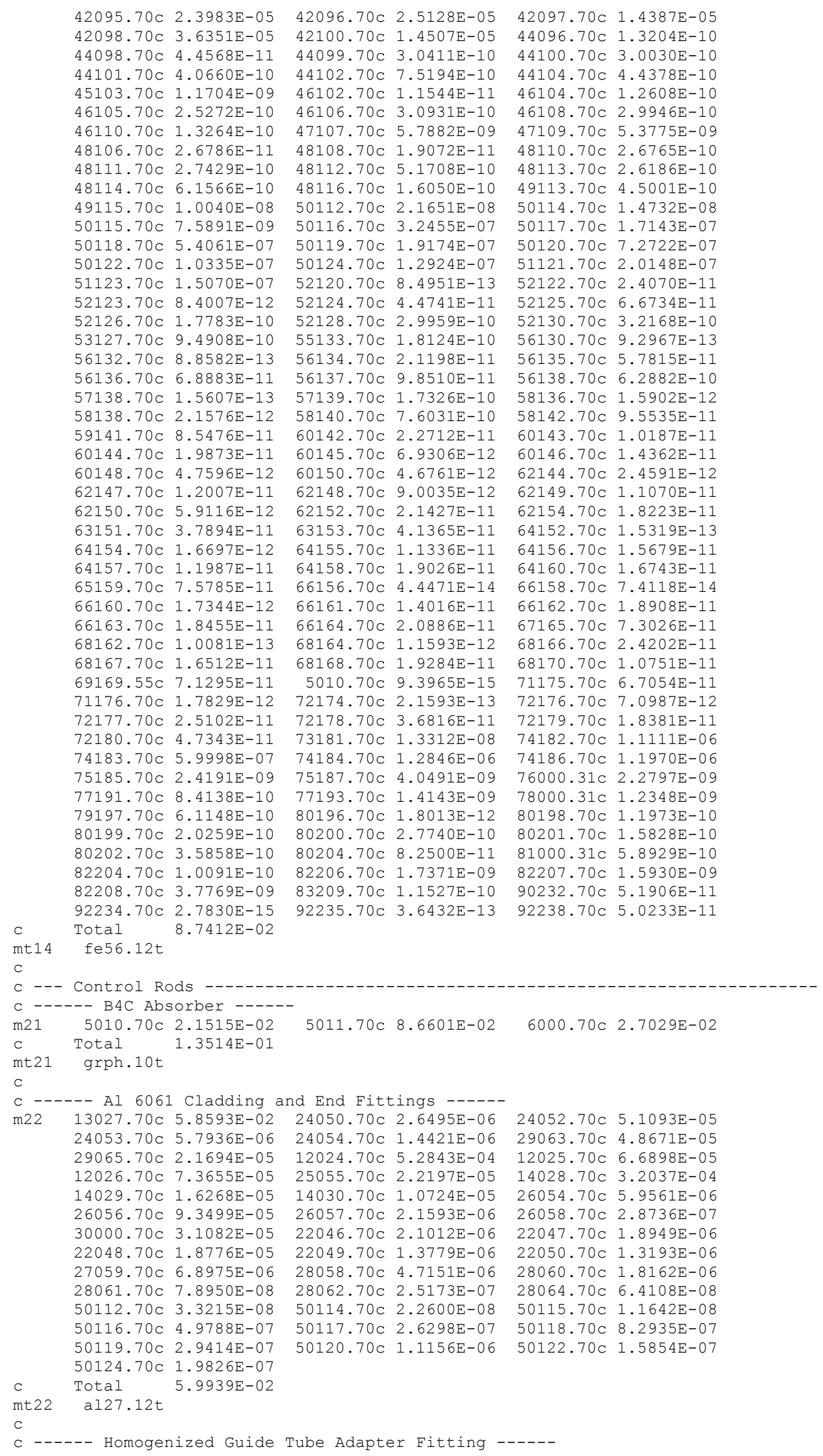




\section{NEA/NSC/DOC(2006)1}

\section{Fundamental - FUND}

\section{NRAD-FUND-RESR-002 \\ CRIT-REAC-COEF}

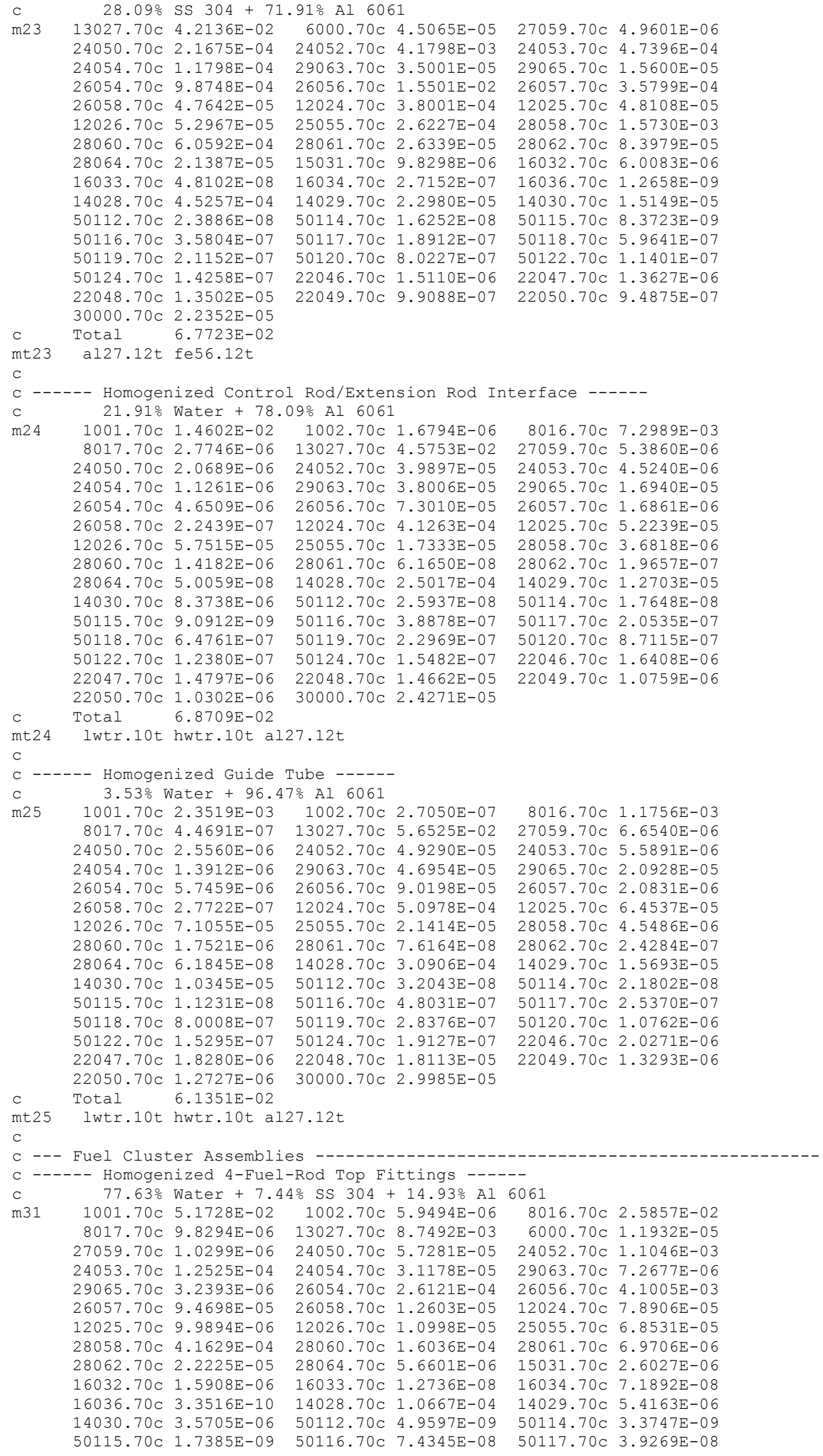




\section{NEA/NSC/DOC(2006)1}

\section{Fundamental - FUND}

\section{NRAD-FUND-RESR-002 \\ CRIT-REAC-COEF}

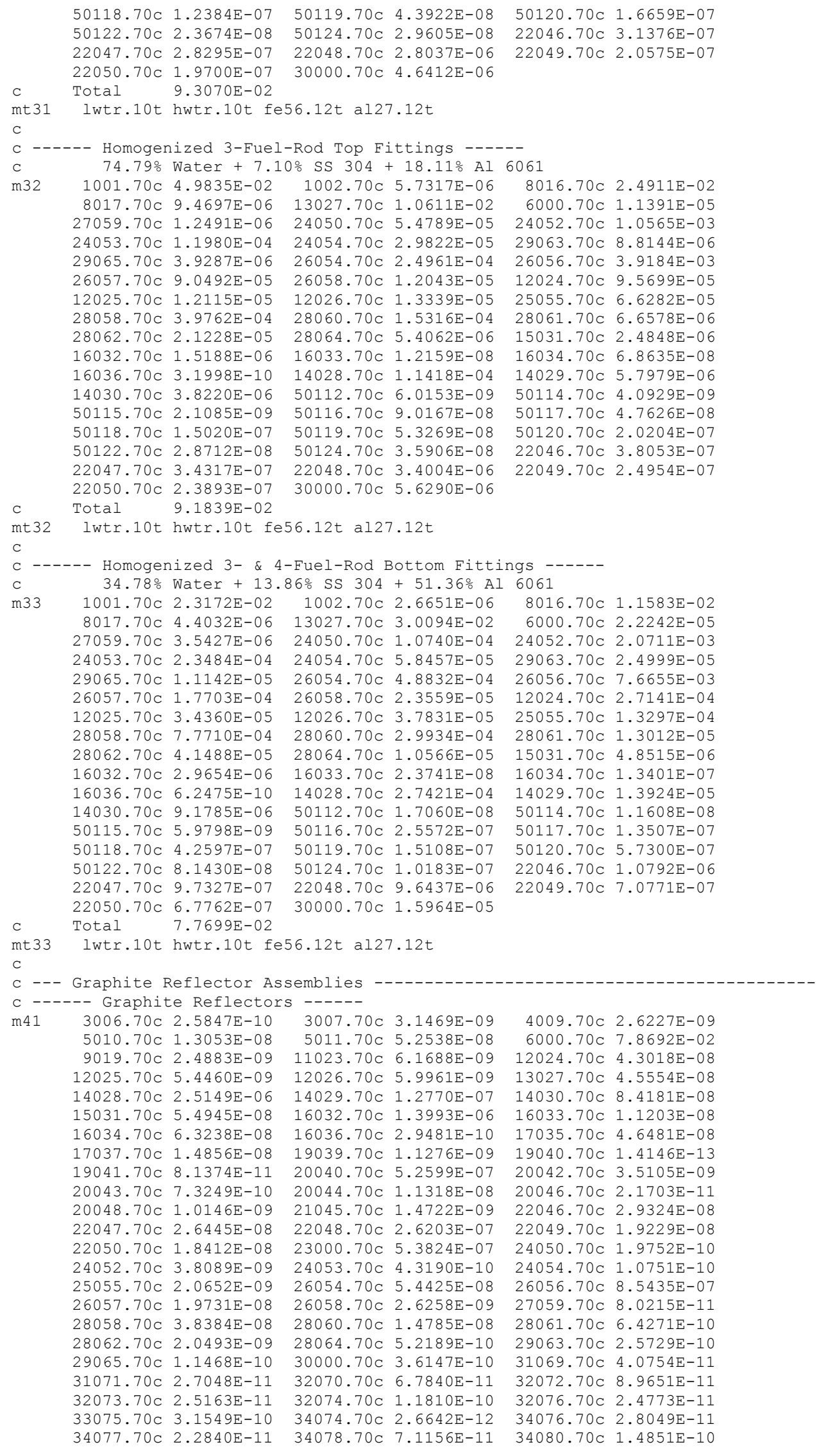


NEA/NSC/DOC(2006)1

\section{Fundamental - FUND}

\section{NRAD-FUND-RESR-002 \\ CRIT-REAC-COEF}

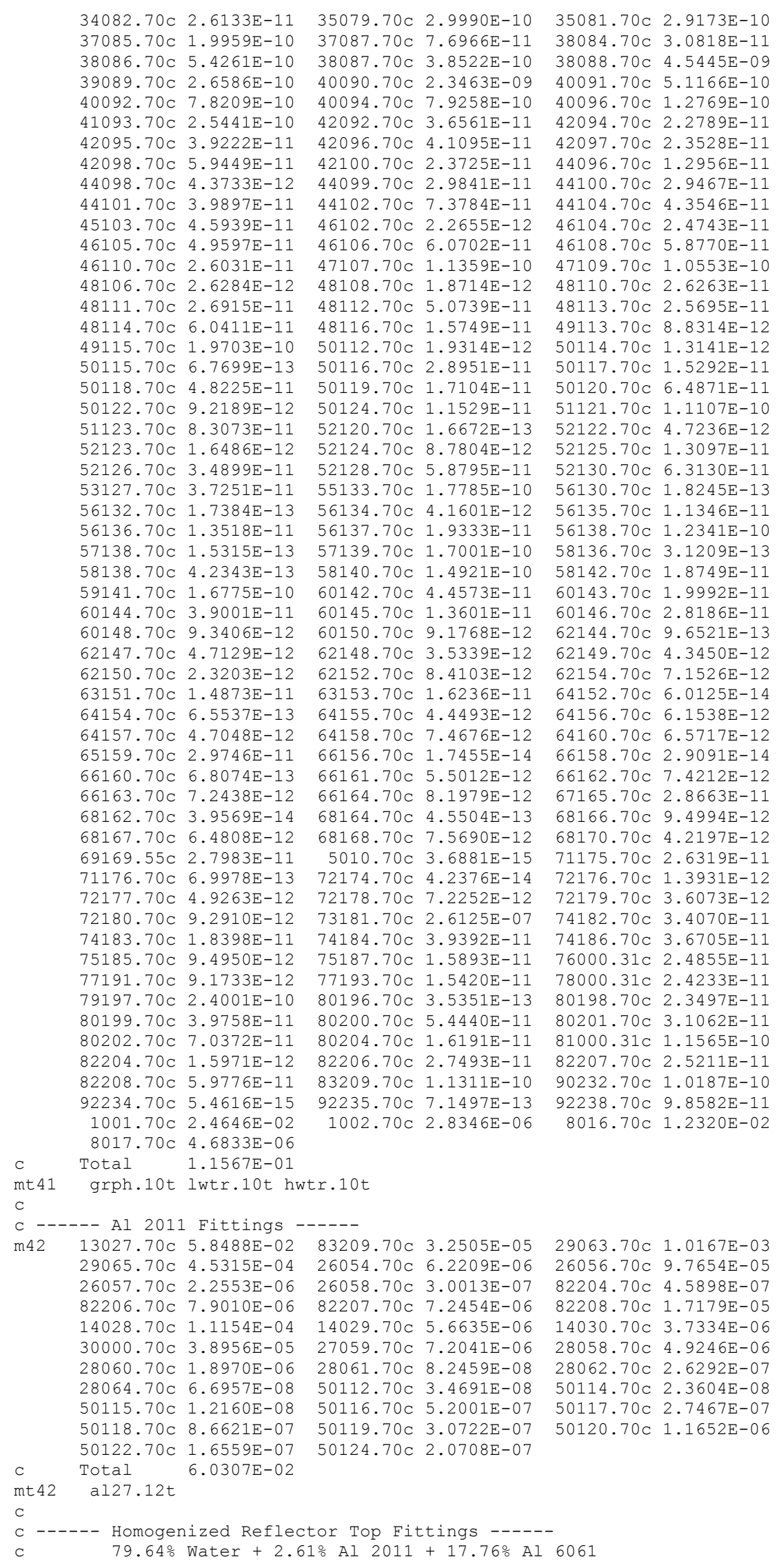

$34082.70 \mathrm{C} 2.6133 \mathrm{E}-11$ $37085.70 \mathrm{C} 1.9959 \mathrm{E}-10$ $6.70 \mathrm{C} 5.4261 \mathrm{E}-10$ $40092.70 \mathrm{C} 7.8209 \mathrm{E}-1$ 1093.70 2.5441E-10 . 3733E-12 $44101.70 \mathrm{C} 3.9897 \mathrm{E}-11$ $.6284 \mathrm{E}-12$ $53127.70 \mathrm{c} 3.7251 \mathrm{E}-11$ 132.70 C $1.7384 \mathrm{E}-13$ $8.70 \mathrm{C} 9.3406 \mathrm{E}-12$ $048 \mathrm{E}-12$ $69 \mathrm{E}-1$ $71176.70 \mathrm{c} \quad 6.9978 \mathrm{E}-13$ $72177.70 \mathrm{C} 4.9263 \mathrm{E}-12$ $72180.70 \mathrm{C} 9.2910 \mathrm{E}-12$ $74183.70 \mathrm{C} 1.8398 \mathrm{E}-11$ $85.70 \mathrm{C} 9.4950 \mathrm{E}-12$ $79197.70 \mathrm{C} 2.4001 \mathrm{E}-10$ $80199.70 \mathrm{C} 3.9758 \mathrm{E}-11$ mt41 grph.10t lwtr.10t hwtr.10t Al 2011 Fittings $27.70 \mathrm{C} 5.8488 \mathrm{E}-02$ $65.70 \mathrm{C} 4.5315 \mathrm{E}-0$ $14028.70 \mathrm{C} 1.1154 \mathrm{E}-04$ $00.70 \mathrm{C} 3.8956 \mathrm{E}-05$ $28064.70 \mathrm{C} \quad 6.6957 \mathrm{E}-08$ $50115.70 \mathrm{C} 1.2160 \mathrm{E}-08$ $83209.70 \mathrm{C} 3.2505 \mathrm{E}-05$ $09 \mathrm{E}-0$ $14029.70 \mathrm{C} 5.6635 \mathrm{E}-06$ C $7.2041 \mathrm{E}-06$ $50119.70 \mathrm{C} 3.0722 \mathrm{E}-07$ c $79.64 \%$ Water $+2.61 \%$ Al $2011+17.76 \%$ Al 6061
$35081.70 \mathrm{C} 2.9173 \mathrm{E}-10$ $38084.70 \mathrm{C} 3.0818 \mathrm{E}-11$ $40096.70 \mathrm{C} \quad 1.2769 \mathrm{E}-10$ $42094.70 \mathrm{C} \quad 2.2789 \mathrm{E}-11$ 42097.70 C 2.3528E-11 $44100.70 \mathrm{C} 2.9467 \mathrm{E}-11$ $44104.70 \mathrm{C} 4.3546 \mathrm{E}-11$ $46104.70 \mathrm{C} 2.4743 \mathrm{E}-11$ $46108.70 \mathrm{C} \quad 5.8770 \mathrm{E}-11$ $47109.70 \mathrm{C} 1.0553 \mathrm{E}-10$ $110.70 \mathrm{C} 2.6263 \mathrm{E}-11$ $49113.70 \mathrm{C} 8.8314 \mathrm{E}-12$ $50114.70 \mathrm{C} 1.3141 \mathrm{E}-12$ $50117.70 \mathrm{C} 1.5292 \mathrm{E}-11$ $51121.70 \mathrm{C} 1.1107 \mathrm{E}-10$ $52122.70 \mathrm{C} \quad 4.7236 \mathrm{E}-12$ $52125.70 \mathrm{C} 1.3097 \mathrm{E}-11$ $52130.70 \mathrm{C} 6.3130 \mathrm{E}-11$ $56130.70 \mathrm{c} 1.8245 \mathrm{E}-13$ $135.70 \mathrm{C} 1.1346 \mathrm{E}-11$ $58136.70 \mathrm{C} \quad 3.1209 \mathrm{E}-13$ $58142.70 \mathrm{C} 1.8749 \mathrm{E}-11$ $60143.70 \mathrm{C} 1.9992 \mathrm{E}-11$ $9.6521 \mathrm{E}-13$ $62149.70 \mathrm{C} 4.3450 \mathrm{E}-12$ $62154.70 \mathrm{C} \quad 7.1526 \mathrm{E}-12$ $64152.70 \mathrm{C} \quad 6.0125 \mathrm{E}-14$ $64156.70 \mathrm{c} 6.1538 \mathrm{E}-12$ $60.70 \mathrm{C} 6.5717 \mathrm{E}-12$ $67165.70 \mathrm{C} 2.8663 \mathrm{E}-11$ $68166.70 \mathrm{C} \quad 9.4994 \mathrm{E}-12$ $7175.70 \mathrm{C} 2.6319 \mathrm{E}-11$ $.70 \mathrm{C} 1.3931 \mathrm{E}-12$ C $3.6073 \mathrm{E}-12$ $74186.70 \mathrm{C} 3.6705 \mathrm{E}-11$ $76000.31 \mathrm{C} 2.4855 \mathrm{E}-11$ $78000.31 \mathrm{C} 2.4233 \mathrm{E}-11$ $80198.70 \mathrm{C} 2.3497 \mathrm{E}-11$ $80201.70 \mathrm{C} 3.1062 \mathrm{E}-11$ $81000.31 \mathrm{C} 1.1565 \mathrm{E}-10$ $92238.70 \mathrm{C} 9.8582 \mathrm{E}-11$

(1)
$68170.70 \mathrm{C} \quad 4.2197 \mathrm{E}-12$ 


\section{NEA/NSC/DOC(2006)1}

\section{Fundamental - FUND}

\section{NRAD-FUND-RESR-002 CRIT-REAC-COEF}

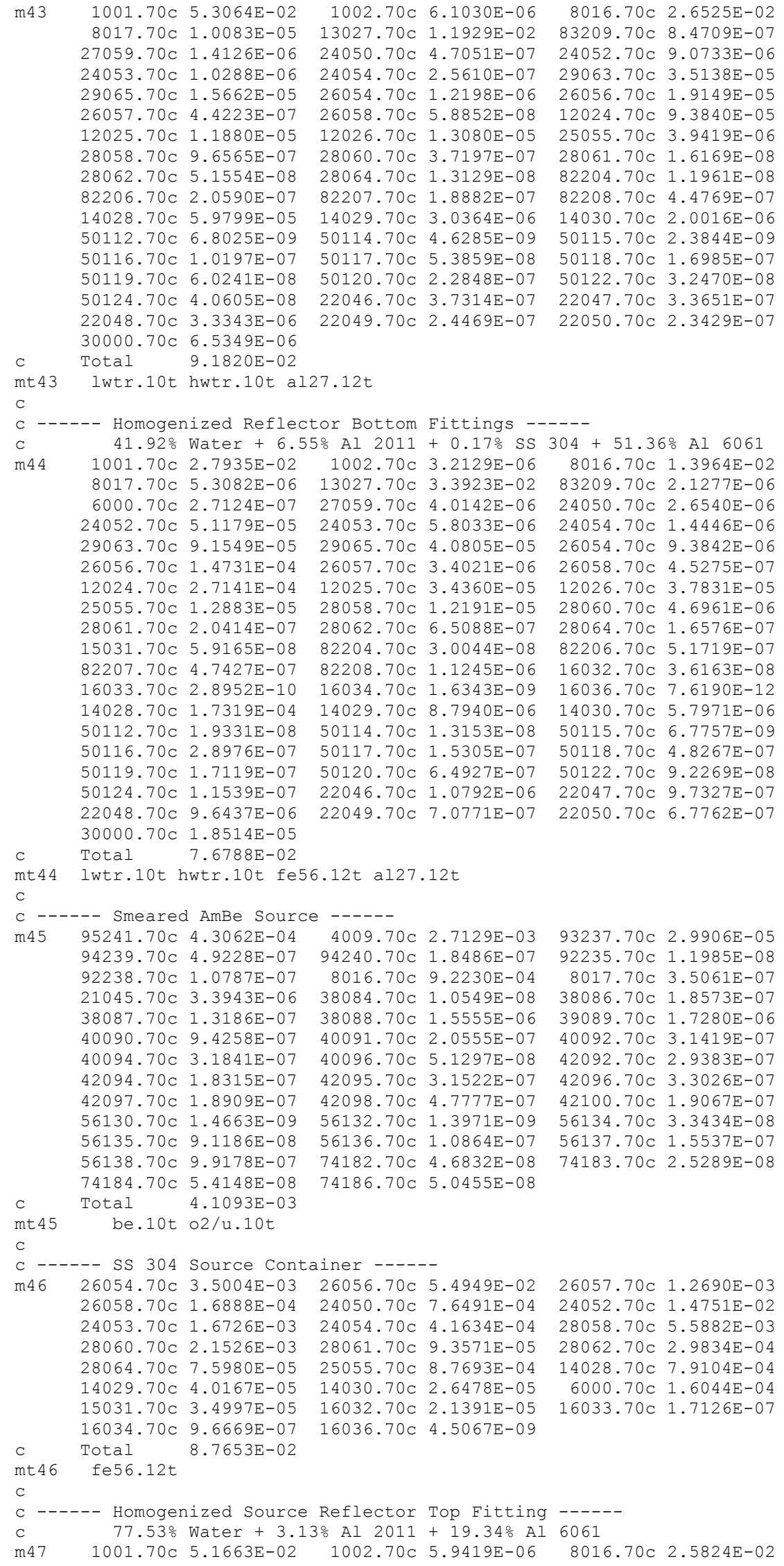




\section{NEA/NSC/DOC(2006)1}

\section{Fundamental - FUND}

\section{NRAD-FUND-RESR-002 CRIT-REAC-COEF}

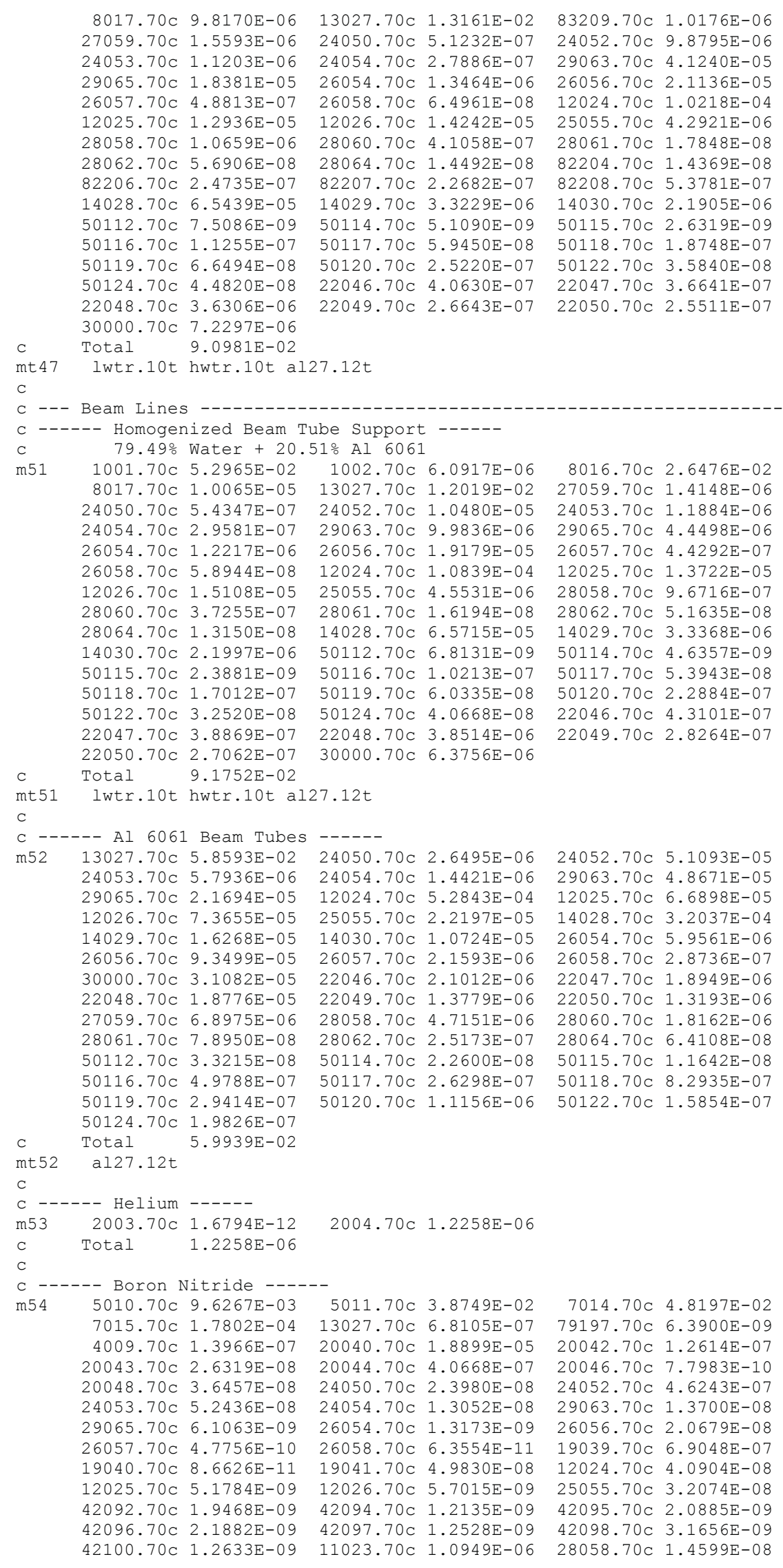




\section{NEA/NSC/DOC(2006)1}

\section{Fundamental - FUND}

\section{NRAD-FUND-RESR-002 \\ CRIT-REAC-COEF}

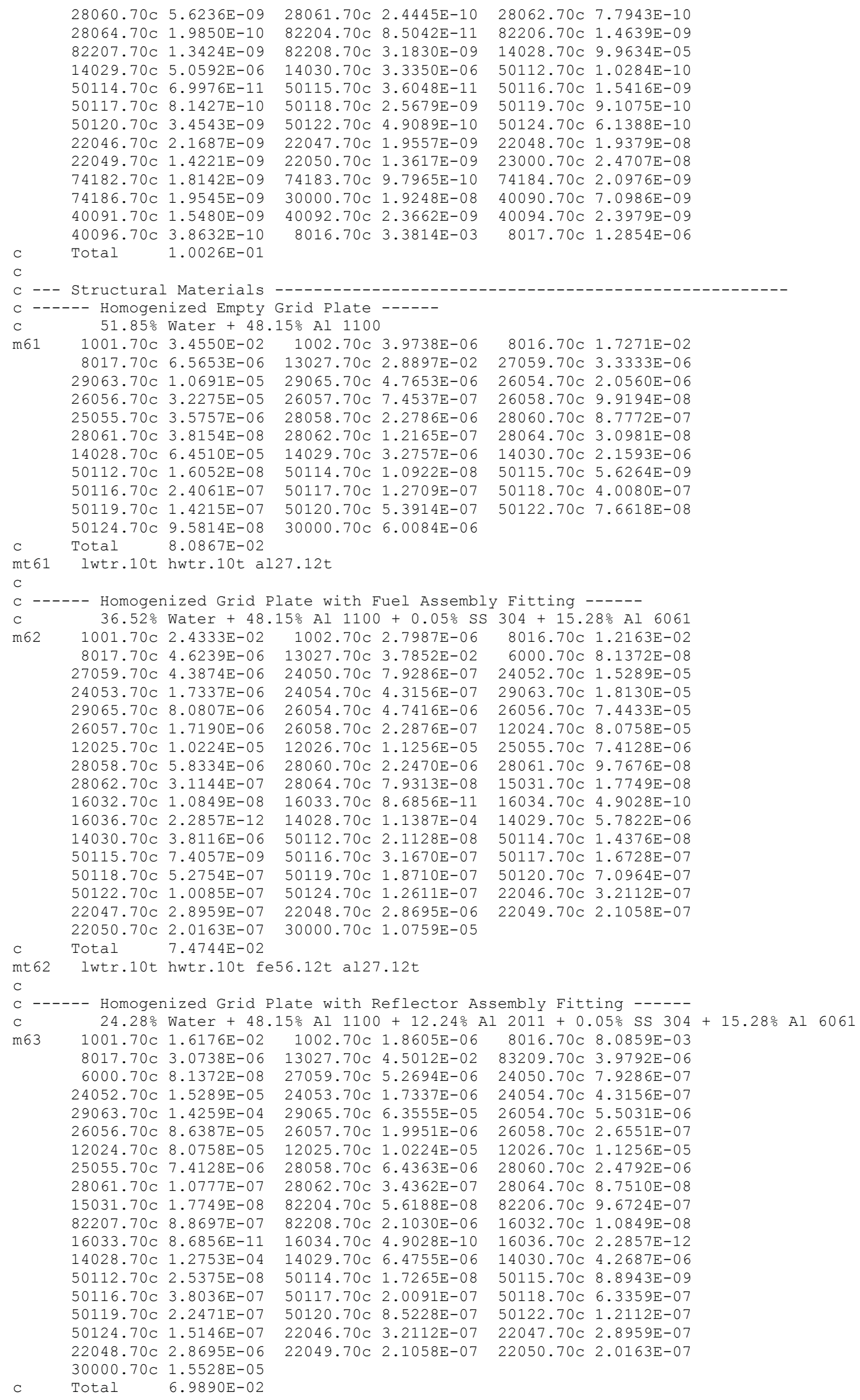




\section{NEA/NSC/DOC(2006)1}

\section{Fundamental - FUND}

\section{NRAD-FUND-RESR-002 \\ CRIT-REAC-COEF}

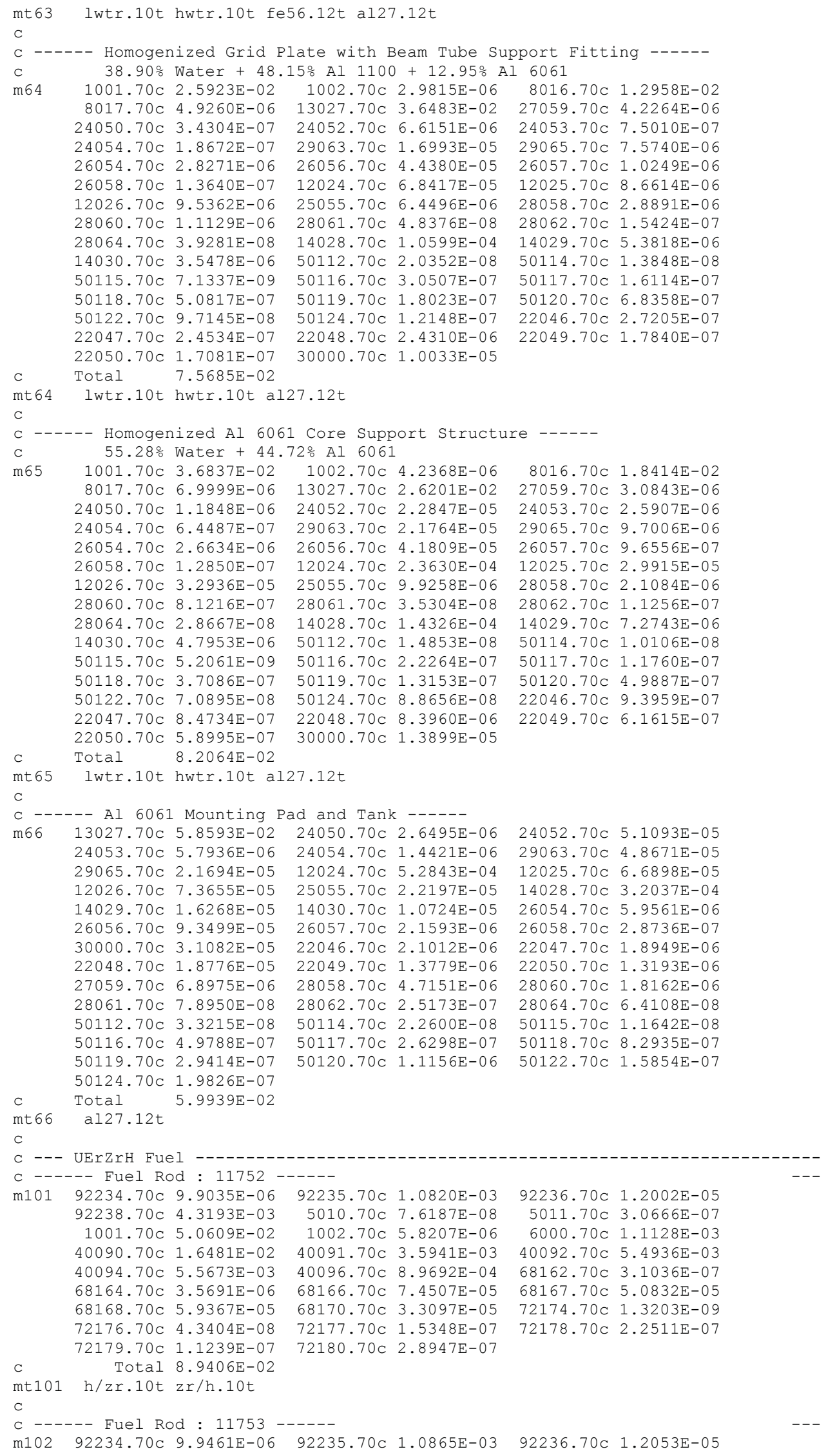




\section{NEA/NSC/DOC(2006)1}

\section{Fundamental - FUND}

\section{NRAD-FUND-RESR-002 CRIT-REAC-COEF}

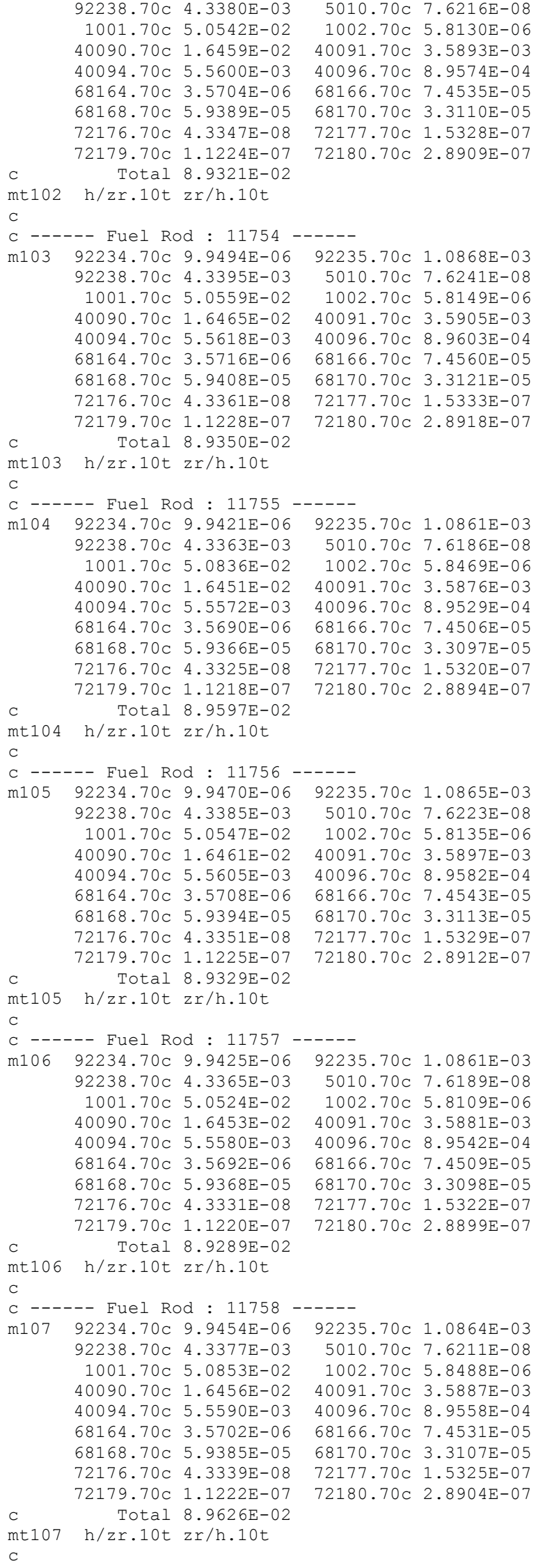

$92236.70 \mathrm{C} \quad 1.2049 \mathrm{E}-05$ $5011.70 \mathrm{C} 3.0667 \mathrm{E}-07$ $6000.70 \mathrm{c} 1.1128 \mathrm{E}-03$ $40092.70 \mathrm{C} 5.4844 \mathrm{E}-03$ $68162.70 \mathrm{C} \quad 3.1036 \mathrm{E}-07$ $68167.70 \mathrm{C} 5.0833 \mathrm{E}-05$ $72174.70 \mathrm{C} 1.3181 \mathrm{E}-09$ $72178.70 \mathrm{C} 2.2473 \mathrm{E}-07$

$92236.70 \mathrm{C} \quad 1.2052 \mathrm{E}-05$ $5011.70 \mathrm{C} 3.0676 \mathrm{E}-07$ $6000.70 \mathrm{C} 1.1131 \mathrm{E}-03$ $40092.70 \mathrm{C} 5.4854 \mathrm{E}-03$ $68162.70 \mathrm{C} 3.1045 \mathrm{E}-07$ $68167.70 \mathrm{C} 5.0848 \mathrm{E}-05$ $72174.70 \mathrm{C} 1.3183 \mathrm{E}-09$ $72178.70 \mathrm{C} 2.2477 \mathrm{E}-07$ $5011.70 \mathrm{C} 3.0688 \mathrm{E}-07$ $6000.70 \mathrm{C} 1.1136 \mathrm{E}-03$ $68162.70 \mathrm{C} 3.1057 \mathrm{E}-07$ $68167.70 \mathrm{C} 5.0868 \mathrm{E}-05$ $92236.70 \mathrm{C} 1.2048 \mathrm{E}-05$ $6000.70 \mathrm{C} 1.1128 \mathrm{E}-03$ $40092.70 \mathrm{C} 5.4837 \mathrm{E}-03$ $68167.70 \mathrm{C} 5.0831 \mathrm{E}-05$ $72174.70 \mathrm{C} 1.3179 \mathrm{E}-09$ $92236.70 \mathrm{C} 1.2054 \mathrm{E}-05$

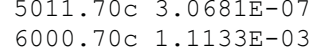
$40092.70 \mathrm{C} 5.4869 \mathrm{E}-03$ $68167.70 \mathrm{C} 5.0856 \mathrm{E}-05$ $72174.70 \mathrm{C} 1.3187 \mathrm{E}-09$ $72178.70 \mathrm{C} \quad 2.2483 \mathrm{E}-07$ 


\section{NEA/NSC/DOC(2006)1}

\section{Fundamental - FUND}

\section{NRAD-FUND-RESR-002}

CRIT-REAC-COEF

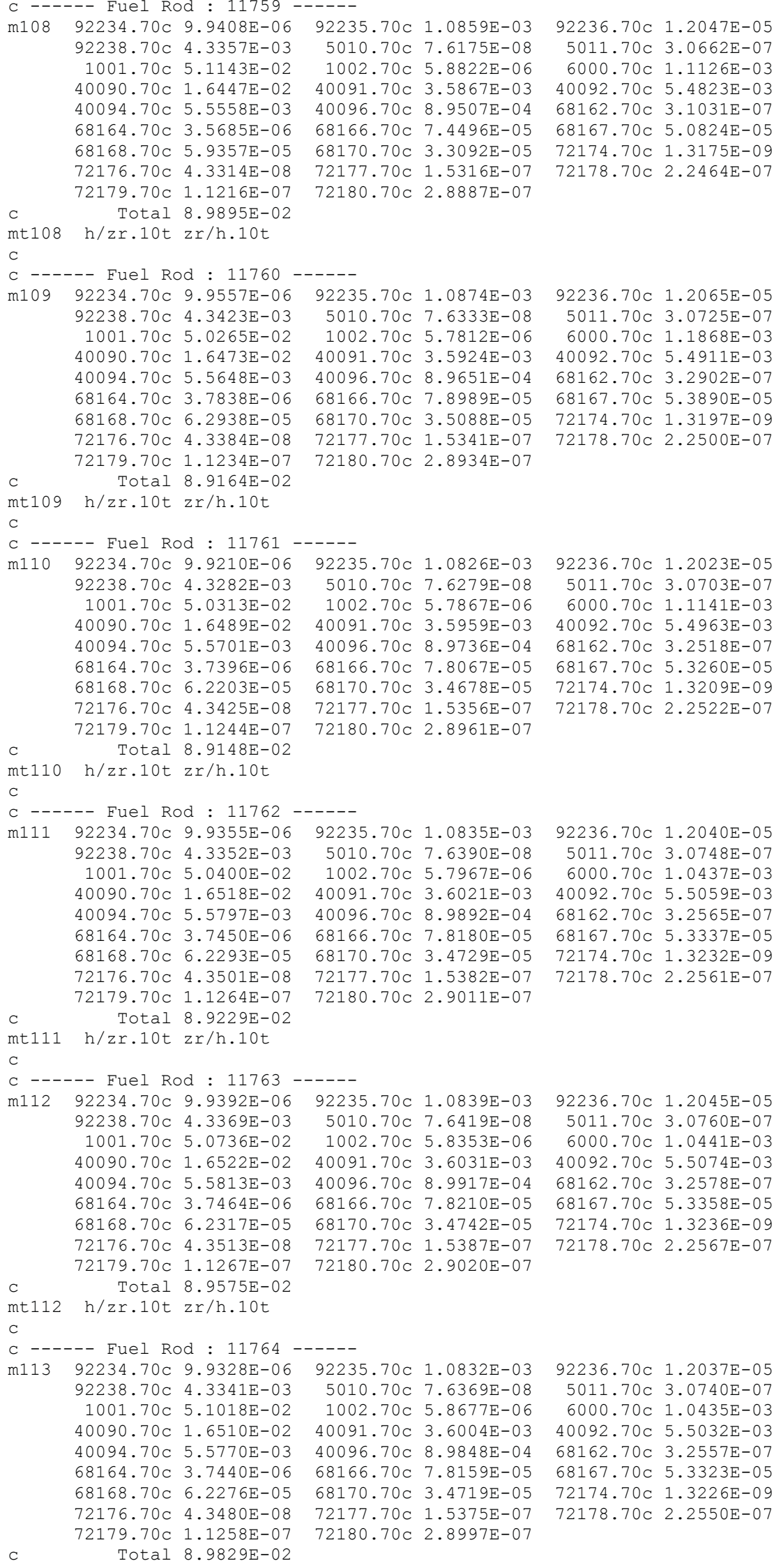

$92236.70 \mathrm{C} \quad 1.2047 \mathrm{E}-05$ $5011.70 \mathrm{C} 3.0662 \mathrm{E}-07$ $6000.70 \mathrm{C} 1.1126 \mathrm{E}-03$ $40092.70 \mathrm{C} 5.4823 \mathrm{E}-03$ $68162.70 \mathrm{C} 3.1031 \mathrm{E}-07$ $68167.70 \mathrm{C} \quad 5.0824 \mathrm{E}-05$ $72174.70 \mathrm{C} 1.3175 \mathrm{E}-09$ $72178.70 \mathrm{C} 2.2464 \mathrm{E}-07$

$92236.70 \mathrm{C} \quad 1.2065 \mathrm{E}-05$ $5011.70 \mathrm{C} 3.0725 \mathrm{E}-07$ $6000.70 \mathrm{C} 1.1868 \mathrm{E}-03$ $40092.70 \mathrm{C} 5.4911 \mathrm{E}-03$ $68162.70 \mathrm{C} \quad 3.2902 \mathrm{E}-07$ $68167.70 \mathrm{C} 5.3890 \mathrm{E}-05$ $72174.70 \mathrm{C} \quad 1.3197 \mathrm{E}-09$ $72178.70 \mathrm{C} 2.2500 \mathrm{E}-07$

$92236.70 \mathrm{C} 1.2023 \mathrm{E}-05$ $5011.70 \mathrm{C} \quad 3.0703 \mathrm{E}-07$ $6000.70 \mathrm{C} 1.1141 \mathrm{E}-03$ $40092.70 \mathrm{C} 5.4963 \mathrm{E}-03$ $68162.70 \mathrm{C} 3.2518 \mathrm{E}-07$ $68167.70 \mathrm{C} 5.3260 \mathrm{E}-05$ $72174.70 \mathrm{C} 1.3209 \mathrm{E}-09$ $72178.70 \mathrm{C} \quad 2.2522 \mathrm{E}-07$

$92236.70 \mathrm{C} \quad 1.2040 \mathrm{E}-05$ $5011.70 \mathrm{C} 3.0748 \mathrm{E}-07$ $6000.70 \mathrm{C} 1.0437 \mathrm{E}-03$ $40092.70 \mathrm{C} 5.5059 \mathrm{E}-03$ $68162.70 \mathrm{C} 3.2565 \mathrm{E}-07$ $68167.70 \mathrm{C} \quad 5.3337 \mathrm{E}-05$ $72174.70 \mathrm{C} \quad 1.3232 \mathrm{E}-09$ $72178.70 \mathrm{C} \quad 2.2561 \mathrm{E}-07$

$92236.70 \mathrm{C} \quad 1.2045 \mathrm{E}-05$ $5011.70 \mathrm{C} 3.0760 \mathrm{E}-07$ $6000.70 \mathrm{C} 1.0441 \mathrm{E}-03$ $40092.70 \mathrm{C} \quad 5.5074 \mathrm{E}-03$ $68162.70 \mathrm{c} 3.2578 \mathrm{E}-07$ $68167.70 \mathrm{C} 5.3358 \mathrm{E}-05$ $72174.70 \mathrm{C} 1.3236 \mathrm{E}-09$ $72178.70 \mathrm{C} 2.2567 \mathrm{E}-07$

$92236.70 \mathrm{C} 1.2037 \mathrm{E}-05$ $5011.70 \mathrm{C} 3.0740 \mathrm{E}-07$ $6000.70 \mathrm{C} 1.0435 \mathrm{E}-03$ $40092.70 \mathrm{C} \quad 5.5032 \mathrm{E}-03$ $68162.70 \mathrm{C} \quad 3.2557 \mathrm{E}-07$ $68167.70 \mathrm{C} 5.3323 \mathrm{E}-05$ $72174.70 \mathrm{C} \quad 1.3226 \mathrm{E}-09$ $72178.70 \mathrm{C} 2.2550 \mathrm{E}-07$ 


\section{NEA/NSC/DOC(2006)1}

\section{Fundamental - FUND}

\section{NRAD-FUND-RESR-002 \\ CRIT-REAC-COEF}

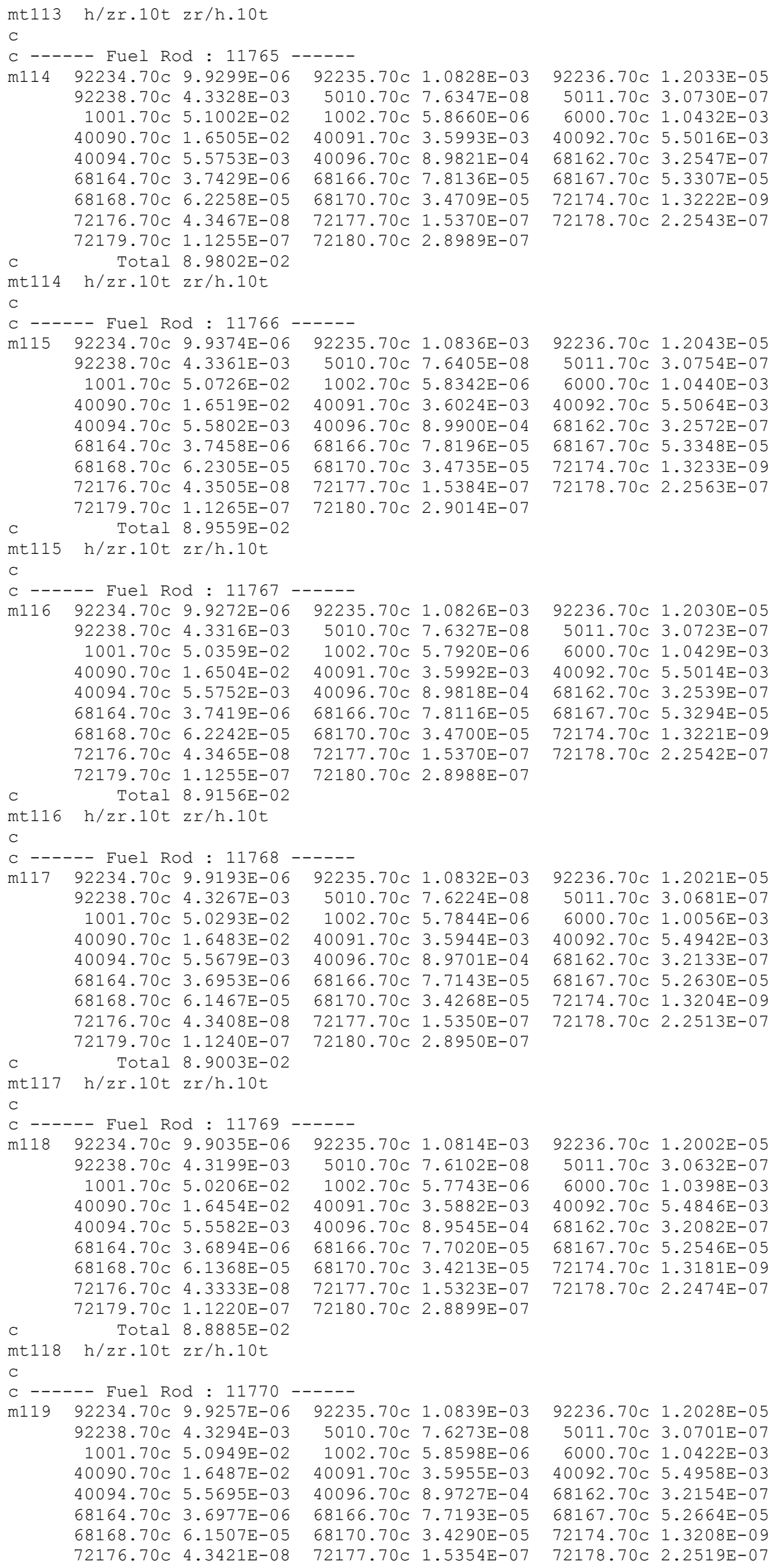

$92236.70 \mathrm{C} 1.2033 \mathrm{E}-05$ $5011.70 \mathrm{C} 3.0730 \mathrm{E}-07$ $6000.70 \mathrm{C} 1.0432 \mathrm{E}-03$ $40092.70 \mathrm{C} 5.5016 \mathrm{E}-03$ $68162.70 \mathrm{C} 3.2547 \mathrm{E}-07$ $68167.70 \mathrm{C} 5.3307 \mathrm{E}-05$ $72174.70 \mathrm{C} 1.3222 \mathrm{E}-09$ $72178.70 \mathrm{C} 2.2543 \mathrm{E}-07$

$92236.70 \mathrm{C} \quad 1.2043 \mathrm{E}-05$ $5011.70 \mathrm{C} 3.0754 \mathrm{E}-07$ $6000.70 \mathrm{C} 1.0440 \mathrm{E}-03$ $40092.70 \mathrm{C} 5.5064 \mathrm{E}-03$ $68162.70 \mathrm{C} 3.2572 \mathrm{E}-07$ $68167.70 \mathrm{C} 5.3348 \mathrm{E}-05$ $72174.70 \mathrm{C} 1.3233 \mathrm{E}-09$ $72178.70 \mathrm{C} 2.2563 \mathrm{E}-07$

$92236.70 \mathrm{C} \quad 1.2030 \mathrm{E}-05$ $5011.70 \mathrm{C} 3.0723 \mathrm{E}-07$ $6000.70 \mathrm{C} 1.0429 \mathrm{E}-03$ $40092.70 \mathrm{C} 5.5014 \mathrm{E}-03$ $68162.70 \mathrm{C} 3.2539 \mathrm{E}-07$ $68167.70 \mathrm{C} 5.3294 \mathrm{E}-05$ $72174.70 \mathrm{C} 1.3221 \mathrm{E}-09$ $72178.70 \mathrm{C} \quad 2.2542 \mathrm{E}-07$

$92236.70 \mathrm{C} \quad 1.2021 \mathrm{E}-05$ $5011.70 \mathrm{C} 3.0681 \mathrm{E}-07$ $6000.70 \mathrm{C} 1.0056 \mathrm{E}-03$ $40092.70 \mathrm{C} 5.4942 \mathrm{E}-03$ $68162.70 \mathrm{C} 3.2133 \mathrm{E}-07$ $68167.70 \mathrm{C} 5.2630 \mathrm{E}-05$ $72174.70 \mathrm{C} \quad 1.3204 \mathrm{E}-09$ $72178.70 \mathrm{C} 2.2513 \mathrm{E}-07$

$92236.70 \mathrm{C} 1.2002 \mathrm{E}-05$ $5011.70 \mathrm{C} 3.0632 \mathrm{E}-07$ $6000.70 \mathrm{C} 1.0398 \mathrm{E}-03$ $40092.70 \mathrm{C} \quad 5.4846 \mathrm{E}-03$ $68162.70 \mathrm{C} 3.2082 \mathrm{E}-07$ $68167.70 \mathrm{C} 5.2546 \mathrm{E}-05$ $72174.70 \mathrm{C}$ 1.3181E-09 $72178.70 \mathrm{C} 2.2474 \mathrm{E}-07$

$92236.70 \mathrm{C} \quad 1.2028 \mathrm{E}-05$ $5011.70 \mathrm{C} \quad 3.0701 \mathrm{E}-07$ $6000.70 \mathrm{C} 1.0422 \mathrm{E}-03$ $40092.70 \mathrm{C} 5.4958 \mathrm{E}-03$ $68162.70 \mathrm{C} \quad 3.2154 \mathrm{E}-07$ $68167.70 \mathrm{C} \quad 5.2664 \mathrm{E}-05$ $72174.70 \mathrm{C} 1.3208 \mathrm{E}-09$ $72178.70 \mathrm{C} \quad 2.2519 \mathrm{E}-07$ 


\section{NEA/NSC/DOC(2006)1}

\section{Fundamental - FUND}

\section{NRAD-FUND-RESR-002 \\ CRIT-REAC-COEF}

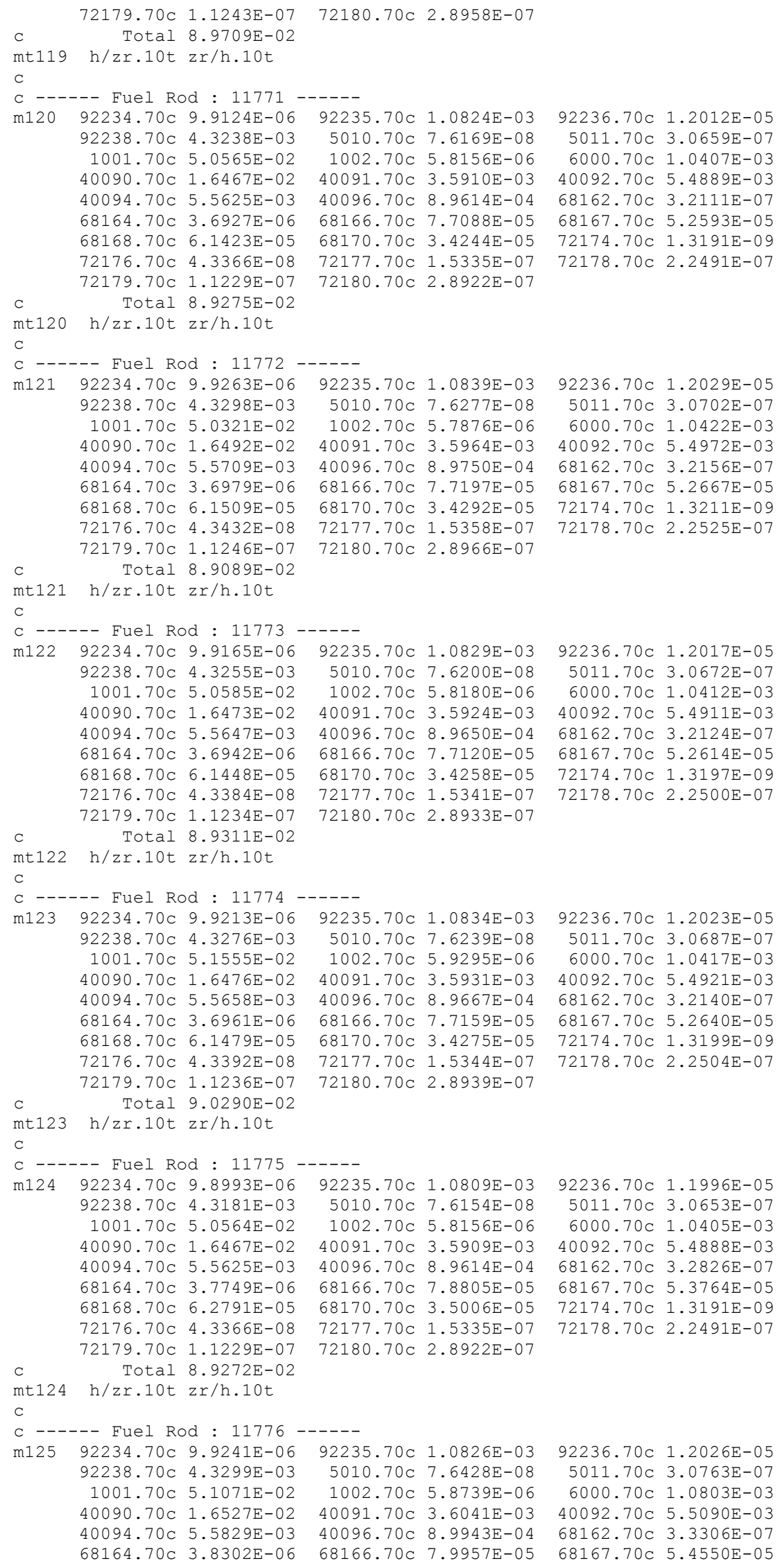

$92236.70 \mathrm{C} \quad 1.2012 \mathrm{E}-05$ $5011.70 \mathrm{C} 3.0659 \mathrm{E}-07$ $6000.70 \mathrm{C} 1.0407 \mathrm{E}-03$ $40092.70 \mathrm{C} 5.4889 \mathrm{E}-03$ $68162.70 \mathrm{C} 3.2111 \mathrm{E}-07$ $68167.70 \mathrm{C} 5.2593 \mathrm{E}-05$ $72174.70 \mathrm{C} 1.3191 \mathrm{E}-09$ $72178.70 \mathrm{C} \quad 2.2491 \mathrm{E}-07$

$92236.70 \mathrm{C} \quad 1.2029 \mathrm{E}-05$ $5011.70 \mathrm{C} 3.0702 \mathrm{E}-07$ $6000.70 \mathrm{C} 1.0422 \mathrm{E}-03$ $40092.70 \mathrm{C} 5.4972 \mathrm{E}-03$ $68162.70 \mathrm{C} 3.2156 \mathrm{E}-07$ $68167.70 \mathrm{C} 5.2667 \mathrm{E}-05$ $72174.70 \mathrm{C} 1.3211 \mathrm{E}-09$ $72178.70 \mathrm{C} 2.2525 \mathrm{E}-07$

$92236.70 \mathrm{C} \quad 1.2017 \mathrm{E}-05$ $5011.70 \mathrm{C} 3.0672 \mathrm{E}-07$ $6000.70 \mathrm{C} 1.0412 \mathrm{E}-03$ $40092.70 \mathrm{C} 5.4911 \mathrm{E}-03$ $68162.70 \mathrm{C} 3.2124 \mathrm{E}-07$ $68167.70 \mathrm{C} 5.2614 \mathrm{E}-05$ $72174.70 \mathrm{C} \quad 1.3197 \mathrm{E}-09$ $72178.70 \mathrm{C} 2.2500 \mathrm{E}-07$

$92236.70 \mathrm{C} \quad 1.2023 \mathrm{E}-05$ $5011.70 \mathrm{c} 3.0687 \mathrm{E}-07$ $6000.70 \mathrm{C} 1.0417 \mathrm{E}-03$ $40092.70 \mathrm{C} 5.4921 \mathrm{E}-03$ $68162.70 \mathrm{C} 3.2140 \mathrm{E}-07$ $68167.70 \mathrm{C} 5.2640 \mathrm{E}-05$ $72174.70 \mathrm{C} \quad 1.3199 \mathrm{E}-09$ $72178.70 \mathrm{C} \quad 2.2504 \mathrm{E}-07$

$92236.70 \mathrm{C} \quad 1.1996 \mathrm{E}-05$ $5011.70 \mathrm{C} 3.0653 \mathrm{E}-07$ $6000.70 \mathrm{C} 1.0405 \mathrm{E}-03$ $40092.70 \mathrm{C} 5.4888 \mathrm{E}-03$ $68162.70 \mathrm{C} \quad 3.2826 \mathrm{E}-07$ $68167.70 \mathrm{C} 5.3764 \mathrm{E}-05$ $72174.70 \mathrm{C} 1.3191 \mathrm{E}-09$ $72178.70 \mathrm{C} 2.2491 \mathrm{E}-07$

$92236.70 \mathrm{C} \quad 1.2026 \mathrm{E}-05$ $5011.70 \mathrm{C} 3.0763 \mathrm{E}-07$ $6000.70 \mathrm{C} 1.0803 \mathrm{E}-03$ $40092.70 \mathrm{C} 5.5090 \mathrm{E}-03$ $68162.70 \mathrm{C} 3.3306 \mathrm{E}-07$ $68167.70 \mathrm{C} 5.4550 \mathrm{E}-05$ 


\section{NEA/NSC/DOC(2006)1}

\section{Fundamental - FUND}

\section{NRAD-FUND-RESR-002 CRIT-REAC-COEF}

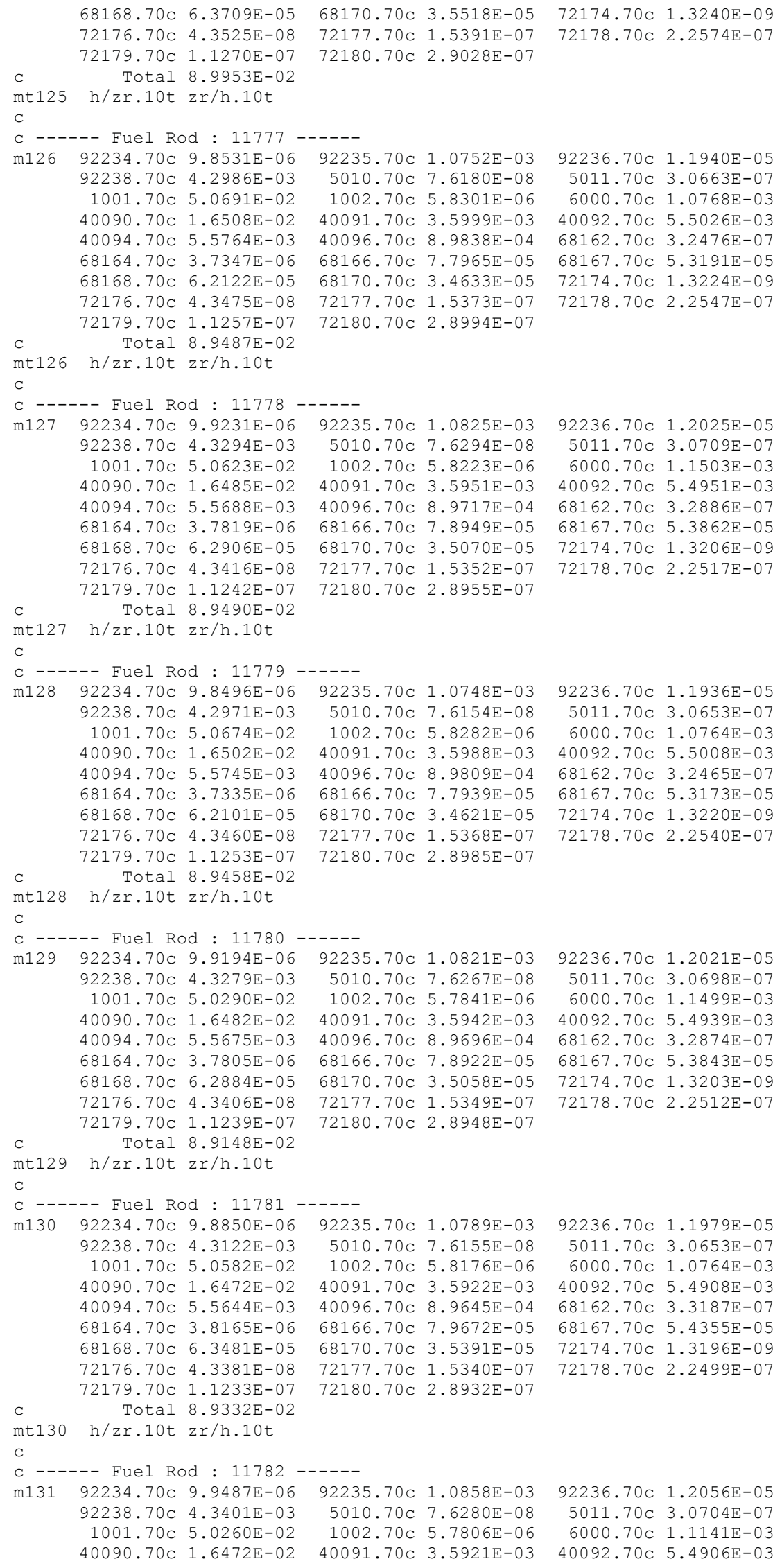

$72174.70 \mathrm{C} 1.3240 \mathrm{E}-09$ $72178.70 \mathrm{C} \quad 2.2574 \mathrm{E}-07$

$92236.70 \mathrm{C} \quad 1.1940 \mathrm{E}-05$ $5011.70 \mathrm{C} 3.0663 \mathrm{E}-07$ $6000.70 \mathrm{C} 1.0768 \mathrm{E}-03$ $40092.70 \mathrm{C} 5.5026 \mathrm{E}-03$ $68162.70 \mathrm{C} 3.2476 \mathrm{E}-07$ $68167.70 \mathrm{C} 5.3191 \mathrm{E}-05$ $72174.70 \mathrm{C} \quad 1.3224 \mathrm{E}-09$ $72178.70 \mathrm{C} \quad 2.2547 \mathrm{E}-07$

$92236.70 \mathrm{C} \quad 1.2025 \mathrm{E}-05$ $5011.70 \mathrm{C} 3.0709 \mathrm{E}-07$ $6000.70 \mathrm{C} 1.1503 \mathrm{E}-03$ $40092.70 \mathrm{C} 5.4951 \mathrm{E}-03$ $68162.70 \mathrm{C} 3.2886 \mathrm{E}-07$ $68167.70 \mathrm{C} 5.3862 \mathrm{E}-05$ $72174.70 \mathrm{C} 1.3206 \mathrm{E}-09$ $72178.70 \mathrm{C} \quad 2.2517 \mathrm{E}-07$

$92236.70 \mathrm{C} 1.1936 \mathrm{E}-05$ $5011.70 \mathrm{C} 3.0653 \mathrm{E}-07$ $6000.70 \mathrm{C} 1.0764 \mathrm{E}-03$ $40092.70 \mathrm{C} 5.5008 \mathrm{E}-03$ $68162.70 \mathrm{C} \quad 3.2465 \mathrm{E}-07$ $68167.70 \mathrm{C} 5.3173 \mathrm{E}-05$ $72174.70 \mathrm{C} 1.3220 \mathrm{E}-09$ $72178.70 \mathrm{C} \quad 2.2540 \mathrm{E}-07$

$92236.70 \mathrm{C} \quad 1.2021 \mathrm{E}-05$ $5011.70 \mathrm{C} 3.0698 \mathrm{E}-07$ $6000.70 \mathrm{C} 1.1499 \mathrm{E}-03$ $40092.70 \mathrm{C} 5.4939 \mathrm{E}-03$ $68162.70 \mathrm{C} 3.2874 \mathrm{E}-07$ $68167.70 \mathrm{C} 5.3843 \mathrm{E}-05$ $72174.70 \mathrm{C}$ 1.3203E-09 $72178.70 \mathrm{C} 2.2512 \mathrm{E}-07$

$92236.70 \mathrm{C} \quad 1.1979 \mathrm{E}-05$ $5011.70 \mathrm{C} 3.0653 \mathrm{E}-07$ $6000.70 \mathrm{C} 1.0764 \mathrm{E}-03$ $40092.70 \mathrm{C} 5.4908 \mathrm{E}-03$ $68162.70 \mathrm{C} 3.3187 \mathrm{E}-07$ $68167.70 \mathrm{C} 5.4355 \mathrm{E}-05$ $72174.70 \mathrm{C} \quad 1.3196 \mathrm{E}-09$ $72178.70 \mathrm{C} \quad 2.2499 \mathrm{E}-07$

$92236.70 \mathrm{C} 1.2056 \mathrm{E}-05$ $5011.70 \mathrm{C} 3.0704 \mathrm{E}-07$ $6000.70 \mathrm{c} 1.1141 \mathrm{E}-03$ $40092.70 \mathrm{C} 5.4906 \mathrm{E}-03$ 


\section{NEA/NSC/DOC(2006)1}

\section{Fundamental - FUND}

\section{NRAD-FUND-RESR-002 CRIT-REAC-COEF}

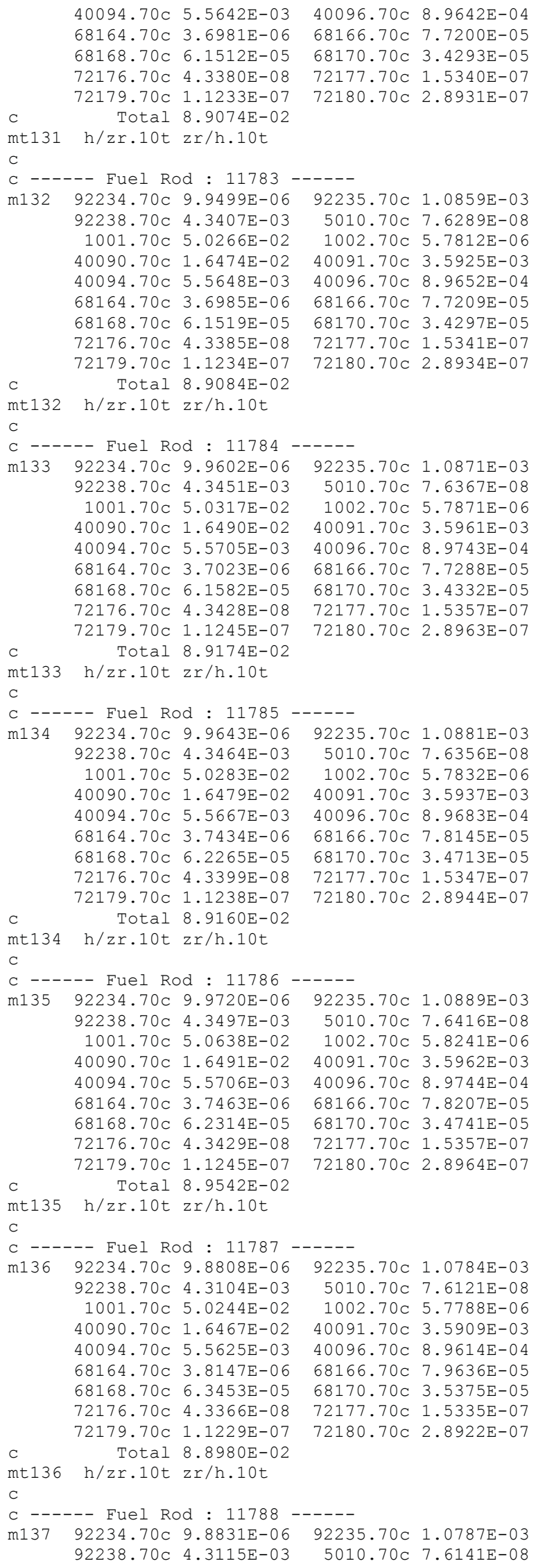

$40094.70 \mathrm{C} 5.5642 \mathrm{E}-03$ $68164.70 \mathrm{C} 3.6981 \mathrm{E}-06$ $68168.70 \mathrm{C} \quad 6.1512 \mathrm{E}-05$ $72176.70 \mathrm{C} 4.3380 \mathrm{E}-08$ $72179.70 \mathrm{C} 1.1233 \mathrm{E}-07$ mt131 h/zr.10t zr/h.10t $\mathrm{C}$ C ------ Fuel Rod : 11783 m132 92234.70c 9.9499E-06 $92238.70 \mathrm{C} 4.3407 \mathrm{E}-03$ $1001.70 \mathrm{C} 5.0266 \mathrm{E}-02$ $40090.70 \mathrm{C} 1.6474 \mathrm{E}-02$ $40094.70 \mathrm{C} 5.5648 \mathrm{E}-03$ $68164.70 \mathrm{C} 3.6985 \mathrm{E}-06$ $68168.70 \mathrm{C} \quad 6.1519 \mathrm{E}-05$ $72176.70 \mathrm{C} \quad 4.3385 \mathrm{E}-08$ $72179.70 \mathrm{C} \quad 1.1234 \mathrm{E}-07$ C Total 8.9084E-02 mt132 h/zr.10t zr/h.10t c C ------ Fuel Rod : 11784 m133 92234.70c 9.9602E-06 $92238.70 \mathrm{C} 4.3451 \mathrm{E}-03$ $1001.70 \mathrm{C} 5.0317 \mathrm{E}-02$ $40090.70 \mathrm{C} 1.6490 \mathrm{E}-02$ $40094.70 \mathrm{C} 5.5705 \mathrm{E}-03$ $68164.70 \mathrm{C} 3.7023 \mathrm{E}-06$ $68168.70 \mathrm{C} \quad 6.1582 \mathrm{E}-05$ $72176.70 \mathrm{C} \quad 4.3428 \mathrm{E}-08$ $72179.70 \mathrm{C} \quad 1.1245 \mathrm{E}-07$ C Total 8.9174E-02 mt133 h/zr.10t zr/h.10t C ------ Fuel Rod : 11785 m13492234.70 9.9643E-06 $92238.70 \mathrm{C} 4.3464 \mathrm{E}-03$ $1001.70 \mathrm{C} 5.0283 \mathrm{E}-02$ $40090.70 \mathrm{C} 1.6479 \mathrm{E}-02$ $40094.70 \mathrm{c} 5.5667 \mathrm{E}-03$ $68164.70 \mathrm{C} \quad 3.7434 \mathrm{E}-06$ $68168.70 \mathrm{c} 6.2265 \mathrm{E}-05$ $72176.70 \mathrm{C} 4.3399 \mathrm{E}-08$ $72179.70 \mathrm{C} 1.1238 \mathrm{E}-07$ C Total 8.9160E-02 mt134 h/zr.10t zr/h.10t c C ------ Fuel Rod : 11786 m135 92234.70C 9.9720E-06 $92238.70 \mathrm{C} \quad 4.3497 \mathrm{E}-03$ $1001.70 \mathrm{C} 5.0638 \mathrm{E}-02$ $40090.70 \mathrm{C} 1.6491 \mathrm{E}-02$ $40094.70 \mathrm{C} 5.5706 \mathrm{E}-03$ $68164.70 \mathrm{c} 3.7463 \mathrm{E}-06$ $68168.70 \mathrm{C} \quad 6.2314 \mathrm{E}-05$ $72176.70 \mathrm{C} \quad 4.3429 \mathrm{E}-08$ $72179.70 \mathrm{C} \quad 1.1245 \mathrm{E}-07$ C Total $8.9542 \mathrm{E}-02$ mt135 h/zr.10t zr/h.10t c c ------ Fuel Rod : 11787 m136 92234.70C 9.8808E-06 92235.70 C 1.0784E-03 $92238.70 \mathrm{C} 4.3104 \mathrm{E}-03 \quad 5010.70 \mathrm{C} 7.6121 \mathrm{E}-08$ $1001.70 \mathrm{C} 5.0244 \mathrm{E}-02 \quad 1002.70 \mathrm{C} 5.7788 \mathrm{E}-06$ $40090.70 \mathrm{C} \quad 1.6467 \mathrm{E}-02 \quad 40091.70 \mathrm{C} 3.5909 \mathrm{E}-03$ $40094.70 \mathrm{C} \quad 5.5625 \mathrm{E}-03 \quad 40096.70 \mathrm{C} \quad 8.9614 \mathrm{E}-04$ $68164.70 \mathrm{c} \quad 3.8147 \mathrm{E}-06 \quad 68166.70 \mathrm{c} 7.9636 \mathrm{E}-05$ $68168.70 \mathrm{C} \quad 6.3453 \mathrm{E}-05 \quad 68170.70 \mathrm{C} \quad 3.5375 \mathrm{E}-05$ $72176.70 \mathrm{C} \quad 4.3366 \mathrm{E}-08 \quad 72177.70 \mathrm{C} \quad 1.5335 \mathrm{E}-07$ $72179.70 \mathrm{C} \quad 1.1229 \mathrm{E}-07 \quad 72180.70 \mathrm{C} \quad 2.8922 \mathrm{E}-07$ C Total $8.8980 \mathrm{E}-02$ mt136 h/zr.10t zr/h.10t $\mathrm{C}$ C ------ Fuel Rod : 11788 ------

m137 92234.70C 9.8831E-06 92235.70 C $1.0787 \mathrm{E}-03$ $92238.70 \mathrm{C} 4.3115 \mathrm{E}-03 \quad 5010.70 \mathrm{C} 7.6141 \mathrm{E}-08$

$68162.70 \mathrm{c} 3.2157 \mathrm{E}-07$ $68167.70 \mathrm{C} 5.2669 \mathrm{E}-05$ $72174.70 \mathrm{C} 1.3195 \mathrm{E}-09$ $72178.70 \mathrm{C} 2.2498 \mathrm{E}-07$

$92236.70 \mathrm{C} 1.2058 \mathrm{E}-05$ $5011.70 \mathrm{C} 3.0707 \mathrm{E}-07$ $6000.70 \mathrm{C} 1.1143 \mathrm{E}-03$ $40092.70 \mathrm{C} 5.4912 \mathrm{E}-03$ $68162.70 \mathrm{C} 3.2161 \mathrm{E}-07$ $68167.70 \mathrm{C} 5.2675 \mathrm{E}-05$ $72174.70 \mathrm{C} 1.3197 \mathrm{E}-09$ $72178.70 \mathrm{C} 2.2501 \mathrm{E}-07$

$92236.70 \mathrm{C} \quad 1.2070 \mathrm{E}-05$ $5011.70 \mathrm{C} 3.0739 \mathrm{E}-07$ $6000.70 \mathrm{C} 1.1154 \mathrm{E}-03$ $40092.70 \mathrm{C} 5.4967 \mathrm{E}-03$ $68162.70 \mathrm{C} \quad 3.2194 \mathrm{E}-07$ $68167.70 \mathrm{C} \quad 5.2729 \mathrm{E}-05$ $72174.70 \mathrm{C} \quad 1.3210 \mathrm{E}-09$ $72178.70 \mathrm{C} 2.2523 \mathrm{E}-07$

$92236.70 \mathrm{C} 1.2075 \mathrm{E}-05$ $5011.70 \mathrm{C} 3.0734 \mathrm{E}-07$ $6000.70 \mathrm{C} 1.1512 \mathrm{E}-03$ $40092.70 \mathrm{C} 5.4931 \mathrm{E}-03$ $68162.70 \mathrm{C} 3.2551 \mathrm{E}-07$ $68167.70 \mathrm{C} 5.3314 \mathrm{E}-05$ $72174.70 \mathrm{C} 1.3201 \mathrm{E}-09$ $72178.70 \mathrm{C} \quad 2.2508 \mathrm{E}-07$

$92236.70 \mathrm{C} \quad 1.2085 \mathrm{E}-05$ $5011.70 \mathrm{C} 3.0758 \mathrm{E}-07$ $6000.70 \mathrm{C} 1.1521 \mathrm{E}-03$ $40092.70 \mathrm{C} 5.4968 \mathrm{E}-03$ $68162.70 \mathrm{C} \quad 3.2577 \mathrm{E}-07$ $68167.70 \mathrm{C} 5.3356 \mathrm{E}-05$ $72174.70 \mathrm{C} 1.3210 \mathrm{E}-09$ $72178.70 \mathrm{C} 2.2524 \mathrm{E}-07$

$92236.70 \mathrm{C}$ 1.1974E-05 $5011.70 \mathrm{C} 3.0640 \mathrm{E}-07$ $6000.70 \mathrm{C} 1.0759 \mathrm{E}-03$ $40092.70 \mathrm{C} 5.4888 \mathrm{E}-03$ $68162.70 \mathrm{C} 3.3172 \mathrm{E}-07$ $68167.70 \mathrm{C} 5.4331 \mathrm{E}-05$ $72174.70 \mathrm{C} 1.3191 \mathrm{E}-09$ $72178.70 \mathrm{C} 2.2491 \mathrm{E}-07$

$92236.70 \mathrm{C} \quad 1.1977 \mathrm{E}-05$ $5011.70 \mathrm{C} 3.0648 \mathrm{E}-07$ 


\section{NEA/NSC/DOC(2006)1}

\section{Fundamental - FUND}

\section{NRAD-FUND-RESR-002 \\ CRIT-REAC-COEF}

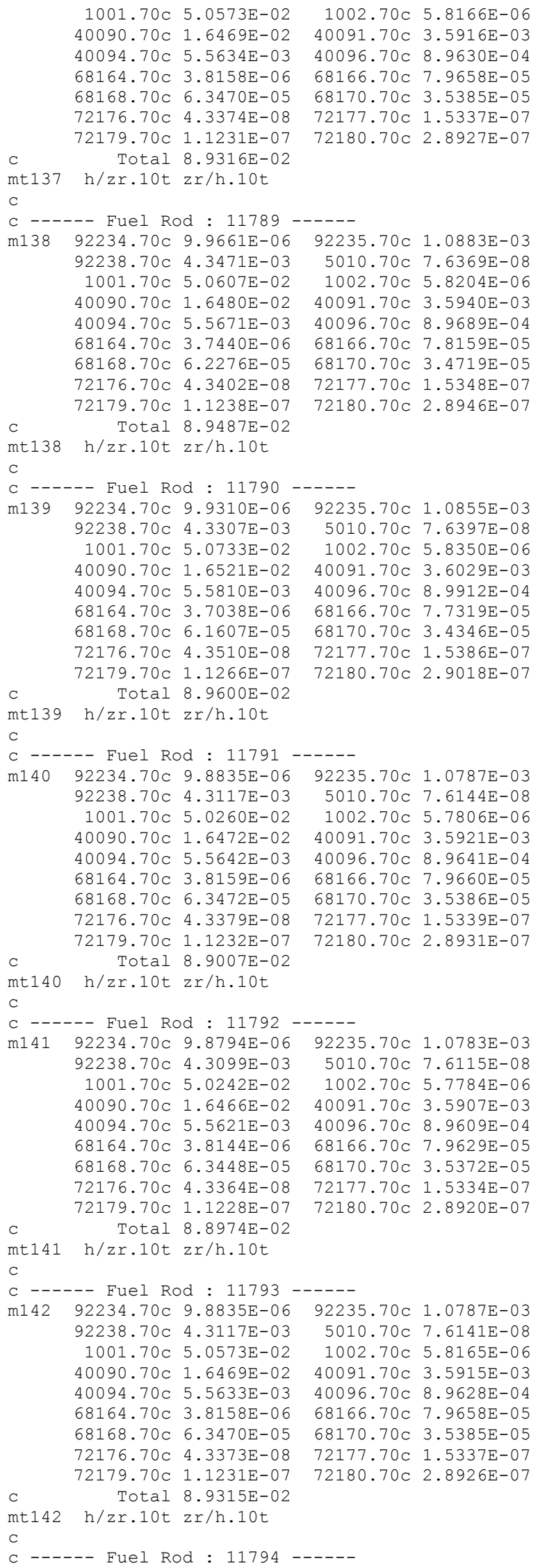

$92236.70 \mathrm{C} \quad 1.1977 \mathrm{E}-05$ $5011.70 \mathrm{C} 3.0648 \mathrm{E}-07$ $6000.70 \mathrm{C} 1.0762 \mathrm{E}-03$ $40092.70 \mathrm{C} 5.4897 \mathrm{E}-03$ $68162.70 \mathrm{C} \quad 3.3181 \mathrm{E}-07$ $68167.70 \mathrm{C} 5.4345 \mathrm{E}-05$ $72174.70 \mathrm{C} 1.3193 \mathrm{E}-09$ $72178.70 \mathrm{C} 2.2495 \mathrm{E}-07$

$5011.70 \mathrm{C} 3.0649 \mathrm{E}-07$ $6000.70 \mathrm{C} 1.0763 \mathrm{E}-03$ . $5.4905 \mathrm{E}-03$

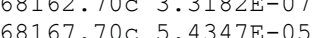
$72174.70 \mathrm{C} 1.3195 \mathrm{E}-09$ $72178.70 \mathrm{C} 2.2498 \mathrm{E}-07$

$92236.70 \mathrm{C} \quad 1.1972 \mathrm{E}-05$ $5011.70 \mathrm{C} \quad 3.0637 \mathrm{E}-07$ $6000.70 \mathrm{C} 1.0759 \mathrm{E}-03$ $40092.70 \mathrm{C} 5.4885 \mathrm{E}-03$ $68162.70 \mathrm{C} 3.3169 \mathrm{E}-07$ $8167.70 \mathrm{C} 5.4326 \mathrm{E}-05$ $72174.70 \mathrm{C} 1.3190 \mathrm{E}-09$ $72178.70 \mathrm{C} \quad 2.2490 \mathrm{E}-07$ 


\section{NEA/NSC/DOC(2006)1}

\section{Fundamental - FUND}

\section{NRAD-FUND-RESR-002 CRIT-REAC-COEF}

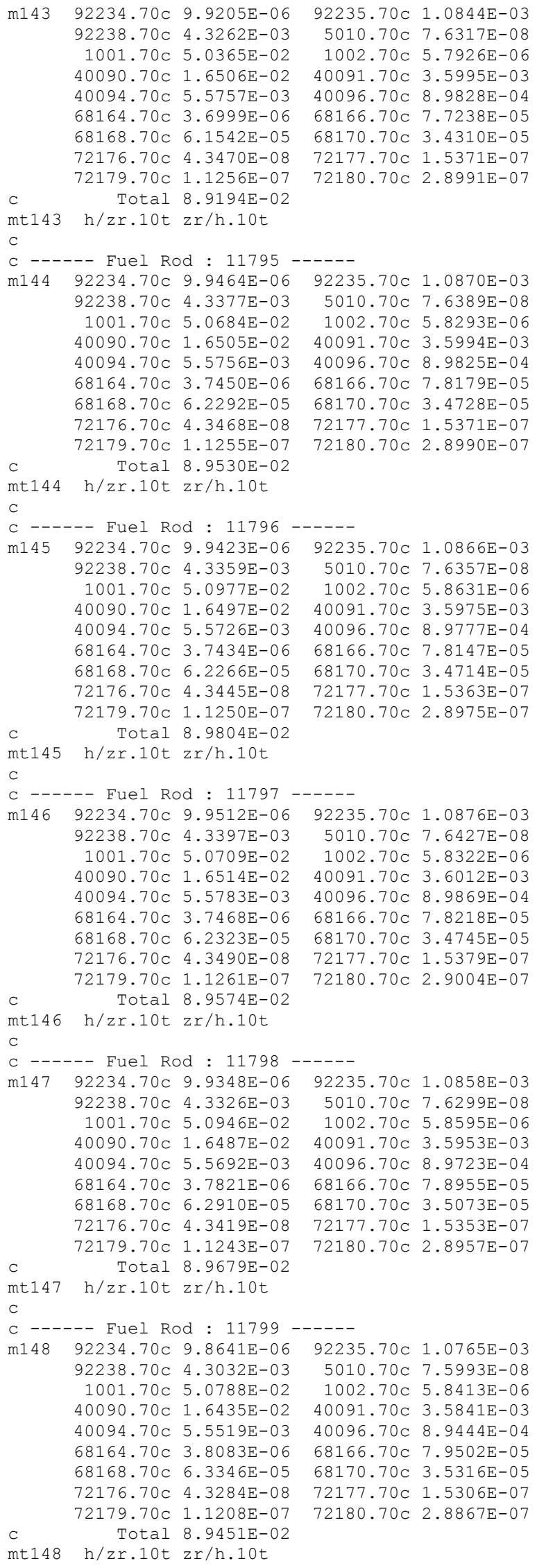

$92236.70 \mathrm{C} \quad 1.2039 \mathrm{E}-05$ $5011.70 \mathrm{C} 3.0711 \mathrm{E}-07$ $6000.70 \mathrm{C} 1.0066 \mathrm{E}-03$ $40092.70 \mathrm{C} 5.4955 \mathrm{E}-03$ $68162.70 \mathrm{C} 3.2888 \mathrm{E}-07$ $68167.70 \mathrm{C} 5.3866 \mathrm{E}-05$ $72174.70 \mathrm{C} \quad 1.3207 \mathrm{E}-09$ $72178.70 \mathrm{C} \quad 2.2518 \mathrm{E}-07$

$92236.70 \mathrm{C} \quad 1.1954 \mathrm{E}-05$ $5011.70 \mathrm{C} 3.0588 \mathrm{E}-07$ $6000.70 \mathrm{C} \quad 1.0741 \mathrm{E}-03$ $40092.70 \mathrm{C} \quad 5.4784 \mathrm{E}-03$ $68162.70 \mathrm{C} 3.3116 \mathrm{E}-07$ $68167.70 \mathrm{C} 5.4239 \mathrm{E}-05$ $72174.70 \mathrm{C} 1.3166 \mathrm{E}-09$ $72178.70 \mathrm{C} \quad 2.2448 \mathrm{E}-07$ 


\section{NEA/NSC/DOC(2006)1}

\section{Fundamental - FUND}

\section{NRAD-FUND-RESR-002 \\ CRIT-REAC-COEF}

$\mathrm{C}$

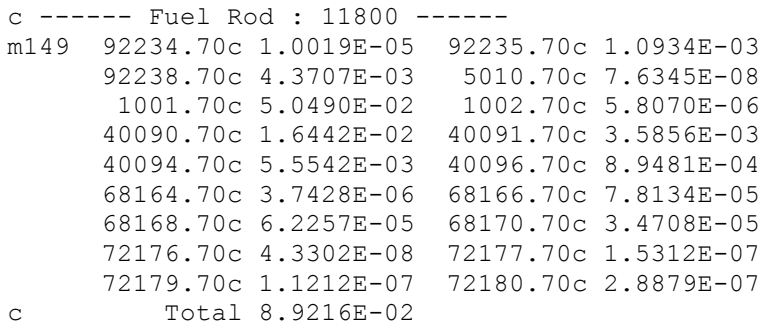
mt149 h/zr.10t zr/h.10t

c

C ------ Fuel Rod : 11801

m150 $92234.70 \mathrm{C} \quad 9.9357 \mathrm{E}-06 \quad 92235.70 \mathrm{C} \quad 1.0864 \mathrm{E}-03$ $92238.70 \mathrm{c} \quad 4.3325 \mathrm{E}-03 \quad 5010.70 \mathrm{c} \quad 7.6306 \mathrm{E}-08$ $1001.70 \mathrm{C} 5.0651 \mathrm{E}-02 \quad 1002.70 \mathrm{C} 5.8255 \mathrm{E}-06$ $40090.70 \mathrm{C} \quad 1.6495 \mathrm{E}-02 \quad 40091.70 \mathrm{C} \quad 3.5971 \mathrm{E}-03$ $40094.70 \mathrm{C} \quad 5.5719 \mathrm{E}-03 \quad 40096.70 \mathrm{c} \quad 8.9767 \mathrm{E}-04$ $68164.70 \mathrm{c} \quad 3.7409 \mathrm{E}-06 \quad 68166.70 \mathrm{c} \quad 7.8095 \mathrm{E}-05$ $68168.70 \mathrm{c} \quad 6.2225 \mathrm{E}-05 \quad 68170.70 \mathrm{c} \quad 3.4691 \mathrm{E}-05$ $72176.70 \mathrm{c} \quad 4.3440 \mathrm{E}-08 \quad 72177.70 \mathrm{c} \quad 1.5361 \mathrm{E}-07$ $72179.70 \mathrm{c} \quad 1.1248 \mathrm{E}-07 \quad 72180.70 \mathrm{c} \quad 2.8971 \mathrm{E}-07$ C Total $8.9361 \mathrm{E}-02$ mt150 h/zr.10t zr/h.10t C C ------ Fuel Rod : 11802

m151 92234.70 C 1.0000E-05 $92235.70 \mathrm{C} 1.0942 \mathrm{E}-03$ $92238.70 \mathrm{C} 4.3598 \mathrm{E}-03 \quad 5010.70 \mathrm{C} 7.6333 \mathrm{E}-08$ $1001.70 \mathrm{C} 5.0204 \mathrm{E}-02 \quad 1002.70 \mathrm{C} 5.7742 \mathrm{E}-06$ $40090.70 \mathrm{C} 1.6453 \mathrm{E}-02 \quad 40091.70 \mathrm{C} 3.5881 \mathrm{E}-03$ $40094.70 \mathrm{C} \quad 5.5580 \mathrm{E}-03 \quad 40096.70 \mathrm{C} \quad 8.9542 \mathrm{E}-04$ $68164.70 \mathrm{c} \quad 3.8670 \mathrm{E}-06 \quad 68166.70 \mathrm{c} \quad 8.0726 \mathrm{E}-05$ $68168.70 \mathrm{C} \quad 6.4321 \mathrm{E}-05 \quad 68170.70 \mathrm{C} \quad 3.5859 \mathrm{E}-05$ $72176.70 \mathrm{C} \quad 4.3332 \mathrm{E}-08 \quad 72177.70 \mathrm{C} \quad 1.5323 \mathrm{E}-07$ $72179.70 \mathrm{C} \quad 1.1220 \mathrm{E}-07 \quad 72180.70 \mathrm{C} \quad 2.8899 \mathrm{E}-07$ C Total $8.8842 \mathrm{E}-02$ mt151 h/zr.10t zr/h.10t

$$
\text { c }
$$
C ------ Fuel Rod : 11803 m152 92234.70c 9.9943E-06 $92238.70 \mathrm{C} 4.3572 \mathrm{E}-03$ $1001.70 \mathrm{C} 5.0489 \mathrm{E}-02$ $40090.70 \mathrm{C} 1.6442 \mathrm{E}-02$ $40094.70 \mathrm{C} 5.5542 \mathrm{E}-03$ $68164.70 \mathrm{C} \quad 3.8647 \mathrm{E}-06$ $68168.70 \mathrm{C} \quad 6.4284 \mathrm{E}-05$ $72176.70 \mathrm{C} \quad 4.3301 \mathrm{E}-08$ $72179.70 \mathrm{C} 1.1212 \mathrm{E}-07$ C Total 8.9101E-02 mt152 h/zr.10t zr/h.10t c C ------ Fuel Rod : 11804 m153 92234.70c 9.9156E-06 92235.70 c $1.0824 \mathrm{E}-03$ $92238.70 \mathrm{C} 4.3255 \mathrm{E}-03$ $1001.70 \mathrm{C} 5.0314 \mathrm{E}-02$ $40090.70 \mathrm{C} \quad 1.6489 \mathrm{E}-02$ $40094.70 \mathrm{C} 5.5701 \mathrm{E}-03$ $68164.70 \mathrm{C} \quad 3.7375 \mathrm{E}-06$ $68168.70 \mathrm{C} 6.2168 \mathrm{E}-05$ $72176.70 \mathrm{C} 4.3426 \mathrm{E}-08$ $72179.70 \mathrm{C} \quad 1.1244 \mathrm{E}-07$ C Total $8.9001 \mathrm{E}-02$ mt153 h/zr.10t zr/h.10t c C ------ Fuel Rod : 11805 m15492234.70C 9.9329E-06 $92238.70 \mathrm{C} 4.3330 \mathrm{E}-03$ $1001.70 \mathrm{C} 5.0718 \mathrm{E}-02$ $40090.70 \mathrm{C} \quad 1.6517 \mathrm{E}-02$ $40094.70 \mathrm{C} 5.5793 \mathrm{E}-03$ $68164.70 \mathrm{C} \quad 3.7441 \mathrm{E}-06$ $68168.70 \mathrm{C} \quad 6.2277 \mathrm{E}-05$ $72176.70 \mathrm{C} 4.3498 \mathrm{E}-08$ $72179.70 \mathrm{C} 1.1263 \mathrm{E}-07$
$92235.70 \mathrm{C} 1.0936 \mathrm{E}-03$ $5010.70 \mathrm{C} 7.6288 \mathrm{E}-08$ $1002.70 \mathrm{C} 5.8069 \mathrm{E}-06$ $40091.70 \mathrm{C} 3.5856 \mathrm{E}-03$ $40096.70 \mathrm{C} 8.9480 \mathrm{E}-04$ $68166.70 \mathrm{C} 8.0678 \mathrm{E}-05$ $68170.70 \mathrm{C} 3.5838 \mathrm{E}-05$ $72177.70 \mathrm{C} \quad 1.5312 \mathrm{E}-07$ $72180.70 \mathrm{C} \quad 2.8879 \mathrm{E}-07$ $5010.70 \mathrm{C} 7.6236 \mathrm{E}-08$ $1002.70 \mathrm{C} 5.7867 \mathrm{E}-06$ $40091.70 \mathrm{C} \quad 3.5959 \mathrm{E}-03$ $40096.70 \mathrm{C} \quad 8.9737 \mathrm{E}-04$ $68166.70 \mathrm{C} 7.8023 \mathrm{E}-05$ $68170.70 \mathrm{C} 3.4659 \mathrm{E}-05$ $72177.70 \mathrm{C} \quad 1.5356 \mathrm{E}-07$ $72180.70 \mathrm{C} \quad 2.8962 \mathrm{E}-07$ $5010.70 \mathrm{c} 7.6371 \mathrm{E}-08$ $1002.70 \mathrm{C} \quad 5.8332 \mathrm{E}-06$ $40091.70 \mathrm{C} 3.6019 \mathrm{E}-03$ $40096.70 \mathrm{C} 8.9886 \mathrm{E}-04$ $68166.70 \mathrm{C} 7.8160 \mathrm{E}-05$ $68170.70 \mathrm{C} \quad 3.4720 \mathrm{E}-05$ $72177.70 \mathrm{C} 1.5381 \mathrm{E}-07$ $72180.70 \mathrm{C} 2.9010 \mathrm{E}-07$
$92236.70 \mathrm{C} \quad 1.2141 \mathrm{E}-05$ $5011.70 \mathrm{C} 3.0730 \mathrm{E}-07$ $6000.70 \mathrm{C} 1.0431 \mathrm{E}-03$ $40092.70 \mathrm{C} 5.4807 \mathrm{E}-03$ $68162.70 \mathrm{C} \quad 3.2546 \mathrm{E}-07$ $68167.70 \mathrm{C} 5.3306 \mathrm{E}-05$ $72174.70 \mathrm{C} 1.3172 \mathrm{E}-09$ $72178.70 \mathrm{C} \quad 2.2458 \mathrm{E}-07$

$92236.70 \mathrm{C} \quad 1.2041 \mathrm{E}-05$ $5011.70 \mathrm{C} 3.0714 \mathrm{E}-07$ $6000.70 \mathrm{C} 9.7070 \mathrm{E}-04$ $40092.70 \mathrm{C} \quad 5.4982 \mathrm{E}-03$ $68162.70 \mathrm{C} 3.2530 \mathrm{E}-07$ $68167.70 \mathrm{C} 5.3279 \mathrm{E}-05$ $72174.70 \mathrm{C} 1.3214 \mathrm{E}-09$ $72178.70 \mathrm{C} 2.2529 \mathrm{E}-07$

$92236.70 \mathrm{C}$ 1.2119E-05 $5011.70 \mathrm{C} 3.0725 \mathrm{E}-07$ $6000.70 \mathrm{C} \quad 9.3508 \mathrm{E}-04$ $40092.70 \mathrm{C} 5.4845 \mathrm{E}-03$ $68162.70 \mathrm{C} 3.3626 \mathrm{E}-07$ $68167.70 \mathrm{C} 5.5074 \mathrm{E}-05$ $72174.70 \mathrm{C} 1.3181 \mathrm{E}-09$ $72178.70 \mathrm{C} 2.2473 \mathrm{E}-07$

$92236.70 \mathrm{C} 1.2111 \mathrm{E}-05$ $5011.70 \mathrm{C} 3.0707 \mathrm{E}-07$ $6000.70 \mathrm{C} 9.3453 \mathrm{E}-04$ $40092.70 \mathrm{C} \quad 5.4807 \mathrm{E}-03$ $68162.70 \mathrm{C} \quad 3.3606 \mathrm{E}-07$ $68167.70 \mathrm{C} 5.5042 \mathrm{E}-05$ $72174.70 \mathrm{C} 1.3172 \mathrm{E}-09$ $72178.70 \mathrm{C} \quad 2.2457 \mathrm{E}-07$

$92236.70 \mathrm{C} \quad 1.2016 \mathrm{E}-05$ $5011.70 \mathrm{C} 3.0686 \mathrm{E}-07$ $6000.70 \mathrm{C} 9.6981 \mathrm{E}-04$ $40092.70 \mathrm{C} 5.4964 \mathrm{E}-03$ $68162.70 \mathrm{C} \quad 3.2500 \mathrm{E}-07$ $68167.70 \mathrm{C} 5.3230 \mathrm{E}-05$ $72174.70 \mathrm{C}$ 1.3209E-09 $72178.70 \mathrm{C} \quad 2.2522 \mathrm{E}-07$

$92236.70 \mathrm{C} \quad 1.2037 \mathrm{E}-05$ $5011.70 \mathrm{C} 3.0740 \mathrm{E}-07$ $6000.70 \mathrm{C} \quad 9.7152 \mathrm{E}-04$ $40092.70 \mathrm{C} 5.5055 \mathrm{E}-03$ $68162.70 \mathrm{C} 3.2557 \mathrm{E}-07$ $68167.70 \mathrm{C} \quad 5.3324 \mathrm{E}-05$ $72174.70 \mathrm{C} 1.3231 \mathrm{E}-09$ $72178.70 \mathrm{C} \quad 2.2559 \mathrm{E}-07$ 
NEA/NSC/DOC(2006)1

\section{Fundamental - FUND}

\section{NRAD-FUND-RESR-002 CRIT-REAC-COEF}

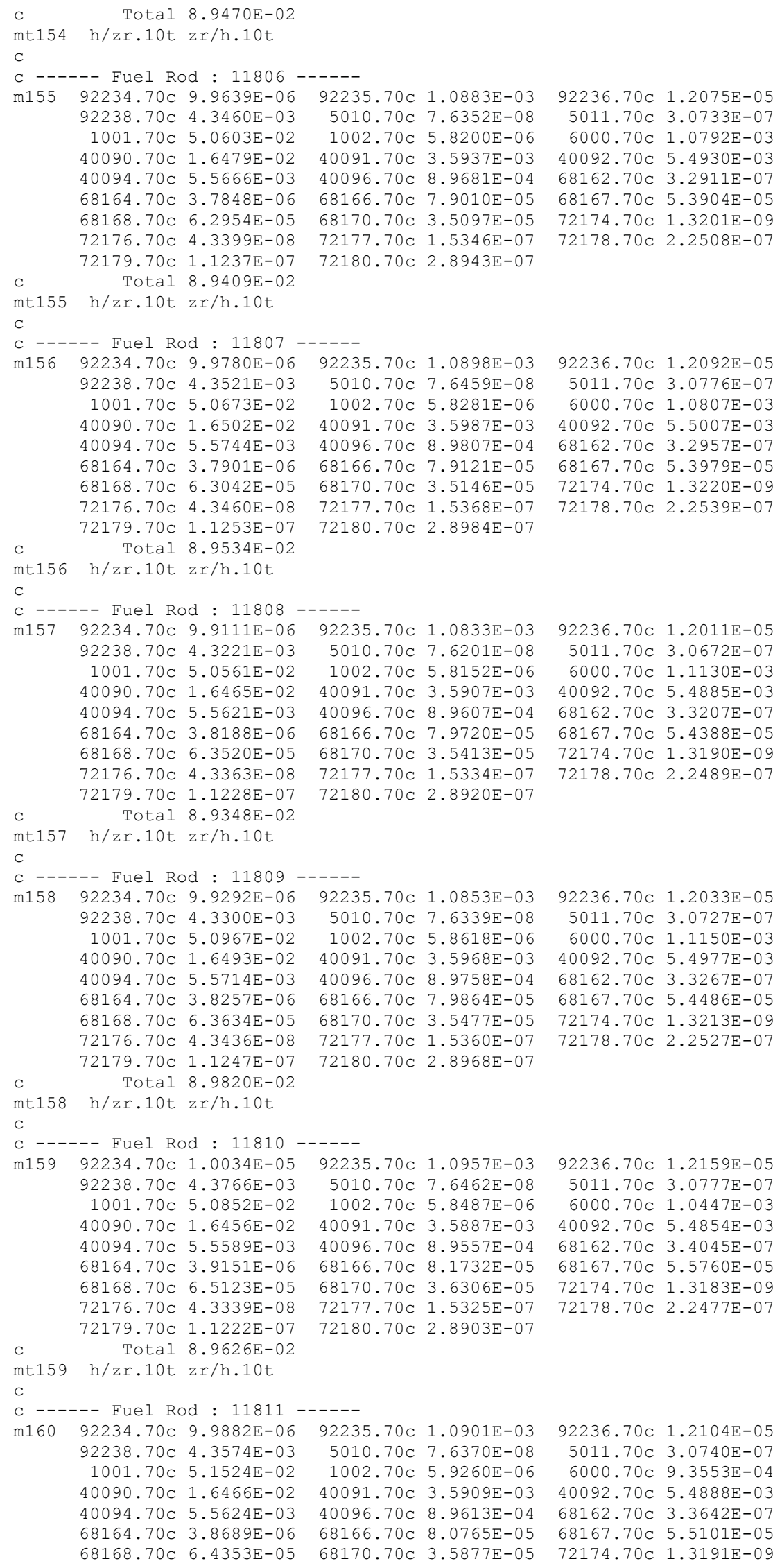

$92236.70 \mathrm{C} \quad 1.2075 \mathrm{E}-05$ $5011.70 \mathrm{C} 3.0733 \mathrm{E}-07$ $6000.70 \mathrm{C} 1.0792 \mathrm{E}-03$ $40092.70 \mathrm{C} 5.4930 \mathrm{E}-03$ $68162.70 \mathrm{C} 3.2911 \mathrm{E}-07$ $68167.70 \mathrm{C} 5.3904 \mathrm{E}-05$ $72174.70 \mathrm{C} 1.3201 \mathrm{E}-09$ $72178.70 \mathrm{C} 2.2508 \mathrm{E}-07$

$92236.70 \mathrm{C} \quad 1.2092 \mathrm{E}-05$ $5011.70 \mathrm{C} 3.0776 \mathrm{E}-07$ $6000.70 \mathrm{C} 1.0807 \mathrm{E}-03$ $40092.70 \mathrm{C} 5.5007 \mathrm{E}-03$ $68162.70 \mathrm{C} 3.2957 \mathrm{E}-07$ $68167.70 \mathrm{C} 5.3979 \mathrm{E}-05$ $72174.70 \mathrm{C} 1.3220 \mathrm{E}-09$ $72178.70 \mathrm{C} \quad 2.2539 \mathrm{E}-07$

$92236.70 \mathrm{C} 1.2011 \mathrm{E}-05$ $5011.70 \mathrm{C} 3.0672 \mathrm{E}-07$ $6000.70 \mathrm{C} 1.1130 \mathrm{E}-03$ $40092.70 \mathrm{C} 5.4885 \mathrm{E}-03$ $68162.70 \mathrm{C} \quad 3.3207 \mathrm{E}-07$ $68167.70 \mathrm{C} 5.4388 \mathrm{E}-05$ $72174.70 \mathrm{C} 1.3190 \mathrm{E}-09$ $72178.70 \mathrm{C} \quad 2.2489 \mathrm{E}-07$

$92236.70 \mathrm{C} \quad 1.2033 \mathrm{E}-05$ $5011.70 \mathrm{C} 3.0727 \mathrm{E}-07$ $6000.70 \mathrm{C} 1.1150 \mathrm{E}-03$ $40092.70 \mathrm{C} 5.4977 \mathrm{E}-03$ $68162.70 \mathrm{C} \quad 3.3267 \mathrm{E}-07$ $68167.70 \mathrm{C} \quad 5.4486 \mathrm{E}-05$ $72174.70 \mathrm{C} 1.3213 \mathrm{E}-09$ $72178.70 \mathrm{C} \quad 2.2527 \mathrm{E}-07$

$92236.70 \mathrm{C} \quad 1.2159 \mathrm{E}-05$ $5011.70 \mathrm{C} 3.0777 \mathrm{E}-07$ $6000.70 \mathrm{C} 1.0447 \mathrm{E}-03$ $40092.70 \mathrm{C} 5.4854 \mathrm{E}-03$ $68162.70 \mathrm{C} 3.4045 \mathrm{E}-07$ $68167.70 \mathrm{C} 5.5760 \mathrm{E}-05$ $72174.70 \mathrm{C} 1.3183 \mathrm{E}-09$ $72178.70 \mathrm{C} \quad 2.2477 \mathrm{E}-07$

$92236.70 \mathrm{C} 1.2104 \mathrm{E}-05$ $5011.70 \mathrm{C} 3.0740 \mathrm{E}-07$ $6000.70 \mathrm{C} 9.3553 \mathrm{E}-04$ $40092.70 \mathrm{C} \quad 5.4888 \mathrm{E}-03$ $68162.70 \mathrm{C} 3.3642 \mathrm{E}-07$ $68167.70 \mathrm{C} 5.5101 \mathrm{E}-05$ 72174.70C 1.3191E-09 


\section{NEA/NSC/DOC(2006)1}

\section{Fundamental - FUND}

\section{NRAD-FUND-RESR-002 CRIT-REAC-COEF}

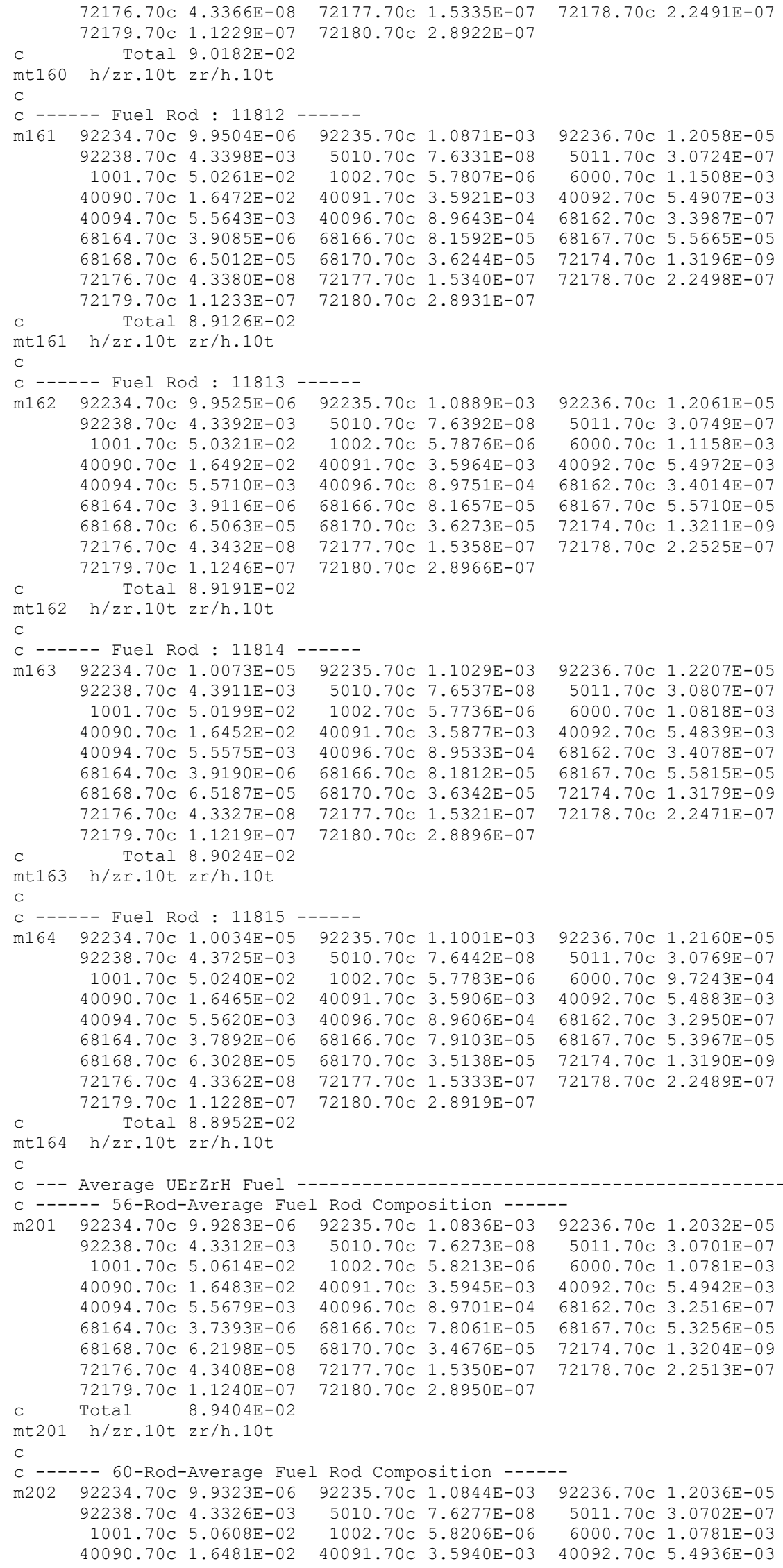
$40090.70 \mathrm{C} 1.6481 \mathrm{E}-02 \quad 40091.70 \mathrm{C} \quad 3.5940 \mathrm{E}-03 \quad 40092.70 \mathrm{C} \quad 5.4936 \mathrm{E}-03$

$92236.70 \mathrm{C} 1.2032 \mathrm{E}-05$ $5011.70 \mathrm{c} 3.0701 \mathrm{E}-07$

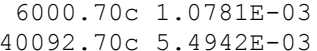
$68162.70 \mathrm{C} 3.2516 \mathrm{E}-07$ $68167.70 \mathrm{c} 5.3256 \mathrm{E}-05$ $72174.70 \mathrm{C} 1.3204 \mathrm{E}-09$ $72178.70 \mathrm{c} 2.2513 \mathrm{E}-07$ 


\section{NEA/NSC/DOC(2006)1}

\section{Fundamental - FUND}

\section{NRAD-FUND-RESR-002 CRIT-REAC-COEF}

\begin{tabular}{|c|c|c|c|c|c|c|}
\hline & $40094.70 \mathrm{C}$ & $5.5672 \mathrm{E}-03$ & $40096.70 \mathrm{C}$ & $8.9691 \mathrm{E}-04$ & $68162.70 \mathrm{C}$ & $3.2517 \mathrm{E}-07$ \\
\hline & $68164.70 \mathrm{C}$ & $3.7395 \mathrm{E}-06$ & $68166.70 \mathrm{C}$ & $7.8064 \mathrm{E}-05$ & $68167.70 \mathrm{C}$ & $5.3258 \mathrm{E}-05$ \\
\hline & $68168.70 \mathrm{C}$ & $6.2200 \mathrm{E}-05$ & $68170.70 \mathrm{C}$ & $3.4677 \mathrm{E}-05$ & $72174.70 \mathrm{C}$ & 1. $3203 E-09$ \\
\hline & $72176.70 \mathrm{C}$ & $4.3403 E-08$ & $72177.70 \mathrm{C}$ & $1.5348 \mathrm{E}-07$ & $72178.70 \mathrm{C}$ & $2.2510 \mathrm{E}-07$ \\
\hline & $72179.70 \mathrm{C}$ & $1.1239 \mathrm{E}-07$ & $72180.70 \mathrm{C}$ & $2.8947 \mathrm{E}-07$ & & \\
\hline C & Total & $8.9397 E-02$ & & & & \\
\hline$m t 202$ & $\mathrm{~h} / \mathrm{zr} .10 \mathrm{t}$ & $\mathrm{zr} / \mathrm{h} .10 \mathrm{t}$ & & & & \\
\hline & & & & & & \\
\hline & -- $62-\operatorname{Rod}$ & -Average Fue & Rod Comp & sition --- & - & \\
\hline m203 & $92234.70 \mathrm{C}$ & $9.9323 \mathrm{E}-06$ & $92235.70 \mathrm{C}$ & $1.0844 \mathrm{E}-03$ & $92236.70 \mathrm{C}$ & $1.2036 \mathrm{E}-05$ \\
\hline & $92238.70 \mathrm{c}$ & $4.3326 \mathrm{E}-03$ & $5010.70 \mathrm{C}$ & $7.6280 \mathrm{E}-08$ & $5011.70 \mathrm{C}$ & $3.0703 E-07$ \\
\hline & $1001.70 \mathrm{C}$ & $5.0611 \mathrm{E}-02$ & $1002.70 \mathrm{C}$ & $5.8209 \mathrm{E}-06$ & $6000.70 \mathrm{C}$ & $1.0782 \mathrm{E}-03$ \\
\hline & $40090.70 \mathrm{C}$ & $1.6482 \mathrm{E}-02$ & $40091.70 \mathrm{C}$ & $3.5942 \mathrm{E}-03$ & $40092.70 \mathrm{C}$ & $5.4939 \mathrm{E}-03$ \\
\hline & $40094.70 \mathrm{C}$ & $5.5675 \mathrm{E}-03$ & $40096.70 \mathrm{C}$ & $8.9696 \mathrm{E}-04$ & $68162.70 \mathrm{C}$ & 3. $2518 \mathrm{E}-07$ \\
\hline & $68164.70 \mathrm{C}$ & $3.7396 \mathrm{E}-06$ & $68166.70 \mathrm{C}$ & $7.8067 \mathrm{E}-05$ & $68167.70 \mathrm{C}$ & $5.3260 \mathrm{E}-05$ \\
\hline & $68168.70 \mathrm{c}$ & $6.2203 E-05$ & $68170.70 \mathrm{C}$ & $3.4678 \mathrm{E}-05$ & $72174.70 \mathrm{C}$ & 1. $3203 E-09$ \\
\hline & $72176.70 \mathrm{C}$ & $4.3406 \mathrm{E}-08$ & $72177.70 \mathrm{C}$ & $1.5349 \mathrm{E}-07$ & $72178.70 \mathrm{C}$ & $2.2512 \mathrm{E}-07$ \\
\hline & $72179.70 \mathrm{C}$ & $1.1239 \mathrm{E}-07$ & $72180.70 \mathrm{C}$ & $2.8948 \mathrm{E}-07$ & & \\
\hline C & Total & $8.9401 E-02$ & & & & \\
\hline mt203 & h/zr.10t & $\mathrm{zr} / \mathrm{h} .10 \mathrm{t}$ & & & & \\
\hline & & & & & & \\
\hline & $---\quad 64-$ Rod & -Average Fue & 1 Rod Comp & sition --- & -- & \\
\hline m204 & $92234.70 \mathrm{C}$ & $9.9363 \mathrm{E}-06$ & $92235.70 \mathrm{C}$ & $1.0851 \mathrm{E}-03$ & $92236.70 \mathrm{C}$ & $1.2041 \mathrm{E}-05$ \\
\hline & $92238.70 \mathrm{C}$ & $4.3340 \mathrm{E}-03$ & $5010.70 \mathrm{C}$ & $7.6286 \mathrm{E}-08$ & $5011.70 \mathrm{C}$ & $3.0706 \mathrm{E}-07$ \\
\hline & $1001.70 \mathrm{C}$ & $5.0608 \mathrm{E}-02$ & $1002.70 \mathrm{C}$ & $5.8206 \mathrm{E}-06$ & $6000.70 \mathrm{C}$ & $1.0783 E-03$ \\
\hline & $40090.70 \mathrm{c}$ & $1.6481 \mathrm{E}-02$ & $40091.70 \mathrm{C}$ & $3.5940 \mathrm{E}-03$ & $40092.70 \mathrm{C}$ & $5.4935 E-03$ \\
\hline & $40094.70 \mathrm{C}$ & $5.5672 \mathrm{E}-03$ & $40096.70 \mathrm{C}$ & $8.9690 \mathrm{E}-04$ & $68162.70 \mathrm{C}$ & $3.2521 \mathrm{E}-07$ \\
\hline & $68164.70 \mathrm{C}$ & $3.7399 \mathrm{E}-06$ & $68166.70 \mathrm{C}$ & $7.8073 \mathrm{E}-05$ & $68167.70 \mathrm{C}$ & 5. $3265 \mathrm{E}-05$ \\
\hline & $68168.70 \mathrm{C}$ & $6.2208 \mathrm{E}-05$ & $68170.70 \mathrm{C}$ & $3.4681 \mathrm{E}-05$ & $72174.70 \mathrm{C}$ & 1. $3202 \mathrm{E}-09$ \\
\hline & $72176.70 \mathrm{C}$ & $4.3403 E-08$ & $72177.70 \mathrm{C}$ & $1.5348 \mathrm{E}-07$ & $72178.70 \mathrm{C}$ & $2.2510 \mathrm{E}-07$ \\
\hline & $72179.70 \mathrm{C}$ & $1.1239 \mathrm{E}-07$ & $72180.70 \mathrm{C}$ & $2.8946 \mathrm{E}-07$ & & \\
\hline & Total & $8.9399 \mathrm{E}-02$ & & & & \\
\hline mt204 & h/zr.10t & $\mathrm{zr} / \mathrm{h} .10 \mathrm{t}$ & & & & \\
\hline & & & & & & \\
\hline C --- & -- Graphi & te Reflector & Rods ---- & & & \\
\hline m205 & $3006.70 \mathrm{c}$ & $2.8481 E-10$ & $3007.70 \mathrm{C}$ & $3.4676 \mathrm{E}-09$ & $4009.70 \mathrm{C}$ & $2.8900 \mathrm{E}-09$ \\
\hline & $5010.70 \mathrm{C}$ & $6.7120 \mathrm{E}-09$ & $5011.70 \mathrm{C}$ & $2.7016 \mathrm{E}-08$ & $6000.70 \mathrm{C}$ & $8.6734 \mathrm{E}-02$ \\
\hline & $9019.70 \mathrm{C}$ & $2.7419 \mathrm{E}-09$ & $11023.70 \mathrm{C}$ & $1.1329 \mathrm{E}-09$ & $12024.70 \mathrm{C}$ & $8.4647 \mathrm{E}-10$ \\
\hline & $12025.70 \mathrm{C}$ & $1.0716 \mathrm{E}-10$ & $12026.70 \mathrm{C}$ & $1.1798 \mathrm{E}-10$ & $13027.70 \mathrm{C}$ & $9.6531 \mathrm{E}-10$ \\
\hline & $14028.70 \mathrm{C}$ & $2.5659 \mathrm{E}-08$ & $14029.70 \mathrm{C}$ & $1.3029 \mathrm{E}-09$ & $14030.70 \mathrm{C}$ & $8.5889 \mathrm{E}-10$ \\
\hline & $15031.70 \mathrm{C}$ & $1.6818 \mathrm{E}-09$ & $16032.70 \mathrm{C}$ & $2.8372 E-08$ & $16033.70 \mathrm{C}$ & $2.2714 \mathrm{E}-10$ \\
\hline & $16034.70 \mathrm{C}$ & $1.2822 \mathrm{E}-09$ & $16036.70 \mathrm{C}$ & $5.9774 \mathrm{E}-12$ & $17035.70 \mathrm{C}$ & $5.3445 \mathrm{E}-09$ \\
\hline & $17037.70 \mathrm{C}$ & $1.7082 \mathrm{E}-09$ & $19039.70 \mathrm{C}$ & $1.2425 \mathrm{E}-09$ & $19040.70 \mathrm{C}$ & 1. $5588 \mathrm{E}-13$ \\
\hline & $19041.70 \mathrm{C}$ & $8.9667 \mathrm{E}-11$ & $20040.70 \mathrm{C}$ & $6.2999 \mathrm{E}-10$ & $20042.70 \mathrm{C}$ & 4. $2047 \mathrm{E}-12$ \\
\hline & $20043.70 \mathrm{C}$ & $8.7733 \mathrm{E}-13$ & $20044.70 \mathrm{C}$ & $1.3556 \mathrm{E}-11$ & $20046.70 \mathrm{C}$ & $2.5995 \mathrm{E}-14$ \\
\hline & $20048.70 \mathrm{c}$ & 1. $2153 \mathrm{E}-12$ & $21045.70 \mathrm{C}$ & $1.1587 \mathrm{E}-10$ & $22046.70 \mathrm{C}$ & $8.9756 \mathrm{E}-12$ \\
\hline & $22047.70 \mathrm{c}$ & $8.0944 \mathrm{E}-12$ & $22048.70 \mathrm{C}$ & $8.0204 \mathrm{E}-11$ & $22049.70 \mathrm{C}$ & $5.8858 \mathrm{E}-12$ \\
\hline & $22050.70 \mathrm{C}$ & $5.6356 \mathrm{E}-12$ & $23000.70 \mathrm{C}$ & $1.0226 \mathrm{E}-10$ & $24050.70 \mathrm{C}$ & $2.1765 \mathrm{E}-10$ \\
\hline & $24052.70 \mathrm{C}$ & $4.1971 \mathrm{E}-09$ & $24053.70 \mathrm{C}$ & $4.7592 \mathrm{E}-10$ & $24054.70 \mathrm{C}$ & $1.1847 \mathrm{E}-10$ \\
\hline & $25055.70 \mathrm{C}$ & $9.4818 \mathrm{E}-11$ & $26054.70 \mathrm{C}$ & $5.4519 \mathrm{E}-12$ & $26056.70 \mathrm{C}$ & $8.5583 \mathrm{E}-11$ \\
\hline & $26057.70 \mathrm{C}$ & $1.9765 \mathrm{E}-12$ & $26058.70 \mathrm{C}$ & $2.6303 \mathrm{E}-13$ & $27059.70 \mathrm{C}$ & $8.8390 \mathrm{E}-11$ \\
\hline & $28058.70 \mathrm{C}$ & $6.0423 \mathrm{E}-11$ & $28060.70 \mathrm{C}$ & $2.3275 \mathrm{E}-11$ & $28061.70 \mathrm{C}$ & $1.0117 \mathrm{E}-12$ \\
\hline & $28062.70 \mathrm{C}$ & $3.2259 \mathrm{E}-12$ & $28064.70 \mathrm{C}$ & $8.2153 \mathrm{E}-13$ & $29063.70 \mathrm{C}$ & $2.8351 \mathrm{E}-10$ \\
\hline & $29065.70 \mathrm{C}$ & $1.2636 \mathrm{E}-10$ & $30000.70 \mathrm{c}$ & $3.9831 \mathrm{E}-10$ & $31069.70 \mathrm{C}$ & $4.4908 \mathrm{E}-11$ \\
\hline & $31071.70 \mathrm{c}$ & $2.9804 \mathrm{E}-11$ & $32070.70 \mathrm{C}$ & 7. $4754 \mathrm{E}-11$ & $32072.70 \mathrm{C}$ & $9.8787 \mathrm{E}-11$ \\
\hline & $32073.70 \mathrm{C}$ & $2.7728 \mathrm{E}-11$ & $32074.70 \mathrm{C}$ & $1.3014 \mathrm{E}-10$ & $32076.70 \mathrm{C}$ & $2.7297 \mathrm{E}-11$ \\
\hline & $33075.70 \mathrm{C}$ & $3.4764 \mathrm{E}-10$ & $34074.70 \mathrm{C}$ & $2.9357 \mathrm{E}-12$ & $34076.70 \mathrm{C}$ & $3.0908 \mathrm{E}-11$ \\
\hline & $34077.70 \mathrm{C}$ & $2.5168 \mathrm{E}-11$ & $34078.70 \mathrm{C}$ & $7.8407 \mathrm{E}-11$ & $34080.70 \mathrm{C}$ & $1.6364 \mathrm{E}-10$ \\
\hline & $34082.70 \mathrm{C}$ & $2.8797 E-11$ & $35079.70 \mathrm{C}$ & $3.3046 \mathrm{E}-10$ & $35081.70 \mathrm{C}$ & $3.2146 \mathrm{E}-10$ \\
\hline & $37085.70 \mathrm{C}$ & $2.1993 \mathrm{E}-10$ & $37087.70 \mathrm{C}$ & $8.4810 \mathrm{E}-11$ & $38084.70 \mathrm{C}$ & $1.6646 \mathrm{E}-12$ \\
\hline & $38086.70 \mathrm{C}$ & $2.9309 \mathrm{E}-11$ & $38087.70 \mathrm{C}$ & $2.0808 \mathrm{E}-11$ & $38088.70 \mathrm{C}$ & $2.4547 \mathrm{E}-10$ \\
\hline & $39089.70 \mathrm{C}$ & $2.9296 \mathrm{E}-10$ & $40090.70 \mathrm{C}$ & $1.4690 \mathrm{E}-10$ & $40091.70 \mathrm{C}$ & $3.2034 \mathrm{E}-11$ \\
\hline & $40092.70 \mathrm{C}$ & $4.8965 \mathrm{E}-11$ & $40094.70 \mathrm{C}$ & $4.9622 \mathrm{E}-11$ & $40096.70 \mathrm{C}$ & $7.9943 E-12$ \\
\hline & $41093.70 \mathrm{C}$ & $2.8034 \mathrm{E}-10$ & $42092.70 \mathrm{C}$ & $4.0287 \mathrm{E}-11$ & $42094.70 \mathrm{C}$ & $2.5112 \mathrm{E}-11$ \\
\hline & $42095.70 \mathrm{C}$ & $4.3219 \mathrm{E}-11$ & $42096.70 \mathrm{C}$ & $4.5283 \mathrm{E}-11$ & $42097.70 \mathrm{C}$ & $2.5926 \mathrm{E}-11$ \\
\hline & $42098.70 \mathrm{C}$ & $6.5508 \mathrm{E}-11$ & $42100.70 \mathrm{C}$ & $2.6143 \mathrm{E}-11$ & $44096.70 \mathrm{C}$ & 1. $4276 \mathrm{E}-11$ \\
\hline & $44098.70 \mathrm{C}$ & $4.8190 \mathrm{E}-12$ & $44099.70 \mathrm{C}$ & $3.2882 \mathrm{E}-11$ & $44100.70 \mathrm{C}$ & $3.2470 \mathrm{E}-11$ \\
\hline & $44101.70 \mathrm{C}$ & $4.3963 \mathrm{E}-11$ & $44102.70 \mathrm{C}$ & $8.1304 \mathrm{E}-11$ & $44104.70 \mathrm{C}$ & $4.7983 E-11$ \\
\hline & $45103.70 \mathrm{C}$ & $5.0620 \mathrm{E}-11$ & $46102.70 \mathrm{C}$ & $2.4964 \mathrm{E}-12$ & $46104.70 \mathrm{C}$ & $2.7264 \mathrm{E}-11$ \\
\hline & $46105.70 \mathrm{C}$ & $5.4651 \mathrm{E}-11$ & $46106.70 \mathrm{C}$ & $6.6888 \mathrm{E}-11$ & $46108.70 \mathrm{C}$ & $6.4759 \mathrm{E}-11$ \\
\hline & $46110.70 \mathrm{C}$ & $2.8684 \mathrm{E}-11$ & $47107.70 \mathrm{C}$ & $1.2517 \mathrm{E}-10$ & $47109.70 \mathrm{C}$ & $1.1629 \mathrm{E}-10$ \\
\hline & $48106.70 \mathrm{C}$ & $2.8963 \mathrm{E}-12$ & $48108.70 \mathrm{C}$ & $2.0621 \mathrm{E}-12$ & $48110.70 \mathrm{C}$ & $2.8940 \mathrm{E}-11$ \\
\hline & $48111.70 \mathrm{C}$ & $2.9658 \mathrm{E}-11$ & $48112.70 \mathrm{C}$ & $5.5910 \mathrm{E}-11$ & $48113.70 \mathrm{C}$ & $2.8314 \mathrm{E}-11$ \\
\hline & $48114.70 \mathrm{C}$ & $6.6568 \mathrm{E}-11$ & $48116.70 \mathrm{C}$ & $1.7354 \mathrm{E}-11$ & $49113.70 \mathrm{C}$ & $9.7314 \mathrm{E}-12$ \\
\hline & $49115.70 \mathrm{C}$ & $2.1711 \mathrm{E}-10$ & $50112.70 \mathrm{C}$ & $2.1282 \mathrm{E}-12$ & $50114.70 \mathrm{C}$ & $1.4481 \mathrm{E}-12$ \\
\hline & $50115.70 \mathrm{C}$ & 7. $4598 \mathrm{E}-13$ & $50116.70 \mathrm{c}$ & $3.1902 \mathrm{E}-11$ & $50117.70 \mathrm{C}$ & $1.6850 \mathrm{E}-11$ \\
\hline
\end{tabular}




\section{NEA/NSC/DOC(2006)1}

\section{Fundamental - FUND}

\section{NRAD-FUND-RESR-002 \\ CRIT-REAC-COEF}

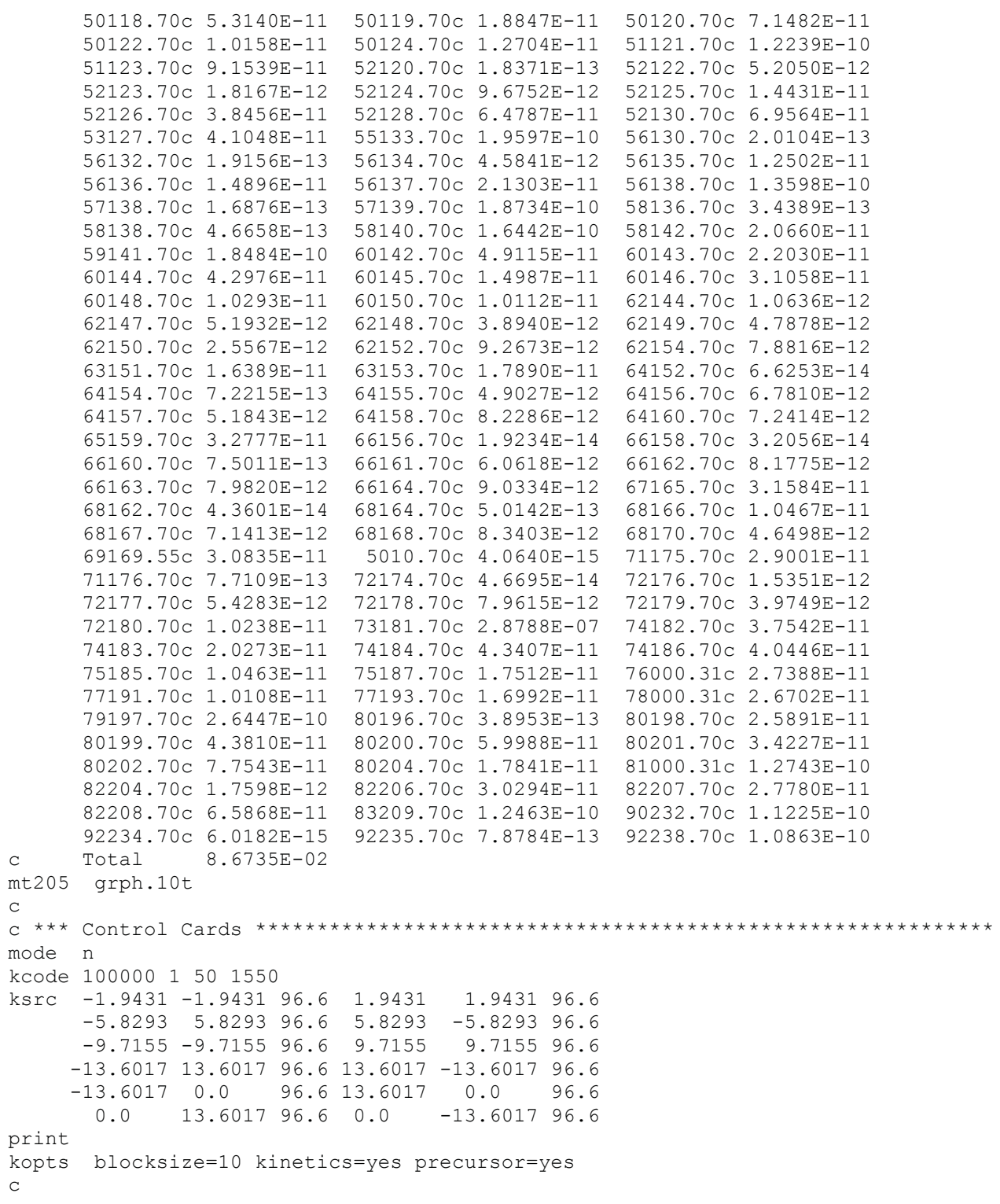




\section{NEA/NSC/DOC(2006)1}

Fundamental - FUND

NRAD-FUND-RESR-002

CRIT-REAC-COEF

\section{APPENDIX D: AS-BUILT FUEL DATA}

A summary of the as-built fuel data obtained from the shipping documentation for the NRAD fuel elements is provided in this appendix. Table D.1 contains data specific to the uranium content of the fuel. Table D.2 contains a summary of additional fuel measurements.

Table D.1. As-Built Fuel Data (Uranium Content).

\begin{tabular}{|c|c|c|c|c|c|}
\hline $\begin{array}{l}\text { Element } \\
\text { Number } \\
\end{array}$ & $\begin{array}{c}\text { Total } \\
\text { Mass (g) } \\
\end{array}$ & $\begin{array}{l}\text { Uranium } \\
\text { Mass (g) } \\
\end{array}$ & $\begin{array}{c}{ }^{235} \mathrm{U} \\
\text { Mass (g) } \\
\end{array}$ & $\begin{array}{l}{ }^{235} \mathrm{U} \\
\text { Enrichment (\%) } \\
\end{array}$ & $\begin{array}{c}\text { Uranium } \\
\text { Content (wt.\%) } \\
\end{array}$ \\
\hline 811752 & 2503.57 & 747.73 & 147.68 & 19.75 & 29.87 \\
\hline 11753 & 2504.51 & 750.94 & 148.29 & 19.75 & 29.98 \\
\hline 11754 & 2505.34 & 751.19 & 148.33 & 19.75 & 29.98 \\
\hline 11755 & 2503.53 & 750.64 & 148.23 & 19.75 & 29.98 \\
\hline 11756 & 2504.75 & 751.01 & 148.29 & 19.75 & 29.98 \\
\hline 11757 & 2503.62 & 750.67 & 148.23 & 19.75 & 29.98 \\
\hline 11758 & 2504.35 & 750.89 & 148.28 & 19.75 & 29.98 \\
\hline 11759 & 2503.18 & 750.54 & 148.21 & 19.75 & 29.98 \\
\hline 11760 & 2508.34 & 751.67 & 148.42 & 19.75 & 29.97 \\
\hline 11761 & 2506.59 & 749.05 & 147.76 & 19.73 & 29.88 \\
\hline 11762 & 2510.22 & 750.14 & 147.88 & 19.71 & 29.88 \\
\hline 11763 & 2511.18 & 750.42 & 147.93 & 19.71 & 29.88 \\
\hline 11764 & 2509.55 & 749.94 & 147.84 & 19.71 & 29.88 \\
\hline 11765 & 2508.80 & 749.72 & 147.79 & 19.71 & 29.88 \\
\hline 11766 & 2510.72 & 750.29 & 147.90 & 19.71 & 29.88 \\
\hline 11767 & 2508.16 & 749.52 & 147.76 & 19.71 & 29.88 \\
\hline 11768 & 2504.76 & 748.92 & 147.84 & 19.74 & 29.90 \\
\hline 11769 & 2500.76 & 747.73 & 147.60 & 19.74 & 29.90 \\
\hline 11770 & 2506.39 & 749.40 & 147.94 & 19.74 & 29.90 \\
\hline 11771 & 2502.98 & 748.40 & 147.73 & 19.74 & 29.90 \\
\hline 11772 & 2506.50 & 749.45 & 147.94 & 19.74 & 29.90 \\
\hline 11773 & 2504.00 & 748.71 & 147.80 & 19.74 & 29.90 \\
\hline 11774 & 2505.26 & 749.07 & 147.87 & 19.74 & 29.90 \\
\hline 11775 & 2502.48 & 747.41 & 147.52 & 19.74 & 29.87 \\
\hline 11776 & 2511.48 & 749.28 & 147.76 & 19.72 & 29.83 \\
\hline 11777 & 2503.32 & 743.92 & 146.75 & 19.73 & 29.72 \\
\hline 11778 & 2507.07 & 749.21 & 147.75 & 19.72 & 29.88 \\
\hline 11779 & 2502.48 & 743.66 & 146.70 & 19.73 & 29.72 \\
\hline 11780 & 2506.19 & 748.93 & 147.69 & 19.72 & 29.88 \\
\hline 11781 & 2502.51 & 746.33 & 147.26 & 19.73 & 29.82 \\
\hline 11782 & 2506.61 & 751.14 & 148.20 & 19.73 & 29.97 \\
\hline 11783 & 2506.90 & 751.23 & 148.21 & 19.73 & 29.97 \\
\hline 11784 & 2509.46 & 752.01 & 148.37 & 19.73 & 29.97 \\
\hline 11785 & 2509.11 & 752.32 & 148.51 & 19.74 & 29.98 \\
\hline 11786 & 2511.09 & 752.90 & 148.62 & 19.74 & 29.98 \\
\hline 11787 & 2501.38 & 746.01 & 147.19 & 19.73 & 29.82 \\
\hline 11788 & 2502.06 & 746.19 & 147.22 & 19.73 & 29.82 \\
\hline 11789 & 2509.55 & 752.45 & 148.54 & 19.74 & 29.98 \\
\hline 11790 & 2510.46 & 749.80 & 148.16 & 19.76 & 29.87 \\
\hline 11791 & 2502.13 & 746.22 & 147.23 & 19.73 & 29.82 \\
\hline 11792 & 2501.18 & 745.91 & 147.17 & 19.73 & 29.82 \\
\hline 11793 & 2502.06 & 746.22 & 147.23 & 19.73 & 29.82 \\
\hline 11794 & 2507.83 & 749.01 & 148.00 & 19.76 & 29.87 \\
\hline
\end{tabular}




\section{NEA/NSC/DOC(2006)1}

Fundamental - FUND

NRAD-FUND-RESR-002

CRIT-REAC-COEF

Table D.1 (cont'd.). As-Built Fuel Data (Uranium Content).

\begin{tabular}{|c|c|c|c|c|c|}
\hline $\begin{array}{l}\text { Element } \\
\text { Number }\end{array}$ & $\begin{array}{c}\text { Total } \\
\text { Mass (g) }\end{array}$ & $\begin{array}{l}\text { Uranium } \\
\text { Mass (g) }\end{array}$ & $\begin{array}{c}{ }^{235} \mathrm{U} \\
\text { Mass (g) }\end{array}$ & $\begin{array}{c}{ }^{235} \mathrm{U} \\
\text { Enrichment (\%) }\end{array}$ & $\begin{array}{c}\text { Uranium } \\
\text { Content (wt.\%) }\end{array}$ \\
\hline 11795 & 2510.20 & 750.97 & 148.36 & 19.76 & 29.92 \\
\hline 11796 & 2509.15 & 750.66 & 148.30 & 19.76 & 29.92 \\
\hline 11797 & 2511.43 & 751.33 & 148.44 & 19.76 & 29.92 \\
\hline 11798 & 2507.25 & 750.09 & 148.19 & 19.76 & 29.92 \\
\hline 11799 & 2497.17 & 744.75 & 146.93 & 19.73 & 29.82 \\
\hline 11800 & 2508.76 & 756.42 & 149.23 & 19.73 & 30.15 \\
\hline 11801 & 2507.48 & 750.16 & 148.28 & 19.77 & 29.92 \\
\hline 11802 & 2508.35 & 755.02 & 149.34 & 19.78 & 30.10 \\
\hline 11803 & 2506.88 & 754.58 & 149.26 & 19.78 & 30.10 \\
\hline 11804 & 2505.18 & 748.64 & 147.73 & 19.73 & 29.88 \\
\hline 11805 & 2509.59 & 749.95 & 147.99 & 19.73 & 29.88 \\
\hline 11806 & 2508.99 & 752.29 & 148.53 & 19.74 & 29.98 \\
\hline 11807 & 2512.51 & 753.35 & 148.74 & 19.74 & 29.98 \\
\hline 11808 & 2504.02 & 748.30 & 147.86 & 19.76 & 29.88 \\
\hline 11809 & 2508.54 & 749.67 & 148.13 & 19.76 & 29.88 \\
\hline 11810 & 2512.59 & 757.55 & 149.54 & 19.74 & 30.15 \\
\hline 11811 & 2509.58 & 754.12 & 148.78 & 19.73 & 30.05 \\
\hline 11812 & 2508.30 & 751.27 & 148.37 & 19.75 & 29.95 \\
\hline 11813 & 2510.30 & 751.43 & 148.62 & 19.78 & 29.93 \\
\hline 11814 & 2515.05 & 760.56 & 150.53 & 19.79 & 30.24 \\
\hline 11815 & 2511.94 & 757.60 & 150.15 & 19.82 & 30.16 \\
\hline $\begin{array}{c}\text { Average } \\
(56 \text { Rods })^{(a)}\end{array}$ & 2506.4 & 749.6 & 147.9 & 19.74 & 29.91 \\
\hline $\begin{array}{c} \pm 1 \sigma^{(\mathrm{b})} \\
(56 \text { Rods })^{(\mathrm{a})}\end{array}$ & 3.5 & 2.5 & 0.5 & 0.01 & 0.07 \\
\hline $\begin{array}{c}\text { Average } \\
(60 \text { Rods })^{(\mathrm{c})}\end{array}$ & 2506.5 & 749.9 & 148.0 & 19.74 & 29.92 \\
\hline $\begin{array}{c} \pm 1 \sigma^{(\mathrm{b})} \\
(60 \text { Rods })^{(\mathrm{c})} \\
\end{array}$ & 3.4 & 2.7 & 0.6 & 0.02 & 0.09 \\
\hline $\begin{array}{c}\text { Average } \\
(62 \text { Rods })^{(\mathrm{d})}\end{array}$ & 2506.6 & 749.9 & 148.0 & 19.74 & 29.92 \\
\hline $\begin{array}{c} \pm 1 \sigma^{(\mathrm{b})} \\
(62 \text { Rods })^{(\mathrm{d})}\end{array}$ & 3.4 & 2.7 & 0.6 & 0.02 & 0.08 \\
\hline $\begin{array}{l}\text { Average } \\
\text { (64 Rods) }\end{array}$ & 2506.8 & 750.2 & 148.1 & 19.74 & 29.93 \\
\hline $\begin{array}{c} \pm 1 \sigma^{(\mathrm{b})} \\
(64 \text { Rods) }\end{array}$ & 3.6 & 3.1 & 0.7 & 0.02 & 0.10 \\
\hline
\end{tabular}

(a) Fifty-six elements are in the initial core critical. Excluded elements include 11800, -801, $-802,-803,-812,-813,-814$, and -815 .

(b) The uncertainty in these values is $1 \sigma$ of the average population and not the average mean.

(c) Sixty elements are in the fully loaded core critical. Excluded elements include -812, $813,-814$, and -815 .

(d) Sixty-two elements are in the intermediary core during the upgrade to sixty-four elements. Excluded elements include -814 and -815 . 
Fundamental - FUND

NRAD-FUND-RESR-002

CRIT-REAC-COEF

Table D.2. As-Built Fuel Data (Additional Measurements).

\begin{tabular}{|c|c|c|c|c|c|c|c|}
\hline $\begin{array}{l}\text { Element } \\
\text { Number }\end{array}$ & $\begin{array}{l}\mathbf{H} / \mathbf{Z r} \\
\text { Ratio }\end{array}$ & $\begin{array}{c}\text { Er } \\
\text { Content } \\
\text { (wt.\%) } \\
\end{array}$ & $\begin{array}{c}\text { C } \\
\text { Content } \\
\text { (wt.\%) } \\
\end{array}$ & $\begin{array}{c}\text { Fuel } \\
\text { Length } \\
(\mathrm{mm})\end{array}$ & $\begin{array}{c}\text { Fuel } \\
\text { Diameter } \\
(\mathbf{m m}) \\
\end{array}$ & $\begin{array}{l}\text { Cladding } \\
\text { ID (mm) }\end{array}$ & $\begin{array}{c}\text { Fuel-Clad } \\
\text { Difference } \\
(\mathrm{mm})\end{array}$ \\
\hline 11752 & 1.58 & 0.86 & 0.31 & 380.4 & 34.800 & 34.89 & 0.090 \\
\hline 11753 & 1.58 & 0.86 & 0.31 & 380.0 & 34.800 & 34.89 & 0.090 \\
\hline 11754 & 1.58 & 0.86 & 0.31 & 380.1 & 34.800 & 34.89 & 0.090 \\
\hline 11755 & 1.59 & 0.86 & 0.31 & 379.8 & 34.800 & 34.89 & 0.090 \\
\hline 11756 & 1.58 & 0.86 & 0.31 & 380.1 & 34.800 & 34.89 & 0.090 \\
\hline 11757 & 1.58 & 0.86 & 0.31 & 380.2 & 34.800 & 34.90 & 0.100 \\
\hline 11758 & 1.59 & 0.86 & 0.31 & 379.9 & 34.800 & 34.89 & 0.090 \\
\hline 11759 & 1.60 & 0.86 & 0.31 & 379.7 & 34.800 & 34.89 & 0.090 \\
\hline 11760 & 1.57 & 0.91 & 0.33 & 380.0 & 34.800 & 34.89 & 0.090 \\
\hline 11761 & 1.57 & 0.90 & 0.31 & 379.2 & 34.803 & 34.89 & 0.087 \\
\hline 11762 & 1.57 & 0.90 & 0.29 & 380.0 & 34.807 & 34.89 & 0.083 \\
\hline 11763 & 1.58 & 0.90 & 0.29 & 379.6 & 34.807 & 34.89 & 0.083 \\
\hline 11764 & 1.59 & 0.90 & 0.29 & 380.0 & 34.807 & 34.89 & 0.083 \\
\hline 11765 & 1.59 & 0.90 & 0.29 & 379.8 & 34.807 & 34.89 & 0.083 \\
\hline 11766 & 1.58 & 0.90 & 0.29 & 380.0 & 34.807 & 34.90 & 0.093 \\
\hline 11767 & 1.57 & 0.90 & 0.29 & 379.6 & 34.803 & 34.89 & 0.087 \\
\hline 11768 & 1.57 & 0.89 & 0.28 & 380.2 & 34.803 & 34.89 & 0.087 \\
\hline 11769 & 1.57 & 0.89 & 0.29 & 379.9 & 34.803 & 34.89 & 0.087 \\
\hline 11770 & 1.59 & 0.89 & 0.29 & 379.9 & 34.807 & 34.89 & 0.083 \\
\hline 11771 & 1.58 & 0.89 & 0.29 & 379.8 & 34.803 & 34.89 & 0.087 \\
\hline 11772 & 1.57 & 0.89 & 0.29 & 380.0 & 34.800 & 34.90 & 0.100 \\
\hline 11773 & 1.58 & 0.89 & 0.29 & 379.8 & 34.803 & 34.90 & 0.097 \\
\hline 11774 & 1.61 & 0.89 & 0.29 & 380.0 & 34.803 & 34.90 & 0.097 \\
\hline 11775 & 1.58 & 0.91 & 0.29 & 380.1 & 34.807 & 34.90 & 0.093 \\
\hline 11776 & 1.59 & 0.92 & 0.30 & 380.4 & 34.810 & 34.90 & 0.090 \\
\hline 11777 & 1.58 & 0.90 & 0.30 & 380.8 & 34.807 & 34.90 & 0.093 \\
\hline 11778 & 1.58 & 0.91 & 0.32 & 380.9 & 34.807 & 34.90 & 0.093 \\
\hline 11779 & 1.58 & 0.90 & 0.30 & 381.0 & 34.803 & 34.89 & 0.087 \\
\hline 11780 & 1.57 & 0.91 & 0.32 & 380.6 & 34.807 & 34.89 & 0.083 \\
\hline 11781 & 1.58 & 0.92 & 0.30 & 380.5 & 34.807 & 34.89 & 0.083 \\
\hline 11782 & 1.57 & 0.89 & 0.31 & 380.3 & 34.810 & 34.90 & 0.090 \\
\hline 11783 & 1.57 & 0.89 & 0.31 & 380.5 & 34.810 & 34.89 & 0.080 \\
\hline 11784 & 1.57 & 0.89 & 0.31 & 380.4 & 34.807 & 34.89 & 0.083 \\
\hline 11785 & 1.57 & 0.90 & 0.32 & 380.6 & 34.810 & 34.89 & 0.080 \\
\hline 11786 & 1.58 & 0.90 & 0.32 & 380.7 & 34.807 & 34.90 & 0.093 \\
\hline 11787 & 1.57 & 0.92 & 0.30 & 380.5 & 34.810 & 34.89 & 0.080 \\
\hline 11788 & 1.58 & 0.92 & 0.30 & 380.4 & 34.807 & 34.89 & 0.083 \\
\hline 11789 & 1.58 & 0.90 & 0.32 & 380.7 & 34.803 & 34.89 & 0.087 \\
\hline 11790 & 1.58 & 0.89 & 0.30 & 380.6 & 34.803 & 34.89 & 0.087 \\
\hline 11791 & 1.57 & 0.92 & 0.30 & 380.5 & 34.803 & 34.89 & 0.087 \\
\hline 11792 & 1.57 & 0.92 & 0.30 & 380.2 & 34.807 & 34.89 & 0.083 \\
\hline 11793 & 1.58 & 0.92 & 0.30 & 380.4 & 34.807 & 34.90 & 0.093 \\
\hline 11794 & 1.57 & 0.89 & 0.30 & 380.6 & 34.803 & 34.90 & 0.097 \\
\hline
\end{tabular}




\section{NEA/NSC/DOC(2006)1}

Fundamental - FUND

NRAD-FUND-RESR-002

CRIT-REAC-COEF

Table D.2 (cont'd.). As-Built Fuel Data (Additional Measurements).

\begin{tabular}{|c|c|c|c|c|c|c|c|}
\hline $\begin{array}{l}\text { Element } \\
\text { Number }\end{array}$ & $\begin{array}{l}\mathrm{H} / \mathrm{Zr} \\
\text { Ratio }\end{array}$ & \begin{tabular}{c}
\multicolumn{1}{c}{ Er } \\
Content \\
$(w t . \%)$ \\
\end{tabular} & $\begin{array}{c}\text { C } \\
\text { Content } \\
\text { (wt. \%) } \\
\end{array}$ & $\begin{array}{c}\text { Fuel } \\
\text { Length } \\
(\mathrm{mm}) \\
\end{array}$ & $\begin{array}{c}\text { Fuel } \\
\text { Diameter } \\
(\mathbf{m m}) \\
\end{array}$ & $\begin{array}{l}\text { Cladding } \\
\text { ID }(\mathrm{mm})\end{array}$ & $\begin{array}{c}\text { Fuel-Clad } \\
\text { Difference } \\
(\mathrm{mm})\end{array}$ \\
\hline 11795 & 1.58 & 0.90 & 0.30 & 380.7 & 34.810 & 34.89 & 0.080 \\
\hline 11796 & 1.59 & 0.90 & 0.30 & 380.8 & 34.810 & 34.90 & 0.090 \\
\hline 11797 & 1.58 & 0.90 & 0.30 & 380.9 & 34.807 & 34.90 & 0.093 \\
\hline 11798 & 1.59 & 0.91 & 0.28 & 380.9 & 34.807 & 34.90 & 0.093 \\
\hline 11799 & 1.59 & 0.92 & 0.30 & 380.1 & 34.803 & 34.89 & 0.087 \\
\hline 11800 & 1.58 & 0.90 & 0.29 & 380.1 & 34.807 & 34.90 & 0.093 \\
\hline 11801 & 1.58 & 0.90 & 0.27 & 380.2 & 34.803 & 34.89 & 0.087 \\
\hline 11802 & 1.57 & 0.93 & 0.26 & 380.2 & 34.800 & 34.89 & 0.090 \\
\hline 11803 & 1.58 & 0.93 & 0.26 & 380.1 & 34.800 & 34.90 & 0.100 \\
\hline 11804 & 1.57 & 0.90 & 0.27 & 380.0 & 34.810 & 34.90 & 0.090 \\
\hline 11805 & 1.58 & 0.90 & 0.27 & 380.3 & 34.810 & 34.90 & 0.090 \\
\hline 11806 & 1.58 & 0.91 & 0.30 & 380.5 & 34.807 & 34.90 & 0.093 \\
\hline 11807 & 1.58 & 0.91 & 0.30 & 380.8 & 34.810 & 34.90 & 0.090 \\
\hline 11808 & 1.58 & 0.92 & 0.31 & 380.1 & 34.810 & 34.89 & 0.080 \\
\hline 11809 & 1.59 & 0.92 & 0.31 & 380.2 & 34.807 & 34.90 & 0.093 \\
\hline 11810 & 1.59 & 0.94 & 0.29 & 380.3 & 34.810 & 34.90 & 0.090 \\
\hline 11811 & 1.61 & 0.93 & 0.26 & 379.6 & 34.810 & 34.89 & 0.080 \\
\hline 11812 & 1.57 & 0.94 & 0.32 & 380.0 & 34.803 & 34.90 & 0.097 \\
\hline 11813 & 1.57 & 0.94 & 0.31 & 380.3 & 34.807 & 34.90 & 0.093 \\
\hline 11814 & 1.57 & 0.94 & 0.30 & 380.2 & 34.810 & 34.90 & 0.090 \\
\hline 11815 & 1.57 & 0.91 & 0.27 & 380.4 & 34.810 & 34.90 & 0.090 \\
\hline $\begin{array}{c}\text { Average } \\
(56 \text { Rods })^{(a)}\end{array}$ & 1.58 & 0.90 & 0.30 & 380.2 & 34.805 & 34.894 & 0.088 \\
\hline $\begin{array}{c} \pm 1 \sigma^{(b)} \\
(56 \text { Rods })^{(a)}\end{array}$ & 0.01 & 0.02 & 0.01 & 0.4 & 0.003 & 0.005 & 0.005 \\
\hline $\begin{array}{c}\text { Average } \\
\left(^{c} 60 \text { Rods }\right)^{(c)}\end{array}$ & 1.58 & 0.90 & 0.30 & 380.2 & 34.805 & 34.894 & 0.089 \\
\hline $\begin{array}{c} \pm 1 \sigma^{(b)} \\
(60 \text { Rods })^{(c)}\end{array}$ & 0.01 & 0.02 & 0.02 & 0.4 & 0.003 & 0.005 & 0.005 \\
\hline $\begin{array}{c}\text { Average } \\
\left(^{\prime 62} \text { Rods }\right)^{(d)}\end{array}$ & 1.58 & 0.90 & 0.30 & 380.2 & 34.805 & 34.894 & 0.089 \\
\hline $\begin{array}{c} \pm 1 \sigma^{(\mathrm{b})} \\
(62 \text { Rods })^{(\mathrm{d})} \\
\end{array}$ & 0.01 & 0.02 & 0.02 & 0.4 & 0.003 & 0.005 & 0.005 \\
\hline $\begin{array}{c}\text { Average } \\
\text { (64 Rods) }\end{array}$ & 1.58 & 0.90 & 0.30 & 380.2 & 34.805 & 34.894 & 0.089 \\
\hline $\begin{array}{c} \pm 1 \sigma^{(\mathrm{b})} \\
(64 \text { Rods })\end{array}$ & 0.01 & 0.02 & 0.02 & 0.4 & 0.003 & 0.005 & 0.005 \\
\hline
\end{tabular}

(a) Fifty-six elements are in the initial core critical. Excluded elements include 11800, -801, -802, -803, -812, $-813,-814$, and -815 .

(b) The uncertainty in these values is $1 \sigma$ of the average population and not the average mean.

(c) Sixty elements are in the fully loaded core critical. Excluded elements include $-812,-813,-814$, and -815 .

(d) Sixty-two elements are in the intermediary core during the upgrade to sixty-four elements. Excluded elements include -814 and -815 . 
NEA/NSC/DOC(2006)1

Fundamental - FUND

NRAD-FUND-RESR-002

CRIT-REAC-COEF

\section{APPENDIX E: CORE LOADING}

Core fuel loading specifications were provided in the start-up logs. ${ }^{\text {a }}$ The core loading arrangement was prepared using a detailed analysis of the as-built fuel data to optimize core excess reactivity.

Positions in the grid are identified with a letter-number pair. For example, the location of the in-core irradiation assembly is identified as C-4. The location of a specific position within an assembly is further designated by its location with respect to the center of the assembly. The location of the in-core irradiation position is identified as C-4 SW.

Table E.1 contains the fuel element identifications for each position, which correspond with the as-built fuel data provided in Tables D.1 and D.2.

Table E.1. As-Built Fuel Positions in Core.

\begin{tabular}{|c|c|c|c|c|c|c|c|c|}
\hline Cluster & Location & $\begin{array}{l}\text { Element } \\
\text { Number }\end{array}$ & Cluster & Location & $\begin{array}{l}\text { Element } \\
\text { Number }\end{array}$ & Cluster & Location & $\begin{array}{l}\text { Element } \\
\text { Number }\end{array}$ \\
\hline \multirow[t]{4}{*}{ Shim 1} & D-2 NW & 11755 & \multirow[t]{4}{*}{ FC-4 } & E-3 NW & 11764 & \multirow[t]{4}{*}{ FC-10 } & B-3 NW & 11776 \\
\hline & $\mathrm{D}-2 \mathrm{NE}$ & 11757 & & E-3 NE & 11765 & & B-3 NE & 11777 \\
\hline & D-2 SE & Shim 1 & & E-3 SE & 11767 & & B-3 SE & 11779 \\
\hline & D-2 SW & 11756 & & E-3 SW & 11766 & & B-3 SW & 11778 \\
\hline \multirow[t]{4}{*}{ Shim 2} & C-2 NW & 11752 & \multirow[t]{4}{*}{ FC-5 } & E-2 NW & 11798 & \multirow[t]{4}{*}{ FC-11 } & B-4 NW & 11785 \\
\hline & $\mathrm{C}-2 \mathrm{NE}$ & Shim 2 & & E-2 NE & 11796 & & B-4 NE & 11787 \\
\hline & C-2 SE & 11754 & & E-2 SE & 11797 & & B-4 SE & 11786 \\
\hline & C-2 SW & 11753 & & E-2 SW & 11799 & & B-4 SW & 11784 \\
\hline \multirow[t]{4}{*}{ Reg } & E-4 NW & 11758 & \multirow[t]{4}{*}{ FC-6 } & C-4 NW & 11761 & \multirow[t]{4}{*}{ FC-12 } & B-2 NW & 11810 \\
\hline & E-4 NE & Reg Rod & & $\mathrm{C}-4 \mathrm{NE}$ & 11762 & & B-2 NE & 11811 \\
\hline & E-4 SE & 11760 & & C-4 SE & 11763 & & B-2 SE & 11808 \\
\hline & E-4 SW & 11759 & & C-4 SW & $\begin{array}{c}\text { Irradiation } \\
\text { Position }\end{array}$ & & B-2 SW & 11809 \\
\hline \multirow[t]{4}{*}{ FC-1 } & D-3 NW & 11772 & \multirow[t]{4}{*}{ FC-7 } & E-5 NW & 11804 & \multirow[t]{4}{*}{ FC-13 } & B-5 NW & 11800 \\
\hline & D-3 NE & 11773 & & E-5 NE & 11806 & & B-5 NE & 11802 \\
\hline & D-3 SE & 11775 & & E-5 SE & 11807 & & B-5 SE & 11803 \\
\hline & D-3 SW & 11774 & & E-5 SW & 11805 & & B-5 SW & 11801 \\
\hline \multirow[t]{4}{*}{ FC-2 } & C-3 NW & 11781 & \multirow[t]{4}{*}{ FC-8 } & D-5 NW & 11790 & \multirow[t]{4}{*}{ FC-14 } & F-4 NW & 11812 \\
\hline & $\mathrm{C}-3 \mathrm{NE}$ & 11782 & & D-5 NE & 11788 & & F-4 NE & 11813 \\
\hline & C-3 SE & 11783 & & D-5 SE & 11791 & & F-4 SE & G1 $1852^{(\mathrm{b})}$ \\
\hline & C-3 SW & 11780 & & D-5 SW & 11789 & & F-4 SW & G1 $1851^{(\mathrm{b})}$ \\
\hline \multirow[t]{4}{*}{ FC-3 } & D-4 NW & 11768 & \multirow[t]{4}{*}{ FC-9 } & C-5 NW & 11795 & \multirow[t]{4}{*}{$\mathrm{FC}-15^{(\mathrm{a})}$} & D-1 NW & G11853 ${ }^{(b)}$ \\
\hline & D-4 NE & 11769 & & C-5 NE & 11792 & & D-1 NE & 11814 \\
\hline & D-4 SE & 11771 & & C-5 SE & 11793 & & D-1 SE & 11815 \\
\hline & D-4 SW & 11770 & & C-5 SW & 11794 & & D-1 SW & G1 $1854^{(\mathrm{b})}$ \\
\hline
\end{tabular}

(a) This fuel cluster is only in the upgraded core configuration (64 fuel elements) and not the intermediary critical configuration using only 62 fuel elements.

(b) These four elements were graphite reflectors.

\footnotetext{
a “NRAD 64 Element Core Upgrade Startup Report,” INL/INT-13-29899 [draft], Idaho National Laboratory (publication date pending). [This reference is not available for public release.]
} 
NEA/NSC/DOC(2006)1

Fundamental - FUND

NRAD-FUND-RESR-002

CRIT-REAC-COEF

\section{APPENDIX F: NRAD AND TRIGA FUEL DESIGN DRAWINGS}

This appendix contains a list of the drawings utilized to develop a detailed model of the NRAD reactor, evaluate uncertainties in the experimental measurements, and then develop a simplified benchmark model. These drawings are not available for public release.

- DWG-734030 rev. 2 (W0170-0108-DE) - Aperture Mechanism Final Design Layout

- DWG-734032 rev. 2 (W0170-0110-DD) - 4 Rod Fuel Cluster Assembly

- DWG-734033 (W0170-0111-DD) - Fuel Rod Assembly

- DWG-734034 rev. 2 (W0170-0112-DD) - Locking Plate for 4 Rod Fuel Cluster Assembly

- DWG-734035 rev. 2 (W0170-0113-DD) - Locking Bolt for 4 Rod Fuel Cluster Assembly

- DWG-734401 rev. 0 (W0170-0195-EE) - NRAD Cluster Fitting Layout

- DWG-734402 rev. 2 (W0170-0196-ED) - NRAD Cluster Fitting for NRAD Assembly

- DWG-735784 rev. 5 (W0170-0845-ED) - Top Handle for 4 Rod Fuel Cluster Assembly

- DWG-735785 rev. 4 (W0170-0846-ED) - Top Handle C2, C4 for 3 Element Top Handle Assembly

- DWG-735786 rev. 5 (W0170-0847-ED) - Top Handle D2, D4 for 3 Element Top Handle Assembly

- DWG-735877 rev. 2 (W0170-0849-EC) - C2, C4 3 Element Locking Plate

- DWG-735789 rev. 2 (W0170-0850-EC) - D2, D4 3 Element Locking Plate

- DWG-735790 rev. 2 (W0170-0851-ED) - D2, D4 3 Element Top Handle Assembly

- DWG-735791 rev. 2 (W0170-0852-ED) - C2, C4 3 Element Top Handle Assembly

- DWG-760123 rev. 4 - Control Rod Guide Tube for 3 Rod Fuel Cluster Assembly

- T0S210B212G - Reflector Fuel Element

- T0S210B213C - Fuel - 15" SST Fuel Element

- T0S210B217E - Rod - Fuel Element

- T0S210B229 - Disc

- T0S250B147C - Top Fitting - Control Rod

- T0S250B148C - Bottom Fitting - Control Rod

- T0S250B226C - Poison - Control Rod

- T4R250B136 - Spacer - Control Rod

- T4R250D135 - Control Rod

- T4S210C107 - Top Fitting - Fuel Rod

- T4S210C108 - Bottom Fitting - Fuel Rod

- T4S210D105 - Fuel Rod Assembly - 4 Rod Fuel Cluster

- W0170-0084-DE-00 - Graphite Element - Reactor Core, NRAD Layout

- W0170-0088-DD-00 - Graphite Element

- W0170-0089-DD-01 - Handle - Graphite Element Assembly

- W0170-0108-DE-02 - Aperture Mechanism Final Design Layout

- W0170-0115-DE-01 - Grid Plate, Core Support, and Instrumentation Thimble Final Design Layout

- W0170-0139-DE-01 - Grid Plate for NRAD Facility

- W0170-0141-DE-00 - Core Support for NRAD Facility

- W0170-0634-DE-00 - Control Rod Drive Installation Final Design Layout

- W0170-0635-DE-02 - Graphite Element with Source Assembly

- W0170-0636-DD-02 - Handle, Graphite Element Source Assembly

- W0170-0637-DD-00 - Graphite Element - Graphite Element Source Assembly

- W0170-0638-DD-01 - Source Tube

- W0170-0639-DC-01 - Source Tube Cap

- W0170-0687-DE-01 - Aperture Mechanism Assembly

- W0170-0688-DE-01 - Lower Beam Tube

- W0170-0689-DE-00 - Upper Beam Tube

- W0170-0694-DE-01 - East Beam Chamber Assembly

- W0170-0698-DD-00 - Support - Beam Chamber Support Assembly 
- W0170-0726-DC-00 - Lower Tube Seal Plate for Aperture Mechanism Assembly

- W0170-0730-DD-01 - Aperture Block Guide

- W0170-0731-DE-00 - Aperture Block Assembly

- W0170-0732-DE-00 - Aperture Block Frame

- W0170-0733-DC-00 - Aperture Block

- W0170-0734-DC-00 - Aperture Block Front Cover

- W0170-0735-DA-00 - Aperture Block Adjusting Screw

- W0170-0742-DC-00 - Aperture Disc

- W0170-0770-DC-00 - Aperture Block Rear Cover

- W0170-0837-EE-00 - 3 Rod Fuel Cluster Assembly

- W0170-4351-EE-01 - North Beam Chamber Assembly

- W0170-4352-ED-01 - Aperture Block Assembly - NRS

- W0170-4353-ED-01 - Aperture Block Frame - NRS

- W0170-4354-EC-01 - Aperture Block - NRS

- W0170-4355-EC-00 - Aperture Block Front Cover - NRS

- W0170-4356-EC-00 - Aperture Block Rear Cover - NRS

- W0170-4644-EE-02 - NRAD Detector Housing Installation 


\section{APPENDIX G: EXAMPLE TRIGA FUEL MICROGRAPHS}

The extra fuel element received by INL with the last NRAD reactor fuel shipment was examined with an electron microscope; example micrographs are shown in Figures G.1 through G.5. The microstructure of the fuel is comprised of two phases. The bright phase (white) is uranium enriched with a little zirconium (couple of wt.\%). The dark matrix phase is zirconium enriched and contains hydrogen. This microstructure is very standard for this type of fuel and can be considered a "typical" microstructure. ${ }^{\text {a }}$ Figures G.4 and G.5 highlight the locations of zirconium and uranium, respectively, in the image shown in Figure G.3.

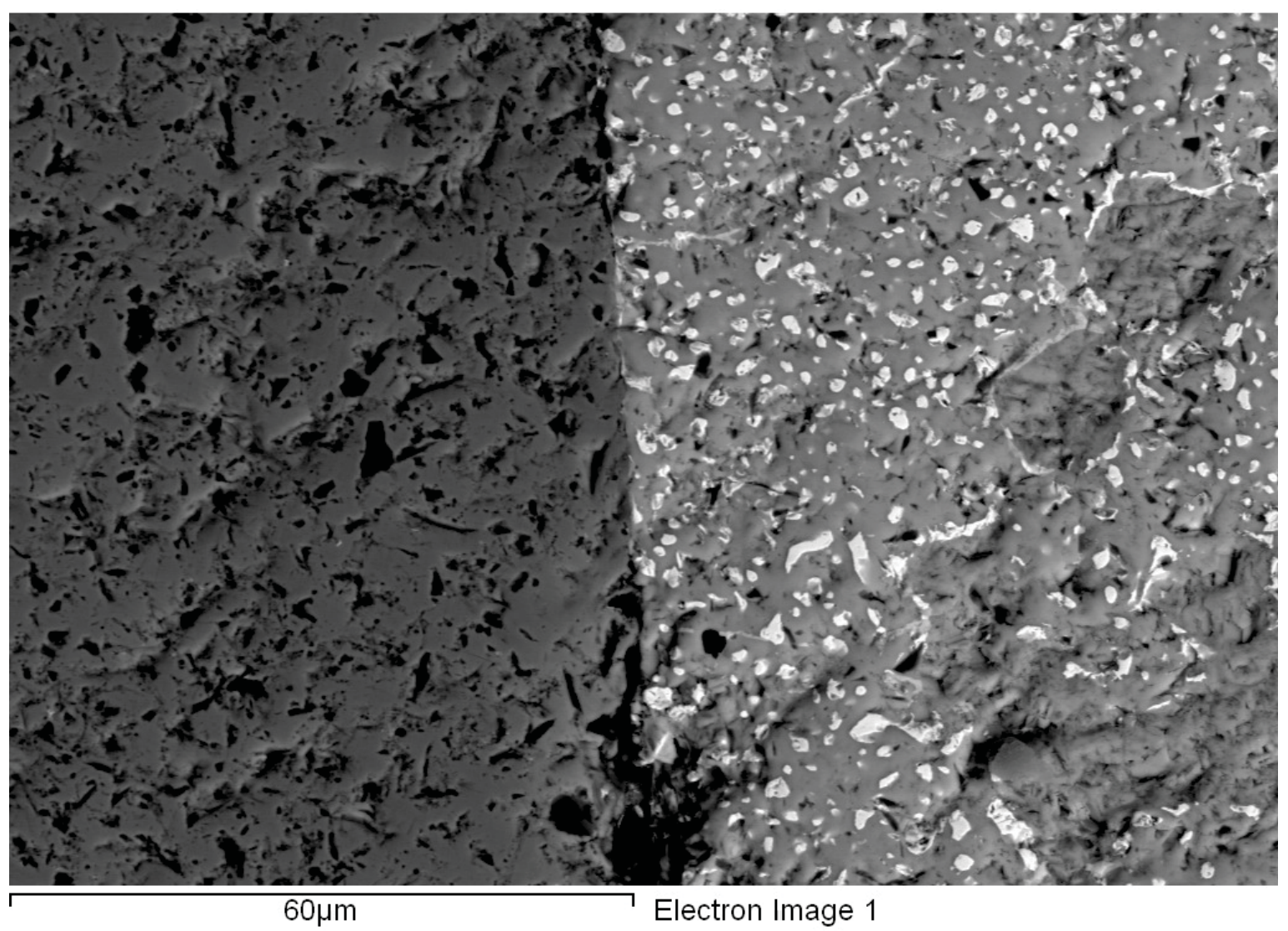

Figure G.1. Micrograph of U-Er-Zr-H Fuel.

\footnotetext{
${ }^{a}$ Personal communication with Dennis D. Keiser at INL (September 7, 2010).
} 
NEA/NSC/DOC(2006)1

Fundamental - FUND

NRAD-FUND-RESR-002

CRIT-REAC-COEF

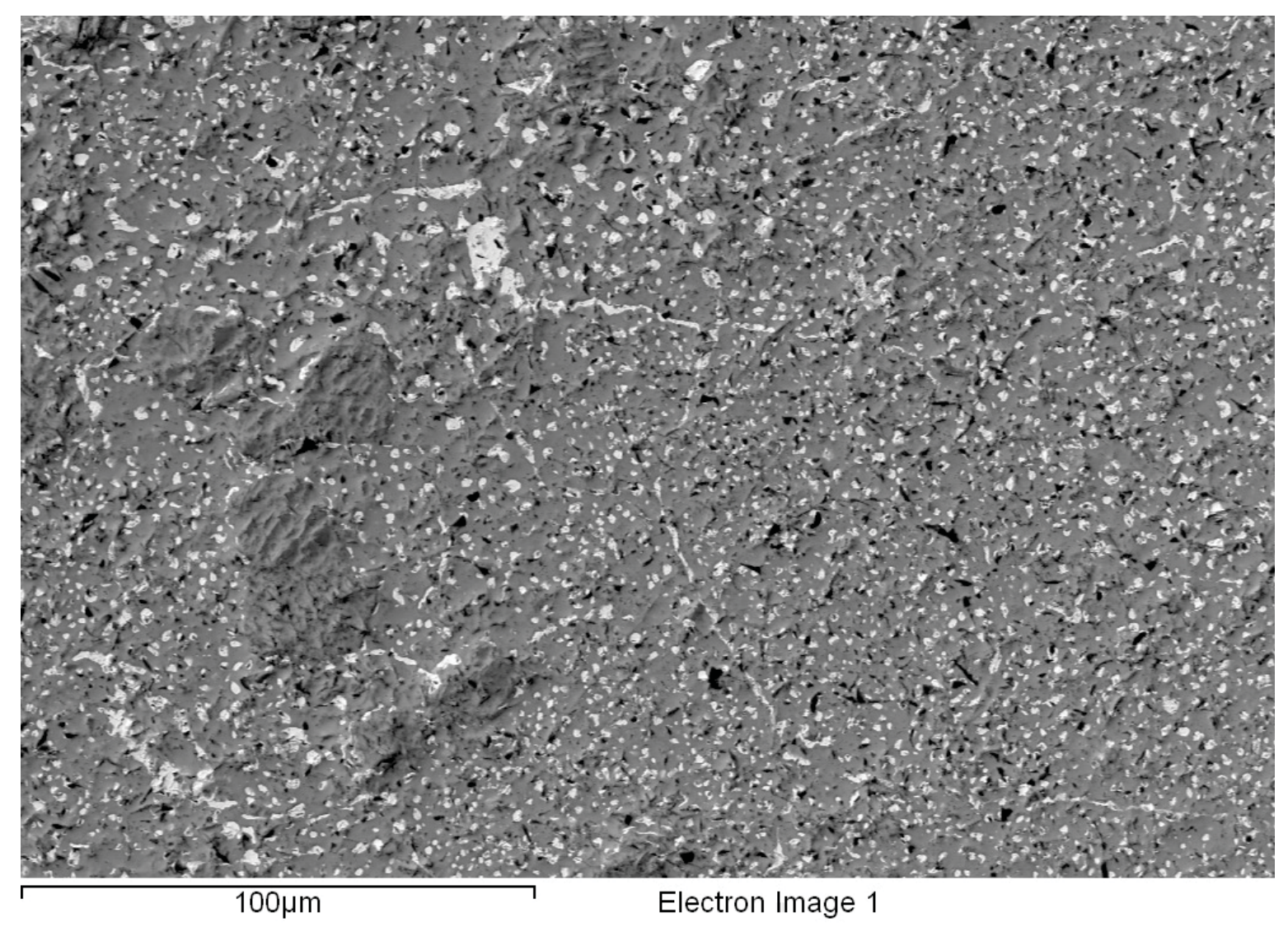

Figure G.2. Micrograph of U-Er-Zr-H Fuel. 
NEA/NSC/DOC(2006)1

Fundamental - FUND

NRAD-FUND-RESR-002

CRIT-REAC-COEF

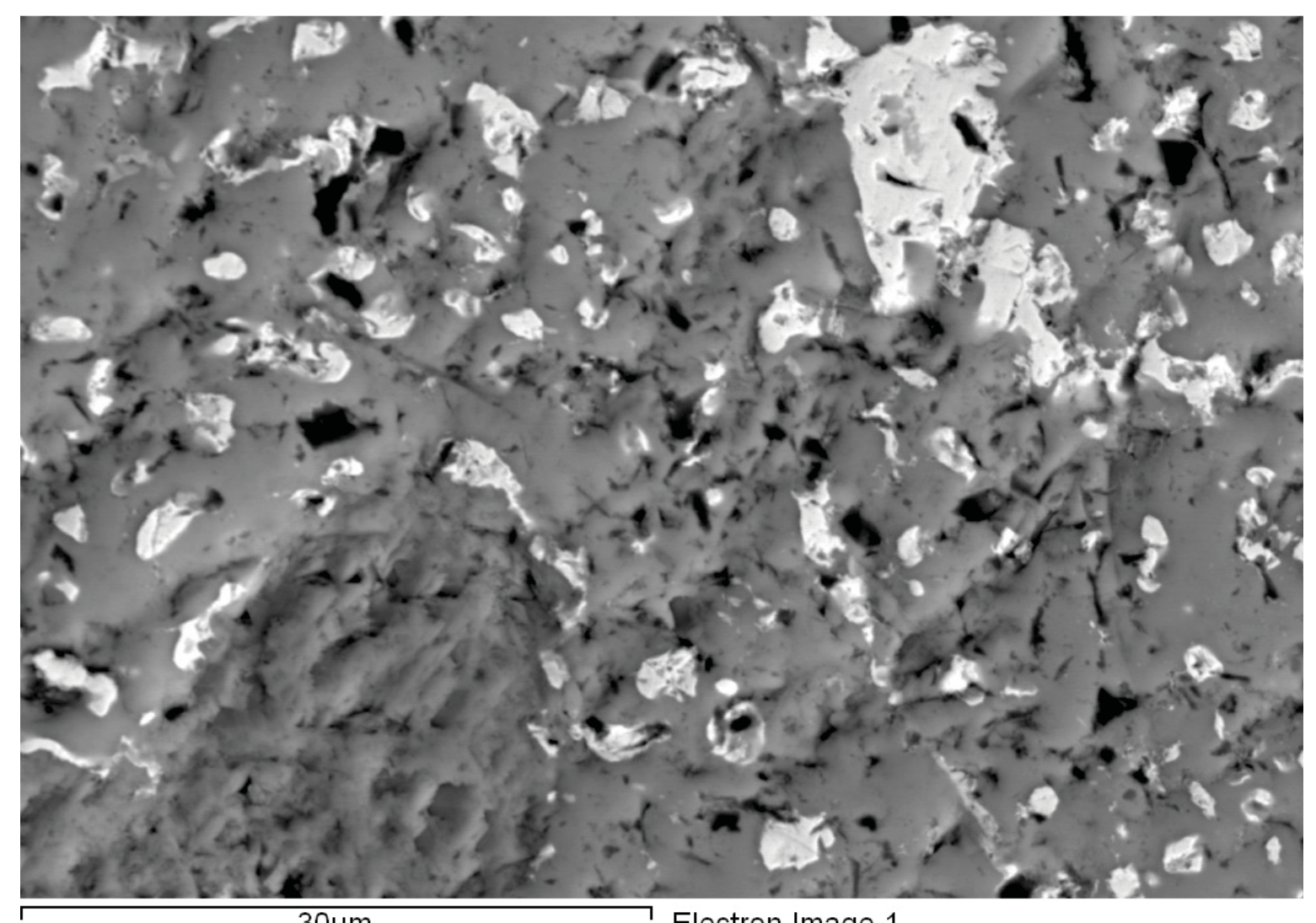

$30 \mu \mathrm{m}$

Electron Image 1

Figure G.3. Micrograph of U-Er-Zr-H Fuel. 
NEA/NSC/DOC(2006)1

Fundamental - FUND

NRAD-FUND-RESR-002

CRIT-REAC-COEF

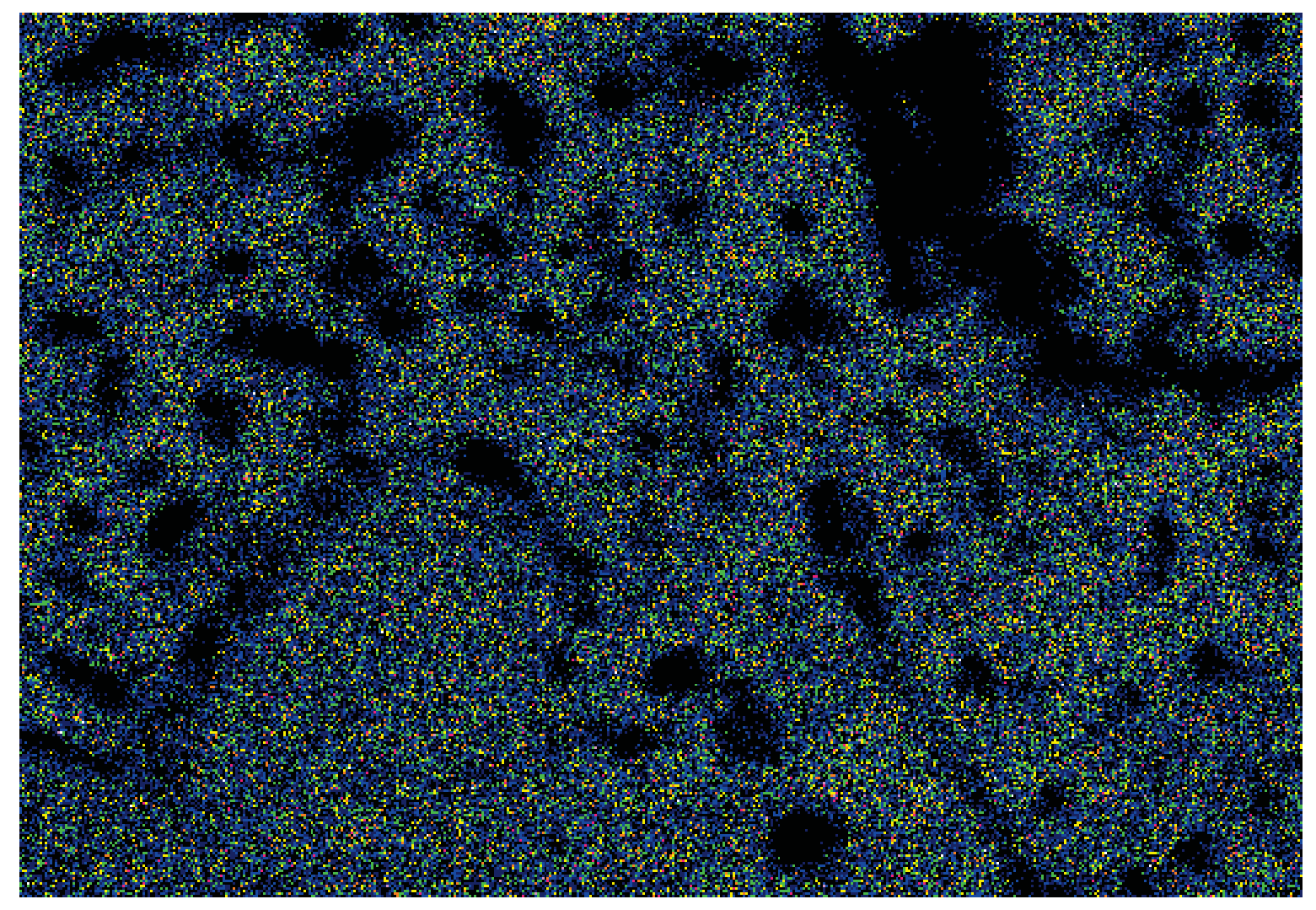

Figure G.4. Micrograph of U-Er-Zr-H Fuel showing Location of Zirconium in Figure G.3. 
NEA/NSC/DOC(2006)1

Fundamental - FUND

NRAD-FUND-RESR-002

CRIT-REAC-COEF

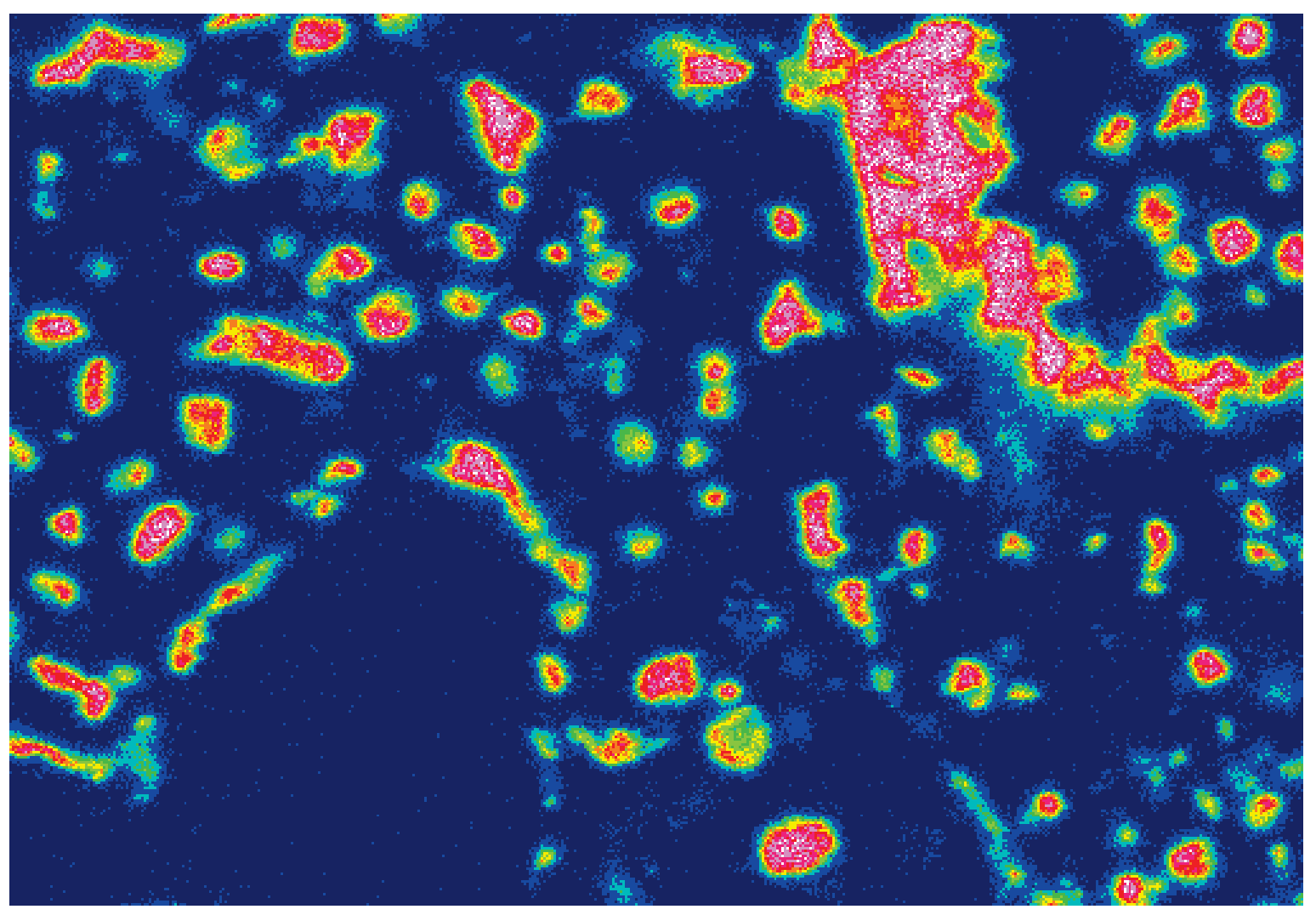

Figure G.5. Micrograph of U-Er-Zr-H Fuel showing Location of Uranium in Figure G.3. 
NRAD-FUND-RESR-002

CRIT-REAC-COEF

\section{APPENDIX H: ADDITIONAL MEASUREMENTS PROVIDED BY CERCA}

\section{H.1 Uranium Measurements}

Five batches of uranium fuel were sampled by CERCA and provided to Anthony Veca of TRIGA International from Laurent Hallé of AREVA-CERCA on May 12, 2010. ${ }^{\mathrm{a}}$ Discussion of the measurement dates and method were not available. A summary of what information was provided is found in Table H.1.

\footnotetext{
a Personal communication with John M. Bolin at General Atomics (April 11, 2011).
} 
NEA/NSC/DOC(2006)1

Fundamental - FUND

NRAD-FUND-RESR-002

CRIT-REAC-COEF

Table H.1. Analysis of Five Uranium Batches.

\begin{tabular}{|c|c|c|c|c|c|c|}
\hline Eléments & $\begin{array}{c}\text { Limites Spécification G } \\
160 \text { Rev } 6\end{array}$ & \multicolumn{5}{|c|}{ Mesures } \\
\hline & & $\begin{array}{c}\text { Lot P30 } \\
230 \\
\end{array}$ & $\begin{array}{c}\text { Lot } 130 \\
\mathrm{~A}\end{array}$ & $\begin{array}{c}\text { Lot } 131 \\
\mathrm{~A}\end{array}$ & $\begin{array}{c}\text { Lot } 133 \\
\mathrm{~A}\end{array}$ & $\begin{array}{c}\text { Lot } 134 \\
\mathrm{~A} \\
\end{array}$ \\
\hline $\mathrm{U} 234$ & $\leq 1,5 \%$ & 0,16 & 0,2 & 0,2 & 0,2 & 0,2 \\
\hline $\mathrm{U} 235$ & $19,55 \% \leq X \leq 19,95 \%$ & 19,86 & 19,73 & 19,79 & 19,84 & 19,84 \\
\hline $\mathrm{U} 236$ & $\leq 4 \%$ & 0,099 & 0,3 & 0,29 & 0,27 & 0,3 \\
\hline $\mathrm{Ag}$ & à mesurer & 1 & 10 & 10 & 10 & 5 \\
\hline $\mathrm{B}$ & $\leq 1 \mathrm{ppm}$ & 0,5 & 0,3 & 0,3 & 0,3 & 0,31 \\
\hline $\mathrm{C}$ & $\leq 800 \mathrm{ppm}$ & 254 & 228 & 277 & 238 & 176 \\
\hline $\mathrm{Cd}$ & $\leq 1 \mathrm{ppm}$ & 0,3 & 0,2 & 0,2 & 02 & 0,2 \\
\hline $\mathrm{Co}$ & à mesurer & 1 & 3 & 3 & 3 & 3 \\
\hline $\mathrm{Cr}$ & à mesurer & 6,5 & 30 & 30 & 30 & 30 \\
\hline $\mathrm{Cu}$ & à mesurer & 5,6 & 13,6 & 19,5 & 13,6 & 10 \\
\hline $\mathrm{Fe}$ & à mesurer & 67 & 83 & 68 & 50 & 101 \\
\hline $\mathrm{Li}$ & $\leq 10 \mathrm{ppm}$ & 1 & 1 & 1 & 1 & 1 \\
\hline $\mathrm{Ni}$ & à mesurer & 28 & 31 & 31 & 34 & 30,7 \\
\hline $\mathrm{Si}$ & $\leq 300 \mathrm{ppm}$ & 26 & 25 & 29 & 29 & 29 \\
\hline $\mathrm{Sn}$ & $\leq 100 \mathrm{ppm}$ & 1 & 5 & 5 & 5 & 5 \\
\hline $\mathrm{Zr}$ & $\leq 250 \mathrm{ppm}$ & 9,7 & 100 & 100 & 100 & 100 \\
\hline \multicolumn{7}{|l|}{ Autres } \\
\hline \multicolumn{2}{|c|}{ Total Equ. Bore Groupe A } & 1,0431 & 0,9487 & 0,9445 & 0,9308 & 0,9261 \\
\hline $\mathrm{Al}$ & $\leq 150 \mathrm{ppm}$ & 10 & 59 & 75 & 50 & 50 \\
\hline $\mathrm{Ca}$ & $\leq 100 \mathrm{ppm}$ & 5 & 50 & 50 & 50 & 50 \\
\hline $\mathrm{Mg}$ & à mesurer & 1 & 6 & 6 & 6 & 6 \\
\hline $\mathrm{N}$ & à mesurer & 1 & 131 & 128 & 128 & 128 \\
\hline $\mathrm{Mn}$ & à mesurer & 11 & 11 & 9 & 9 & 9 \\
\hline Mo & à mesurer & 2,3 & 18 & 18 & 18 & 18 \\
\hline $\mathrm{V}$ & à mesurer & 1 & 2 & 2 & 2 & 2 \\
\hline $\mathrm{P}$ & à mesurer & 20 & 17 & 23 & 23 & 23 \\
\hline $\mathrm{Pb}$ & à mesurer & 1 & 4 & 4 & 4 & 4 \\
\hline $\mathrm{W}$ & $\leq 100 \mathrm{ppm}$ & 2,6 & 14 & 14 & 14 & 14 \\
\hline Total & $\leq 1500 \mathrm{ppm}$ & 546,5 & 842,1 & 903 & 818,1 & 795,21 \\
\hline \multicolumn{2}{|c|}{ Element Groupe B si dépassement } & 0 & 0 & 0 & 0 & 0 \\
\hline $\begin{array}{l}\text { Total Groupe A + } \\
\text { Groupe B } \\
\end{array}$ & $\leq 2,5 \mathrm{ppm}$ & 1,0431 & 0,9487 & 0,9445 & 0,9308 & 0,9261 \\
\hline
\end{tabular}




\section{H.2 Zirconium Measurement}

An impurity analysis was performed by CERCA on an "R sponge", which is zirconium material used in the manufacture of the fuel elements and zirconium rod. The measurement results were also provided to Anthony Veca of TRIGA International from Laurent Hallé of AREVA-CERCA on May 12, 2010. ${ }^{a}$ Discussion of the measurement dates and method were not available. A summary of what information was provided is found in Table H.2.

Table H.2. Impurity Analysis of R Sponge.

\begin{tabular}{|c|c|c|}
\hline \multicolumn{3}{|c|}{ Analyses sur Lingotin / PV No 20080036} \\
\hline Eléments & Résultats d'analyses en ppm & Spécification G 530 Rev. 0 \\
\hline $\mathrm{Al}$ & 24 & 75 \\
\hline $\mathrm{B}$ & $<0,5$ & 0,5 \\
\hline $\mathrm{C}$ & $<15$ & 250 \\
\hline $\mathrm{Cd}$ & $<0,5$ & 0,5 \\
\hline $\mathrm{Co}$ & $<10$ & 20 \\
\hline $\mathrm{Cr}$ & 45 & 200 \\
\hline $\mathrm{Cu}$ & $<20$ & 30 \\
\hline $\mathrm{Fe}$ & 277 & $*$ \\
\hline $\mathrm{Hf}$ & 46 & 100 \\
\hline $\mathrm{Mn}$ & 11 & 50 \\
\hline Mo & $<20$ & 50 \\
\hline $\mathrm{N}$ & 11 & 50 \\
\hline $\mathrm{Ni}$ & $<10$ & 70 \\
\hline $\mathrm{O}$ & 525 & 1400 \\
\hline $\mathrm{Si}$ & $<30$ & 120 \\
\hline $\mathrm{Ti}$ & $<10$ & 50 \\
\hline $\mathrm{U}$ & $<1,5$ & 3 \\
\hline W & $<20$ & 50 \\
\hline $\mathrm{Fe}+\mathrm{Cr}+\mathrm{Ni}$ & 332 & 600 \\
\hline
\end{tabular}

${ }^{a}$ Personal communication with John M. Bolin at General Atomics (April 11, 2011). 